\title{
Electric Vehicle Preparedness Utilization Task 3: Detailed Assessment of Target Electrification Vehicles at Joint Base Lewis McChord
}

Stephen Schey Jim Francfort

August 2014

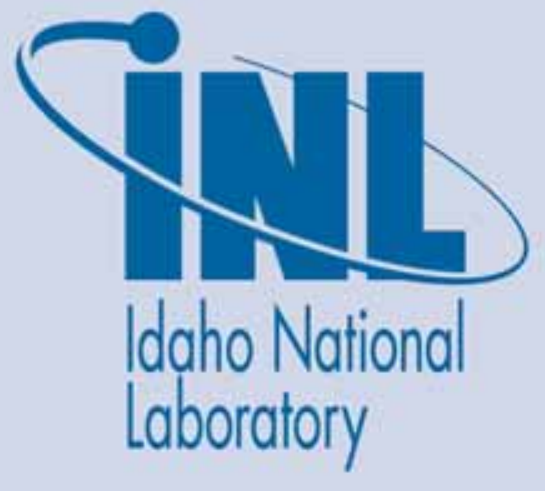

The INL is a U.S. Department of Energy National Laboratory operated by Battelle Energy Alliance 


\section{DISCLAIMER}

This information was prepared as an account of work sponsored by an agency of the U.S. Government. Neither the U.S. Government nor any agency thereof, nor any of their employees, makes any warranty, expressed or implied, or assumes any legal liability or responsibility for the accuracy, completeness, or usefulness, of any information, apparatus, product, or process disclosed, or represents that its use would not infringe privately owned rights. References herein to any specific commercial product, process, or service by trade name, trade mark, manufacturer, or otherwise, does not necessarily constitute or imply its endorsement, recommendation, or favoring by the U.S. Government or any agency thereof. The views and opinions of authors expressed herein do not necessarily state or reflect those of the U.S. Government or any agency thereof. 


\title{
Electric Vehicle Preparedness Utilization Task 3: Detailed Assessment of Target Electrification Vehicles at Joint Base Lewis McChord
}

\author{
Stephen Schey \\ Jim Francfort ${ }^{2}$ \\ ${ }^{1}$ Stephen Schey, Project Manager, Infrastructure Planning and Analysis, Intertek Testing Services, \\ North America, Phoenix, AZ \\ ${ }^{2} \mathrm{Jim}$ Francfort, Vehicle Systems Principal Investigator, Idaho National Laboratory operated by \\ Battelle Energy Alliance, Idaho Falls, ID
}

August 2014

Idaho National Laboratory
Idaho Falls, Idaho 83415

http://avt.inl.gov

Prepared for the

U.S. Department of Energy

Office of Nuclear Energy

Under DOE Idaho Operations Office

Contract DE-AC07-05ID14517 


\section{ABSTRACT}

Battelle Energy Alliance, LLC, managing and operating contractor for the U.S. Department of Energy's Idaho National Laboratory, is the lead laboratory for U.S. Department of Energy Advanced Vehicle Testing. Battelle Energy Alliance, LLC contracted with Intertek Testing Services, North America (Intertek) to conduct several U.S. Department of Defense based studies to identify potential U.S. Department of Defense transportation systems that are strong candidates for introduction or expansion of plug-in electric vehicles (PEVs).

Task 2 involved identifying daily operational characteristics of select vehicles and initiating data logging of vehicle movements in order to characterize the vehicle's mission. Individual observations of these selected vehicles provide the basis for recommendations related to PEV adoption and whether a battery electric vehicle or plug-in hybrid electric vehicle (collectively referred to as PEVs) can fulfill the mission requirements and provide observations related to placement of PEV charging infrastructure.

This report provides the results of the data analysis and observations related to replacement of current vehicles with PEVs. This fulfills part of the Task 3 requirements. Task 3 also includes an assessment of the charging infrastructure required to support this replacement, which is the subject of a separate report.

Intertek acknowledges the support of Idaho National Laboratory and Joint Base Lewis McChord fleet managers and personnel for participation in this study.

Intertek is pleased to provide this report and is encouraged by enthusiasm and support from Joint Base Lewis McChord personnel. 


\section{EXECUTIVE SUMMARY}

Federal agencies are mandated ${ }^{a}$ to purchase alternative fuel vehicles, increase consumption of alternative fuels, and reduce petroleum consumption. Available plug-in electric vehicles (PEVs) provide an attractive option in the selection of alternative fuel vehicles. PEVs, which consist of both battery electric vehicles (BEVs) and plug-in hybrid electric vehicles (PHEVs), have significant advantages over internal combustion engine (ICE) vehicles in terms of energy efficiency, reduced petroleum consumption, and reduced production of greenhouse gas (GHG) emissions, and they provide performance benefits with quieter, smoother operation. This study intended to evaluate the extent to which Joint Base Lewis McChord (JBLM) could convert part or all of their fleet of vehicles from petroleum-fueled vehicles to PEVs.

It is likely that more fuel efficient ICE vehicles, including hybrid electric vehicles, exist that may provide improvements for the current fleet; however, this study's focus is on replacing ICE vehicles with suitable PEVs.

BEVs provide the greatest benefit when it comes to fuel and emissions savings because all motive power is provided by the energy stored in the onboard battery pack. These vehicles use no petroleum and emit no pollutants at their point of use. PHEVs provide similar savings when their battery provides the motive power, but they also have the ability to extend their operating range with an onboard ICE. Because a PHEV can meet all transportation range needs, the adoption of a PHEV will be dependent on its ability to meet other transportation needs such as cargo or passenger carrying. Operation of PHEVs in battery-only mode can be increased with opportunity charging at available charging stations; however, it should be noted that not all PHEVs have a mode in which the battery provides all motive power at all speeds. This study focuses on the mission requirements of the fleet of vehicles with the objective to identify vehicles that may be replaced with PEVs, with emphasis on BEVs that provide maximum benefit.

JBLM has a sub-installation in the Yakima Training Center. The joint base is $647 \mathrm{~m}^{2}$, with $142 \mathrm{~m}^{2}$ for the main base and $505 \mathrm{~m}^{2}$ for the Yakima Training Center. The geographic size of JBLM creates significant travel demands on its vehicle fleet and provides opportunities for conversion of some vehicles to PEVs. JBLM identified 1,595 vehicles in its fleet; four JBLM fleet managers selected 60 vehicles to be representative of their fleets for participation in this study. Fleet vehicle mission categories are defined in Section 4 and, while the JBLM vehicles conduct many different missions, three (i.e., pool, support, and transport missions) were selected by fleet management to be part of this fleet evaluation. The selected vehicles included many vehicle types.

This report actually provides five reports: one for each of the fleets participating in the monitoring and an overall report. It observes that a mix of BEVs and PHEVs are capable of performing most of the required missions and of providing an alternative vehicle for the pool, support, and transport vehicles, because while some vehicles travel long distances, the group could support some

\footnotetext{
${ }^{a}$ Energy Policy act of 1992, Energy Policy Act of 2005, Executive Order 13423, and Energy Independence and Security Act of
} 2007. 
BEVs for the short trips and PHEVs for the longer trips. The recommended mix of vehicles will provide sufficient range for individual trips and time is available each day for charging to accommodate multiple trips per day. Replacement of vehicles in the current fleet could result in significant reductions in the emission of GHGs and in petroleum use, as well as reduced fleet operating costs.

PEVs currently commercially available cannot replace certain vehicles and missions (such as those requiring heavy-duty trucks, passenger vans, and specialty usage vehicles), some of which were included in this study. However, based on data collected for the monitored vehicles, the 60-vehicle fleet subset could possibly consist of two conventional heavy-duty trucks, 11 conventional passenger vans, $28 \mathrm{BEVs}$, and 19 PHEVs. Additional replacement may be possible as more PEVs of different types become commercially available.

Fuel Cost for All Monitored Vehicles

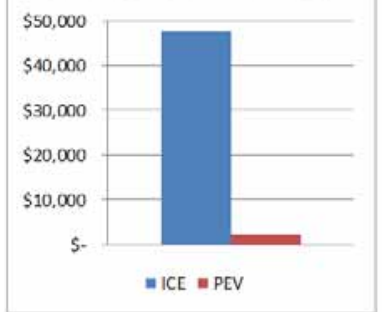

Tacoma Power provides the electric power for JBLM and its generation capacity consists mostly of hydroelectricity. Hydroelectricity generally provides lower electrical costs and lower generation GHG emissions than the national averages. The replacement of the 47 internal combustion vehicles with PEVs potentially results in an annual fuel savings of over $\$ 47,000$ (95\% reduction) and GHG savings of over $223,000 \mathrm{lb}-\mathrm{CO}_{2} \mathrm{e}(\mathbf{9 4 \%}$ reduction).

The monitored vehicles represent 60 vehicles of 1,382 on-road-rated vehicles in these represented fleets. Assuming that the balance of these fleets operate in a manner similar to those monitored and without consideration of specific cargo or other mission requirements not previously identified, Intertek suggests the total fleet composition could consist of 111 conventional heavy-duty trucks, 263 conventional passenger vans, 57 conventional buses, five conventional specialty vehicles, 573 BEVs, and 373 PHEVs.

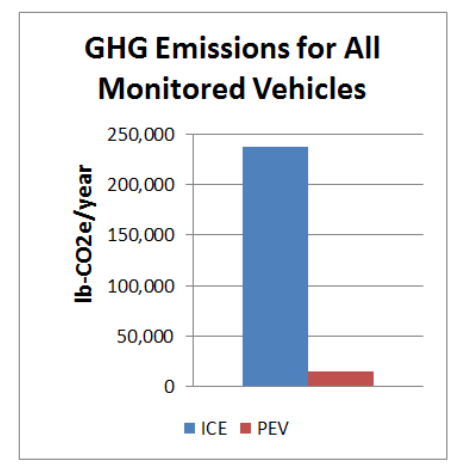
This replacement of ICE vehicles with PEVs could result in an annual fuel savings of over $\mathbf{\$ 1}$ million (95\% reduction) and annual GHG savings of over $740,000 \mathrm{lb}-\mathrm{CO}_{2} \mathrm{e}(76 \%$ reduction).

The entire non-tactical fleet of vehicles at JBLM includes 190 vehicles not counted in the above figures because they were not part of the monitored vehicles. Additional evaluation of these vehicles likely will result in more potential PEV replacements and added savings. The average vehicle monitored travels approximately 4,500 miles per year. This is an average of 375 miles per month or 94 miles per week. This may reflect the opportunity to increase the percentage of BEVs over that analyzed in Section 5. Intertek suggests JBLM may wish to move forward in the near future with the replacement of pool, support, and transport vehicles with PEVs as current budget and vehicle replacement schedules allow. Certainly, the vehicle types studied in this report may be candidates for immediate replacement. 


\section{CONTENTS}

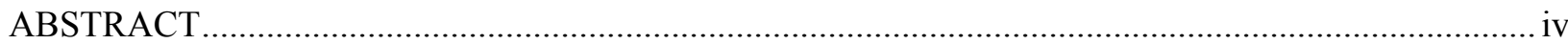

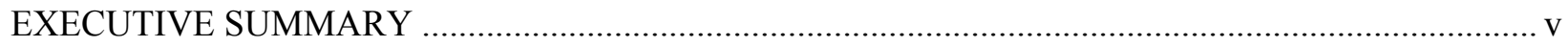

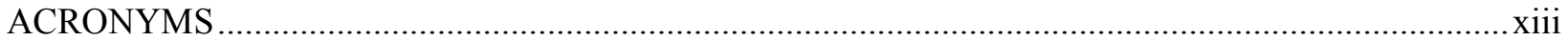

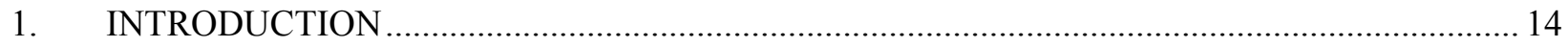

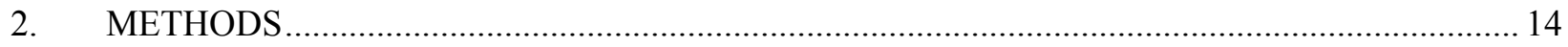

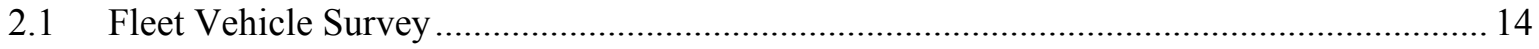

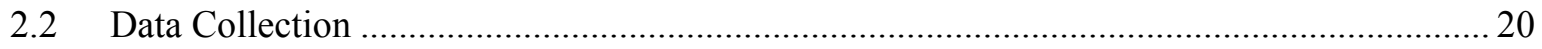

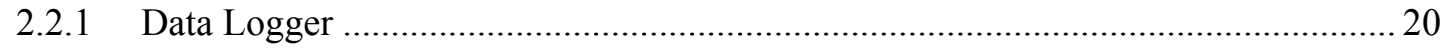

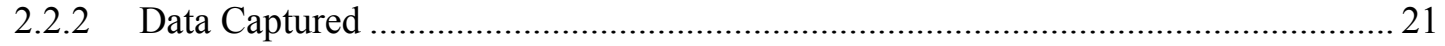

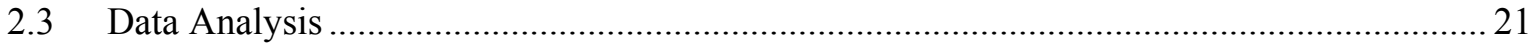

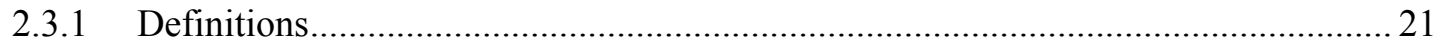

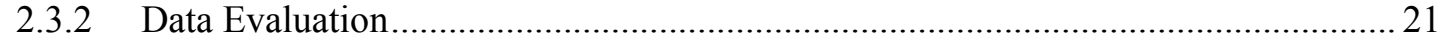

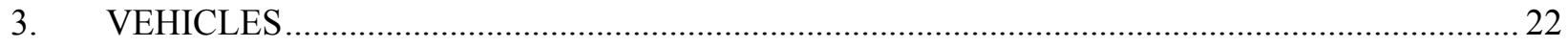

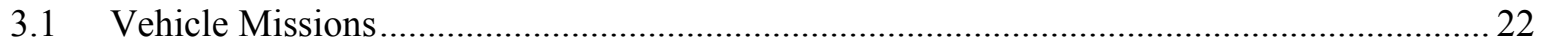

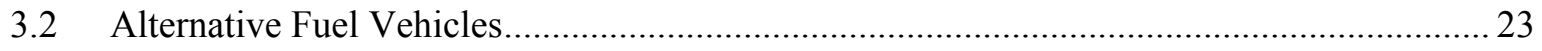

3.3 Battery Electric Vehicle and Plug-In Hybrid Electric Vehicle Benefits/Challenges ............. 24

3.3.1 Battery Electric Vehicle Benefits/Challenges ........................................................... 24

3.3.2 Plug-In Hybrid Electric Vehicle Benefits/Challenges ............................................25

3.4 Plug-In Hybrid Electric Vehicle Availability.................................................................. 25

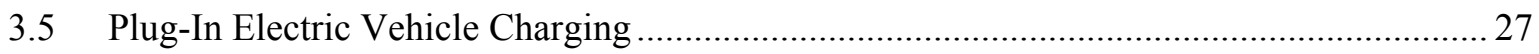

3.5.1 Electric Vehicle Supply Equipment Design...................................................... 27

3.5.2 Electric Vehicle Supply Equipment Stations ......................................................... 31

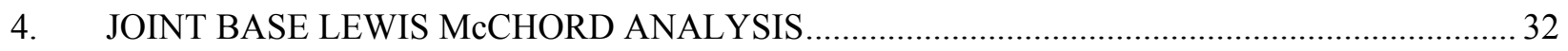

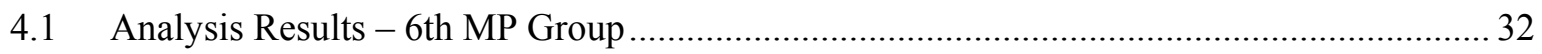

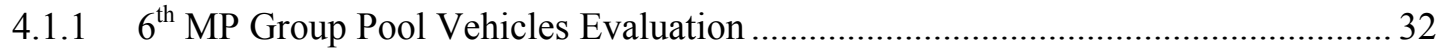

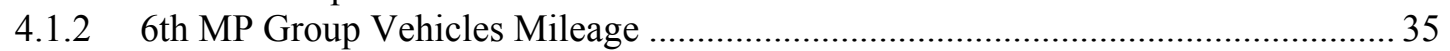

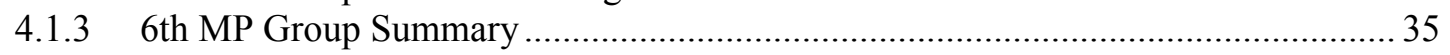

4.2 Analysis Results - Directorate of Community Activities Group .......................................... 36 
4.2.1 Directorate of Community Activities Pool Vehicles Analysis................................... 36

4.2.2 Directorate of Community Activities Support Group Support Vehicles

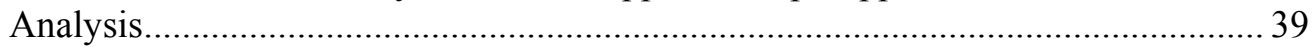

4.2.3 Directorate of Community Activities Support Group Vehicles Mileage .................. 40

4.2.4 Directorate of Community Activities Support Group Summary .............................. 41

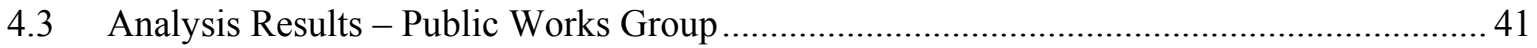

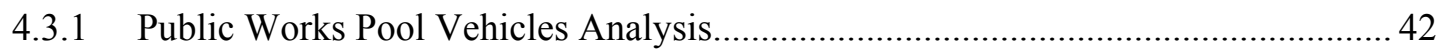

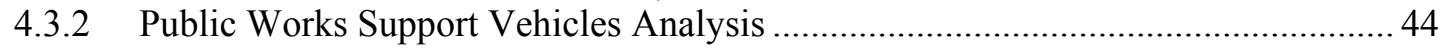

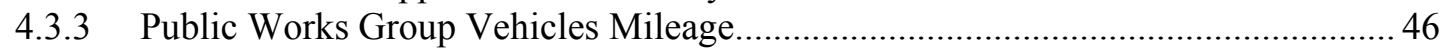

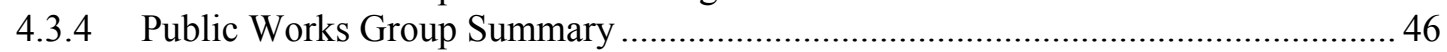

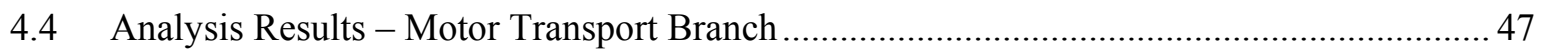

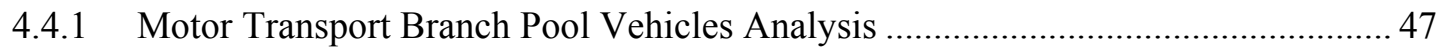

4.4.2 Motor Transport Branch Support Vehicles Analysis ............................................. 50

4.4.3 Motor Transport Branch Transport Vehicles Analysis ............................................. 53

4.4.4 Motor Transport Branch Vehicles Mileage............................................................ 55

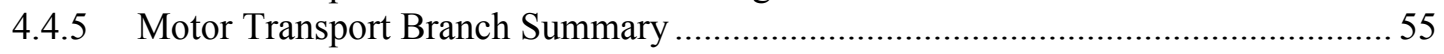

4.5 Balance of Joint Base Lewis McChord Fleet .......................................................................... 56

5. GREENHOUSE GAS EMISSIONS AVOIDED AND FUEL COST REDUCTION

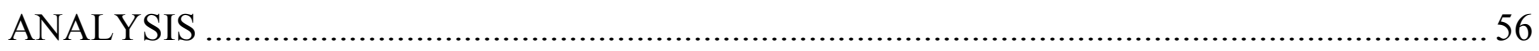

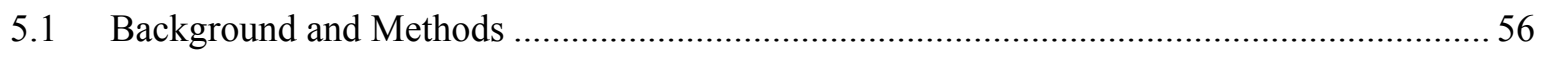

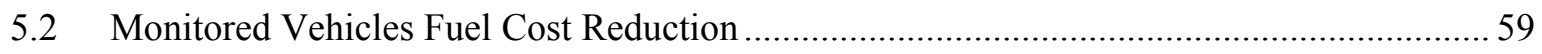

5.3 Monitored Vehicles Greenhouse Gas Emissions Reduction .............................................. 60

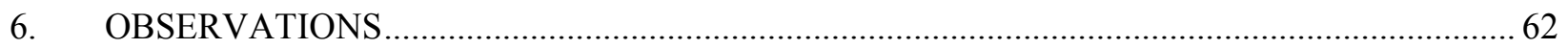

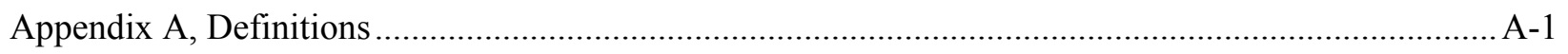

Appendix B, 6th MP Group Vehicle Data Sheets........................................................................ B-1

Appendix C, DCA Support Group Vehicle Data Sheets................................................................... C-1

Appendix D, Public Works Vehicle Data Sheets.............................................................................. D-1

Appendix E, Motor Transport Branch Vehicle Data Sheets ........................................................... E-1

Appendix F, 6th MP Group Vehicle Analysis ..............................................................................

Appendix G, DCA Support Group Vehicle Analysis ........................................................................

Appendix H, Public Works Group Vehicle Analysis.........................................................................

Appendix I, Motor Transport Branch Vehicle Analysis ......................................................................... 
Appendix J, Greenhouse Gas Emissions Avoided and fuel Cost Reduction Analysis $-6^{\text {th }}$ MP

Group

Appendix K, Greenhouse Gas Emissions Avoided and fuel Cost Reduction Analysis - DCA

Support Group

Appendix L, Greenhouse Gas Emissions Avoided and fuel Cost Reduction Analysis - Public

Works Group

Appendix M, Greenhouse Gas Emissions Avoided and fuel Cost Reduction Analysis - Motor

Transport Branch

\section{FIGURES}

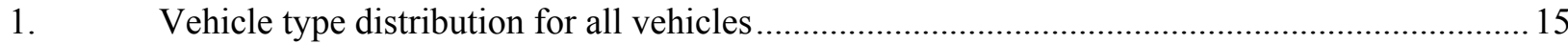

2. Vehicle type distribution for vehicles with data loggers ................................................. 16

3. Model year distribution for vehicles with data loggers ................................................... 16

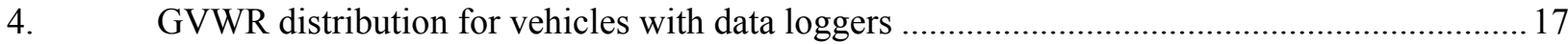

5. Distribution of cumulative distance driven for vehicles with data loggers ............................ 17

6. Distribution of monthly distance driven for vehicles with data loggers ................................. 18

7. Survey results for vehicles with data loggers: How much longer do you expect to keep

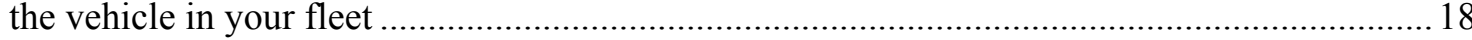

8. Survey results for vehicles with data loggers: Is this vehicle used off-base? ......................... 19

9. Survey results for vehicles with data loggers: Are the vehicles used during specific hours or at any time during the day?

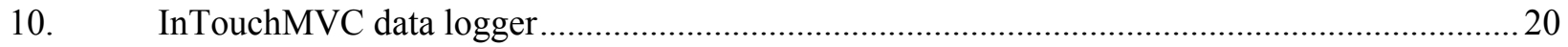

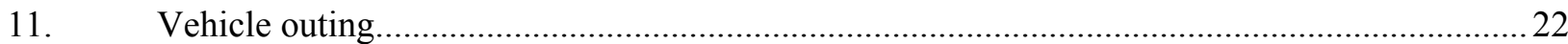

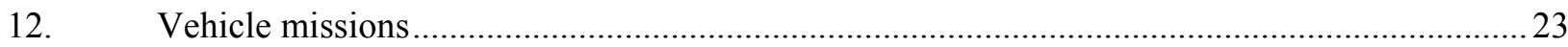

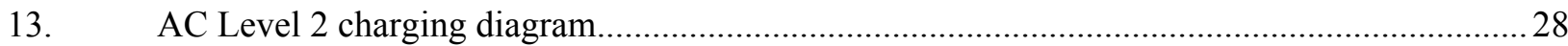

14. Society of Automotive Engineers charging configurations and ratings terminology ...............29

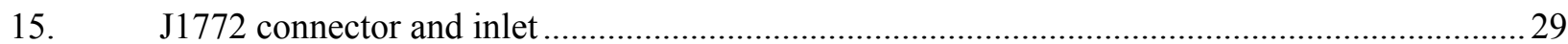

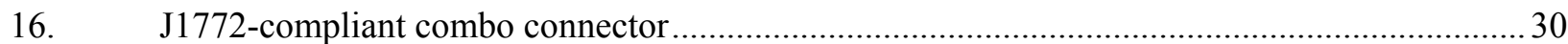

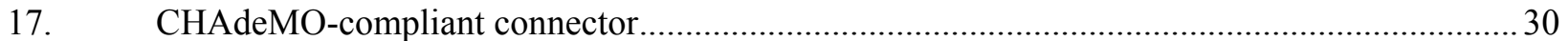




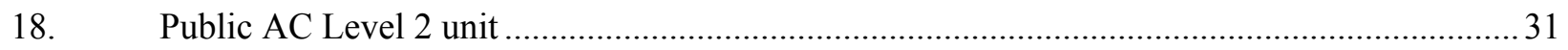

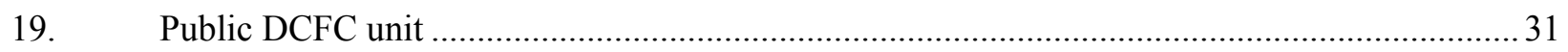

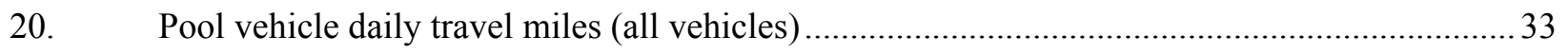

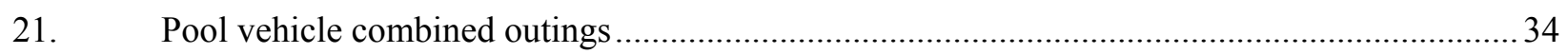

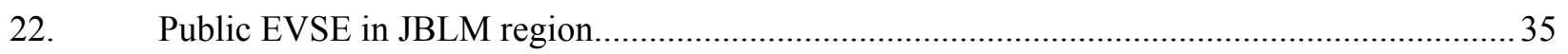

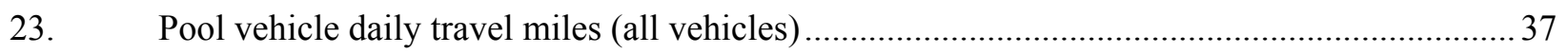

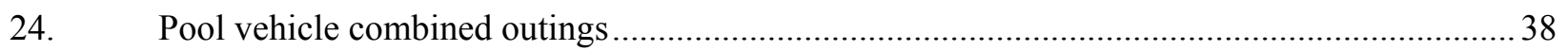

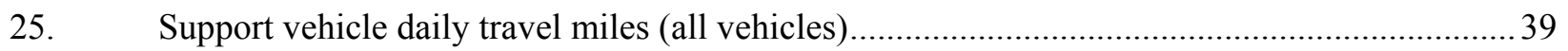

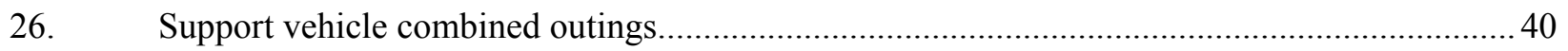

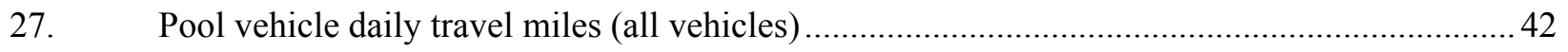

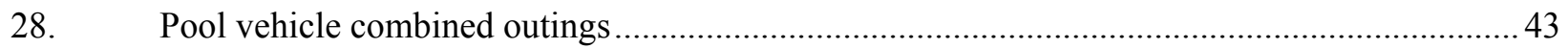

29. Support vehicle daily travel miles and usage time (all vehicles) ........................................... 45

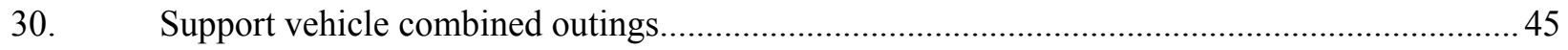

31. Motor Transport Branch pool vehicle daily travel miles (all vehicles) ................................. 48

32. Motor Transport Branch pool vehicle outings (all vehicles) ................................................ 49

33. Motor Transport Branch pool vehicle outings (all vehicles) truncated at 150 miles ................. 49

34. Motor Transport Branch support vehicle daily travel miles (all vehicles) ...............................51

35. Motor Transport Branch support vehicle combined outings ................................................ 51

36. Motor Transport Branch support vehicle outings (all vehicles) truncated to 200 miles............52

37. Motor Transport Branch transport vehicle daily travel miles (all vehicles) .............................54

38. Motor Transport Branch transport vehicle combined outings ..............................................5

\section{TABLES}

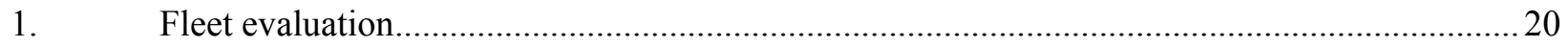

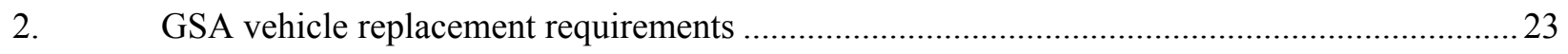

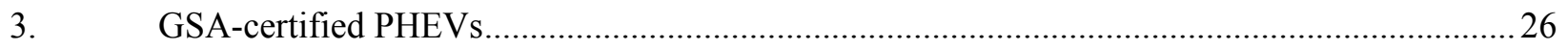




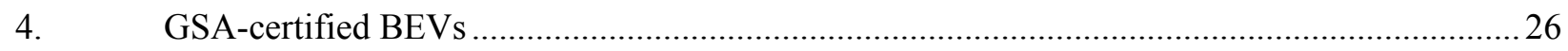

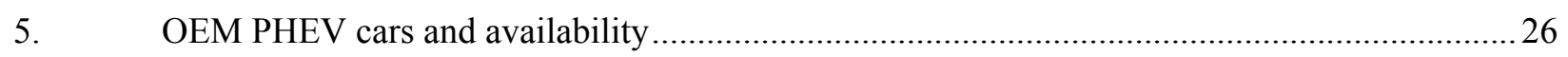

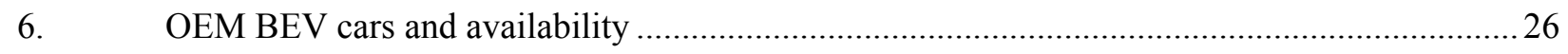

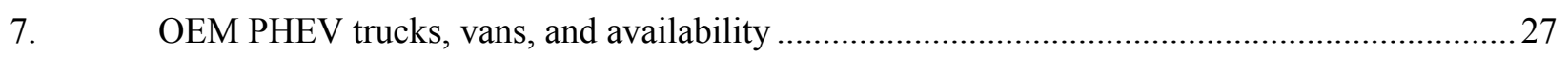

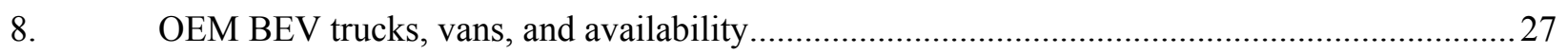

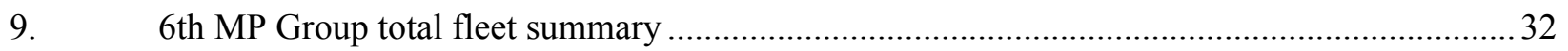

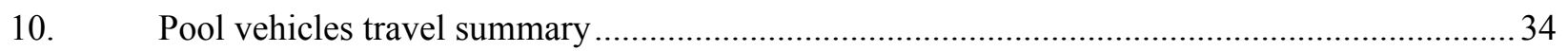

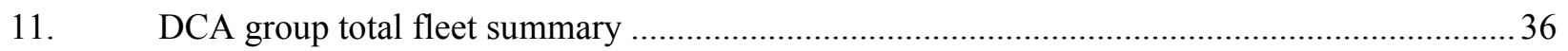

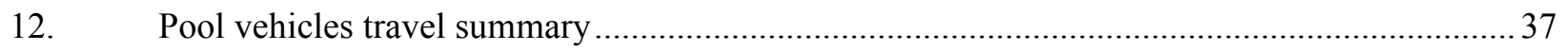

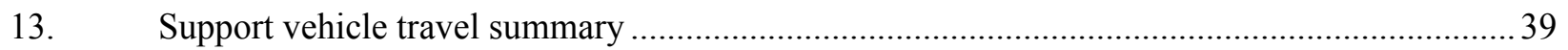

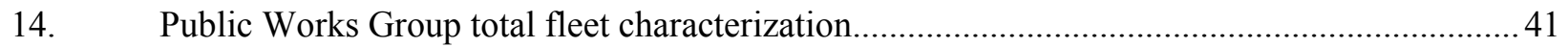

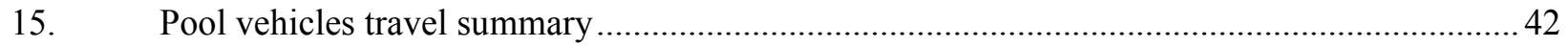

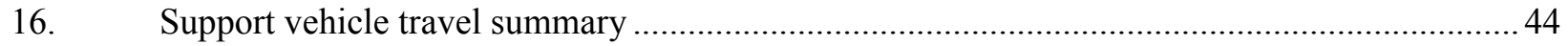

17. Motor Transport Branch fleet vehicles by type and mission ............................................. 47

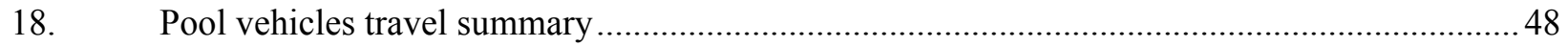

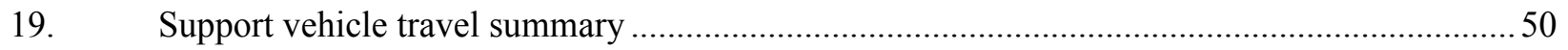

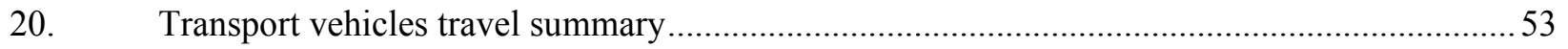

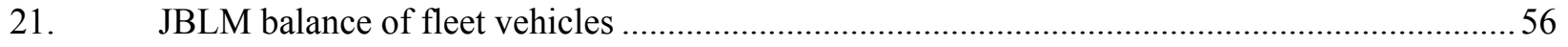

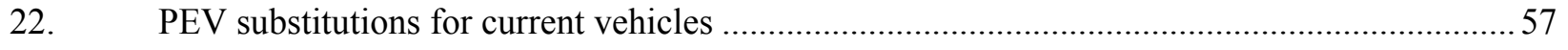

23. Monitored pool mission PEV replacement fuel cost reduction ............................................59

24. Monitored support mission PEV replacement fuel cost reduction (Washington State) .............59

25. Monitored transport mission PEV replacement fuel cost reduction (Washington State) ...........60

26. Monitored vehicle PEV replacement fuel cost reduction (Washington State) all vehicles ........60

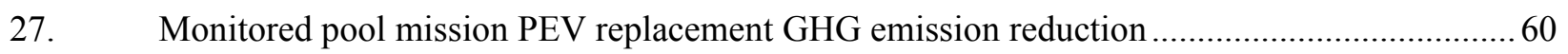

28. Monitored support mission PEV replacement GHG emission reduction ............................... 61

29. Monitored transport mission PEV replacement GHG emission reduction .............................. 61 
30. Monitored vehicle PEV replacement GHG emission reduction (Washington State) all vehicles

31. Projected fuel costs and GHG reduction potential for all vehicles in monitored fleets.............61 


\section{ACRONYMS}

AC Alternating current

BEA Battelle Energy Alliance, LLC

BEV battery electric vehicle

CD Charge depletion

CS Charge sustaining

DC Direct current

EPA U.S. Environmental Protection Agency

EVSE electric vehicle supply equipment

GHG greenhouse gas emissions

GVWR gross vehicle weight rating

GSA General Services Administration

ICE internal combustion engine

INL Idaho National Laboratory

Intertek Intertek Testing Services, North America

JBLM Joint Base Lewis McChord

LSV Low speed vehicle

MOU memorandum of understanding

OEM original equipment manufacturer

PEV plug-in electric vehicle (includes BEVs and PHEVs, but not hybrid electric vehicles)

PHEV plug-in hybrid electric vehicle

SUV sports utility vehicle

VIN vehicle identification number 


\section{Electric Vehicle Preparedness Utilization Task 3: Detailed Assessment of Target Electrification Vehicles at Joint Base Lewis McChord}

\section{INTRODUCTION}

The U.S. Department of Energy and the U.S. Department of Defense signed a memorandum of understanding on July 22, 2010, for strengthening the coordination of efforts to enhance national energy security and to demonstrate federal government leadership in transitioning the United States to a low-carbon economy. The memorandum of understanding included efforts in the areas of energy efficiency, fossil fuels, alternative fuels, efficient transportation technologies and fueling infrastructure, grid security, smart grid, and energy storage.

In support of the memorandum of understanding, the Idaho National Laboratory, with funding provided by the U.S. Department of Energy's Vehicle Technologies Office and Federal Energy Management Program, directed Intertek Testing Services, North America (Intertek) to conduct several U.S. Department of Defense based studies to identify potential transportation systems that are strong candidates for introduction or expansion of plug-in electric vehicles (PEVs). Intertek previously has conducted similar fleet, city, state, and countrywide studies using their micro-climate assessment process, which consists of the following four main tasks:

- Task 1: Conduct a fleet and infrastructure assessment

- Task 2: Develop target electrification vehicles

- Task 3: Perform detailed assessment of target electrification vehicles and charging infrastructure

- Task 4: Perform economic analysis of target electrification.

Assessment of the potential for replacing Joint Base Lewis McChord (JBLM; in Tacoma, Washington) fleet vehicles with PEVs starts with assessment of the fleet vehicles' missions and vehicle characteristics. This assessment was conducted through a written survey, instrumentation of vehicles, and field interviews. The Task 1 report provided a summary and assessment of General Services Administration (GSA) data and survey results.

PEVs generally are classified into two vehicle types: battery electric vehicles (BEVs) and plug-in hybrid electric vehicles (PHEVs). A BEV contains an onboard battery that provides all motive power. PHEVs also have an onboard battery that provides some motive power by an onboard battery that is supplemented by another power source (such as a gasoline engine). Collectively, BEVs and PHEVs are referred to as PEVs.

The Task 1 effort led to identification of fleet vehicles that appear to be good candidates for replacement by PEVs. Task 2 selected a number of vehicles within the candidate groups for further monitoring and analysis through addition of vehicle data loggers. The data loggers were installed and data collected on these selected vehicles. This Task 3 report provides a summary and details of that data collection. At the same time, the electrical distribution system at JBLM was reviewed as input for the charging infrastructure assessment. The charging infrastructure assessment is the subject of a separate report.

\section{METHODS}

\subsection{Fleet Vehicle Survey}

JBLM identified 60 vehicles for further study, as identified in the Task 2 report. This subset of vehicles contains eight sedans, seven minivans, four sports utility vehicles (SUV), 20 pickup trucks, 
seven cargo vans, 11 passenger vans, and three heavy-duty trucks. This distribution is approximately representative of the entire non-tactical fleet. Figure 1 shows vehicle type distribution for all vehicles for comparison (taken from Task 1).

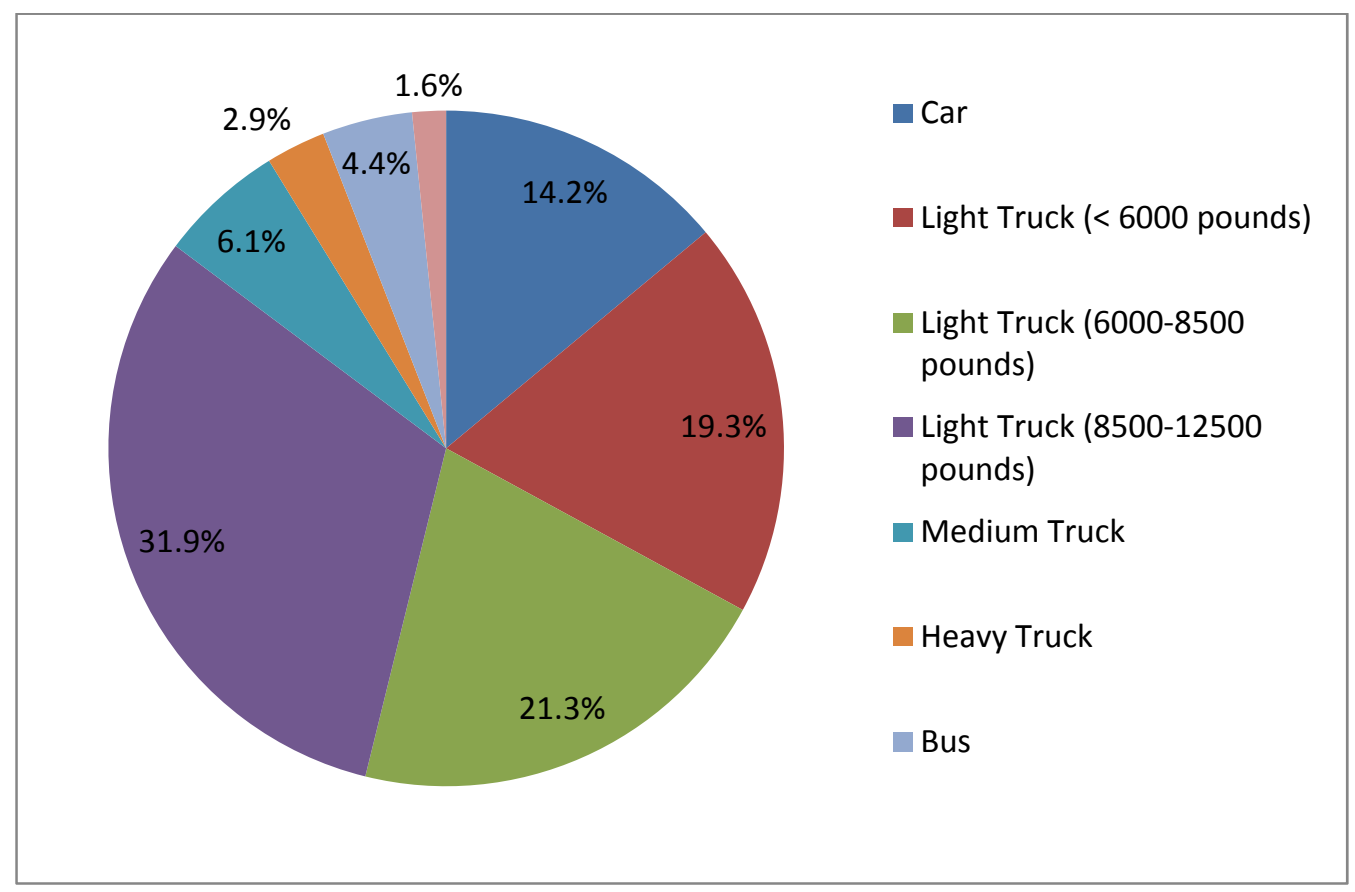

Figure 1. Vehicle type distribution for all vehicles.

Figures 2 through 6 present distributions for model year, gross vehicle weight rating (GVWR), cumulative distance driven, and monthly distance driven. The figures show that the selected vehicles are representative of a wide range of vehicle and mission types.

Additionally, the fleet vehicles are used for a variety of purposes by several different divisions on base. These include Public Works, Motor Transport Branch, Directorate of Community Activities, and $6^{\text {th }}$ MP Group, Directorate of Family Morale, Welfare and Recreation, Madigan Army Medical Center, Criminal Investigation Division, Directorate of Logistics, and the Department of Emergency Services.

Figures 7 through 9 present survey results for the selected vehicles. Respondents have completed surveys for 23 of the selected vehicles. As can be seen in the figures, the responses vary widely; however, the responses match reasonably well with the fleet composition.

JBLM identified 1,593 fleet vehicles in its non-tactical, onroad fleet. The four fleet managers involved in the selection of vehicles for monitoring manage 1,405 of these vehicles. Table 1 identifies these vehicles by mission type. (Note that Section 3 provides descriptions of the vehicle mission types.) Subtracting the low-speed vehicles, 1,382 vehicles are potentially considered for replacement by PEVs.

Intertek coordinated with the JBLM fleet managers to identify the specific vehicles for inclusion in the study. The four fleet managers assessed their wide range of vehicles and made selections of high-interest vehicles based on vehicle missions and vehicle type/class. Selection also favored vehicles used at least twice a week. Because data loggers rely on the vehicle's battery power, non-use of the vehicle can result in the vehicle having a depleted battery. Intertek received no reports of depleted batteries during the study at JBLM. 


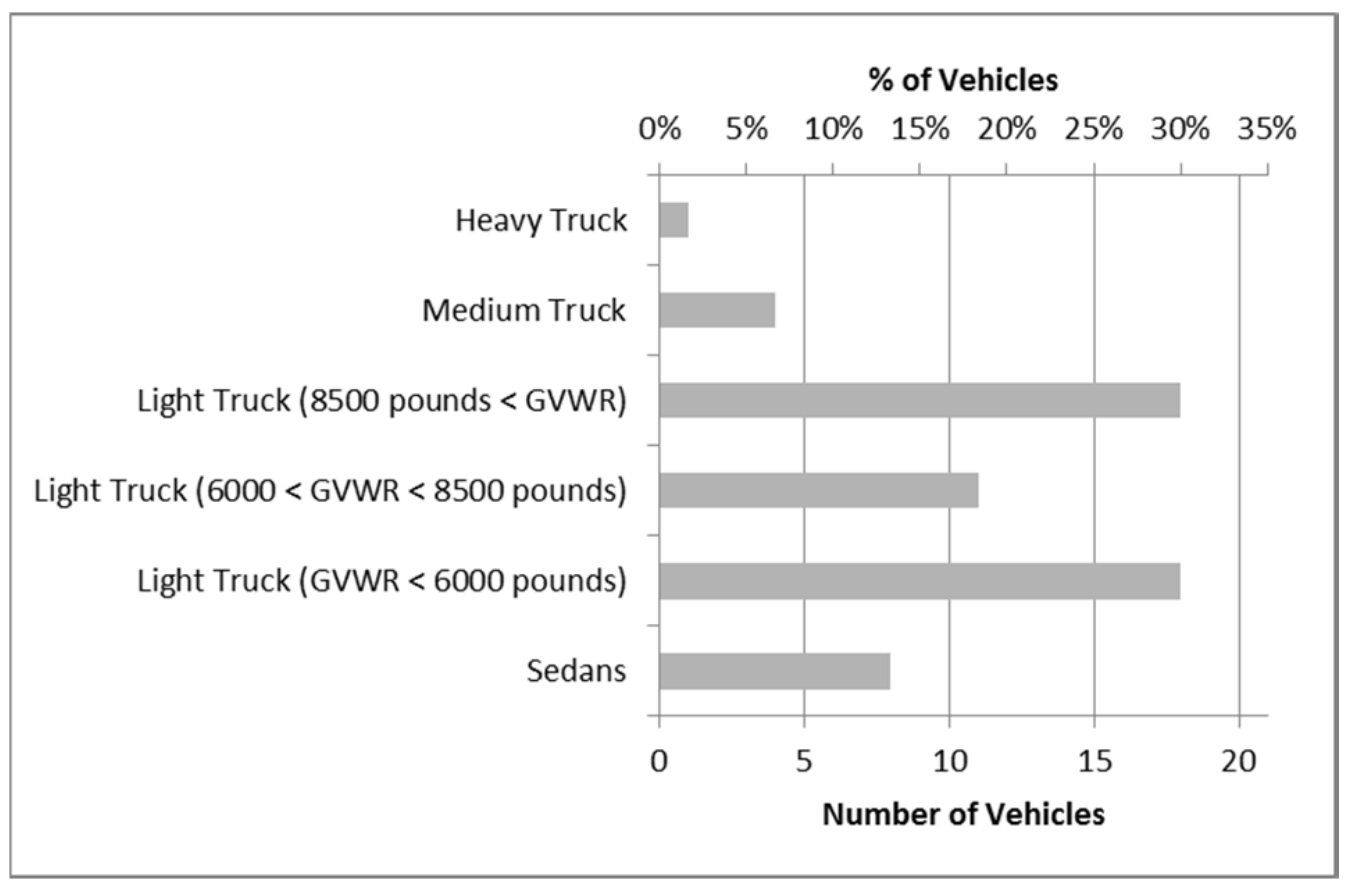

Figure 2. Vehicle type distribution for vehicles with data loggers.

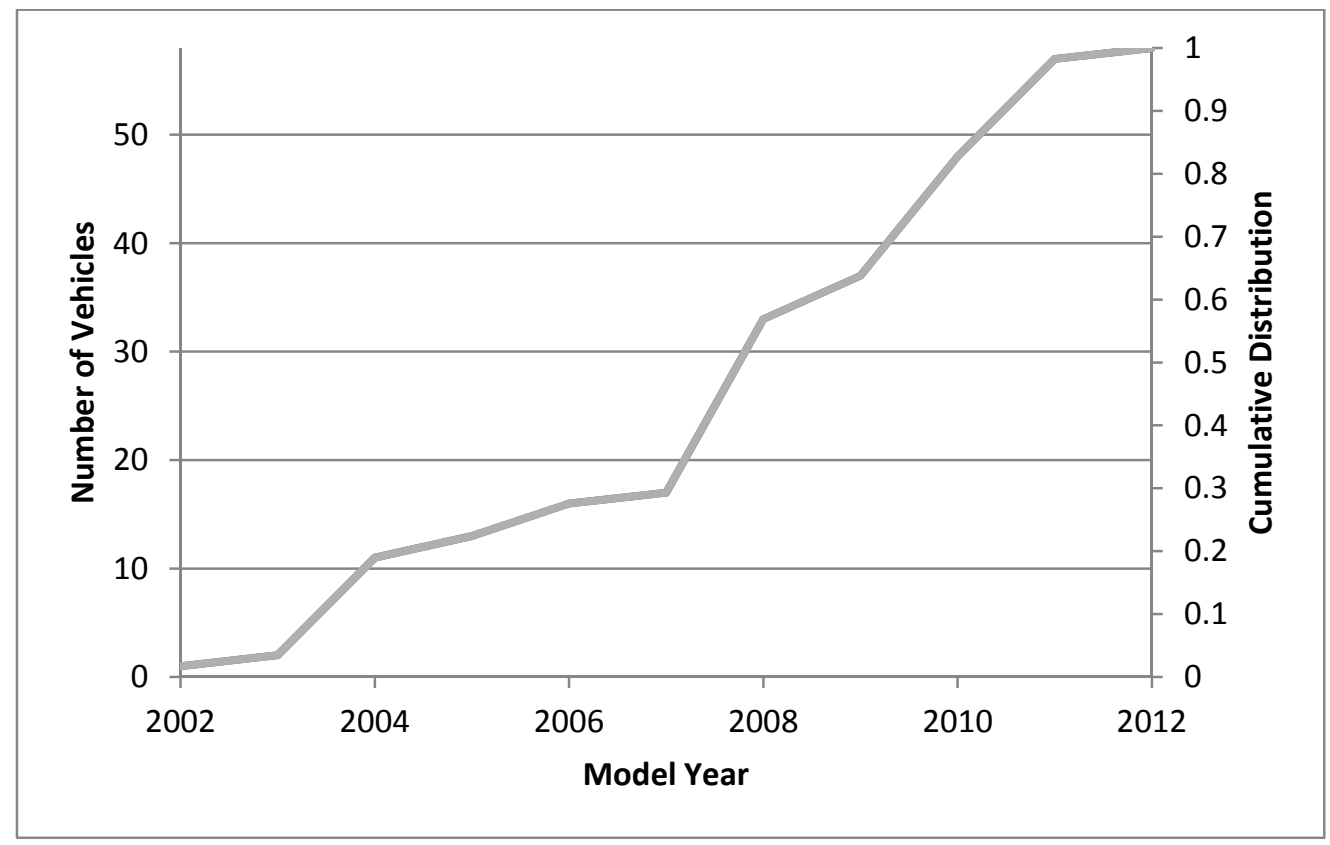

Figure 3. Model year distribution for vehicles with data loggers. 


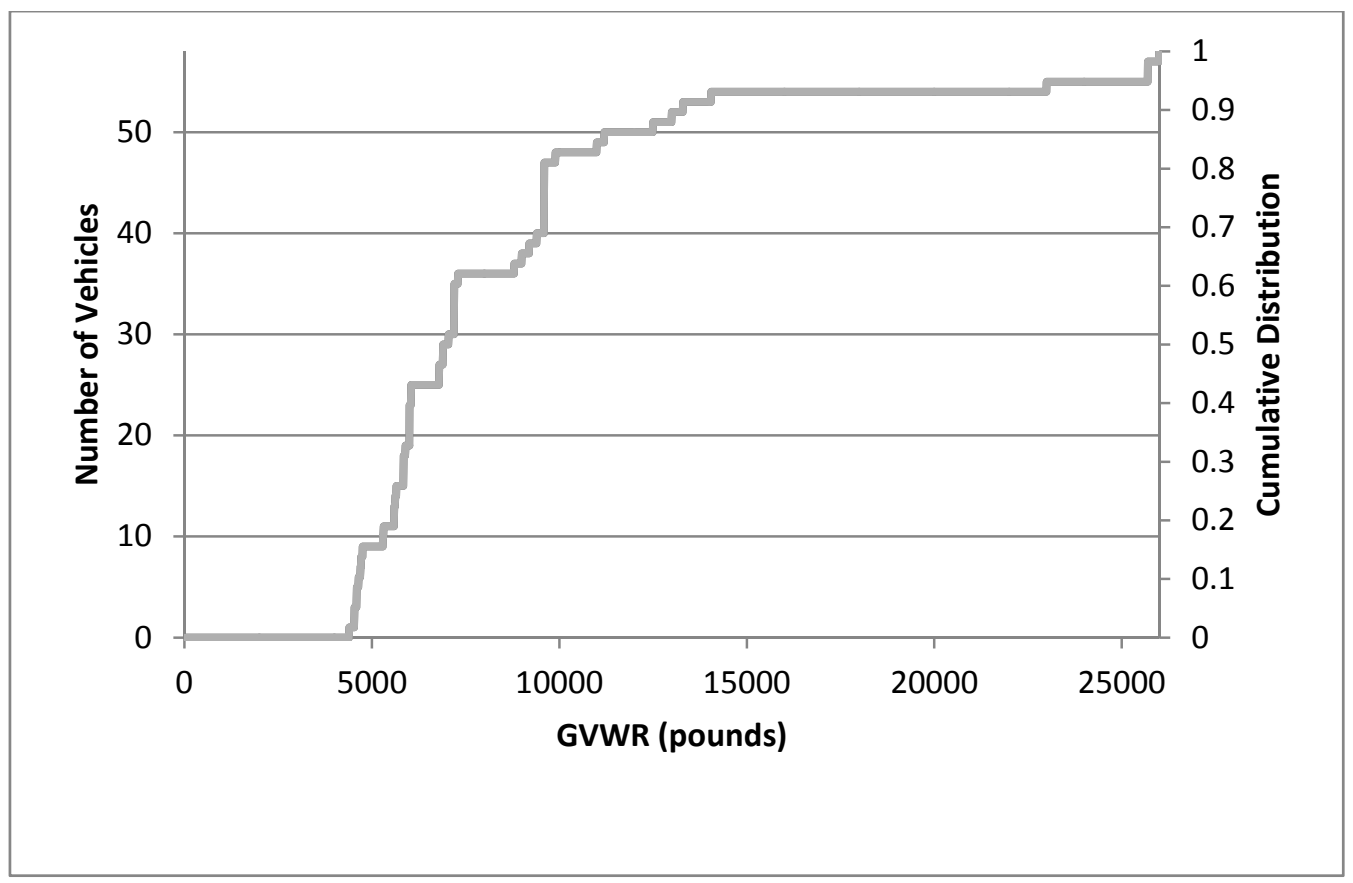

Figure 4. GVWR distribution for vehicles with data loggers.

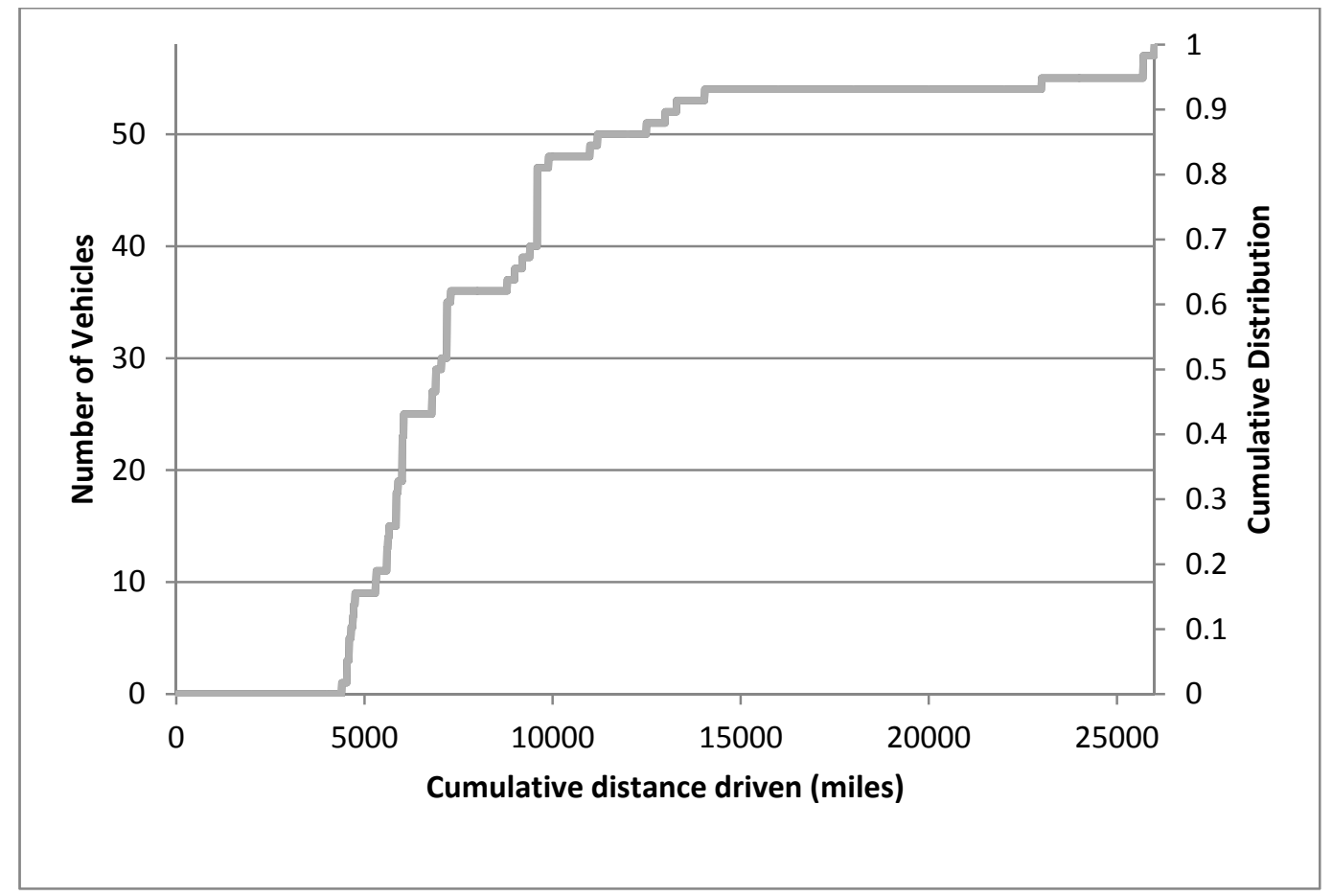

Figure 5. Distribution of cumulative distance driven for vehicles with data loggers. 


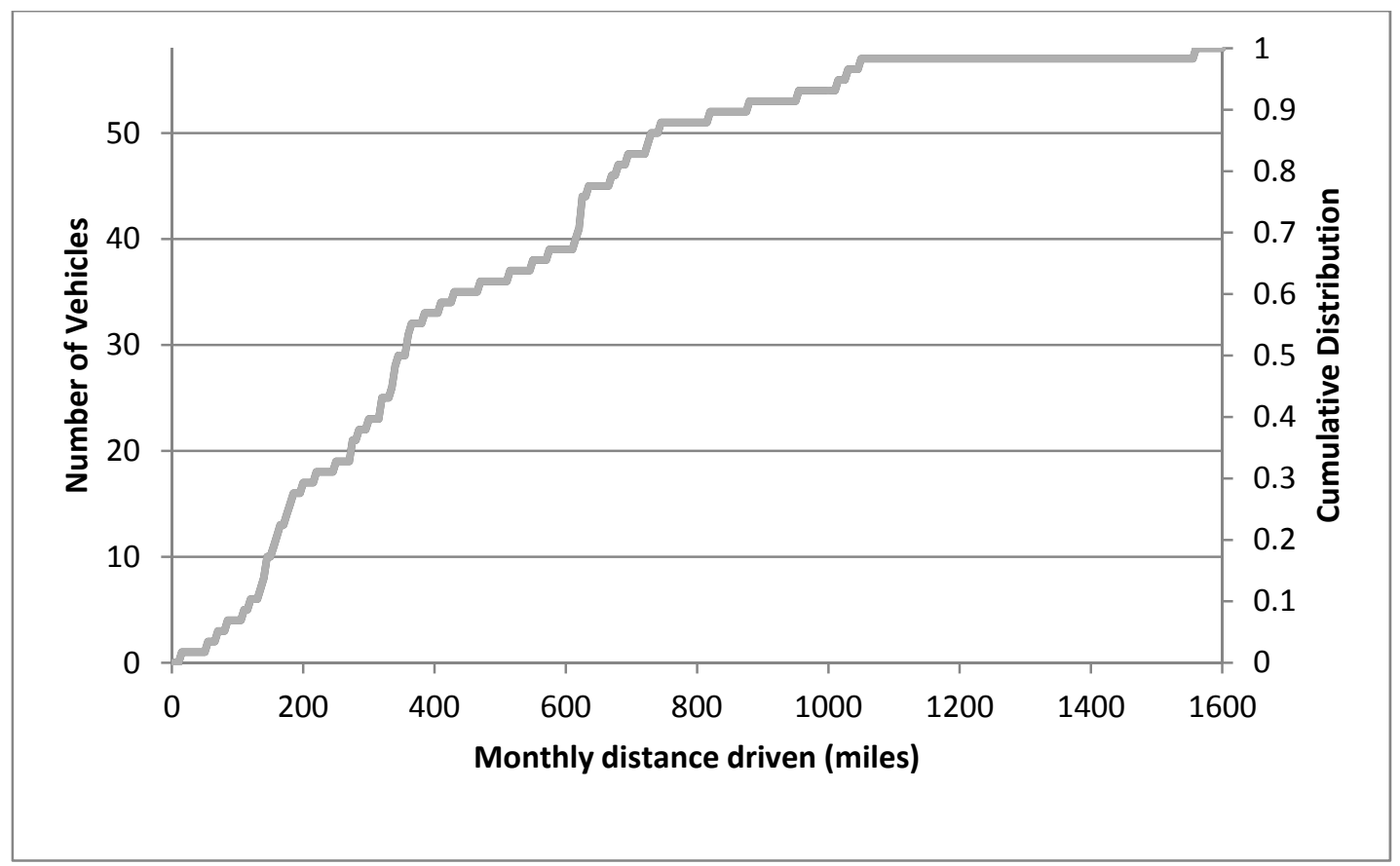

Figure 6. Distribution of monthly distance driven for vehicles with data loggers.

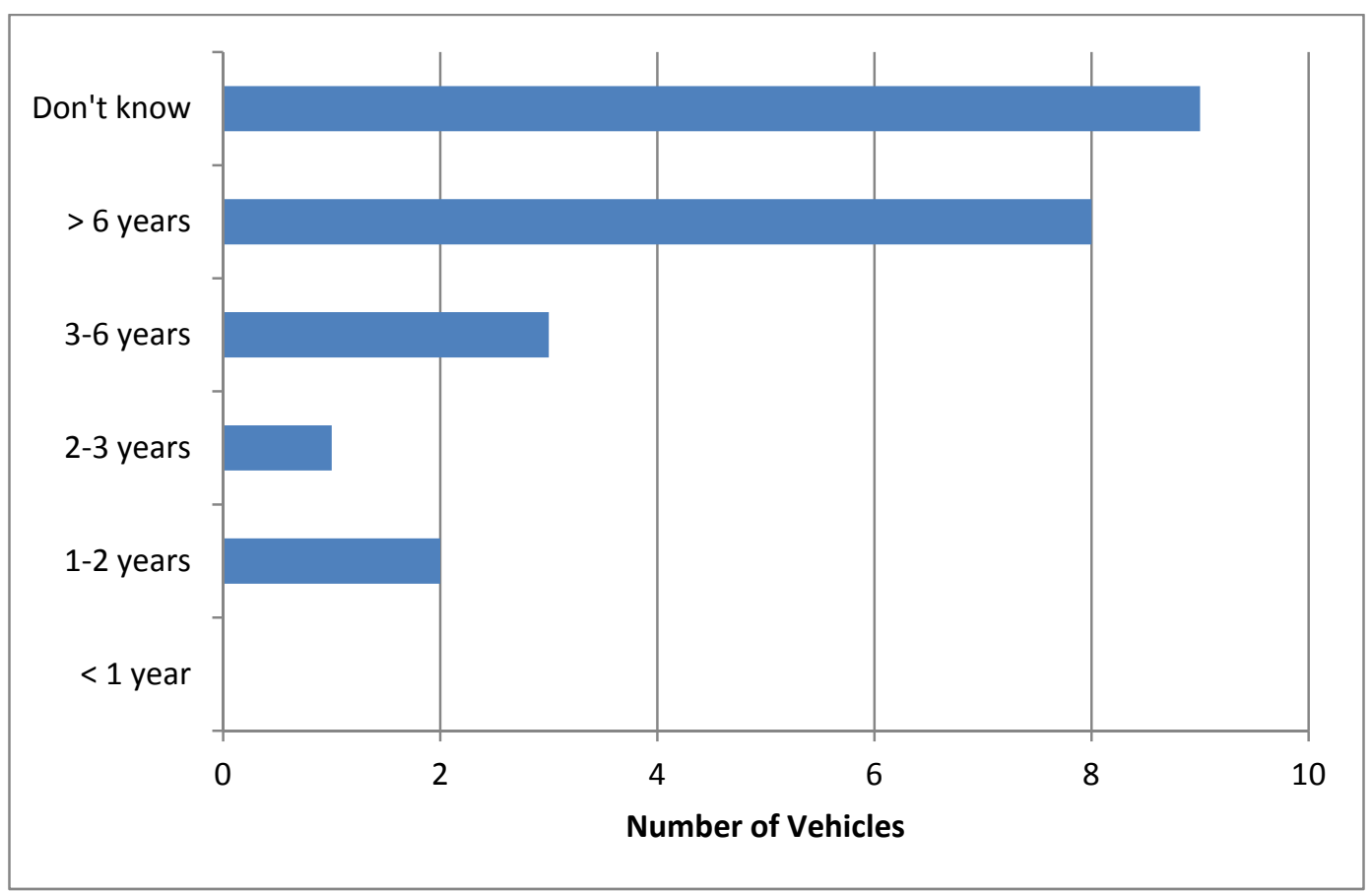

Figure 7. Survey results for vehicles with data loggers: How much longer do you expect to keep the vehicle in your fleet? 


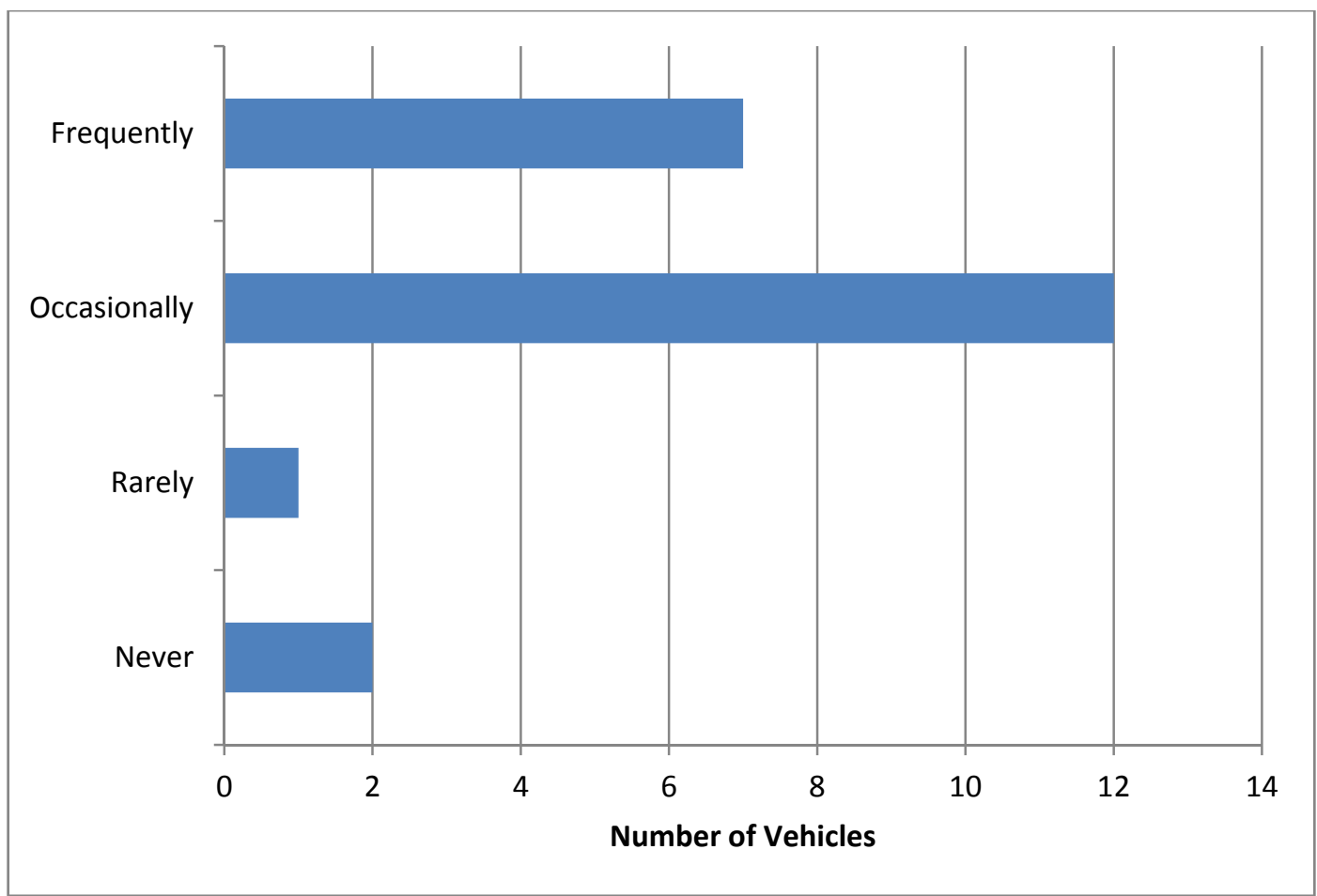

Figure 8. Survey results for vehicles with data loggers: Is this vehicle used off-base?

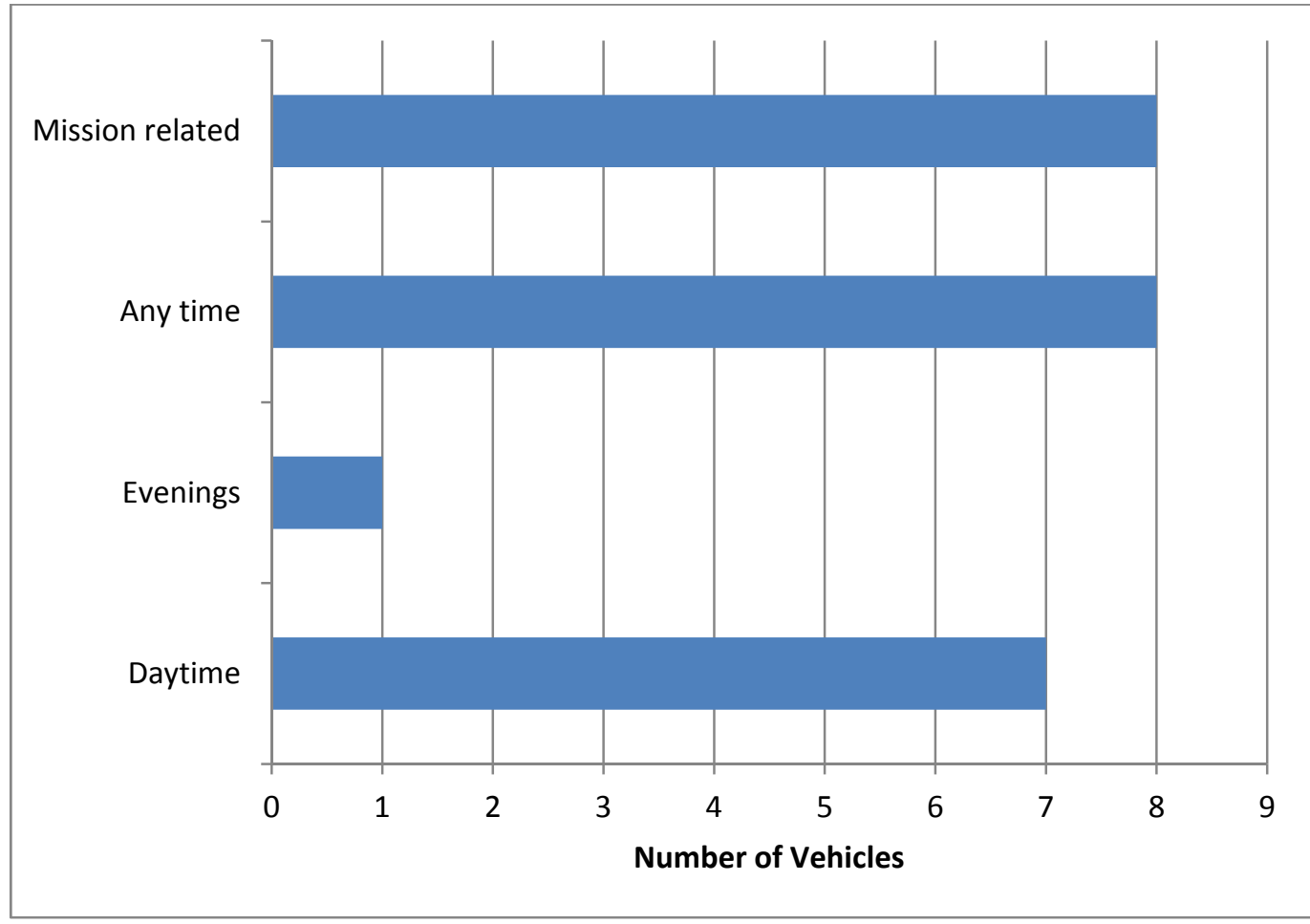

Figure 9. Survey results for vehicles with data loggers: Are the vehicles used during specific hours or at any time during the day? 
Table 1. Fleet evaluation.

\begin{tabular}{lccc}
\multicolumn{1}{c}{ Vehicle Mission } & $\begin{array}{c}\text { Study } \\
\text { Vehicles }\end{array}$ & $\begin{array}{c}\text { Total Fleet } \\
\text { Reported }\end{array}$ & $\begin{array}{c}\text { Percentage } \\
\text { Studied }\end{array}$ \\
\hline Pool Vehicles & 35 & 633 & $5.5 \%$ \\
Enforcement Vehicles & & & $0 \%$ \\
Support Vehicles & 19 & 458 & $4.2 \%$ \\
Transport Vehicles & 6 & 229 & $2.6 \%$ \\
Specialty Vehicles & & 5 & $0 \%$ \\
Shuttle/Bus & & 57 & $0 \%$ \\
Low Speed Vehicles & & 23 & $0 \%$ \\
Total Fleet Vehicles & 60 & 1,405 & $4.3 \%$ \\
\hline
\end{tabular}

\subsection{Data Collection}

Individual privacy concerns exist when monitoring vehicle movement with data loggers. Data collection occurs through vehicle identification as identified by Intertek, data logger number, and vehicle identification number (VIN) or agency-assigned vehicle number. Intertek receives no information related to the vehicle operator and provides no raw data to the fleet managers. In this manner, Intertek does not collect, analyze, or report on individual driving habits.

\subsubsection{Data Logger}

Non-intrusive data loggers produced by InTouchMVC ${ }^{2}$ and depicted in Figure 10 were installed into the vehicle's onboard diagnostic port to collect and transmit the relevant data. Installation of the data logger and manual recording of information about the vehicle that ties the logger and vehicle together in the data typically takes less than 5 minutes. Once installed and activated (during vehicle use), the data loggers transmit vehicle information every minute during vehicle operation by cellular communication to the data center.

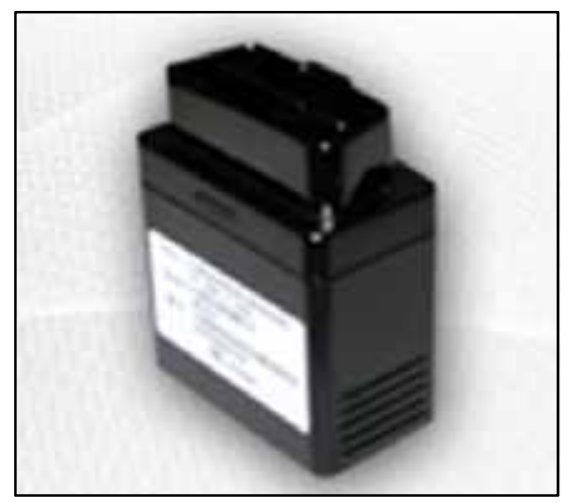

Figure 10. InTouchMVC data logger. ${ }^{3}$

Intertek maintains the data logger's connectivity and verifies data transmission weekly. Missing data (reported as "null" values) are frequently the result of lost global positioning system reception, logger

\footnotetext{
${ }^{2}$ www.intouchmvc.com [accessed July 30, 2014].

${ }^{3}$ ibid.
} 
device removal, or extended periods in regions with insufficient cellular reception. Intertek filters the vehicle and data logger information if these null values present a significant impact on the data collected and no resolution is possible. This report also identifies the statistics on this validation process.

JBLM requested and installed 60 data loggers into their fleet vehicles (i.e., 35 pool vehicles, six transport vehicles, and 19 support vehicles). JBLM removed and shipped the data loggers to Intertek at the conclusion of the data collection period.

\subsubsection{Data Captured}

Data consist of key-on events, key-off events, and position updates logged every minute while the vehicle is keyed-on. InTouchMVC fleet reporting converted these data points into records of trip events, stop events, and idle events.

From these data points, the following information was available for evaluation:

- Trip start and stop time and location

- Trip distance and duration

- Idle start time, location, and duration

- Stop start time, location, and duration.

\subsection{Data Analysis}

\subsubsection{Definitions}

Figure 11 illustrates a vehicle outing, which is comprised of trips, stops, and idle events, that may occur over one day or several days. The following list provides a definition of these terms:

1. Outing: An outing is the combination of trips and stops that begin at the home base and includes all travel until the vehicle returns home.

2. Trip: A trip begins with a key-on event and ends with the next key-off event.

3. Vehicle stop: A vehicle stop includes a key-off/key-on event pair.

4. Idle time: Idle time is the amount of time a vehicle spends stationary after a key-on event when the vehicle is not moving for a period of 3 minutes or longer.

5. Trip travel time: Trip travel time is the amount of time required to complete a trip, excluding stops but including idle time.

Definitions of additional analysis and survey terms are as follows:

1. Operating shift: Fleet manager-defined period worked

2. Study days: Days during which the data loggers are connected

3. Vehicle days: Study days during which a vehicle is used

4. Null values: Data record unusable for analysis for various reasons.

\subsubsection{Data Evaluation}

Processing the data involves removal of null values and aggregation by different spatial and temporal scales. Aggregation was by day, by trip, and by outing to produce figures showing the patterns of use. Aggregation by vehicle mission followed to characterize use for the agency fleet. Section 4 presents these results. Data were extrapolated to provide overall fleet usage and benefit analysis when fleet information was provided. Section 5 presents these benefits. Intertek observations are included in Section 6. 


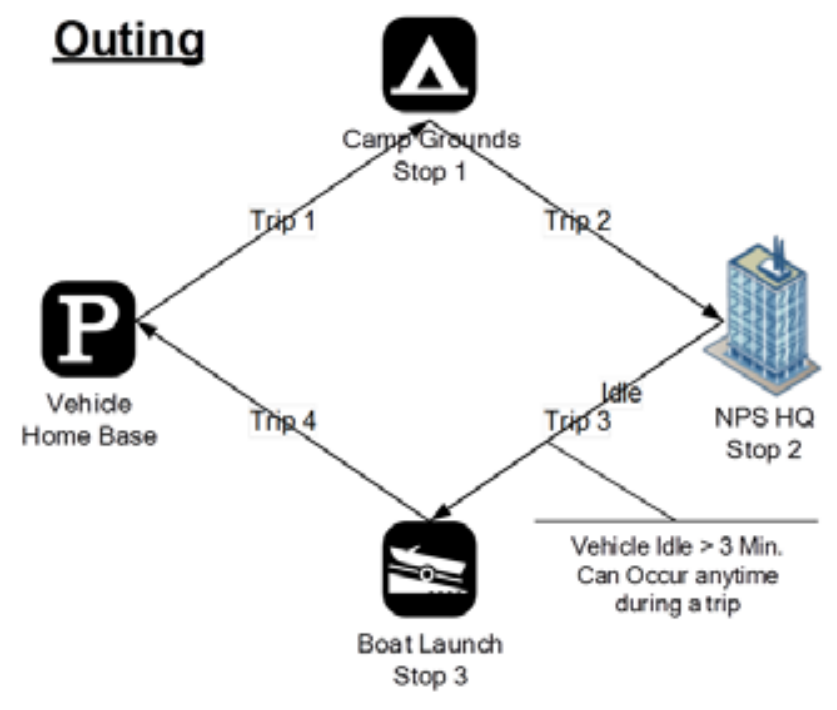

Figure 11. Vehicle outing.

Statistical data analysis uses Python 2.7 with the Matlab Plotting Library graphics environment (Matplotlib) and spatial display with ESRI ArcGIS. ${ }^{4}$ Frequency distributions summarize the travel behavior of each vehicle and vehicle mission during the study period. Rounding of the tables and figures are to three significant digits.

\section{VEHICLES}

\subsection{Vehicle Missions}

Vehicle mission is an important characteristic in the fleet study. Information used to define the vehicle mission includes the vehicle's configuration, vehicle use, classification per 40 CFR Part 600.315-82 and the U.S. Environmental Protection Agency (EPA), the participating agency use, and generally understood vehicle uses. Based on fleet information gathered, Intertek has established the following seven mission/vehicle categories for analysis, which are depicted in Figure 12:

1. Pool vehicles: A pool vehicle is any automobile (other than the low-speed vehicles identified below) manufactured primarily for use in passenger transportation, with not more than 10 passengers.

2. Enforcement vehicles: Vehicles specifically approved in an agency's appropriation act for use in apprehension, surveillance, police, or other law enforcement work. This category also includes site security vehicles, parking enforcement, and general use, but the vehicles are capable of requirements to support enforcement activities. Appendix A provides further definition.

3. Support vehicles: Vehicles assigned to a specific work function or group to support the mission of that group. Vehicles are generally passenger vehicles or light-duty pickup trucks and may contain after-market modifications to support the mission.

5. Transport vehicles: Light, medium, or heavy-duty trucks used to transport an operator and tools or equipment of a non-specific design or nature. The vehicle's uses include repair, maintenance, or delivery.

6. Specialty vehicles: Vehicles designed to accommodate a specific purpose or mission (such as ambulances, mobile cranes, and handicap controls).

\footnotetext{
${ }^{4}$ www.esri.com [accessed January 10, 2014].
} 
7. Shuttles/buses: Vehicles designed to carry more than 12 passengers and further outlined in 49 CFR 532.2.

8. Low-speed vehicles: Vehicles that are legally limited to roads with posted speed limits up to 35 or $45 \mathrm{mph}$ (depending on state law) and that have a limited load-carrying capability.

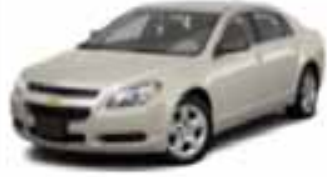

Pool Vehicle

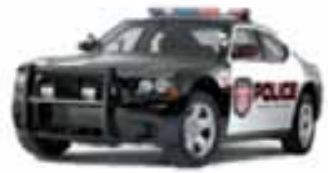

Enforcement Vehicle

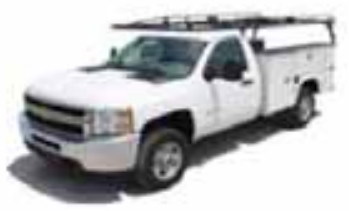

Support Vehicle

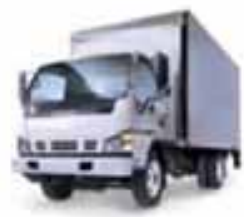

Transport Vehicle

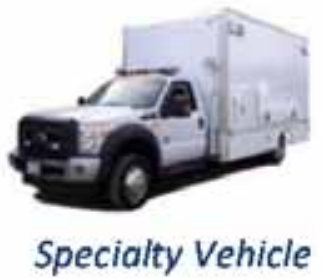

Specialty Vehicle

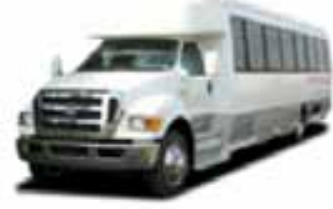

Shuttle / Bus

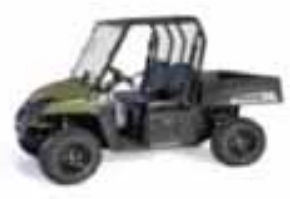

Low Speed

Vehicles

Figure 12. Vehicle missions.

\subsection{Alternative Fuel Vehicles}

As the operating agency, JBLM has a unique opportunity to plan for the adoption of BEVs and PHEVs, along with planning for supporting infrastructure. The adoption of PHEVs and BEVs is a primary goal of GSA and supports many directives in this area.

As GSA increases its certification of PHEVs and BEVs, agencies can plan for vehicle replacement through GSA for passenger vehicles and trucks. Table 2 presents the replacement requirements for fleet vehicles. Note that both the age and mileage requirements need to be met in order for the vehicle to qualify for replacement, except where noted as "or."

Table 2. GSA vehicle replacement requirements.

\begin{tabular}{|l|c|c|c|}
\hline \multirow{4}{*}{ GSA Vehicle Replacement Requirements } \\
& Fuel Type & Years & Miles \\
\hline Passenger vehicles & Gasoline or & 3 & 36,000 \\
& alternative fuel & 4 & 24,000 \\
& vehicle & 5 & Any mileage \\
& Hybrid & Any age & 75,000 \\
& Low-speed BEV & 5 & Any mileage \\
& & 6 & Any mileage \\
\hline
\end{tabular}

${ }^{5}$ http://www.gsa.gov/graphics/fas/VehicleReplacementStandardsJune2011Redux.pdf [accessed January 10, 2014]. 


\begin{tabular}{|l|c|c|c|}
\hline \multicolumn{3}{|c|}{ GSA Vehicle Replacement Requirements } \\
& Fuel Type & Years & Miles \\
\hline Light trucks 4 2 & Non-diesel & 7 & 65,000 \\
& Diesel & 8 or & 150,000 \\
& Hybrid & 7 & Any mileage \\
\hline Light trucks 4 x & Non-diesel & 7 or & 60,000 \\
& Diesel & 8 or & 150,000 \\
& Hybrid & 7 & Any mileage \\
\hline
\end{tabular}

\subsection{Battery Electric Vehicle and Plug-In Hybrid Electric Vehicle Benefits/Challenges}

BEVs are powered completely by the battery energy storage system onboard the vehicle. The Nissan LEAF is an example of a BEV. Because the BEV has no other energy source for propulsion, the range, power requirements, and mission of the needed vehicle factor greatly in purchasing decisions.

Maximizing BEV capabilities typically requires batteries more than an order of magnitude larger than the batteries in hybrid electric vehicles.

PHEV obtain their power from two energy sources. The typical PHEV configuration uses a battery and an ICE, powered by either gasoline or diesel. PHEV designs differ between manufacturers. All PHEVs have a charge-depleting (CD) mode, in which the battery discharges its stored energy to propel the vehicle, and a charge-sustaining (CS) mode (or extended range mode) that is entered after CD mode is complete, in which the battery and ICE work together to provide propulsion, while the state of charge of the battery is maintained between set limits. Some CD modes are purely electric while other vehicle designers employ the engine to supplement the battery power during the initial battery depletion to a set state of charge (usually below 50\%).

\subsubsection{Battery Electric Vehicle Benefits/Challenges}

EPA identifies the following benefits and challenges of BEVs ${ }^{6}$ :

- Energy efficient: Electric vehicles convert about 59 to $62 \%$ of electrical energy from the grid to power at the wheels, whereas conventional gasoline vehicles only convert about 17 to $21 \%$ of the energy stored in gasoline to power at the wheels.

- Environmentally friendly: PEVs emit no tailpipe pollutants, although the power plant producing the electricity may emit them. Electricity from nuclear, hydro, solar, or wind-powered plants causes no air pollutants.

- Performance benefits: Electric motors provide quiet, smooth operation and exhibit maximum torque at zero and low speeds, while also requiring less maintenance than ICEs.

- Reduce energy dependence: Electricity is a domestic energy source.

EPA also identifies challenges associated with BEVs, including the following:

- Driving range: Most BEVs can only travel about 100 to 200 miles (or less) before recharging, whereas gasoline vehicles can often travel over 300 miles before refueling and some much further.

${ }^{6}$ http://www.fueleconomy.gov/feg/evtech.shtml [accessed December 27, 2013] 
- Recharge time: Fully recharging the battery pack can take 4 to 8 hours. Even a "fast charge" to $80 \%$ capacity can take 30 minutes.

- Battery cost: The large battery packs are expensive and may need to be replaced one or more times.

- Bulk and weight: Battery packs are heavy and take up considerable vehicle space.

\subsubsection{Plug-In Hybrid Electric Vehicle Benefits/Challenges}

EPA identifies the following benefits and challenges of PHEVs ${ }^{7}$.

- Less petroleum use: PHEVs are expected to use about 40 to $60 \%$ less petroleum than conventional vehicles. Because electricity is produced primarily from domestic resources, PHEVs reduce dependence on oil.

- Fewer GHG emissions: PHEVs are expected to emit fewer GHG emissions than conventional vehicles, but, as with BEVs, the difference depends largely on the type of power plant supplying the electricity.

- Higher vehicle costs, lower fuel costs: PHEVs will likely cost $\$ 1,000$ to $\$ 7,000$ more than comparable non-PHEVs. Fuel will cost less because electricity is much cheaper than gasoline, but the fuel savings depends on how much of the driving is done on the off-board electrical energy.

- Recharging takes time: Recharging the battery typically takes several hours. However, PHEVs do not have to be plugged in to be driven. They can be fueled solely with gasoline, but will not achieve maximum range, fuel economy, or fuel savings without charging.

- Measuring fuel economy: Because a PHEV can operate on electricity alone, gasoline alone, or a mixture of the two, EPA provides a fuel economy estimate for gasoline-only operation (CS mode), electric-only operation (all-electric CD mode), or combined gasoline and electric operation (blended CD mode).

In most cases, the PEV's retail cost is higher than a non-PEV model. This incremental purchase cost may be a fleet budget challenge; however, many original equipment manufacturers (OEMs) have offered incentives to encourage the use and adoption of BEVs and PHEVs. Some OEMs have recently reduced the vehicle cost, while also increasing vehicle range. Additionally, federal and state incentives have increased the attractiveness of purchasing a PEV. A common assumption is that increasing PEV sales will result in a reduction in this incremental purchase cost and a positive feedback loop will ensue.

\subsection{Plug-In Hybrid Electric Vehicle Availability}

GSA provides a summary of the light and medium-duty passenger vehicles that are available for lease or purchase through the GSA portal ${ }^{8}$, although not all BEVs and PHEVs currently on the market are 'certified' to be GSA replacements. Vehicles not on the GSA list of 'certified' vehicles require an agency to self-certify a functional need or alternative measures for exemptions. Tables 3 and 4 summarize the vehicles that may be suitable replacements and are certified replacements through GSA. Note that the "CD/CS" column provides the EPA fuel economy values for CD and CS modes. The fuel economy of CD mode is provided in units of miles-per-gallon-of-gasoline-equivalent (MPGe). This metric allows for electricity consumption during CD mode to be compared with fuel consumption during CS mode (or against conventional vehicles). The Nissan Leaf and Mitsubishi i-MiEV are not included in the alternative fuel guide for 2014, but they have appeared in previous guides.

\footnotetext{
${ }^{7}$ http://www.fueleconomy.gov/feg/phevtech.shtml [accessed July 19, 2013].

${ }^{8}$ http://www.gsa.gov/portal/content/104211 [accessed August 1, 2014].
} 
Replacement is dependent on vehicle configuration characteristics and vehicle mission. Further evaluation related to vehicle purpose, mission, and need should be completed.

Tables 5 through 8 provide summaries of PHEVs and BEVs either currently available or near commercialization in both passenger cars and pickup trucks, but do not appear on the GSA 'certified' vehicle list. These vehicles may qualify for use by the agency through demonstrating a functional need.

Table 3. GSA-certified PHEVs.

\begin{tabular}{lcccc}
\multicolumn{1}{c}{ Make/Model } & GSA Class & Type & CD/CS & GSA Incremental Price \\
\hline Chevrolet Volt & Sedan, Subcompact & PHEV & $98 \mathrm{MPGe} / 37 \mathrm{mpg}$ & $\$ 17,087.18$ \\
Ford C-MAX Energi & Sedan, Subcompact & PHEV & $100 / 38 \mathrm{mpg}$ & $\$ 14,899.52$ \\
Ford Fusion Energi & Sedan, Compact & PHEV & $100 / 38 \mathrm{mpg}$ & $\$ 19,289.99$ \\
\hline
\end{tabular}

Table 4. GSA-certified BEVs.

\begin{tabular}{ccccc} 
Make/Model & GSA Class & Type & City/Highway & GSA Incremental Price \\
\hline Ford Focus Electric & Sedan, Subcompact & BEV & $110 / 99 \mathrm{MPGe}$ & $\$ 16,573.09$ \\
\hline
\end{tabular}

Note that EPA differs in vehicle class. EPA identifies the Volt as a compact, the C-MAX Energi as a midsize, the Fusion Energi as a midsize, and the Focus as a compact. ${ }^{9}$

Table 5. OEM PHEV cars and availability.

\begin{tabular}{ccc} 
Make & Model & $\begin{array}{c}\text { Model Year/Estimated Year } \\
\text { for Commercialization }\end{array}$ \\
\hline Chevrolet & Volt & 2011 \\
Ford & C-MAX Energi & 2013 \\
Ford & Fusion Energi & 2013 \\
Toyota & Prius PHEV & 2012 \\
Honda & Accord PHEV & 2014 \\
BMW & i3 w Range Extender & 2014 \\
BMW & i8 & 2015 (estimate) \\
Audi & A3 eTron PHEV & 2015 (estimate) \\
Volvo & V60 Plug-in & 2016 (estimate) \\
\hline
\end{tabular}

Table 6. OEM BEV cars and availability.

\begin{tabular}{ccc} 
Make & Model & $\begin{array}{c}\text { Model Year/Estimated Year } \\
\text { for Commercialization }\end{array}$ \\
\hline Nissan & Leaf & 2011 \\
Ford & Focus Electric & 2012 \\
Tesla & Model S & 2012 \\
Fiat & $500 \mathrm{e}$ & 2013 \\
Honda & Fit EV & 2013 \\
BMW & i3 & 2014 \\
\hline
\end{tabular}

\footnotetext{
${ }^{9}$ http://www.fueleconomy.gov/feg/Find.do?action=sbs\&id=34130 [accessed August 1, 2014]
} 


\begin{tabular}{ccc}
\hline Make & Model & $\begin{array}{c}\text { Model Year/Estimated Year } \\
\text { for Commercialization }\end{array}$ \\
\hline Chevrolet & Spark EV & 2014 \\
smart & ED & 2014 \\
Kia & Soul EV & 2014 (estimate) \\
Mercedes-Benz & B-Class ED & 2015 (estimate) \\
Tesla & Model X & 2015 (estimate) \\
Volkswagen & Golf e-Golf & 2015 (estimate) \\
Volvo & C30 Electric & 2016 (estimate) \\
\hline
\end{tabular}

Table 7. OEM PHEV trucks, vans, and availability.

\begin{tabular}{ccc} 
Make & Model & $\begin{array}{c}\text { Model Year/Estimated Date for } \\
\text { Commercialization }\end{array}$ \\
\hline Via & VTRUX VR300 & 2013 \\
Mitsubishi & Outlander PHEV & 2015 (estimate) \\
Land Rover & Range Rover Sport & 2016 (estimate) \\
\hline
\end{tabular}

Table 8. OEM BEV trucks, vans, and availability.

\begin{tabular}{ccc} 
Make & Model & $\begin{array}{c}\text { Model Year/Estimated Date for } \\
\text { Commercialization }\end{array}$ \\
\hline Toyota & RAV4 EV & 2013 (California only - \\
& & elsewhere 2015 estimate) \\
Nissan & eNV200 & 2015 (estimate) \\
\hline
\end{tabular}

As further indication of the expanding market for PEVs, companies are offering after-market vehicle upgrades involving the addition of plug-in capabilities to OEM vehicles. For example, Echo Automotive headquartered in Scottsdale, Arizona offers a “...low-cost, bolt-on, plug-in hybrid system that can quickly be installed on new or existing fleet vehicles to increase fuel efficiency and decrease operating costs - all without affecting the OEM power train or requiring costly infrastructure." ${ }^{10}$ Options such as this company's conversions might be of benefit to the passenger vans identified in the JBLM fleet, but for which no replacement PEV is currently available.

\subsection{Plug-In Electric Vehicle Charging}

Refueling electric vehicles presents some challenges and some opportunities not encountered when refueling petroleum-fueled vehicles. Recharging the battery of a PHEV follows the same methodology as that for BEVs. This section provides basic information on recharging PEVs.

\subsubsection{Electric Vehicle Supply Equipment Design}

3.5.1.1 Charging Components. Electric vehicle supply equipment (EVSE) stations deliver electric power from the utility to the applicable charge port on the vehicle. Figure 13 illustrates the primary components of a typical alternating current (AC) Level 2 EVSE.

\footnotetext{
${ }^{10} \mathrm{http}: / /$ www.echoautomotive.com/index.php?option=com_content\&view=article\&id=8 [accessed July 14, 2014].
} 


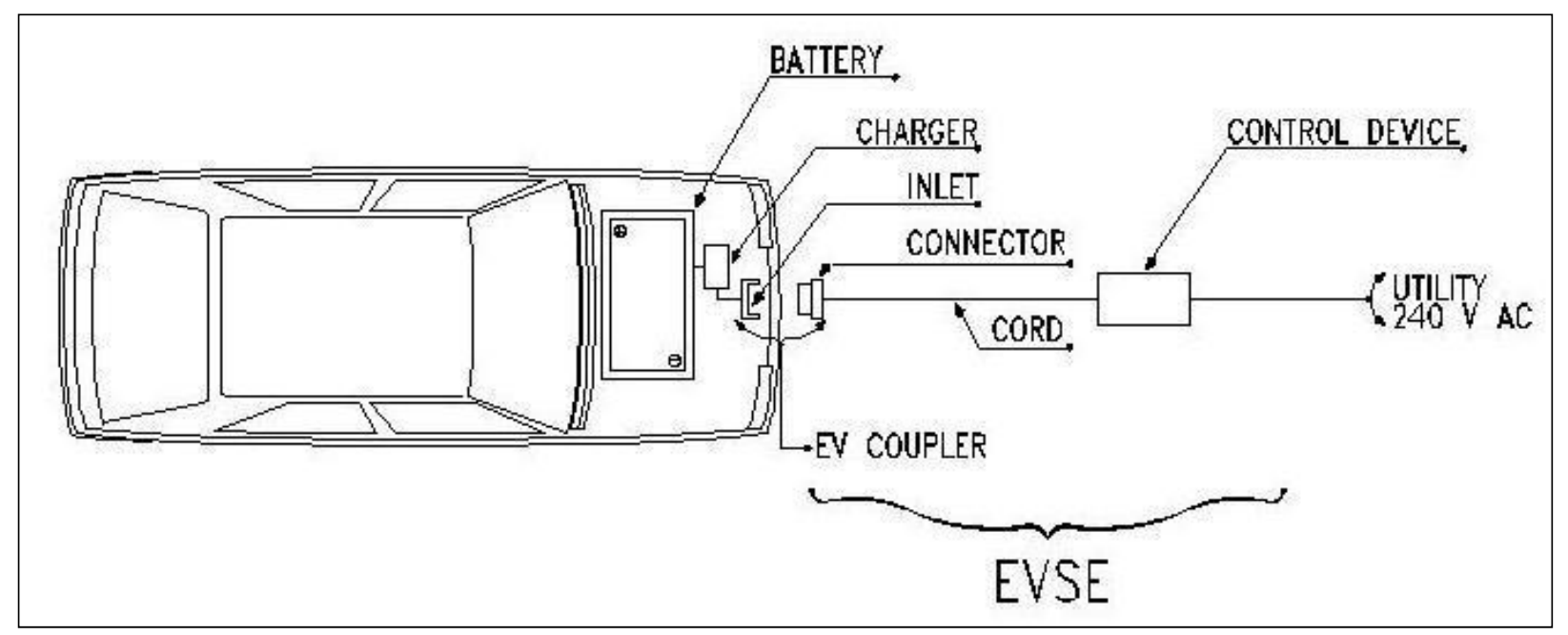

Figure 13. AC Level 2 charging diagram. ${ }^{11}$

The electric utility delivers AC current to the charging location. The conversion from AC to the direct current (DC) electricity necessary for battery charging can occur either on or off board the vehicle. Section 3.5.1.2 provides further explanation of the different EVSE configurations. For onboard conversion, AC current flows through the PEV inlet to the onboard charger. The charger converts AC to the DC current required to charge the battery. A connector attached to the EVSE inserts into a PEV inlet to establish an electrical connection to the PEV for charging and information/data exchange. Off-board conversion, also known as DC charging, proceeds in a similar manner except that the AC to DC conversion occurs in a charger that is off board the vehicle and, thus, bypasses any onboard charger. For both AC and DC charging, the PEV's battery management system on board the vehicle controls the battery rate of charge, among other functions. All current PEVs have an onboard charger; some BEVs (but no PHEVs currently) accommodate DC charging.

3.5.1.2 Charging Configurations and Ratings. The Society of Automotive Engineers standardized the requirements, configurations, and equipment followed by most PEV suppliers in the United States in the J1772 Standard. Figure 14 summarizes these attributes and the estimated recharge times. Actual recharge times depend on the onboard equipment, including the charger, battery, and battery management system.

Most PEV manufacturers supply an AC Level 1 cordset with the vehicle, which provides sufficient capabilities for some drivers, but more typically provides an emergency backup capability because of the long recharge times. AC recharging capabilities found in the public arena more typically are AC Level 2. Figure 15 depicts a typical J1772-compliant inlet and connector for both AC Levels 1 and 2.

The J1772 standard also identifies requirements for DC charging. For PEVs that accept both AC and DC inputs, the SAE approved a single connector and inlet design. Figure 16 shows this connector, which is colloquially known as the J1772 "combo connector."

Some PEVs delivered in the United States prior to the approval of the J1772 standard for DC charging employed the CHAdeMO standard for connector and inlet design. Figure 17 shows this connector. EVSE units that are either J1772-compliant or CHAdeMO-compliant are both known as DC fast chargers (DCFCs).

\footnotetext{
${ }^{11}$ http://www.theevproject.com/downloads/documents/Electric\%20Vehicle\%20Charging\%20Infrastructure\%20Deployment $\% 20$ Guidelines $\% 20$ for $\% 20$ the $\% 20$ Greater\%20Phoenix\%20Area\%20Ver\%203.2.pdf [accessed January 15, 2014].
} 


\begin{tabular}{|c|c|c|c|}
\hline \multicolumn{4}{|c|}{ SAE Charging Configurations and Ratings Terminology } \\
\hline \multirow{5}{*}{$\begin{array}{l}\text { AC level } 1 \\
\left.\text { (SAE } J 1772^{\text {mM }}\right)\end{array}$} & PEV includes on-board charger & \multirow[t]{5}{*}{ *DC Level 1} & EVSE includes an off-board charger \\
\hline & $\begin{array}{l}120 \mathrm{~V}, 1.4 \mathrm{~kW} @ 12 \mathrm{amp} \\
120 \mathrm{~V}, 1.9 \mathrm{~kW} @ 16 \mathrm{amp}\end{array}$ & & $200-450 \mathrm{~V} \mathrm{DC}$, up to $36 \mathrm{~kW}(80 \mathrm{~A})$ \\
\hline & Est. charge time: & & Est. charge time ( $20 \mathrm{~kW}$ off-board charger): \\
\hline & PHEV: $7 \mathrm{hrs}\left(\mathrm{SOC}^{*}-0 \%\right.$ to full) & & PHEV: $22 \mathrm{~min}$. (SOC* $-0 \%$ to $80 \% 6$ ) \\
\hline & BEV: $17 \mathrm{hrs}$ (SOC-20\% to full) & & BEV: 1.2 hrs. (SOC $-20 \%$ to $100 \%)$ \\
\hline \multirow[t]{11}{*}{$\begin{array}{l}\text { AC level } 2 \\
\text { (SAE J1772 }\end{array}$} & $\begin{array}{l}\text { PEV includes on-board charger (see below for different } \\
\text { types) }\end{array}$ & \multirow[t]{6}{*}{ *DC Level 2} & EVSE includes an off-board charger \\
\hline & $240 \mathrm{~V}$, up to $19.2 \mathrm{~kW}(80 \mathrm{~A})$ & & $200-450 \mathrm{~V} \mathrm{DC}$, up to $90 \mathrm{~kW}(200 \mathrm{~A})$ \\
\hline & Est. charge time for $3.3 \mathrm{~kW}$ on-board charger & & Est. charge time ( $45 \mathrm{~kW}$ off-board charger): \\
\hline & PEV: 3 hrs (SOC* $-0 \%$ to full) & & PHEV: $10 \mathrm{~min}$. (SOC* $-0 \%$ to $80 \%$ ) \\
\hline & BEV: $7 \mathrm{hrs}$ (SOC $-20 \%$ to full) & & BEV: $20 \mathrm{~min}$. (SOC $-20 \%$ to $80 \%$ ) \\
\hline & Est. charge time for $7 \mathrm{~kW}$ on-board charger & & \\
\hline & PEV: 1.5 hrs (SOC* $-0 \%$ to full) & \multirow[t]{6}{*}{ *DC Level 3 (TBD) } & EVSE includes an off-board charger \\
\hline & BEV: 3.5 hrs (SOC $-20 \%$ to full) & & $200-600 \mathrm{~V} \mathrm{DC}$ (proposed) up to $240 \mathrm{~kW}(400 \mathrm{~A})$ \\
\hline & Est. charge time for $20 \mathrm{~kW}$ on-board charger & & Est. charge time ( $45 \mathrm{~kW}$ off-board charger): \\
\hline & PEV: $22 \mathrm{~min}$. (SOC* $-0 \%$ to full) & & BEV (only): $<10 \mathrm{~min}$. (SOC* $-0 \%$ to $80 \%$ ) \\
\hline & BEV: $1.2 \mathrm{hrs}$ (SOC $-20 \%$ to full) & & \\
\hline •AC Level 3 (TBD) & $>20 \mathrm{~kW}$, single phase and 3 phase & & \\
\hline \multicolumn{4}{|c|}{$\begin{array}{l}\text { "Not finalized } \\
\text { Voltages are nominal configuration voltages, not coupler ratings } \\
\text { Rated Power is at nominal configuration operating voltage and coupler rated current } \\
\text { Ideal charge times assume } 90 \% \text { efficient chargers, } 150 \mathrm{~W} \text { to } 12 \mathrm{~V} \text { loads and no balancin }\end{array}$} \\
\hline \multicolumn{4}{|c|}{$\begin{array}{l}\text { Notes: } \\
\text { 1) BEV ( } 25 \mathrm{kWh} \text { usable pack size) charging always starts at } 20 \% \mathrm{SOC} \text {, faster than a } \\
100 \%\end{array}$} \\
\hline
\end{tabular}

Figure 10. Society of Automotive Engineers charging configurations and ratings terminology. ${ }^{12}$

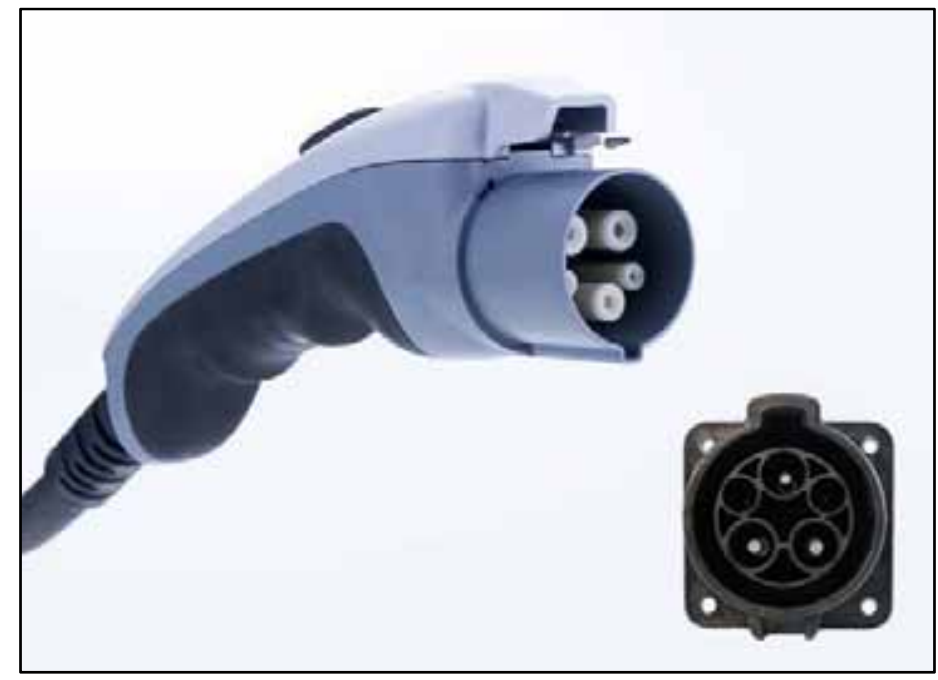

Figure 11. J1772 connector and inlet. ${ }^{13}$

${ }^{12}$ http://www.sae.org/smartgrid/chargingspeeds.pdf [accessed January 15, 2014].

${ }^{13}$ http://carstations.com/types/j09 [accessed January 15, 2014]. 

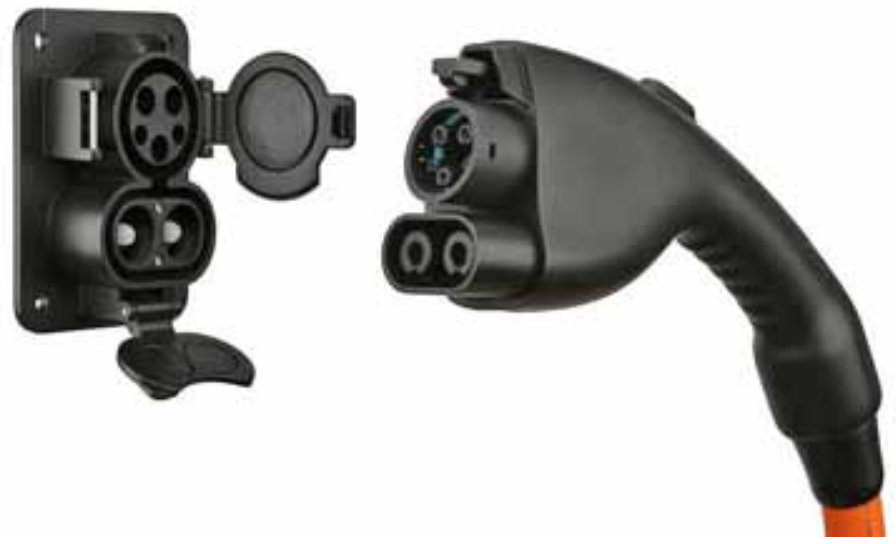

Figure 12. J1772-compliant combo connector. ${ }^{14}$

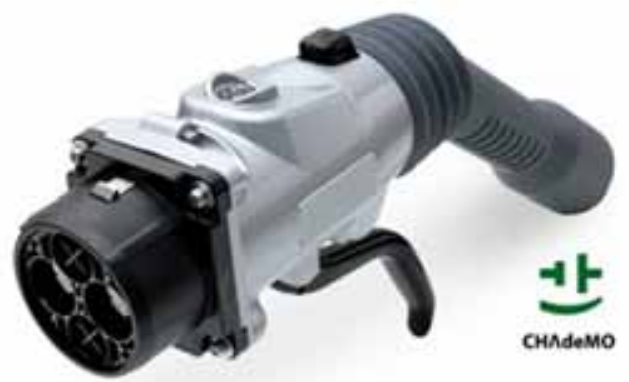

Figure 13. CHAdeMO-compliant connector. ${ }^{15}$

The presence of the two separate standards for DC charging presents challenges for vehicle owners to ensure that the EVSE accessed provides the appropriate connector for their vehicle inlet. Not all PEV suppliers include DC charging options. BEV suppliers more typically provide DC inlets than PHEV suppliers, because the rapid recharging provides opportunities for expanded vehicle range with minimal operator wait times. PHEV operators can rely on the gasoline drive in the event they deplete the vehicle's battery; at present, no PHEV on the market or near commercialization has DC charging capability (although the Mitsubishi Outlander PHEV is rumored to be offering DC charging capability as an option). It is noted that DC Level 1 and DC Level 2 charging are commonly combined and labeled DCFC.

Because the battery of a BEV is typically much larger than that of a PHEV, recharge times are longer (see Figure 7). BEVs that see daily mileage near the limits of the advertised range do better when recharged using AC Level 2 EVSE or DCFC, because AC Level 1 recharge times are usually extensive. PHEVs, on the other hand, generally can use AC Level 1 EVSE for overnight charging to ensure a fully charged battery at the start of daily use. AC Level 2 EVSE units provide greater range in the shortest amount of time when intermediate or opportunity charging. DCFC provides the fastest recharge capability for those vehicles equipped with DCFC inlets.

\footnotetext{
${ }^{14}$ http://www.zemotoring.com/news/2012/10/sae-standardizes-j1772-fast-dc-charging-up-to-100-kw [accessed January 15, 2014].

${ }^{15}$ https://radio.azpm.org/p/azspot/2012/5/10/1632-electric-cars/ [accessed January 15, 2014].
} 


\subsubsection{Electric Vehicle Supply Equipment Stations}

AC Level 2 charging is the predominant rating of publicly accessible EVSE because of its wide acceptance by auto manufacturers and faster recharge times than AC Level 1. Purchase and installation costs are more manageable than DCFCs and less space is required. There are several manufacturers of AC Level 2 equipment and the agency should review brands for comparison purposes. Figure 18 provides an example of a public AC Level 2 EVSE unit. ${ }^{16}$

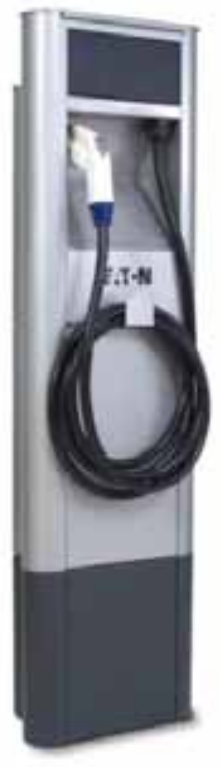

Figure 14. Public AC Level 2 unit.

DCFCs also are available from several manufacturers. Figure 19 illustrates one such charger. ${ }^{17}$ This particular unit uses the CHAdeMO connector standard.

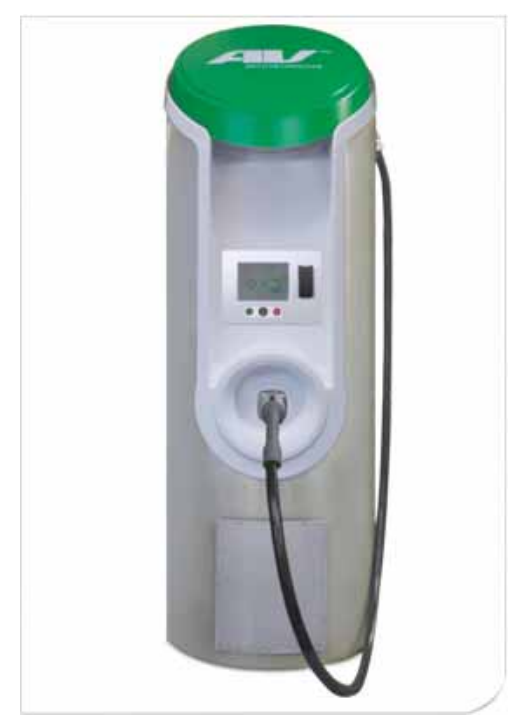

Figure 15. Public DCFC unit.

${ }^{16}$ www.eaton.com/ [accessed January 29, 2014].

${ }^{17} \mathrm{http}$ ://evsolutions.avinc.com/products/public_charging/public_charging_b [Accessed April 16, 2014]. 
In general, installation costs are higher for DCFC because of the higher voltage requirements and the inclusion of the AC to DC converter and other safety and design features. Costs for both types are highly dependent on site characteristics such as distance to the nearest power source, asphalt or concrete cutting and repair, conduit requirements, and payment systems, if any.

Payment and equipment control systems included by some suppliers provide the potential for use by privately owned vehicles for a fee, but allow agency fleet vehicle use without direct payment. These systems allow for accurate record keeping of vehicle charging requirements.

\section{JOINT BASE LEWIS McCHORD ANALYSIS}

Sixty vehicles belonging to four different fleet managers were included in the study at JBLM. The specific requirements of each fleet manager necessitate that first these data be analyzed by fleet then followed by aggregating across all vehicles.

\subsection{Analysis Results - 6th MP Group}

This section summarizes and aggregates data collection for the $6^{\text {th }}$ MP Group. The details of each vehicle monitored are included in Appendix B. Appendix F presents the full detailed analysis.

The $6^{\text {th }}$ MP Group fleet contains 20 vehicles. Table 9 provides a summary of all vehicles in this fleet by mission type and vehicle type. Three vehicles were monitored as part of this study, including one SUV, one minivan, and one pickup truck.

Table 9. 6th MP Group total fleet summary.

\begin{tabular}{ccccccccccc} 
& & & & & & & \multicolumn{3}{c}{ Pickup } & MD or \\
Sedan & Sedan & Sedan & & Mini & Cargo & Pass. & or LD & HD \\
Mission & Compact & Midsize & Large & SUV & -van & Van & Van & Truck & Truck & Total \\
\hline $\begin{array}{c}\text { Pool } \\
\text { Other }\end{array}$ & 3 & 3 & 5 & 2 & 2 & & 1 & 4 & 20 \\
\hline Total & 3 & 3 & 5 & 2 & 2 & & 1 & 4 & 0 \\
\hline
\end{tabular}

\subsection{1 $\quad 6^{\text {th }}$ MP Group Pool Vehicles Evaluation}

Grouping the vehicles by mission creates an aggregated view of mission requirements to provide observations related to PEV replacement. All vehicles assigned to the $6^{\text {th }}$ MP Group are pool vehicles.

Pool vehicles are typically light-duty motor vehicles for use in passenger transportation, with not more than 10 passengers. Pool missions can vary by agency, location, and jurisdiction; however, they typically utilize sedans, minivans, vans, or small pickup trucks and typically do not carry specific cargo or equipment.

Incorporation of BEVs and/or PHEVs into the pool mission is a definite possibility. Pool vehicles used for shorter trips or outings qualify for BEV or PHEV replacement, while other pool vehicle activities that are associated with longer trips may require PHEV capabilities.

4.1.1.1 Summary for 6th MP Group Pool Vehicles. Appendix B provides the vehicle data sheets for each of the three pool vehicles monitored and Appendix F provides the detailed analysis that is summarized in this section. Table 10 summarizes pool travel during the study period for those days in which the vehicle was driven. Vehicle use occurred primarily between 0900 and 1900 hours daily. The vehicles monitored traveled 2,052 miles, logged 108 hours, and idled for 21 hours during the 63-day study period. 
Table 10. Pool vehicles travel summary.

\begin{tabular}{lcccc}
\hline \multicolumn{4}{c}{ Pool Vehicles Travel Summary } & \\
& $\begin{array}{c}\text { Per Day } \\
\text { Average/Peak }\end{array}$ & $\begin{array}{c}\text { Per Outing } \\
\text { Average/Peak }\end{array}$ & $\begin{array}{c}\text { Per Trip } \\
\text { Average/Peak }\end{array}$ & Total \\
\hline Travel Distance (Miles) & $22.1 / 224$ & $11.3 / 156$ & $4.5 / 83$ & 2,050 \\
Travel Time (Minutes) & $69.6 / 361$ & $35.6 / 443$ & $14.2 / 181$ & 6,477 \\
Idle Time (Minutes) & $13.6 / \mathrm{NA}$ & $7.0 / \mathrm{NA}$ & $2.8 / \mathrm{NA}$ & 1,269 \\
\hline
\end{tabular}

The distance a PEV can travel in CD mode between charge opportunities is the most important factor in considering vehicle replacement. The two most significant factors in vehicle analysis include the vehicle daily travel and vehicle outings. Section 2.3 provides the definitions of these terms. In both graphs of daily travel and outings, the distance axis is divided into 10-mile segments, with green bars indicating all travel less than 40 miles. Forty miles is a typical PHEV range in CD mode. The blue bars indicate travel between 40 and 70 miles. Seventy miles is considered to be within the BEV safe range (blue and green bars). That is, while BEV range can vary based on several factors, most BEVs provide at least 70 miles of vehicle range on a single battery charge. All travel greater than 70 miles is shown by the gray bars and indicate travel beyond the capability of a BEV. Figure 20 shows the daily travel summary for the monitored vehicles. As an example, the figure shows that almost $50 \%$ of daily travel was less than 10 miles per day.

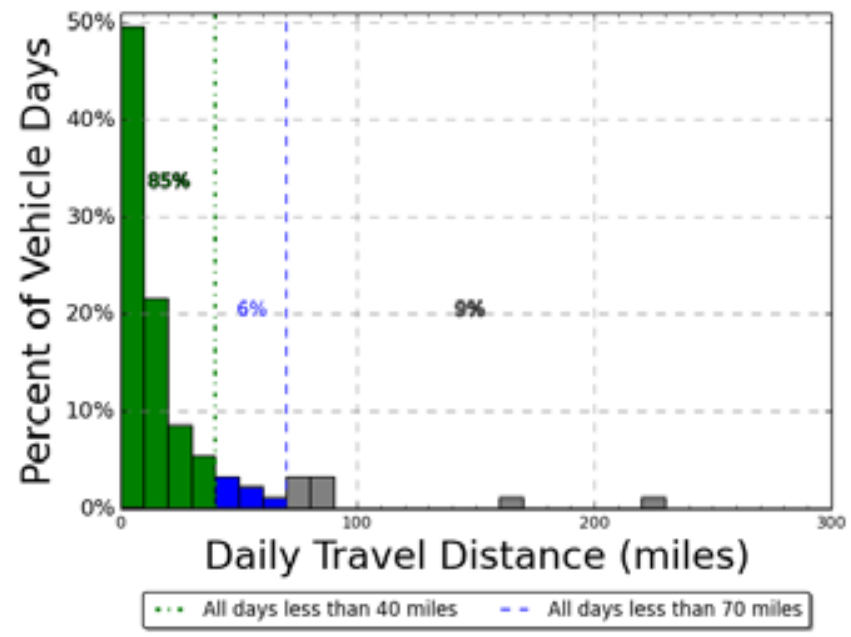

Figure 16. Pool vehicle daily travel miles (all vehicles).

The average travel distance per day when driven for pool vehicles was 22.1 miles. On $91 \%$ of these vehicle days, the daily travel was less than the 70 miles and within the BEV safe range. Meanwhile, only $9 \%$ percent of pool daily travel was greater than 70 miles, with $85 \%$ of vehicle travel days less than 40 miles. A very basic look might suggest that considering only daily travel, a fleet consisting of $91 \%$ BEVs and 9\% PHEVs would meet vehicle travel needs. However, other considerations will apply.

Figure 21 shows the outings for all vehicles. The figure notes that $75 \%$ of all vehicle outings travel was less than 10 miles.

The average travel outing when driven for pool vehicles was 11.3 miles. On $95 \%$ of these vehicle outings, the distance traveled was less than the 70 miles and considered to be within the BEV safe range. Meanwhile, only $5 \%$ of pool outing travel was greater than 70 miles, with $93 \%$ of vehicle travel outings less than the 40 miles considered to be within the CD range of a PHEV. 


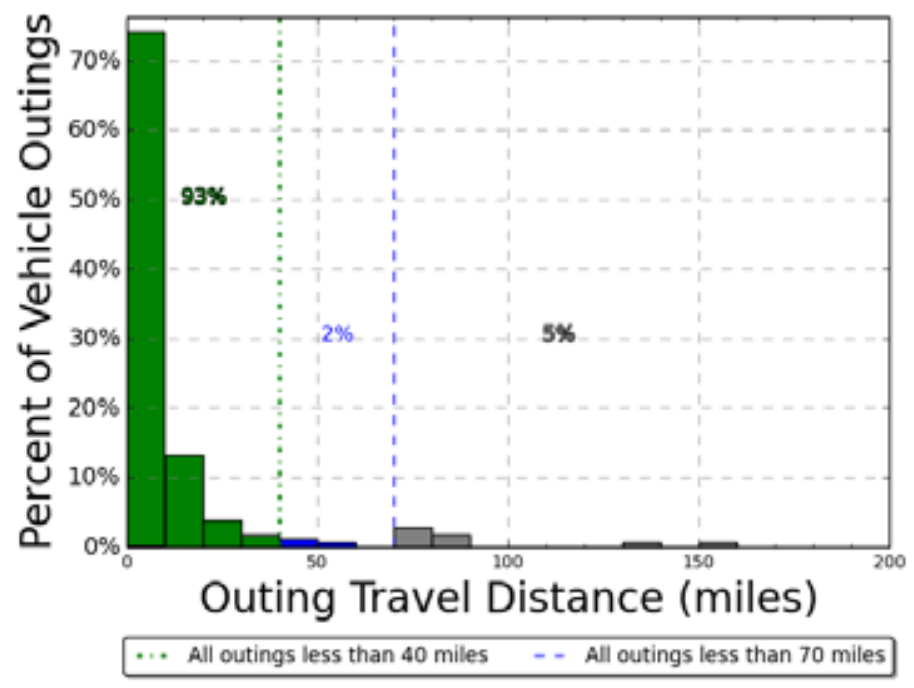

Figure 17. Pool vehicle combined outings.

4.1.1.2 6th MP Group Pool Vehicle Observations/Summary. In summary, the vast majority of daily travel and outings are short and well within the capabilities of BEVs. This is consistent with the optimum goal to incorporate as many BEVs as possible to realize the advantages of reduced petroleum usage and reduced emissions of GHG. A conservative approach to the vehicle usage suggests one PHEV with two BEVs would meet the needs of the pool vehicles.

Considering a full complement of 20 pool vehicles in the 6th MP Group fleet, Intertek suggests that a mixed fleet may be possible. While one of the vehicles is a passenger van and there are currently no PEVs in this class, the remaining vehicles could be replaced. These remaining vehicles were not monitored, but using the data collected for the three that were, Intertek suggests a fleet of 12 BEVs and seven PHEVs conservatively meets vehicle travel requirements.

4.1.1.3 6th MP Group Pool Vehicle Charging Needs. As noted previously, AC Level 2 (240-VAC) overnight charging of BEVs is typical, whereas overnight charging of PHEVs can usually be accomplished with AC Level 1 (110-VAC) charging. Intertek's experience suggests that each vehicle should have an assigned charging location at its home base. Assigned stations require less management attention to ensure completion of overnight charging. BEVs and PHEVs not assigned to these locations also benefit during visits to the location as part of their normal operation. For the entire fleet of pool vehicles, two BEVs require two AC Level 2 EVSE units for overnight charging and one PHEV requires one AC Level 1 outlet for home base charging. Intertek recommends a minimum of two EVSE at each location to maximize charge capability without a significant increase in installation costs. The PHEVs can utilize the AC Level 2 EVSE at the home base during the day to increase the amount of vehicle miles traveled in CD mode.

At times, fleet vehicles obtain benefit from using public charging infrastructure. Figure 22 displays the availability of public charging at the time of this writing for the JBLM area. The green-colored sites are AC sites, indicating AC Level 1 and Level 2 public locations and the orange-colored sites are DCFCs.

There is significant development in public charging infrastructure in the JBLM area due to the great public interest in PEV adoption and earlier emphasis on infrastructure through DOE-granted programs and EVSE supplier interests. For the 6th MP Group fleet that was monitored, all travel was within the JBLM base, but this may not be the case for all 6th MP Group vehicles. 


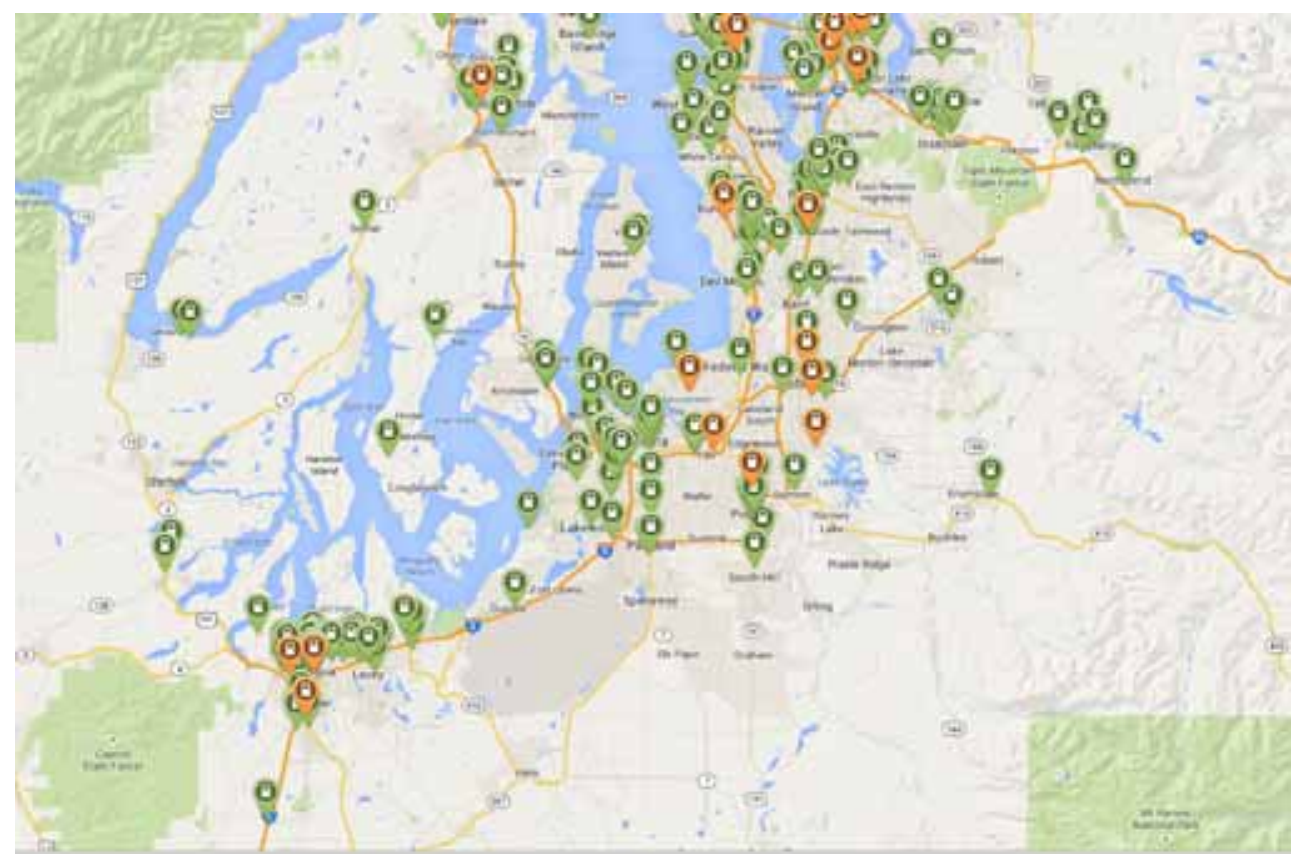

Figure 18. Public EVSE in JBLM region. ${ }^{18}$

\subsubsection{6th MP Group Vehicles Mileage}

The vehicle's annual miles factored into the calculations for replacement of vehicles as noted in Section 5 and Appendix F. The actual miles measured during the study were extrapolated to identify calculated annual miles in the study. JBLM has also provided vehicle information that identified the average monthly miles and vehicle mileage in April 2012.

For the entire 6th MP Group fleet, the average monthly miles traveled was 509 miles for an average annual travel total of 6,114 miles. On an average basis, this reflects positively on the use of BEVs in the fleet.

\subsubsection{6th MP Group Summary}

This study provides observations for both the vehicles monitored and for the entire non-tactical fleet of vehicles identified with the 6th MP Group. The study indicates that PEVs offer alternatives to vehicles in the existing fleet, provided that any specific cargo requirements may be met by the PEV. In general, a mixed fleet of BEVs and PHEVs is suggested.

The fleet of pool vehicles in this study included one SUV, one minivan, and one pickup truck. Section 3.4 provides information on PEVs currently or soon to be available in the automotive market. Without consideration of specific cargo requirements, replacement PEVs currently exist for all these

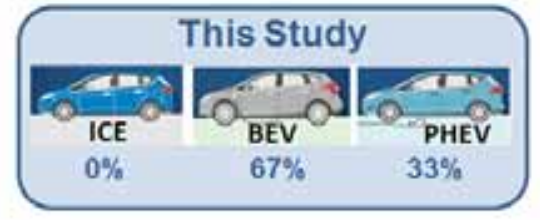
vehicles. Appendix F provides the details of the observations and summary and, based on these travel data, Intertek suggests that replacing these three vehicles with two BEVs and one PHEV would meet current mission requirements.

The vehicles studied were utilized on $69 \%$ of the study days and averaged 1.2 hours of use per day. While daily usage was quite low, the vehicles were used often enough that eliminating a vehicle is not recommended.

\footnotetext{
${ }^{18}$ http://www.plugshare.com/ [accessed June 19, 2014].
} 
Considering a full complement of 20 pool vehicles in the 6th MP Group fleet, Intertek suggests that a mixed fleet may be possible. While one of the vehicles is a passenger van and there currently are no PEVs in this class, the remaining vehicles may be replaced. These remaining vehicles were not monitored, but using the data collected for the three that were, Intertek suggests a fleet of 12 BEVs

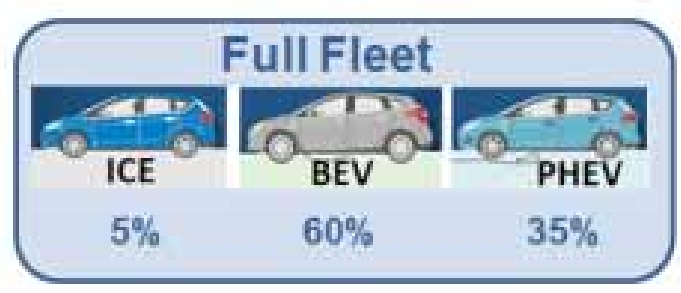
and seven PHEVs conservatively meets vehicle travel requirements.

With potential replacement by PEVs established, Section 5 and Appendix J provide further evaluation of the benefits of such replacements. This will be factored into further observations and suggestions related to the business case and schedule for any replacements for the 6th MP Group. Those observations will be addressed in Task 4 of this project.

\subsection{Analysis Results - Directorate of Community Activities Group}

The Directorate of Community Activities (DCA) support group fleet contains 52 vehicles. Table 10 provides a summary of the all vehicles in the DCA Support Group fleet by mission and vehicle type. Four vehicles were monitored as part of this study, including one pickup truck, one heavy-duty truck, one cargo van, and one passenger van. This section summarizes and aggregates data collection for the DCA Support Group. The details of each vehicle monitored are included in Appendix C. Appendix G presents the full detailed analysis for the vehicles monitored and for the group as a whole.

Table 10. DCA group total fleet summary.

\begin{tabular}{|c|c|c|c|c|c|c|c|c|c|c|c|}
\hline Mission & $\begin{array}{c}\text { Sedan } \\
\text { Compact/ } \\
\text { Subcompact }\end{array}$ & $\begin{array}{c}\text { Sedan } \\
\text { Midsize }\end{array}$ & $\begin{array}{l}\text { Sedan } \\
\text { Large }\end{array}$ & SUV & $\begin{array}{l}\text { Mini } \\
\text {-van }\end{array}$ & $\begin{array}{c}\text { Cargo } \\
\text { Van } \\
\end{array}$ & $\begin{array}{l}\text { Pass } \\
\text { Van }\end{array}$ & $\begin{array}{l}\text { Pickup } \\
\text { or LD } \\
\text { Truck } \\
\end{array}$ & $\begin{array}{l}\text { MD or } \\
\text { HD } \\
\text { Truck }\end{array}$ & Bus & Tota \\
\hline Pool & & & & & 1 & 2 & 2 & 3 & 3 & 1 & 12 \\
\hline Support & 8 & 2 & & & & 6 & 6 & 16 & 2 & & 40 \\
\hline Total & 8 & 2 & & & 1 & 8 & 8 & 19 & 5 & 1 & 52 \\
\hline
\end{tabular}

Grouping the vehicles by mission creates an aggregated view of mission requirements to provide observations related to PEV replacement. Analysis by mission type is provided in the following subsections.

\subsubsection{Directorate of Community Activities Pool Vehicles Analysis}

Pool vehicles are typically light-duty motor vehicles for use in passenger transportation, with not more than 10 passengers. Pool missions can vary by agency, location, and jurisdiction. For the DCA Support Group, the pool vehicles include a cargo van and a heavy-duty truck. Although there currently are no PEVs available to replace the heavy-duty truck, it is assumed that the usage of these pool vehicles can be of value in considering the remaining pool vehicles in the larger DCA fleet. PEVs are currently available to replace the balance of the vehicles.

Incorporation of BEVs and/or PHEVs into the pool mission is a definite possibility. Pool vehicles used for shorter trips or outings qualify for BEV or PHEV replacement, while other pool vehicle activities that are associated with longer trips may require PHEV capabilities.

4.2.1.1 Summary for Directorate of Community Activities Pool Vehicles. Appendix C provides the vehicle data sheets for each of the pool vehicles monitored. This section aggregates data for both pool vehicles. Table 11 summarizes pool travel during the study period for those days in which the vehicle was driven. Vehicle use occurred primarily between 0800 and 1500 hours daily. The vehicles traveled 409 miles, logged 32 hours, and idled for 7 hours during the 63-day study period. 
Table 11. Pool vehicles travel summary.

\begin{tabular}{lcccc}
\hline & Pool Vehicles Travel Summary & & \\
& $\begin{array}{c}\text { Per Day } \\
\text { Average/Peak }\end{array}$ & $\begin{array}{c}\text { Per Outing } \\
\text { Average/Peak }\end{array}$ & $\begin{array}{c}\text { Per Trip } \\
\text { Average/Peak }\end{array}$ & Total \\
\hline Travel Distance (Miles) & $8.5 / 53.5$ & $6.1 / 53.5$ & $1.8 / 20.2$ & 408.7 \\
Travel Time (Minutes) & $40.1 / 123.0$ & $28.7 / 133.0$ & $8.3 / 55.0$ & $1,926.0$ \\
Idle Time (Minutes) & $9.1 / \mathrm{NA}$ & $6.5 / \mathrm{NA}$ & $1.9 / \mathrm{NA}$ & 435.0 \\
\hline
\end{tabular}

The distance a PEV can travel in CD mode between charge opportunities is the most important factor in considering vehicle replacement. The two most significant factors in vehicle analysis include the vehicle daily travel and vehicle outings. Section 2.3 provides the definitions of these terms. Figure 23 shows the daily travel summary for pool vehicles.

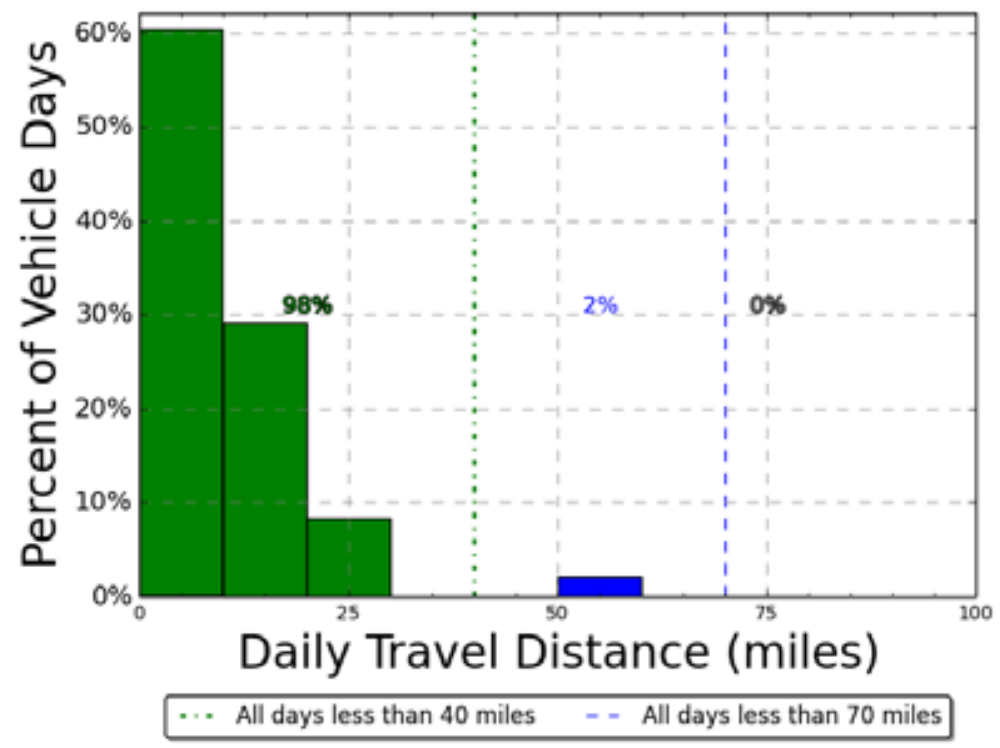

Figure 23. Pool vehicle daily travel miles (all vehicles).

The average travel distance per day when driven for pool vehicles was 8.5 miles. On all vehicle travel days, the daily travel was less than the 70 miles considered to be within the BEV safe range (blue and green bars in Figure 23). Meanwhile, 98\% of vehicle travel days were less than 40 miles considered to be within the CD mode of a PHEV (green bars of Figure 23). Figure 24 shows the outings for all pool vehicles.

Appendix C provides the details of each of the pool vehicle's outings. Neither vehicle exceeded 70 miles in a single outing.

The average travel outing when driven for pool vehicles was 6.1 miles. All outings were less than the 70 miles considered to be within the BEV safe range. Furthermore, 99\% percent of pool outings were less than 40 miles considered to be within the CD mode range of a PHEV. 


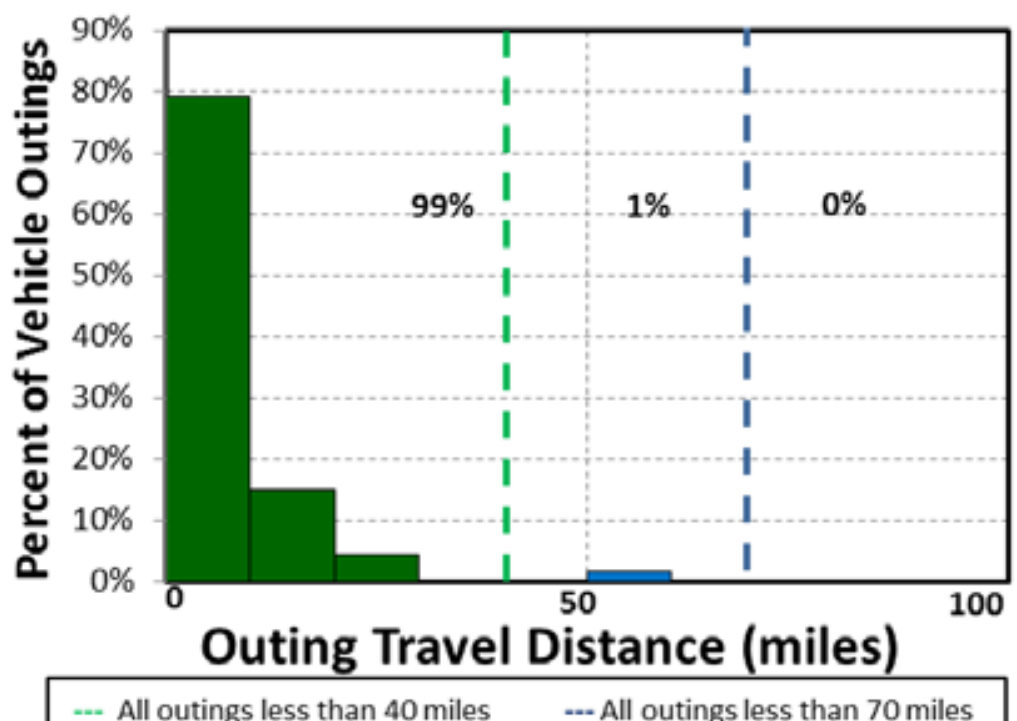

Figure 19. Pool vehicle combined outings.

4.2.1.2 Pool Vehicle Observations/Summary. In summary, the vast majority of daily travel and outings are short and well within the capabilities of BEVs. This is consistent with the optimum goal to incorporate as many BEVs as possible to realize the advantages of reduced petroleum usage and reduced emissions of GHG.

The fleet of pool vehicles in this study included one heavy-duty truck and one cargo van. While no PEV is currently available to replace heavy-duty trucks, other vehicles in the pool fleet have replacements available. Section 3.4 provides information on PEVs currently or soon to be available in the automotive market.

Considering a full complement of 12 pool vehicles in the DCA Support Group pool fleet, Intertek suggests that in extrapolating the collected data to the entire fleet, a mixed fleet consisting of four BEVs, two PHEVs, two conventional passenger vans, three conventional heavy-duty trucks, and one conventional bus may be possible.

4.2.1.3 Pool Vehicle Charging Needs. As noted previously, AC Level 2 overnight charging of BEVs is typical, whereas overnight charging of PHEVs can be accomplished using AC Level 1 charging.

Intertek's experience suggests that each vehicle should have an assigned charging location at their home base. Assigned stations require less management attention to ensure completion of overnight charging. BEVs and PHEVs not assigned to these locations also benefit during visits to the location as part of their normal operation. For the entire fleet of pool vehicles, four BEVs require four AC Level 2 EVSE units for overnight charging and two PHEVs require two AC Level 1 outlets for home base charging. Intertek recommends a minimum of two EVSE at each location to maximize charge capability without a significant increase in installation costs. The PHEVs can utilize the AC Level 2 EVSE at the home base during the day to increase the amount of vehicle miles traveled in CD mode.

At times, fleet vehicles obtain benefit from using public charging infrastructure. Figure 22 displays the availability of public charging at the time of this writing for the JBLM area. Because all travel was within the JBLM base, there may be little benefit in using public charging for the DCA Support Group pool vehicles. 


\subsubsection{Directorate of Community Activities Support Group Support Vehicles Analysis}

Support vehicles provide a specific work function, facilitating the mission of a particular group. The vehicles are generally passenger or light-duty pickup trucks and may contain after-market modifications to support the mission. While assigned to maintenance and service areas, missions may vary depending on agency needs.

\subsubsection{Summary for Directorate of Community Activities Support Group Support}

Vehicles. Appendix $C$ provides the vehicle data sheets for each of the pickup truck and passenger van support vehicles monitored. This section aggregates the data for both support vehicles.

Table 12 summarizes support vehicle travel during the study period. Vehicle use occurred primarily between 0800 and 1600 hours daily. Support vehicles traveled 4,677 miles, logged 136 hours, and idled for 14 hours during the study period.

Table 12. Support vehicle travel summary.

\begin{tabular}{lcccc}
\hline \multicolumn{4}{c}{ Support Vehicle Travel Summary } & \\
& $\begin{array}{c}\text { Per Day } \\
\text { Average/Peak }\end{array}$ & $\begin{array}{c}\text { Per Outing } \\
\text { Average/Peak }\end{array}$ & $\begin{array}{c}\text { Per Trip } \\
\text { Average/Peak }\end{array}$ & Total \\
\hline Travel Distance (Miles) & $61.5 / 354.1$ & $30.6 / 354.1$ & $12.3 / 129.4$ & 4,677 \\
Travel Time (Minutes) & $108.0 / 544.0$ & $53.6 / 544.0$ & $21.7 / 222.0$ & 8,208 \\
Idle Time (Minutes) & $11.5 / \mathrm{NA}$ & $2.3 / \mathrm{NA}$ & $2.3 / \mathrm{NA}$ & 872 \\
\hline
\end{tabular}

Again, daily travel and outings provide the greatest insight into vehicle use for PEV replacement considerations. Figure 25 shows the travel summary for support vehicles.

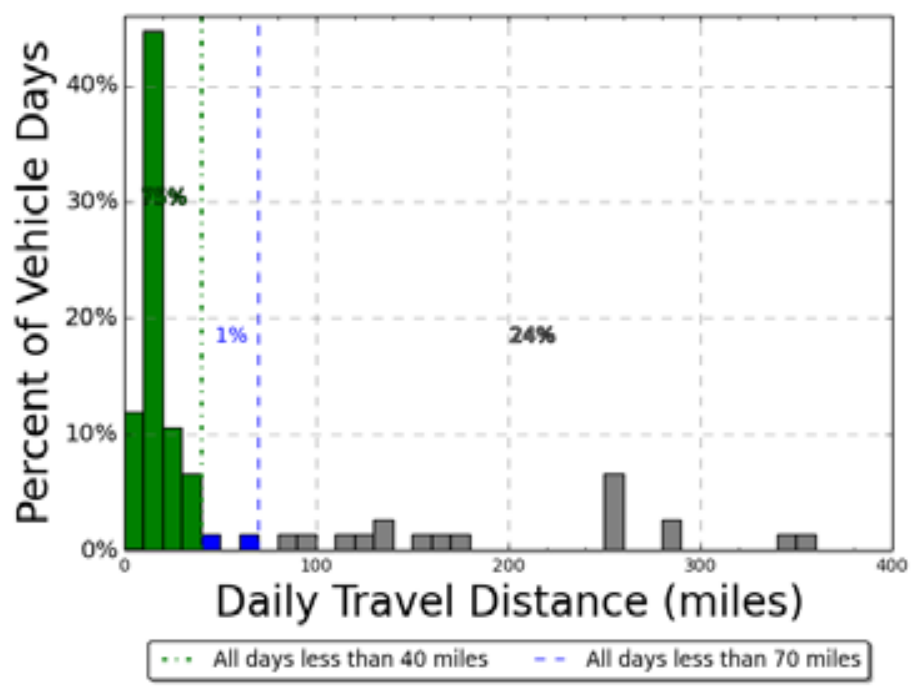

Figure 25. Support vehicle daily travel miles (all vehicles).

The average travel distance per day, when driven for support vehicles, was 61.5 miles. On $76 \%$ of these vehicle days, the daily travel was less than the 70 miles considered to be within the BEV safe range. Meanwhile, $24 \%$ percent of support vehicle daily travel was greater than 70 miles. Furthermore, $75 \%$ of vehicle travel days were less than the 40 miles considered to be within the CD mode range of a PHEV. Figure 20 shows the outings for all support vehicles combined. 


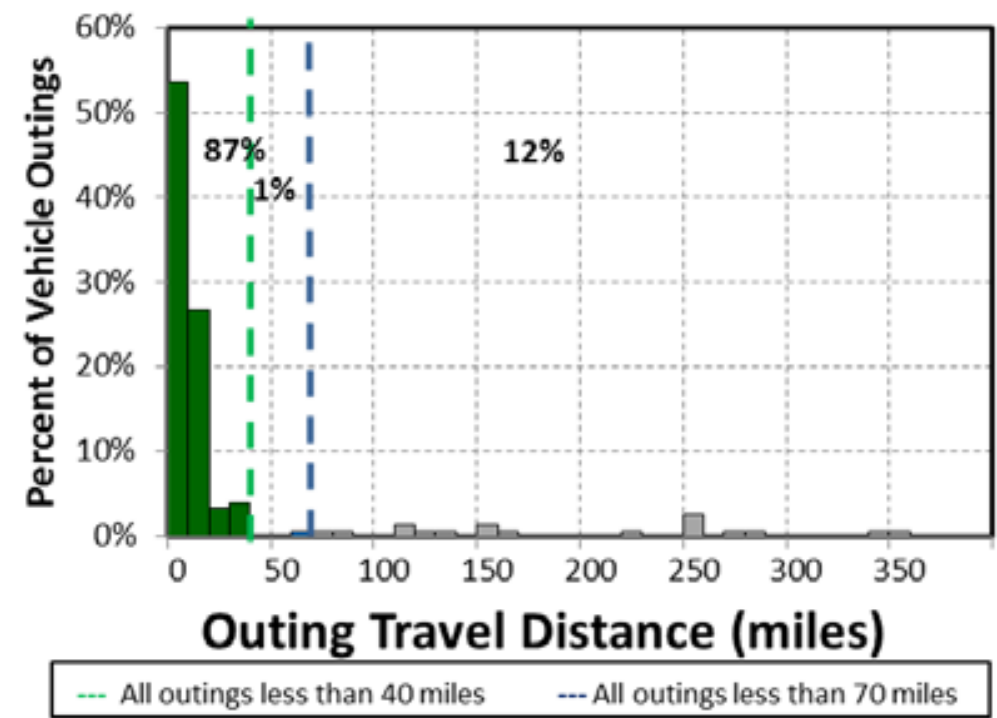

Figure 20. Support vehicle combined outings.

The average travel outing when driven for support vehicles was 30.6 miles. On $88 \%$ of these vehicle outings, the distance traveled was less than the 70 miles considered to be within the BEV safe range. Meanwhile, $12 \%$ of support outing travel was greater than 70 miles. Furthermore, $87 \%$ of vehicle travel outings were less than the 40 miles considered to be within the CD mode range of a PHEV.

\subsubsection{Directorate of Community Activities Support Group Support Vehicle}

Observations/Summary. Again, the vast majority of daily travel and outings were short and well within the capabilities of BEVs. This is consistent with the optimum goal to incorporate as many BEVs as possible to realize the advantages of reduced petroleum usage and reduced emissions of GHG.

The fleet of support vehicles in this study included one pickup truck and one passenger van. While no PEVs are currently available to replace the passenger van, other vehicles in the entire support fleet have replacements available. Section 3.4 provides information on PEVs currently or soon to be available in the automotive market.

Considering a full complement of 40 support vehicles in the entire DCA Support Group fleet, Intertek suggests that in extrapolating the collected data to the entire fleet, a mixed fleet consisting of $20 \mathrm{BEVs}$, 12 PHEVs, six conventional passenger vans, and two conventional heavy-duty trucks may be possible.

\subsubsection{Directorate of Community Activities Support Group Support Vehicle Charging}

Needs. For the entire fleet of support vehicles, 20 BEVs require 20 AC Level 2 EVSE units for overnight charging and 12 PHEVs require $12 \mathrm{AC}$ Level 1 outlets for home base.

Greater management attention provides the possibility of reducing the overall number of AC Level 2 EVSE. A ratio of two AC Level 2 charging stations to three vehicles typically sustains a normal fleet operation. Fleet managers rotate vehicles on the charger to complete charging of all vehicles in the allotted time. This analysis does assume a fully recharged battery at the start of each day. JBLM will gain experience in this management as the PEV fleet grows.

\subsubsection{Directorate of Community Activities Support Group Vehicles Mileage}

The vehicle's annual miles factor into the calculations for replacement of vehicles as noted in Section 5 and Appendix G. The actual miles measured during the study are extrapolated to identify the calculated annual miles in the study. JBLM has also provided vehicle information that identified the average monthly miles and vehicle mileage in April 2012. 
For the entire DCA Support Group fleet, the average travel provided by JBLM was 274 miles per month for an average annual travel of 3,291 miles. On an average basis, this reflects positively on the use of BEVs in the fleet.

\subsubsection{Directorate of Community Activities Support Group Summary}

This study provides observations for both the vehicles monitored and for the entire non-tactical fleet of vehicles identified with the DCA Support Group. The study indicates that PEVs offer alternatives to vehicles in the existing fleet, provided that any specific cargo requirements may be met by the PEV. In general, a mixed fleet of BEVs and PHEVs is suggested.

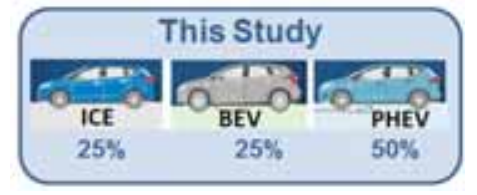

The vehicles studied were utilized on $69 \%$ of the study days and averaged 1.3 hours of use per day. While daily usage was quite low, the vehicles were used often enough that eliminating one of these vehicles is not recommended.

Considering a full complement of 52 vehicles in the DCA Support Group fleet, Intertek suggests that a mixed fleet may be possible. Intertek suggests that a fleet of one conventional bus, eight conventional passenger vans, five heavy-duty trucks, 24 BEVs, and 14 PHEVs would conservatively meet the balance of vehicle travel requirements.

With the potential replacement by PEVs established, Section 5 and Appendix K provide further evaluation of the benefits of such replacements. This will be factored into further observations and suggestions related to the business case and schedule for any replacements for the DCA Support Group. Those observations will be addressed in Task 4 of this project.

\subsection{Analysis Results - Public Works Group}

The Public Works Group fleet contains 250 vehicles. Table 13 identifies these vehicles by vehicle type according to site records. The mission assignments identified in Table 13 are based on survey responses received and extrapolation to the balance of the fleet. Fourteen vehicles were monitored as part of this study, including nine pickup trucks, two minivans, and three passenger vans. This section summarizes and aggregates data collection for the Public Works Group. The details of each vehicle monitored are included in Appendix D. Appendix H presents the full detailed analysis for the vehicles monitored and for the group as a whole.

Table 13. Public Works Group total fleet characterization.

\begin{tabular}{|c|c|c|c|c|c|c|c|c|c|c|c|}
\hline Mission & $\begin{array}{c}\text { Sedan } \\
\text { Compact/ } \\
\text { Subcompact }\end{array}$ & $\begin{array}{c}\text { Sedan } \\
\text { Midsize/ } \\
\text { Large }\end{array}$ & $\begin{array}{l}\text { Mini- } \\
\text { van }\end{array}$ & SUV & $\begin{array}{l}\text { Spec } \\
\text { ialty }\end{array}$ & $\begin{array}{c}\text { Cargo } \\
\text { Van }\end{array}$ & $\begin{array}{c}\text { Pass. } \\
\text { Van }\end{array}$ & $\begin{array}{l}\text { Pickup } \\
\text { or LD } \\
\text { Truck }\end{array}$ & $\begin{array}{c}\text { MD or } \\
\text { HD } \\
\text { Truck }\end{array}$ & Bus & Total \\
\hline Pool & 5 & 2 & 2 & 7 & & 8 & 35 & 48 & & & 107 \\
\hline Transport & & & & & & & & 8 & 17 & & 25 \\
\hline Specialty & & & & & 1 & & & & & & 1 \\
\hline
\end{tabular}


Grouping the vehicles by mission creates an aggregated view of mission requirements to provide observations related to PEV replacement. Analysis by mission type is provided in the following subsections.

\subsubsection{Public Works Pool Vehicles Analysis}

Pool vehicles typically are light-duty motor vehicles for use in passenger transportation, with not more than 10 passengers. Pool missions can vary by agency, location, and jurisdiction. For Public Works, the pool vehicles include four pickups, two passenger vans, and two minivans. Although there currently are no PEVs available to replace passenger vans, it is assumed that usage of these pool vehicles can be of value in considering the remaining pool vehicles in the Public Works fleet. Pickups and minivans may be replaced by currently available PEVs.

Incorporation of BEVs and/or PHEVs into the pool mission is a definite possibility. Pool vehicles used for shorter trips or outings qualify for BEV or PHEV replacement, while other pool vehicle activities that are associated with longer trips may require PHEV capabilities.

4.3.1.1 Summary for Public Works Pool Vehicles. Appendix D provides the vehicle data sheets for each of the pool vehicles monitored. This section aggregates data for all pool vehicles. Table 14 summarizes pool vehicle travel during the study period for those days in which the vehicle was driven. Vehicle use occurred primarily between 0700 and 1500 hours daily. They traveled 3,620 miles, logged 259 hours, and idled for 76 hours during the 63-day study period.

Table 14. Pool vehicles travel summary.

\begin{tabular}{lcccc}
\hline & Pool Vehicles Travel Summary & & \\
& Per Day & Per Outing & Per Trip & \\
& Average/Peak & Average/Peak & Average/Peak & Total \\
\hline Travel Distance (Miles) & $13.8 / 270.7$ & $5.3 / 168.6$ & $2.2 / 132.0$ & $3,621.3$ \\
Travel Time (Minutes) & $59.2 / 297.0$ & $23.0 / 247.0$ & $9.3 / 139.0$ & 15,563 \\
Idle Time (Minutes) & $17.5 / \mathrm{NA}$ & $6.9 / \mathrm{NA}$ & $2.7 / \mathrm{NA}$ & 4,595 \\
\hline
\end{tabular}

The distance a PEV can travel in CD mode between charge opportunities is the most important factor in considering vehicle replacement. The two most significant factors in vehicle analysis include vehicle daily travel and vehicle outings. Section 2.3 provides the definitions of these terms. Figure 21 shows the travel summary for all monitored pool vehicles.

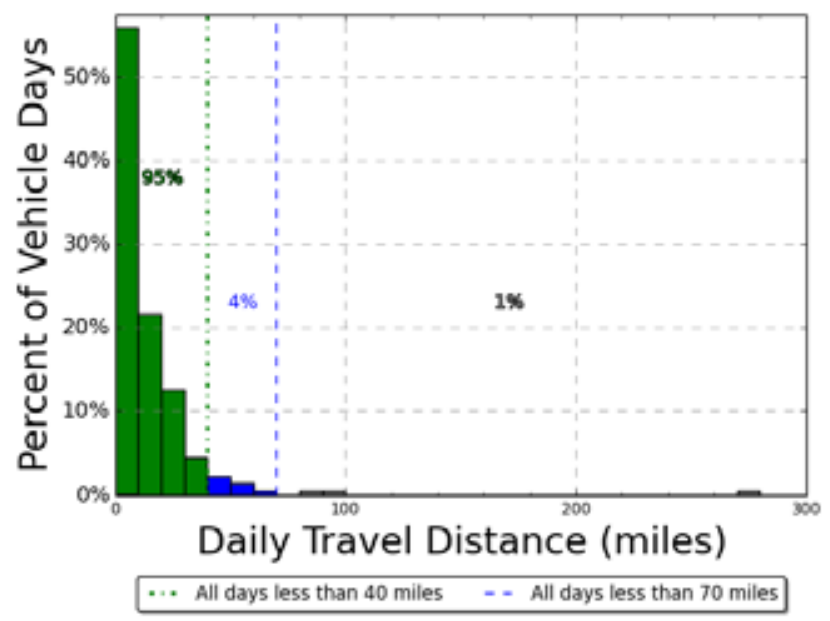

Figure 21. Pool vehicle daily travel miles (all vehicles). 
The average travel distance per day when driven for pool vehicles was 13.8 miles. On $99 \%$ of the vehicle travel days, the daily travel was less than the 70 miles considered to be within the BEV safe range (blue and green bars in Figure 21). Meanwhile, 95\% of vehicle travel days were less than the 40 miles considered to be within the CD range of a PHEV (green bars of Figure 21).

The pool vehicles were used, on average, $52 \%$ of the study days. However, there were periods where each vehicle operated several days in a row and days that several vehicles were in use. Figure 22 shows the outings for all vehicles.

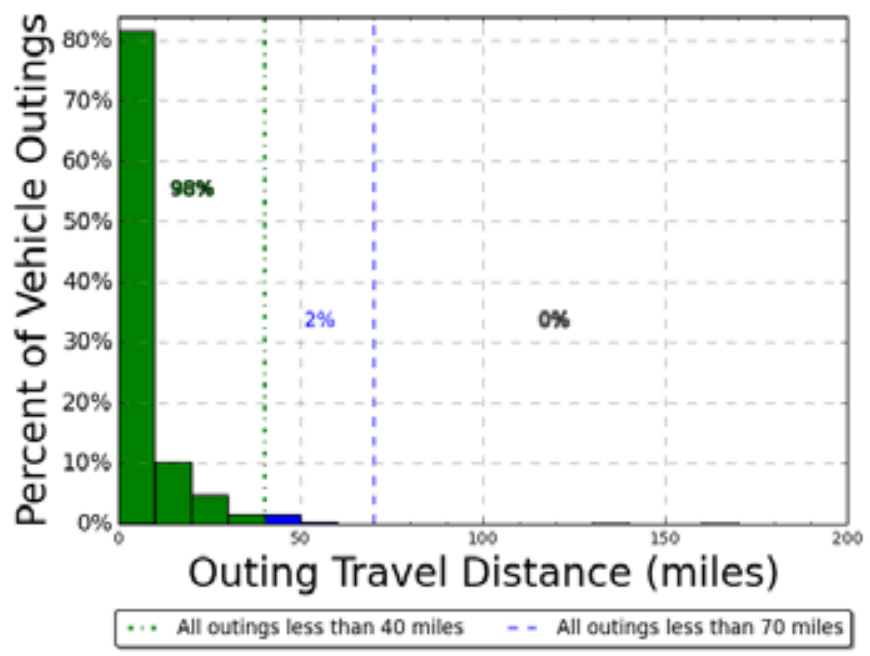

Figure 22. Pool vehicle combined outings.

Appendix D provides the details of each of the pool vehicle's outings. The average travel outing when driven for pool vehicles was 5.2 miles. All outings (except two), or essentially 100\%, were less than the 70 miles considered to be within the BEV safe range. Furthermore, $98 \%$ percent of pool outings were less than the 40 miles considered to be within the CD mode range of a PHEV.

4.3.1.2 Pool Vehicle Observations/Summary. The vast majority of daily travel and outings are short and well within the capabilities of BEVs. This is consistent with the optimum goal to incorporate as many BEVs as possible to realize the advantages of reduced petroleum usage and reduced emissions of GHG.

The fleet of pool vehicles in this study included four pickup trucks, two minivans, and two passenger vans. While no PEV is currently available to replace the passenger van, other vehicles in the entire pool fleet have replacements available and Intertek would suggest four suitably styled BEVs and two PHEVs could meet mission requirements. Section 3.4 provides information on PEVs currently or soon to be available in the automotive market and Section 5 provides details on the suggestions.

Considering a full complement of 107 pool vehicles in the entire Public Works Group fleet, Intertek suggests that in extrapolating the collected data to the entire fleet, a mixed fleet of 57 BEVs, 15 PHEVs, and 35 conventional passenger vans may be possible.

The vehicle summary shows sufficient time for charging at the base location during the course of the day and additional opportunities at intermediate charging stations. These stations also provide charging opportunities for the visiting public, whose fees may assist in offsetting operating costs.

4.3.1.3 Pool Vehicle Charging Needs. Upon review of these data, Intertek suggests replacement of the Public Works pool fleet with 57 BEVs and 15 PHEVs, while retaining 35 conventional passenger vans. 
As noted previously, AC Level 2 overnight charging of BEVs is typical, whereas overnight charging of PHEVs can be accomplished with AC Level 1 charging.

Intertek's experience suggests that each vehicle have an assigned charging location at their home base. Assigned stations require less management attention to ensure completion of overnight charging. BEVs and PHEVs not assigned to these locations also benefit during visits to the location as part of their normal operation. Intertek recommends a minimum of two EVSE at each location to maximize charge capability without a significant increase in installation costs. The PHEVs can utilize the AC Level 2 EVSE at the home base during the day to increase the amount of vehicle miles traveled in CD mode.

At times, fleet vehicles obtain benefit from using public charging infrastructure. Figure 18 displays the availability of public charging for the JBLM area at the time of this writing. Because all travel was within the JBLM base, there may be little benefit in using public charging for the DCA Support Group pool vehicles.

\subsubsection{Public Works Support Vehicles Analysis}

Support vehicles provide a specific work function, facilitating the mission of a particular group. The vehicles are generally passenger or light-duty pickup trucks and may contain after-market modifications to support the mission. While assigned to maintenance and service areas, missions may vary depending on agency needs.

As shown above, Public Works support vehicles that were monitored included five conventional pickup trucks and one conventional passenger van.

4.3.2.1 Summary for Public Works Support Vehicles. Appendix D provides the vehicle data sheets for each of the six support vehicles monitored. This section aggregates the data for all support vehicles.

Table 15 summarizes support vehicle travel during the study period. Vehicle use occurred primarily between 0700 and 1500 hours daily. The six support vehicles traveled 5,244 miles, logged 300 hours, and idled for 62 hours during the study period.

Table 15. Support vehicle travel summary.

\begin{tabular}{lcccc}
\hline \multicolumn{4}{c}{ Support Vehicle Travel Summary } & \\
& Per Day & Per Outing & Per Trip & \\
& Average/Peak & Average/Peak & Average/Peak & Total \\
\hline Travel Distance (Miles) & $25.6 / 598.5$ & $7.6 / 608.8$ & $3.4 / 236.9$ & 5,244 \\
Travel Time (Minutes) & $88.1 / 585$ & $26.2 / 628$ & $11.6 / 215$ & 18,053 \\
Idle Time (Minutes) & $18.2 / \mathrm{NA}$ & $5.4 / \mathrm{NA}$ & $2.4 / \mathrm{NA}$ & 3,722 \\
\hline
\end{tabular}

The distance a PEV can travel in CD mode between charge opportunities is the most important factor in considering vehicle replacement. The two most significant factors in vehicle analysis include the vehicle daily travel and vehicle outings. Section 2.3 provides the definitions of these terms. Figure 23 shows the travel summary for the support vehicles monitored.

The average travel distance per day when driven for support vehicles was 25.6 miles. On $96 \%$ of these vehicle days, the daily travel was less than the 70 miles considered to be within the BEV safe range. Meanwhile, $4 \%$ percent of support vehicle daily travel was greater than 70 miles. Furthermore, $88 \%$ of vehicle travel days were less than the 40 miles considered to be within the CD mode range of a PHEV. Figure 24 shows the outings for all support vehicles combined.

Appendix D provides the details of each of the support vehicle's daily travel. The extended outage of Vehicle G43-1892H dominated the highest distance with a single outing of 608 miles and also accounts 
for this highest daily travel. All other outings remained below the 70-mile range on all vehicle days and outings.

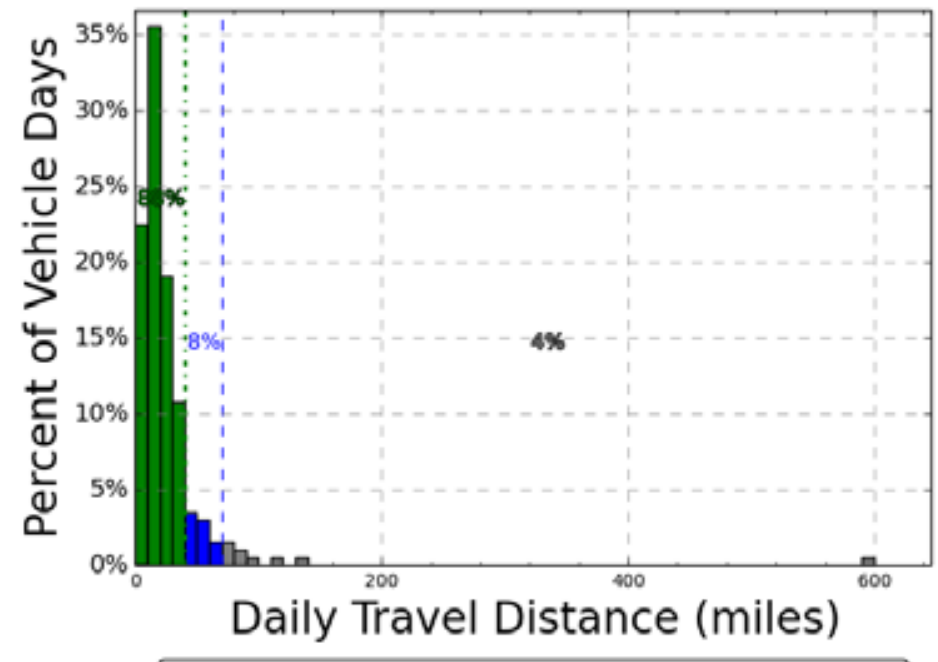

-.. All days less than 40 miles _- All days less than 70 miles

Figure 23. Support vehicle daily travel miles and usage time (all vehicles).

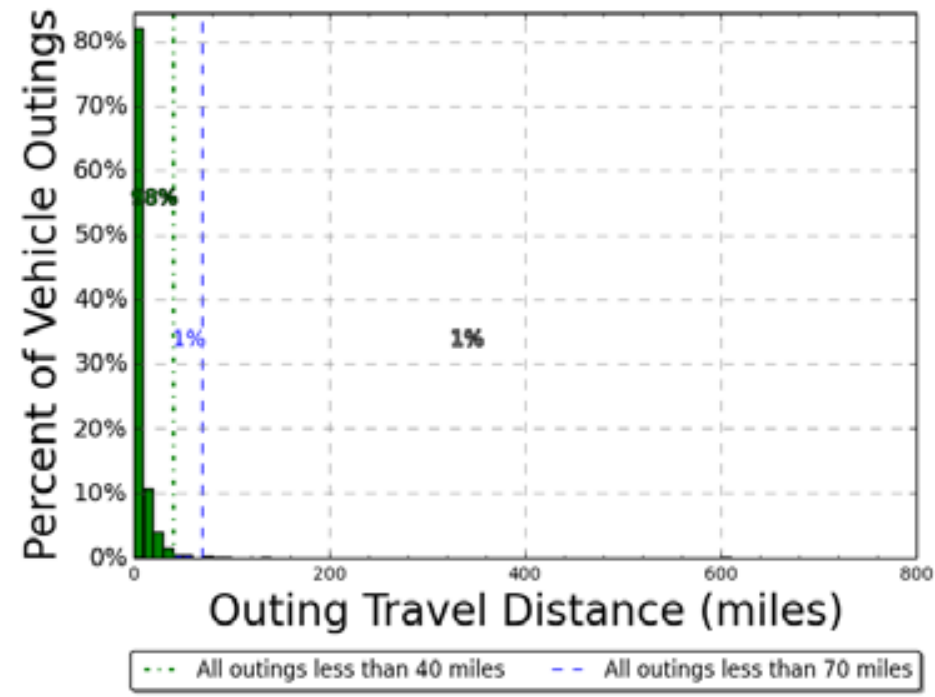

Figure 24. Support vehicle combined outings.

The average travel outing when driven for support vehicles was 7.6 miles. On $99 \%$ of these vehicle outings, the distance traveled was less than the 70 miles considered to be within the BEV safe range. Furthermore, $98 \%$ of vehicle travel outings were less than the 40 miles considered to be within the CD mode range of a PHEV.

4.3.2.2 Public Works Support Vehicle Observations/Summary. The vast majority of daily travel and outings are short and well within the capabilities of BEVs. This is consistent with the optimum goal to incorporate as many BEVs as possible to realize the advantages of reduced petroleum usage and reduced emissions of GHG.

The fleet of pool vehicles in this study included five pickup trucks and one passenger van. While no PEV is currently available to replace the passenger van, other vehicles in the pool fleet that were 
monitored have replacements available. Intertek would suggest four suitably styled BEVs and one PHEV could meet mission requirements. Section 3.4 provides information on PEVs currently or soon to be available in the automotive market and Section 5 provides details on the suggestions.

Considering a full complement of 117 pool vehicles in the entire Public Works Group support fleet, Intertek suggests that in extrapolating the collected data to the entire fleet, a mixed fleet may of $67 \mathrm{BEVs}$, 17 PHEVs, 16 conventional heavy-duty trucks, and 17 conventional passenger vans may be possible.

The vehicle summary shows sufficient time for charging at the base location during the course of the day and additional opportunities at intermediate charging stations. These stations also provide charging opportunities for the visiting public, whose fees may assist in offsetting operating costs.

4.3.2.3 Public Works Support Vehicle Charging Needs. As noted above, AC Level 2 overnight charging of BEVs is typical, whereas overnight charging of PHEVs can be accomplished with $\mathrm{AC}$ Level 1 charging. Opportunity charging at intermediate stops obtains the greater benefits from AC Level 2 EVSE. Most vehicles returned to their home base daily, with the exception of long trips lasting several days.

Greater management attention provides the possibility of reducing the overall number of AC Level 2 EVSE units. A ratio of two AC Level 2 charging stations to three vehicles typically sustains a normal fleet operation. Fleet managers rotate vehicles on the charger to complete charging of all vehicles in the allotted time. This analysis does assume a fully recharged battery at the start of each day. JBLM will gain experience in this management as the PEV fleet grows.

\subsubsection{Public Works Group Vehicles Mileage}

The vehicle's annual miles factor into the calculations for replacement of the vehicle as noted in Section 5 and Appendix H. The actual miles measured during the study were extrapolated to identify the calculated annual miles in the study. JBLM has also provided vehicle information that identified the average monthly miles and vehicle mileage in April 2012.

For the entire Public Works Group fleet, the average monthly miles traveled were 335 miles for an average annual travel of 4,024 miles. This is relatively low mileage and, on an average basis, this reflects positively on the use of BEVs in the fleet.

\subsubsection{Public Works Group Summary}

This study provides observations for both the vehicles monitored and for the entire non-tactical fleet of vehicles identified with the Public Works Group. The study indicates that PEVs offer alternatives to existing vehicles, provided that any specific cargo requirements may be met by the PEV. In general, a

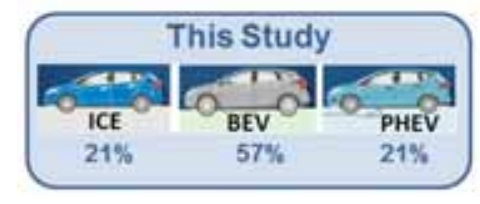
mixed fleet of BEVs and PHEVs is suggested.

The vehicles monitored in this study included three conventional passenger vans, nine pickup trucks, and two minivans. Based on the travel data, Intertek suggests that retaining the passenger vans and replacing the remaining vehicles with three PHEVs and eight BEVs would meet current mission requirements. Section 5 identifies potential replacement PEVs and Appendix $\mathrm{H}$ provides specific recommendations.

The vehicles studied were utilized on $74 \%$ of the study days and averaged 1.1 hours of use per day. While daily usage is quite low, the vehicles were used often enough that eliminating one of these vehicles is not recommended.

The Public Works Group's full fleet of vehicles contains 250 vehicles. Intertek suggests retaining the conventional specialty vehicle, 52 conventional passenger vans, and 33 conventional heavy-duty trucks for now, and 
suggests a fleet of $128 \mathrm{BEVs}$ and 36 PHEVs would conservatively meet the balance of vehicle travel requirements.

With the potential replacement by PEVs established, Section 5 and Appendix M provide further evaluation of the benefits of such replacements. This will be factored into further observations and suggestions related to the business case and schedule for any replacements for the Public Works Group. Those observations will be addressed in Task 4 of this project.

\subsection{Analysis Results - Motor Transport Branch}

The Motor Transport Branch fleet contains 1,060 vehicles, not including the low-speed vehicles and non-powered trailer type vehicles. Table 16 identifies these vehicles by vehicle type according to site records. The mission assignments identified in this table are based on survey responses received and extrapolated to the entire fleet.

Table 16. Motor Transport Branch fleet vehicles by type and mission.

\begin{tabular}{|c|c|c|c|c|c|c|c|c|c|c|c|}
\hline Mission & $\begin{array}{c}\text { Sedan } \\
\text { Compact/ } \\
\text { Subcompact }\end{array}$ & $\begin{array}{c}\text { Sedan } \\
\text { Midsize/ } \\
\text { Large }\end{array}$ & $\begin{array}{l}\text { Mini } \\
\text {-van }\end{array}$ & SUV & $\begin{array}{l}\text { Speci } \\
\text { alty }\end{array}$ & $\begin{array}{c}\text { Cargo } \\
\text { Van }\end{array}$ & $\begin{array}{c}\text { Pass. } \\
\text { Van }\end{array}$ & $\begin{array}{l}\text { Pickup } \\
\text { or LD } \\
\text { Truck }\end{array}$ & $\begin{array}{l}\text { MD or } \\
\text { HD } \\
\text { Truck }\end{array}$ & Bus & Total \\
\hline Pool & 20 & 36 & 59 & 23 & & 72 & 168 & 117 & & & 495 \\
\hline Support & 3 & 60 & 29 & 92 & & 6 & 18 & 93 & & & 301 \\
\hline Transport & 3 & & 10 & & & 32 & 16 & 70 & 73 & & 204 \\
\hline Specialty & & & & & 4 & & & & & & 4 \\
\hline Bus & & & & & & & & & & 56 & 56 \\
\hline Total & 26 & 96 & 98 & 115 & 4 & 110 & 202 & 280 & 73 & 56 & 1,060 \\
\hline
\end{tabular}

Grouping the vehicles by mission creates an aggregated view of mission requirements to provide observations related to PEV replacement. Analysis by mission type is provided in the following subsections.

\subsubsection{Motor Transport Branch Pool Vehicles Analysis}

Pool vehicles are typically light-duty motor vehicles for use in passenger transportation, with not more than 10 passengers. Pool missions can vary by agency, location, and jurisdiction, and for Motor Transport Branch, the pool vehicles include minivans, sedans, pickup trucks, cargo and passenger vans, and an SUV. Although there currently are no PEVs available to replace the passenger van vehicle, it is assumed that the usage of all these pool vehicles can be of value in considering the remaining pool vehicles in the Motor Transport fleet. The other vehicles may be replaced by currently available PEVs.

Incorporation of BEVs and/or PHEVs into the pool mission is a definite possibility. Pool vehicles used for shorter trips or outings qualify for BEV or PHEV replacement, while other pool vehicle activities that are associated with longer trips may require PHEV capabilities.

4.4.1.1 Summary for Motor Transport Branch Pool Vehicles. Appendix E provides the vehicle data sheets for each of the 23 pool vehicles monitored. This section aggregates data for all pool vehicles. Table 17 summarizes pool travel during the study period for those days in which the vehicle was driven. Vehicle use occurred at all hours of the day, but primarily between 0700 and 1800 hours. They traveled 23,746 miles, logged 1,158 hours, and idled for 312 hours during the 63-day study period.

The distance a PEV can travel in CD mode between charge opportunities is the most important factor in considering vehicle replacement. The two most significant factors in vehicle analysis then include the vehicle daily travel and vehicle outings. Section 2.3 provides the definitions of these terms. Figure 25 shows the travel summary for Motor Transport Branch pool vehicles. 
Table 17. Pool vehicles travel summary.

\begin{tabular}{lcccc}
\hline \multicolumn{4}{c}{ Pool Vehicles Travel Summary } & \\
& Per Day & Per Outing & Per Trip & \\
& Average/Peak & Average/Peak & Average/Peak & Total \\
\hline Travel Distance (Miles) & $35.2 / 571.2$ & $11.9 / 1,566.9$ & $4.4 / 202.5$ & 23,746 \\
Travel Time (Minutes) & $103.1 / 777.0$ & $34.8 / 1,897$ & $12.7 / 257.0$ & 69,499 \\
Idle Time (Minutes) & $27.8 / \mathrm{NA}$ & $9.4 / \mathrm{NA}$ & $3.4 / \mathrm{NA}$ & 18,748 \\
\hline
\end{tabular}

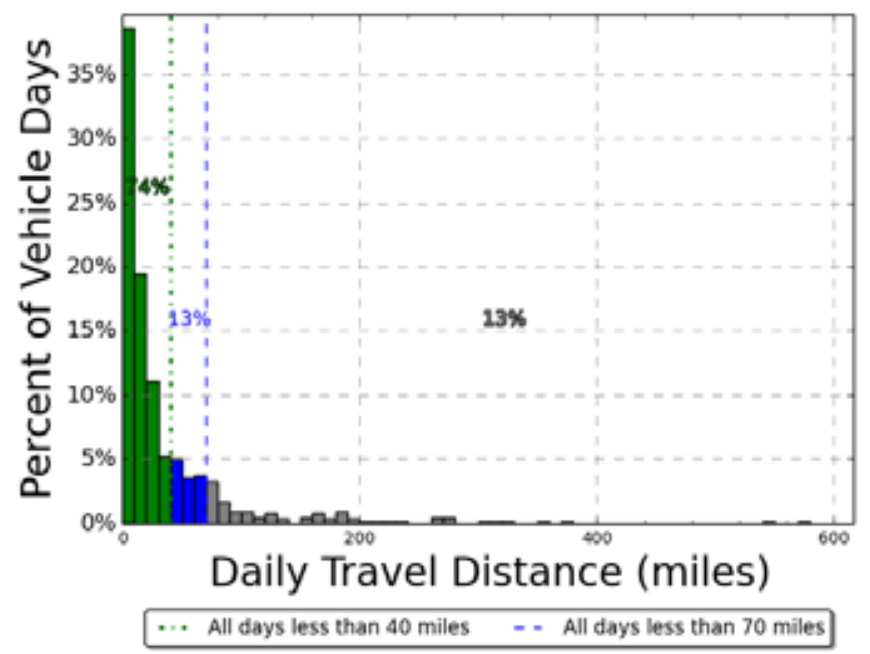

Figure 25. Motor Transport Branch pool vehicle daily travel miles (all vehicles).

The average travel distance per day when driven for pool vehicles was 35.2 miles. On $87 \%$ of the vehicle travel days, the daily travel was less than the 70 miles considered to be within the BEV safe range (blue and green bars in Figure 25). Meanwhile, 74\% of vehicle travel days were less than the 40 miles considered to be within the CD range of a PHEV (green bars of Figure 25). However, 13\% of daily travel exceeds the 70-mile range. Figure 26 displays the summary of outings for all pool vehicles.

The outings graph is dominated by the highest outing recorded of 1,599.9 miles by Passenger Van 113 (Vehicle G43-3881H) during an April excursion to Idaho and Washington. Appendix E shows this vehicle having several outings exceeding 70 miles. The majority of high-distance outings were experienced by Minivan 84, Sedan 110, Pickup 10, and most of the passenger vans in a manner similar to the daily travel maximums noted above. The other pool vehicles experienced 85 miles or less in their maximum outings. Truncating the graph at 150 miles provides a clearer view of the left side of the above graph. Figure 27 provides the truncated graph.

Appendix E provides details for each of the pool vehicle's outings. The average travel outing when driven for pool vehicles was 11.9 miles. Meanwhile, $75 \%$ of all outings for all 23 vehicles in the pool mission were less than 10 miles. Furthermore, $95 \%$ of all outings were less than the 70 miles considered to be within the BEV safe range. However, $90 \%$ of pool vehicle outings were less than 40 miles considered to be within the CD mode range of a PHEV. 


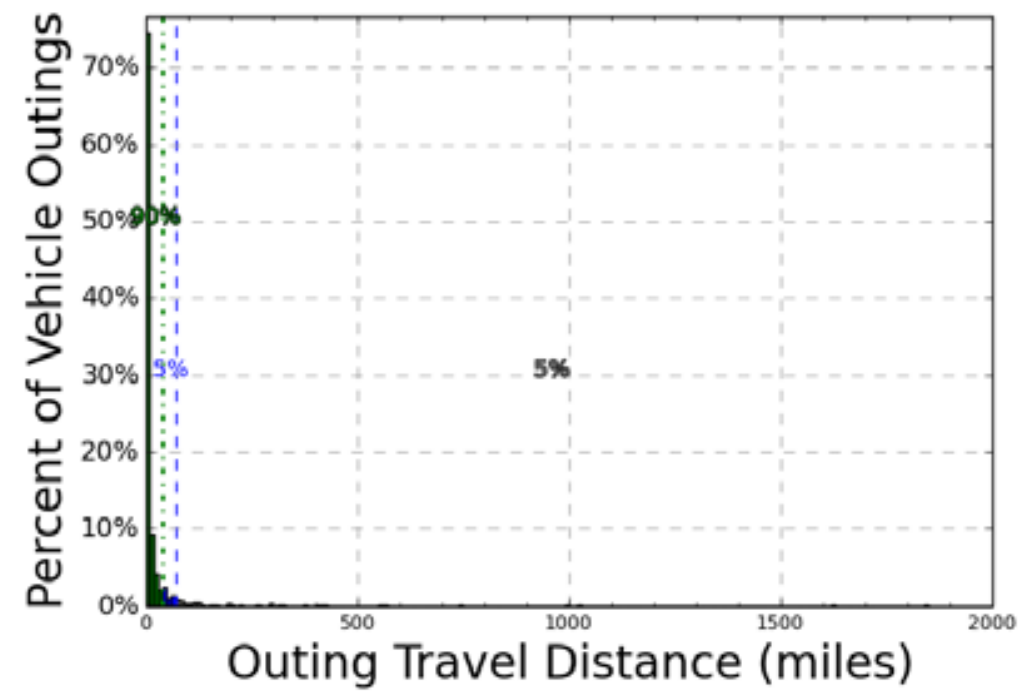

All outings less than 40 miles $\quad-$ All outings less than 70 miles

Figure 26. Motor Transport Branch pool vehicle outings (all vehicles).

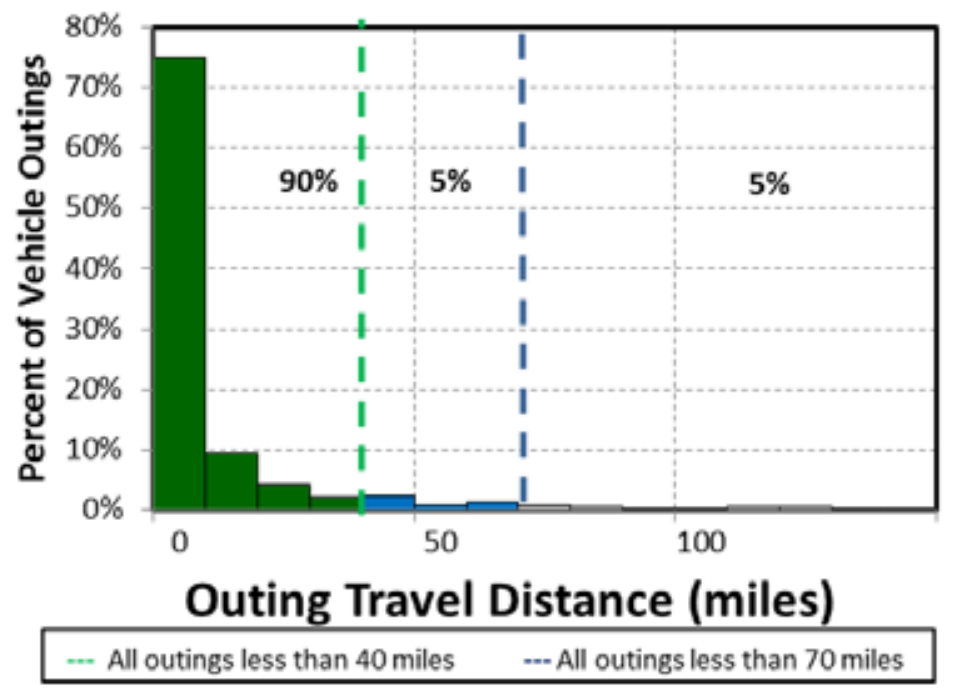

Figure 27. Motor Transport Branch pool vehicle outings (all vehicles) truncated at 150 miles.

4.4.1.2 Motor Transport Branch Pool Vehicle Observations/Summary. The vast majority of daily travel and outings were short and well within the capabilities of BEVs. This was consistent with the optimum goal to incorporate as many BEVs as possible to realize the advantages of reduced petroleum usage and reduced emissions of GHG.

The fleet of pool vehicles in this study included three minivans, four pickups, five sedans, one SUV, three cargo vans, and seven passenger vans. While no PEVs are currently available to replace the passenger van, other vehicles in the entire pool fleet have replacements available and Intertek would suggest that $10 \mathrm{BEVs}$ and six PHEVs could meet mission requirements. Section 3.4 provides information on PEVs currently or soon to be available in the automotive market and Section 5 provides details on the suggestions. 
Considering a full complement of 495 pool vehicles in the entire Motor Transport Branch fleet, Intertek suggests that by extrapolating the collected data to the entire fleet, a mixed fleet of $196 \mathrm{BEVs}$, 131 PHEVs, and 168 conventional passenger vans may be possible.

The vehicle summary shows sufficient time for charging at the base location during the course of the day and additional opportunities at intermediate charging stations. These stations also provide charging opportunities for the visiting public, whose fees may assist in offsetting operating costs.

4.4.1.3 Motor Transport Branch Pool Vehicle Charging Needs. As noted previously, AC Level 2 overnight charging of BEVs is typical, whereas overnight charging of PHEVs can be accomplished with AC Level 1 charging.

Intertek's experience suggests that each vehicle have an assigned charging location at their home base. Assigned stations require less management attention to ensure completion of overnight charging. BEVs and PHEVs not assigned to these locations also benefit from the charging stations during visits to the location as part of their normal operation. Intertek recommends a minimum of two EVSE at each location to maximize charge capability without a significant increase in installation costs. The PHEVs can utilize the AC Level 2 EVSE at the home base during the day to increase the amount of vehicle miles traveled in CD mode.

At times, fleet vehicles obtain benefit from using public charging infrastructure. Figure 18 displays the availability of public charging for the JBLM area at the time of this writing. Significant travel occurs off base by several vehicles that may find benefit in increased range for these vehicles.

\subsubsection{Motor Transport Branch Support Vehicles Analysis}

Support vehicles provide a specific work function, facilitating the mission of a particular group. The vehicles are generally passenger vehicles or light-duty pickup trucks and may contain after-market modifications to support the mission. While assigned to maintenance and service areas, missions may vary depending on agency needs.

4.4.2.1 Summary for Motor Transport Branch Support Vehicles. Appendix E provides the vehicle data sheets for each of the 11 support vehicles monitored. This section aggregates the data for all support vehicles.

Table 18 summarizes support vehicle travel during the study period. Vehicle use may occur at any hour, but primarily occurred between 0700 and 1500 hours daily. Support vehicles traveled 19,336 miles, logged 1,886 hours, and idled for 989 hours during the study period.

Table 18. Support vehicle travel summary.

\begin{tabular}{lcccc}
\hline \multicolumn{4}{c}{ Support Vehicle Travel Summary } & \\
& Per Day & Per Outing & Per Trip & \\
& Average/Peak & Average/Peak & Average/Peak & Total \\
\hline Travel Distance (Miles) & $46.9 / 555.0$ & $13.3 / 1,236$ & $5.3 / 245.6$ & 19,336 \\
Travel Time (Minutes) & $274.8 / 1,502$ & $78.0 / 1,440$ & $30.8 / 512.0$ & 113,202 \\
Idle Time (Minutes) & $58.2 / \mathrm{NA}$ & $16.5 / \mathrm{NA}$ & $6.5 / \mathrm{NA}$ & 59,355 \\
\hline
\end{tabular}

The distance a PEV can travel in CD mode between charge opportunities is the most important factor in considering vehicle replacement. The two most significant factors in vehicle analysis include the vehicle daily travel and vehicle outings. Figure 28 shows the travel summary for support vehicles by vehicle. 


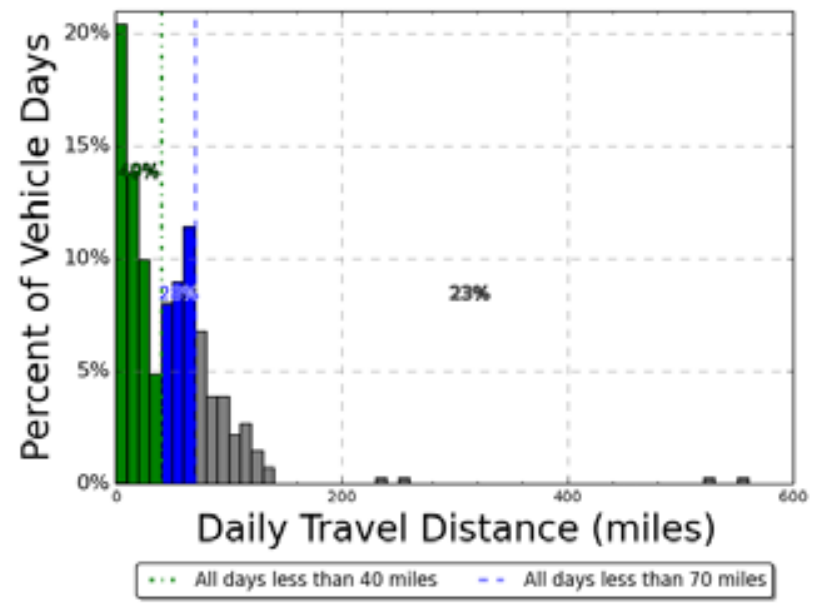

Figure 28. Motor Transport Branch support vehicle daily travel miles (all vehicles).

Sedans 119 and 16 (i.e., Vehicles G10-6379 L and G11-0493 L) and Minivan 112 (i.e., Vehicle G41-1392G) dominate the maximum daily travel with maximums of 1,236 miles, 237 miles, and 253 miles, respectively. All other vehicles in this group had maximum daily travel less than 92 miles. Pickup \#15 (i.e., Vehicle G42-0698K) was used most frequently, experiencing travel $92 \%$ of the study days.

The average travel distance per day when driven for support vehicles was 46.9 miles. On $77 \%$ of these vehicle days, the daily travel was less than the 70 miles considered to be within the BEV safe range. Meanwhile, $23 \%$ percent of support vehicle daily travel was greater than 70 miles. Furthermore, $49 \%$ of vehicle travel days were less than the 40 miles considered to be within the CD range of a PHEV. Figure 29 shows the outings for all support vehicles combined.

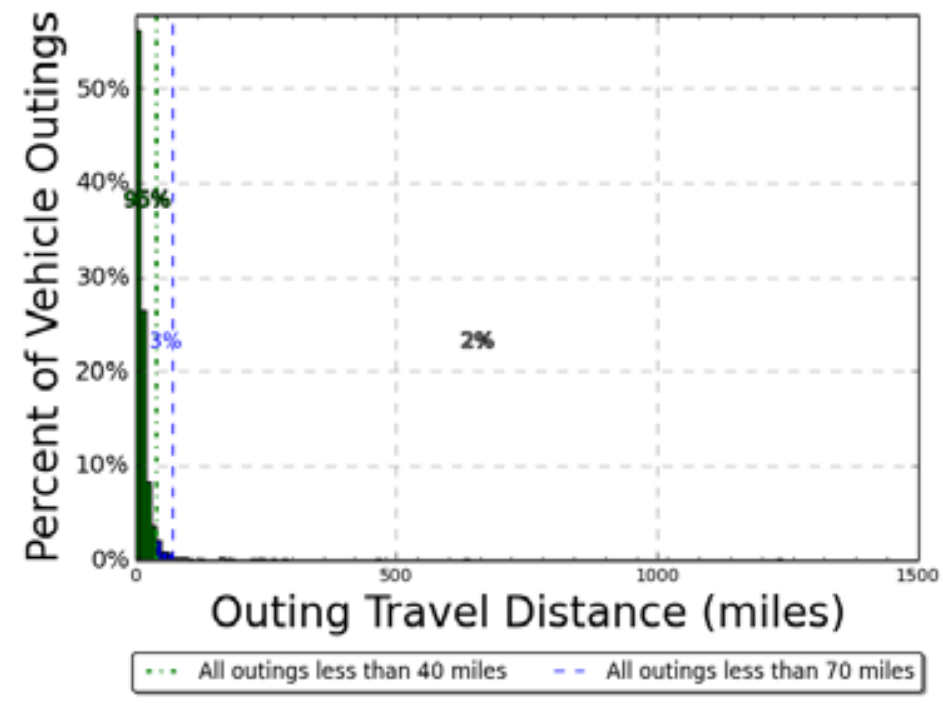

Figure 29. Motor Transport Branch support vehicle combined outings.

Sedans 119 and 16 and Minivan 112 dominate the maximum outings traveled with maximums of 1,236 miles, 237 miles, and 253 miles, respectively. All other vehicles in this group had maximum outings less than 92 miles. 
Because the single highest travel of Sedan 119 sets the upper limit of distance in Figure 29, the same figure is duplicated in Figure 36, but it is truncated at 200 miles to more clearly show the lower outing distances.

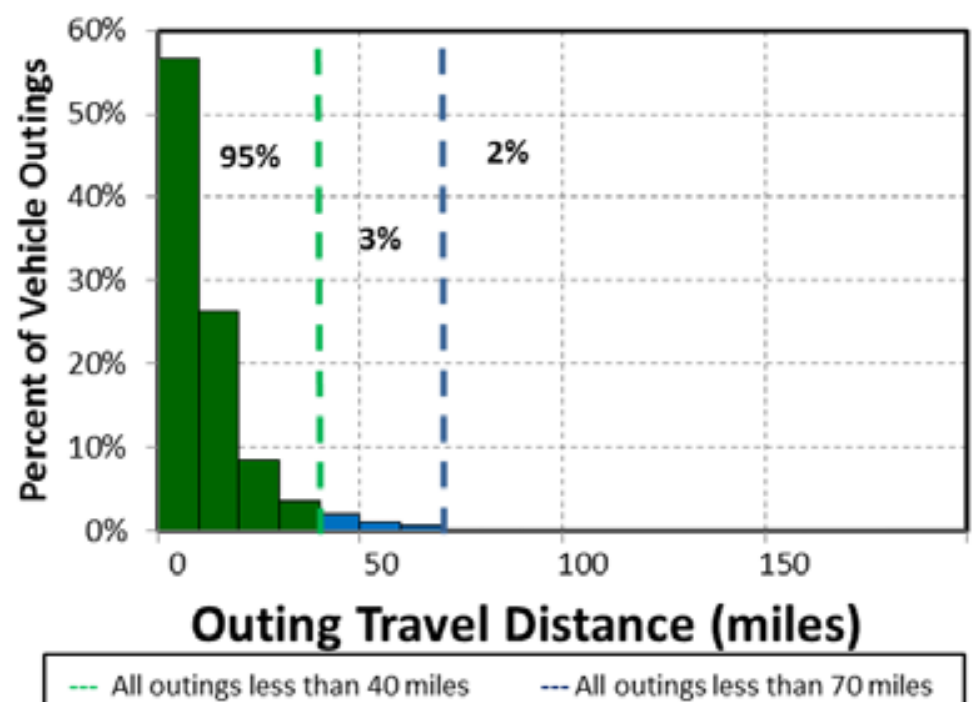

Figure 30. Motor Transport Branch support vehicle outings (all vehicles) truncated to 200 miles.

The average travel outing when driven for support vehicles was 13.3 miles. On $98 \%$ of these vehicle outings, the distance traveled was less than the 70 miles considered to be within the BEV safe range. Meanwhile, $2 \%$ of support outing travel was greater than 70 miles. Furthermore, $95 \%$ of vehicle travel outings were less than the 40 miles considered to be within the CD range of a PHEV.

4.4.2.2 Motor Transport Branch Support Vehicle Observations/Summary. As with the pool fleet, the vast majority of daily travel and outings for the support fleet were short and well within the capabilities of BEVs. This is consistent with the optimum goal to incorporate as many BEVs as possible to realize the advantages of reduced petroleum usage and reduced emissions of GHG.

The fleet of support vehicles in this study included two minivans, three pickups, three sedans, two SUVs, and one cargo van. Intertek would suggest that six BEVs and five PHEVs could meet mission requirements. Section 3.4 provides information on PEVs currently or soon to be available in the automotive market and Section 5 provides details on the suggestions.

Considering a full complement of 301 support vehicles in the entire Motor Transport Branch fleet, Intertek suggests that by extrapolating the collected data to the entire fleet, a mixed fleet of $155 \mathrm{BEVs}$, 128 PHEVs, and 18 conventional passenger vans may be possible.

The vehicle summary shows sufficient time for charging at the base location during the course of the day and additional opportunities at intermediate charging stations. These stations also provide charging opportunities for the visiting public, whose fees may assist in offsetting operating costs.

4.4.2.3 Motor Transport Branch Support Vehicle Charging Needs. As noted above, AC Level 2 overnight charging of BEVs is typical, whereas overnight charging of PHEVs can be accomplished using AC Level 1 charging. Opportunity charging at intermediate stops obtains the greater benefits from AC Level 2 EVSE. Most vehicles returned to their home base daily, with the exception of long trips lasting several days. 
Greater management attention provides the possibility of reducing the overall number of AC Level 2 EVSE. A ratio of two AC Level 2 charging stations to three vehicles typically sustains a normal fleet operation. Fleet managers rotate vehicles on the charger to complete charging of all vehicles in the allotted time. This analysis does assume a fully recharged battery at the start of each day. JBLM will gain experience in this management as the PEV fleet grows.

\subsubsection{Motor Transport Branch Transport Vehicles Analysis}

Transport vehicles are typically light or heavy-duty motor vehicles for use in cargo transportation and typically not for personnel transport. Transport missions can vary by agency, location, and jurisdiction. For the Motor Transport Branch, the transport vehicles include pickup trucks, heavy-duty trucks, passenger vans, and cargo vans. Although there currently are no PEVs available to replace heavy-duty trucks and passenger vans, it is assumed that usage of these transport vehicles can be of value in considering the remaining transport vehicles in the Motor Transport Branch fleet. The other vehicles may be replaced by currently available PEVs.

Incorporation of BEVs and/or PHEVs into the transport mission is a definite possibility. Transport vehicles used for shorter trips or outings qualify for BEV or PHEV replacement, while other transport vehicle activities that are associated with longer trips may require PHEV capabilities.

4.4.3.1 Summary for Motor Transport Branch Transport Vehicles. Appendix E provides the vehicle data sheets for each of the transport vehicles monitored. This section aggregates data for all transport vehicles. Table 19 summarizes transport vehicle travel during the study period for those days in which the vehicle was driven. Vehicle use occurred primarily between 0600 and 1700 hours daily. The vehicles traveled 1,803 miles, logged 148 hours, and idled for 77 hours during the 63-day study period.

Table 19. Transport vehicles travel summary.

\begin{tabular}{lcccc}
\hline \multicolumn{5}{c}{ Transport Vehicles Travel Summary } \\
& $\begin{array}{c}\text { Per Day } \\
\text { Average/Peak }\end{array}$ & $\begin{array}{c}\text { Per Outing } \\
\text { Average/Peak }\end{array}$ & $\begin{array}{c}\text { Per Trip } \\
\text { Average/Peak }\end{array}$ & Total \\
\hline Travel Distance (Miles) & $53.0 / 393.8$ & $22.9 / 393.8$ & $6.5 / 142.5$ & 1,803 \\
Travel Time (Minutes) & $237.9 / 669.0$ & $102.5 / 673.0$ & $29.2 / 218.0$ & 8,090 \\
Idle Time (Minutes) & $136.6 / \mathrm{NA}$ & 58.8/NA & $16.8 / \mathrm{NA}$ & 4,643 \\
\hline
\end{tabular}

The distance a PEV can travel in CD mode between charge opportunities is the most important factor in considering vehicle replacement. The two most significant factors in vehicle analysis include the vehicle daily travel and vehicle outings. Figure 31 shows the travel summary for transport vehicles. Four vehicles failed to report sufficient data for analysis, as noted in the vehicle data sheets of Appendix E. This is most likely due to infrequent use because there were few data points logged.

The average travel distance per day when driven for transport vehicles was 53.0 miles. On $72 \%$ of vehicle travel days, the daily travel was less than the 70 miles considered to be within the BEV safe range (blue and green bars in Figure 31). Meanwhile, 69\% of vehicle travel days were less than the 40 miles considered to be within the CD mode range of a PHEV (green bars of Figure 31). Figure 32 shows the outings for all vehicles.

Appendix E provides the details of each of the transport vehicle's outings. Pickup Truck 111 (i.e., Vehicle G63-3881H) was used on the three longest outings and the longest daily travel.

The average travel outing for transport vehicles when driven was 22.9 miles. Meanwhile, $90 \%$ percent of transport outings were less than the 40 miles considered to be within the CD mode range of a PHEV. 


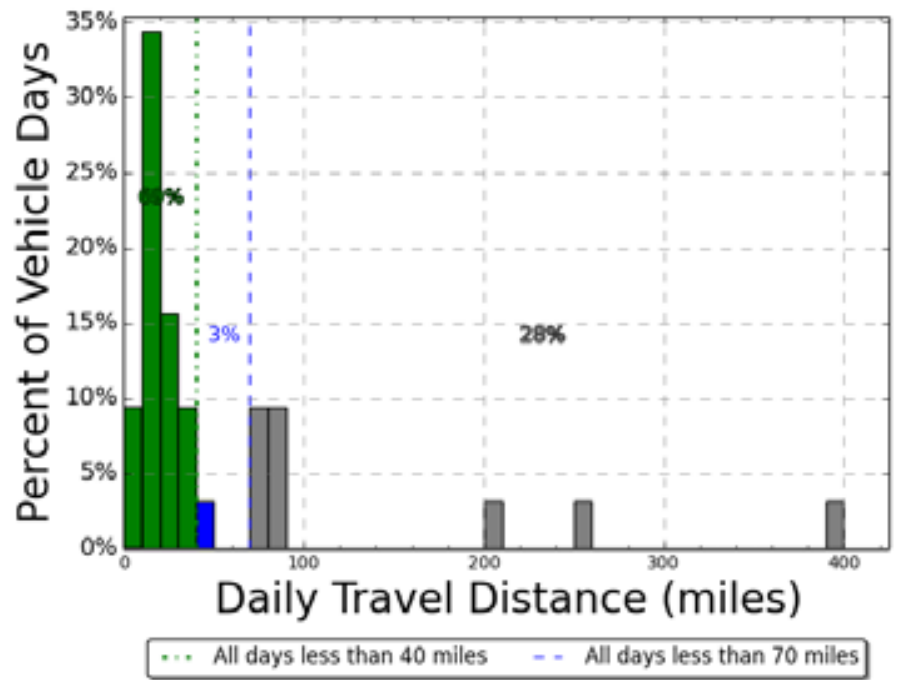

Figure 31. Motor Transport Branch transport vehicle daily travel miles (all vehicles).

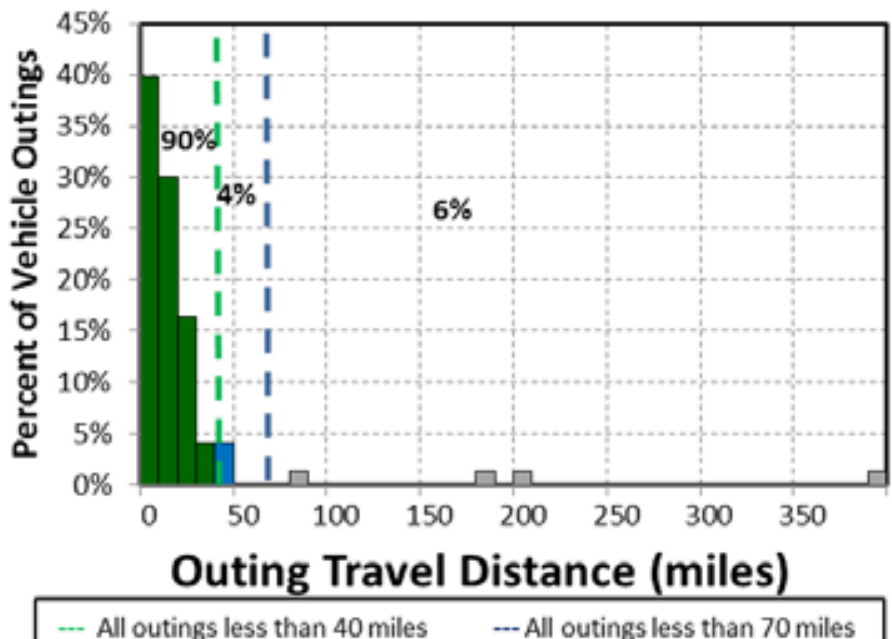

Figure 32. Motor Transport Branch transport vehicle combined outings.

4.4.3.2 Motor Transport Branch Transport Vehicle Observations/Summary. Again, the vast majority of daily travel and outings for the transport fleet were short and well within the capabilities of BEVs. This is consistent with the optimum goal to incorporate as many BEVs as possible to realize the advantages of reduced petroleum usage and reduced emissions of GHG.

The fleet of transport vehicles in this study included two pickups, two heavy-duty trucks, and two cargo vans. However, there currently are no PEV replacements for heavy-duty trucks. Intertek would suggest that two suitable styled BEVs and two PHEVs could meet mission requirements. Section 3.4 provides information on PEVs currently or soon to be available in the automotive market and Section 5 provides details on the suggestions.

Considering a full complement of 204 transport vehicles in the entire Motor Transport Branch fleet, Intertek suggests that by extrapolating the collected data to the entire fleet, a mixed fleet of $58 \mathrm{BEVs}$, 57 PHEVs, 73 conventional heavy-duty trucks, and 16 conventional passenger vans may be possible. 
The vehicle summary shows sufficient time for charging at the base location during the course of the day and additional opportunities at intermediate charging stations. These stations also provide charging opportunities for the visiting public, whose fees may assist in offsetting operating costs.

4.4.3.3 Motor Transport Branch Transport Vehicle Charging Needs. As noted previously, AC Level 2 overnight charging of BEVs is typical, whereas overnight charging of PHEVs uses the AC Level 1 outlet.

Intertek's experience suggests that each vehicle have an assigned charging location at their home base. Assigned stations require less management attention to ensure completion of overnight charging. BEVs and PHEVs not assigned to these locations also benefit by charging during visits to the location as part of their normal operation. The PHEVs can utilize the AC Level 2 EVSE at the home base during the day to increase the amount of vehicle miles traveled in CD mode.

At times, fleet vehicles obtain benefit from using public charging infrastructure. Figure 18 displays the availability of public charging at the time of this writing for the JBLM area. This may be of benefit for local travel, but the availability of public EVSE cannot be assured and is not considered as part of this evaluation.

\subsubsection{Motor Transport Branch Vehicles Mileage}

The vehicle's annual miles factor into the calculations for replacement of vehicles as noted in Section 5 and Appendix I. The actual miles measured during the study were extrapolated to identify calculated annual miles in the study. JBLM has also provided vehicle information that identified the average monthly miles and vehicle mileage in April 2012.

For the entire Motor Transport Branch fleet, the average monthly miles traveled were 527 miles for an average annual travel of 6,328 miles. In general, there is good correlation between the JBLM-provided averages and the study's calculated annual mileage. The JBLM-provided mileage information were used in the calculations when available, except for Logger 15, where the study information appears more reasonable. Overall, this annual mileage is relatively low and reflects positively on the use of BEVs in the fleet.

\subsubsection{Motor Transport Branch Summary}

This study provides observations for both the vehicles monitored and for the entire non-tactical fleet of vehicles identified with the Motor Transport Branch. The study indicates that PEVs offer alternatives to vehicles in the existing fleet, provided any specific cargo requirements are met by the PEV. In general, a mixed fleet of BEVs and PHEVs is suggested.

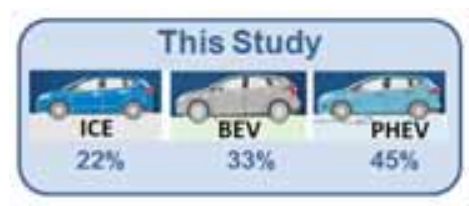

The vehicles monitored in this study included eight sedans, five minivans, three SUVs, six cargo vans, seven passenger vans, nine pickup trucks, and two heavy-duty trucks (all conventional ICE based). Based on the travel data, Intertek suggests that retaining the seven passenger vans and two heavy-duty trucks and replacing the remaining vehicles with 13 PHEVs and 18 BEVs would meet current mission requirements. Section 5 identifies potential replacement PEVs and Appendix I provides specific recommendations.

The vehicles studied were utilized on $68 \%$ of the study days and averaged 2.3 hours of use per day. Daily usage was quite low, although most vehicles show frequent use.

The Motor Transport Branch full fleet of vehicles contains 1,060 vehicles. Intertek suggests that retaining the four conventional specialty vehicles, 202 conventional passenger vans, 56 conventional buses, and 73 conventional

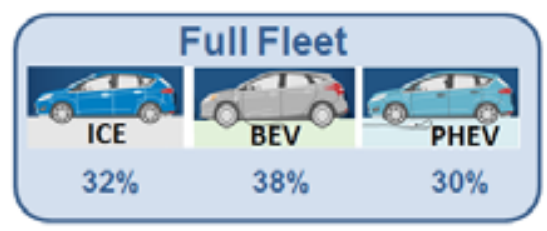


heavy-duty trucks for now and a fleet of 409 BEVs and 316 PHEVs would conservatively meet the vehicle travel requirements.

With the potential replacement by PEVs established, Section 5 and Appendix M provide further evaluation of the benefits of such replacements. This will be factored into further observations and suggestions related to the business case and schedule for any replacements for the Public Works Group. Those observations will be addressed in Task 4 of this project.

\subsection{Balance of Joint Base Lewis McChord Fleet}

The balance of the JBLM fleet consists of vehicles assigned to several agencies. Table 20 provides the balance of vehicles at JBLM using information provided by JBLM and sorted by vehicle type.

Table 20. JBLM balance of fleet vehicles.

\begin{tabular}{|c|c|c|c|c|c|c|c|c|c|c|c|}
\hline & $\begin{array}{c}\text { Sedan } \\
\text { Compact/ } \\
\text { Subcompact }\end{array}$ & $\begin{array}{c}\text { Sedan } \\
\text { Midsize/ } \\
\text { Large } \\
\end{array}$ & $\begin{array}{l}\text { Mini } \\
\text {-van }\end{array}$ & SUV & Specialty & $\begin{array}{c}\text { Cargo } \\
\text { Van } \\
\end{array}$ & $\begin{array}{c}\text { Pass. } \\
\text { Van }\end{array}$ & $\begin{array}{l}\text { Pickup } \\
\text { or } \\
\text { Light- } \\
\text { Duty } \\
\text { Truck } \\
\end{array}$ & $\begin{array}{l}\text { Middle- } \\
\text { Duty or } \\
\text { Heavy- } \\
\text { Duty } \\
\text { Truck }\end{array}$ & Bus & Total \\
\hline Total & 12 & 18 & 25 & 44 & 1 & 10 & 25 & 51 & 3 & 1 & 190 \\
\hline
\end{tabular}

PEV replacement vehicles are available for all the above vehicle types, with the exception of the heavy-duty trucks, some specialty vehicles, and passenger vans. Further analysis would be required to identify missions and to provide specific observations. However, PEV are currently available to potentially replace all sedans, minivans, SUVs, cargo vans, and pickup trucks.

\section{GREENHOUSE GAS EMISSIONS AVOIDED AND FUEL COST REDUCTION ANALYSIS}

\subsection{Background and Methods}

PEV substitution for an existing conventional vehicle avoids GHG emissions and reduces fuel costs. The GHG emissions avoided occur due to the difference in emissions associated with power plant electricity generation versus fuel combustion that occurs in the engine of a conventional vehicle. This analysis does not account for life-cycle emissions that occur outside of electricity generation and fuel combustion phases (i.e., materials and resource extraction, production supply-chains, and decommissioning are not accounted for). These phases are beyond the scope of this report due to the significant effort required to conduct an accurate environmental life-cycle assessment for a transportation system in a very specific setting. The analysis used is known as a "tank-to-wheel" analysis, rather than a "well-to-wheel" analysis that would include the aforementioned phases. Cost reduction also occurs because the cost of electricity is much less than the cost of gasoline and PEVs are more efficient than conventional ICE vehicles. Because fuel logs were not kept, the mileage accumulated by each vehicle during the study is compared to the average miles reported by JBLM. The JBLM report provides the source of fuel consumption estimates for the study vehicles.

Several PEV types are available for potential replacement in the JBLM fleets as shown in Section 3. For this analysis, Table 21 provides the vehicles suggested as replacement vehicles for those identified in the analysis of Section 4. The EPA class of the replacement PEV is the same or similar to the current vehicle class. The energy consumption values for each PEV are displayed with the vehicle; note that for PHEVs, the energy consumption is only for CD mode. 
Table 21. PEV substitutions for current vehicles.

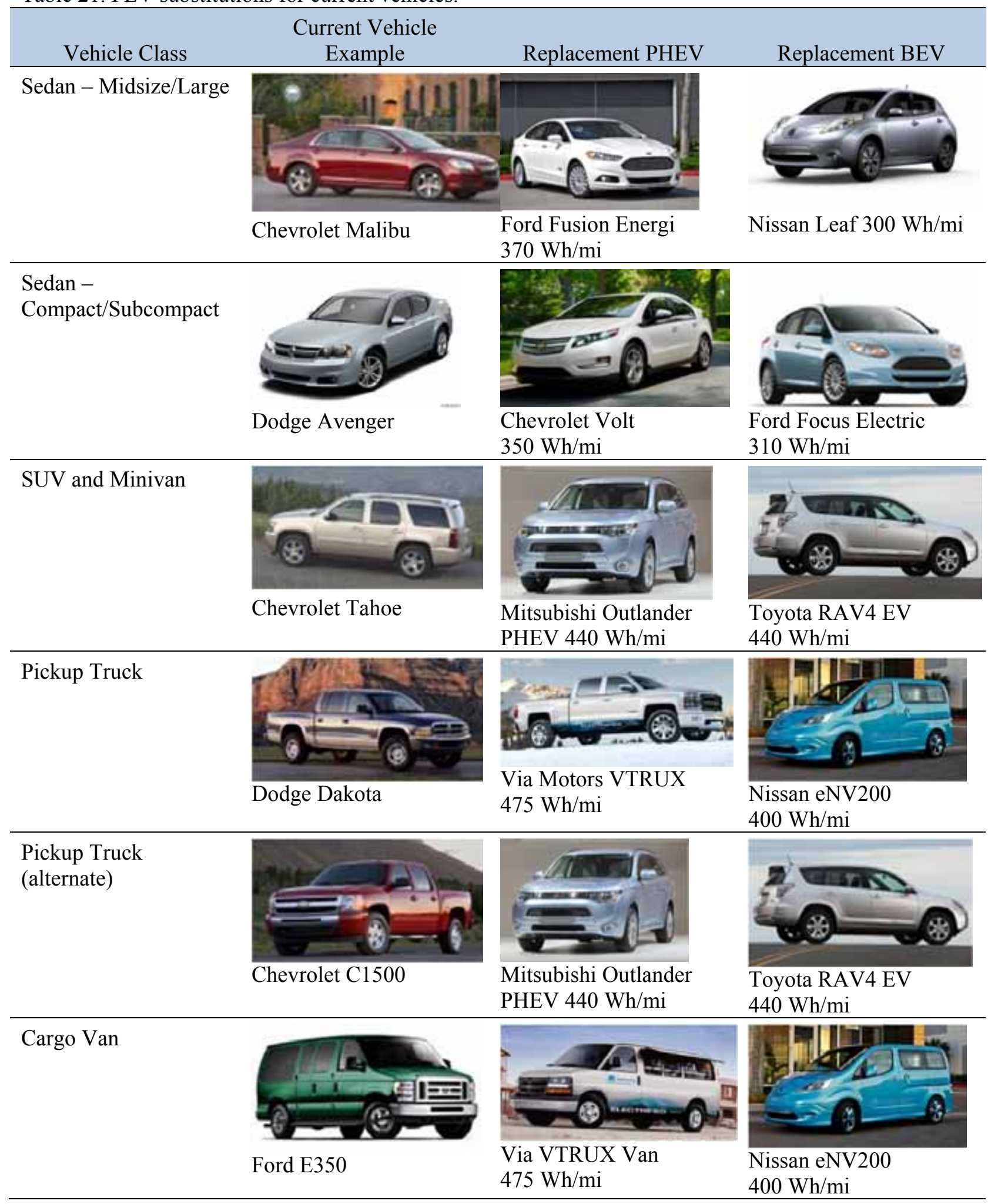


In order to perform the analysis, EPA fuel economy ratings are used. ${ }^{19}$ The ratings for each vehicle are recorded in the vehicle data sheets of Appendices B through E. Because these data are estimates, assumptions include the following:

1. PHEVs operate in CD mode only for the percentage of travel less than 40 miles per day. This is reasonable for most daily operations, as described in Section 4, and is conservative because additional charge time exists between most outings. It is also conservative in that the replacement PEV typically will have greater fuel economy when operating in CS mode. BEVs operate in electric mode for $100 \%$ of travel.

2. Annual miles in the study are compared to JBLM reported miles. JBLM reported miles are used as records over a greater period. The JBLM reported miles are extrapolated to a full 365-day year. Miles in CD mode are the extrapolated miles times percent of daily travel less than 40 miles for the PHEV replacement and full extrapolated miles for the BEV replacement.

3. The energy consumption for the Mitsubishi Outlander is the same as the RAV4 and the energy consumption for the Via Motors vehicles and Nissan eNV200 are estimated because the EPA has not yet created ratings for these vehicles.

4. Some of the existing pickup trucks may be replaced by SUV-type vehicles as shown above.

5. The conventional heavy-duty trucks and passenger vans are not replaced.

Calculations provided for GHG emissions and fuel savings include both a total U.S. perspective and a perspective for the local area. The electricity generation mix of power plants for the total United States is different from the local mix of generation in the JBLM area. Likewise, the national average cost for petroleum fuel is different from the local cost for fuel. This analysis includes both approaches in order to allow for local evaluation and to provide the potential benefit for fleet vehicles in other locations of the United States that may be of interest. The final report from Intertek to Idaho National Laboratory primarily will consider the national figures.

For the GHG emissions avoided portion of the analysis, the GHG emissions (in pounds of carbon dioxide equivalent, which accounts for other GHGs such as methane and nitrous oxide, $1 \mathrm{~b}-\mathrm{CO}_{2} \mathrm{e}$ ) from combustion of gasoline is $20.1 \mathrm{lb}-\mathrm{CO}_{2} \mathrm{e} /$ gallon. ${ }^{20}$ The United States' average for GHG emissions for the production of electricity is $1.53 \mathrm{lb}-\mathrm{CO}_{2} \mathrm{e} / \mathrm{kWh}^{21}$

JBLM reported receiving base power from Tacoma Power. Tacoma Power reports a mix of its own generation and power provided by other sources in its 2013 Integrated Resource Plan. ${ }^{22}$ EPA reports GHG emissions from the production of electricity. The annual report is available in the Emissions and Generation Resource Integrated Database. The most recent publication is for $2010 .^{23}$ Using the generation mix reported by Tacoma Power in 2013 and the Emissions and Generation Resource Integrated Database plant reports, emissions for 2010 for the production of electricity were $0.1743 \mathrm{lb}-\mathrm{CO}_{2} \mathrm{e} / \mathrm{kWh}$. This emission rate reflects the high local reliance on hydroelectricity as the generation source and, thus, emissions are much lower than the national average.

GHG emissions avoided are the annual GHG emitted by the current vehicle (total annual gallons gasoline $\times$ GHG emissions/gallon) minus the annual GHG emitted by the replacement PEV (total annual

\footnotetext{
${ }^{19} \mathrm{http}: / /$ www.fueleconomy.gov/feg/Find.do?action=sbs\&id=33558 [accessed February 2, 2014].

${ }^{20} \mathrm{http} / / / \mathrm{www}$. theevproject.com/cms-assets/documents/106077-891082.ghg.pdf for the methodology for gasoline [accessed 19 July 2013].

${ }^{21}$ ibid

${ }^{22}$ http://www.tacomapower.org/file viewer.aspx?id=27545 [accessed 30 June 2014].

${ }^{23} \mathrm{http}$ //www.epa.gov/cleanenergy/energy-resources/egrid/ [accessed 8 June 2014].
} 
$\mathrm{kWh} \times \mathrm{GHG}$ emissions $/ \mathrm{kWh}$ ). For the PHEVs, only the percentages of outings less than 40 miles are counted for the annual miles saved in CD mode.

For the cost-avoided piece of the analysis, EPA provides links to current fuel prices. At this report, fuel costs for regular gasoline are \$3.679/gallon for the United States and \$4.009/gallon for the Tacoma, Washington area. ${ }^{24}$ Electrical cost assumptions are $0.13 \$ / \mathrm{kWh}$ for the United States and $0.02783 \$ / \mathrm{kWh}$ for industrial customers on Schedule CP in the Tacoma Power service territory. ${ }^{25}$ Therefore, fuel costs savings are the current vehicle's calculated annual gasoline cost (total annual gallons gasoline $\times$ cost/gallon) minus the electricity cost (total annual $\mathrm{kWh} \times \operatorname{cost} / \mathrm{kWh}$ ) of the replacement PEV traveling the same distance.

The miles calculated above for CD mode yields estimates for yearly GHG emissions avoided and fuel cost reductions. Appendices J through M provide the details of the results of analyses for each of the fleets studied. While the appendices provide both national and local figures, only the local Tacoma area figures are reported here for clarity.

\subsection{Monitored Vehicles Fuel Cost Reduction}

Tables 23, 24, and 25 provide the summary of potential fuel cost reduction with the replacement of monitored vehicles in the mission identified with PEVs as noted in Appendices J through M. Note that no replacements are suggested for passenger vans and heavy-duty trucks. Only the local Washington State fuel costs are considered in these tables. However, because Washington State fuel costs are higher than the national average, local gasoline costs are higher than national figures. Also, because Tacoma Power relies more on cheaper hydroelectric power than the average of all national power providers, electrical fuel costs in Washington State are lower. The comparison to national averages occurs in the appendices.

During the study, both the Public Works Group and the Motor Transport Branch identified the vehicle with Logger 84 as part of their fleet. The appendices include this vehicle in both fleets, but omit this vehicle from the Motor Transport Branch fleet for the totals shown in these tables. Table 25 provides a total of all vehicles monitored.

Table 22. Monitored pool mission PEV replacement fuel cost reduction.

\begin{tabular}{|c|c|c|c|c|c|c|c|c|}
\hline Fleet Group & $\begin{array}{c}\text { Number of } \\
\text { Vehicles }\end{array}$ & $\begin{array}{l}\text { Avg \% of } \\
\text { Travel CD } \\
\text { Mode }\end{array}$ & $\begin{array}{l}\text { Annual } \\
\text { Miles CD } \\
\text { Mode }\end{array}$ & $\begin{array}{c}\text { Gas Gallons } \\
\text { Saved }\end{array}$ & $\begin{array}{c}\text { Annual Gas } \\
\text { Cost WA }\end{array}$ & $\begin{array}{l}\text { Annual } \\
\text { Elect Fuel } \\
\text { Cost WA }\end{array}$ & $\begin{array}{c}\text { Annual Fuel } \\
\text { Saving WA }\end{array}$ & $\begin{array}{c}\text { Annual Fuel } \\
\text { Reduction } \\
\text { WA \% }\end{array}$ \\
\hline 6th MP Group & 3 & $97 \%$ & 17,065 & 859 & 3,442 & 182 & 3,259 & $95 \%$ \\
\hline DCA Support Gp & 2 & $100 \%$ & 3,276 & 234 & 937 & 39 & 898 & $96 \%$ \\
\hline Public Works & 6 & $96 \%$ & 17,638 & 1,027 & 4,116 & 206 & 3,910 & $95 \%$ \\
\hline Motor Transport & 15 & $88 \%$ & 66,838 & 3,806 & 15,260 & 738 & 14,522 & $95 \%$ \\
\hline Total & 26 & & 104,817 & 5,926 & 23,755 & 1,165 & 22,589 & $95 \%$ \\
\hline
\end{tabular}

Table 23. Monitored support mission PEV replacement fuel cost reduction (Washington State).

\begin{tabular}{|c|c|c|c|c|c|c|c|c|}
\hline Fleet Group & $\begin{array}{c}\text { Number of } \\
\text { Vehicles }\end{array}$ & $\begin{array}{l}\text { Avg \% of } \\
\text { Travel CD } \\
\text { Mode }\end{array}$ & $\begin{array}{c}\text { Annual } \\
\text { Miles CD } \\
\text { Mode }\end{array}$ & $\begin{array}{c}\text { Gas Gallons } \\
\text { Saved }\end{array}$ & $\begin{array}{c}\text { Annual Gas } \\
\text { Cost WA }\end{array}$ & $\begin{array}{c}\text { Annual } \\
\text { Elect Fuel } \\
\text { Cost WA }\end{array}$ & $\begin{array}{c}\text { Annual Fuel } \\
\text { Saving WA }\end{array}$ & $\begin{array}{c}\text { Annual Fuel } \\
\text { Reduction } \\
\text { WA \% }\end{array}$ \\
\hline 6th MP Group & NA & NA & NA & NA & NA & NA & NA & NA \\
\hline DCA Support Gp & 1 & $98 \%$ & 2,940 & 128 & 512 & 39 & 474 & $93 \%$ \\
\hline Public Works & 5 & $88 \%$ & 18,574 & 1,152 & 4,617 & 226 & 4,392 & $95 \%$ \\
\hline Motor Transport & 11 & $88 \%$ & 64,364 & 3,653 & 14,645 & 688 & 13,956 & $95 \%$ \\
\hline Total & 17 & & 85,877 & 4,933 & 19,774 & 953 & 18,822 & $95 \%$ \\
\hline
\end{tabular}

${ }^{24}$ http://www.tacomagasprices.com/ [accessed June 30, 2014].

${ }^{25}$ https://www.mytpu.org/file_viewer.aspx?id=6168 [Accessed June 30, 2014]. 
Table 24. Monitored transport mission PEV replacement fuel cost reduction (Washington State).

\begin{tabular}{|c|c|c|c|c|c|c|c|c|}
\hline Fleet Group & $\begin{array}{l}\text { Number of } \\
\text { Vehicles }\end{array}$ & $\begin{array}{c}\text { Avg \% of } \\
\text { Travel CD } \\
\text { Mode }\end{array}$ & $\begin{array}{l}\text { Annual } \\
\text { Miles CD } \\
\text { Mode }\end{array}$ & $\begin{array}{c}\text { Gas Gallons } \\
\text { Saved }\end{array}$ & $\begin{array}{c}\text { Annual Gas } \\
\text { Cost WA }\end{array}$ & $\begin{array}{c}\text { Annual } \\
\text { Elect Fuel } \\
\text { Cost WA } \\
\end{array}$ & $\begin{array}{c}\text { Annual Fuel } \\
\text { Saving WA }\end{array}$ & $\begin{array}{c}\text { Annual Fuel } \\
\text { Reduction } \\
\text { WA \% }\end{array}$ \\
\hline 6th MP Group & NA & NA & NA & NA & NA & NA & NA & NA \\
\hline DCA Support Gp & NA & NA & NA & NA & NA & NA & NA & NA \\
\hline Public Works & NA & NA & NA & NA & NA & NA & NA & NA \\
\hline Motor Transport & 4 & $82 \%$ & 13,256 & 987 & 3,955 & 164 & 3,791 & $96 \%$ \\
\hline Total & 4 & & 13,256 & 987 & 3,955 & 164 & 3,791 & $96 \%$ \\
\hline
\end{tabular}

Table 25. Monitored vehicle PEV replacement fuel cost reduction (Washington State) all vehicles.

\begin{tabular}{|c|c|c|c|c|c|c|c|c|c|}
\hline Fleet Group & $\begin{array}{l}\text { Number of } \\
\text { Vehicles }\end{array}$ & $\begin{array}{l}\text { Avg \% of } \\
\text { Travel CD } \\
\text { Mode }\end{array}$ & $\begin{array}{l}\text { Annual } \\
\text { Miles CD } \\
\text { Mode }\end{array}$ & $\begin{array}{c}\text { Gas Gallons } \\
\text { Saved }\end{array}$ & $\begin{array}{c}\text { Annual Gas } \\
\text { Cost WA }\end{array}$ & & $\begin{array}{l}\text { Inual } \\
\text { ct Fuel } \\
\text { st WA }\end{array}$ & $\begin{array}{c}\text { Annual Fuel } \\
\text { Saving WA }\end{array}$ & $\begin{array}{c}\text { Annual Fuel } \\
\text { Reduction } \\
\text { WA \% }\end{array}$ \\
\hline 6th MP Group & 3 & $97 \%$ & 17,065 & 859 & 3,442 & $\$$ & 182 & 3,259 & $95 \%$ \\
\hline DCA Support Gp & 3 & $99 \%$ & 6,216 & 362 & 1,449 & $\$$ & 78 & 1,372 & $95 \%$ \\
\hline Public Works & 11 & $92 \%$ & 36,212 & 2,178 & 8,733 & $\$$ & 432 & 8,302 & $95 \%$ \\
\hline Motor Transport & 30 & $86 \%$ & 144,457 & 8,446 & 33,860 & $\$$ & 1,590 & 32,270 & $95 \%$ \\
\hline Total & 47 & & 203,950 & 11,845 & 47,484 & $\$$ & 2,282 & 45,202 & $95 \%$ \\
\hline Average/vehicle & & & 4,339 & 252 & 1,010 & $\$$ & 49 & 962 & $95 \%$ \\
\hline
\end{tabular}

In summary, if all possible monitored vehicles were replaced with PEVs, nearly 12,000 gallons of gasoline would be avoided each year. This would save over $\$ 47,000$ in gasoline fuel costs, while only using about $\$ 2,300$ of electricity. As shown in Table 31, there is an average of over $\$ 1,000$ savings in fuel cost per vehicle annually when replaced by a PEV. Appendices $\mathrm{J}$ through $\mathrm{M}$ show vehicles with higher annual miles having potential fuel savings of over $\$ 4,000$ annually.

\subsection{Monitored Vehicles Greenhouse Gas Emissions Reduction}

Tables 27, 28, and 29 provide the summary of potential GHG emission reduction with the replacement of monitored vehicles with PEVs in the mission identified as noted in Appendices $\mathrm{J}$ through M. Again, no replacements are suggested for passenger vans and heavy-duty trucks. Only the local Washington State GHG reductions are considered in these tables. However, as mentioned previously, because JBLM receives it power from Tacoma Power and Tacoma Power relies more on cleaner hydroelectric power than the average of all national power providers, electrical emissions in Washington State are lower. Electrical emissions are significantly lower than gasoline emissions. Table 29 provides a total of all vehicles monitored.

Table 26. Monitored pool mission PEV replacement GHG emission reduction.

\begin{tabular}{|l|r|r|r|r|r|r|r|}
\hline \multicolumn{1}{|c|}{ Fleet Group } & $\begin{array}{c}\text { Number } \\
\text { of } \\
\text { Vehicles }\end{array}$ & $\begin{array}{c}\text { Avg \% of } \\
\text { Travel CD } \\
\text { Mode }\end{array}$ & $\begin{array}{c}\text { Annual Miles } \\
\text { CD Mode }\end{array}$ & $\begin{array}{c}\text { Annual GHG } \\
\text { Emission ICE } \\
\text { lb-CO2e }\end{array}$ & $\begin{array}{c}\text { Annual PEV } \\
\text { GHG WA } \\
\text { lb-CO2e }\end{array}$ & $\begin{array}{c}\text { Annual PEV } \\
\text { GHG Sav WA } \\
\text { Ib-CO2e }\end{array}$ & $\begin{array}{c}\text { Annual GHG } \\
\text { Reduction } \\
\text { WA \% }\end{array}$ \\
\hline 6th MP Group & 3 & $97 \%$ & 11,674 & 17,253 & 1,140 & 16,113 & $93 \%$ \\
\hline DCA Support Gp & 2 & $100 \%$ & 2,368 & 4,703 & 247 & 4,456 & 19,347 \\
Public Works & 6 & $96 \%$ & 15,168 & 20,637 & 1,290 & $95 \%$ \\
Motor Transport & 16 & $88 \%$ & 37,077 & 76,509 & 4,620 & 71,889 & $94 \%$ \\
\hline Total & 27 & & 66,286 & 119,102 & 7,297 & 111,805 & $94 \%$ \\
\hline
\end{tabular}


Table 27. Monitored support mission PEV replacement GHG emission reduction.

\begin{tabular}{|l|r|r|r|r|r|r|r|}
\hline Fleet Group & $\begin{array}{c}\text { Number } \\
\text { of } \\
\text { Vehicles }\end{array}$ & $\begin{array}{c}\text { Avg \% of } \\
\text { Travel CD } \\
\text { Mode }\end{array}$ & $\begin{array}{c}\text { Annual Miles } \\
\text { CD Mode }\end{array}$ & $\begin{array}{c}\text { Annual GHG } \\
\text { Emission ICE } \\
\text { Ib-CO2e }\end{array}$ & $\begin{array}{c}\text { Annual PEV } \\
\text { GHG WA } \\
\text { lb-CO2e }\end{array}$ & $\begin{array}{c}\text { Annual PEV } \\
\text { GHG Sav WA } \\
\text { lb-CO2e }\end{array}$ & $\begin{array}{c}\text { Annual GHG } \\
\text { Reduction } \\
\text { WA \% }\end{array}$ \\
\hline 6th MP Group & NA & NA & NA & NA & NA & NA & NA \\
DCA Support Gp & 1 & $100 \%$ & 2,940 & 2,569 & 243 & 2,326 & $91 \%$ \\
Public Works & 5 & $96 \%$ & 18,574 & 23,150 & 1,414 & 21,736 & $94 \%$ \\
Motor Transport & 11 & $88 \%$ & 64,364 & 73,424 & 4,312 & 69,112 & $94 \%$ \\
\hline Total & 17 & & 85,877 & 99,142 & 5,969 & 93,174 & $94 \%$ \\
\hline
\end{tabular}

Table 28. Monitored transport mission PEV replacement GHG emission reduction.

\begin{tabular}{|l|c|c|c|c|c|c|c|}
\hline Fleet Group & $\begin{array}{c}\text { Number } \\
\text { of } \\
\text { Vehicles }\end{array}$ & $\begin{array}{c}\text { Avg \% of } \\
\text { Travel CD } \\
\text { Mode }\end{array}$ & $\begin{array}{c}\text { Annual Miles } \\
\text { CD Mode }\end{array}$ & $\begin{array}{c}\text { Annual GHG } \\
\text { Emission ICE } \\
\text { lb-CO2e }\end{array}$ & $\begin{array}{c}\text { Annual PEV } \\
\text { GHG WA } \\
\text { lb-CO2e }\end{array}$ & $\begin{array}{c}\text { Annual PEV } \\
\text { GHG Sav WA } \\
\text { lb-CO2e }\end{array}$ & $\begin{array}{c}\text { Annual GHG } \\
\text { Reduction } \\
\text { WA \% }\end{array}$ \\
\hline 6th MP Group & NA & NA & NA & NA & NA & NA & NA \\
DCA Support Gp & NA & NA & NA & NA & NA & NA & NA \\
Public Works & NA & NA & NA & NA & NA & NA & NA \\
Motor Transport & 4 & $88 \%$ & 13,256 & 19,830 & 1,026 & 18,804 & $95 \%$ \\
\hline Total & 4 & & 13,256 & 19,830 & 1,026 & 18,804 & $95 \%$ \\
\hline
\end{tabular}

Table 29. Monitored vehicle PEV replacement GHG emission reduction (Washington State) all vehicles.

\begin{tabular}{|c|c|c|c|c|c|c|c|}
\hline Fleet Group & $\begin{array}{c}\text { Number } \\
\text { of } \\
\text { Vehicles }\end{array}$ & $\begin{array}{c}\text { Avg \% of } \\
\text { Travel CD } \\
\text { Mode }\end{array}$ & $\begin{array}{c}\text { Annual Miles } \\
\text { CD Mode }\end{array}$ & $\begin{array}{c}\text { Annual GHG } \\
\text { Emission ICE } \\
\text { Ib-CO2e }\end{array}$ & $\begin{array}{c}\text { Annual PEV } \\
\text { GHG WA } \\
\text { Ib-CO2e }\end{array}$ & \begin{tabular}{|c|} 
Annual PEV \\
GHG Sav WA \\
Ib-CO2e \\
\end{tabular} & $\begin{array}{c}\text { Annual GHG } \\
\text { Reduction } \\
\text { WA \% } \\
\end{array}$ \\
\hline 6th MP Group & 3 & $97 \%$ & 11,674 & 17,253 & 1,140 & 16,113 & $93 \%$ \\
\hline DCA Support Gp & 3 & $99 \%$ & 5,308 & 7,272 & 490 & 6,782 & $93 \%$ \\
\hline Public Works & 11 & $92 \%$ & 33,742 & 43,787 & 2,704 & 41,083 & $94 \%$ \\
\hline Motor Transport & 30 & $86 \%$ & 114,696 & 169,762 & 9,958 & 159,805 & $94 \%$ \\
\hline Total & 47 & & 165,419 & 238,074 & 14,292 & 223,783 & $94 \%$ \\
\hline \multicolumn{2}{|l|}{ Average/vehicle } & & 3,520 & 5,065 & 304 & 4,761 & $94 \%$ \\
\hline
\end{tabular}

In summary, if all possible monitored conventional vehicles are replaced with PEVs, GHG emissions are reduced nearly $224,000 \mathrm{lb}-\mathrm{CO}_{2}$ e per year. On average, each vehicle replaced results in over 4,750 lb- $\mathrm{CO}_{2}$ e reduction in GHG emissions per year. Appendices $\mathrm{F}$ through I show vehicles with higher annual miles having potential GHG emission reductions of over 22,000 lb- $\mathrm{CO}_{2} \mathrm{e}$ annually.

The appendices also identify the potential if all appropriate vehicles in these fleets are replaced by PEVs using the averages identified for each. Table 30 shows these results.

Table 30. Projected fuel costs and GHG reduction potential for all vehicles in monitored fleets.

\begin{tabular}{|r|r|r|r|r|r|r|r|r|}
\hline Annual Miles CD & $\begin{array}{c}\text { Annual Gas } \\
\text { Cost WA }\end{array}$ & $\begin{array}{c}\text { Annual } \\
\text { Elect Fuel } \\
\text { Cost WA }\end{array}$ & $\begin{array}{c}\text { Annual Fuel } \\
\text { Saving WA }\end{array}$ & $\begin{array}{c}\text { Annual } \\
\text { Fuel Red } \\
\text { WA } \%\end{array}$ & $\begin{array}{c}\text { Annual GHG } \\
\text { Emission ICE } \\
\text { lb-CO2e }\end{array}$ & $\begin{array}{c}\text { Annual PEV } \\
\text { GHG WA } \\
\text { lb-CO2e }\end{array}$ & $\begin{array}{c}\text { Annual PEV } \\
\text { GHG Sav WA } \\
\text { lb-CO2e }\end{array}$ & $\begin{array}{c}\text { Annual GHG } \\
\text { Reduction } \\
\text { WA } \%\end{array}$ \\
\hline $4,333,622$ & $\$ 1,065,302$ & $\$ 49,957$ & $\$ 1,015,345$ & $95 \%$ & 977,613 & 233,359 & 744,251 & $76 \%$ \\
\hline
\end{tabular}

For the vehicles represented by these four groups, the annual potential fuel savings are over $\$ 1$ million and the potential annual GHG reduction is over 370 tons $-\mathrm{CO}_{2} \mathrm{e}$. 


\section{OBSERVATIONS}

Intertek appreciates the opportunity to present the results of this evaluation. The following observations provide input to the next phases of this study:

- Suggested PEV replacements lead to identification of charging infrastructure needs and locations to be reported separately as part of Task 3 .

- Suggested PEV replacements can be considered with vehicle age to prepare a replacement schedule as part of Task 4 .

- The replacement schedule will identify the charging infrastructure deployment schedule.

- Vehicle and EVSE schedules can factor into budget considerations for implementing vehicle replacements.

- Vehicle and EVSE schedules can factor into base objectives in fuel cost reductions and GHG emissions reductions.

The analysis of Section 5 shows average vehicle travels as less than 3,600 miles per year. This is an average of 300 miles per month or 75 miles per week. This may reflect the opportunity to increase the percentage of BEVs over that analyzed in Section 5.

Intertek suggests that JBLM may wish to move forward in the near future with replacement of pool, support, and transport vehicles with PEVs as current budget and vehicle replacement schedules allow. Certainly, the vehicle types studied in this report may be candidates for immediate replacement. 


\section{Appendix A}

\section{Definitions}

Alternative fuel

City fuel economy (MPG)

Conventional fuel

Daily travel

Diesel fuel

E85

Electric vehicle

Ethanol-fueled vehicle

Federal vehicle standards

Government motor vehicle

Gross vehicle weight rating

GSA fleet
An alternative fuel means any fuel other than gasoline and diesel fuels, such as methanol, ethanol, and gaseous fuels (40 CFR 86.1803-01). A fuel type other than petroleum-based gasoline or diesel as defined by the Energy Policy Act (examples include ethanol, methanol, compressed natural gas, propane, and electrical energy).

City fuel economy means the city fuel economy determined by operating a vehicle (or vehicles) over the driving schedule in the federal emission test procedure or determined according to the vehicle-specific 5-cycle or derived 5-cycle procedures (40 CFR 600.001).

A petroleum-based fuel (examples include gasoline and diesel fuel).

The sum of daily trips and stops in one day.

Diesel means a type of engine with operating characteristics significantly similar to the theoretical diesel combustion cycle. The non-use of a throttle during normal operation is indicative of a diesel engine (49 CFR 86-1803).

Ethanol fuel blend of up to $85 \%$ denatured ethanol fuel and gasoline or other hydrocarbons by volume.

Electric vehicle means a motor vehicle that is powered solely by an electric motor drawing current from a rechargeable energy storage system, such as from storage batteries or other portable electrical energy storage devices, including hydrogen fuel cells, provided that

(1) The vehicle is capable of drawing recharge energy from a source off the vehicle, such as residential electric service

(2) The vehicle must be certified to the emission standards of Bin \#1 of Table S04-1 in $\S 86.1811-09$ (c)(6)

(3) The vehicle does not have an onboard combustion engine/generator system as a means of providing electrical energy (40 CFR 86-1803).

Ethanol-fueled vehicle-means any motor vehicle or motor vehicle engine that is engineered and designed to be operated using ethanol fuel (i.e., a fuel that contains at least $50 \%$ ethanol $\left(\mathrm{C}_{2} \mathrm{H}_{5} \mathrm{OH}\right)$ by volume) as fuel (40 CFR 86.1803-01).

The document that establishes classifications for various types and sizes of vehicles, general requirements, and equipment options. It is issued annually by the GSA Vehicle Acquisition and Leasing Service's Automotive Division.

Any motor vehicle that the government owns or leases. This includes motor vehicles obtained through purchase, excess, forfeiture, commercial lease, or GSA fleet lease.

Gross vehicle weight rating (GVWR) means the value specified by the vehicle manufacturer as the maximum design loaded weight of a single vehicle (e.g., vocational vehicle) (US Government Printing Office 2009)

GSA fleet lease means obtaining a motor vehicle from the General Services Administration fleet (GSA fleet) (41 CFR 102-34). 
Heavy light-duty truck

Highway fuel economy (Hwy MPG)

Hybrid electric vehicle

Idle time

Law enforcement

Light-duty motor vehicle Light-duty truck
Heavy light-duty truck means any light-duty truck rated greater than 6,000 lb GVWR. The light-duty truck 3 (LDT3) and LDT4 classifications comprise the heavy light-duty truck category (40 CFR 86.1803-01).

Highway fuel economy means the highway fuel economy determined either by operating a vehicle (or vehicles) over the driving schedule in the federal highway fuel economy test procedure or determined according to either the vehicle-specific, 5-cycle equation, or the derived 5-cycle equation for highway fuel economy (40 CFR 600.001).

Hybrid electric vehicle means a motor vehicle that draws propulsion energy from onboard sources of stored energy that are both an internal combustion engine or heat engine using consumable fuel and a rechargeable energy storage system (such as a battery, capacitor, hydraulic accumulator, or flywheel), where recharge energy for the energy storage system comes solely from sources on board the vehicle.

Idle time is logged whenever a vehicle idles with the engine running for 3 minutes or longer.

Law enforcement motor vehicle means a light-duty motor vehicle that is specifically approved in an agency-s appropriation act for use in apprehension, surveillance, police, or other law enforcement work or specifically designed for use in law enforcement. If not identified in an agency's appropriation language, a motor vehicle qualifies as a law enforcement motor vehicle only in the following cases:

(1) A passenger automobile having heavy-duty components for electrical, cooling, and suspension systems and at least the next higher cubic inch displacement or more powerful engine than is standard for the automobile concerned

(2) A light truck having emergency warning lights and identified with markings such as "police"

(3) An unmarked motor vehicle certified by the agency head as essential for the safe and efficient performance of intelligence, counterintelligence, protective, or other law enforcement duties

(4) A forfeited motor vehicle seized by a federal agency that subsequently is used for performing law enforcement activities (41 CFR Part 102-34.35).

Any motor vehicle with a GVWR of 8,500 pounds or less (41 CFR 102-34). Light-duty truck means any motor vehicle rated at 8,500 pounds GVWR or less, which has a curb weight of 6,000 pounds or less and, which has a basic vehicle frontal area of 45 square feet or less, which is as follows:

(1) Designed primarily for purposes of transportation of property or is a derivation of such a vehicle

(2) Designed primarily for transportation of persons and has a capacity of more than 12 persons

(3) Available with special features, enabling off-street or off-highway operation and use.

LDT1 means any light light-duty truck up through 3,750-lb loaded vehicle weight.

LDT2 means any light light-duty truck greater than 3,750-lb loaded vehicle weight. 


\section{Light-duty vehicle \\ Low-speed vehicle \\ Light-duty vehicle means a passenger car or passenger car derivative capable of seating 12 passengers or less. \\ Low-speed vehicle means a motor vehicle \\ (1) That is 4-wheeled \\ (2) Whose speed attainable in $1.6 \mathrm{~km}$ (1 mile) is more than 32 kilometers per hour (20 miles per hour) and not more than 40 kilometers per hour (25 miles per hour) on a paved level surface \\ (3) Whose GVWR is less than 1,361 kilograms (3,000 pounds) (49 CFR 571.3 - Definitions).}

Medium-duty passenger vehicle

Model year

$M P G$

$M P G e$

Non-passenger automobile
LDT3 means any heavy light-duty truck up through 5,750-lb adjusted loaded vehicle weight.

LDT4 means any heavy light-duty truck greater than 5,750-lb adjusted loaded vehicle weight (US Government Printing Office 2009)

Medium-duty passenger vehicle means any heavy-duty vehicle (as defined in this subpart) with a GVWR of less than 10,000 pounds that is designed primarily for transportation of persons. The medium-duty passenger vehicle definition does not include any vehicle which

(1) Is an "incomplete truck" as defined in this subpart

(2) Has a seating capacity of more than 12 persons

(3) Is designed for more than 9 persons in seating rearward of the driver's seat

(4) Is equipped with an open cargo area (for example, a pick-up truck box or bed) of 72.0 inches in interior length or more. A covered box not readily accessible from the passenger compartment will be considered an open cargo area for purposes of this definition (US Government Printing Office 2009)

Model year means the manufacturer's annual production period (as determined by the administrator), which includes January 1 of such calendar year; provided that if the manufacturer has no annual production period, the term "model year" shall mean the calendar year (40 CFR 86-1803.01).

"MPG" or "mpg" means miles per gallon. This generally may be used to describe fuel economy as a quantity or it may be used as the units associated with a particular value.

MPGe means miles per gallon equivalent. This generally is used to quantify a fuel economy value for vehicles that use a fuel other than gasoline. The value represents miles the vehicle can drive with the energy equivalent of one gallon of gasoline:

(c) SCF means standard cubic feet

(d) SUV means sport utility vehicle

(e) CREE means carbon-related exhaust emissions [76 FR 39527, July 6, 2011].

A non-passenger automobile means an automobile that is not a passenger automobile or a work truck and includes vehicles described in paragraphs (a) and (b) of 49 CFR 523.5. 
Owning agency

Passenger automobile

Pickup truck

Plug-in hybrid electric vehicle

Vehicle class

Vehicle configuration

Vehicle days

Vehicle home base

Vehicle study period
Owning agency means the executive agency that holds the vehicle title, manufacturer's Certificate of Origin or is the lessee of a commercial lease. This term does not apply to agencies that lease motor vehicles from the GSA fleet (41 CFR Part 102-34.35).

A passenger automobile is any automobile (other than an automobile capable of off-highway operation) manufactured primarily for use in the transportation of not more than 10 individuals (49 CFR 523.4 - Passenger automobile). A sedan or station wagon designed primarily to transport people (41 CFR 102-34).

Pickup truck means a non-passenger automobile, which has a passenger compartment and an open cargo bed (49 CFR 523.2).

PHEV means a hybrid electric vehicle that has the capability to charge the battery from an off-vehicle electric source, such that the off-vehicle source cannot be connected to the vehicle while the vehicle is in motion (40 CFR 86.1803).

The designation of motor vehicle types that include sedans, station wagons, ambulances, buses, and trucks, or different categories of vehicles according to Federal vehicle standards and further defined in 49 CFR 600.315-82.

Vehicle configuration means a unique combination of basic engine, engine code, inertia weight class, transmission configuration, and axle ratio.

The number of days a vehicle was driven or utilized during the (vehicle) study period.

The primary assigned outing beginning and ending parking location for the vehicle.

The time period the vehicle, within the study, has been equipped with a data logger. 


\section{Appendix B}

\section{6th MP Group Vehicle Data Sheets}

Table B-1. JBLM 6th MP Group vehicle index.

\begin{tabular}{ccccccc}
\hline Log & Fleet Vehicle Id & Make & Model & Year & EPA Class & Mission \\
\hline 82 & G61-0546L & GMC & Terrain & 2011 & SUV & Pool \\
86 & G61-0689A & Ford & Ranger & 2004 & Pickup Truck & Pool \\
103 & G41-5433B & Dodge & Gr Caravan & 2006 & Minivan & Pool \\
\hline
\end{tabular}


Vehicle G61-0546L

\begin{tabular}{|l|l|c|}
\hline & Make/Model/Year & GMC/Terrain/2011 \\
\hline EPA Class Size & SUV \\
\hline Mission & Pool \\
\hline Contact & C Simmons/6th MP Group \\
\cline { 2 - 3 } & Parking Location & Building 4291 \\
\cline { 2 - 3 } & Fleet Vehicle ID & G61-0546L \\
\hline & Fuel Type & Gas/Eth \\
\hline & EPA Label/MPG (City/Hwy/Combined) & $16 / 22 / 19 ~ 12 / 17 / 14$ \\
\hline & EPA GHG Emissions (Grams CO $/$ Mi) & $468 / 450$ \\
\hline & Study Logger ID & Logger 82 \\
\cline { 2 - 3 } & Total Vehicle Days/Total Study Days & $33 / 63$ \\
\hline
\end{tabular}

\begin{tabular}{|l|c|c|c|c|}
\hline \multirow{2}{*}{} & \multicolumn{4}{|c|}{ Vehicle G61-0546L Travel Summary } \\
& $\begin{array}{c}\text { Per Day } \\
\text { Average/Peak }\end{array}$ & $\begin{array}{c}\text { Per Outing } \\
\text { Average/Peak }\end{array}$ & $\begin{array}{c}\text { Per Trip } \\
\text { Average/Peak }\end{array}$ & Total \\
\hline Travel Distance (Miles) & $25.7 / 167$ & $15.4 / 156.1$ & $8.7 / 83$ & 849 \\
\hline Travel Time (Minutes) & $72 / 223$ & $43.2 / 253$ & $24.3 / 181$ & 2,378 \\
\hline Idle Time (Minutes) & $15.2 / \mathrm{NA}$ & $9.1 / \mathrm{NA}$ & $5.1 / \mathrm{NA}$ & 503 \\
\hline
\end{tabular}

\begin{tabular}{|c|c|c|c|c|}
\hline \multicolumn{2}{|c|}{ Total Stops } & \multicolumn{2}{c|}{ Stop Duration } \\
\hline $\begin{array}{c}\text { Distance From } \\
\text { Home Base (Miles) }\end{array}$ & Stops & Percentages & Stop Duration (Hours) & Stops \\
\hline Less than 10 & 97 & 95.1 & Less than 1 & 59 \\
\hline 10 to 20 & 0 & 0 & 1 to 4 & 9 \\
\hline 20 to 40 & 5 & 4.9 & 4 to 8 & 2 \\
\hline 40 to 60 & 0 & 0 & Greater than 8 & 32 \\
\hline
\end{tabular}

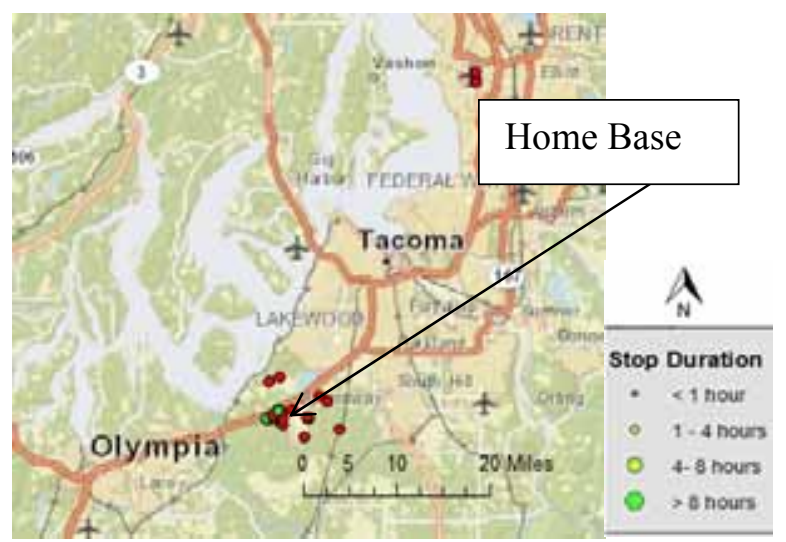

Figure B-1. Vehicle G61-0546L stops.

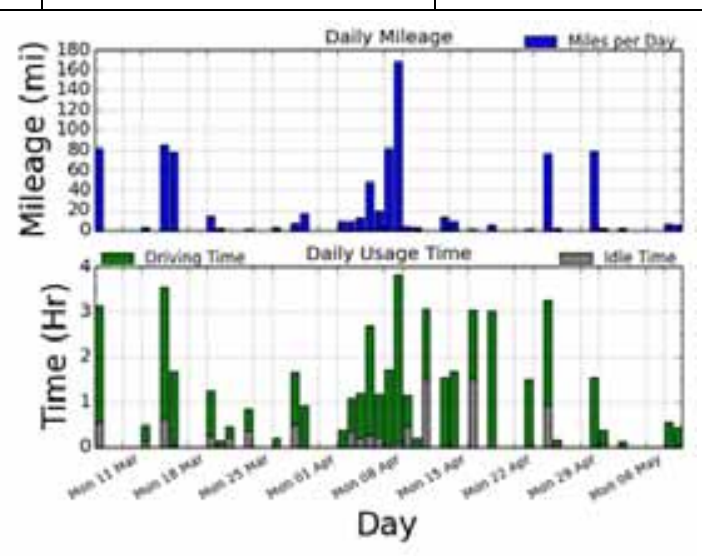

Figure B-2. Vehicle G61-0546L history. 

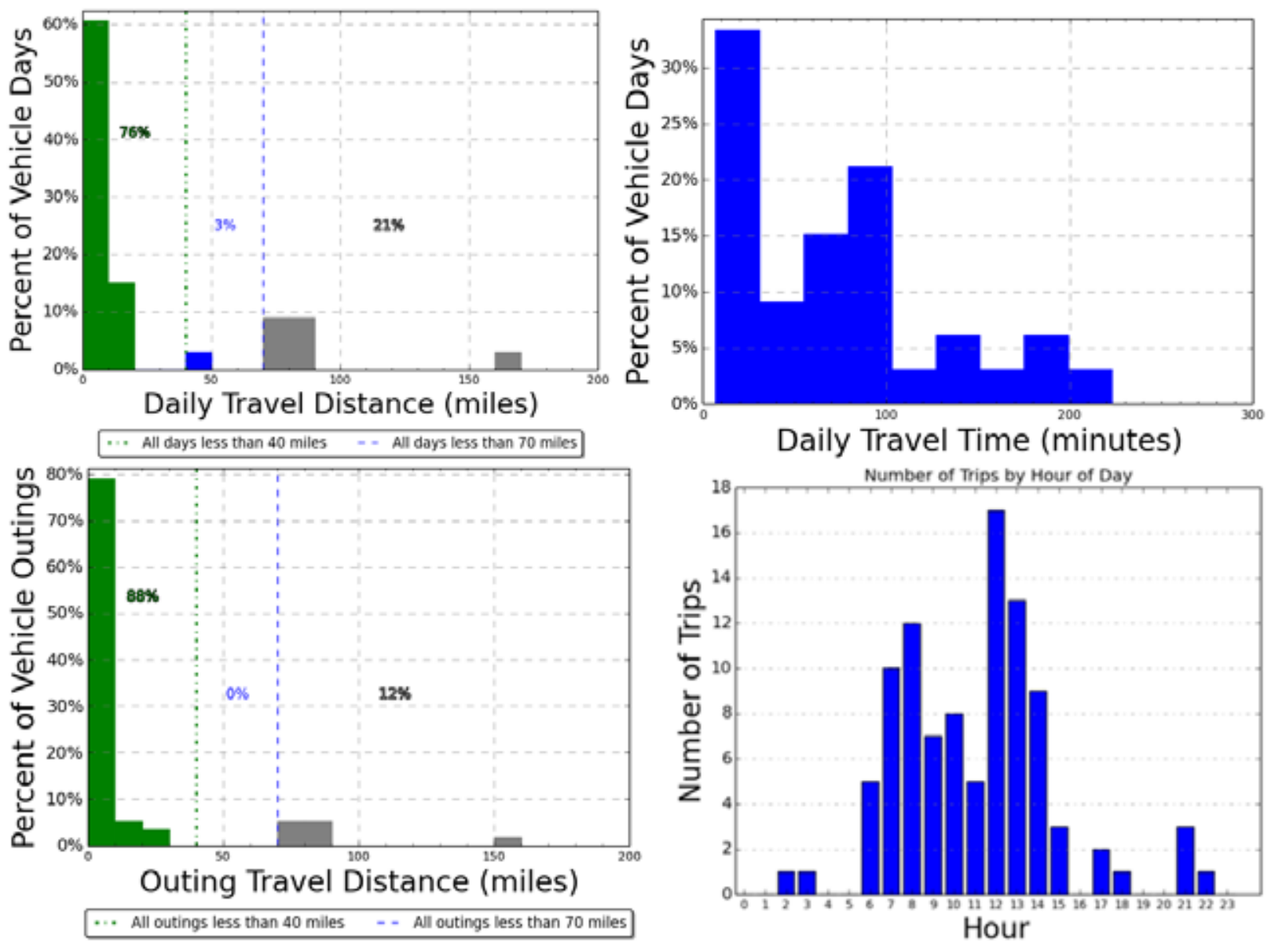

Figure B-3. Vehicle G61-0546L travel graphs.

\section{Vehicle G61-0546L Observations}

Logger 82 collected data on this vehicle for 33 days of the 63-day study period. Data validation occurred on $99.5 \%$ of the vehicle data. Base information indicated this vehicle averages 516 miles per month. The odometer reading in January 2012 was 5,162.The vehicle is a pool vehicle typically parked in the pool parking area on Idaho Ave near Building 4291.

The responses to the survey as part of this study show the expected retention of this vehicle is access to this vehicle and the number of persons carried varies. The vehicle frequently travels off base. Although ethanol is available as a fuel, it is never used.

Stop data for this vehicle show that for all but three of the 36 recorded stops of greater than 2-hours duration were at the pool parking area.

The longest single outing of the vehicle was 156 miles of just more than 4.2 hours. The longest single trip was of 83 miles. However, this long trip was not the norm for this vehicle, with $88 \%$ of the outings less than 70 miles and $79 \%$ of the daily travel was less than 70 miles. These data suggest that a BEV could provide most of the travel, but a PHEV would be required for the longer trips. The BEV or PHEV that could replace this vehicle should be able to support other requirements that may exist for this pool vehicle. 


\begin{tabular}{|l|l|c|}
\hline Vehicle G61-0689A & Ford/Ranger /2004 \\
\hline \multirow{5}{*}{ www.edmunds.com } & Standard Pickup Truck \\
\hline & EPA Class Size & Pool \\
\hline & Contact & C Simmons/6th MP Group \\
\cline { 2 - 3 } & Parking Location & G61-0689A \\
\cline { 2 - 3 } & Fleet Vehicle ID & Gas \\
\cline { 2 - 3 } & Fuel Type & $21 / 27 / 23$ \\
\cline { 2 - 3 } & EPA Label/MPG (City/Hwy/Combined) & 386 \\
\cline { 2 - 3 } & EPA GHG Emissions (Grams $\left.\mathrm{CO}_{2} / \mathrm{Mi}\right)$ & Logger 86 \\
\cline { 2 - 3 } & Study Logger ID & $24 / 63$ \\
\cline { 2 - 3 } & Total Vehicle Days/Total Study Days & (1) \\
\hline
\end{tabular}

\begin{tabular}{|l|c|c|c|c|}
\hline \multicolumn{5}{|c|}{ Vehicle G61-0689A Travel Summary } \\
\hline & $\begin{array}{c}\text { Per Day } \\
\text { Average/Peak }\end{array}$ & $\begin{array}{c}\text { Per Outing } \\
\text { Average/Peak }\end{array}$ & $\begin{array}{c}\text { Per Trip } \\
\text { Average/Peak }\end{array}$ & Total \\
\hline Travel Distance (Miles) & $19.1 / 51.8$ & $9.2 / 41.8$ & $3.11 / 26$ & 458 \\
\hline Travel Time (Minutes) & $70 / 203$ & $33.8 / 197$ & $11.5 / 119$ & 1,688 \\
\hline Idle Time (Minutes) & $13.8 / \mathrm{NA}$ & $6.6 / \mathrm{NA}$ & $2.2 / \mathrm{NA}$ & 330 \\
\hline
\end{tabular}

\begin{tabular}{|c|c|c|c|c|}
\hline \multicolumn{2}{|c|}{ Total Stops } & \multicolumn{2}{c|}{ Stop Duration } \\
\hline $\begin{array}{c}\text { Distance From } \\
\text { Home Base (Miles) }\end{array}$ & Stops & Percentages & Stop Duration (Hours) & Stops \\
\hline Less than 10 & 187 & 99.5 & Less than 1 & 131 \\
\hline 10 to 20 & 1 & 0.5 & 1 to 4 & 22 \\
\hline 20 to 40 & 0 & 0 & 4 to 8 & 0 \\
\hline 40 to 60 & 0 & 0 & Greater than 8 & 35 \\
\hline
\end{tabular}

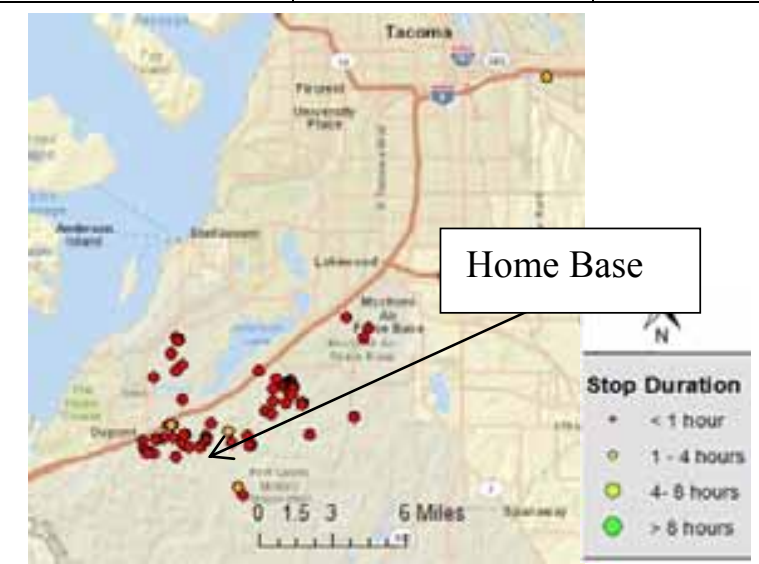

Figure B-4. Vehicle G61-0689A stops.

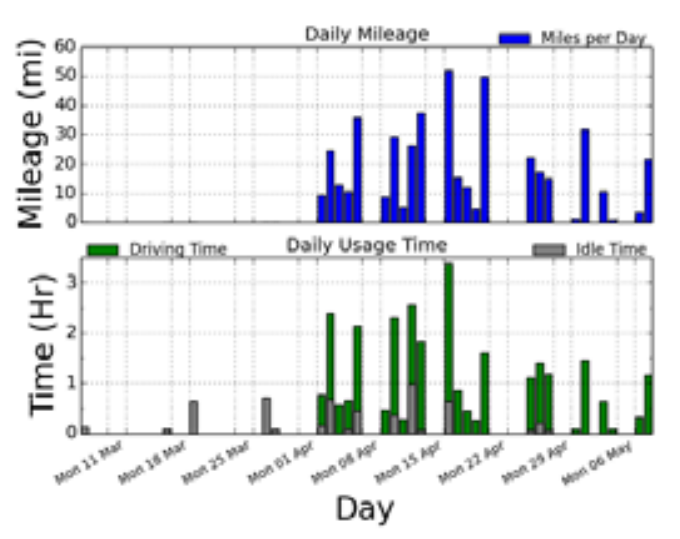

Figure B-5. Vehicle G61-0689A history. 


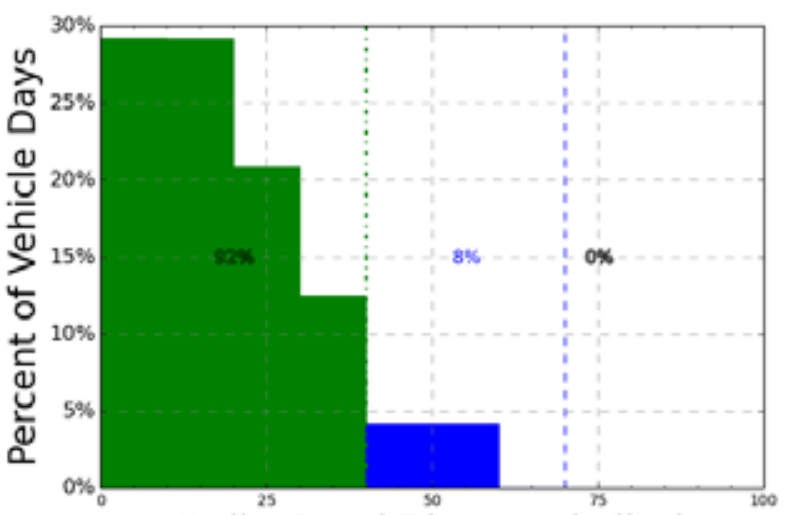

Daily Travel Distance (miles)

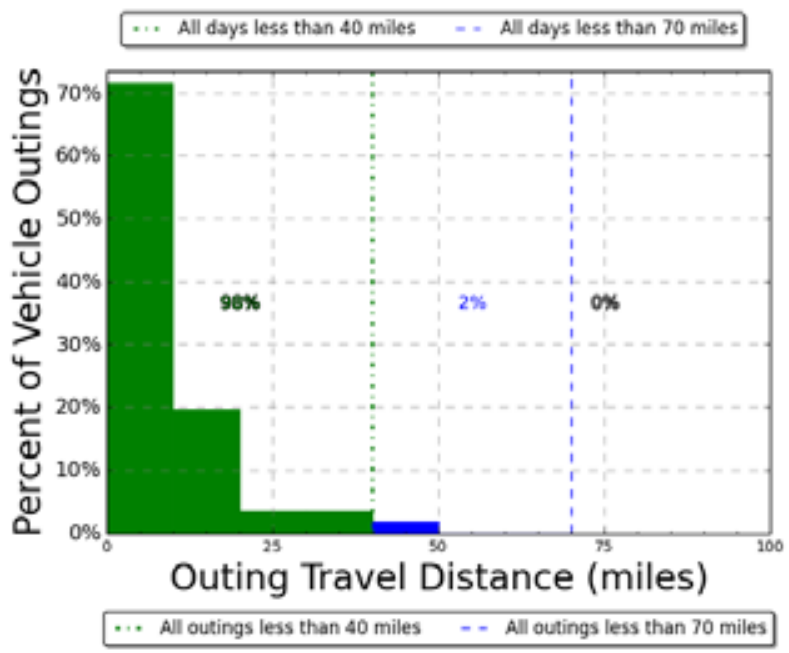

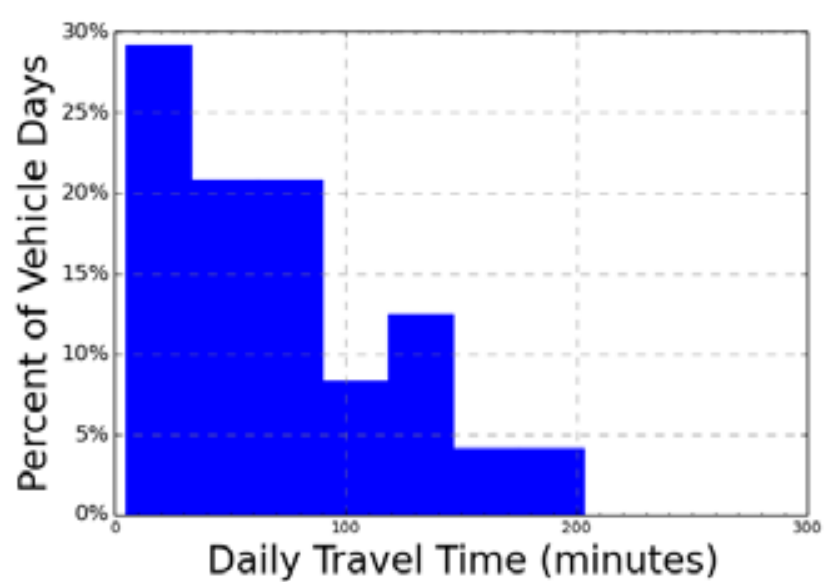

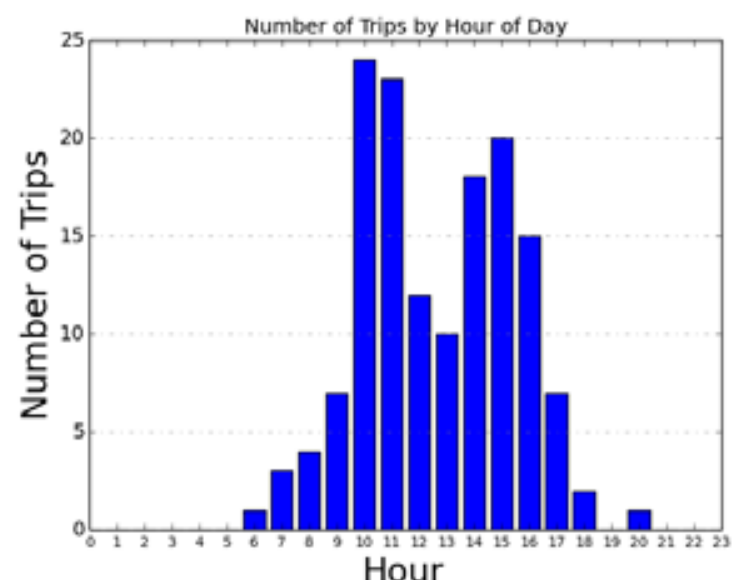

Figure B-4. Vehicle G61-0689A travel graphs.

\section{Vehicle G61-0689A Observations}

Logger 86 collected data on this vehicle for 24 days of the 63-day study period. Data validation occurred on $99.7 \%$ of the vehicle data. Base survey information indicated this vehicle averages 198 miles per month. The odometer reading in January 2012 was 22,243 . The vehicle is a pool vehicle typically parked in the pool parking area on Idaho Ave near Building 4291.

The responses to the survey as part of this study showed the expected retention of this vehicle is unknown. This vehicle typically operates 11 to 40 miles per day. There are 6 to 10 persons who typically have access to this vehicle and the number of persons carried varies. Specific cargo or material carry requirements were not identified.

Stop data for this vehicle show that for all but two of the 44 recorded stops of greater than 2-hours duration were at the pool parking area.

The longest single outing of the vehicle was 41.8 miles of just more than 3 hours. The longest single trip was of 26 miles and the longest daily travel was 51.8. These data suggest it is within the advertised range of a typical BEV, which is approximately 70 miles. Intermediate charging stations could support longer trips without causing a change in the mission. Sufficient daily time is available for intermediate charging. A BEV could replace this vehicle and be able to support the mission. 


\section{Vehicle G41-5433B}

\begin{tabular}{|l|l|c|}
\hline & Make/Model/Year & Dodge/Grand Caravan/2006 \\
\cline { 1 - 2 } & EPA Class Size & Minivan \\
\hline Mission & Pool \\
\hline Contact & C Simmons/6th MP Group \\
\cline { 2 - 3 } & Parking Location & Guilding 4291 \\
\cline { 2 - 3 } & Fleet Vehicle ID & Gas/ETH \\
\hline & Fuel Type & $17 / 24 / 2011 / 16 / 13$ \\
\hline & EPA Label/MPG (City/Hwy/Combined) & $444 / 484$ \\
\cline { 2 - 3 } & EPA GHG Emissions (Grams CO $/$ Mi) & Logger 103 \\
\hline & Study Logger ID & $36 / 63$ \\
\hline
\end{tabular}

\begin{tabular}{|l|c|c|c|c|}
\hline \multicolumn{5}{|c|}{ Vehicle G41-5433B Travel Summary } \\
\hline & $\begin{array}{c}\text { Per Day } \\
\text { Average/Peak }\end{array}$ & $\begin{array}{c}\text { Per Outing } \\
\text { Average/Peak }\end{array}$ & $\begin{array}{c}\text { Per Trip } \\
\text { Average/Peak }\end{array}$ & Total \\
\hline Travel Distance (Miles) & $20.7 / 224$ & $9.7 / 134.5$ & $3.5 / 77.5$ & 745 \\
\hline Travel Time (Minutes) & $67 / 361$ & $31.3 / 443$ & $11.4 / 105$ & 2,411 \\
\hline Idle Time (Minutes) & $12 / \mathrm{NA}$ & $5.7 / \mathrm{NA}$ & $2.1 / \mathrm{NA}$ & 436 \\
\hline
\end{tabular}

\begin{tabular}{|c|c|c|c|c|}
\hline \multicolumn{2}{|c|}{ Total Stops } & \multicolumn{2}{c|}{ Stop Duration } \\
\hline $\begin{array}{c}\text { Distance From } \\
\text { Home Base (Miles) }\end{array}$ & Stops & Percentages & Stop Duration (Hours) & Stops \\
\hline Less than 10 & 211 & 96.8 & Less than 1 & 145 \\
\hline 10 to 20 & 0 & 0 & 1 to 4 & 34 \\
\hline 20 to 40 & 7 & 3.2 & 4 to 8 & 5 \\
\hline 40 to 60 & 0 & 0 & Greater than 8 & 34 \\
\hline
\end{tabular}

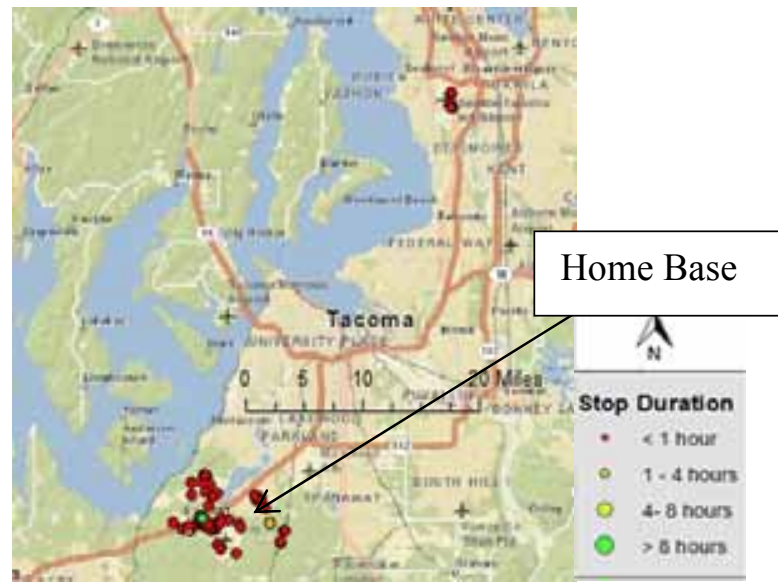

Figure B-7. Vehicle G41-5433B stops.

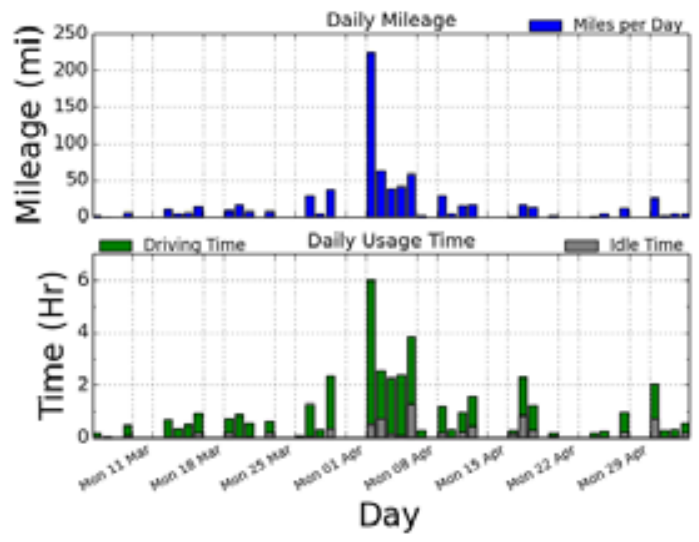

Figure B-8. Vehicle G41-5433B history. 

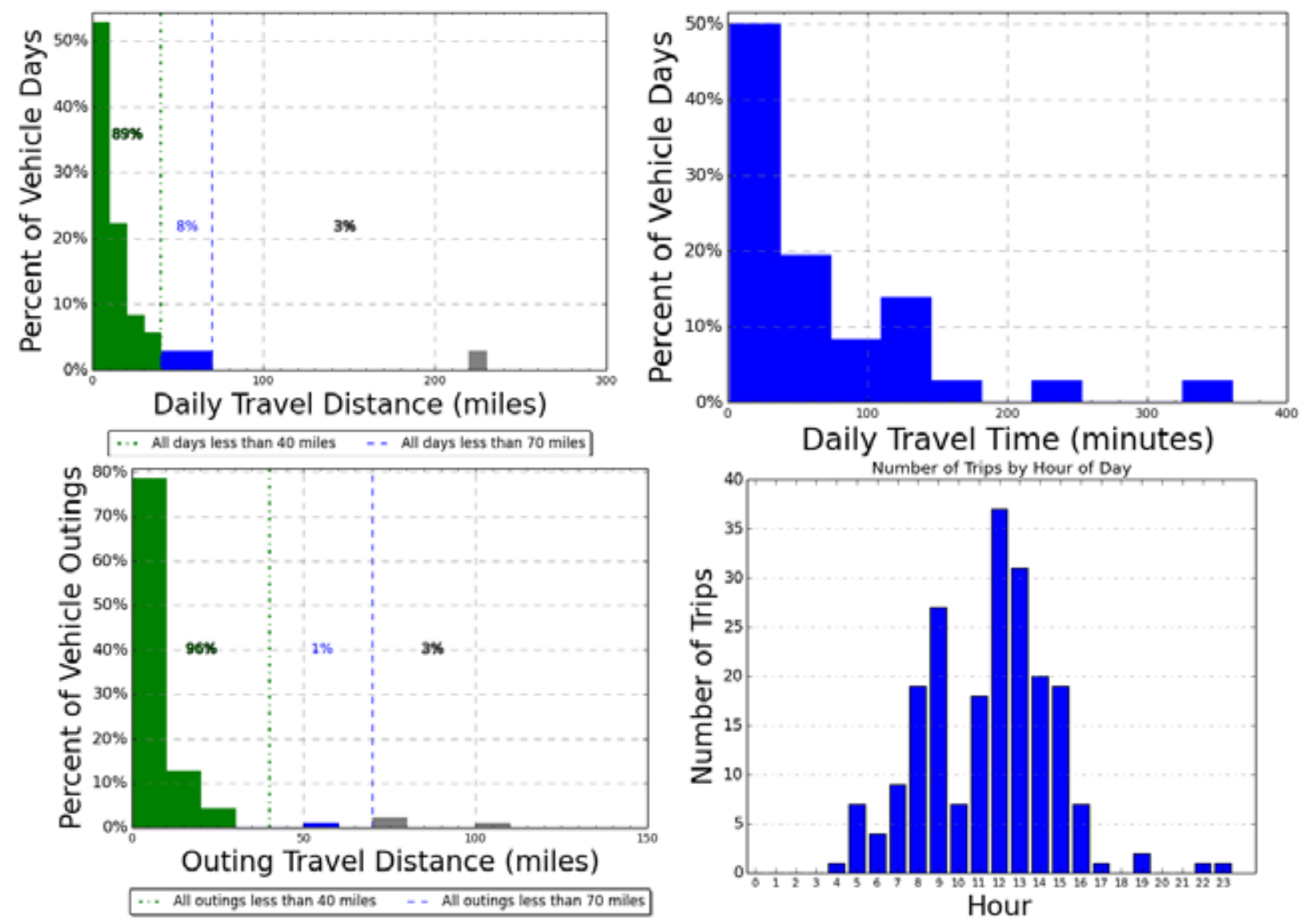

Figure B-5. Vehicle G41-5433B travel graphs.

\section{Vehicle G41-5433B Observations}

Logger 103 collected data on this vehicle for 36 days of the 63-day study period. Data validation occurred on $100 \%$ of the vehicle data. Base survey information indicated this vehicle averages 639 miles per month. The odometer reading in January 2012 was 44,804 . The vehicle is a pool vehicle typically parked in the pool parking area on Idaho Ave near Building 4291.

The responses to the survey as part of this study showed the expected retention of this vehicle is unknown. This vehicle typically operates 11 to 40 miles per day. There are 6 to 10 persons who typically have access to this vehicle and the number of persons carried varies. The vehicle frequently travels off base. Although ethanol is available as a fuel, it is never used.

Stop data for this vehicle show that $80 \%$ of the 56 recorded stops of greater than 2-hours duration were at the pool parking area. The remaining stops were distributed among seven other locations.

The longest single outing of the vehicle was 135 miles of about 7.5 hours. The longest single trip was 78 miles. However, this long trip is not the norm for this vehicle, with $97 \%$ of the outings less than 70 miles and $97 \%$ of the daily travel was less than 70 miles. These data suggest that a BEV could provide most of the travel, but a PHEV would be required for the longer trips. The BEV or PHEV could replace this vehicle if it is able to support the other requirements that may exist for this pool vehicle. 


\section{Appendix C}

\section{DCA Support Group Vehicle Data Sheets}

Table C-1. JBLM DCA support vehicle index.

\begin{tabular}{ccccccc}
\hline Log & Fleet Vehicle Id & Make & Model & Year & EPA Class & Mission \\
\hline 83 & G41-74299 & Ford & Ranger & 2004 & Pickup Truck & Support \\
94 & G71-0684A & Chevrolet & C6500 Stake & 2005 & Pickup Truck HD & Pool \\
96 & G43-1195H & Chevrolet & 15 Pas Van & 2011 & Passenger Van & Support \\
99 & G42-0289G & Chevrolet & G1300 & 2008 & Cargo Van & Pool \\
\hline
\end{tabular}


Vehicle G41-74299

\begin{tabular}{|c|c|c|}
\hline \multirow{4}{*}{ 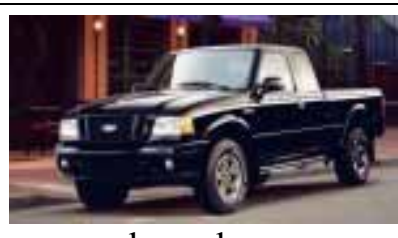 } & Make/Model/Year & Ford/Ranger/2004 \\
\hline & EPA Class Size & Standard Pickup Truck \\
\hline & Mission & Support \\
\hline & Contact & D. Pettengill/DCA Support \\
\hline \multirow{7}{*}{ www.edmunds.com } & Parking Location & Building 8050 \\
\hline & Fleet Vehicle ID & G41-74299 \\
\hline & Fuel Type & Gas \\
\hline & EPA Label/MPG (City/Hwy/Combined) & $21 / 27 / 23$ \\
\hline & EPA GHG Emissions (Grams $\mathrm{CO}_{2} / \mathrm{Mi}$ ) & 386 \\
\hline & Study Logger ID & Logger 83 \\
\hline & Total Vehicle Days/Total Study Days & $44 / 63$ \\
\hline
\end{tabular}

\begin{tabular}{|l|c|c|c|c|}
\hline \multicolumn{5}{|c|}{ Vehicle G41-74299 Travel Summary } \\
\hline & $\begin{array}{c}\text { Per Day } \\
\text { Average/Peak }\end{array}$ & $\begin{array}{c}\text { Per Outing } \\
\text { Average/Peak }\end{array}$ & $\begin{array}{c}\text { Per Trip } \\
\text { Average/Peak }\end{array}$ & Total \\
\hline Travel Distance (Miles) & $18 / 63.3$ & $11.6 / 63.3$ & $4.2 / 28.8$ & 790 \\
\hline Travel Time (Minutes) & $50.4 / 163$ & $32.6 / 163$ & $11.7 / 81$ & 2,218 \\
\hline Idle Time (Minutes) & $1.7 / \mathrm{NA}$ & $1.1 / \mathrm{NA}$ & $0.4 / \mathrm{NA}$ & 76 \\
\hline
\end{tabular}

\begin{tabular}{|c|c|c|c|c|}
\hline \multicolumn{2}{|c|}{ Total Stops } & \multicolumn{2}{c|}{ Stop Duration } \\
\hline $\begin{array}{c}\text { Distance From } \\
\text { Home Base (Miles) }\end{array}$ & Stops & Percentages & Stop Duration (Hours) & Stops \\
\hline Less than 10 & 168 & $100 \%$ & Less than 2 & 78 \\
\hline 10 to 20 & 0 & $0 \%$ & 2 to 4 & 14 \\
\hline 20 to 40 & 0 & $0 \%$ & 4 to 8 & 32 \\
\hline 40 to 60 & 0 & $0 \%$ & Greater than 8 & 44 \\
\hline
\end{tabular}

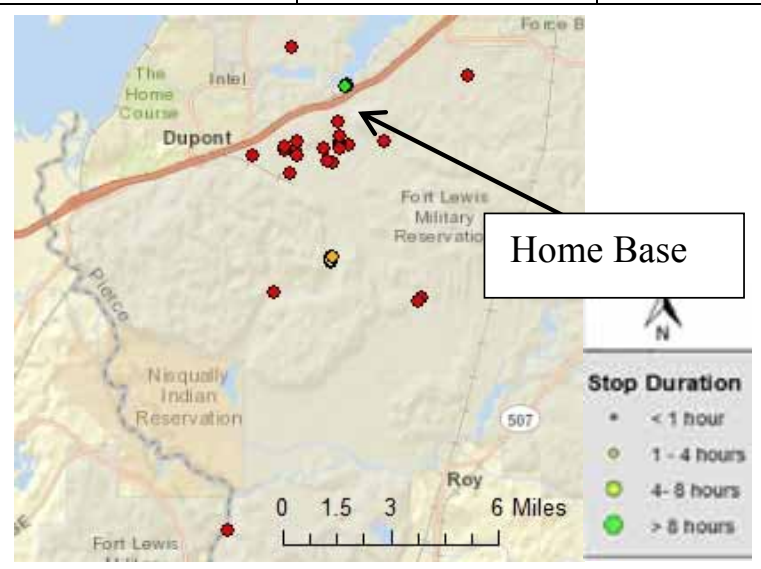

Figure C-6. Vehicle G41-74299 stops.

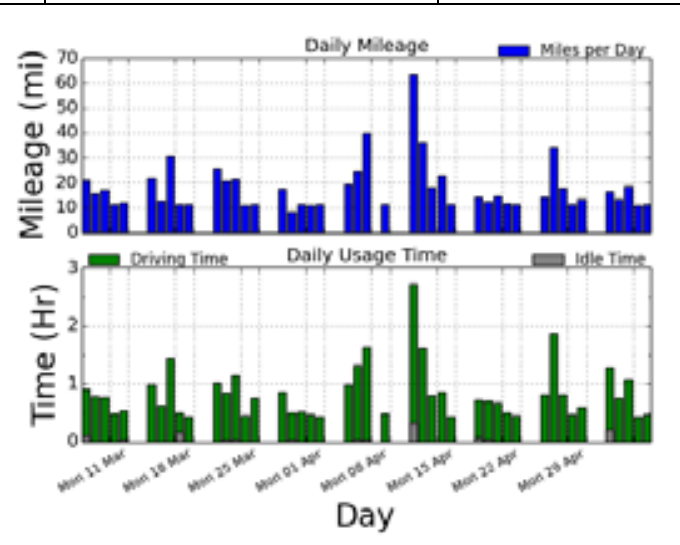

Figure C-7. Vehicle G41-74299 history. 

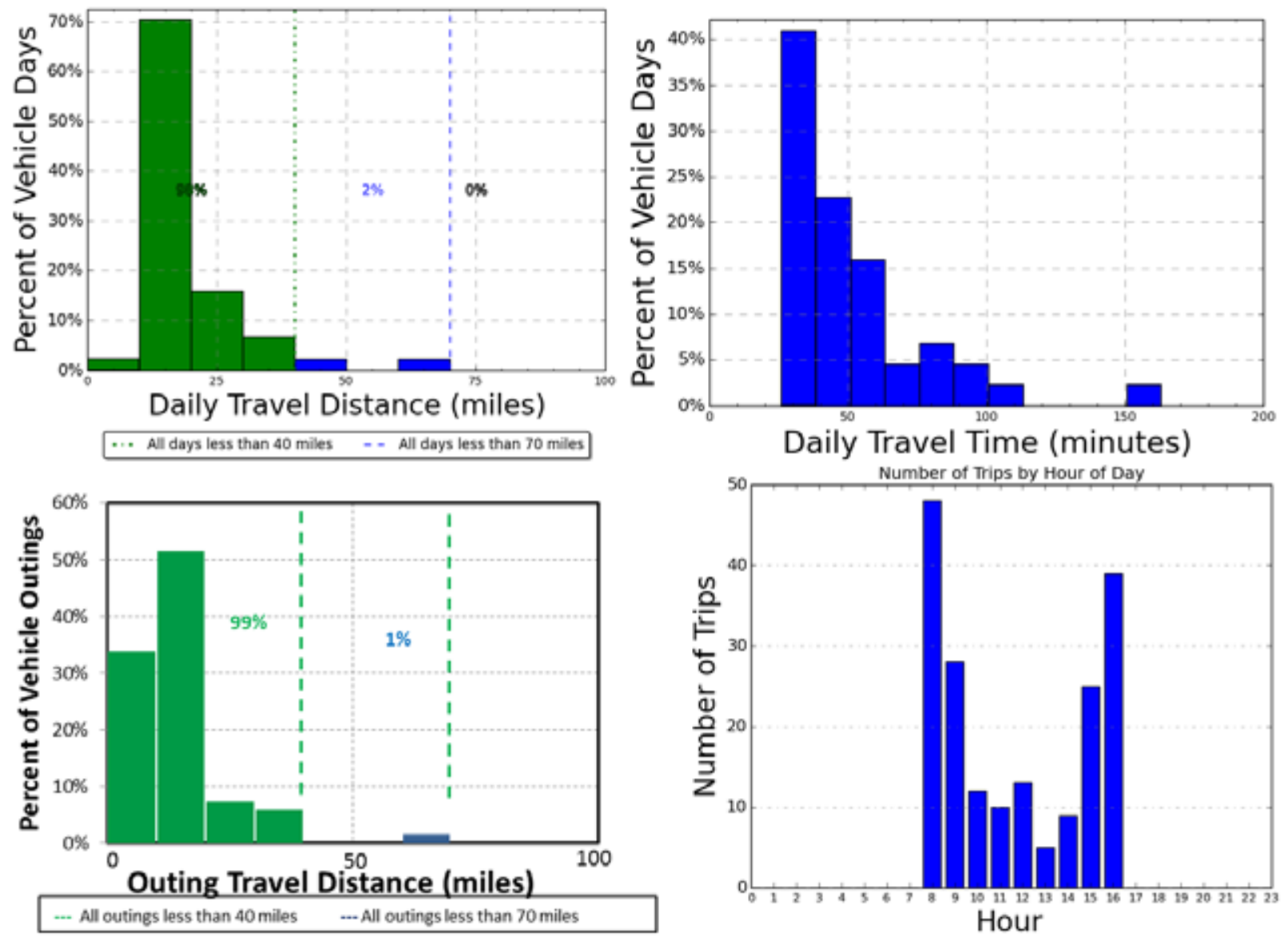

Figure C-8. Vehicle G41-74299 travel graphs.

\section{Vehicle G41-74299Observations}

Logger 83 collected data on this vehicle for 44 days of the 63-day study period. Data validation occurred on $98.7 \%$ of the vehicle data. Base information indicated this vehicle averages 262 miles per month. The odometer reading in January 2012 was 19,601. The vehicle supports the rifle range and parks in the Northwest Adventure Center Building 8050.

The responses to the survey as part of this study showed the expected retention of this vehicle is 3 to 5 more years. This vehicle typically operated 6 to 10 miles per day. There were 2 to 5 persons who typically had access to this vehicle and it usually carried one person. The vehicle occasionally travelled off base. Expected usage was from 1,000 to 1,500 hours Wednesday through Sunday. The vehicle is assigned to DFMWR Outdoor Recreation, transports ammunition to and from the range, and is considered an administrative support vehicle.

The longest single outing of the vehicle was 63 miles, which consumed the entire day of April 10, but required less than 3 hours of driving. The longest single trip was of 28.8 miles, which also occurred during the same outing. One hundred percent of the outings were less than 70 miles and all of the daily travel was less than the 70 miles that is the typical range of a BEV. These data suggest that a BEV could provide the necessary range for daily travel. The BEV could replace this vehicle if it was able to support the other requirements that may exist for this support vehicle. The BEV appears to be able to carry the materials identified in the survey. 
Vehicle G71-0684A

\begin{tabular}{|l|l|c|}
\hline & Make/Model/Year & Chevrolet/C6500 Stake/2005 \\
\cline { 2 - 3 } & EPA Class Size & Stake Truck \\
\hline www.youtube.com & Mission & Pool \\
\cline { 2 - 3 } & Contact & D Pettengill/DCA Support \\
\cline { 2 - 3 } & Parking Location & Guilding 2057 \\
\hline & Fleet Vehicle ID & Diesel \\
\hline & Fuel Type & Not available \\
\hline & EPA Label/MPG (City/Hwy/Combined) & Not available \\
\hline & EPA GHG Emissions (Grams $\left.\mathrm{CO}_{2} / \mathrm{Mi}\right)$ & Logger 94 \\
\hline & Study Logger ID & $25 / 63$ \\
\hline
\end{tabular}

\begin{tabular}{|l|c|c|c|c|}
\hline \multicolumn{5}{|c|}{ Vehicle G71-0684A Travel Summary } \\
& $\begin{array}{c}\text { Per Day } \\
\text { Average/Peak }\end{array}$ & $\begin{array}{c}\text { Per Outing } \\
\text { Average/Peak }\end{array}$ & $\begin{array}{c}\text { Per Trip } \\
\text { Average/Peak }\end{array}$ & Total \\
\hline Travel Distance (Miles) & $8.2 / 26.6$ & $5.1 / 26.5$ & $1.8 / 10.5$ & 206 \\
\hline Travel Time (Minutes) & $46 / 106$ & $28.8 / 133$ & $9.8 / 43$ & 1,151 \\
\hline Idle Time (Minutes) & $13.7 / \mathrm{NA}$ & $8.6 / \mathrm{NA}$ & $2.9 / \mathrm{NA}$ & 343 \\
\hline
\end{tabular}

\begin{tabular}{|c|c|c|c|c|}
\hline \multicolumn{2}{|c|}{ Total Stops } & \multicolumn{2}{c|}{ Stop Duration } \\
\hline $\begin{array}{c}\text { Distance From } \\
\text { Home Base (Miles) }\end{array}$ & Stops & Percentages & $\begin{array}{c}\text { Stop Duration } \\
\text { (Hours) }\end{array}$ & Stops \\
\hline Less than 10 & 116 & 100 & Less than 1 & 86 \\
\hline 10 to 20 & 0 & 0 & 1 to 4 & 3 \\
\hline 20 to 40 & 0 & 0 & 4 to 8 & 3 \\
\hline 40 to 60 & 0 & 0 & Greater than 8 & 24 \\
\hline
\end{tabular}

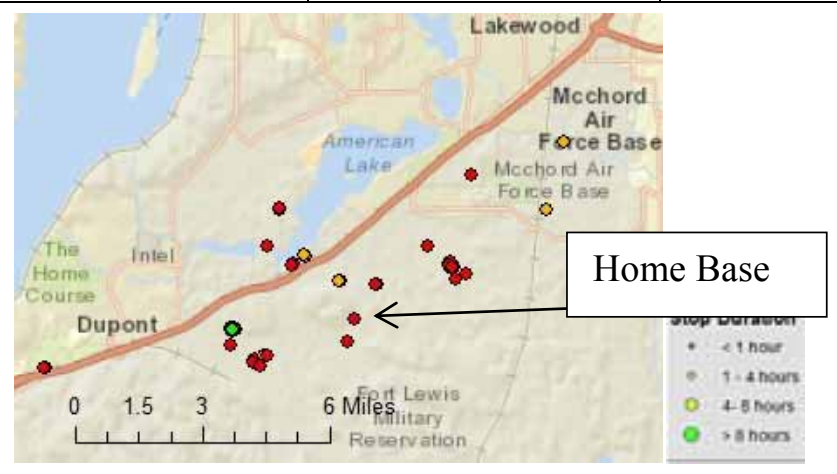

Figure C-4. Vehicle G71-0684A stops.

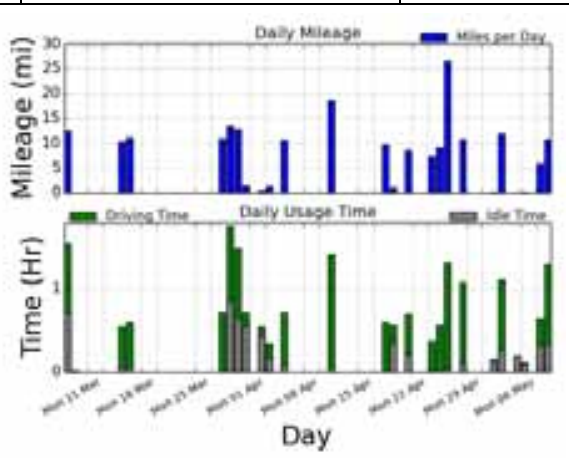

Figure C-5. Vehicle G71-0684A history. 

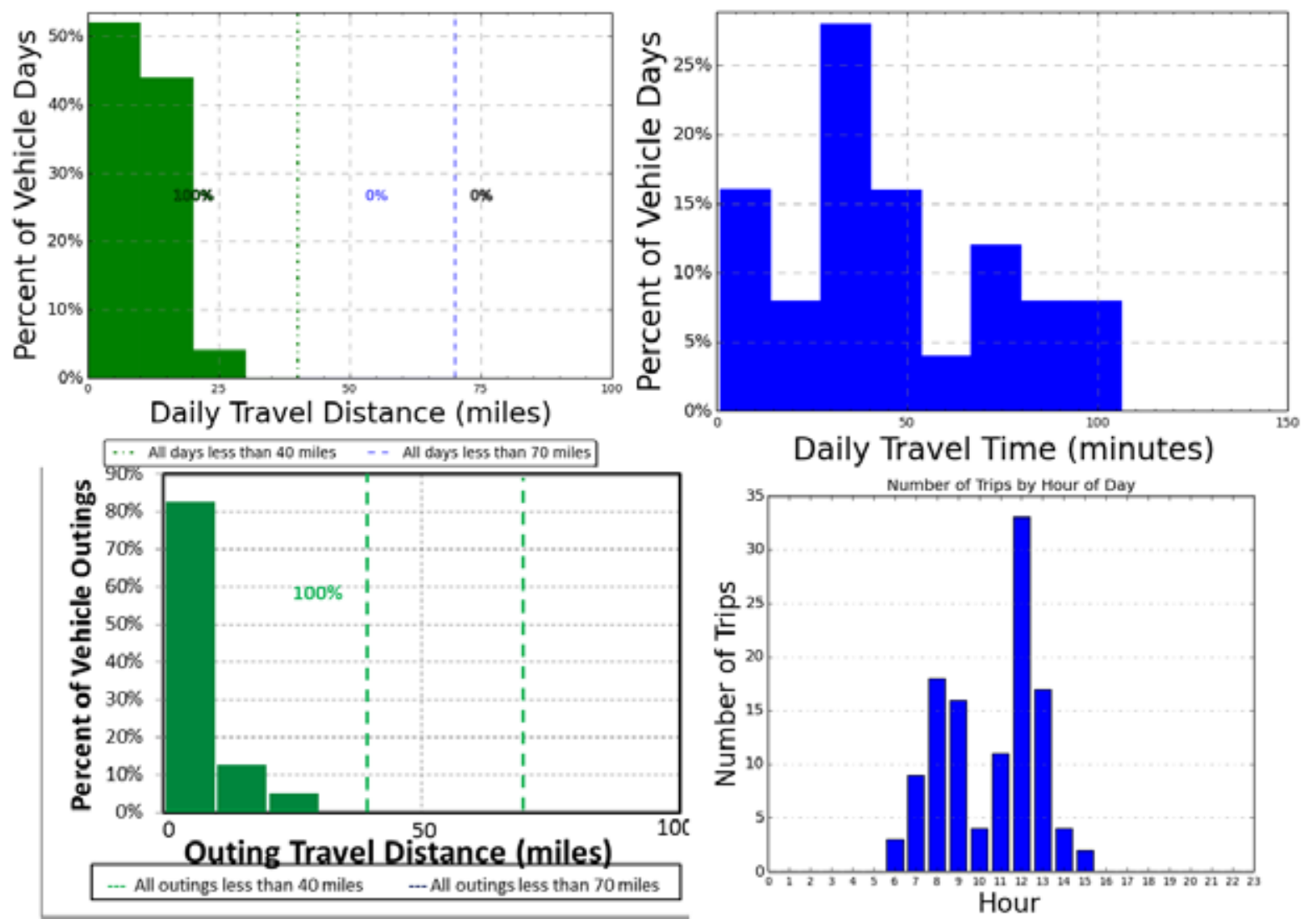

Figure C-9. Vehicle G71-0684A travel graphs.

\section{Vehicle G71-0684A Observations}

Logger 94 collected data on this vehicle for 25 days of the 63-day study period. Data validation occurred on $100 \%$ of the vehicle data. Base information indicated this vehicle averages 123 miles per month. The odometer reading in January 2012 was 10,640. The vehicle supports the rifle range and parks in the pool parking area near Building 2057.

The responses to the survey as part of this study showed the expected retention of this vehicle is greater than 6 more years. This vehicle typically operated 6 to 10 miles per day. More than 20 persons typically had access to this vehicle and it usually carried one person. The vehicle occasionally travelled off base. The vehicle is assigned to Fleet Mission Support and is considered a pool vehicle. The vehicle typically uses biodiesel fuel and carries a wide range of cargo and equipment.

The longest single outing of the vehicle was 26 miles that consumed just over 2 hours of driving. The longest single trip was 10.5 miles. All of the outings were less than 70 miles and all of the daily travel was less than 70 miles that typically is the range of a BEV. In fact all daily travel and outings are less than 40 miles; the CD portion of a typical PHEV motive power. These data suggest that a BEV could provide the necessary range for daily travel. Unfortunately, this vehicle is a heavy-duty truck and no BEV or PHEV exists that can replace this vehicle at this writing. PHEV demonstration vehicles may exist and JBLM may consider this replacement when commercially available. 
Vehicle G43-1195H

\begin{tabular}{|l|l|c|}
\hline & Make/Model/Year & Chevrolet/15 Pas Van/2011 \\
\cline { 2 - 3 } & EPA Class Size* & Passenger Van \\
\hline Mission & Support \\
\hline Contact & Building 8050 \\
\cline { 2 - 3 } & Parking Location & G43-1195H \\
\hline Fleet Vehicle ID & Gas/ETH \\
\hline Fuel Type & $11 / 16 / 128 / 12 / 9$ \\
\hline & EPA Label/MPG (City/Hwy/Combined) & $741 / 699$ \\
\hline & EPA GHG Emissions (Grams CO $/$ Mi) & Logger 96 \\
\cline { 2 - 3 } & Study Logger ID & $32 / 63$ \\
\cline { 2 - 3 } & Total Vehicle Days/Total Study Days & \\
\hline
\end{tabular}

\begin{tabular}{|l|c|c|c|c|}
\hline \multicolumn{5}{|c|}{ Vehicle G43-1195H Travel Summary } \\
\hline & $\begin{array}{c}\text { Per Day } \\
\text { Average/Peak }\end{array}$ & $\begin{array}{c}\text { Per Outing } \\
\text { Average/Peak }\end{array}$ & $\begin{array}{c}\text { Per Trip } \\
\text { Average/Peak }\end{array}$ & Total \\
\hline Travel Distance (Miles) & $121.5 / 354.1$ & $45.7 / 354.1$ & $20.7 / 129.4$ & 3,887 \\
\hline Travel Time (Minutes) & $187 / 544$ & $70.5 / 544$ & $31.9 / 222$ & 5,990 \\
\hline Idle Time (Minutes) & $24.9 / \mathrm{NA}$ & $9.4 / \mathrm{NA}$ & $4.2 / \mathrm{NA}$ & 796 \\
\hline
\end{tabular}

\begin{tabular}{|c|c|c|c|c|}
\hline \multicolumn{2}{|c|}{ Total Stops } & \multicolumn{2}{c|}{ Stop Duration } \\
\hline $\begin{array}{c}\text { Distance From } \\
\text { Home Base (Miles) }\end{array}$ & Stops & Percentages & Stop Duration (Hours) & Stops \\
\hline Less than 10 & 144 & 66.1 & Less than 2 & 166 \\
\hline 10 to 20 & 6 & 2.8 & 2 to 4 & 10 \\
\hline 20 to 40 & 12 & 5.5 & 4 to 8 & 7 \\
\hline 40 to 60 & 22 & 25.6 & Greater than 8 & 35 \\
\hline
\end{tabular}

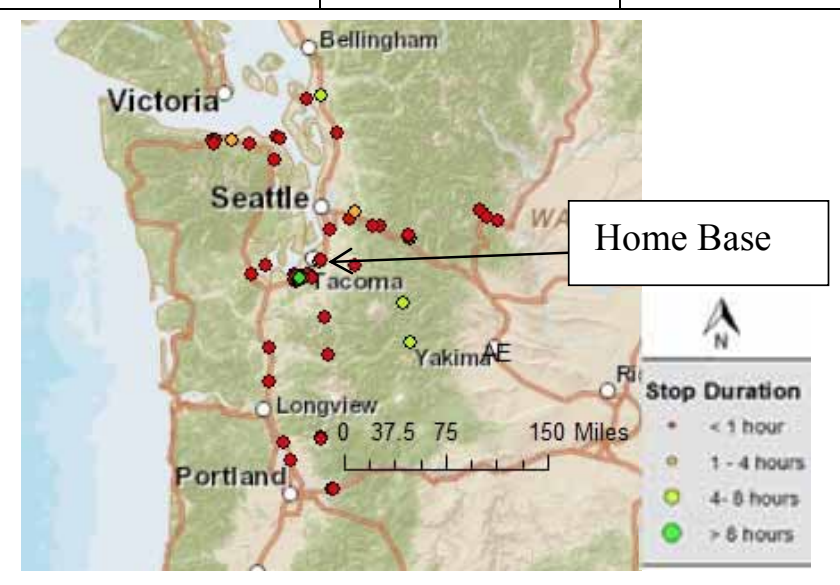

Figure C-7. Vehicle G43-1195H stops.

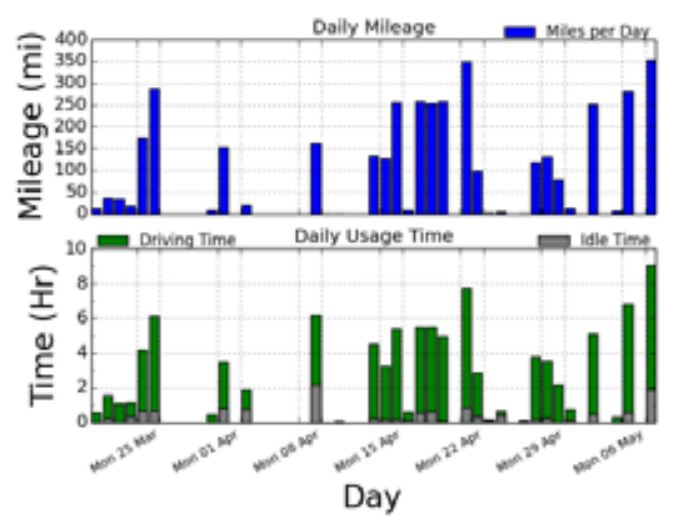

Figure C-8. Vehicle G43-1195H history. 

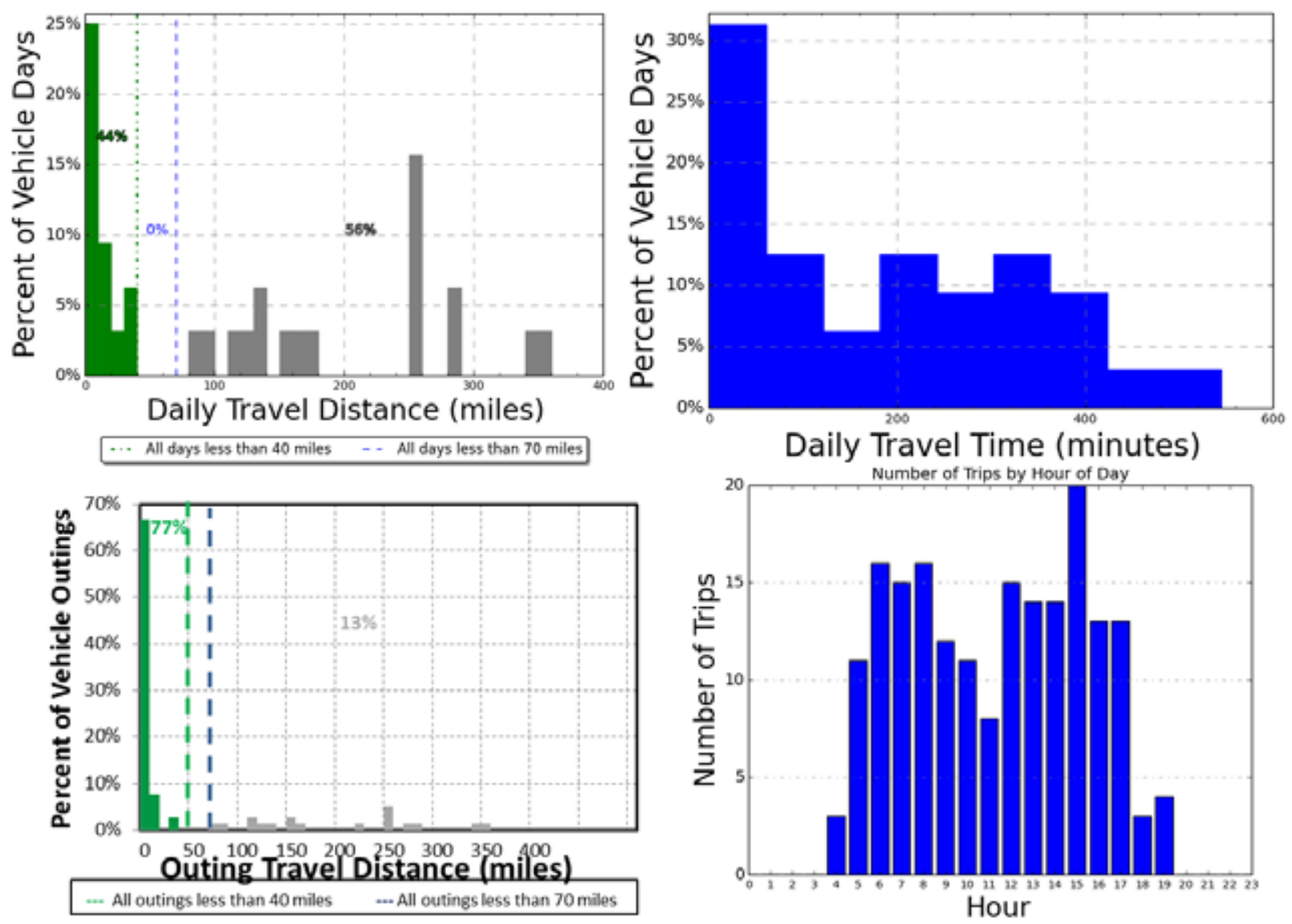

Figure C-10. Vehicle G43-1195H travel graphs.

\section{Vehicle G43-1195H Observations}

Logger 96 collected data on this vehicle for 32 days of the 63-day study period. Data validation occurred on $98.6 \%$ of the vehicle data. Base information indicated this vehicle averages 1,025 miles per month. The odometer reading in January 2012 was 10,594. The vehicle is a recreational trip vehicle and parks in the office parking area near Building 8050.

The responses to the survey as part of this study showed that the expected retention of this vehicle is between 3 and 6 more years. This vehicle typically operated between 100 and 150 miles per day. Two to five persons had access to this vehicle and it usually carried 12 to 15 persons at a time. The vehicle frequently travels off base. The vehicle typically uses E-85 ethanol fuel and carries equipment related to its use as a recreational trip transport vehicle.

The longest single outing of the vehicle occurred on May 6th and was 354 miles of approximately 9-hours duration. This outing involved travel to Woodland, White Salmon, and Duluth, WA. Long trips are frequent occurrences for this vehicle, with 9 days of travel exceeding 250 miles. Yet, $77 \%$ of the outings were less than 70 miles and $44 \%$ of the daily travel was less than 70 miles. Twenty-five percent of daily travel and nearly $70 \%$ of outings were less than 10 miles. These data suggest that a BEV could provide most of the travel, but a PHEV would be required for the longer trips. The number of vans in the total fleet may support this mix. The BEV or PHEV could replace this vehicle if they were able to support meet the other requirements that may exist for this support vehicle. 


\begin{tabular}{|c|c|c|}
\hline 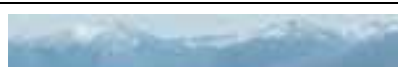 & Make/Model/Year & Chevrolet/G1300/2008 \\
\hline & EPA Class Size* & Cargo Van \\
\hline & Mission & Pool \\
\hline www.edmunds.com & Contact & D Pettengill/DCA Support \\
\hline & Parking Location & Bldg 2057 \\
\hline & Fleet Vehicle ID & G42-0289G \\
\hline & Fuel Type & Gas/ETH \\
\hline & EPA Label/MPG (City/Hwy/Combined) & $12 / 16 / 149 / 12 / 10$ \\
\hline & EPA GHG Emissions (Grams $\mathrm{CO}_{2} / \mathrm{Mi}$ ) & $635 / 630$ \\
\hline & Study Logger ID & Logger 99 \\
\hline & Total Vehicle Days/Total Study Days & $23 / 63$ \\
\hline
\end{tabular}

\begin{tabular}{|l|c|c|c|c|}
\hline \multicolumn{5}{|c|}{ Vehicle G42-0289G Travel Summary } \\
\hline & $\begin{array}{c}\text { Per Day } \\
\text { Average/Peak }\end{array}$ & $\begin{array}{c}\text { Per Outing } \\
\text { Average/Peak }\end{array}$ & $\begin{array}{c}\text { Per Trip } \\
\text { Average/Peak }\end{array}$ & Total \\
\hline Travel Distance (Miles) & $8.8 / 53.5$ & $7.5 / 53.5$ & $1.8 / 20.2$ & 203 \\
\hline Travel Time (Minutes) & $34 / 123$ & $28.7 / 123$ & $6.7 / 55$ & 775 \\
\hline Idle Time (Minutes) & $4.0 / \mathrm{NA}$ & $3.4 / \mathrm{NA}$ & $0.8 / \mathrm{NA}$ & 92 \\
\hline
\end{tabular}

\begin{tabular}{|c|c|c|c|c|}
\hline \multicolumn{2}{|c|}{ Total Stops } & \multicolumn{2}{c|}{ Stop Duration } \\
\hline $\begin{array}{c}\text { Distance From } \\
\text { Home Base (Miles) }\end{array}$ & Stops & Percentages & Stop Duration (Hours) & Stops \\
\hline Less than 10 & 115 & $98.3 \%$ & Less than 2 & 83 \\
\hline 10 to 20 & 2 & $1.7 \%$ & 2 to 4 & 8 \\
\hline 20 to 40 & 0 & $0 \%$ & 4 to 8 & 3 \\
\hline 40 to 60 & 0 & $0 \%$ & Greater than 8 & 23 \\
\hline
\end{tabular}

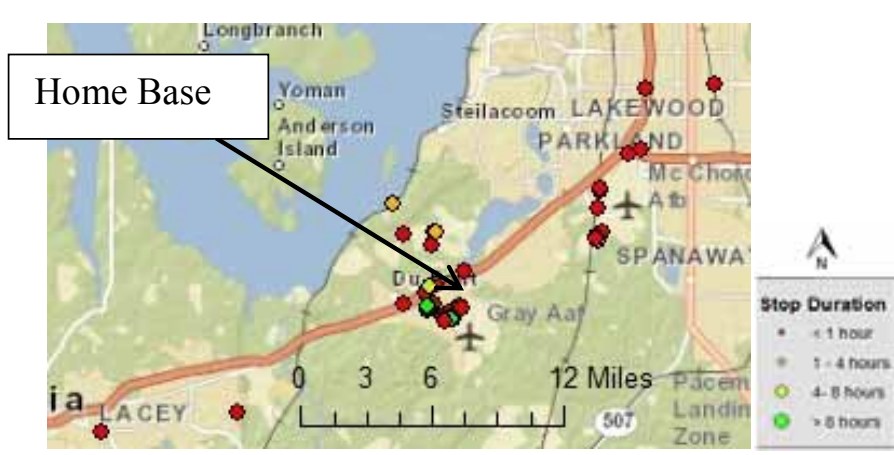

Figure C-10. Vehicle G42-0289G stops.

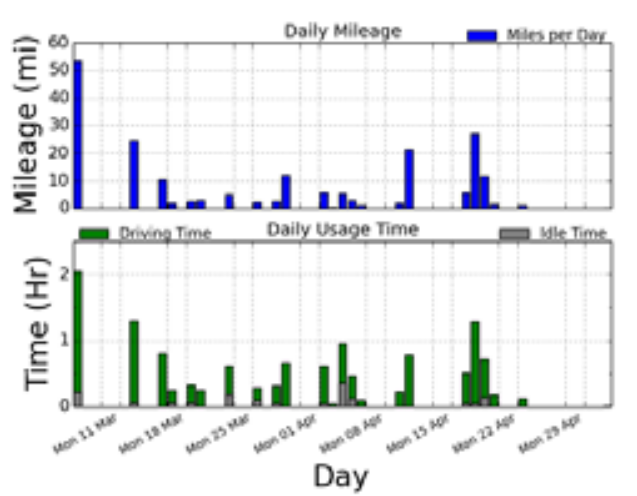

Figure C-11. Vehicle G42-0289G history. 


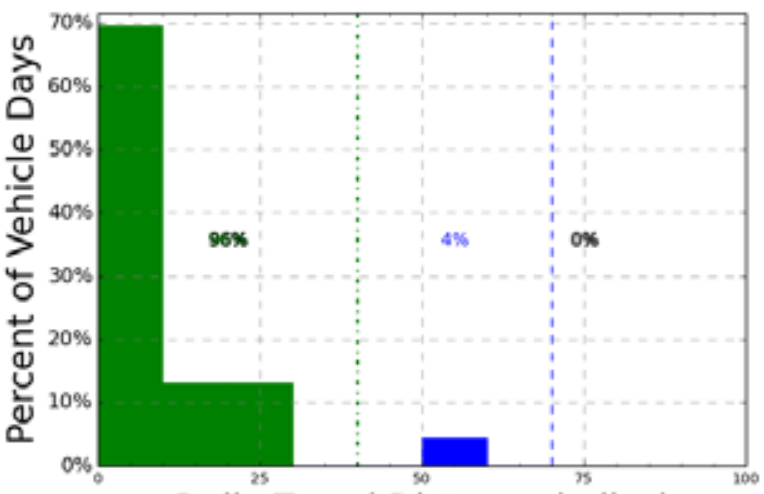

Daily Travel Distance (miles)
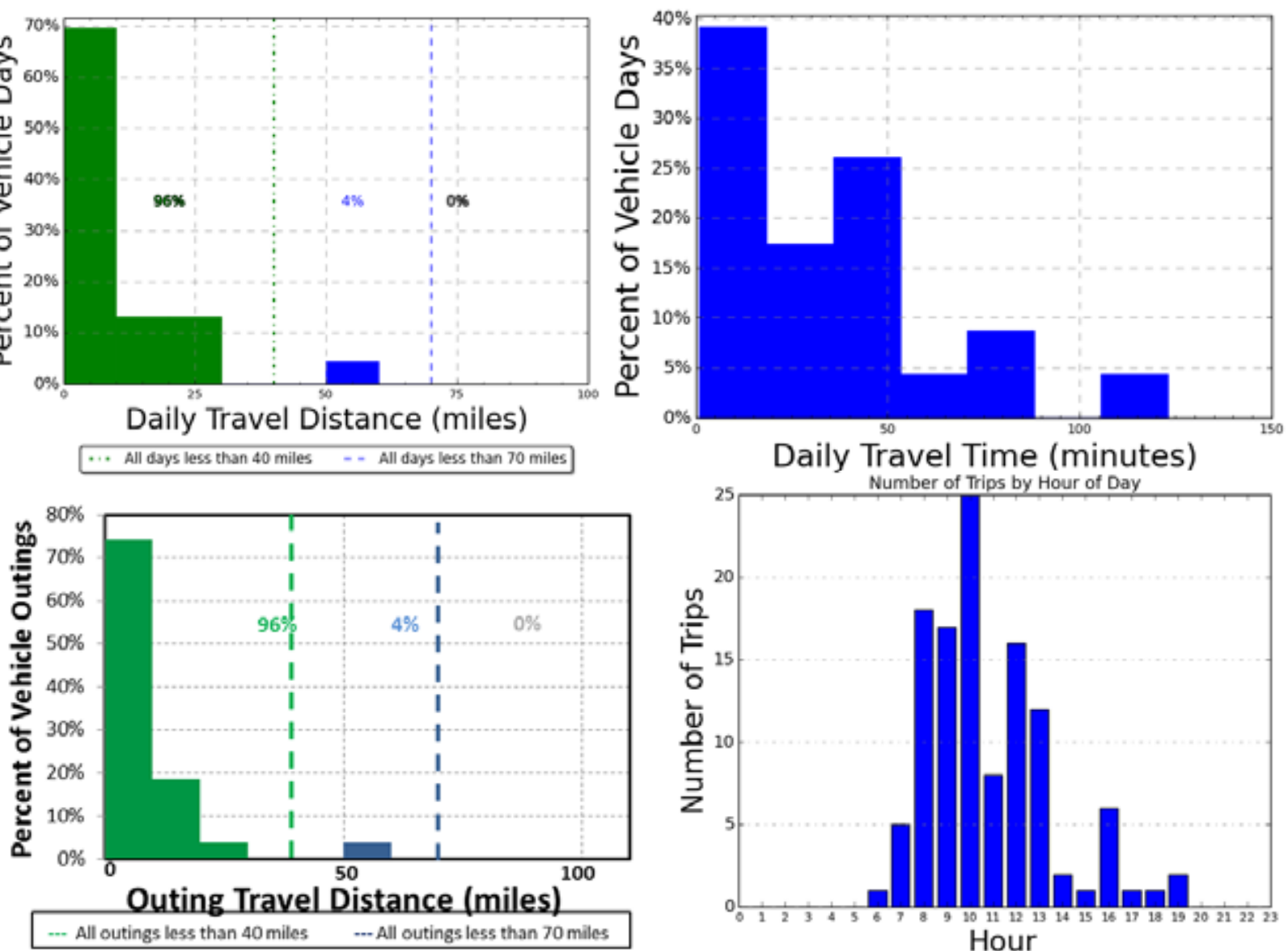

Figure C-11. Vehicle G42-0289G travel graphs.

\section{Vehicle G42-0289G Observations}

Logger 99 collected data on this vehicle for 23 days of the 63-day study period. Data validation occurred on $100 \%$ of the vehicle data. Base information indicated this vehicle averages 157 miles per month. The odometer reading in January 2012 was 7,018. The vehicle is a pool vehicle assigned to Fleet Mission Support and parks in the DFMWR Motor Pool parking area near Building 2057.

The responses to the survey as a part of this study showed that the expected retention of this vehicle is greater than 6 more years. This vehicle typically operated between 6 and 10 miles per day and two to five persons had access to this vehicle, with it usually carrying two persons at a time. The vehicle occasionally travelled off base. The vehicle typically uses E-85 ethanol fuel and is available to support all activities assigned to MWR.

The longest single outing of the vehicle occurred on March 6th and was 53.5 miles of approximately 2 hours duration. This outing involved travel to Tacoma, Olympia East, and Lacy, WA. All of the outings were less than 70 miles and all of the daily travel was less than 70 miles that is typically the range of a BEV. All but 4\% of all daily travel and outings were less than 40 miles; the CD portion of a typical PHEV motive power. These data suggest that a BEV could provide the necessary range for daily travel. Unfortunately, this vehicle is a cargo van and no BEV or PHEV exists that can replace this vehicle unless the cargo is of small volume. Because DCA Support has many vans in its pool, replacement by a BEV may be possible. 


\section{Appendix D}

\section{Public Works Vehicle Data Sheets}

Table D-1. JBLM Public Works vehicle index.

\begin{tabular}{ccccccc}
\hline $\begin{array}{c}\text { Logger } \\
\text { No. }\end{array}$ & Fleet Vehicle & \multicolumn{5}{c}{ Vehicle Index } \\
\hline 1 & Id & Make & Model & Year & EPA Class & Mission \\
\hline 2 & G42-1054F & FORD & F150 & 2010 & Pickup truck & Pool \\
3 & G71-0133L & FORD & E450 & 2008 & Pickup truck & Pool \\
4 & G43-0944G & CHEVROLET & G3500 & 2008 & Passenger van & Pool \\
5 & G43-0822G & FORD & F350 & 2008 & Pickup truck & Pupport \\
84 & G41-1100K & DODGE & GRCARAVAN & 2010 & Minivan & Pool \\
87 & G42-0619K & CHEVROLET & C1500 & 2010 & Pickup truck & Pool \\
88 & G41-1180K & DODGE & GRCARAVAN & 2010 & Minivan & Pool \\
90 & G43-1892H & CHEVROLET & C2500HD & 2009 & Pickup truck & Support \\
91 & G43-1961H & CHEVROLET & C3500 & 2009 & Pickup truck & Support \\
92 & G42-0505A & CHEVROLET & G1300 & 2004 & Passenger van & Support \\
95 & G43-1155L & FORD & F350 & 2011 & Pickup truck & Support \\
98 & G41-1605L & DODGE & DAKOTA & 2011 & Pickup truck & Support \\
100 & G42-0610K & CHEVROLET & C1500 & 2010 & Pickup truck & Pool \\
\hline
\end{tabular}


Vehicle G42-0658K

\begin{tabular}{|c|c|c|}
\hline D. & Make/Model/Year & Ford/F150/2010 \\
\hline & EPA Class Size & Standard Pickup Truck \\
\hline 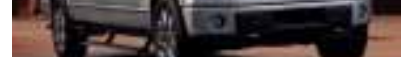 & Mission & Pool Vehicle \\
\hline www.edmunds.com & Contact & J Ross/Public Works \\
\hline & Parking Location & Bldg 2044/Adkison/N $3^{\text {rd }} \mathrm{St}$ \\
\hline & Fleet Vehicle ID & G42-0658K \\
\hline & Fuel Type & Gas/ETH \\
\hline & EPA Label/MPG (City/Hwy/Combined) & $14 / 20 / 16 \quad 10 / 14 / 12$ \\
\hline & EPA GHG Emissions (Grams $\mathrm{CO}_{2} / \mathrm{Mi}$ ) & $555 / 525$ \\
\hline & Study Logger ID & Logger 1 \\
\hline & Total Vehicle Days/Total Study Days & $37 / 63$ \\
\hline
\end{tabular}

\begin{tabular}{|l|c|c|c|c|}
\hline \multicolumn{5}{|c|}{ Vehicle G42-0658K Travel Summary } \\
\hline & $\begin{array}{c}\text { Per Day } \\
\text { Average/Peak }\end{array}$ & $\begin{array}{c}\text { Per Outing } \\
\text { Average/Peak }\end{array}$ & $\begin{array}{c}\text { Per Trip } \\
\text { Average/Peak }\end{array}$ & Total \\
\hline Travel Distance (Miles) & $29.3 / 95.8$ & $12.3 / 50.6$ & $4.6 / 23.4$ & 1,083 \\
\hline Travel Time (Minutes) & $70 / 149$ & $29.4 / 96.0$ & $11 / 43$ & 2,590 \\
\hline Idle Time (Minutes) & 6/NA & $2.5 /$ NA & $0.9 /$ NA & 223 \\
\hline
\end{tabular}

\begin{tabular}{|c|c|c|c|c|}
\hline \multicolumn{2}{|c|}{ Total Stops } & \multicolumn{2}{c|}{ Stop Duration } \\
\hline $\begin{array}{c}\text { Distance From } \\
\text { Home Base (Miles) }\end{array}$ & Stops & Percentages & Stop Duration (Hours) & Stops \\
\hline Less than 10 & 229 & 98.3 & Less than 2 & 186 \\
\hline 10 to 20 & 4 & 1.7 & 2 to 4 & 11 \\
\hline 20 to 40 & 0 & 0 & 4 to 8 & 2 \\
\hline 40 to 60 & 0 & 0 & Greater than 8 & 34 \\
\hline
\end{tabular}

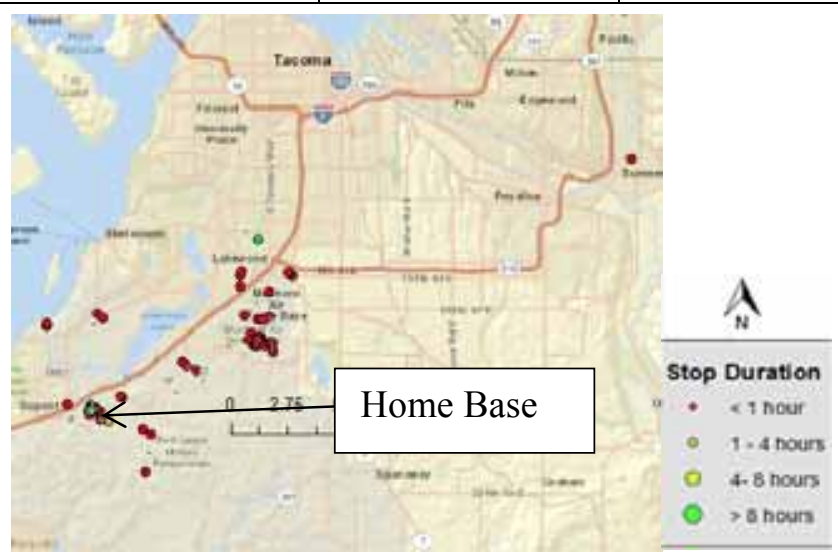

Figure D-12. Vehicle G42-0658K stops.

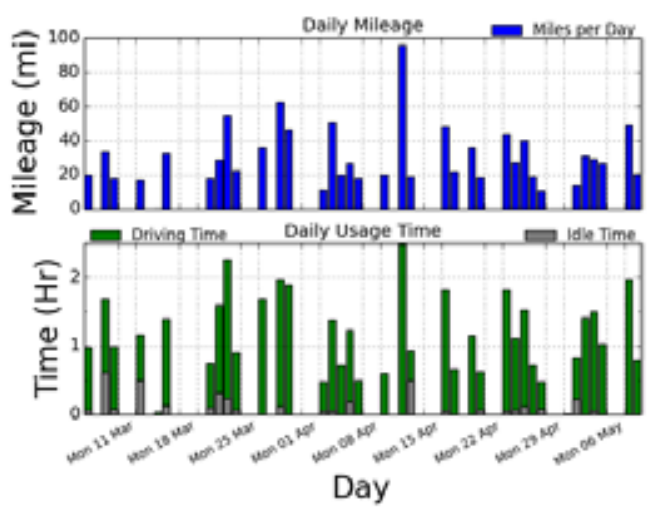

Figure D-13. Vehicle G42-0658K history. 


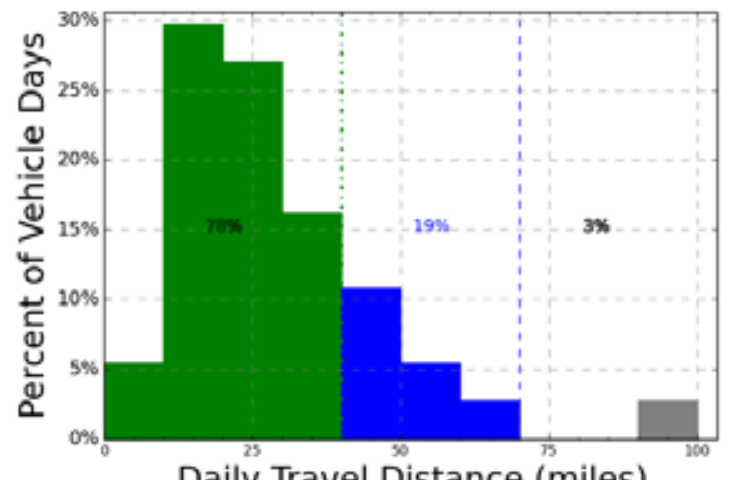

Daily Travel Distance (miles)
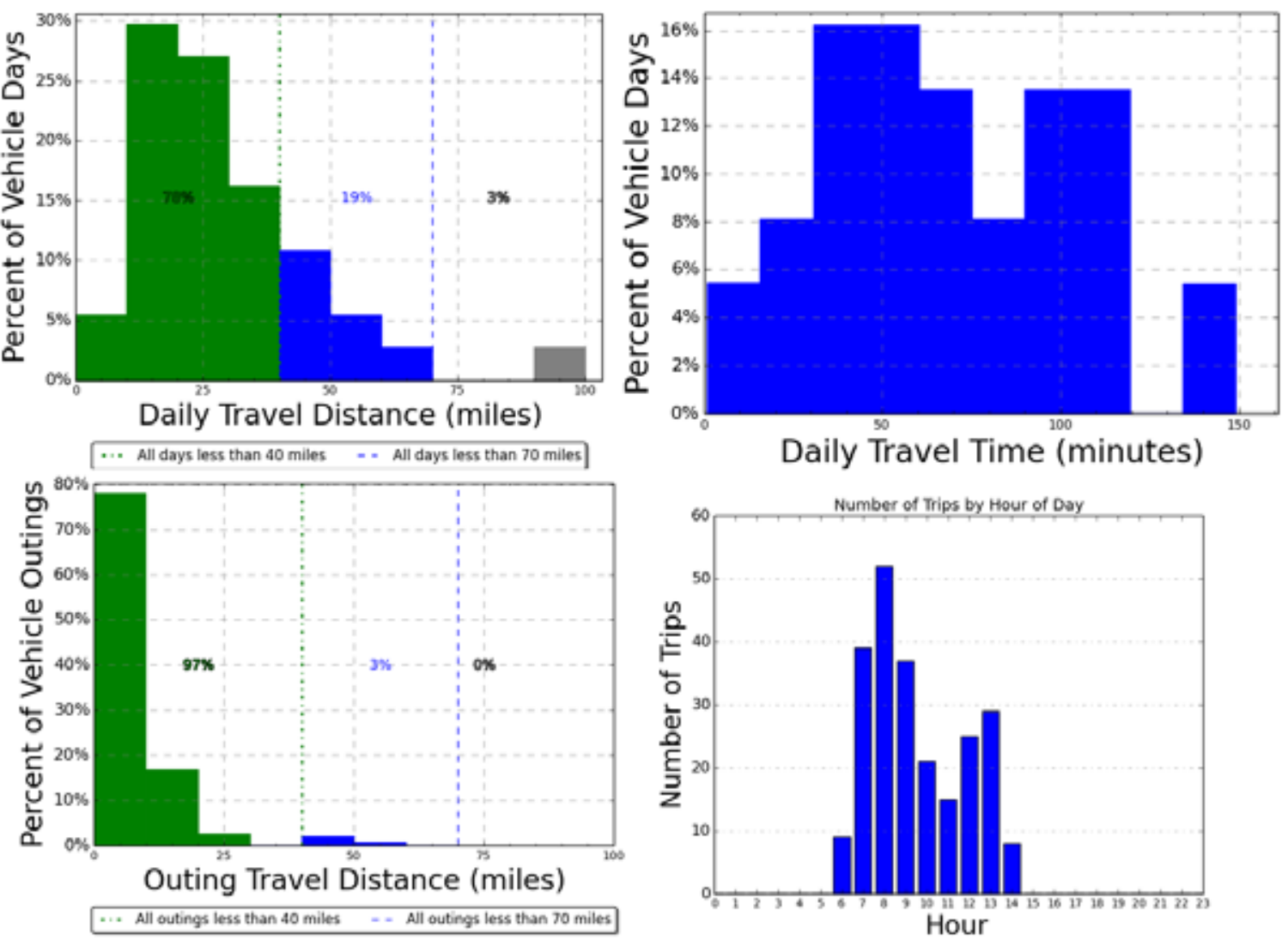

Daily Travel Time (minutes)

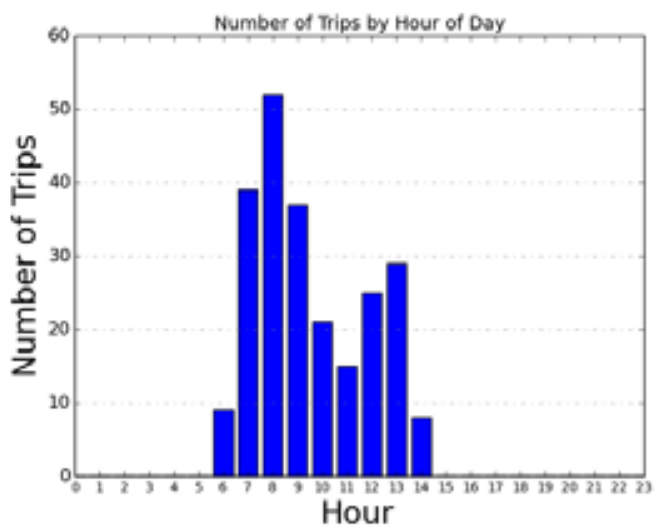

Figure D-14. Vehicle G42-0658K travel graphs.

\section{Vehicle G42-0658K Observations}

Information provided on the vehicle survey form for this vehicle indicated that this is a pool vehicle accessed by 2 to 5 people and typically is parked in the office parking lot near Building 2044. Expected use was over 50 miles per month, one person as passenger, used off-base 2 or 3 times per month, and used during dayshift hours of 0700 to 1630 . The alternate fuel E-85 is a frequently used fuel. Public Works expects this vehicle will remain with the fleet for another 6 years or more. The vehicle is used for transportation to GSA vehicle incidents, use for the McChord Airfield Driver Certification Program manager, and use for the McChord Civil Engineer Squadron LMR manager for all squadron radio issues.

Site fuel records show average travel is 336 miles per month and the odometer read 7,005 in April 2012. The vehicle typically carries only documentation or portable handheld radios. Use is for transportation between bases for coordination, repair, or instruction of various assigned programs and processes.

Logger 1 collected data on this vehicle for a period of 37 days of the 63 -study day period. Validation occurred on $98.5 \%$ of the input data. All but one stop exceeding the 2-hour duration occurred at the home base. The longest single trip and outing were within the typically advertised range of a BEV of approximately 70 miles. The longest day's travel was 96 miles; however, that day also had sufficient stop time to recharge the battery.

A BEV may provide the acceptable performance of this vehicle should the BEV meet the other mission requirements. The survey information suggests that no other special requirements exist. A PHEV would travel all but $3 \%$ of the outings on $\mathrm{CD}$ mode and would provide an alternative for this vehicle. 


\begin{tabular}{|l|l|c|}
\hline & Make/Model/Year & Ford/F150/2008 \\
\cline { 2 - 3 } & EPA Class Size & Standard Pickup Truck \\
\cline { 2 - 3 } & Mission & Pool \\
\hline Contact & J Ross/Public Works \\
\hline Parking Location & Bldg 2044/Adkison/N 3 ${ }^{\text {rd }}$ St \\
\hline & Fleet Vehicle ID & Gas-1054F \\
\hline & Fuel Type & $14 / 20 / 16$ \\
\hline & EPA Label/MPG (City/Hwy/Combined) & 555 \\
\cline { 2 - 3 } & EPA GHG Emissions (Grams CO $/$ Mi) & Logger 2 \\
\cline { 2 - 3 } & Study Logger ID & $35 / 63$ \\
\cline { 2 - 3 } & Total Vehicle Days/Total Study Days & Gas \\
\hline
\end{tabular}

\begin{tabular}{|l|c|c|c|c|}
\hline \multicolumn{5}{|c|}{ Vehicle G42-1054F Travel Summary } \\
\hline & $\begin{array}{c}\text { Per Day } \\
\text { Average/Peak }\end{array}$ & $\begin{array}{c}\text { Per Outing } \\
\text { Average/Peak }\end{array}$ & $\begin{array}{c}\text { Per Trip } \\
\text { Average/Peak }\end{array}$ & Total \\
\hline Travel Distance (Miles) & $15.4 / 82.0$ & $6.4 / 42.8$ & $2.5 / 36$ & 540 \\
\hline Travel Time (Minutes) & $62 / 248$ & $25.5 / 247$ & $10.1 / 88$ & 2,170 \\
\hline Idle Time (Minutes) & $13.4 / \mathrm{NA}$ & $5.5 / \mathrm{NA}$ & $2.2 / \mathrm{NA}$ & 470 \\
\hline
\end{tabular}

\begin{tabular}{|c|c|c|c|c|}
\hline \multicolumn{2}{|c|}{ Total Stops } & \multicolumn{2}{c|}{ Stop Duration } \\
\hline $\begin{array}{c}\text { Distance From } \\
\text { Home Base (Miles) }\end{array}$ & Stops & Percentages & Stop Duration (Hours) & Stops \\
\hline Less than 10 & 242 & 98 & Less than 2 & 201 \\
\hline 10 to 20 & 5 & 2 & 2 to 4 & 12 \\
\hline 20 to 40 & 0 & 0 & 4 to 8 & 3 \\
\hline 40 to 60 & 0 & 0 & Greater than 8 & 31 \\
\hline
\end{tabular}

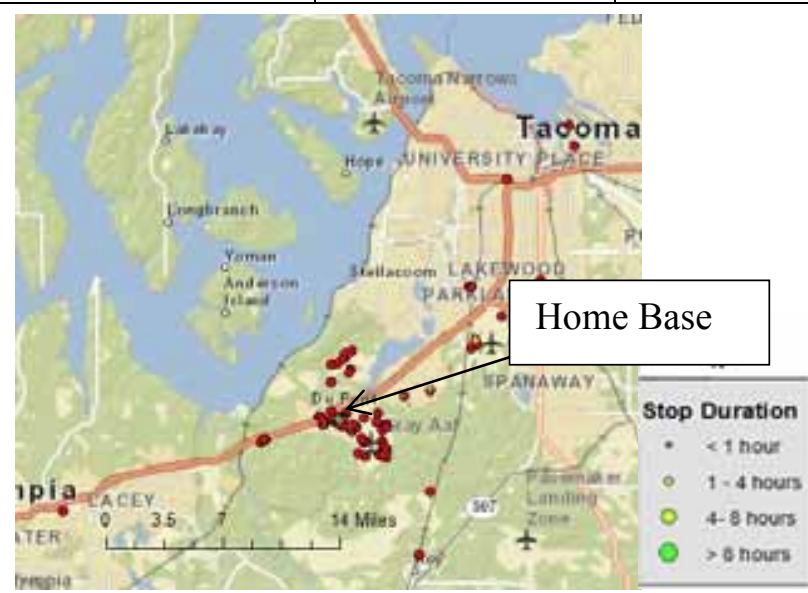

Figure D-4. Vehicle G42-1054F stops.

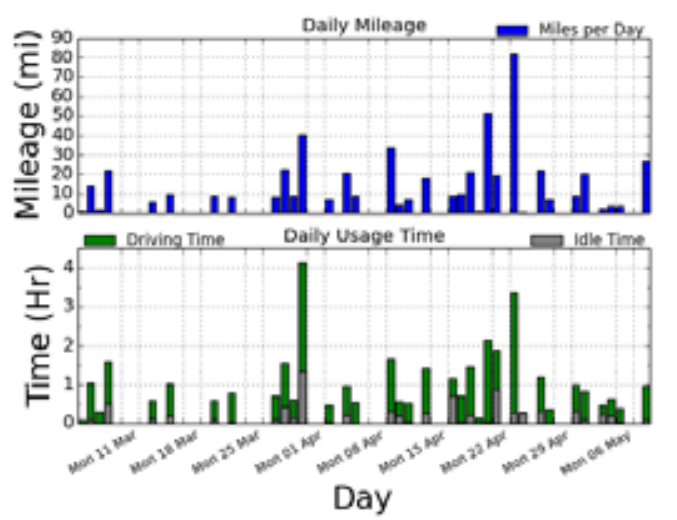

Figure D-5. Vehicle G42-1054F history. 


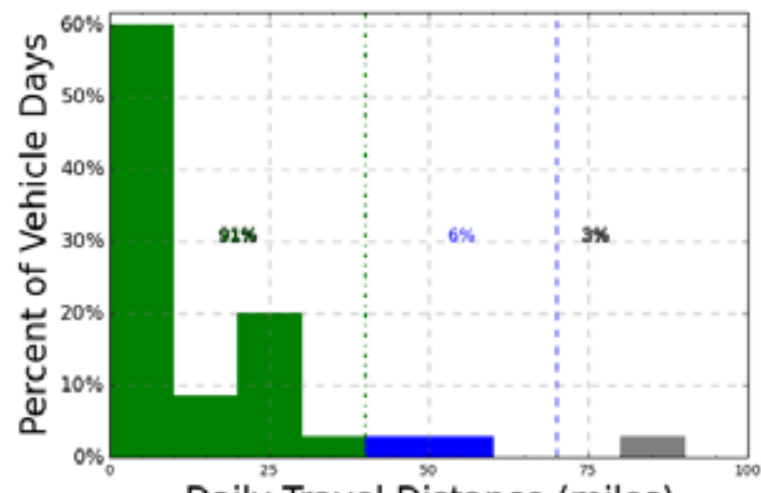

Daily Travel Distance (miles)
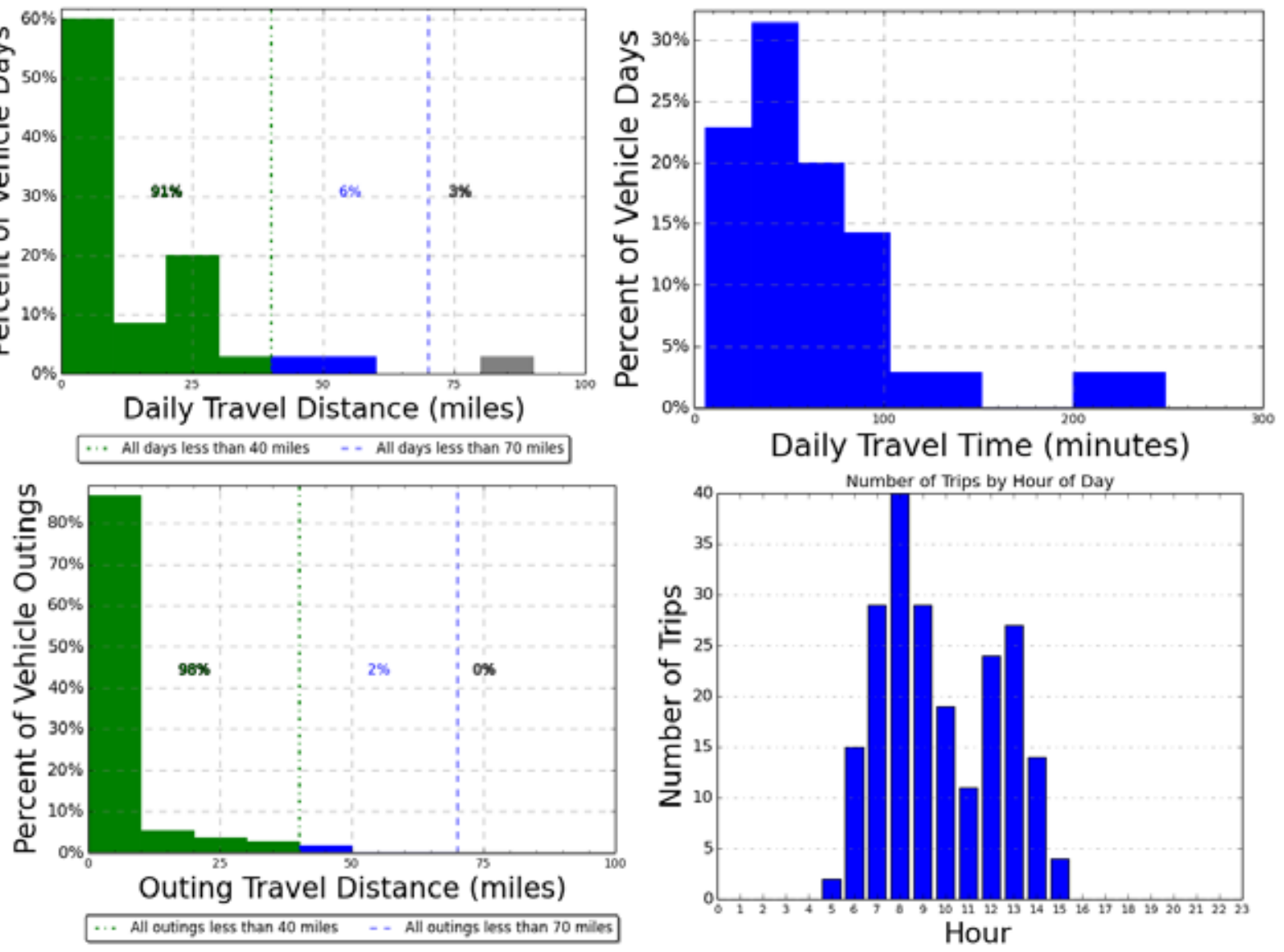

Figure D-15. Vehicle G42-1054F travel graphs.

\section{Vehicle G42-1054F Observations}

Survey information was not available for this vehicle. Stop data suggest this vehicle is typically parked near Building 2044 at Adkison Ave/N 4th St/N 3rd St/Utah Ave. Site data reports an odometer reading of 34,940 in January 2012 and low monthly mileage.

Logger 2 collected data on this vehicle for a period of 35 days of the 63-day study period. Validation occurred on $99.6 \%$ of the vehicle data. All stops of greater than 2-hours duration occurred at the home base. The longest single trip and outing were within the typically advertised range of a BEV of approximately 70 miles. The longest day's travel was 82 miles; however, that day also had sufficient stop time to recharge the battery. Only $2 \%$ of the outings exceeded the maximum $\mathrm{CD}$ range of 40 miles for a PHEV.

A BEV may provide acceptable performance for this vehicle should the BEV meet the other mission requirements. Information is unavailable that suggests special requirements exist. Daily travel requirements also allow use of a PHEV traveling all day in CD mode, thus providing an alternative for this vehicle. 
Vehicle G71-0133L

\begin{tabular}{|c|c|c|}
\hline \multirow{11}{*}{ 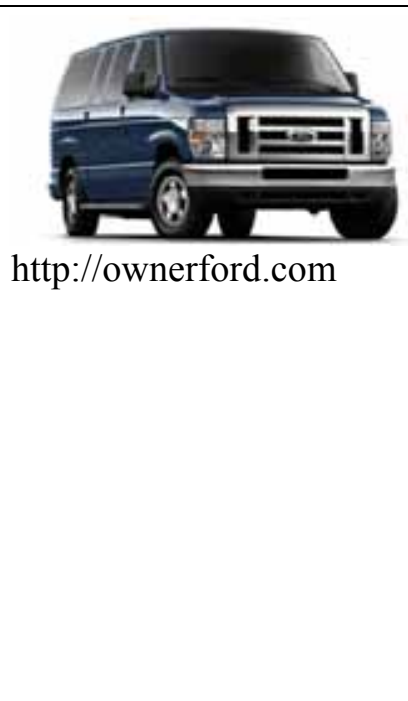 } & Make/Model/Year & Ford/E450/2011 \\
\hline & EPA Class Size & Vans, Passenger Type \\
\hline & Mission & Pool \\
\hline & Contact & J Ross/Public Works \\
\hline & Parking Location & Bldg 2063/N. 4th St \\
\hline & Fleet Vehicle ID & G71-0133L \\
\hline & Fuel Type & Gas/ETH \\
\hline & EPA Label/MPG (City/Hwy/Combined)* & $11 / 15 / 139 / 11 / 10$ \\
\hline & EPA GHG Emissions (Grams $\left.\mathrm{CO}_{2} / \mathrm{Mi}\right)^{*}$ & $684 / 630$ \\
\hline & Study Logger ID & Logger 3 \\
\hline & Total Vehicle Days/Total Study Days & $41 / 63$ \\
\hline
\end{tabular}

\begin{tabular}{|l|c|c|c|c|}
\hline \multicolumn{5}{|c|}{ Vehicle G71-0133L Travel Summary } \\
\hline & $\begin{array}{c}\text { Per Day } \\
\text { Average/Peak }\end{array}$ & $\begin{array}{c}\text { Per Outing } \\
\text { Average/Peak }\end{array}$ & $\begin{array}{c}\text { Per Trip } \\
\text { Average/Peak }\end{array}$ & Total \\
\hline Travel Distance (Miles) & $11.5 / 39.4$ & $2.9 / 22.1$ & $1.2 / 12.8$ & 470 \\
\hline Travel Time (Minutes) & $94 / 181$ & $24.0 / 87$ & $9.7 / 74$ & 3,867 \\
\hline Idle Time (Minutes) & $41.3 / \mathrm{NA}$ & $10.5 / \mathrm{NA}$ & $4.3 / \mathrm{NA}$ & 1,694 \\
\hline
\end{tabular}

\begin{tabular}{|c|c|c|c|c|}
\hline \multicolumn{2}{|c|}{ Total Stops } & \multicolumn{2}{c|}{ Stop Duration } \\
\hline $\begin{array}{c}\text { Distance From } \\
\text { Home Base (Miles) }\end{array}$ & Stops & Percentages & Stop Duration (Hours) & Stops \\
\hline Less than 10 & 430 & 100 & Less than 2 & 361 \\
\hline 10 to 20 & 0 & 0 & 2 to 4 & 23 \\
\hline 20 to 40 & 0 & 0 & 4 to 8 & 8 \\
\hline 40 to 60 & 0 & 0 & Greater than 8 & 38 \\
\hline
\end{tabular}

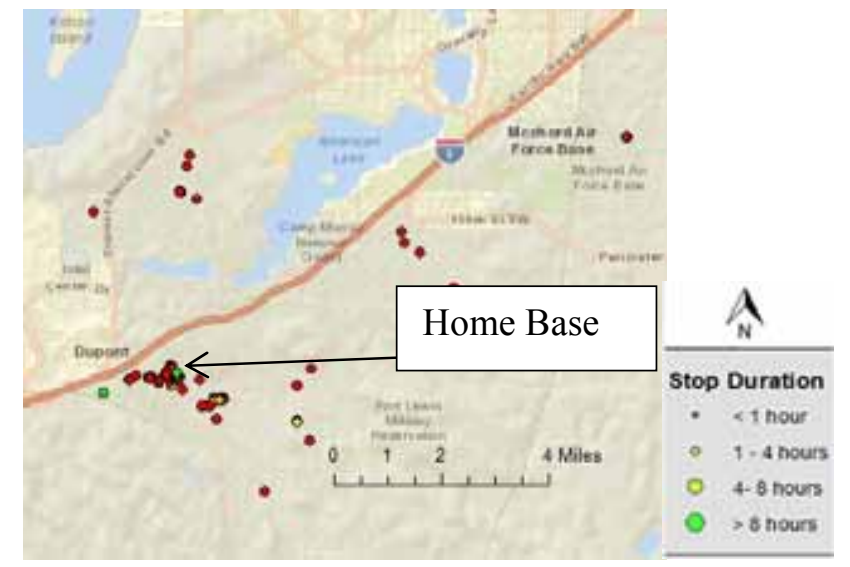

Figure D-7. Vehicle G71-0133L stops.

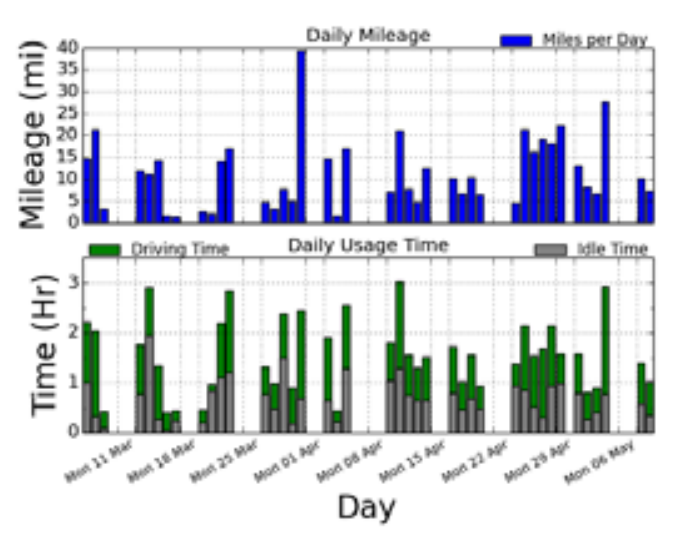

Figure D-8. Vehicle G71-0133L history.

*2011 Ford E350 Van information. EPA figures for 2011 Ford E450 are not available. 


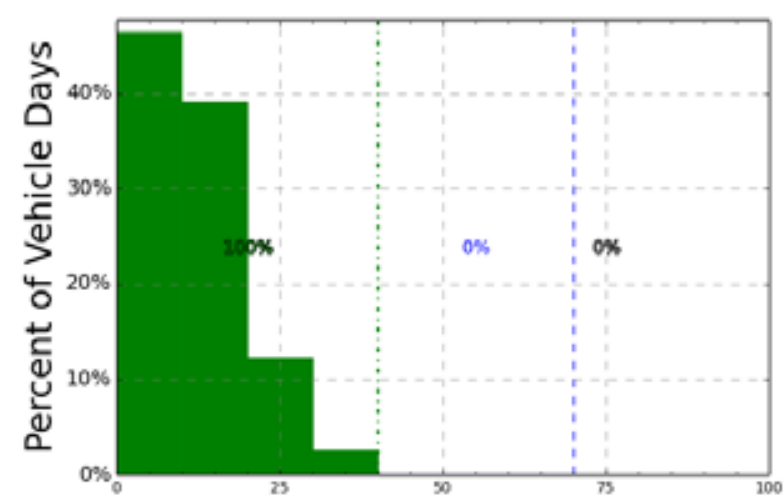

Daily Travel Distance (miles)

All days less than 40 miles - - All days less than 70 miles

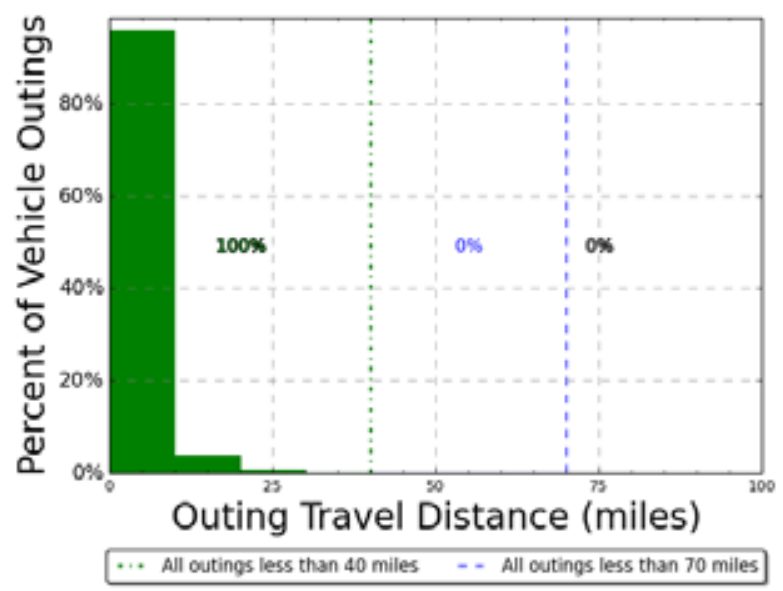

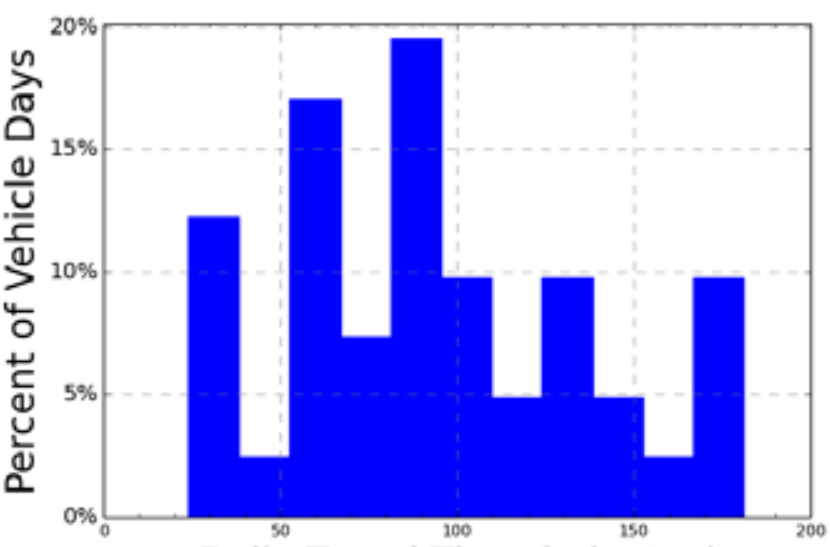

Daily Travel Time (minutes)

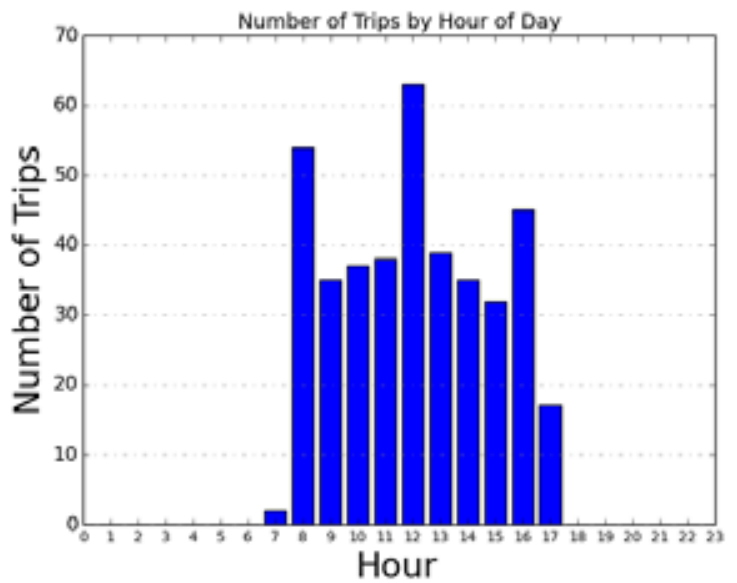

Figure D-16. Vehicle G71-0133L travel graphs.

\section{Vehicle G71-0133L Observations}

Vehicle survey information was not available for this vehicle. Data loggers show the primary home base is near Building 2063 on Adkison Ave/N $4^{\text {th }} \mathrm{St} / \mathrm{N} 3^{\text {rd }} \mathrm{St} / \mathrm{Utah}$ Ave. JBLM records indicated the vehicle travels 275 miles per month and the odometer read 5,677 in May 2012.

Logger 3 collected data on this vehicle for a period of 41 days of the 63-day study period. Validation occurred on $99.8 \%$ of the vehicle data. Fifty-eight percent of stops greater than 2-hours duration occurred primarily at the home base, with $24 \%$ occurring on Liggett Ave, and $13 \%$ on 9th Division Road. The longest single trip, outing, and daily travel were within the typically advertised range of a BEV of approximately 70 miles. None of the outings exceeded the maximum CD range of 40 miles for a PHEV.

A BEV may provide acceptable performance for this vehicle should the BEV meet the other mission requirements. Information that suggests special requirements exist is unavailable. Daily travel requirements also allow the use of a PHEV traveling all day in $\mathrm{CD}$ mode, thus providing an alternative for this vehicle. 


\begin{tabular}{|l|l|c|}
\hline & Make/Model/Year & Chevrolet/G3500 Express /2008 \\
\cline { 2 - 3 } & EPA Class Size & Passenger Van \\
\cline { 2 - 3 } & Mission & Pool \\
\hline http://autos.aol.com/cars & Contact & J Ross/Public Works \\
\cline { 2 - 3 } & Parking Location & Bldg 2044/Utah Ave \\
\cline { 2 - 3 } & Fleet Vehicle ID & G43-0944G \\
\cline { 2 - 3 } & Fuel Type & Diesel \\
\cline { 2 - 3 } & EPA Label/MPG (City/Hwy) & $14 / 17 / 15$ \\
\cline { 2 - 3 } & EPA GHG Emissions (Grams $\left.\mathrm{CO}_{2} / \mathrm{Mi}\right)$ & Not available \\
\cline { 2 - 3 } & Study Logger ID & Logger 4 \\
\cline { 2 - 3 } & Total Vehicle Days/Total Study Days & $34 / 63$ \\
\hline
\end{tabular}

\begin{tabular}{|l|c|c|c|c|}
\hline \multicolumn{5}{|c|}{ Vehicle G43-0944G Travel Summary } \\
\hline & $\begin{array}{c}\text { Per Day } \\
\text { Average/Peak }\end{array}$ & $\begin{array}{c}\text { Per Outing } \\
\text { Average/Peak }\end{array}$ & $\begin{array}{c}\text { Per Trip } \\
\text { Average/Peak }\end{array}$ & Total \\
\hline Travel Distance (Miles) & $8.0 / 20.3$ & $2.0 / 15.4$ & $0.8 / 14.5$ & 272 \\
\hline Travel Time (Minutes) & $77 / 149$ & $19.7 / 80.0$ & $7.8 / 58$ & 2,618 \\
\hline Idle Time (Minutes) & $37.8 / \mathrm{NA}$ & $9.7 / \mathrm{NA}$ & $3.8 / \mathrm{NA}$ & 1,284 \\
\hline
\end{tabular}

\begin{tabular}{|c|c|c|c|c|}
\hline \multicolumn{2}{|c|}{ Total Stops } & \multicolumn{2}{c|}{ Stop Duration } \\
\hline $\begin{array}{c}\text { Distance From } \\
\text { Home Base (Miles) }\end{array}$ & Stops & Percentages & Stop Duration (Hours) & Stops \\
\hline Less than 10 & 289 & 100 & Less than 2 & 225 \\
\hline 10 to 20 & 0 & 0 & 2 to 4 & 23 \\
\hline 20 to 40 & 0 & 0 & 4 to 8 & 9 \\
\hline 40 to 60 & 0 & 0 & Greater than 8 & 32 \\
\hline
\end{tabular}

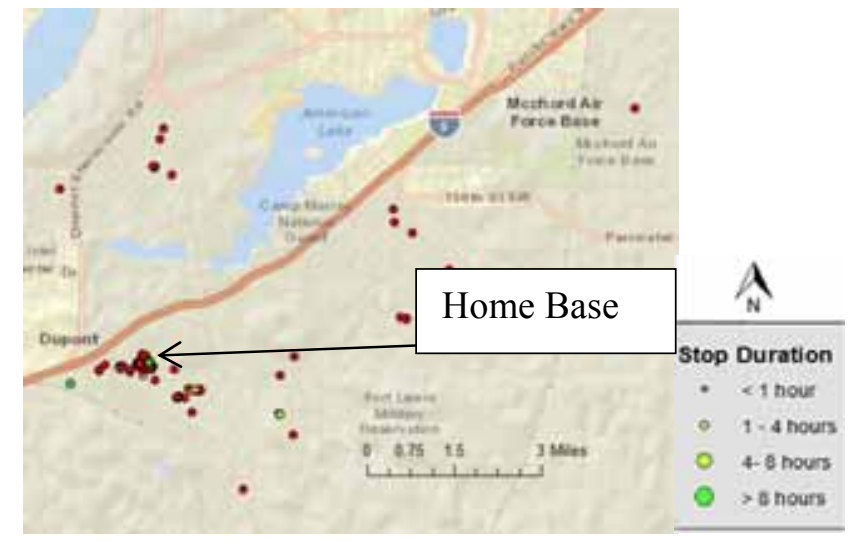

Figure D-10. Vehicle G43-0944G stops.

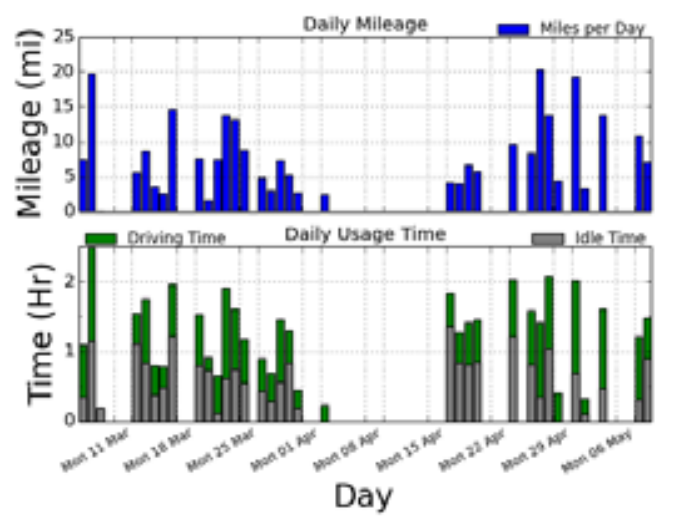

Figure D-11. Vehicle G43-0944G history. 


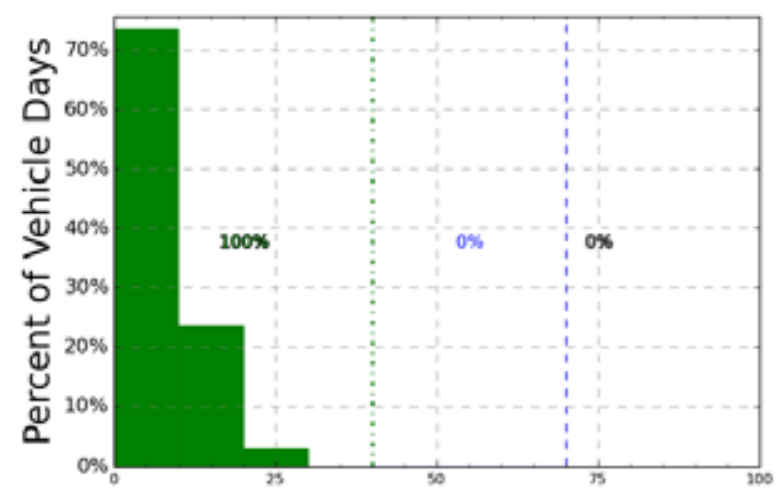

Daily Travel Distance (miles)

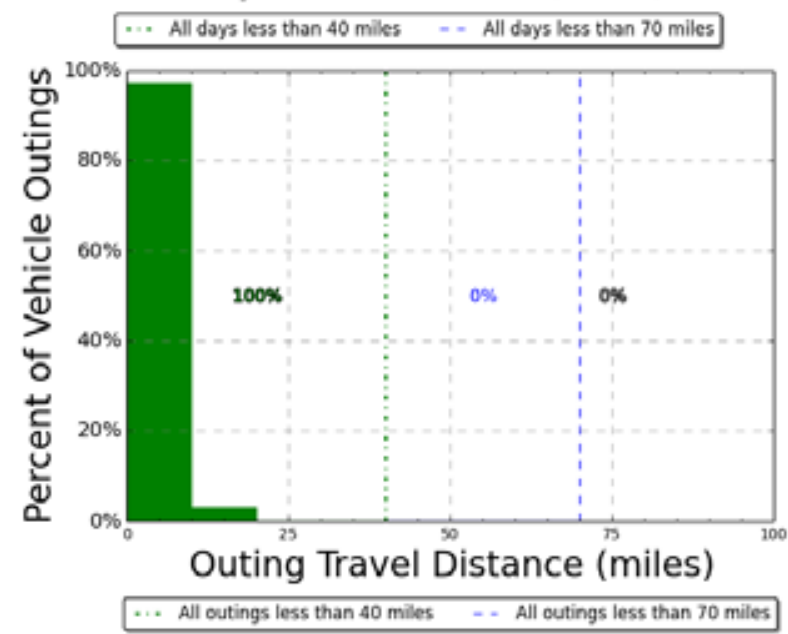

Figure D-17. Vehicle G43-0944G travel graphs.

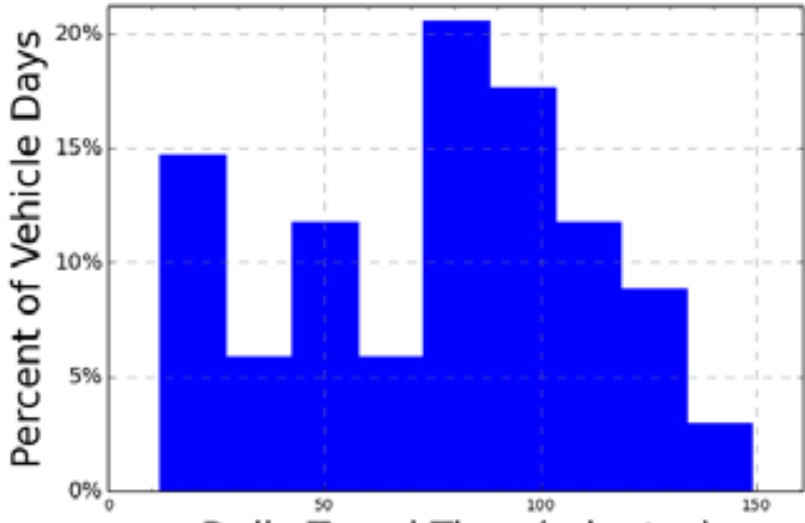

Daily Travel Time (minutes) Number of Trips by Hour of Day

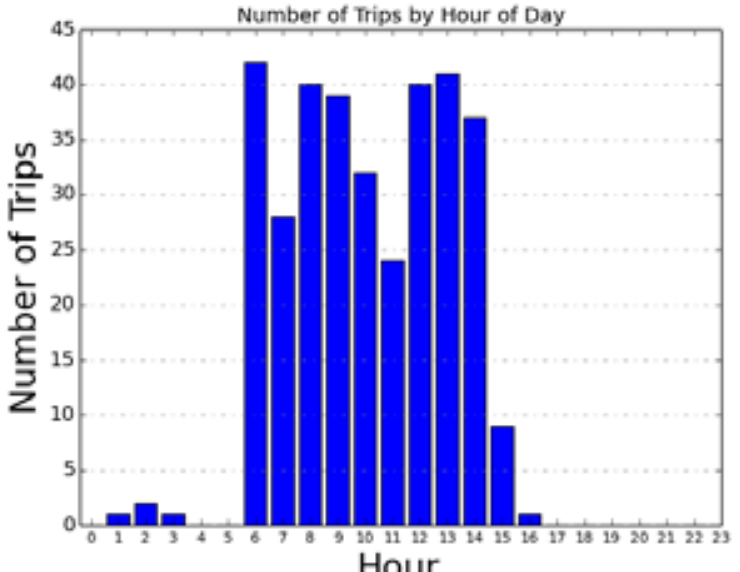

\section{Vehicle G43-0944G Observations}

Vehicle survey information was not available for this vehicle. Site records report the vehicle is used 145 miles per month on average and the odometer read 6,849 in May 2012. Data logger information suggests the home base for this vehicle is near Building 2044 on Utah Ave.

Logger 4 collected data on this vehicle for 34 days of the 63-day study period. Validation occurred on $99.9 \%$ of the vehicle data. Forty-five percent of stops of greater than 2-hours duration occurred at the home base. The remaining stops varied among many locations, with $21 \%$ on Pendleton and $8 \%$ on North $3^{\text {rd }}$ Street. The longest single trip, outing, and daily travel were within the typically advertised range of a BEV of approximately 70 miles. None of the outings exceeded the maximum CD range of 40 miles for a PHEV.

A BEV may provide acceptable performance for this vehicle should the BEV meet other mission requirements. Information is unavailable, suggesting special requirements exist. Daily travel requirements also allow the use of a PHEV traveling all day in CD mode, thus providing an alternative for this vehicle. 


\begin{tabular}{|l|l|c|}
\hline \multirow{4}{*}{$\begin{array}{l}\text { http://autos.yahoo.com/use } \\
\text { d-cars }\end{array}$} & Make/Model/Year & Pickup Trucks \\
\cline { 2 - 3 } & EPA Class Size & Support \\
\hline & Mission & J Ross/Public Works \\
\hline Contact & Bldg 2044/Utah Ave \\
\cline { 2 - 3 } & Parking Location & G43-0822G \\
\cline { 2 - 3 } & Fleet Vehicle ID & Gas \\
\cline { 2 - 3 } & Fuel Type & $14 / 19 / 16$ \\
\hline & EPA Label/MPG (City/Hwy)* & 555 \\
\cline { 2 - 3 } & EPA GHG Emissions (Grams $\left.\mathrm{CO}_{2} / \mathrm{Mi}\right)^{*}$ & Logger 5 \\
\cline { 2 - 3 } & Study Logger ID & $45 / 63$ \\
\cline { 2 - 3 } & Total Vehicle Days/Total Study Days & \\
\hline
\end{tabular}

\begin{tabular}{|l|c|c|c|c|}
\hline \multicolumn{5}{|c|}{ Vehicle G43-0822G Travel Summary } \\
\hline & $\begin{array}{c}\text { Per Day } \\
\text { Average/Peak }\end{array}$ & $\begin{array}{c}\text { Per Outing } \\
\text { Average/Peak }\end{array}$ & $\begin{array}{c}\text { Per Trip } \\
\text { Average/Peak }\end{array}$ & Total \\
\hline Travel Distance (Miles) & $22.3 / 42.4$ & $5.6 / 22.1$ & $2.6 / 9.4$ & 1,005 \\
\hline Travel Time (Minutes) & $75 / 129$ & $18.8 / 74$ & $8.7 / 30$ & 3,391 \\
\hline Idle Time (Minutes) & $8.3 / \mathrm{NA}$ & $2.1 / \mathrm{NA}$ & $1.0 / \mathrm{NA}$ & 372 \\
\hline
\end{tabular}

\begin{tabular}{|c|c|c|c|c|}
\hline \multicolumn{2}{|c|}{ Total Stops } & \multicolumn{2}{c|}{ Stop Duration } \\
\hline $\begin{array}{c}\text { Distance From } \\
\text { Home Base (Miles) }\end{array}$ & Stops & Percentages & Stop Duration (Hours) & Stops \\
\hline Less than 10 & 343 & 100 & Less than 2 & 277 \\
\hline 10 to 20 & 0 & 0 & 2 to 4 & 24 \\
\hline 20 to 40 & 0 & 0 & 4 to 8 & 0 \\
\hline 40 to 60 & 0 & 0 & Greater than 8 & 48 \\
\hline
\end{tabular}

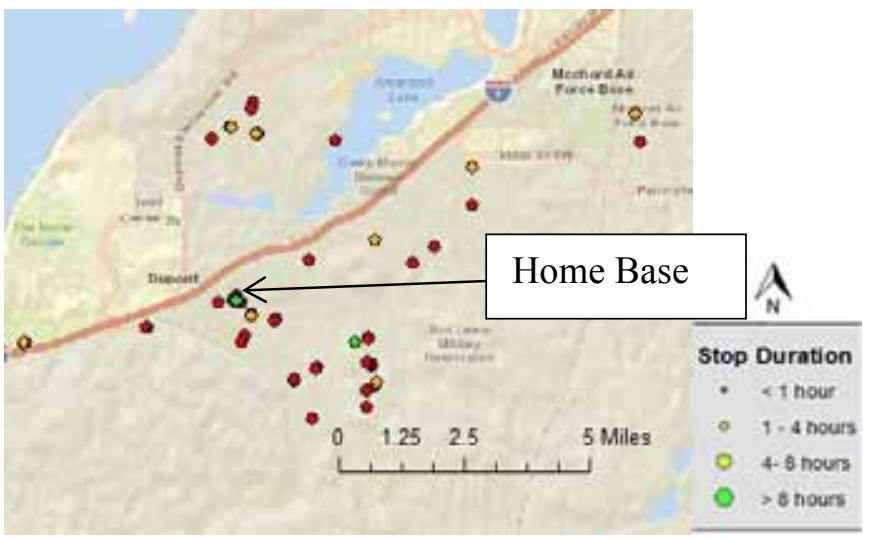

Figure D-13. Vehicle G43-0822G stops. *2008 Ford F150 truck information provided. EPA figures for Ford F350 are not available.

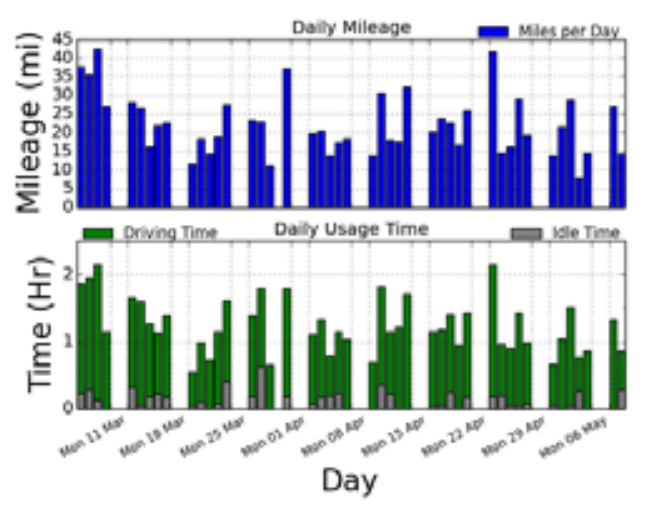

Figure D-14. Vehicle G43-0822G history. 

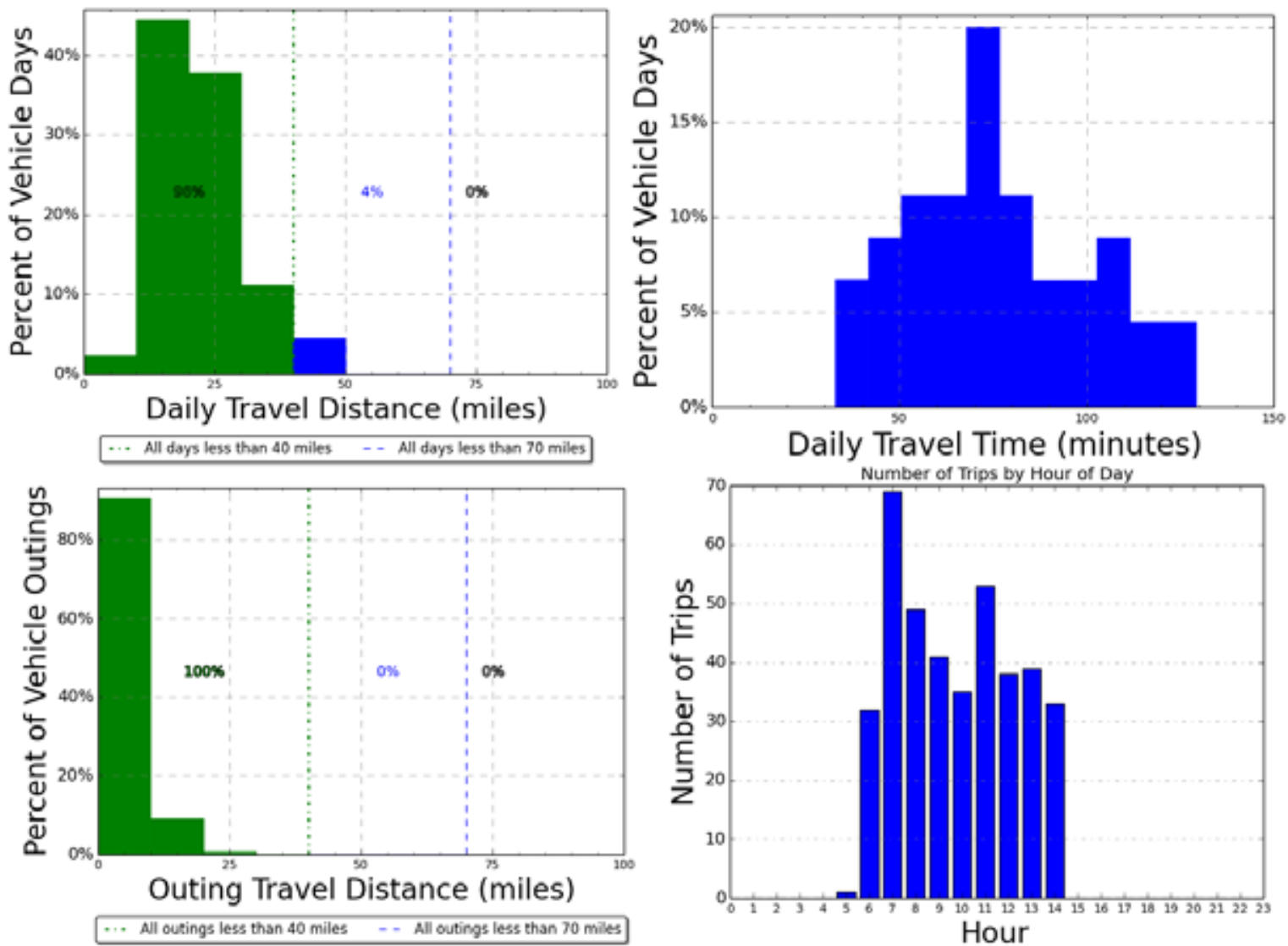

Figure D-18. Vehicle G43-0822G travel graphs.

\section{Vehicle G43-0822G Observations}

Vehicle survey information was not available for this vehicle. Site records report this vehicle travels an average of 470 miles per month. The odometer read 22,101 in May 2012. Vehicle data suggest the vehicle is home based near Building 2044 on Utah Avenue.

Logger 5 collected data on this vehicle for 45 days of the 63-day study period. Validation occurred on $99.4 \%$ of the vehicle data. Sixty-nine percent of stops greater than 2-hours duration occurred at the home base. The remaining stops varied among several locations, with $14 \%$ on 41 st Division Drive and $6 \%$ on Faith Avenue. The longest single trip, outing, and daily travel were within the typically advertised range of a BEV of approximately 70 miles. None of the outings exceeded the maximum CD range for a PHEV of 40 miles.

A BEV may provide acceptable performance for this vehicle should the BEV meet other mission requirements. Information is unavailable, suggesting special requirements exist. Daily travel requirements also allow use of a PHEV traveling all day in CD mode, thus providing an alternative for this vehicle. 
Vehicle G41-1100K

\begin{tabular}{|l|l|c|}
\hline \multirow{4}{*}{ http://autos.yahoo.com/ } & Make/Model/Year & Dodge/Grand Caravan/2010 \\
\cline { 2 - 3 } & EPA Class Size & Minivan \\
\hline & Mission & Pool \\
\hline & Contact & Bldg 2012/Pendleton Ave \\
\cline { 2 - 3 } & Farking Location & G41-1100K \\
\cline { 2 - 3 } & Fueet Vehicle ID & Gas/ETH \\
\cline { 2 - 3 } & EPA Label/MPG (City/Hwy) & $17 / 24 / 1912 / 17 / 13$ \\
\hline & EPA GHG Emissions (Grams $\left.\mathrm{CO}_{2} / \mathrm{Mi}\right)$ & $468 / 484$ \\
\cline { 2 - 3 } & Study Logger ID & Logger 84 \\
\cline { 2 - 3 } & Total Vehicle Days/Total Study Days & $28 / 63$ \\
\hline
\end{tabular}

\begin{tabular}{|l|c|c|c|c|}
\hline \multicolumn{5}{|c|}{ Vehicle G41-1100K Travel Summary } \\
\hline & $\begin{array}{c}\text { Per Day } \\
\text { Average/Peak }\end{array}$ & $\begin{array}{c}\text { Per Outing } \\
\text { Average/Peak }\end{array}$ & $\begin{array}{c}\text { Per Trip } \\
\text { Average/Peak }\end{array}$ & Total \\
\hline Travel Distance (Miles) & $20.5 / 270.7$ & $19.8 / 168.6$ & $5.3 / 132$ & 573 \\
\hline Travel Time (Minutes) & $44 / 297$ & $42.1 / 223$ & $11.2 / 139$ & 1,221 \\
\hline Idle Time (Minutes) & $1.3 / \mathrm{NA}$ & $1.2 / \mathrm{NA}$ & $0.3 / \mathrm{NA}$ & 36 \\
\hline
\end{tabular}

\begin{tabular}{|c|c|c|c|c|}
\hline \multicolumn{2}{|c|}{ Total Stops } & \multicolumn{2}{c|}{ Stop Duration } \\
\hline $\begin{array}{c}\text { Distance From } \\
\text { Home Base (Miles) }\end{array}$ & Stops & Percentages & Stop Duration (Hours) & Stops \\
\hline Less than 10 & 103 & 96.3 & Less than 2 & 70 \\
\hline 10 to 20 & 0 & 0 & 2 to 4 & 7 \\
\hline 20 to 60 & 0 & 0 & 4 to 8 & 4 \\
\hline Greater than 60 & 4 & 3.7 & Greater than 8 & 26 \\
\hline
\end{tabular}

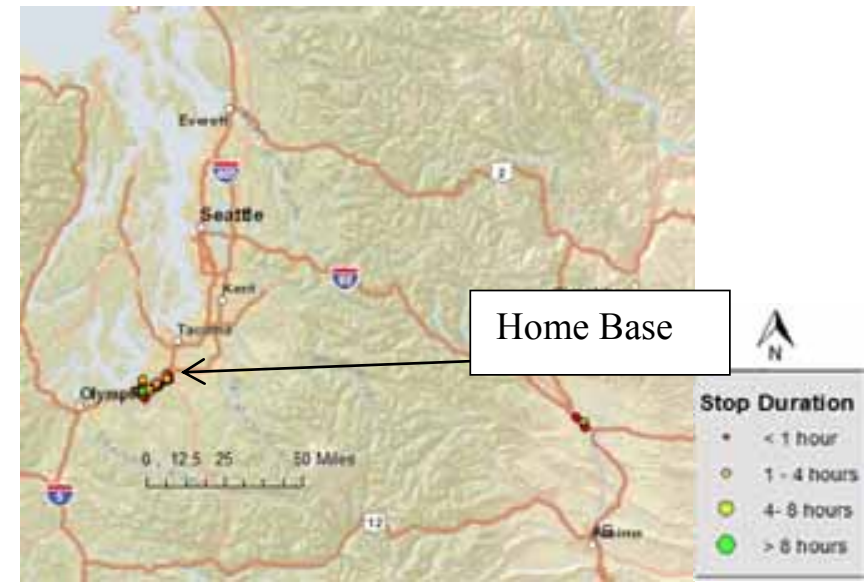

Figure D-16. Vehicle G41-1100K stops.

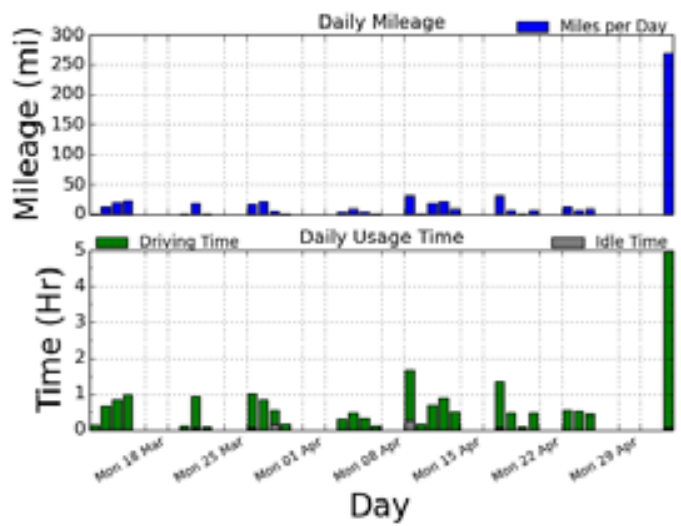

Figure D-17. Vehicle G41-1100K history. 

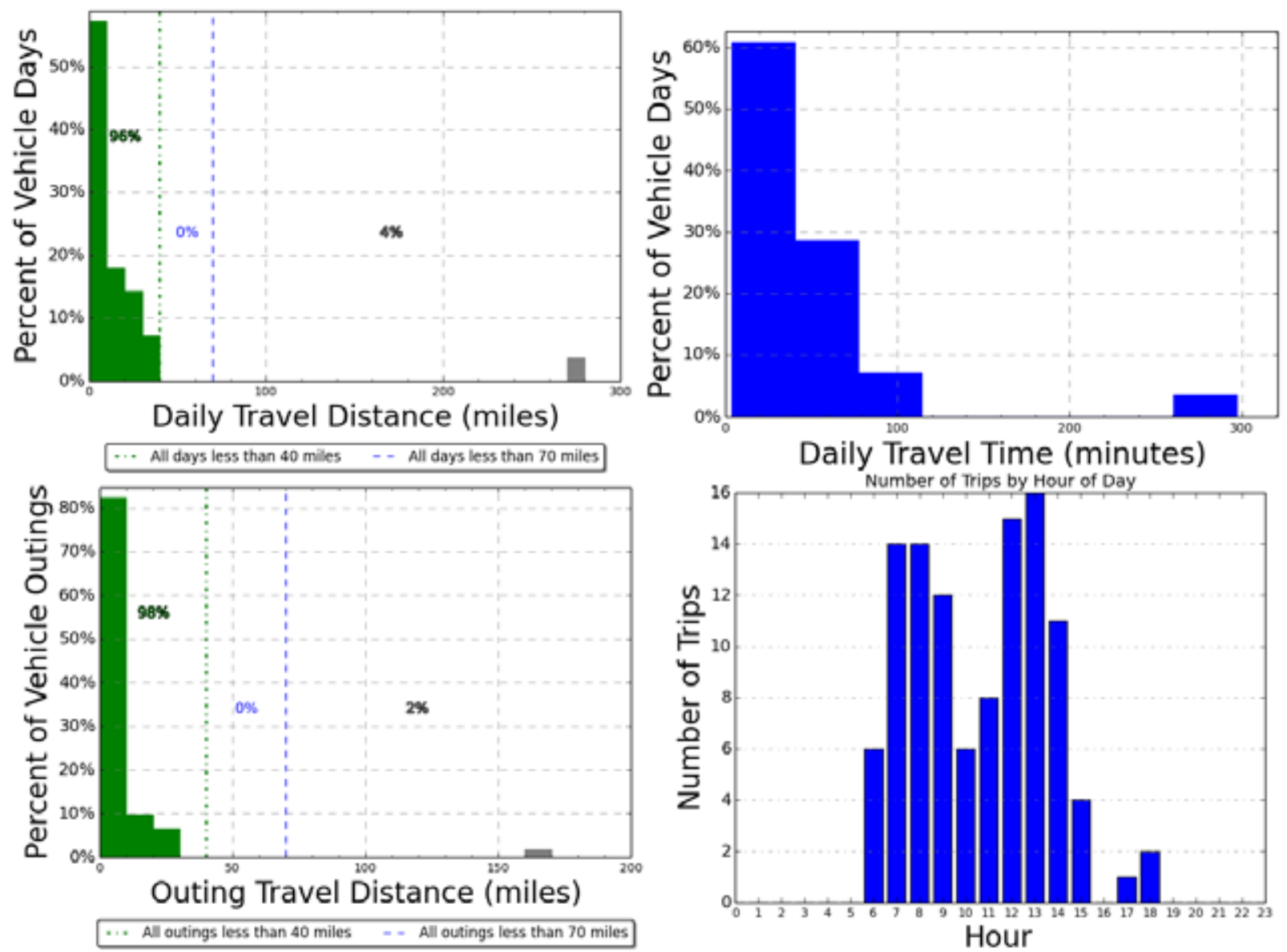

Figure D-19. Vehicle G41-1100K travel graphs.

\section{Vehicle G41-1100K Observations}

Information provided on the vehicle survey form for this vehicle indicated that this is a pool vehicle assigned to Environmental Services and is accessible by 50 people. It parks in the office parking lot near Building 2012 on Pendleton Avenue. The alternate fuel E-85 is almost exclusively used. Public Works expects this vehicle will remain with the fleet for 3 to 6 years. This vehicle travels for a wide variety of missions related to Pollution Prevention, Sustainability, Informational Tours, Transporting Dignitaries, Kids Fest, Earth Day Events, Armed Forces Day, Freedom Fest, McChord Field Rodeo, and Air Shows. Site fuel records show average travel is 336 miles per month and the odometer read 5,087 in April 2012. It carries no specific cargo or equipment on a regular basis.

Logger 84 collected data on this vehicle for 28 days of the 63-day study. Validation occurred on $97.8 \%$ of the vehicle data. Forty-one percent of stops greater than 2 hours occurred at the home base on Pendleton Avenue, with $19 \%$ on $4{ }^{\text {th }}$ Street and $16 \%$ on Kaufman Avenue. The longest single trip, outing, and daily travel occurred on May 1, 2013, on a trip to Ellensburg Washington. Other than that one day, all trips, outings, and daily travel were within the typically advertised range of a BEV of approximately 70 miles. None of the remaining outings exceeded the maximum CD range for a PHEV of 40 miles.

While a BEV may not provide the acceptable performance of this specific vehicle's travel, it is part of a pool that could contain other vehicles capable of this long trip. Should the BEV meet other mission requirements, it would meet $98 \%$ of this vehicle's usage. Information about other mission requirements is unavailable, suggesting special requirements exist. Daily travel requirements also allow for use of a PHEV traveling all but one day in CD mode, thus providing an alternative for this vehicle. 


\begin{tabular}{|l|l|c|}
\hline & Make/Model/Year & Chevrolet/C1500/2010 \\
\cline { 2 - 3 } & EPA Class Size & Standard Pickup Trucks \\
\hline Mission & Pool \\
\hline Contact & J Ross/Public Works \\
\hline Parking Location & Bldg 555/Lincoln Blvd \\
\hline Fleet Vehicle ID & G42-0619K \\
\hline & Fuel Type & Gas/ETH \\
\hline EPA Label/MPG (City/Hwy) & $15 / 21 / 1711 / 16 / 13$ \\
\hline & EPA GHG Emissions (Grams $\left.\mathrm{CO}_{2} / \mathrm{Mi}\right)$ & $523 / 484$ \\
\hline & Study Logger ID & Logger 87 \\
\cline { 2 - 3 } & Total Vehicle Days/Total Study Days & $30 / 63$ \\
\hline
\end{tabular}

\begin{tabular}{|l|c|c|c|c|}
\hline \multicolumn{5}{|c|}{ Vehicle G42-0619K Travel Summary } \\
\hline & $\begin{array}{c}\text { Per Day } \\
\text { Average/Peak }\end{array}$ & $\begin{array}{c}\text { Per Outing } \\
\text { Average/Peak }\end{array}$ & $\begin{array}{c}\text { Per Trip } \\
\text { Average/Peak }\end{array}$ & Total \\
\hline Travel Distance (Miles) & $4.4 / 17.5$ & $2.1 / 14.6$ & $0.9 / 11.5$ & 132 \\
\hline Travel Time (Minutes) & $32 / 145$ & $14.9 / 140$ & $6.3 / 62$ & 955 \\
\hline Idle Time (Minutes) & $11.1 / \mathrm{NA}$ & $5.2 / \mathrm{NA}$ & $2.2 / \mathrm{NA}$ & 332 \\
\hline
\end{tabular}

\begin{tabular}{|c|c|c|c|c|}
\hline \multicolumn{2}{|c|}{ Total Stops } & \multicolumn{2}{c|}{ Stop Duration } \\
\hline $\begin{array}{c}\text { Distance From } \\
\text { Home Base (Miles) }\end{array}$ & Stops & Percentages & Stop Duration (Hours) & Stops \\
\hline Less than 10 & 157 & 100 & Less than 2 & 117 \\
\hline 10 to 20 & 0 & 0 & 2 to 4 & 6 \\
\hline 20 to 40 & 0 & 0 & 4 to 8 & 4 \\
\hline 40 to 60 & 0 & 0 & Greater than 8 & 30 \\
\hline
\end{tabular}

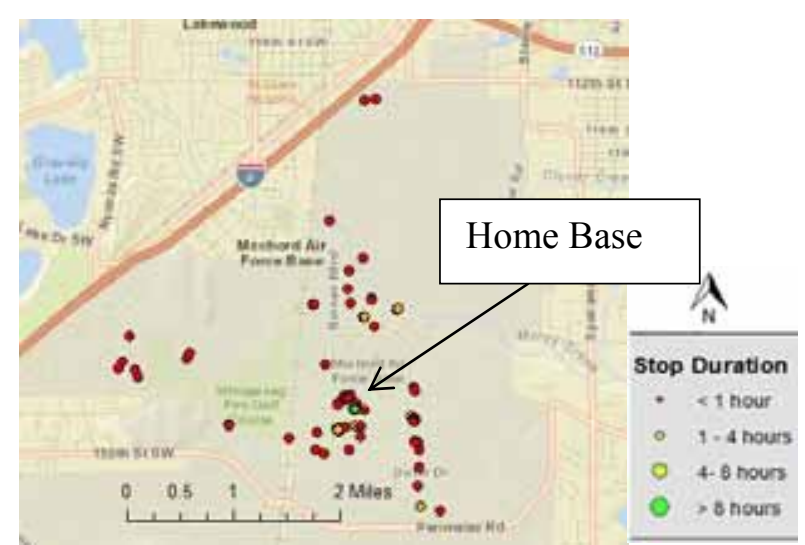

Figure D-19. Vehicle G42-0619K stops.

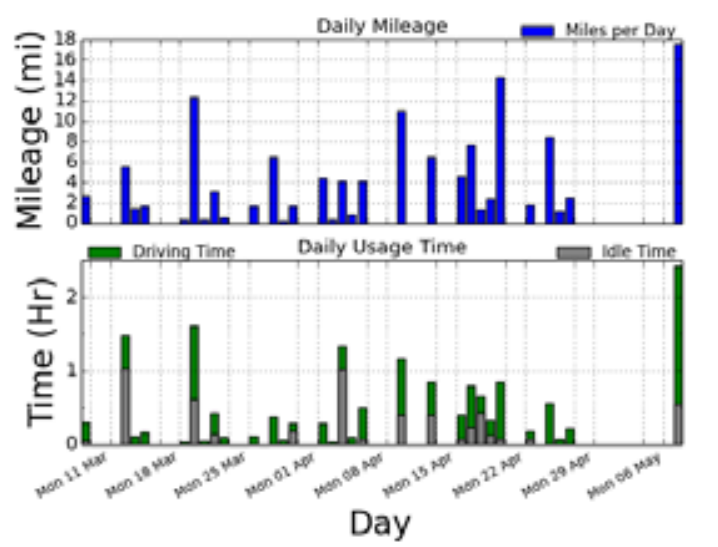

Figure D-20. Vehicle G42-0619K history. 

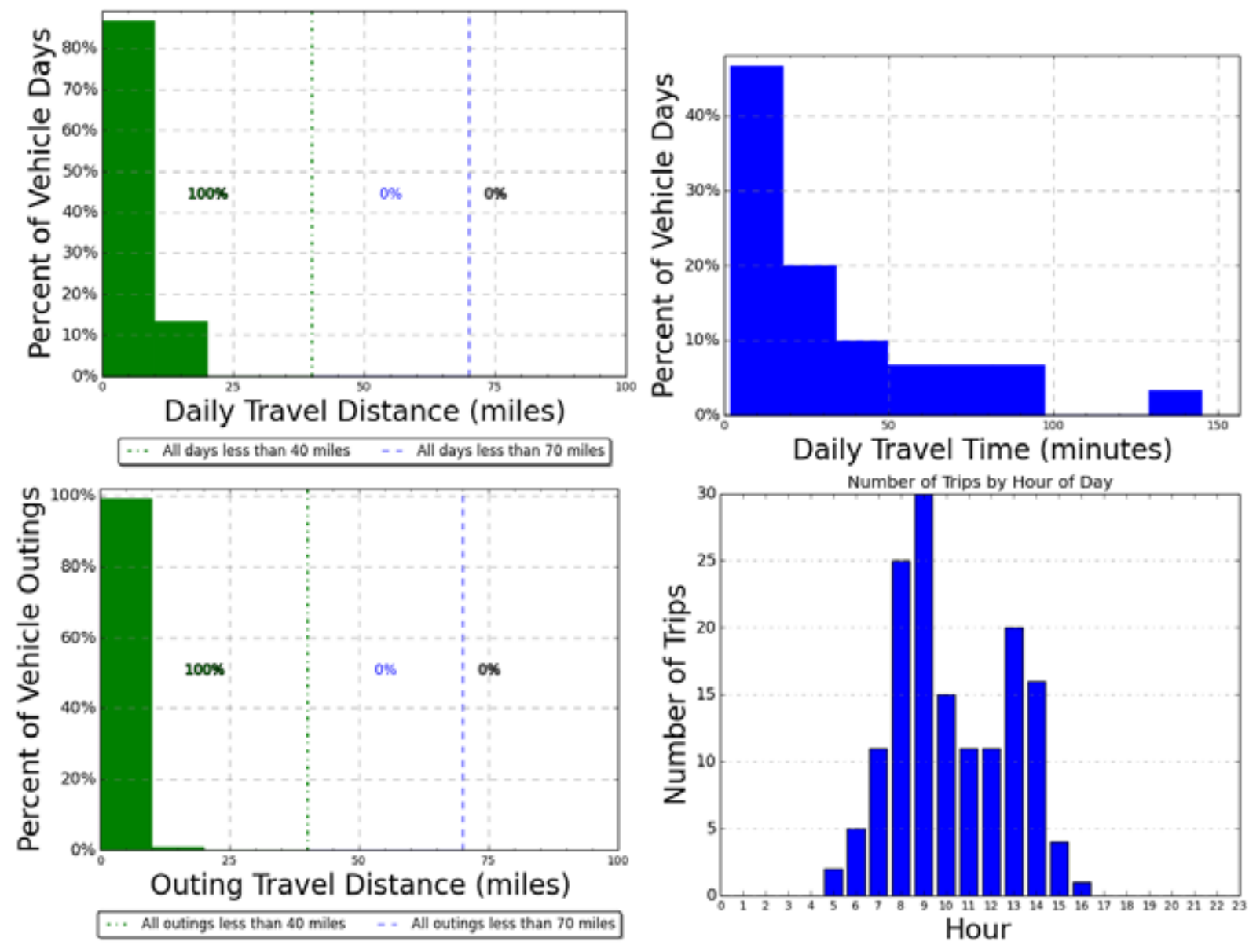

Figure D-20. Vehicle G42-0619K travel graphs.

\section{Vehicle G42-0619K Observations}

Vehicle survey information is not available for this vehicle. Logger data suggest the home base is located near Building 555 on Lincoln Boulevard. Site records report the vehicle travels approximately 163 miles per month and the odometer read 3,991 in May 2012.

Logger 87 collected data on this vehicle for 30 days of the 63-day study period. Validation occurred on $100 \%$ of the vehicle data. Ninety-two percent of all stops greater than 2-hours duration occurred at the home base. The longest single trip, outing, and daily travel were within the typically advertised range of a $\mathrm{BEV}$ of approximately 70 miles. None of the outings exceeded the maximum CD range for a PHEV of 40 miles.

A BEV may provide acceptable performance for this vehicle should the BEV meet other mission requirements. Information is unavailable, suggesting special requirements exist. Daily travel requirements also allow use of a PHEV traveling all day in $\mathrm{CD}$ mode, thus providing an alternative for this vehicle. 
Vehicle G41-1180K

\begin{tabular}{|l|l|c|}
\hline \multirow{4}{*}{ http://autos.yahoo.com/ } & Make/Model/Year & Dodge/Grand Caravan/2010 \\
\cline { 2 - 3 } & EPA Class Size & Minivan \\
\hline & Mission & Pool \\
\hline & Pontact & Bldg 540/A St SW \\
\cline { 2 - 3 } & Fleet Vehicle ID & G41-1180K \\
\hline & Fuel Type & Gas/ETH \\
\hline EPA Label/MPG (City/Hwy) & $17 / 24 / 1912 / 17 / 13$ \\
\hline & EPA GHG Emissions (Grams $\left.\mathrm{CO}_{2} / \mathrm{Mi}\right)$ & $468 / 484$ \\
\hline & Study Logger ID & Logger 88 \\
\hline & Total Vehicle Days/Total Study Days & $38 / 63$ \\
\hline
\end{tabular}

\begin{tabular}{|l|c|c|c|c|}
\hline \multicolumn{5}{|c|}{ Vehicle G41-1180K Travel Summary } \\
\hline & $\begin{array}{c}\text { Per Day } \\
\text { Average/Peak }\end{array}$ & $\begin{array}{c}\text { Per Outing } \\
\text { Average/Peak }\end{array}$ & $\begin{array}{c}\text { Per Trip } \\
\text { Average/Peak }\end{array}$ & Total \\
\hline Travel Distance (Miles) & $7.4 / 27.7$ & $3.5 / 18.8$ & $1.7 / 16.8$ & 282 \\
\hline Travel Time (Minutes) & $34 / 198$ & $15.8 / 86$ & $7.8 / 68$ & 1,280 \\
\hline Idle Time (Minutes) & $13.7 / \mathrm{NA}$ & $6.4 / \mathrm{NA}$ & $3.1 / \mathrm{NA}$ & 519 \\
\hline
\end{tabular}

\begin{tabular}{|c|c|c|c|c|}
\hline \multicolumn{2}{|c|}{ Total Stops } & \multicolumn{3}{c|}{ Stop Duration } \\
\hline $\begin{array}{c}\text { Distance From } \\
\text { Home Base (Miles) }\end{array}$ & Stops & Percentages & Stop Duration (Hours) & Stops \\
\hline Less than 10 & 176 & 100 & Less than 2 & 119 \\
\hline 10 to 20 & 0 & 0 & 2 to 4 & 39 \\
\hline 20 to 40 & 0 & 0 & 4 to 8 & Greater than 8 \\
\hline 40 to 60 & 0 & 0 & \\
\hline
\end{tabular}

Figure D-22. Vehicle G41-1180K stops.

Figure D-23. Vehicle G41-1180K history. 

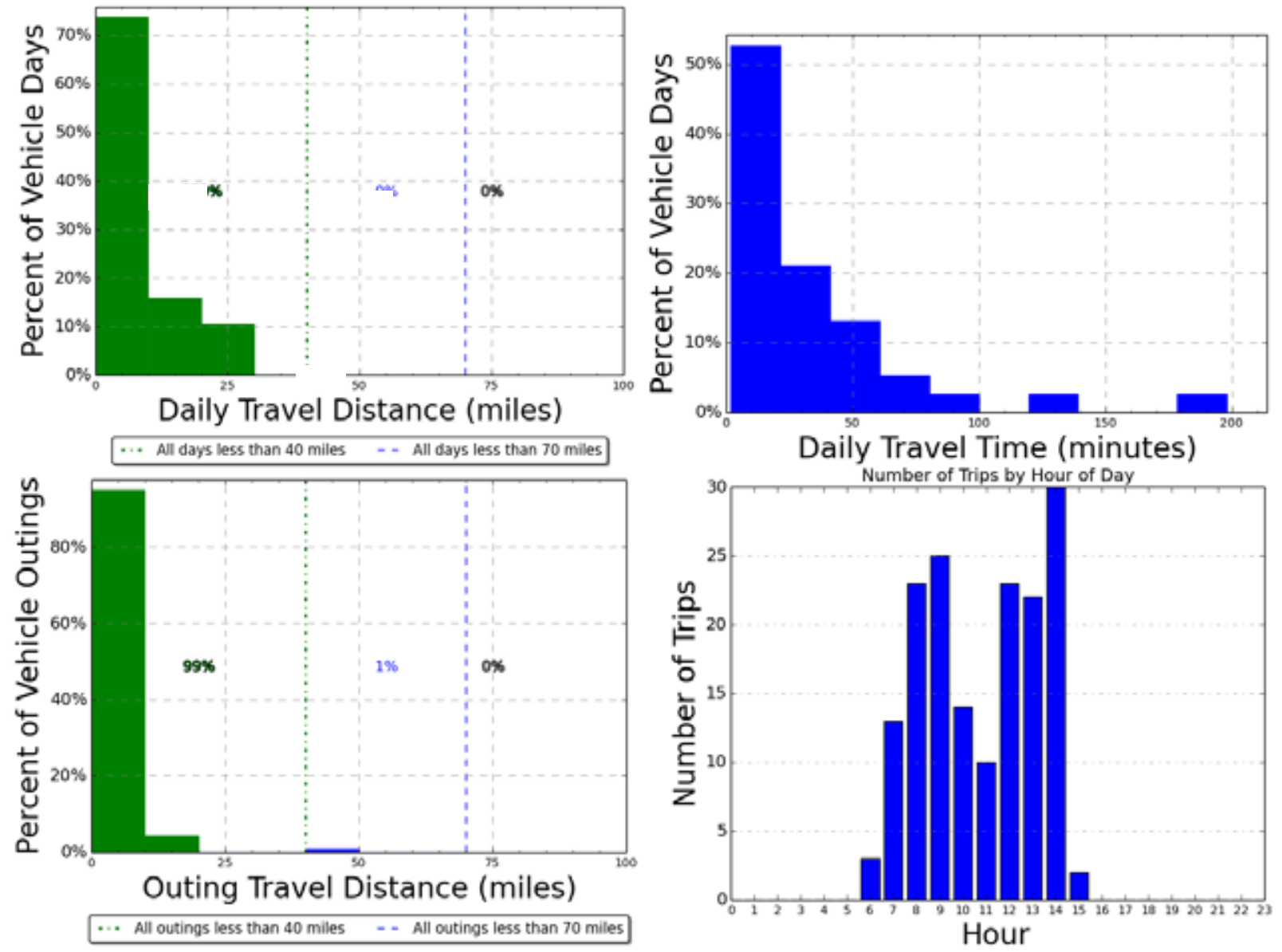

Figure D-21. Vehicle G41-1180K travel graphs.

\section{Vehicle G41-1180K Observations}

The vehicle survey reports that this vehicle is a pool vehicle, assigned primarily to a single person and parks near Building 540. DPW expects to retain it for another 2 to 3 years. The vehicle travels less than 10 miles per day and occasionally travels off base, with a typical outing of 11 to 40 miles; it may be used any time during the day. Up to 20 persons have access to this vehicle and it typically carries two people.

Site records report the vehicle travels approximately 83 miles per month and the odometer read 5,172 in May 2012. The vehicle typically parks across from Building 2012.

Logger 88 collected data on this vehicle for 38 days of the 63-day study period. Validation occurred on $98.9 \%$ of the vehicle data. Ninety-five percent of stops greater than 2-hours duration occurred at the home base. The longest single trip, outing, and daily travel were within the typically advertised range of a BEV of approximately 70 miles. None of the outings exceeded the maximum CD range for a PHEV of 40 miles.

A BEV may provide acceptable performance for this vehicle should the BEV meet other mission requirements. Information is unavailable, suggesting special requirements exist. Daily travel requirements also allow use of a PHEV traveling all day in CD mode, thus providing an alternative for this vehicle. 


\begin{tabular}{|l|l|c|}
\hline & Make/Model/Year & Chevrolet/C2500HD/2009 \\
\cline { 2 - 3 } & EPA Class Size* & Pickup Truck \\
\cline { 2 - 3 } & Mission & Support \\
\hline Contact & J Ross/Public Works \\
\cline { 2 - 3 } & Parking Location & $6^{\text {th }}$ St SW \\
\cline { 2 - 3 } & Fleet Vehicle ID & G43-1892H \\
\cline { 2 - 3 } & Fuel Type & Gas \\
\cline { 2 - 3 } & EPA Label/MPG (City/Hwy)* & $14 / 19 / 16$ \\
\cline { 2 - 3 } & EPA GHG Emissions (Grams $\left.\mathrm{CO}_{2} / \mathrm{Mi}\right)^{*}$ & 555 \\
\hline & Study Logger ID & Logger 90 \\
\cline { 2 - 3 } & Total Vehicle Days/Total Study Days & $43 / 63$ \\
\hline
\end{tabular}

\begin{tabular}{|l|c|c|c|c|}
\hline \multicolumn{5}{|c|}{ Vehicle G43-1892H Travel Summary } \\
\hline & $\begin{array}{c}\text { Per Day } \\
\text { Average/Peak }\end{array}$ & $\begin{array}{c}\text { Per Outing } \\
\text { Average/Peak }\end{array}$ & $\begin{array}{c}\text { Per Trip } \\
\text { Average/Peak }\end{array}$ & Total \\
\hline Travel Distance (Miles) & $24.8 / 598.5$ & $6.5 / 608.8$ & $3.4 / 236.9$ & 1,066 \\
\hline Travel Time (Minutes) & $90 / 585$ & $23.5 / 628$ & $12.2 / 215$ & 3,857 \\
\hline Idle Time (Minutes) & $30.4 / \mathrm{NA}$ & $8.0 / \mathrm{NA}$ & $4.2 / \mathrm{NA}$ & 1,308 \\
\hline
\end{tabular}

\begin{tabular}{|c|c|c|c|c|}
\hline \multicolumn{2}{|c|}{ Total Stops } & \multicolumn{2}{c|}{ Stop Duration } \\
\hline $\begin{array}{c}\text { Distance From } \\
\text { Home Base (Miles) }\end{array}$ & Stops & Percentages & Stop Duration (Hours) & Stops \\
\hline Less than 10 & 390 & 98.5 & Less than 2 & 328 \\
\hline 10 to 20 & 0 & 0 & 2 to 4 & 23 \\
\hline 20 to 40 & 0 & 0 & 4 to 8 & 3 \\
\hline 40 to 60 & 6 & 1.5 & Greater than 8 & 42 \\
\hline
\end{tabular}

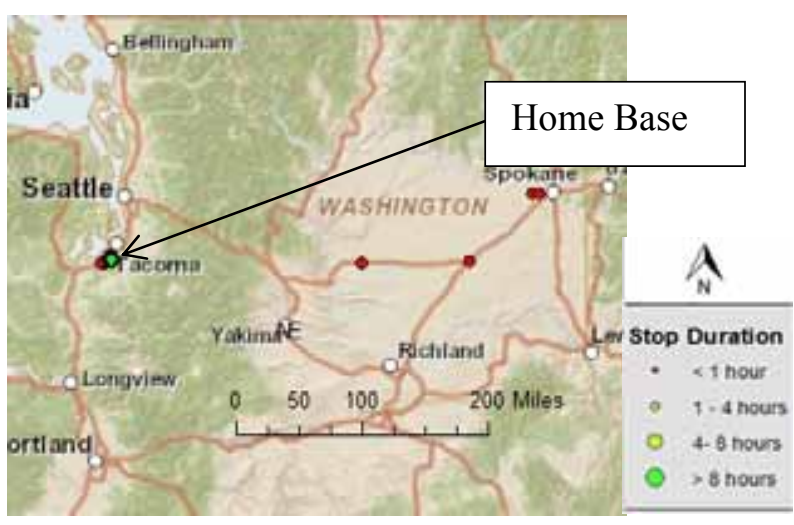

Figure D-25. Vehicle G43-1892H stops. *2009 Chevrolet Silverado C15 information provided. EPA figures for 2009 Chevrolet C2500HD are not available.

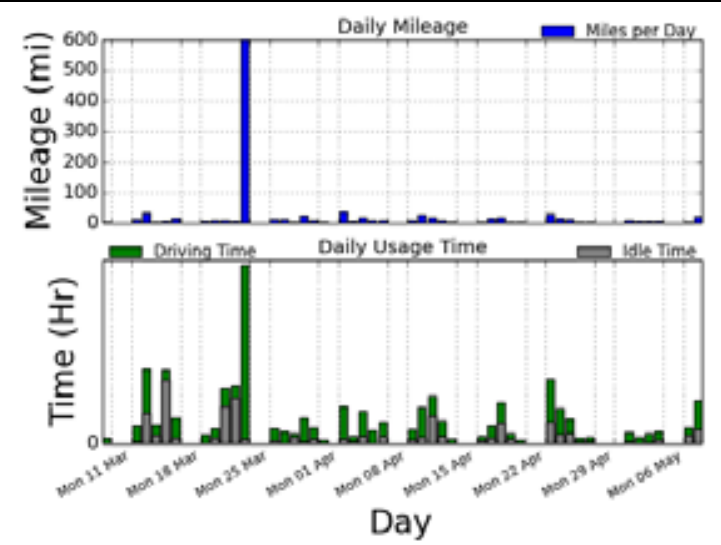

Figure D-26. Vehicle G43-1892H history. 

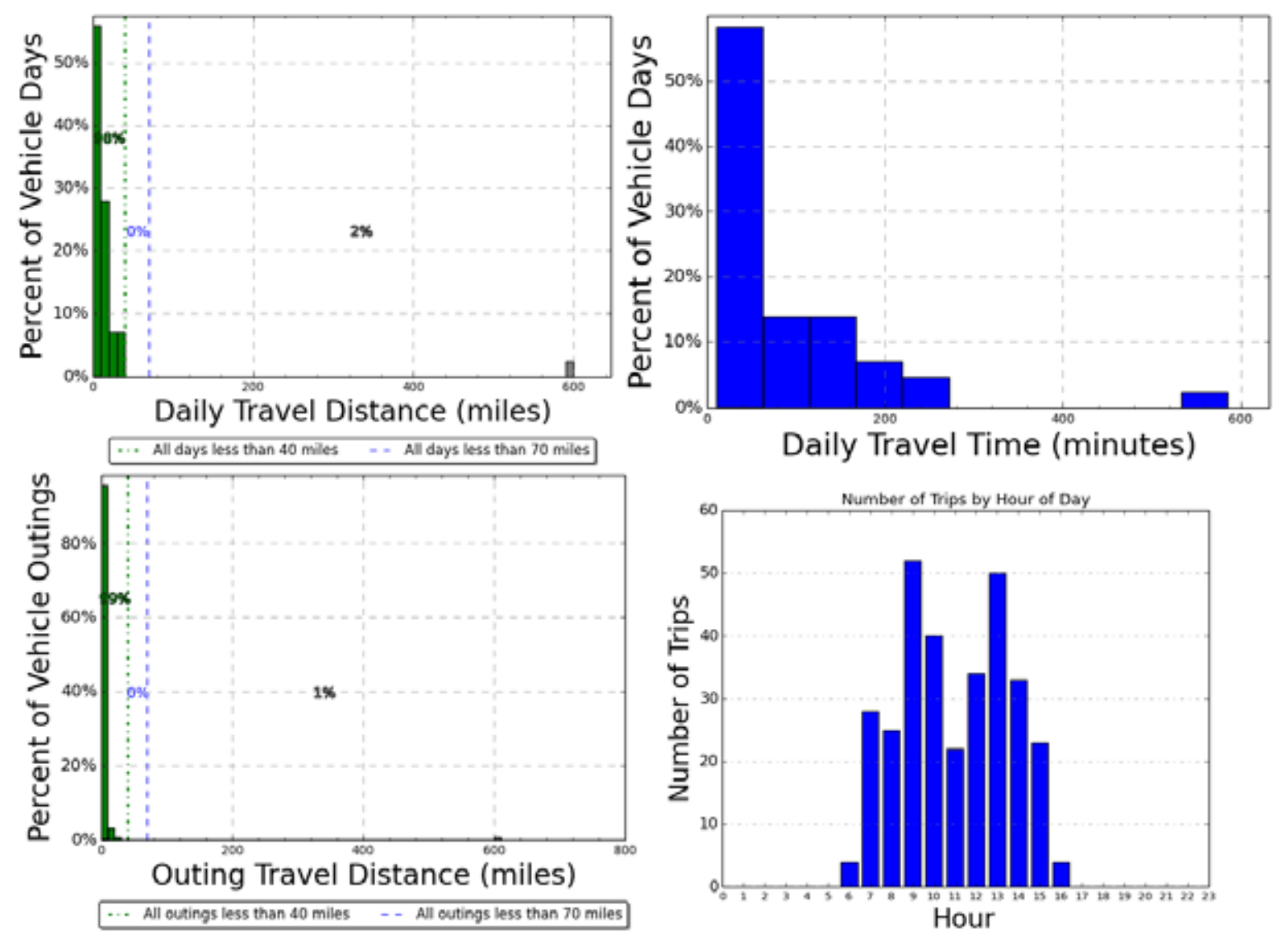

Figure D-22. Vehicle G43-1892H travel graphs.

\section{Vehicle G43-1892H Observations}

Vehicle survey information is not available for this vehicle. Logger data suggests the home base is located in the 300 building area on $6^{\text {th }}$ Street SW. Site records report the vehicle travels approximately 300 miles per month and the odometer read 9,150 in May 2012.

Logger 90 collected data on this vehicle for 43 days of the 63-day study period. Validation occurred on $87.8 \%$ of the vehicle data. Ninety percent of all vehicle stops greater than 2-hours duration occurred at the home base.

The longest single outing of 609 miles occurred on March 22 and included a single long trip to Fairchild Air Force Base near Spokane. The outing distance is longer than the daily maximum because the outing took more than 1 day. Other than this single outing, the maximum outing was 13.1 miles. Other than that one outing, all trips, outings, and daily travel are within the typically advertised range of a BEV of approximately 70 miles. None of the remaining outings exceeded the maximum CD range for a PHEV of 40 miles.

While a BEV may not provide acceptable performance for this specific vehicle's travel, it is part of a pool of vehicles. Other vehicles may be relied on for trips of this length. Should the BEV meet other mission requirements, it would meet $99 \%$ of this vehicle's usage. Information is unavailable suggesting, special requirements exist. Daily travel requirements also allow use of a PHEV traveling all but one day in $\mathrm{CD}$ mode, thus providing an alternative for this vehicle. 


\begin{tabular}{|c|c|c|}
\hline \multirow{4}{*}{$\sum_{0=0}^{2}$} & Make/Model/Year & Chevrolet/C3500/2009 \\
\hline & EPA Class Size* & Pickup Truck \\
\hline & Mission & Support \\
\hline & Contact & J Ross/Public Works \\
\hline \multirow{7}{*}{ www.edmunds.com } & Parking Location & 6th St SW \\
\hline & Fleet Vehicle ID & G43-1961H \\
\hline & Fuel Type & Gas \\
\hline & EPA Label/MPG (City/Hwy)* & $14 / 19 / 16$ \\
\hline & EPA GHG Emissions (Grams $\mathrm{CO}_{2} / \mathrm{Mi}$ )* & 555 \\
\hline & Study Logger ID & Logger 91 \\
\hline & Total Vehicle Days/Total Study Days & $41 / 63$ \\
\hline
\end{tabular}

\begin{tabular}{|l|c|c|c|c|}
\hline \multicolumn{5}{|c|}{ Vehicle G43-1961H Travel Summary } \\
\hline & $\begin{array}{c}\text { Per Day } \\
\text { Average/Peak }\end{array}$ & $\begin{array}{c}\text { Per Outing } \\
\text { Average/Peak }\end{array}$ & $\begin{array}{c}\text { Per Trip } \\
\text { Average/10.0/Peak }\end{array}$ & Total \\
\hline Travel Distance (Miles) & $17.1 / 32.4$ & $3.9 / 25.8$ & $1.6 / 19.7$ & 701 \\
\hline Travel Time (Minutes) & $104 / 215$ & $24.0 / 186$ & $10.0 / 168$ & 4,272 \\
\hline Idle Time (Minutes) & $35.4 / \mathrm{NA}$ & $8.2 / \mathrm{NA}$ & $3.4 / \mathrm{NA}$ & 1,452 \\
\hline
\end{tabular}

\begin{tabular}{|c|c|c|c|c|}
\hline \multicolumn{3}{|c|}{ Total Stops } & \multicolumn{2}{c|}{ Stop Duration } \\
\hline $\begin{array}{c}\text { Distance From } \\
\text { Home Base (Miles) }\end{array}$ & Stops & Percentages & Stop Duration (Hours) & Stops \\
\hline Less than 10 & 541 & 100 & Less than 2 & 480 \\
\hline 10 to 20 & 0 & 0 & 2 to 4 & 19 \\
\hline 20 to 40 & 0 & 0 & 4 to 8 & 1 \\
\hline 40 to 60 & 0 & 0 & Greater than 8 & 41 \\
\hline
\end{tabular}

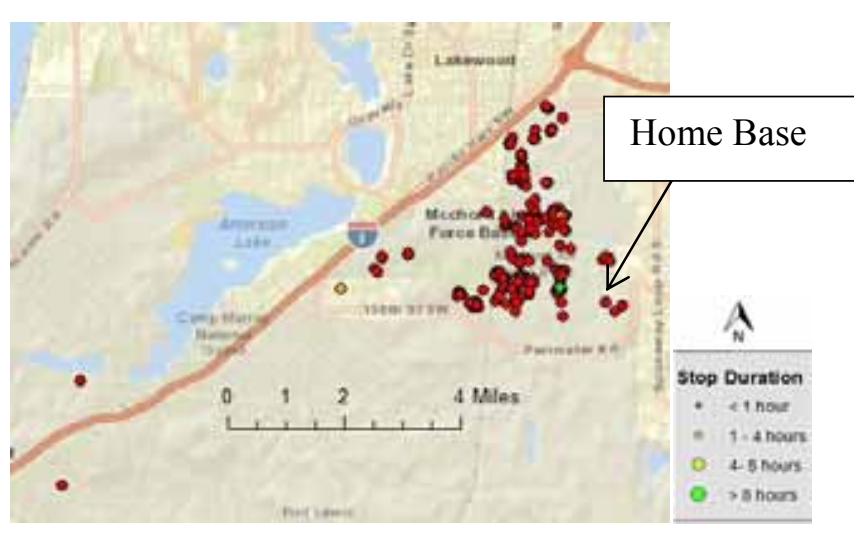

Figure D-28. Vehicle G43-1961H stops.

*2009 Chevrolet Silverado C15 information provided. EPA figures for 2009 Chevrolet C3500 are not available. 


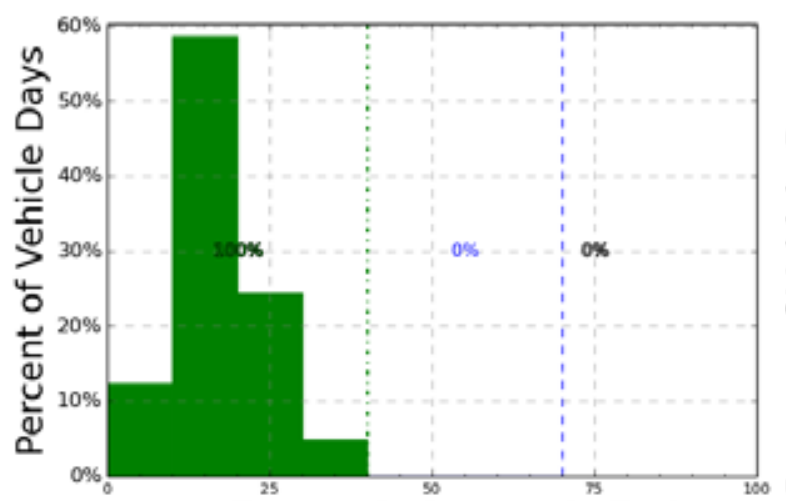

Daily Travel Distance (miles)

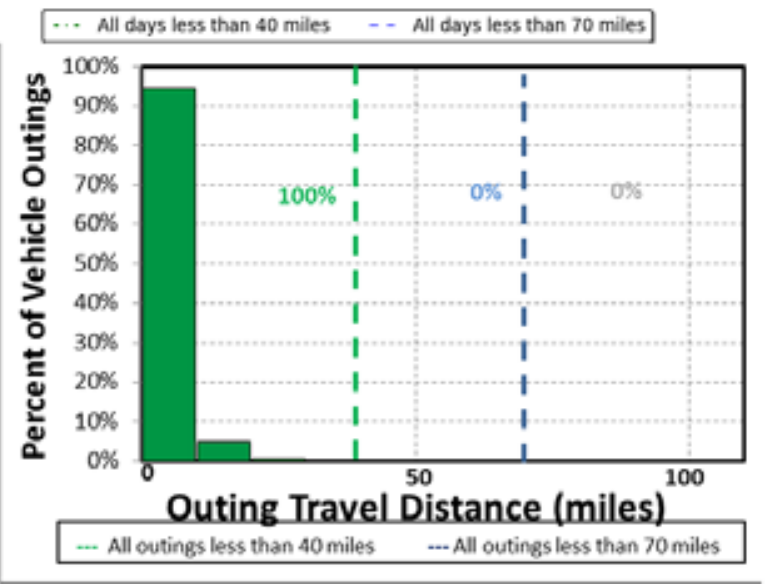

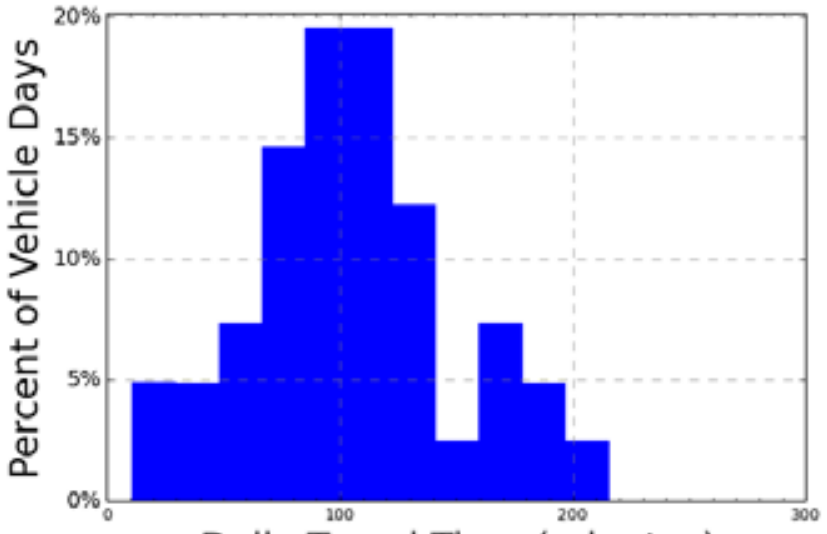

Daily Travel Time (minutes)

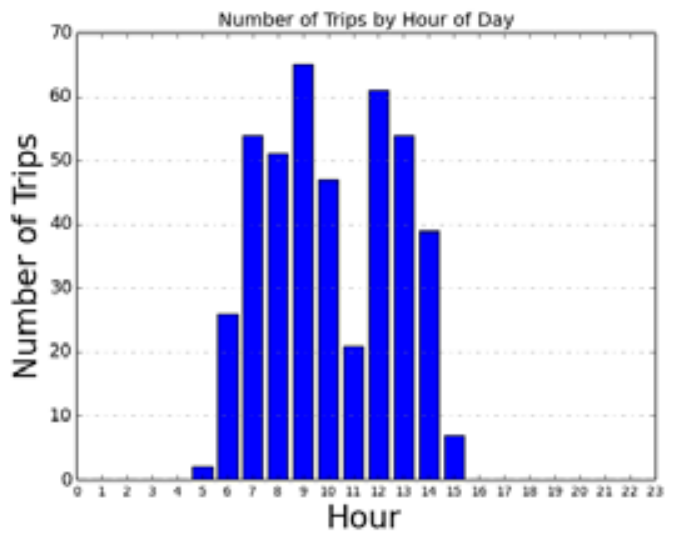

Figure D-23. Vehicle G43-1961H travel graphs.

\section{Vehicle G43-1961H Observations}

Vehicle survey information is not available for this vehicle. Data logger information suggests this vehicle's home base is in the 300 building area on 6th Street SW. Site records report the vehicle travels approximately 364 miles per month and the odometer read 12,209 in May 2012.

Logger 91 collected data on this vehicle for 41 days of the 63-day study period. Validation occurred on $100 \%$ of the vehicle data. Ninety-eight percent of the recorded stops greater than 2-hours duration occurred at the home base. The longest single trip, outing, and daily travel were within the typically advertised range of a BEV of approximately 70 miles. None of the outings or daily travel exceeded the maximum $\mathrm{CD}$ range for a PHEV of 40 miles.

A BEV may provide acceptable performance for this vehicle should the BEV meet other mission requirements. Information is unavailable, suggesting special requirements exist. Daily travel requirements also allow use of a PHEV traveling all day in CD mode, thus providing an alternative for this vehicle. 
Vehicle G42-0505A

\begin{tabular}{|l|l|c|}
\hline \multirow{5}{*}{ www.edmunds.com } & Make/Model/Year & Chevrolet/G1500 Express /2004 \\
\cline { 2 - 3 } & EPA Class Size & Passenger Van \\
\hline Mission & Support \\
\hline Contact & J Ross/Public Works \\
\cline { 2 - 3 } & Parking Location & G42-0505A \\
\hline Fleet Vehicle ID & Gas \\
\hline & Fuel Type & $14 / 18 / 15$ \\
\hline & EPA Label/MPG (City/Hwy) & 592 \\
\hline & EPA GHG Emissions (Grams $\left.\mathrm{CO}_{2} / \mathrm{Mi}\right)$ & Logger 92 \\
\cline { 2 - 3 } & Study Logger ID & $35 / 63$ \\
\cline { 2 - 3 } & Total Vehicle Days/Total Study Days & \\
\hline
\end{tabular}

\begin{tabular}{|l|c|c|c|c|}
\hline \multicolumn{5}{|c|}{ Vehicle G42-0505A Travel Summary } \\
\hline & $\begin{array}{c}\text { Per Day } \\
\text { Average/Peak }\end{array}$ & $\begin{array}{c}\text { Per Outing } \\
\text { Average/Peak }\end{array}$ & $\begin{array}{c}\text { Per Trip } \\
\text { Average/Peak }\end{array}$ & Total \\
\hline Travel Distance (Miles) & $17.8 / 40.1$ & $11.5 / 36.5$ & $3.9 / 15.3$ & 622 \\
\hline Travel Time (Minutes) & $53 / 138$ & $34.6 / 113$ & $11.7 / 107$ & 1,867 \\
\hline Idle Time (Minutes) & $6.5 / \mathrm{NA}$ & $4.2 / \mathrm{NA}$ & $1.4 / \mathrm{NA}$ & 229 \\
\hline
\end{tabular}

\begin{tabular}{|c|c|c|c|c|}
\hline \multicolumn{2}{|c|}{ Total Stops } & \multicolumn{2}{c|}{ Stop Duration } \\
\hline $\begin{array}{c}\text { Distance From } \\
\text { Home Base (Miles) }\end{array}$ & Stops & Percentages & Stop Duration (Hours) & Stops \\
\hline Less than 10 & 154 & 100 & Less than 2 & 93 \\
\hline 10 to 20 & 0 & 0 & 2 to 4 & 13 \\
\hline 20 to 40 & 0 & 0 & 4 to 8 & 7 \\
\hline 40 to 60 & 0 & 0 & Greater than 8 & 41 \\
\hline
\end{tabular}

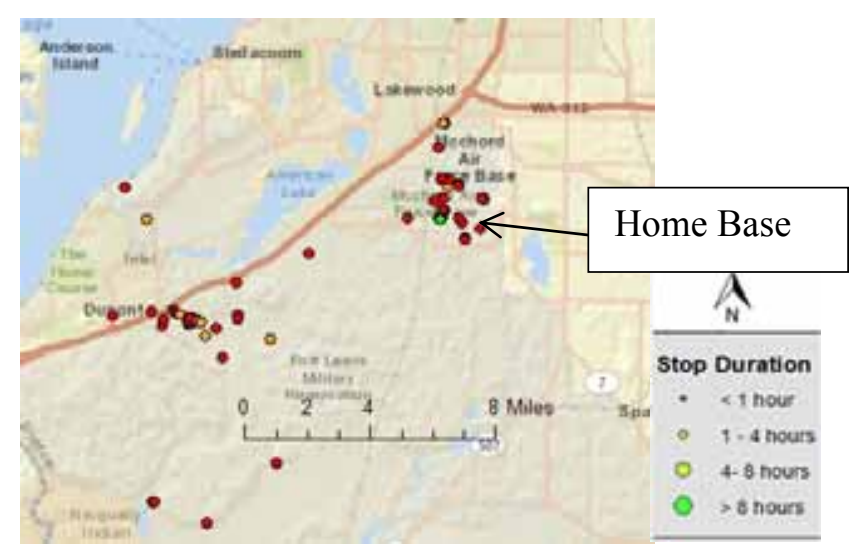

Figure D-31. Vehicle G42-0505A stops.

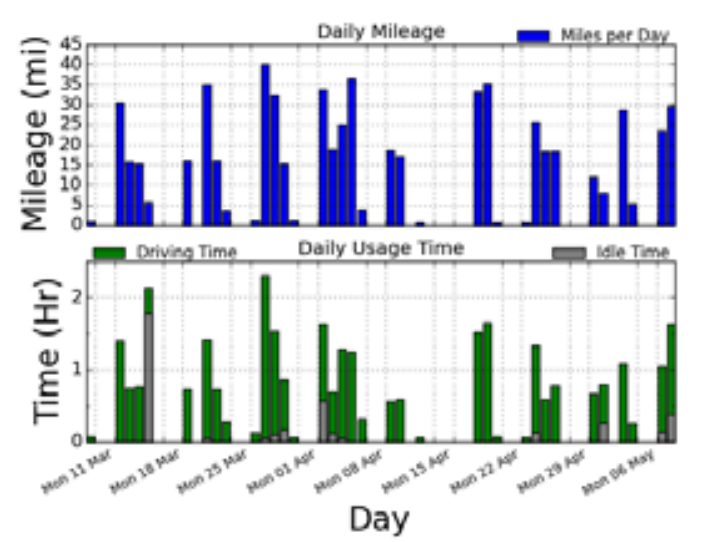

Figure D-32. Vehicle G42-0505A history. 

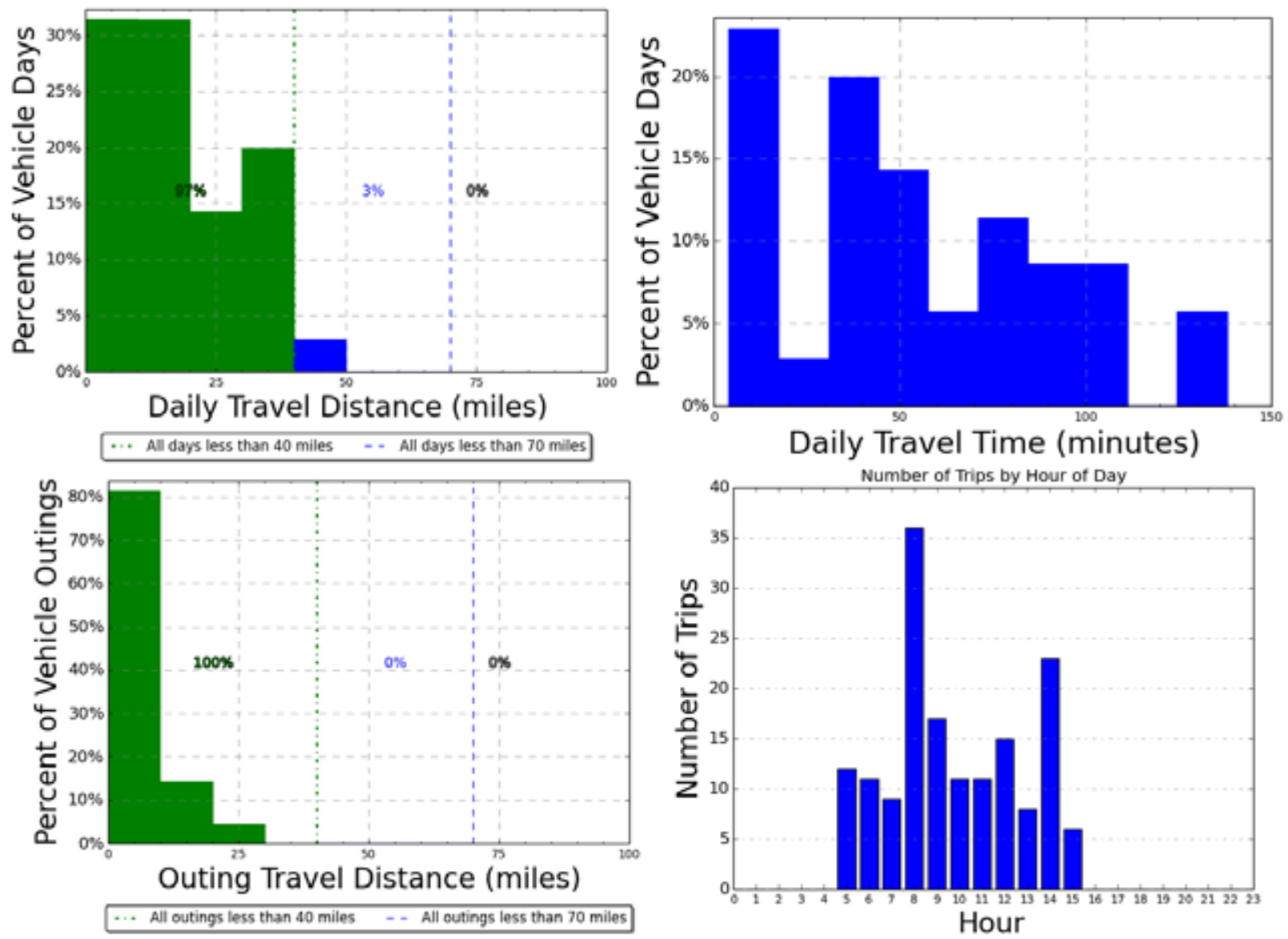

Figure D-24. Vehicle G42-0505A travel graphs.

\section{Vehicle G42-0505A Observations}

The project survey response identifies this vehicle as a pool vehicle that is assigned to a specific person, Information Technology/GeoSpatial Support Section, to transport personnel and survey/GIS equipment to carry out land surveying operations and the collection of geospatial data. GeoSpatial Support provides support to the Operations/Maintenance branch of DPW in execution of their assigned tasks. When supporting surveying and geospatial data tasks, the van carries survey equipment.

Site records report this vehicle travels approximately 383 miles per month and the odometer read 25,346 in April 2012. The vehicle parks in the office parking lot at Building 555 at McChord Field or Building 2012 at Lewis. DPW expects to retain the vehicle more than 6 years. Two to five persons have access to the vehicle. It travels off base occasionally to attend meetings in Seattle, transport personnel to and from SeaTac Airport, and other trips. When used off base, typical travel is between 40 and 100 miles, with an average outing of 90 miles. Operation occurs during normal duty hours of 0700 to 1630 .

Logger 92 collected data on this vehicle for 35 days of the 63-day study period. Validation occurred on $99.4 \%$ of the vehicle data. Sixty-three percent of the recorded stops greater than 2-hours duration occurred at the home base, with $22 \%$ of the stops on Pendleton Avenue and $22 \%$ of the stops in DuPont, WA. The longest single trip, outing, and daily travel were within the typically advertised range of a BEV of approximately 70 miles. None of the outings exceeded the maximum CD range for a PHEV of 40 miles. A BEV may provide acceptable performance for this vehicle should the BEV meet other mission requirements. Information is unavailable, suggesting special requirements exist. Daily travel requirements also allow use of a PHEV traveling all day in CD mode, thus providing an alternative for this vehicle. 
Vehicle G43-1155L

\begin{tabular}{|l|l|c|}
\hline & Make/Model/Year & Ford/F350/2011 \\
\cline { 2 - 3 } & EPA Class Size* & Pickup Truck \\
\hline Mission & Support \\
\hline Contact & J Ross/Public Works \\
\cline { 2 - 3 } & Parking Location & Bldg 2044/Utah Ave \\
\cline { 2 - 3 } & Fleet Vehicle ID & G43-1155L \\
\hline & Fuel Type & Gas/ETH \\
\cline { 2 - 3 } & EPA Label/MPG (City/Hwy)* & $15 / 21 / 1711 / 15 / 13$ \\
\hline & EPA GHG Emissions (Grams $\left.\mathrm{CO}_{2} / \mathrm{Mi}\right)^{*}$ & $523 / 484$ \\
\cline { 2 - 3 } & Study Logger ID & Logger 95 \\
\cline { 2 - 3 } & Total Vehicle Days/Total Study Days & $35 / 63$ \\
\hline
\end{tabular}

\begin{tabular}{|l|c|c|c|c|}
\hline \multicolumn{5}{|c|}{ Vehicle G43-1155L Travel Summary } \\
\hline & $\begin{array}{c}\text { Per Day } \\
\text { Average/Peak }\end{array}$ & $\begin{array}{c}\text { Per Outing } \\
\text { Average/Peak }\end{array}$ & $\begin{array}{c}\text { Per Trip } \\
\text { Average/Peak }\end{array}$ & Total \\
\hline Travel Distance (Miles) & $51.4 / 139$ & $17.5 / 132.6$ & $7.1 / 44.3$ & 1,798 \\
\hline Travel Time (Minutes) & $129 / 302$ & $43.9 / 209$ & $17.9 / 81$ & 4,522 \\
\hline Idle Time (Minutes) & $10.1 / \mathrm{NA}$ & $3.4 / \mathrm{NA}$ & $1.4 / \mathrm{NA}$ & 353 \\
\hline
\end{tabular}

\begin{tabular}{|c|c|c|c|c|}
\hline \multicolumn{2}{|c|}{ Total Stops } & \multicolumn{2}{c|}{ Stop Duration } \\
\hline $\begin{array}{c}\text { Distance From } \\
\text { Home Base (Miles) }\end{array}$ & Stops & Percentages & Stop Duration (Hours) & Stops \\
\hline Less than 10 & 207 & 82.8 & Less than 2 & 201 \\
\hline 10 to 20 & 40 & 16 & 2 to 4 & 12 \\
\hline 20 to 40 & 3 & 1.2 & 4 to 8 & 1 \\
\hline 40 to 60 & 0 & 0 & Greater than 8 & 36 \\
\hline
\end{tabular}

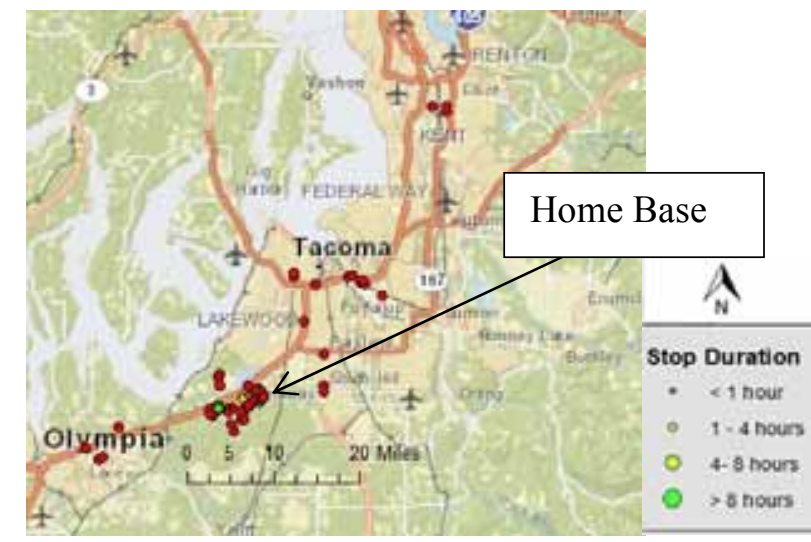

Figure D-34. Vehicle G43-1155L stops.

*2011 Ford F150 information provided. EPA figures for 2011 Ford F350 are not available. 


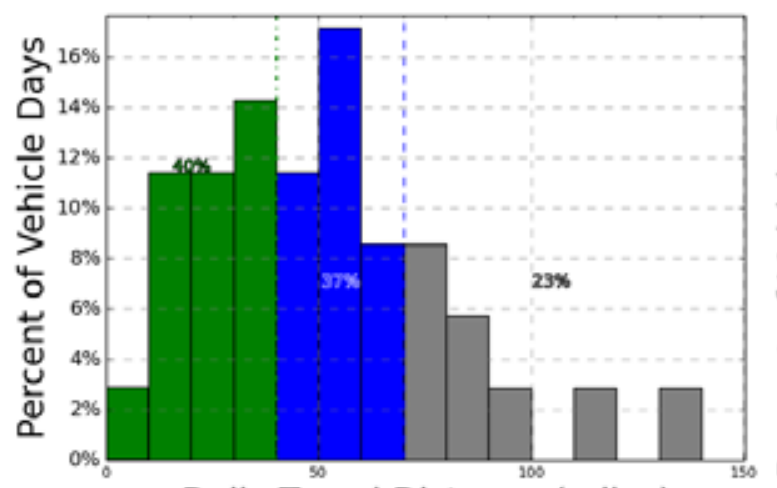

Daily Travel Distance (miles)

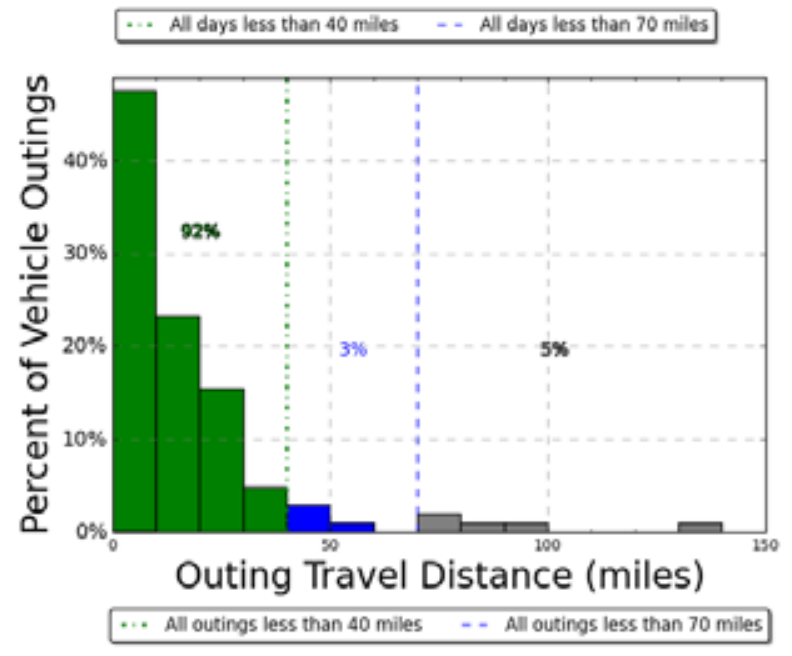

Figure D-25. Vehicle G43-1155L travel graphs.

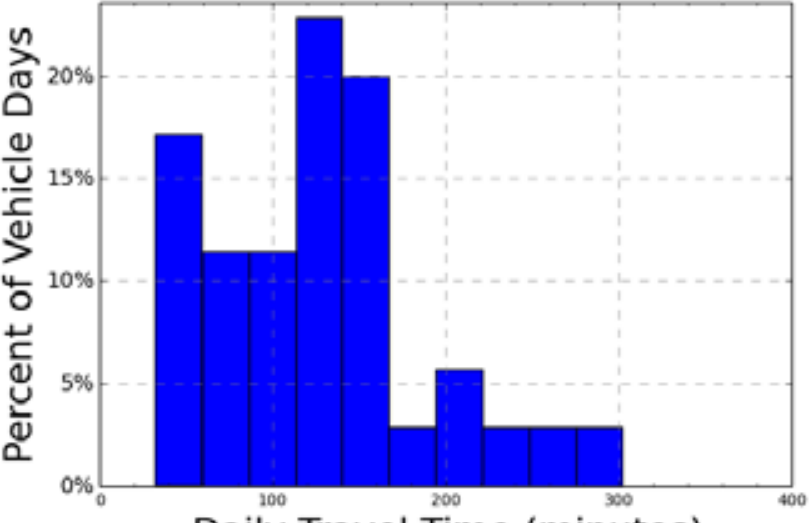

Daily Travel Time (minutes)

Number of Trips by Hour of Day

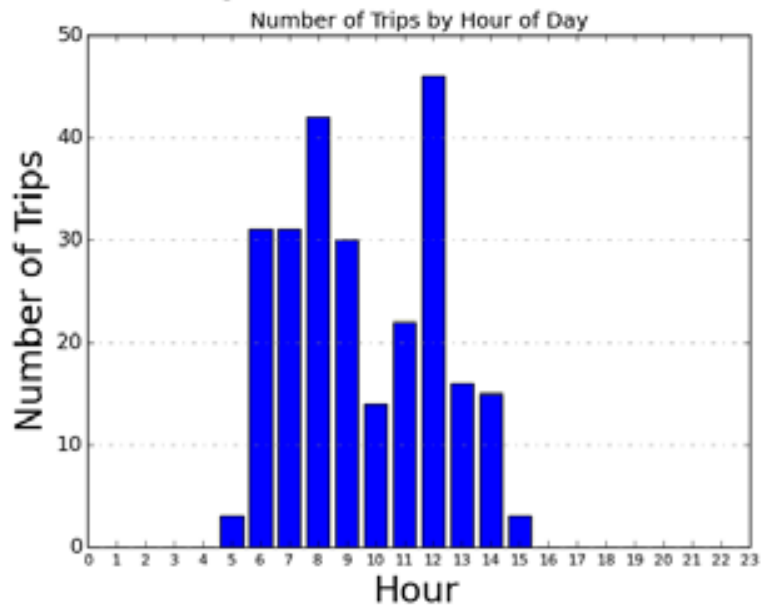

\section{Vehicle G43-1155L Observations}

Vehicle survey information is not available for this vehicle. Data logger information suggests this vehicle's home base is on Utah Avenue near Building 2044. Site records report the vehicle travels approximately 406 miles per month and the odometer read 4,481 in May 2012.

Logger 95 collected data on this vehicle for 35 days of the 63-day study period. Validation occurred on $99.6 \%$ of the vehicle data. All of the recorded stops greater than the 2-hour duration occurred at the home base.

Seventy-seven percent of all vehicle travel days were within the 70-mile BEV advertised range of 70 miles, while $23 \%$ of the vehicle travel days exceed this range. Ninety-five percent of the outings were within the BEV range. With management attention, a BEV that is charged between outings may meet the mission objectives. However, several of the longer trips suggest that a PHEV would be a more suitable replacement. Ninety-two percent of the outings and $40 \%$ of the daily travel are within the battery only motive power for a PHEV. 
Vehicle G41-1605L

\begin{tabular}{|l|l|c|}
\hline \multirow{4}{*}{ www.edmunds.com } & Make/Model/ ear & Dodge/Dakota/2011 \\
\cline { 2 - 3 } & EPA Class Size & Standard Pickup Truck \\
\cline { 2 - 3 } & Mission & Support \\
\hline Contact & J Ross/Public Works \\
\cline { 2 - 3 } & Parking Location & Bldg 2044 \\
\cline { 2 - 3 } & Fleet Vehicle ID & G41-1605L \\
\cline { 2 - 3 } & Fuel Type & Gas/ETH \\
\cline { 2 - 3 } & EPA Label/MPG (City/Hwy) & 14/19/16 9/13/10 \\
\cline { 2 - 3 } & EPA GHG Emissions (Grams CO $\left.\mathrm{CO}_{2} / \mathrm{Mi}\right)$ & Logger 98 \\
\cline { 2 - 3 } & Study Logger ID & $6 / 63$ \\
\cline { 2 - 3 } & Total Vehicle Days/Total Study Days & \\
\hline
\end{tabular}

\begin{tabular}{|l|c|c|c|c|}
\hline \multicolumn{5}{|c|}{ Vehicle G41-1605L Travel Summary } \\
\hline & $\begin{array}{c}\text { Per Day } \\
\text { Average/Peak }\end{array}$ & $\begin{array}{c}\text { Per Outing } \\
\text { Average/Peak }\end{array}$ & $\begin{array}{c}\text { Per Trip } \\
\text { Average/Peak }\end{array}$ & Total \\
\hline Travel Distance (Miles) & $8.6 / 19.8$ & $7.4 / 29.0$ & $4.7 / 19.8$ & 52 \\
\hline Travel Time (Minutes) & $24 / 49$ & $20.6 / 71.0$ & $13.1 / 48$ & 144 \\
\hline Idle Time (Minutes) & $1.3 / \mathrm{NA}$ & $1.1 / \mathrm{NA}$ & $0.7 / \mathrm{NA}$ & 8 \\
\hline
\end{tabular}

\begin{tabular}{|c|c|c|c|c|}
\hline \multicolumn{2}{|c|}{ Total Stops } & \multicolumn{2}{c|}{ Stop Duration } \\
\hline $\begin{array}{c}\text { Distance From } \\
\text { Home Base (Miles) }\end{array}$ & Stops & Percentages & Stop Duration (Hours) & Stops \\
\hline Less than 10 & 11 & 100 & Less than 2 & 6 \\
\hline 10 to 20 & 0 & 0 & 2 to 4 & 0 \\
\hline 20 to 40 & 0 & 0 & 4 to 8 & 0 \\
\hline 40 to 60 & 0 & 0 & Greater than 8 & 5 \\
\hline
\end{tabular}

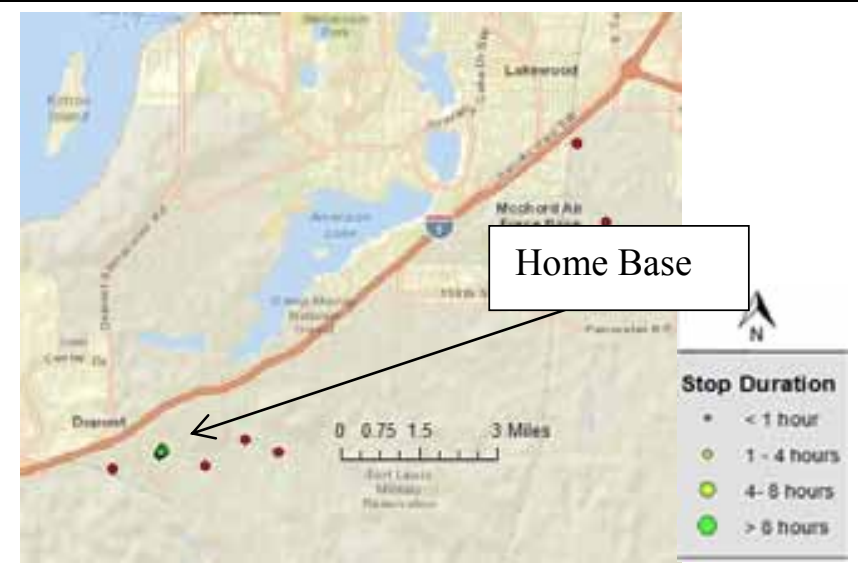

Figure D-37. Vehicle G41-1605L stops.

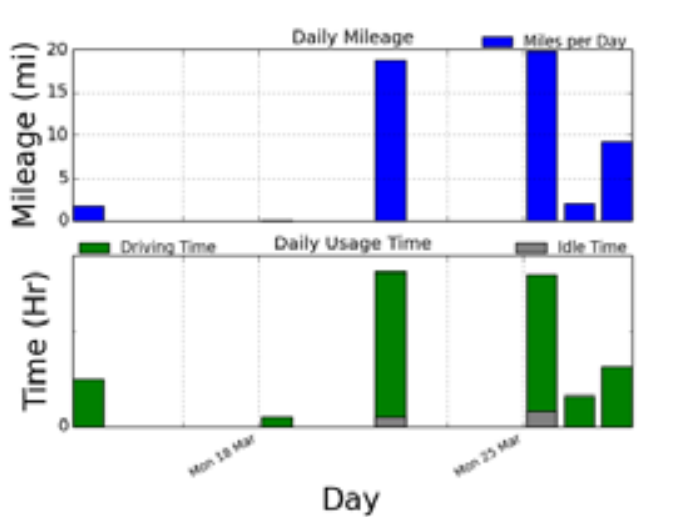

Figure D-38. Vehicle G41-1605L history. 

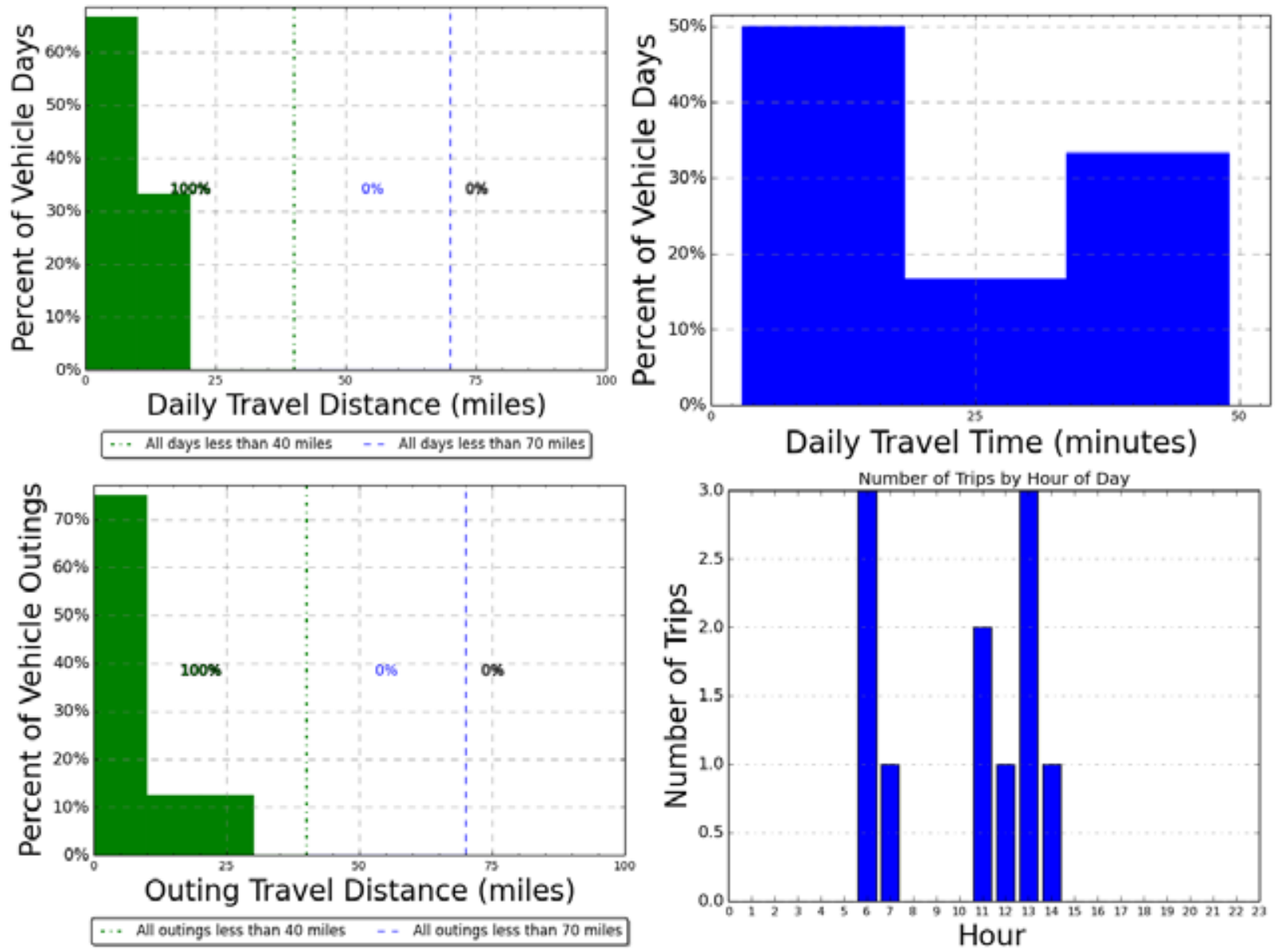

Figure D-26. Vehicle G41-1605L travel graphs.

\section{Vehicle G41-1605L Observations}

Vehicle survey information is not available for this vehicle. Data logger information suggests this vehicle's home base is on Pendleton Avenue near Building 2044. Site records report the vehicle travels approximately 171 miles per month and the odometer read 2,158 in May 2012.

Logger 98 collected data on this vehicle for 6 days of the 63-day study period. Validation occurred on $96.2 \%$ of the vehicle data. All recorded stops greater than the 2-hour duration occurred at the home base. The longest single trip, outing, and daily travel were within the typically advertised range of a BEV of approximately 70 miles. None of the outings exceeded the maximum CD range for a PHEV of 40 miles.

A BEV may provide acceptable performance for this vehicle should the BEV meet other mission requirements. Information is unavailable, suggesting special requirements exist. Daily travel requirements also allow use of a PHEV traveling all day in CD mode, thus providing an alternative for this vehicle. 
Vehicle G42-0610K

\begin{tabular}{|c|c|c|}
\hline \multirow{4}{*}{ (6) } & Make/Model/Year & Chevrolet/C1500/2010 \\
\hline & EPA Class Size & Standard Pickup Truck \\
\hline & Mission & Pool \\
\hline & Contact & J Ross/Public Works \\
\hline \multirow{7}{*}{ www.edmunds.com } & Parking Location & Bldg 2044/Pendleton Ave \\
\hline & Fleet Vehicle ID & G42-0610K \\
\hline & Fuel Type & Gas/ETH \\
\hline & EPA Label/MPG (City/Hwy/Combined) & $15 / 21 / 17 \quad 11 / 16 / 13$ \\
\hline & EPA GHG Emissions (Grams $\mathrm{CO}_{2} / \mathrm{Mi}$ ) & $523 / 484$ \\
\hline & Study Logger ID & Logger 100 \\
\hline & Total Vehicle Days/Total Study Days & $20 / 63$ \\
\hline
\end{tabular}

\begin{tabular}{|l|c|c|c|c|}
\hline \multicolumn{5}{|c|}{ Vehicle G42-0610K Travel Summary } \\
\hline & $\begin{array}{c}\text { Per Day } \\
\text { Average/Peak }\end{array}$ & $\begin{array}{c}\text { Per Outing } \\
\text { Average/Peak }\end{array}$ & $\begin{array}{c}\text { Per Trip } \\
\text { Average/Peak }\end{array}$ & Total \\
\hline Travel Distance (Miles) & $13.4 / 34.5$ & $10.7 / 27.5$ & $3.8 / 15.4$ & 269 \\
\hline Travel Time (Minutes) & $43 / 128$ & $34.5 / 79$ & $12.1 / 44$ & 862 \\
\hline Idle Time (Minutes) & $1.9 / \mathrm{NA}$ & $1.5 / \mathrm{NA}$ & $0.5 / \mathrm{NA}$ & 37 \\
\hline
\end{tabular}

\begin{tabular}{|c|c|c|c|c|c|}
\hline \multicolumn{2}{|c|}{ Total Stops } & \multicolumn{3}{c|}{ Stop Duration } \\
\hline $\begin{array}{c}\text { Distance From } \\
\text { Home Base (Miles) }\end{array}$ & Stops & Percentages & Stop Duration (Hours) & Stops \\
\hline Less than 10 & 72 & 100 & Less than 2 & 48 \\
\hline 10 to 20 & 0 & 0 & 2 to 4 & 4 \\
\hline 20 to 40 & 0 & 0 & Greater than 8 & 20 \\
\hline 40 to 60 & 0 & 0 & \\
\hline
\end{tabular}

Figure D-40. Vehicle G42-0610K stops.

Figure D-41. Vehicle G42-0610K history. 

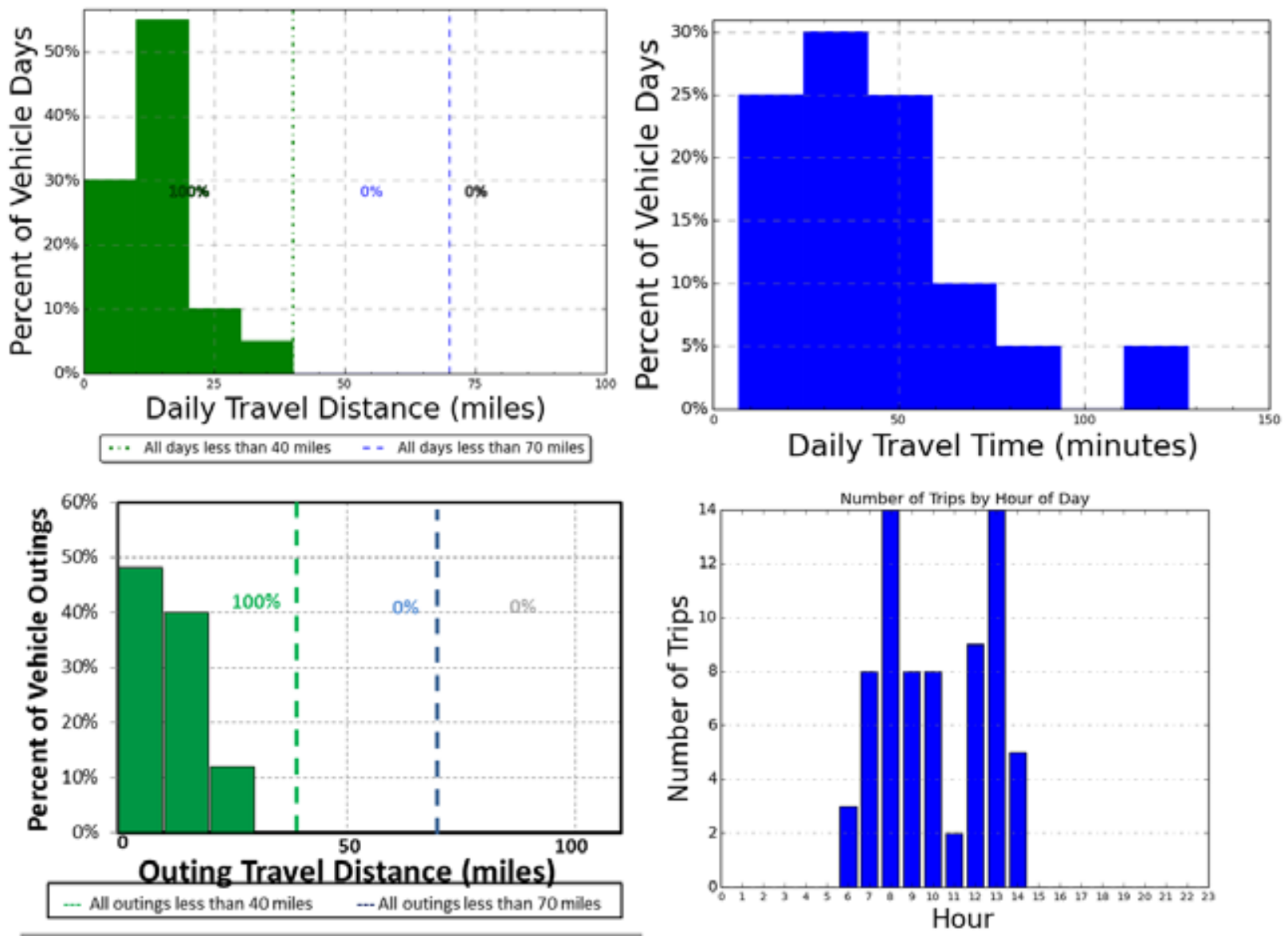

Figure D-27. Vehicle G42-0610K travel graphs.

\section{Vehicle G42-0610K Observations}

Public Works reports this is a pool vehicle, accessible by more than 20 persons, that typically parks in the lot near Building 2044. The expected retention of this vehicle is currently unknown. On a typical weekday, it travels between 11 and 40 miles and usually contains two persons. It does not regularly carry particular cargo or equipment.

Site records report this vehicle travels an average 281 miles per month. Its odometer read 6,557 in April 2012. This vehicle rarely travels off base.

Logger 100 collected data on this vehicle for 20 days of the 63-day study period. Validation occurred on $96.2 \%$ of the vehicle data. The longest single trip, outing, and daily travel were within the typically advertised range of a BEV of approximately 70 miles. None of the outings and daily travel exceeded the maximum $\mathrm{CD}$ range for a $\mathrm{PHEV}$ of 40 miles.

A BEV may provide acceptable performance for this vehicle should the BEV meet other mission requirements. Information is unavailable, suggesting special requirements exist. Daily travel requirements also allow use of a PHEV traveling all day in $\mathrm{CD}$ mode, thus providing an alternative for this vehicle. 


\section{Appendix E Motor Transport Branch Vehicle Data Sheets}

Table E-2. JBLM Motor Transport Branch vehicle index.

\begin{tabular}{|c|c|c|c|c|c|c|}
\hline \multicolumn{7}{|c|}{ Vehicle Index } \\
\hline $\log$ & Fleet Vehicle Id & Make & Model & Year & EPA Class & Mission \\
\hline 6 & G43-0875K & Ford & E350 & 2010 & Cargo Van & Pool \\
\hline 7 & G41-1288A & Ford & SPORT TRAC & 2004 & Pickup Truck & Pool \\
\hline 8 & G43-4937A & Ford & E350 & 2004 & Cargo Van & Pool \\
\hline 9 & G10-7664F & Dodge & AVENGER & 2008 & Compact Sedan & Pool \\
\hline 10 & G41-65991 & Dodge & DAKOTA & 2002 & Pickup Truck & Pool \\
\hline 11 & G11-2676G & Chevrolet & IMPALA & 2008 & Large Car & Pool \\
\hline 12 & G43-3717A & Ford & E350 & 2004 & Cargo Van & Pool \\
\hline 13 & G11-0678K & Chevrolet & IMPALA & 2010 & Large Car & Support \\
\hline 14 & G62-4526H & Chevrolet & TAHOE & 2009 & SUV & Support \\
\hline 15 & G42-0698K & Chevrolet & C1500 & 2011 & Pickup Truck & Support \\
\hline 16 & G11-0493L & Chevrolet & IMPALA & 2012 & Large Car & Support \\
\hline 17 & G71-0062G & Ford & F750 & 2008 & Stake Truck & Transport \\
\hline 18 & G62-1094L & Chevrolet & AVALANCHE & 2011 & SUV & Support \\
\hline 19 & G41-1395G & Chevrolet & UPLANDER & 2008 & Minivan & Pool \\
\hline 20 & G61-1155D & Ford & ESCAPE HYB & 2006 & SUV & Pool \\
\hline 81 & G10-2878L & Chevrolet & MALIBU & 2011 & Midsize Sedan & Pool \\
\hline 84 & G41-1100K & Dodge & GRCARAVAN & 2010 & Minivan & Pool \\
\hline 85 & G62-0979G & Dodge & 1500 & 2008 & Pickup Truck & Pool \\
\hline 89 & G71-0674A & Ford & F650 18'BO & 2004 & Delivery Van & Transport \\
\hline 93 & G41-1373G & Dodge & DAKOTA & 2008 & Pickup Truck & Support \\
\hline 97 & G41-1367G & Dodge & DAKOTA & 2008 & Pickup Truck & Pool \\
\hline 101 & G43-0792K & Chevrolet & CG3300 & 2010 & Passenger Van & Pool \\
\hline 102 & G43-0801K & Chevrolet & CG3300 & 2010 & Passenger Van & Pool \\
\hline 104 & G42-0988F & Chevrolet & EXPRESS 13 & 2007 & Cargo Van & Support \\
\hline 105 & G43-0860G & Chevrolet & CG3300 & 2008 & Passenger Van & Pool \\
\hline 106 & G43-1389K & Chevrolet & CG3300 & 2010 & Passenger Van & Pool \\
\hline 107 & G41-1180G & Chevrolet & UPLANDER & 2008 & Minivan & Support \\
\hline 108 & G11-2675G & Chevrolet & IMPALA & 2008 & Large Sedan & Pool \\
\hline 109 & G43-1191L & Chevrolet & CG3300 & 2011 & Passenger Van & Pool \\
\hline 110 & G12-0662H & Ford & FUSION HEV & 2010 & Midsize Sedan & Pool \\
\hline 111 & G63-0271A & Ford & F350STAKE & 2004 & Stake Truck & Transport \\
\hline 112 & G41-1392G & Chevrolet & UPLANDER & 2008 & Minivan & Support \\
\hline 113 & G43-3881H & Ford & E350 & 2009 & Passenger Van & Pool \\
\hline 114 & G43-25839 & Ford & F350 & 2003 & Pickup Truck & Transport \\
\hline 115 & G41-1376G & Dodge & DAKOTA & 2008 & Pickup Truck & Support \\
\hline 116 & G41-1161G & Chevrolet & UPLANDER & 2008 & Minivan & Pool \\
\hline 117 & G43-0790K & Chevrolet & CG3300 & 2010 & Passenger Van & Pool \\
\hline 118 & G82-0509A & Ford & F650 STAKE & 2004 & Stake Truck & Transport \\
\hline 119 & G10-6379L & Dodge & AVENGER & 2011 & Midsize Sedan & Support \\
\hline 120 & G42-3471A & Chevrolet & G2300 & 2005 & Cargo Van & Transport \\
\hline
\end{tabular}




\begin{tabular}{|l|l|c|}
\hline & Make/Model/Year & Ford/E350/2010 \\
\cline { 2 - 3 } & EPA Class Size & Cargo Van \\
\hline & Mission & Pool \\
\hline Contact & J. Lamantia/Motor Transport \\
\hline & Parking Location & G43-0875K \\
\hline Fleet Vehicle ID & Gas/Eth \\
\hline Fuel Type & $12 / 15 / 139 / 12 / 10$ \\
\hline & EPA Label/MPG $($ City/Hwy/Combined)* & $684 / 630$ \\
\hline & EPA GHG Emissions $(\text { Grams CO } / \mathrm{Mi})^{*}$ & Logger 6 \\
\hline & Study Logger ID & $34 / 63$ \\
\hline
\end{tabular}

\begin{tabular}{|l|c|c|c|c|}
\hline \multicolumn{5}{|c|}{ Vehicle G43-0875K Travel Summary } \\
\hline & $\begin{array}{c}\text { Per Day } \\
\text { Average/Peak }\end{array}$ & $\begin{array}{c}\text { Per Outing } \\
\text { Average/Peak }\end{array}$ & $\begin{array}{c}\text { Per Trip } \\
\text { Average/Peak }\end{array}$ & Total \\
\hline Travel Distance (Miles) & $19.5 / 51.7$ & $0.8 / 8.9$ & $0.6 / 7.9$ & 664 \\
\hline Travel Time (Minutes) & $219 / 777$ & $9.2 / 128$ & $6.9 / 113$ & 7,454 \\
\hline Idle Time (Minutes) & $89.8 / \mathrm{NA}$ & $3.8 / \mathrm{NA}$ & $2.8 / \mathrm{NA}$ & 3,054 \\
\hline
\end{tabular}

\begin{tabular}{|c|c|c|c|c|}
\hline \multicolumn{2}{|c|}{ Total Stops } & \multicolumn{2}{c|}{ Stop Duration } \\
\hline $\begin{array}{c}\text { Distance From } \\
\text { Home Base (Miles) }\end{array}$ & Stops & Percentages & Stop Duration (Hours) & Stops \\
\hline Less than 10 & 1,162 & $100 \%$ & Less than 2 & 1,099 \\
\hline 10 to 20 & 0 & $0 \%$ & 2 to 4 & 44 \\
\hline 20 to 40 & 0 & $0 \%$ & 4 to 8 & 8 \\
\hline 40 to 60 & 0 & $0 \%$ & Greater than 8 & 11 \\
\hline
\end{tabular}

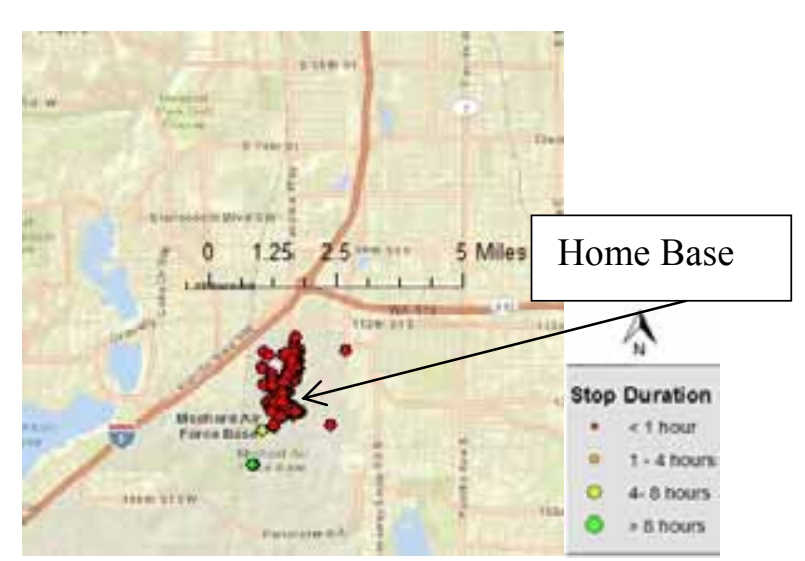

Figure E-28. Vehicle G43-0875K stops.

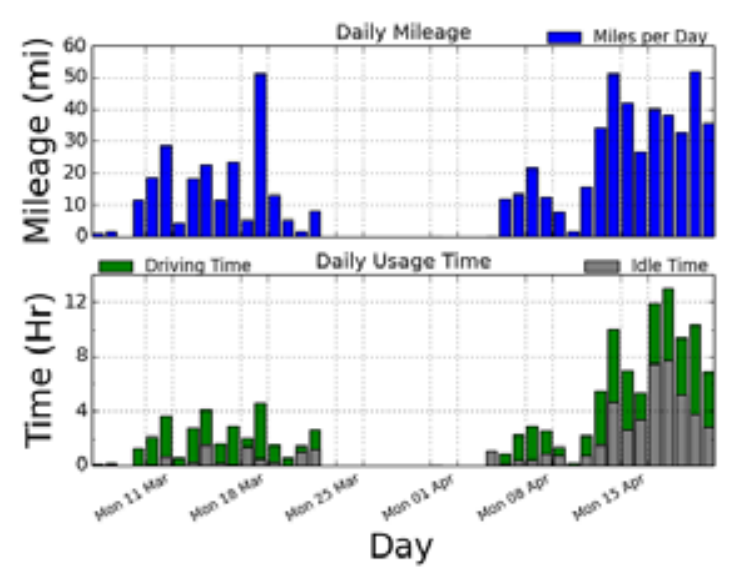

Figure E-29. Vehicle G43-0875K history. *2011 Ford E350 Van information provided. EPA figures for 2010 Ford E350 not available. 


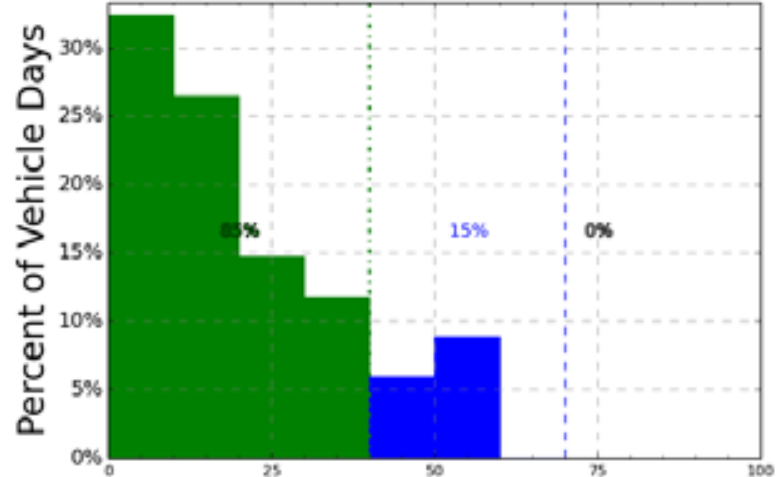

Daily Travel Distance (miles)

All days less than 40 miles - - All days less than 70 miles

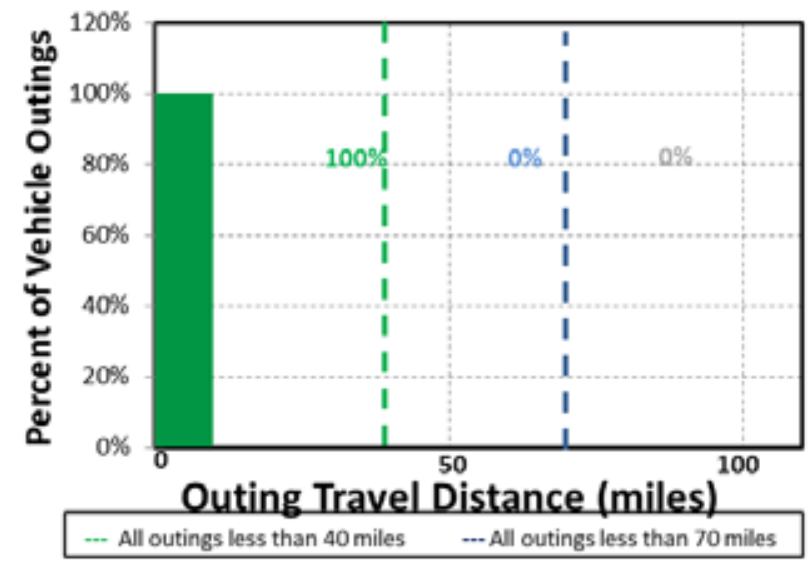

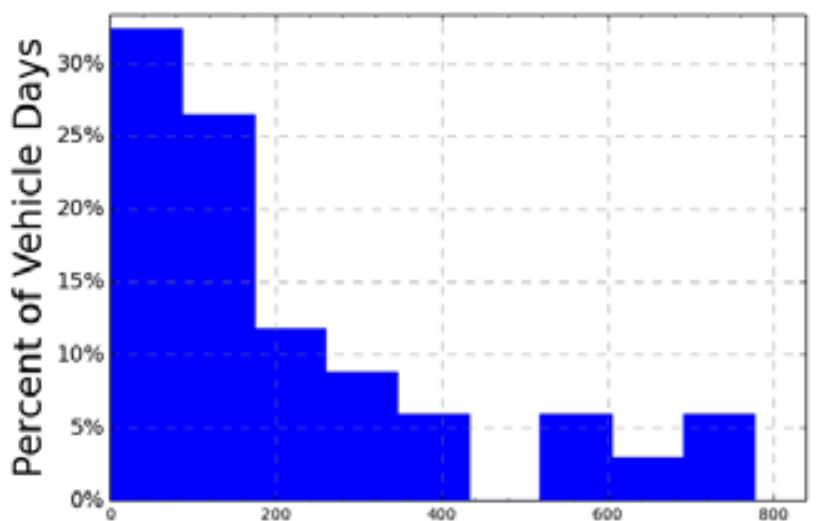

Daily Travel Time (minutes)

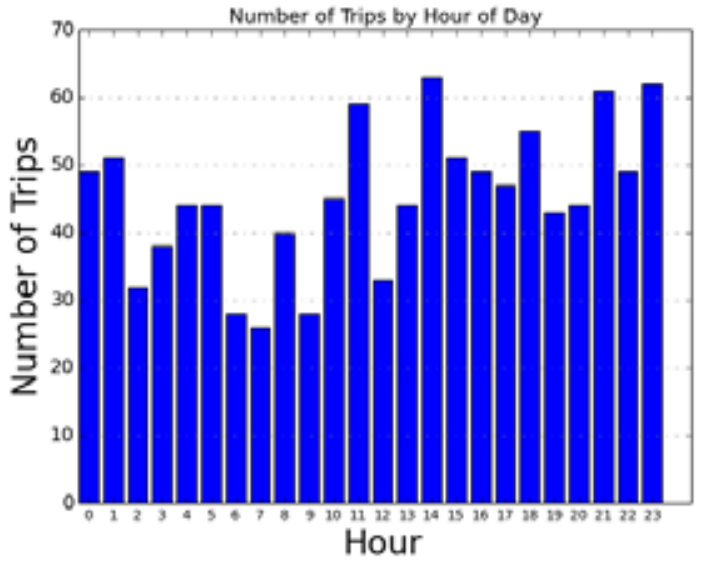

Figure E-30. Vehicle G43-0875K travel graphs.

\section{Vehicle G43-0875K Observations}

Survey information was not available for this vehicle. Stop data suggests it typically parks near J Ramp on Levitow Blvd (E St NW) or $2^{\text {nd }}$ St NW. Site data reports an odometer reading of 15,214 in May 2012 with an average of 1,556 miles per month.

Logger 6 collected data on this vehicle for a period of 34 days of the 63-day study period. Validation occurred on $99.5 \%$ of the input data. All trips and outings were less than 10 miles and thus, were within the typically advertised range of a BEV of approximately 70 miles. The longest day's travel was 52 miles, which was also within the BEV range.

This vehicle had an exceptionally high number of trips at 1085 trips in 34 days for an average of 32 trips per day monitored. However, all of the trips are of short range at an average of 0.6 miles each.

This is a large cargo van and no BEV is currently available for replacement. However, since survey information was not available, it is not known if special cargo requirements would preclude replacement by a smaller vehicle. Thus, a BEV may provide the acceptable performance of this vehicle should the $\mathrm{BEV}$ meet other mission requirements. 


\begin{tabular}{|c|c|c|c|c|}
\hline & \multicolumn{2}{|l|}{ Make/Model/Year } & \multicolumn{2}{|c|}{ Ford/Sport Trac /2004 } \\
\hline & \multicolumn{2}{|l|}{ EPA Class Size } & \multicolumn{2}{|c|}{ Standard Pickup Truck } \\
\hline$-\pi$ en & \multicolumn{2}{|l|}{ Mission } & \multicolumn{2}{|c|}{ Pool } \\
\hline & \multicolumn{2}{|l|}{ Contact } & \multicolumn{2}{|c|}{ J. Lamantia/Motor Transport } \\
\hline & \multicolumn{2}{|l|}{ Parking Location } & \multicolumn{2}{|c|}{ Bldg 100/Col. Joe Jackson Blvd } \\
\hline & \multicolumn{2}{|l|}{ Fleet Vehicle ID } & \multicolumn{2}{|c|}{ G41-1288A } \\
\hline & \multicolumn{2}{|l|}{ Fuel Type } & \multicolumn{2}{|c|}{ Gas/Eth } \\
\hline & \multicolumn{2}{|c|}{$\begin{array}{l}\text { EPA Label/MPG } \\
\text { (City/Hwy/Combined) }\end{array}$} & \multicolumn{2}{|c|}{$14 / 20 / 16 \quad 10 / 14 / 12$} \\
\hline & \multicolumn{2}{|c|}{ EPA GHG Emissions (Grams $\left.\mathrm{CO}_{2} / \mathrm{Mi}\right)$} & \multicolumn{2}{|c|}{$555 / 525$} \\
\hline & \multicolumn{2}{|c|}{ Study Logger ID } & \multicolumn{2}{|c|}{ Logger 7} \\
\hline & \multicolumn{2}{|c|}{ Total Vehicle Days/Total Study Days } & \multicolumn{2}{|c|}{$44 / 63$} \\
\hline \multicolumn{5}{|c|}{ Vehicle G41-1288A Travel Summary } \\
\hline & $\begin{array}{c}\text { Per Day } \\
\text { Average/Peak }\end{array}$ & $\begin{array}{c}\text { Per Outing } \\
\text { Average/Peak } \\
\end{array}$ & $\begin{array}{c}\text { Per Trip } \\
\text { Average/Peak } \\
\end{array}$ & Total \\
\hline Travel Distance (Miles) & $2.7 / 12.9$ & $1.7 / 9.2$ & $1.0 / 8.2$ & 121 \\
\hline Travel Time (Minutes) & $18 / 88.0$ & $11.1 / 54$ & $6.2 / 48$ & 786 \\
\hline Idle Time (Minutes) & $4.0 / \mathrm{NA}$ & $2.5 / \mathrm{NA}$ & $1.4 / \mathrm{NA}$ & 174 \\
\hline
\end{tabular}

\begin{tabular}{|c|c|c|c|c|}
\hline & \multicolumn{3}{c|}{ Stop Duration } \\
\hline $\begin{array}{c}\text { Distance From } \\
\text { Home Base (Miles) }\end{array}$ & Stops & Percentages & Stop Duration (Hours) & Stops \\
\hline Less than 10 & 119 & $100 \%$ & Less than 2 & 73 \\
\hline 10 to 20 & 0 & $0 \%$ & 2 to 4 & 4 \\
\hline 20 to 40 & 0 & $0 \%$ & 4 to 8 & Greater than 8 \\
\hline 40 to 60 & 0 & $0 \%$ & \\
\hline
\end{tabular}

Figure E-4. Vehicle G41-1288A stops.

Figure E-5. Vehicle G41-1288A history. 

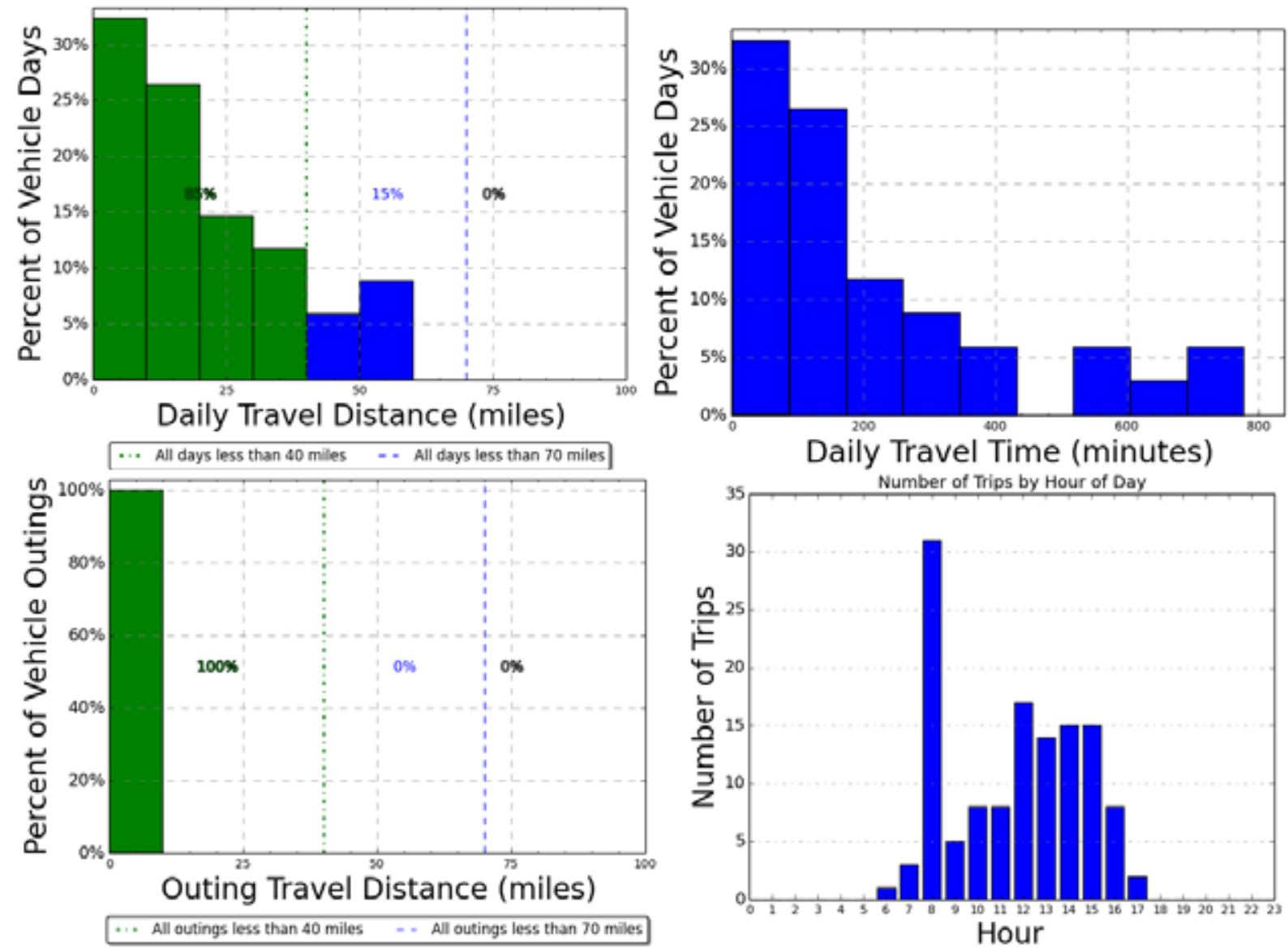

Figure E-31. Vehicle G41-1288A travel graphs.

\section{Vehicle G41-1288A Observations}

Logger 7 collected data on this vehicle for a period of 44 days of the 63-day study period. Validation occurred on $91.5 \%$ of the input data. Survey information was not available for this vehicle. Stop data suggests it typically parks near Bldg 100/Col. Joe Jackson Blvd. Site data reports an odometer reading of 14,555 in May 2012 with an average of 53 miles per month.

All trips and outings were less than 10 miles and thus, were within the typically advertised range of a BEV of approximately 70 miles. The longest day's travel was 12.9 miles that was also within the BEV range. Based upon travel alone, a BEV could be a suitable replacement.

This is a pickup truck. Since survey information was not available, it is not known if special cargo requirements would preclude replacement by a smaller vehicle, SUV, or minivan. Thus, a BEV may provide the acceptable performance of this vehicle should the BEV meet other mission requirements. 


\section{Vehicle G43-4937A}

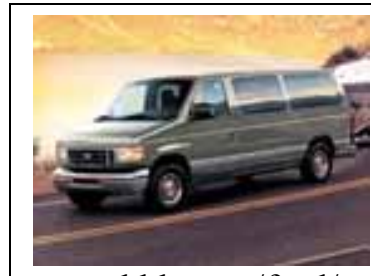

www.kbb.com/ford/

\begin{tabular}{|l|c|}
\hline Make/Model/Year & Ford/E350 /2004 \\
\hline EPA Class Size & Cargo Van \\
\hline Mission & Pool \\
\hline Contact & J. Lamantia/Motor Transport \\
\hline Parking Location & C Ramp/ $7^{\text {th }}$ St NE \\
\hline Fleet Vehicle ID & G43-4937A \\
\hline Fuel Type & Gas \\
\hline EPA Label/MPG $($ City/Hwy/Combined)* & $14 / 18 / 15$ \\
\hline EPA GHG Emissions $($ Grams CO $/$ Mi) & 592 \\
\hline Study Logger ID & Logger 8 \\
\hline Total Vehicle Days/Total Study Days & $9 / 63$ \\
\hline
\end{tabular}

\begin{tabular}{|l|c|c|c|c|}
\hline \multicolumn{5}{|c|}{ Vehicle G43-4937A Travel Summary } \\
\hline & $\begin{array}{c}\text { Per Day } \\
\text { Average/Peak }\end{array}$ & $\begin{array}{c}\text { Per Outing } \\
\text { Average/Peak }\end{array}$ & $\begin{array}{c}\text { Per Trip } \\
\text { Average/Peak }\end{array}$ & Total \\
\hline Travel Distance (Miles) & $13.1 / 21.6$ & $1.8 / 6.9$ & $0.7 / 6.1$ & 118 \\
\hline Travel Time (Minutes) & $82 / 129.0$ & $11.5 / 31.0$ & $4.6 / 28$ & 739 \\
\hline Idle Time (Minutes) & 56/NA & $7.9 / \mathrm{NA}$ & $3.1 / \mathrm{NA}$ & 504 \\
\hline
\end{tabular}

\begin{tabular}{|c|c|c|c|c|}
\hline \multicolumn{2}{|c|}{ Total Stops } & \multicolumn{2}{c|}{ Stop Duration } \\
\hline $\begin{array}{l}\text { Distance From } \\
\text { Home Base (Miles) }\end{array}$ & Stops & Percentages & Stop Duration (Hours) & Stops \\
\hline Less than 10 & 454 & $100 \%$ & Less than 2 & 365 \\
\hline 10 to 20 & 0 & $0 \%$ & 2 to 4 & 57 \\
\hline 20 to 40 & 0 & $0 \%$ & 4 to 8 & 15 \\
\hline 40 to 60 & 0 & $0 \%$ & Greater than 8 & 17 \\
\hline
\end{tabular}

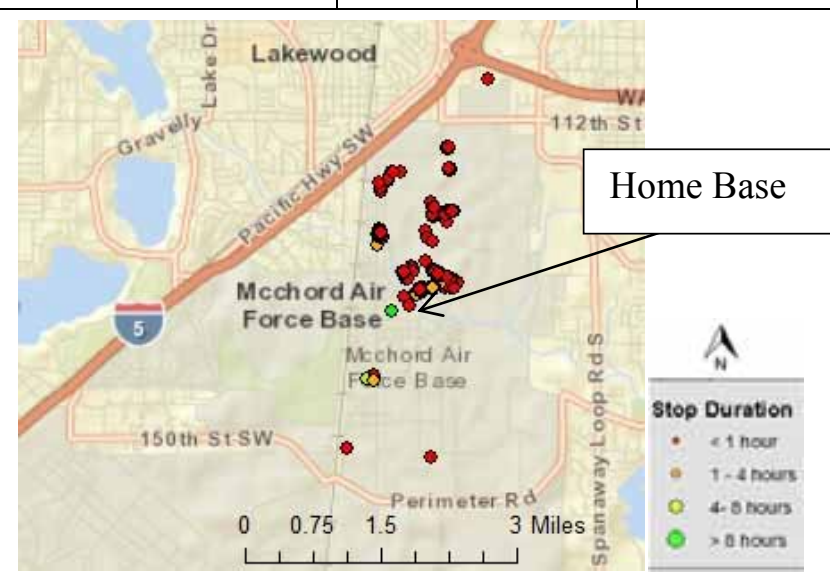

Figure E-7. Vehicle G43-4937A stops.

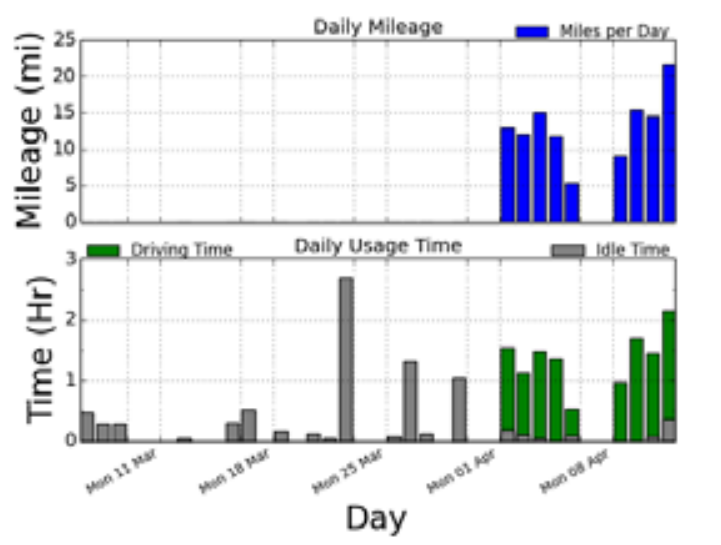

Figure D-32. Vehicle G43-4937A history.

*2004 Ford E250 information. EPA figures for 2004 Ford E350 not available. 

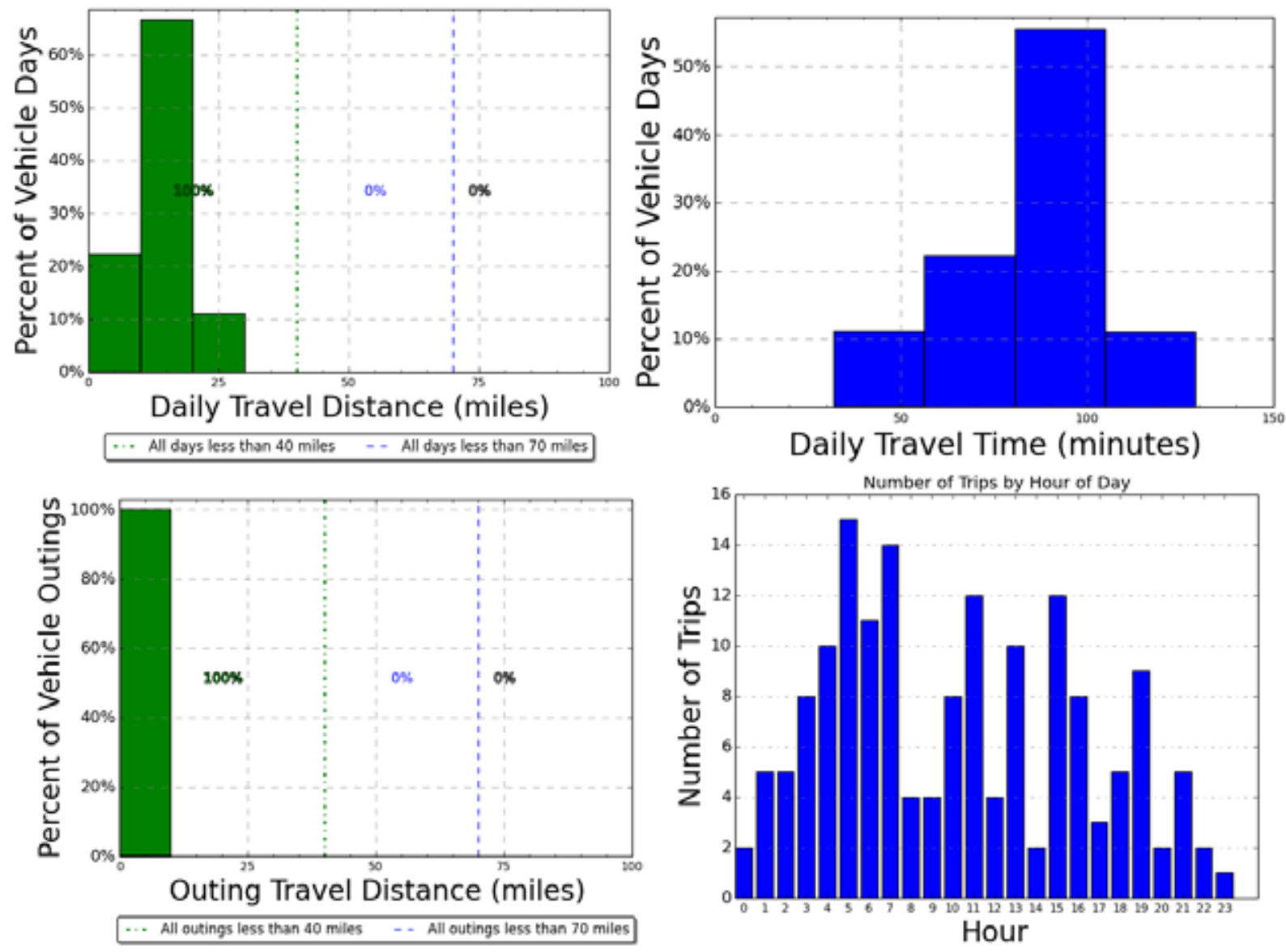

Figure E-33. Vehicle G43-4937A travel graphs.

\section{Vehicle G43-4937A Observations}

Logger 8 collected data on this vehicle for a period of 9 days of the 63-day study period. Validation occurred on $99.3 \%$ of the input data. Survey information was not available for this vehicle. Stop data suggests it typically parks on $7^{\text {th }}$ Street NW near C Ramp. Site data reports an odometer reading of 30,040 in May 2012 with an average of 338 miles per month.

All trips and outings were less than 10 miles and thus, were within the typically advertised range of a BEV of approximately 70 miles. The longest day's travel was 21.6 miles that was also within the BEV range. Based upon travel alone, a BEV could be a suitable replacement.

This is a large cargo van and no BEV is currently available for replacement. However, since survey information was not available, it is not known if special cargo requirements would preclude replacement by a smaller vehicle. Thus, a BEV may provide the acceptable performance of this vehicle should the $\mathrm{BEV}$ meet other mission requirements. 
Vehicle G10-7664F

\begin{tabular}{|c|c|c|}
\hline \multirow{11}{*}{ www.edmunds.com/ } & Make/Model/Year & Dodge/Avenger / 2008 \\
\hline & EPA Class Size & Compact Sedan \\
\hline & Mission & Pool \\
\hline & Contact & J. Lamantia/Motor Transport \\
\hline & Parking Location & Bldg 100/ Westcott Hills \\
\hline & Fleet Vehicle ID & G10-7664F \\
\hline & Fuel Type & Gas/Eth \\
\hline & EPA Label/MPG (City/Hwy/Combined)* & $19 / 27 / 22 \quad 13 / 20 / 16$ \\
\hline & EPA GHG Emissions (Grams $\left.\mathrm{CO}_{2} / \mathrm{Mi}\right) *$ & $404 / 393$ \\
\hline & Study Logger ID & Logger 9 \\
\hline & Total Vehicle Days/Total Study Days & $25 / 63$ \\
\hline
\end{tabular}

\begin{tabular}{|l|c|c|c|c|}
\hline \multicolumn{5}{|c|}{ Vehicle G10-7664F Travel Summary } \\
\hline & $\begin{array}{c}\text { Per Day } \\
\text { Average/Peak }\end{array}$ & $\begin{array}{c}\text { Per Outing } \\
\text { Average/Peak }\end{array}$ & $\begin{array}{c}\text { Per Trip } \\
\text { Average/Peak }\end{array}$ & Total \\
\hline Travel Distance (Miles) & $6.2 / 25.6$ & $7.8 / 30.2$ & $2.2 / 11.5$ & 156 \\
\hline Travel Time (Minutes) & $25 / 75$ & $31.9 / 125$ & $9.0 / 57$ & 637 \\
\hline Idle Time (Minutes) & $8.4 / \mathrm{NA}$ & $10.5 / \mathrm{NA}$ & $3.0 / \mathrm{NA}$ & 210 \\
\hline
\end{tabular}

\begin{tabular}{|c|c|c|c|c|}
\hline \multicolumn{2}{|c|}{ Total Stops } & \multicolumn{2}{c|}{ Stop Duration } \\
\hline $\begin{array}{c}\text { Distance From } \\
\text { Home Base (Miles) }\end{array}$ & Stops & Percentages & Stop Duration (Hours) & Stops \\
\hline Less than 10 & 79 & $100 \%$ & Less than 2 & 44 \\
\hline 10 to 20 & 0 & $0 \%$ & 2 to 4 & 6 \\
\hline 20 to 40 & 0 & $0 \%$ & 4 to 8 & 5 \\
\hline 40 to 60 & 0 & $0 \%$ & Greater than 8 & 24 \\
\hline
\end{tabular}

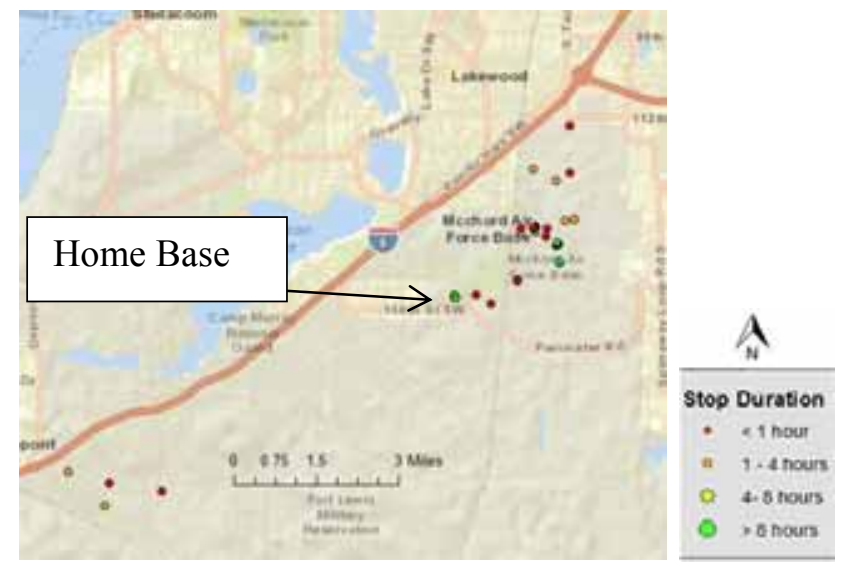

Figure E-10. Vehicle G10-7664F stops.

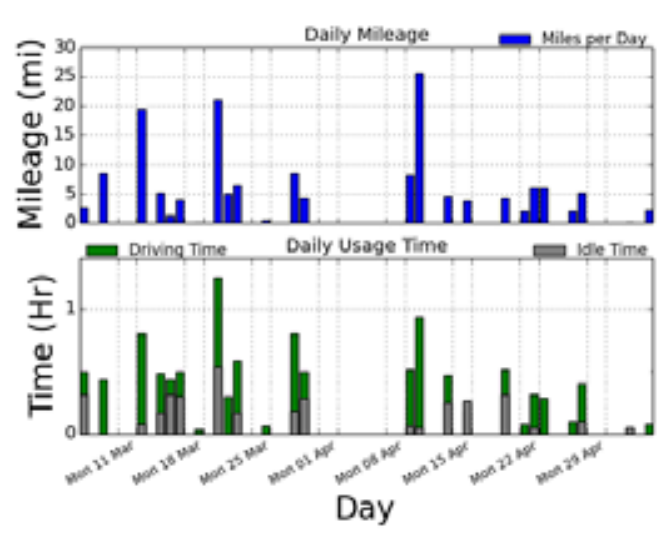

Figure E-11. Vehicle G10-7664F history. 


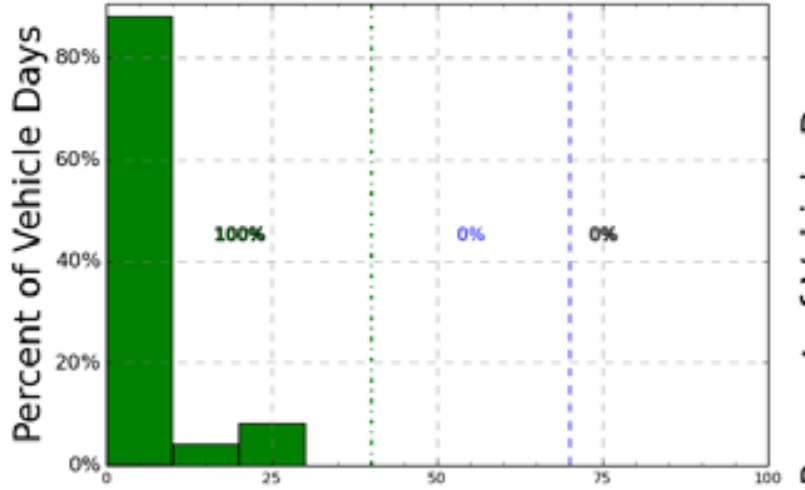

Daily Travel Distance (miles)
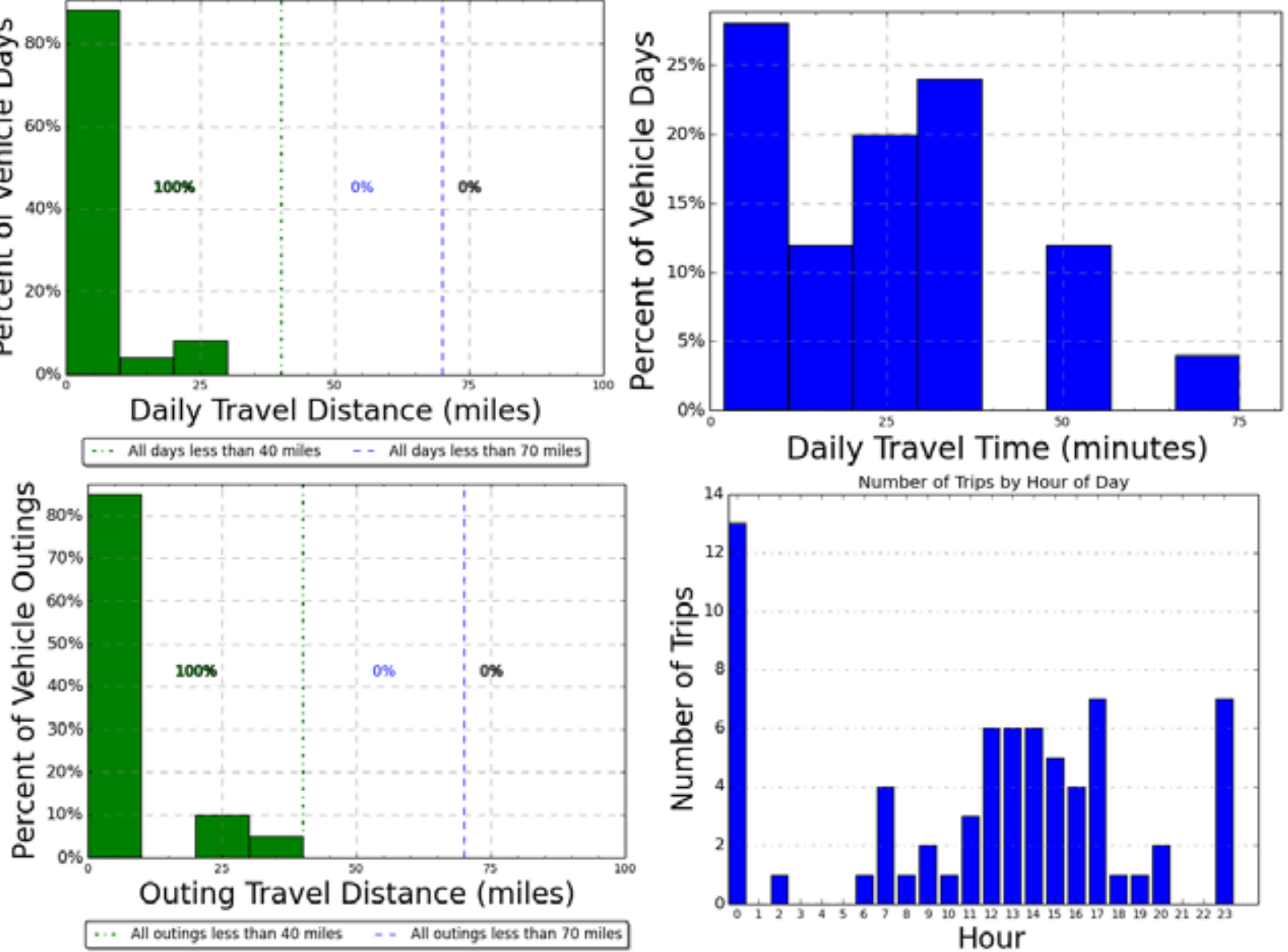

Daily Travel Time (minutes)

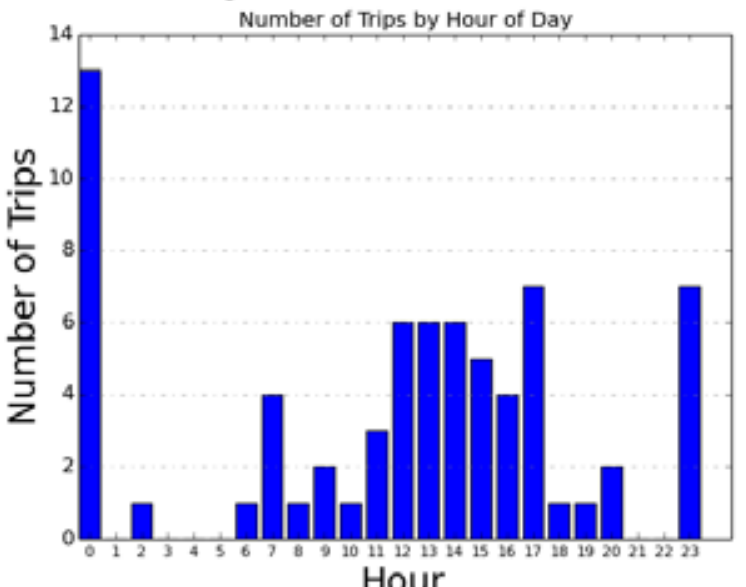

Hour

Figure E-34. Vehicle G10-7664F travel graphs.

\section{Vehicle G10-7664F Observations}

Logger 9 collected data on this vehicle for a period of 25 days of the 63-day study period. Validation occurred on $93.2 \%$ of the input data. Survey information was not available for this vehicle. Stop data suggests it typically parks near Westcott Hills Housing on Lincoln Blvd. It also stops frequently at Bldg 100 near Col Joe Jackson Blvd. Site data reports an odometer reading of 12,358 in May 2012 with an average of 69 miles per month.

All trips and outings were less than 40 miles and thus, were within the typically advertised range of a BEV of approximately 70 miles. The longest day's travel was 25.6 miles that was also within the BEV range. The longest single outing was 30.2 miles because the vehicle did not return to the home base over the evening. Based upon travel alone, a BEV could be a suitable replacement.

This is a compact sedan and BEVs are available for replacement. The BEV may provide the acceptable performance of this vehicle. 


\begin{tabular}{|c|c|c|}
\hline$\pi t^{P} 34$ is & Make/Model/Year & Dodge/Dakota/2002 \\
\hline 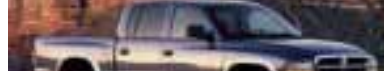 & EPA Class Size & Standard Pickup Truck \\
\hline 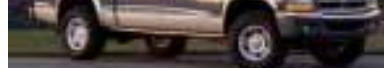 & Mission & Pool \\
\hline \multirow{8}{*}{ www.edmunds.com/ } & Contact & J. Lamantia/ Transport \\
\hline & Parking Location & Bldg 100/Barrack St or $2^{\text {nd }} \mathrm{St}$ \\
\hline & Fleet Vehicle ID & G41-65991 \\
\hline & Fuel Type & Gas \\
\hline & EPA Label/MPG (City/Hwy/Combined)* & $16 / 18 / 17$ \\
\hline & EPA GHG Emissions (Grams $\left.\mathrm{CO}_{2} / \mathrm{Mi}\right)^{*}$ & 523 \\
\hline & Study Logger ID & Logger 10 \\
\hline & Total Vehicle Days/Total Study Days & $40 / 63$ \\
\hline
\end{tabular}

\begin{tabular}{|l|c|c|c|c|}
\hline \multicolumn{5}{|c|}{ Vehicle G41-65991Travel Summary } \\
\hline & $\begin{array}{c}\text { Per Day } \\
\text { Average/Peak }\end{array}$ & $\begin{array}{c}\text { Per Outing } \\
\text { Average/Peak }\end{array}$ & $\begin{array}{c}\text { Per Trip } \\
\text { Average/Peak }\end{array}$ & Total \\
\hline Travel Distance (Miles) & $77.4 / 264.4$ & $63.2 / 264.4$ & $18.1 / 133.6$ & 3,096 \\
\hline Travel Time (Minutes) & $121 / 284$ & $98.6 / 284$ & $28.2 / 146$ & 4,829 \\
\hline Idle Time (Minutes) & $17.9 / \mathrm{NA}$ & $14.6 / \mathrm{NA}$ & $4.2 / \mathrm{NA}$ & 717 \\
\hline
\end{tabular}

\begin{tabular}{|c|c|c|c|c|}
\hline \multicolumn{2}{|c|}{ Total Stops } & \multicolumn{2}{c|}{ Stop Duration } \\
\hline $\begin{array}{c}\text { Distance From } \\
\text { Home Base (Miles) }\end{array}$ & Stops & Percentages & Stop Duration (Hours) & Stops \\
\hline Less than 10 & 90 & $55.9 \%$ & Less than 2 & 106 \\
\hline 10 to 20 & 9 & $5.6 \%$ & 2 to 4 & 14 \\
\hline 20 to 40 & 32 & $19.9 \%$ & 4 to 8 & 2 \\
\hline 40 to 60 & 30 & $18.7 \%$ & Greater than 8 & 39 \\
\hline
\end{tabular}

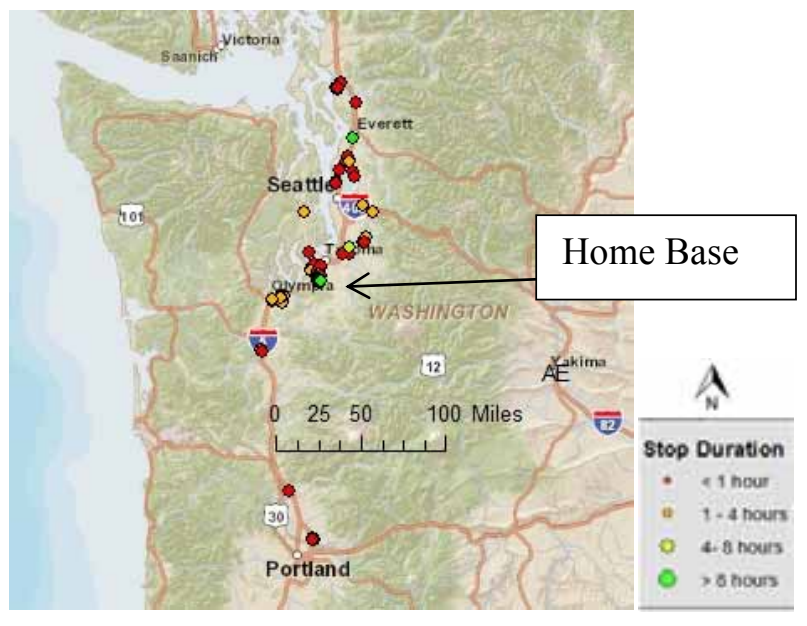

Figure E-13. Vehicle G41-65991 stops.

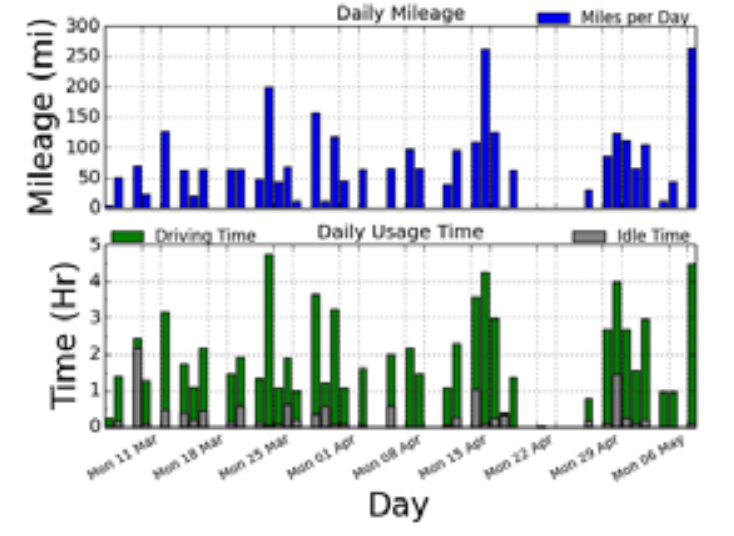

Figure E-14. Vehicle G41-65991 history. 

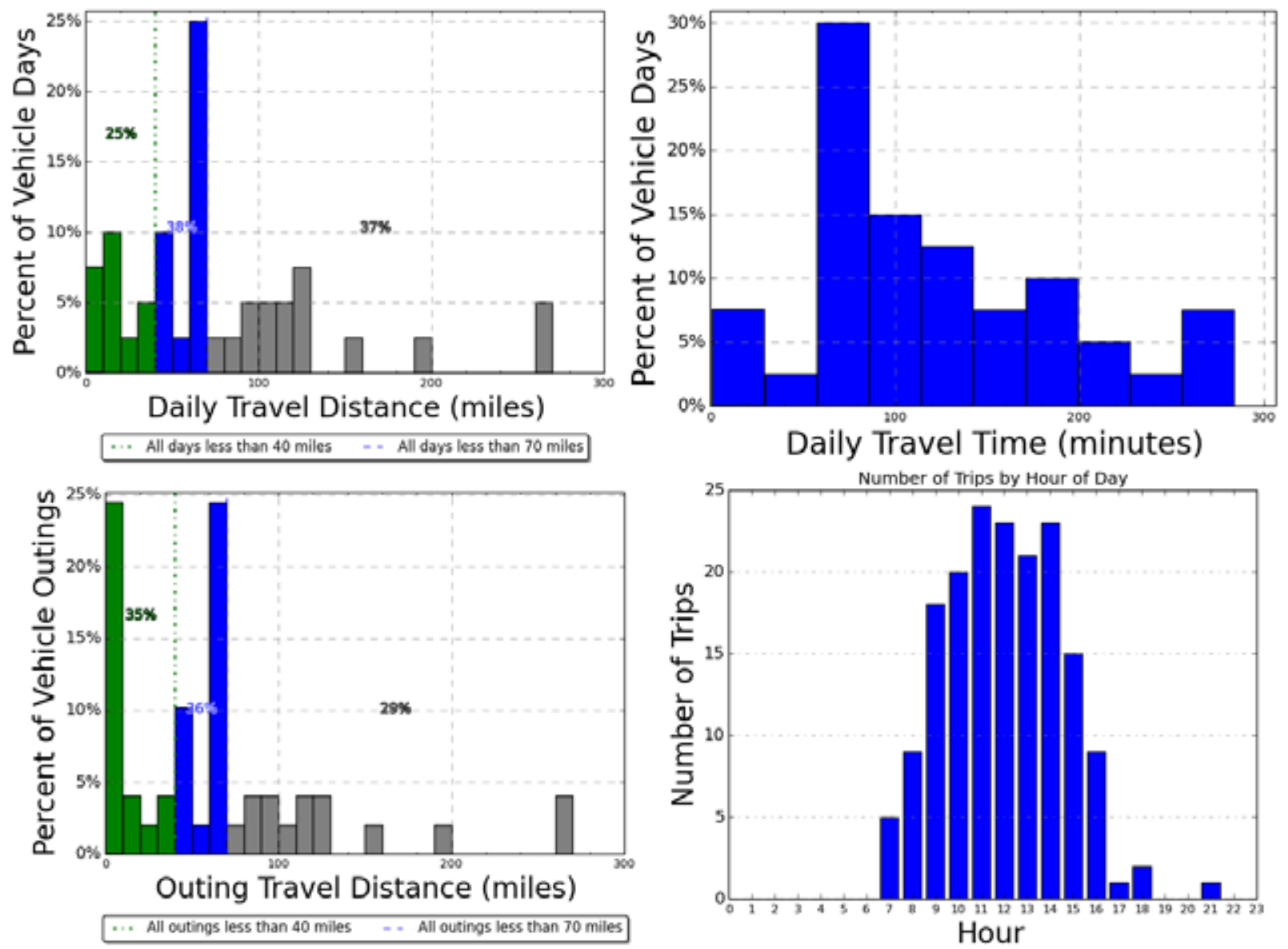

Figure E-35. Vehicle G41-65991travel graphs.

\section{Vehicle G41-659910bservations}

Logger 10 collected data on this vehicle for a period of 40 days of the 63-day study period. Validation occurred on $98.3 \%$ of the input data. Survey information was not available for this vehicle. Stop data suggests it typically parks near Bldg 100 on Barrack or $2^{\text {nd }}$ St SW. Site data reports an odometer reading of 18,370 in May 2012 with an average of 176 miles per month.

$63 \%$ of all vehicle travel days were within the 70 - mile BEV safe range (blue and green bars on Figure Appendix E-15) while 35\% of the vehicle travel days were within the 40-mile PHEV safe range (green bars).

The longest single outing of 264 miles occurred on June 6 but several outings and daily travel exceeded the battery only limits of BEVs and PHEVs. 29\% of outings and $37 \%$ of travel days exceeded those limits. The stop locations of greater than 2 hours show $65 \%$ at the home base location, $9 \%$ at B Street and the remainder at various other sites.

These data indicate that choosing a BEV for this duty may require intermediate charging stations opportunities at either the home base or a frequent intermediate stop. Yet, some travel days did not allow sufficient recharge opportunities or sufficient recharge time. Thus, a PHEV is required for the days that involve extended trips. A combination of BEVs and PHEVs may be desirable for this fleet. 
Vehicle G11-2676G

\begin{tabular}{|l|l|c|}
\hline \multirow{4}{*}{ www.edmunds.com } & Make/Model/Year & Chevrolet/Impala/2008 \\
\cline { 2 - 3 } & EPA Class Size & Large Cars \\
\cline { 2 - 3 } & Mission & Pool \\
\cline { 2 - 3 } & Contact & C. Sallinger/Motor Transport \\
\cline { 2 - 3 } & Parking Location & Gldg 9190/Sansone St \\
\cline { 2 - 3 } & Fleet Vehicle ID & Gas/E85 \\
\hline & Fuel Type & $18 / 29 / 2214 / 21 / 16$ \\
\hline & EPA Label/MPG (City/Hwy/Combined)* & $404 / 393$ \\
\hline & EPA GHG Emissions (Grams CO $/$ Mi)* & Logger 11 \\
\cline { 2 - 3 } & Study Logger ID & $15 / 63$ \\
\cline { 2 - 3 } & Total Vehicle Days/Total Study Days & \\
\hline
\end{tabular}

\begin{tabular}{|l|c|c|c|c|}
\hline \multicolumn{5}{|c|}{ Vehicle G11-2676G Travel Summary } \\
& $\begin{array}{c}\text { Per Day } \\
\text { Average/Peak }\end{array}$ & $\begin{array}{c}\text { Per Outing } \\
\text { Average/Peak }\end{array}$ & $\begin{array}{c}\text { Per Trip } \\
\text { Average/Peak }\end{array}$ & Total \\
\hline Travel Distance (Miles) & $12.6 / 29.8$ & $11.8 / 54.8$ & $3.9 / 19.3$ & 189 \\
\hline Travel Time (Minutes) & $43 / 172$ & $39.9 / 260$ & $13.3 / 144$ & 638 \\
\hline Idle Time (Minutes) & $8.2 / \mathrm{NA}$ & $7.7 / \mathrm{NA}$ & $2.6 / \mathrm{NA}$ & 123 \\
\hline
\end{tabular}

\begin{tabular}{|c|c|c|c|c|}
\hline \multicolumn{2}{|c|}{ Total Stops } & \multicolumn{2}{c|}{ Stop Duration } \\
\hline $\begin{array}{c}\text { Distance From } \\
\text { Home Base (Miles) }\end{array}$ & Stops & Percentages & Stop Duration (Hours) & Stops \\
\hline Less than 10 & 50 & $94.3 \%$ & Less than 2 & 34 \\
\hline 10 to 20 & 3 & $5.7 \%$ & 2 to 4 & 3 \\
\hline 20 to 40 & 0 & $0 \%$ & 4 to 8 & 0 \\
\hline 40 to 60 & 0 & $0 \%$ & Greater than 8 & 16 \\
\hline
\end{tabular}

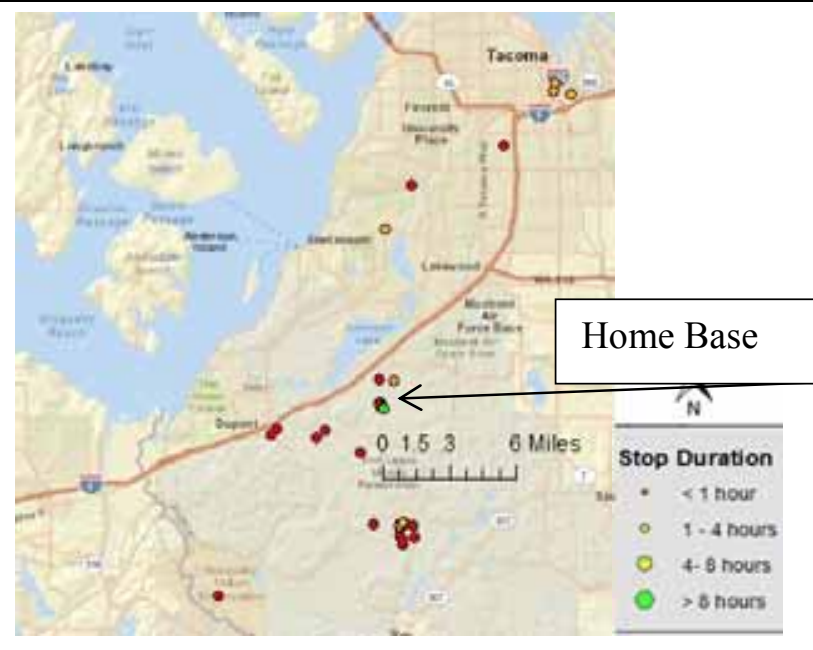

Figure E-16. Vehicle G11-2676G stops.

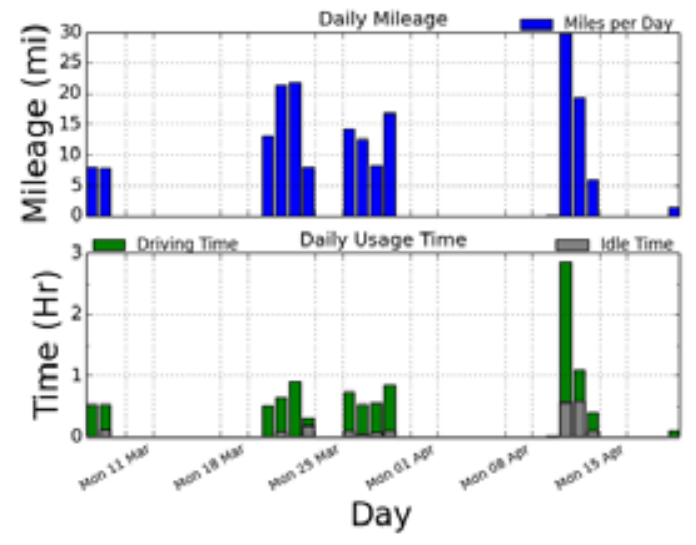

Figure E-17. Vehicle G11-2676G history. 

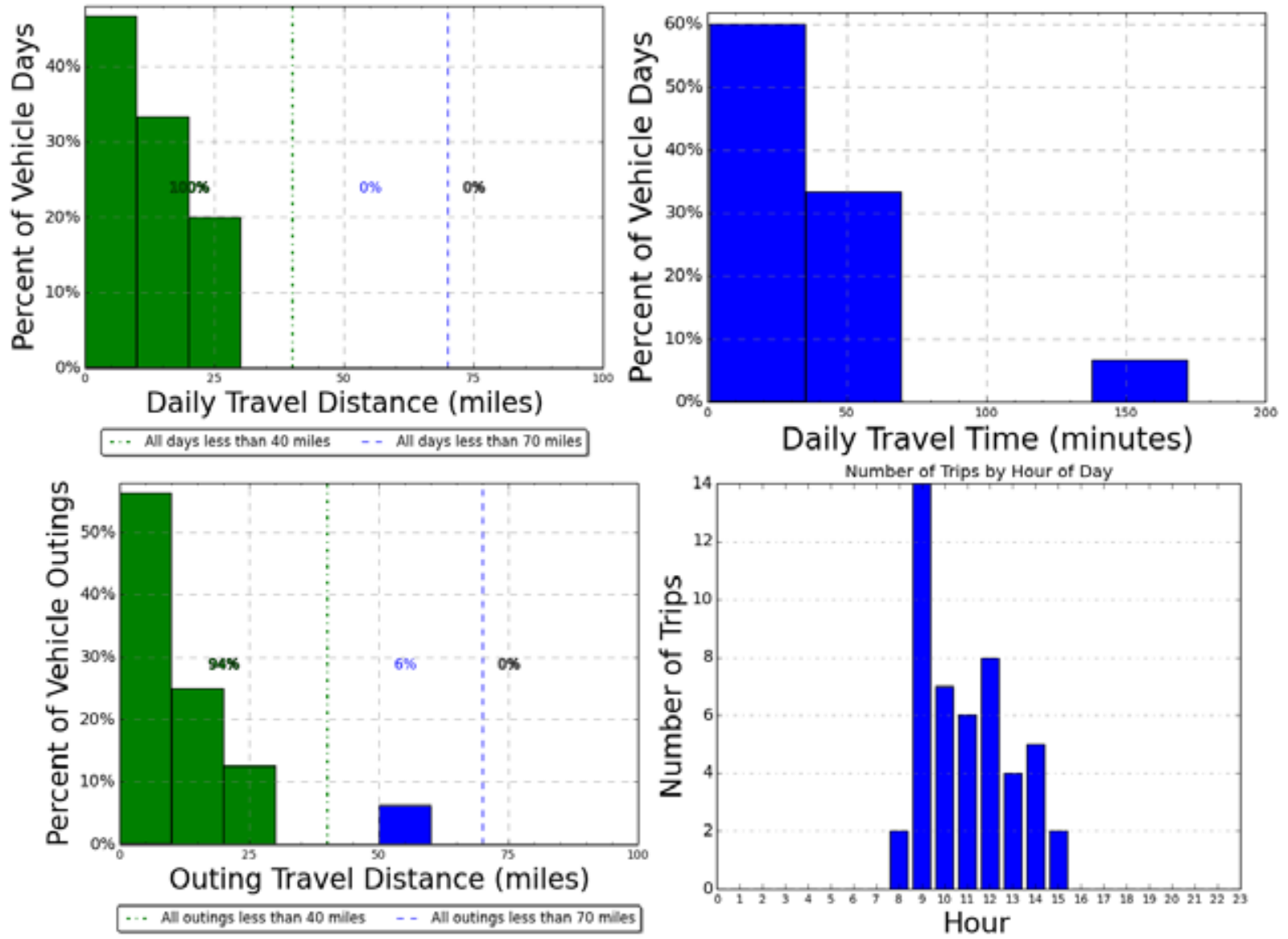

Figure E-36. Vehicle G11-2676G travel graphs.

\section{Vehicle G11-2676G Observations}

Logger 11 collected data on this vehicle for a period of 15 days of the 63-day study period. Validation occurred on $92.3 \%$ of the input data. The project survey response reports this vehicle travels less than 40 miles on a typical weekday. It frequently travels off base. Its use is primarily during daytime only. It parks regularly near Bldg 9190 on Sansone Street. Motor Transports expects to retain this vehicle more than six years.

Site data reports an odometer reading of 33,389 in May 2012 with an average of 667 miles per month.

All trips and outings were less than 70 miles and thus, were within the typically advertised range of a BEV of approximately 70 miles. The longest day's travel was 29.8 miles that was also within the BEV range. The longest single outing was 54.8 miles because the vehicle did not return to the home base over the evening. Based upon travel alone, a BEV could be a suitable replacement.

This is a large sedan and BEVs are available for replacement. The BEV would be expected to provide the acceptable performance of this vehicle. 


\begin{tabular}{|c|c|c|}
\hline \multirow{4}{*}{ 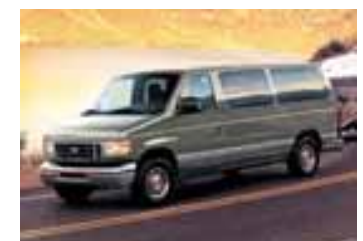 } & Make/Model/Year & Ford/E350 Econoline/2004 \\
\hline & EPA Class Size & Cargo Van \\
\hline & Mission & Pool \\
\hline & Contact & C. Sallinger/Motor Transport \\
\hline \multirow[t]{7}{*}{ www.edmunds.com } & Parking Location & Bldg $2027 / \mathrm{N} 8^{\text {th }}$ St \\
\hline & Fleet Vehicle ID & G42-0658k \\
\hline & Fuel Type & Diesel \\
\hline & EPA Label/MPG (City/Hwy/Combined)* & $13 / 16 / 14$ \\
\hline & EPA GHG Emissions (Grams $\left.\mathrm{CO}_{2} / \mathrm{Mi}\right)^{*}$ & 592 \\
\hline & Study Logger ID & Logger 12 \\
\hline & Total Vehicle Days/Total Study Days & $13 / 63$ \\
\hline
\end{tabular}

\begin{tabular}{|l|c|c|c|c|}
\hline \multicolumn{5}{|c|}{ Vehicle G42-0658k Travel Summary } \\
& $\begin{array}{c}\text { Per Day } \\
\text { Average/Peak }\end{array}$ & $\begin{array}{c}\text { Per Outing } \\
\text { Average/Peak }\end{array}$ & $\begin{array}{c}\text { Per Trip } \\
\text { Average/Peak }\end{array}$ & Total \\
\hline Travel Distance (Miles) & $13.4 / 78.2$ & $5.6 / 77.4$ & $2.5 / 39.0$ & 174 \\
\hline Travel Time (Minutes) & $48 / 214$ & $20.1 / 206$ & $10 / 139$ & 623 \\
\hline Idle Time (Minutes) & $10.7 / \mathrm{NA}$ & $4.5 / \mathrm{NA}$ & $2.2 / \mathrm{NA}$ & 139 \\
\hline
\end{tabular}

\begin{tabular}{|c|c|c|c|c|}
\hline \multicolumn{2}{|c|}{ Total Stops } & \multicolumn{2}{c|}{ Stop Duration } \\
\hline $\begin{array}{c}\text { Distance From } \\
\text { Home Base (Miles) }\end{array}$ & Stops & Percentages & Stop Duration (Hours) & Stops \\
\hline Less than 10 & 62 & $98.4 \%$ & Less than 2 & 47 \\
\hline 10 to 20 & 0 & $0 \%$ & 2 to 4 & 4 \\
\hline 20 to 40 & 1 & $1.6 \%$ & 4 to 8 & 2 \\
\hline 40 to 60 & 0 & $0 \%$ & Greater than 8 & 10 \\
\hline
\end{tabular}

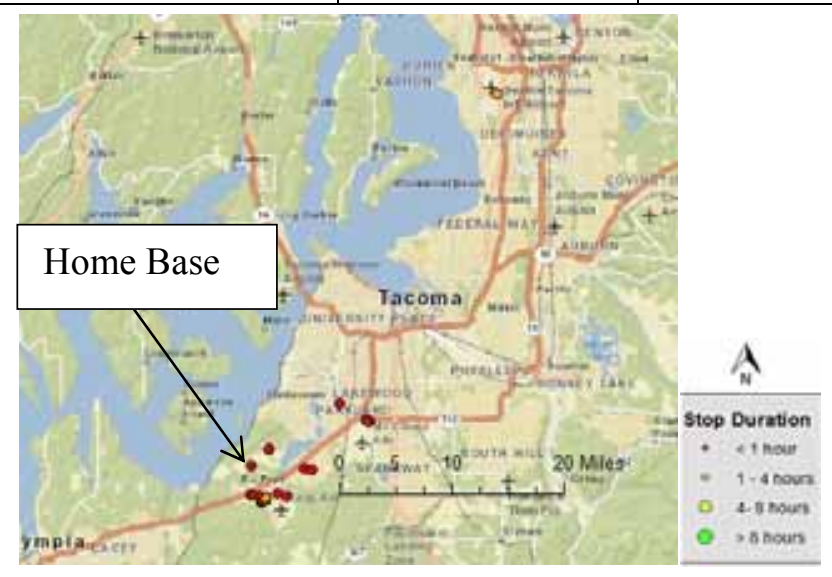

Figure E-19. Vehicle G42-0658k stops.

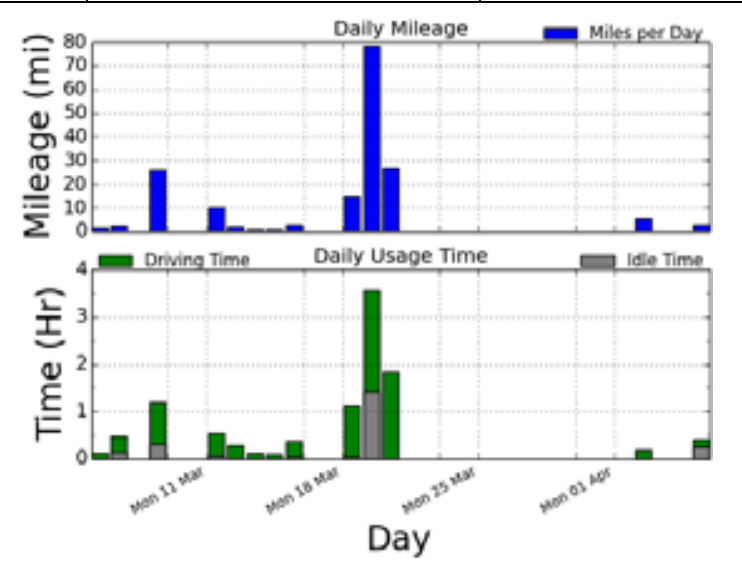

Figure E-20. Vehicle G42-0658k history.

*2004 Ford E250 information. EPA figures for 2004 Ford E350 not available. 

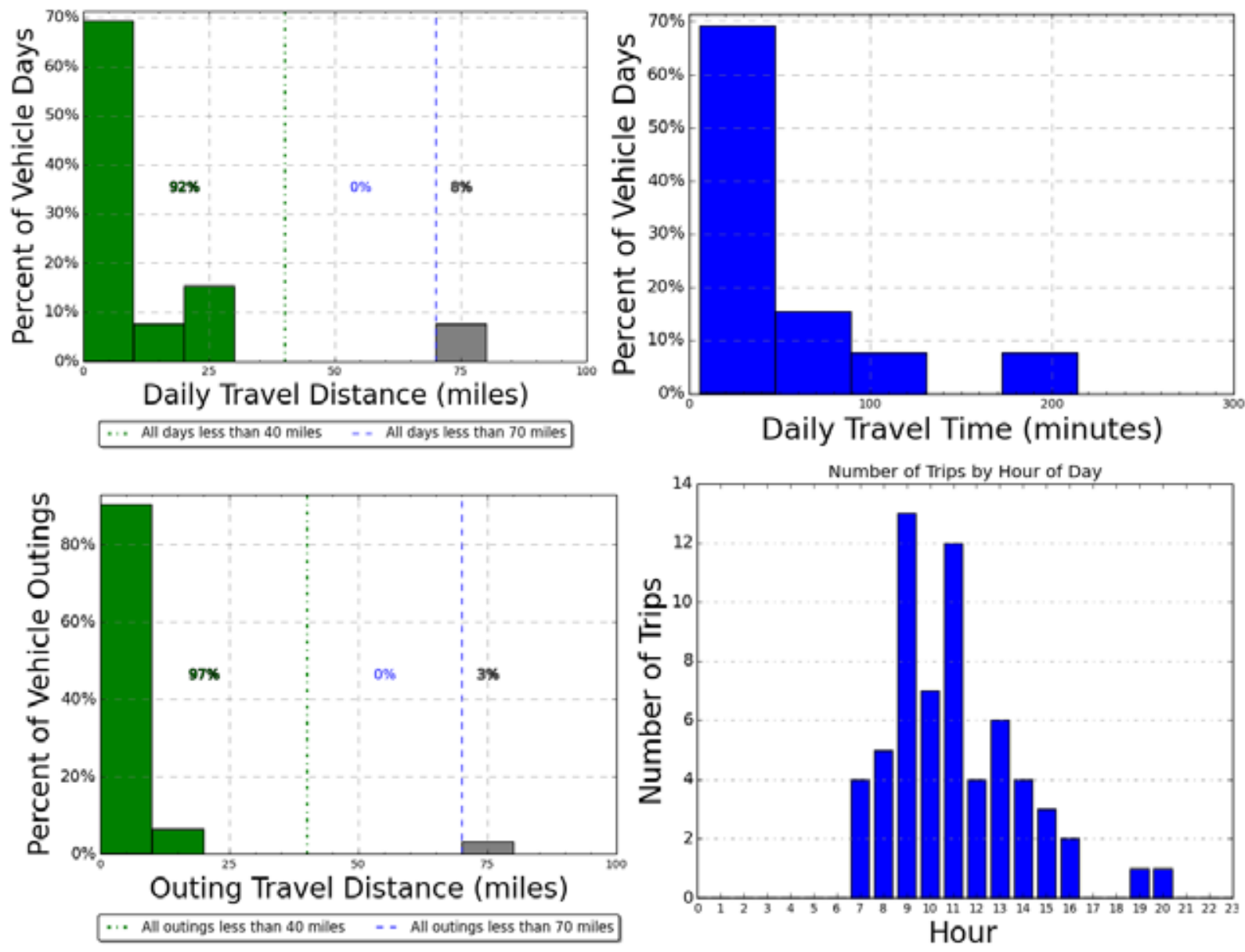

Figure E-37. Vehicle G42-0658k travel graphs.

\section{Vehicle G42-0658k Observations}

Logger 12 collected data on this vehicle for a period of 13 days of the 63-day study period. Validation occurred on $96.6 \%$ of the input data. Survey information was not available for this vehicle. Stop data suggests it typically parks near Bldg 2027 on N $8^{\text {th }}$ St. Site data reports an odometer reading of 37,338 in May 2012 with an average of 631 miles per month.

$92 \%$ of all vehicle travel days were within the 70-mile BEV safe range (green bars on Figure D-4) and within the 40 -mile PHEV safe range. $8 \%$ of the vehicle travel days exceed this BEV range.

The longest single outing and daily travel of 78 miles occurred on March 19 for a round trip to SEATAC airport. That outing took 3.4 hours of driving but the vehicle was away from home base all day.

These data indicate that choosing a BEV for this duty may require intermediate charging stations opportunities at either the home base or a frequent intermediate stop. Yet, some travel days did not allow sufficient recharge opportunities or sufficient recharge time. Thus, a PHEV is required for the days that involve extended trips. A combination of BEVs and PHEVs may be desirable for this fleet. 
Vehicle G11-0678K

\begin{tabular}{|c|c|c|}
\hline \multirow{3}{*}{$\frac{\pi}{6}-\frac{2}{6}$} & Make/Model/Year & Chevrolet/Impala/2010 \\
\hline & EPA Class Size & Large Sedan \\
\hline & Mission & Support \\
\hline \multirow{8}{*}{ www.edmunds.com } & Contact & C. Sallinger/Motor Transport \\
\hline & Parking Location & Bldg $100 / 2^{\text {nd }}$ St NW \\
\hline & Fleet Vehicle ID & G11-0678K \\
\hline & Fuel Type & Gas/ETH \\
\hline & EPA Label/MPG (City/Hwy/Combined)* & $18 / 29 / 22 \quad 14 / 22 / 17$ \\
\hline & EPA GHG Emissions (Grams $\left.\mathrm{CO}_{2} / \mathrm{Mi}\right)^{*}$ & $404 / 370$ \\
\hline & Study Logger ID & Logger 13 \\
\hline & Total Vehicle Days/Total Study Days & $39 / 63$ \\
\hline
\end{tabular}

\begin{tabular}{|l|c|c|c|c|}
\hline \multicolumn{5}{|c|}{ Vehicle G11-0678K Travel Summary } \\
\hline & $\begin{array}{c}\text { Per Day } \\
\text { Average/Peak }\end{array}$ & $\begin{array}{c}\text { Per Outing } \\
\text { Average/Peak }\end{array}$ & $\begin{array}{c}\text { Per Trip } \\
\text { Average/Peak }\end{array}$ & Total \\
\hline Travel Distance (Miles) & $18.3 / 40.1$ & $9.0 / 33.4$ & $4.2 / 19$ & 713 \\
\hline Travel Time (Minutes) & $57 / 208$ & $28.3 / 394$ & $13.3 / 206$ & 2,232 \\
\hline Idle Time (Minutes) & $15.9 / \mathrm{NA}$ & $7.9 / \mathrm{NA}$ & $3.7 / \mathrm{NA}$ & 621 \\
\hline
\end{tabular}

\begin{tabular}{|c|c|c|c|c|}
\hline \multicolumn{2}{|c|}{ Total Stops } & \multicolumn{2}{c|}{ Stop Duration } \\
\hline $\begin{array}{c}\text { Distance From } \\
\text { Home Base (Miles) }\end{array}$ & Stops & Percentages & Stop Duration (Hours) & Stops \\
\hline Less than 10 & 175 & $100 \%$ & Less than 2 & 124 \\
\hline 10 to 20 & 0 & $0 \%$ & 2 to 4 & 14 \\
\hline 20 to 40 & 0 & $0 \%$ & 4 to 8 & 1 \\
\hline 40 to 60 & 0 & $0 \%$ & Greater than 8 & 36 \\
\hline
\end{tabular}

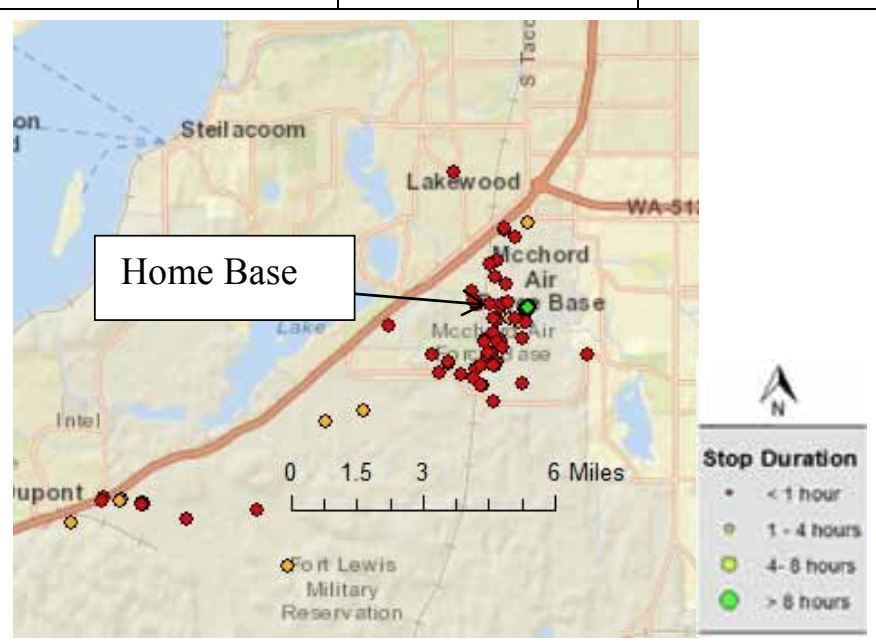

Figure E-22. Vehicle G11-0678K stops.

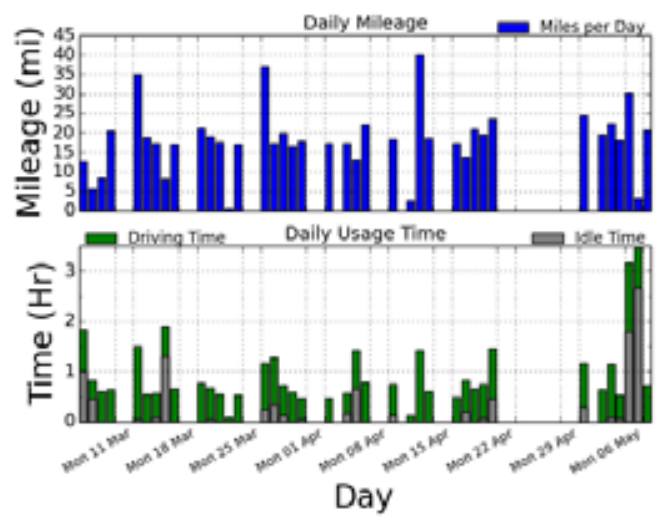

Figure E-23. Vehicle G11-0678K history. 


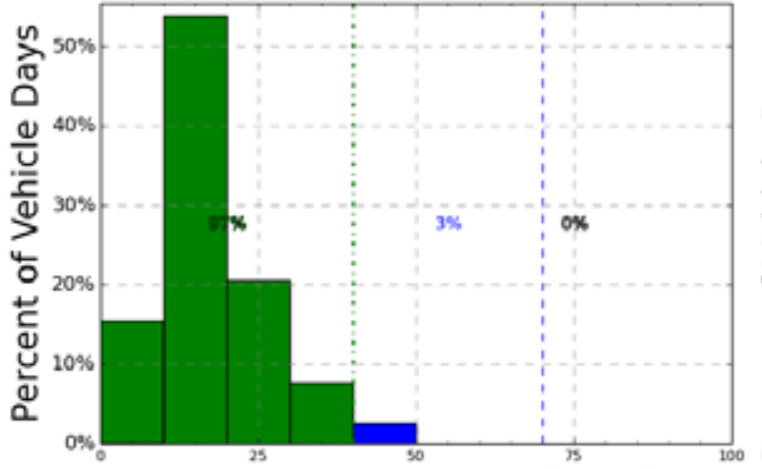

Daily Travel Distance (miles)

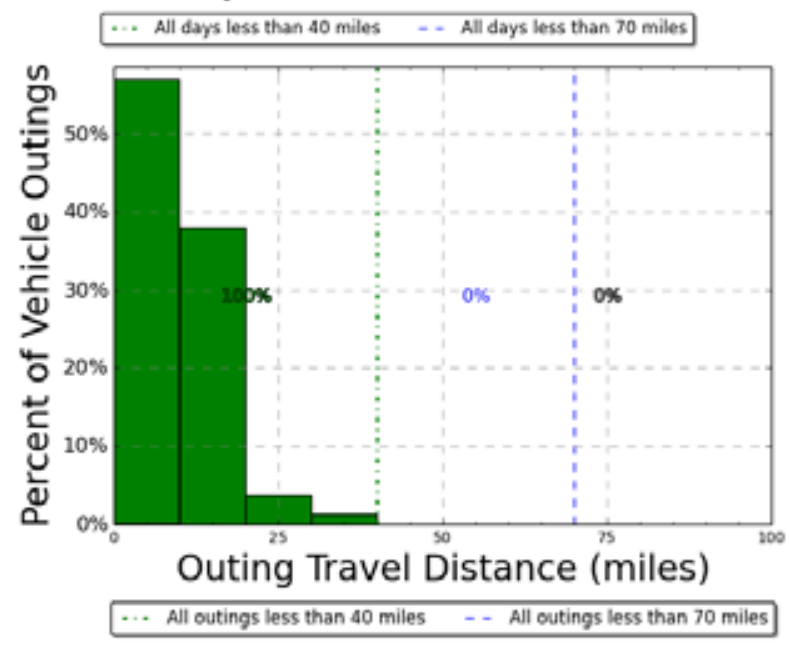

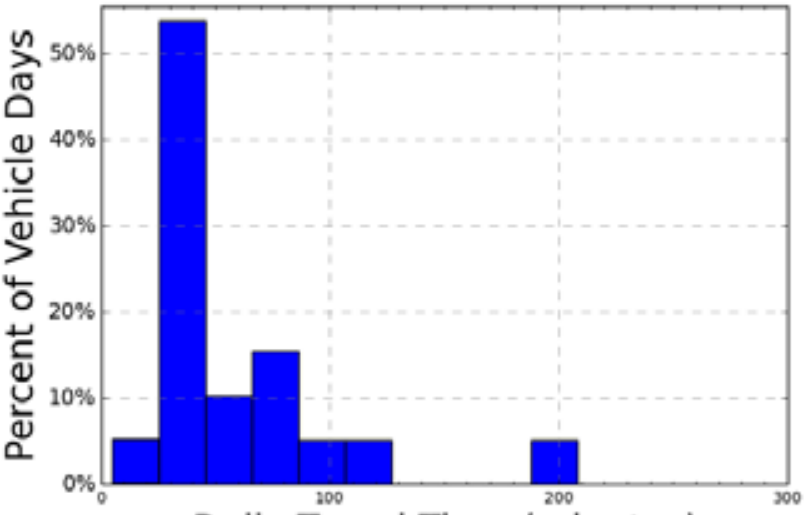

Daily Travel Time (minutes) Number of Trips by Hour of Day

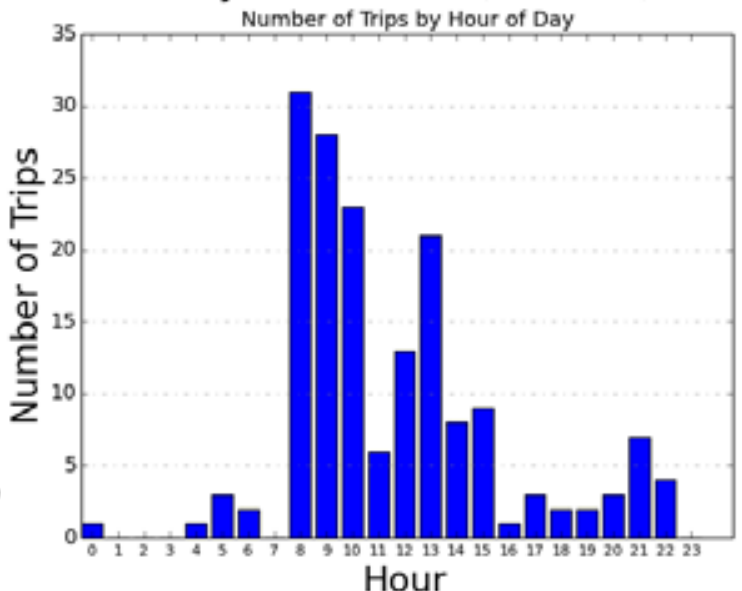

Figure E-38. Vehicle G11-0678K travel graphs.

\section{Vehicle G11-0678K Observations}

Logger 13 collected data on this vehicle for a period of 39 days of the 63-day study period. Validation occurred on $98.8 \%$ of the input data. Survey information was not available for this vehicle. Stop data suggests it typically parks near Bldg 100 on $2^{\text {nd }}$ St NW. Site data reports an odometer reading of 3,078 in May 2012 with an average of 139 miles per month.

All trips and outings were less than 70 miles and thus, were within the typically advertised range of a BEV of approximately 70 miles. The longest day's travel was 40.1 miles that was also within the BEV range. The longest single outing was 33.4 miles which is also well within the BEV range. Based upon travel alone, a BEV could be a suitable replacement.

This is a large sedan and BEVs are available for replacement. The BEV would be expected to provide the acceptable performance of this vehicle. 


\section{Vehicle G62-4526H}

\begin{tabular}{|l|l|c|}
\hline & Make/Model/Year & Chevrolet/Tahoe/2009 \\
\cline { 1 - 2 } & EPA Class Size & Sports Utility Vehicle \\
\cline { 2 - 3 } & Mission & Support \\
\cline { 2 - 3 } & Contact & C. Sallinger/Motor Transport \\
\cline { 2 - 3 } & Parking Location & G62-4526H \\
\cline { 2 - 3 } & Fleet Vehicle ID & Gas/ETH \\
\cline { 2 - 3 } & Fuel Type & $14 / 20 / 16 ~ 10 / 15 / 12$ \\
\cline { 2 - 3 } & EPA Label/MPG (City/Hwy/Combined)* & $555 / 525$ \\
\cline { 2 - 3 } & EPA GHG Emissions (Grams CO $\left.\mathrm{CO}_{2} / \mathrm{Mi}\right)^{*}$ & Logger 14 \\
\cline { 2 - 3 } & Study Logger ID & $41 / 63$ \\
\cline { 2 - 3 } & Total Vehicle Days/Total Study Days & Dve \\
\hline
\end{tabular}

\begin{tabular}{|l|c|c|c|c|}
\hline \multicolumn{5}{|c|}{ Vehicle G62-4526H Travel Summary } \\
\hline & $\begin{array}{c}\text { Per Day } \\
\text { Average/Peak }\end{array}$ & $\begin{array}{c}\text { Per Outing } \\
\text { Average/Peak }\end{array}$ & $\begin{array}{c}\text { Per Trip } \\
\text { Average/Peak }\end{array}$ & Total \\
\hline Travel Distance (Miles) & $26.3 / 133.2$ & $11.5 / 69.5$ & $4.1 / 30.9$ & 1,078 \\
\hline Travel Time (Minutes) & $109 / 571$ & $47.4 / 281$ & $17.1 / 165$ & 4,454 \\
\hline Idle Time (Minutes) & $29.7 / \mathrm{NA}$ & $13.0 / \mathrm{NA}$ & $4.7 / \mathrm{NA}$ & 1,218 \\
\hline
\end{tabular}

\begin{tabular}{|c|c|c|c|c|}
\hline \multicolumn{2}{|c|}{ Total Stops } & \multicolumn{2}{c|}{ Stop Duration } \\
\hline $\begin{array}{c}\text { Distance From } \\
\text { Home Base (Miles) }\end{array}$ & Stops & Percentages & Stop Duration (Hours) & Stops \\
\hline Less than 10 & 279 & $100 \%$ & Less than 2 & 220 \\
\hline 10 to 20 & 0 & $0 \%$ & 2 to 4 & 9 \\
\hline 20 to 40 & 0 & $0 \%$ & 4 to 8 & 17 \\
\hline 40 to 60 & 0 & $0 \%$ & Greater than 8 & 32 \\
\hline
\end{tabular}

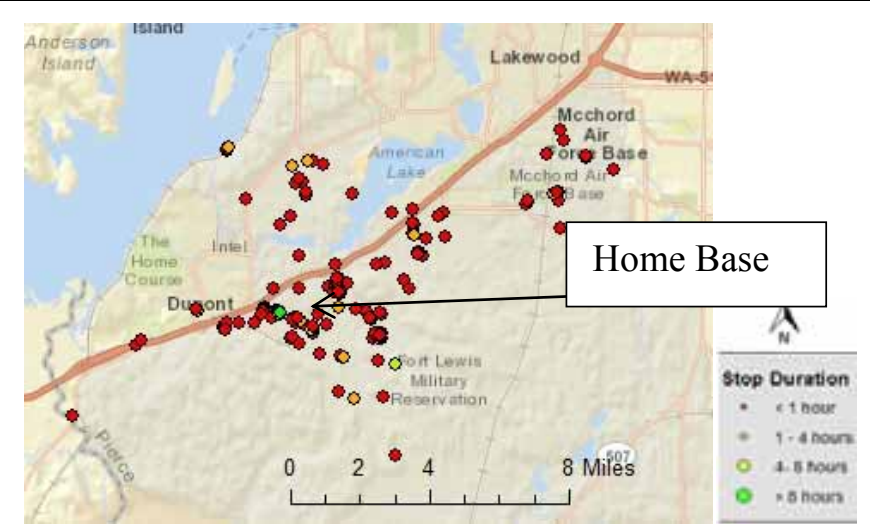

Figure E-25. Vehicle G62-4526H stops.

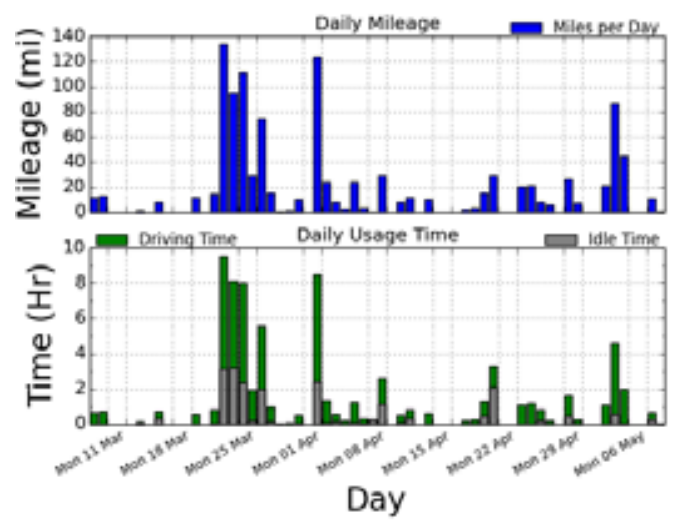

Figure E-26. Vehicle G62-4526H history. 

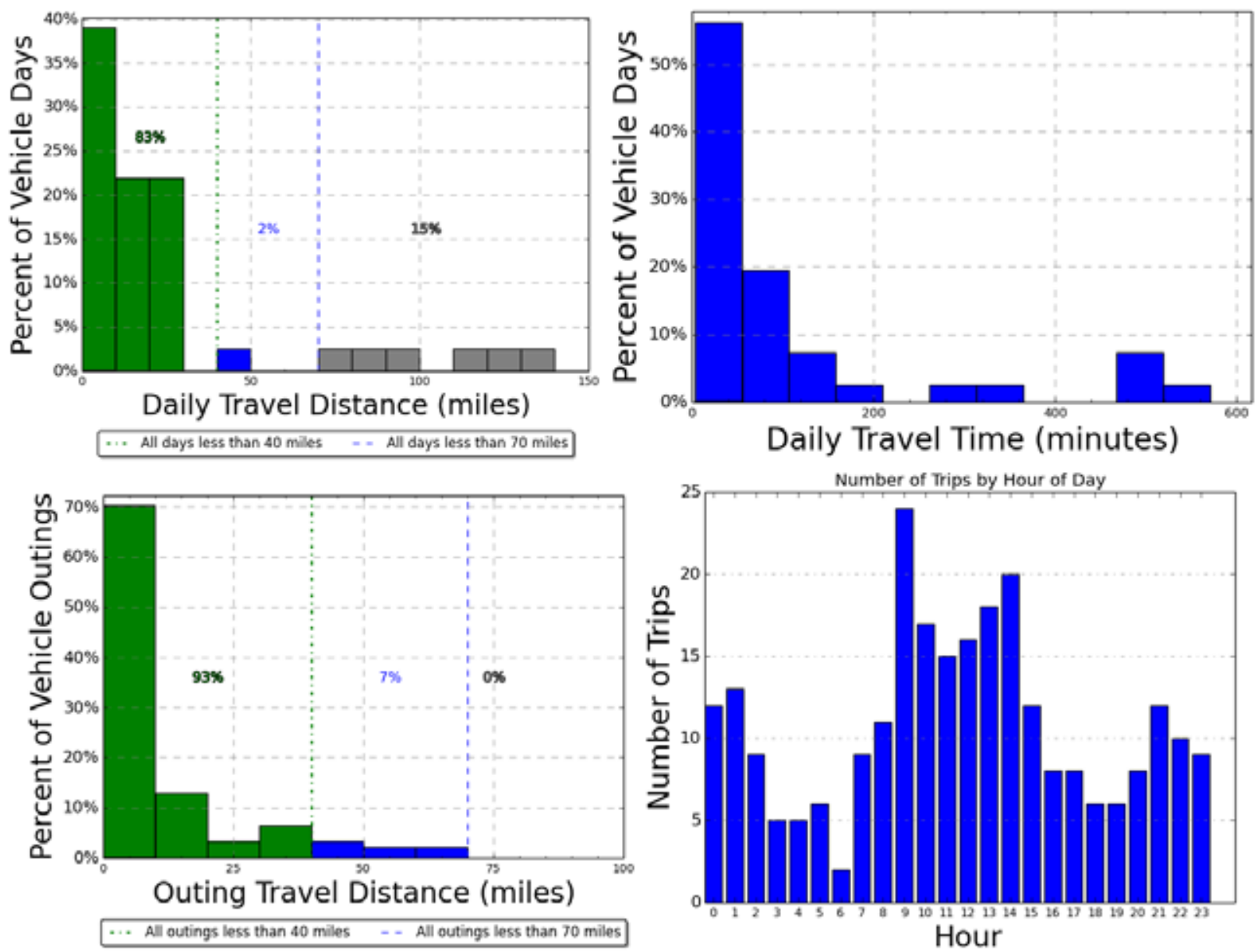

Figure E-39. Vehicle G62-4526H travel graphs.

\section{Vehicle G62-4526H Observations}

Logger 14 collected data on this vehicle for a period of 41 days of the 63-day study period. Validation occurred on $83.3 \%$ of the input data. Survey information was not available for this vehicle. Stop data suggests it typically parks near Bldg 2007 on Pendleton Ave. Site data reports an odometer reading of 34,934 in May 2012 with an average of 1027 miles per month.

The longest travel day of 133.2 miles occurred on March 21 and consisted of five outings; the longest of which was 69.5 miles. There was insufficient time between this outing and the previous outing of 22.5 miles for any recharge.

Eighty-five percent of all vehicle travel days were within the 70-mile BEV safe range (green and blue bars on Figure E-27) and essentially all outings are within this range, and $15 \%$ of daily travel is beyond the range capabilities of a BEV.

These data indicate that choosing a BEV for this duty may require intermediate charging stations opportunities at either the home base or a frequent intermediate stop. Yet, some travel days did not allow sufficient recharge opportunities or sufficient recharge time. Thus, a PHEV is required for the days that involve extended trips. A combination of BEVs and PHEVs may be desirable for this fleet. 


\begin{tabular}{|l|l|c|}
\hline \multirow{4}{*}{ www.edmunds.com } & Make/Model/Year & Chevrolet/C1500/2011 \\
\cline { 1 - 2 } & EPA Class Size & Standard Pickup Truck \\
\cline { 2 - 3 } & Mission & Support \\
\cline { 2 - 3 } & Contact & J. Lamantia/Motor Transport \\
\cline { 2 - 3 } & Parking Location & G42-0698K \\
\cline { 2 - 3 } & Fleet Vehicle ID & Gas/ETH \\
\cline { 2 - 3 } & Fuel Type & $15 / 21 / 1711 / 16 / 13$ \\
\cline { 2 - 3 } & EPA Label/MPG (City/Hwy/Combined)* & $523 / 484$ \\
\cline { 2 - 3 } & EPA GHG Emissions (Grams $\left.\mathrm{CO}_{2} / \mathrm{Mi}\right)^{*}$ & Logger 15 \\
\cline { 2 - 3 } & Study Logger ID & $58 / 63$ \\
\cline { 2 - 3 } & Total Vehicle Days/Total Study Days & Namp \\
\hline
\end{tabular}

\begin{tabular}{|l|c|c|c|c|}
\hline \multicolumn{5}{|c|}{ Vehicle G42-0698K Travel Summary } \\
\hline & $\begin{array}{c}\text { Per Day } \\
\text { Average/Peak }\end{array}$ & $\begin{array}{c}\text { Per Outing } \\
\text { Average/Peak }\end{array}$ & $\begin{array}{c}\text { Per Trip } \\
\text { Average/Peak }\end{array}$ & Total \\
\hline Travel Distance (Miles) & $68.8 / 119.2$ & $10.4 / 71.5$ & $4.7 / 46.4$ & 3,989 \\
\hline Travel Time (Minutes) & $933 / 1,502$ & $141.2 / 1,029$ & $63.6 / 512$ & 54,095 \\
\hline Idle Time (Minutes) & $72.9 / \mathrm{NA}$ & $11.0 / \mathrm{NA}$ & $5.0 / \mathrm{NA}$ & 4,229 \\
\hline
\end{tabular}

\begin{tabular}{|c|c|c|c|c|}
\hline \multicolumn{2}{|c|}{ Total Stops } & \multicolumn{2}{c|}{ Stop Duration } \\
\hline $\begin{array}{c}\text { Distance From } \\
\text { Home Base (Miles) }\end{array}$ & Stops & Percentages & Stop Duration (Hours) & Stops \\
\hline Less than 10 & 2495 & $100 \%$ & Less than 2 & 2,413 \\
\hline 10 to 20 & 0 & $0 \%$ & 2 to 4 & 74 \\
\hline 20 to 40 & 0 & $0 \%$ & 4 to 8 & 8 \\
\hline 40 to 60 & 0 & $0 \%$ & Greater than 8 & 0 \\
\hline
\end{tabular}

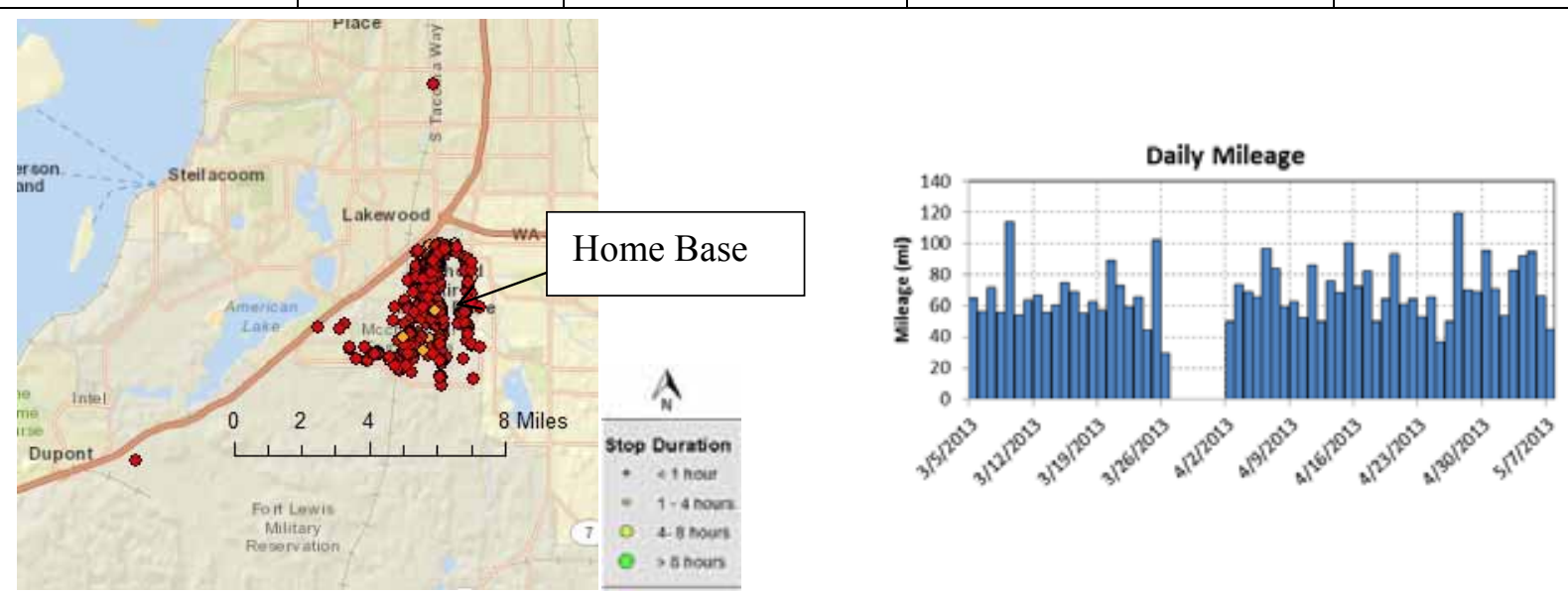

Figure E-28. Vehicle G42-0698K stops.

Figure E-29. Vehicle G42-0698K history. 

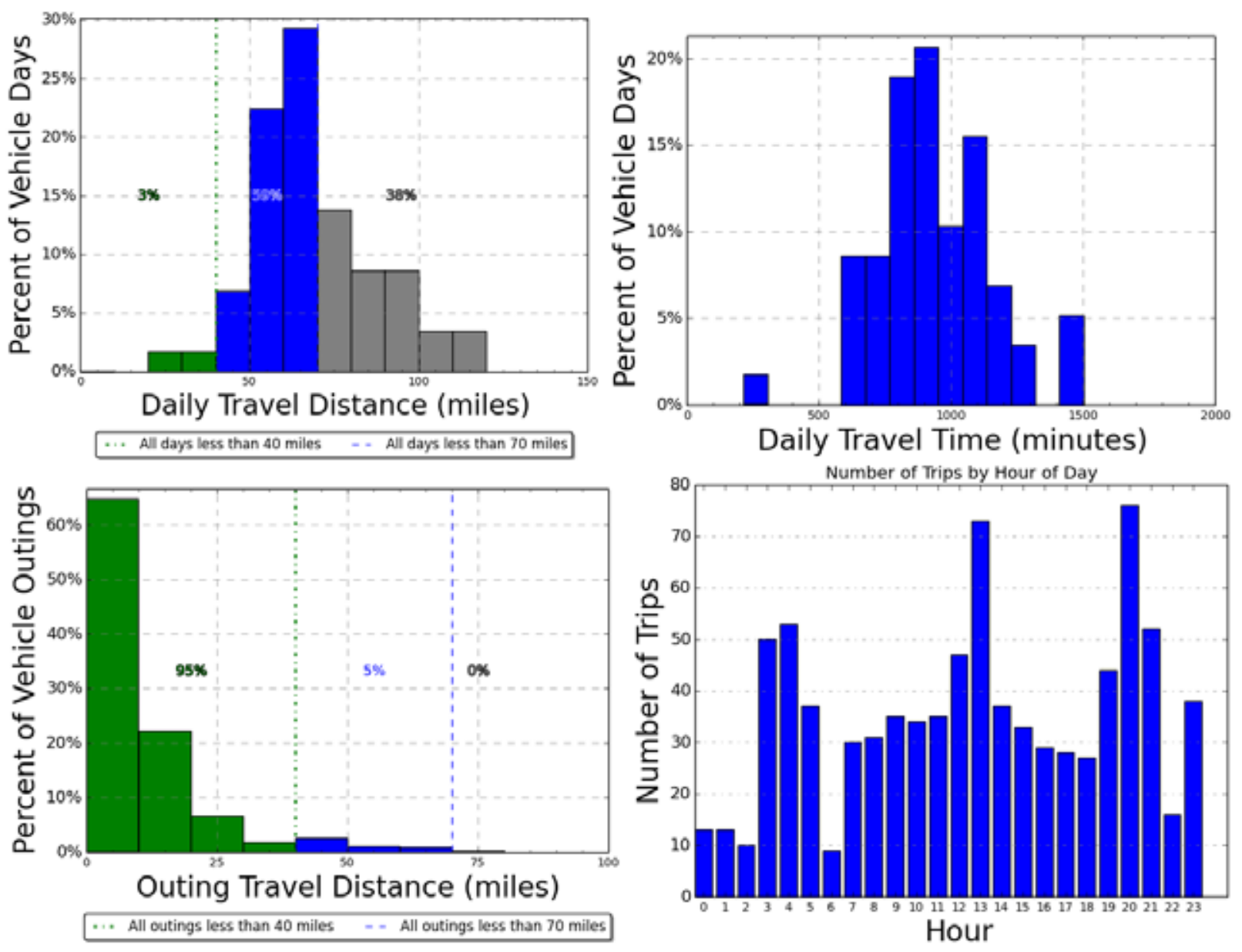

Figure E-40. Vehicle G42-0698K travel graphs.

\section{Vehicle G42-0698K Observations}

Logger 15 collected data on this vehicle for a period of 58 days of the 63-day study period. Validation occurred on $95.1 \%$ of the input data. Survey information was not available for this vehicle. Stop data suggests it typically parks near D Ramp on $2^{\text {nd }}$ St NW and McCarthy Blvd. Site data reports an odometer reading of 18,097 in May 2012 with an average of 1046 miles per month.

The data shows extensive usage with usage possible at all hours of the day with most vehicle travel characterized typically by very short trips (average of 4.7 miles). It operated all but 5 days of the 63-day study period. During the study period, the vehicle traveled a total distance of 3,989 miles over 900 hours. Sixty-two percent of all vehicle travel days were within the 70-mile BEV safe range (green and blue bars on Figure E-30), while all the outings were within this range, and $38 \%$ of the vehicle travel days exceed this BEV range capability.

Logger 15 data was inconsistent in reporting idle times. Idle time was corrected but total idle and travel time was not included in the history graphs.

While travel data might suggest a BEV could replace this vehicle for most trips, the high usage suggests a PHEV is more suitable assuming that it can accommodate any other vehicle requirements such as carrying capacity. 
Vehicle G11-0493L

\begin{tabular}{|c|c|c|}
\hline \multirow{3}{*}{$8-8,4$} & Make/Model/Year & Chevrolet/Impala/2012 \\
\hline & EPA Class Size & Large Sedan \\
\hline & Mission & Support \\
\hline \multirow[t]{8}{*}{ www.edmunds.com } & Contact & C. Sallinger/Motor Transport \\
\hline & Parking Location & Bldg 2007/Pendleton Ave \\
\hline & Fleet Vehicle ID & G11-0493L \\
\hline & Fuel Type & Gas/ETH \\
\hline & EPA Label/MPG (City/Hwy/Combined)* & $18 / 30 / 22 \quad 13 / 22 / 16$ \\
\hline & EPA GHG Emissions (Grams $\left.\mathrm{CO}_{2} / \mathrm{Mi}\right)^{*}$ & $404 / 393$ \\
\hline & Study Logger ID & Logger 16 \\
\hline & Total Vehicle Days/Total Study Days & $55 / 63$ \\
\hline
\end{tabular}

\begin{tabular}{|l|c|c|c|c|}
\hline \multicolumn{5}{|c|}{ Vehicle G11-0493L Travel Summary } \\
\hline & $\begin{array}{c}\text { Per Day } \\
\text { Average/Peak }\end{array}$ & $\begin{array}{c}\text { Per Outing } \\
\text { Average/Peak }\end{array}$ & $\begin{array}{c}\text { Per Trip } \\
\text { Average/Peak }\end{array}$ & Total \\
\hline Travel Distance (Miles) & $65.3 / 130.3$ & $14.0 / 236.8$ & $7.0 / 67.3$ & 3,591 \\
\hline Travel Time (Minutes) & $476 / 1,333$ & $102.3 / 1,440$ & $50.8 / 466$ & 26,180 \\
\hline Idle Time (Minutes) & $268.7 / \mathrm{NA}$ & $57.7 / \mathrm{NA}$ & $27.7 / \mathrm{NA}$ & 14,777 \\
\hline
\end{tabular}

\begin{tabular}{|c|c|c|c|c|}
\hline \multicolumn{2}{|c|}{ Total Stops } & \multicolumn{2}{c|}{ Stop Duration } \\
\hline $\begin{array}{c}\text { Distance From } \\
\text { Home Base (Miles) }\end{array}$ & Stops & Percentages & Stop Duration (Hours) & Stops \\
\hline Less than 10 & 1,009 & $100 \%$ & Less than 2 & 921 \\
\hline 10 to 20 & 0 & $0 \%$ & 2 to 4 & 27 \\
\hline 20 to 40 & 0 & $0 \%$ & 4 to 8 & 19 \\
\hline 40 to 60 & 0 & $0 \%$ & Greater than 8 & 42 \\
\hline
\end{tabular}

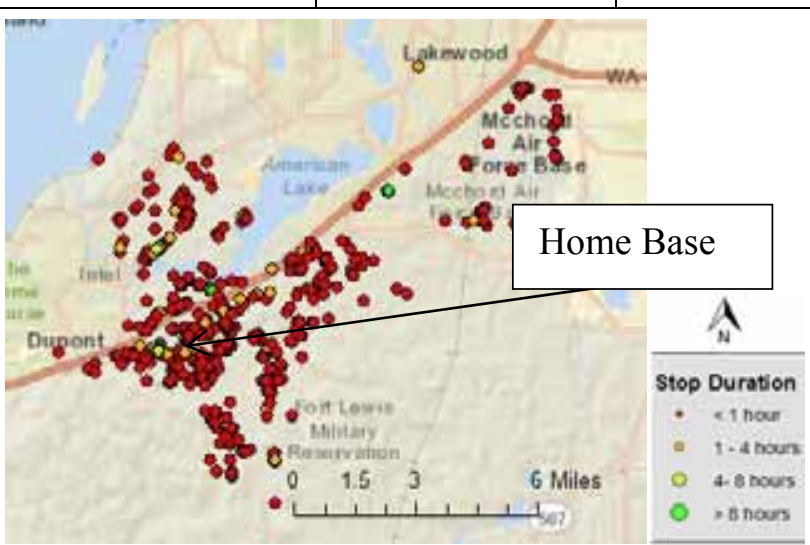

Figure E-31. Vehicle G11-0493L stops.

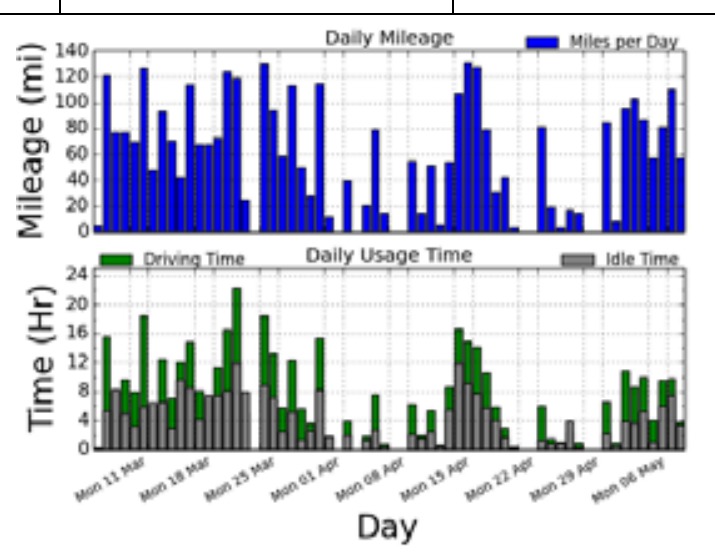

Figure E-32. Vehicle G11-0493L history. 

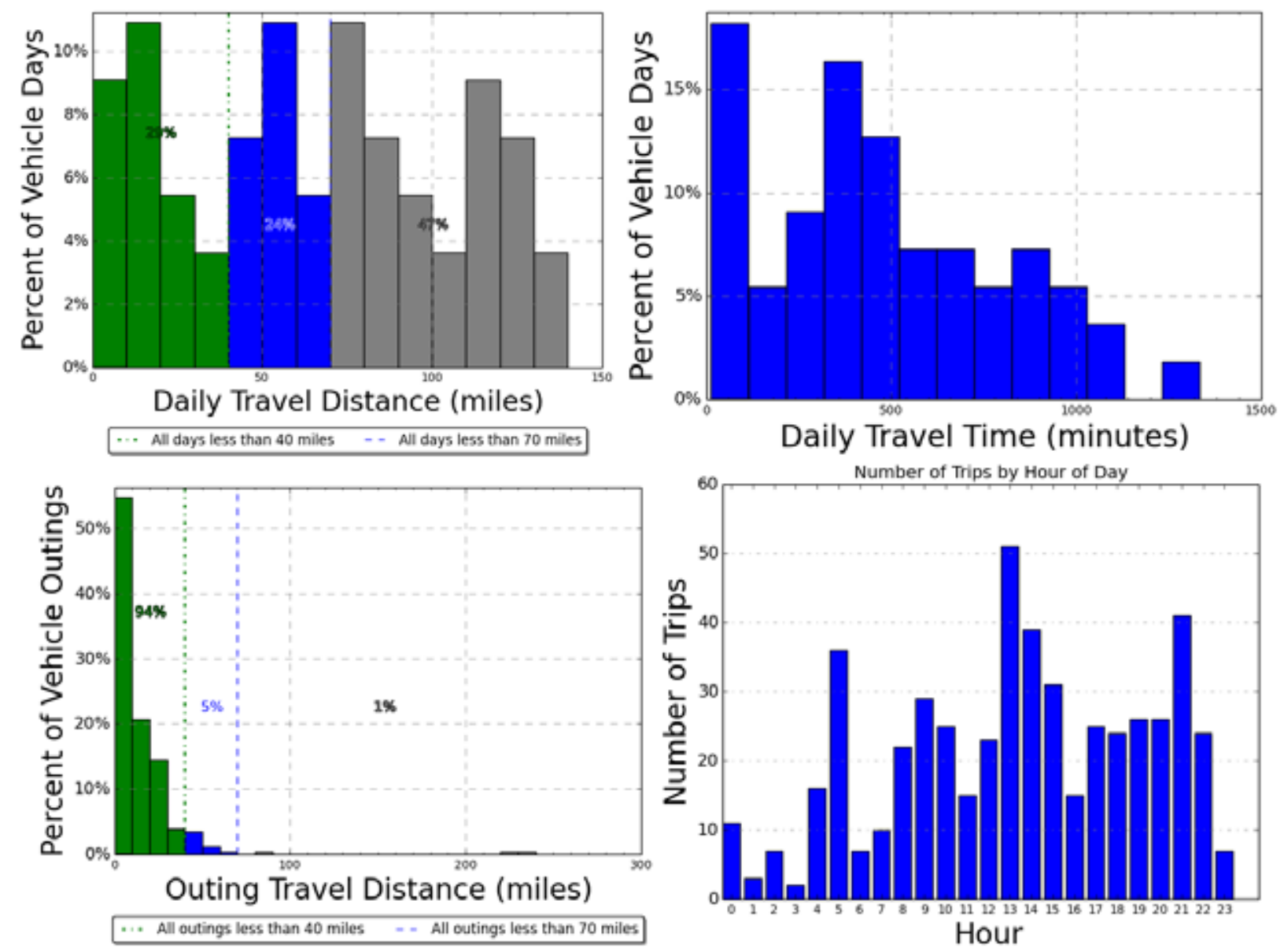

Figure E-41. Vehicle G11-0493L travel graphs.

\section{Vehicle G11-0493L Observations}

Logger 16 collected data on this vehicle for a period of 55 days of the 63-day study period. Validation occurred on $95.3 \%$ of the input data. Survey information was not available for this vehicle. Stop data suggests it typically parks near Bldg 2007 on Pendleton Ave. Site data reports an odometer reading of 4,330 in May 2012 with an average of 614 miles per month.

The data shows extensive usage with usage possible at all hours of the day. It operated all but 8 days of the 63-day study period. During the study period, the vehicle traveled a total distance of 3,591 miles over 436 hours. However, this vehicle also shows extensive idle times with almost 250 hours spent idling. Fifty-three percent of all vehicle travel days were within the 70-mile BEV safe range (green and blue bars on Figure E-33), while all the outings but one were within this range, and $47 \%$ of the vehicle travel days exceed this BEV range capability.

The vehicle travel is characterized typically by short trips (average of 7 miles) requiring 50 minutes but more than half that time is idle (27.7 minutes each).

While travel data might suggest a BEV could replace this vehicle for most trips, the high usage suggests a PHEV is more suitable assuming that it can accommodate any other vehicle requirements such as carrying capacity. 


\begin{tabular}{|c|c|c|c|c|}
\hline 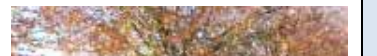 & \multicolumn{2}{|l|}{ Make/Model/Year } & \multicolumn{2}{|c|}{ Ford/F750/2008 } \\
\hline 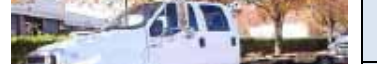 & \multicolumn{2}{|l|}{ EPA Class Size } & \multicolumn{2}{|c|}{ Stake Truck } \\
\hline $5405 x-10$ & \multicolumn{2}{|l|}{ Mission } & \multicolumn{2}{|c|}{ Transport } \\
\hline $2 \frac{1}{2}, x=203$ & \multicolumn{2}{|l|}{ Contact } & \multicolumn{2}{|c|}{ C. Sallinger/Motor Transport } \\
\hline \multirow{7}{*}{$\begin{array}{l}\text { www. } \\
\text { commercialtrucktrader.com }\end{array}$} & \multicolumn{2}{|l|}{ Parking Location } & \multicolumn{2}{|c|}{ Bldg R9641 } \\
\hline & \multicolumn{2}{|l|}{ Fleet Vehicle ID } & \multicolumn{2}{|c|}{ G71-0062G } \\
\hline & \multicolumn{2}{|l|}{ Fuel Type } & \multicolumn{2}{|c|}{ Diesel } \\
\hline & \multicolumn{2}{|c|}{ EPA Label/MPG (City/Hwy/Combined)* } & \multicolumn{2}{|c|}{ Not available } \\
\hline & \multicolumn{2}{|c|}{ EPA GHG Emissions (Grams $\left.\mathrm{CO}_{2} / \mathrm{Mi}\right)^{*}$} & \multicolumn{2}{|c|}{ Not available } \\
\hline & \multicolumn{2}{|l|}{ Study Logger ID } & \multicolumn{2}{|c|}{ Logger 17} \\
\hline & \multicolumn{2}{|c|}{ Total Vehicle Days/Total Study Days } & \multicolumn{2}{|c|}{ No data } \\
\hline \multicolumn{5}{|c|}{ Vehicle G71-0062G Travel Summary } \\
\hline & $\begin{array}{c}\text { Per Day } \\
\text { Average/Peak }\end{array}$ & $\begin{array}{c}\text { Per Outing } \\
\text { Average/Peak }\end{array}$ & $\begin{array}{c}\text { Per Trip } \\
\text { Average/Peak }\end{array}$ & Total \\
\hline Travel Distance (Miles) & No Data & No Data & No Data & No Data \\
\hline Travel Time (Minutes) & No Data & No Data & No Data & No Data \\
\hline Idle Time (Minutes) & No Data & No Data & No Data & No Data \\
\hline
\end{tabular}

\begin{tabular}{|c|c|c|c|c|}
\hline \multicolumn{2}{|c|}{ Total Stops } & \multicolumn{2}{c|}{ Stop Duration } \\
\hline $\begin{array}{c}\text { Distance From } \\
\text { Home Base (Miles) }\end{array}$ & Stops & Percentages & Stop Duration (Hours) & Stops \\
\hline Less than 10 & No Data & No Data & Less than 2 & No Data \\
\hline 10 to 20 & No Data & No Data & 2 to 4 & No Data \\
\hline 20 to 40 & No Data & No Data & 4 to 8 & No Data \\
\hline 40 to 60 & No Data & No Data & Greater than 8 & No Data \\
\hline
\end{tabular}

\section{Vehicle G71-0062G Observations}

Survey information was not available for this vehicle. For unknown reasons, Logger 17 transmitted no information other than a single entry. Site data reports an odometer reading of 7,871 in May 2012 with an average of 159 miles per month. No further information is available.

This is a heavy-duty stake truck. No PEV is currently available as a replacement for this vehicle. 
Vehicle G62-1094L

\begin{tabular}{|c|c|c|}
\hline \multirow{3}{*}{$\frac{1}{3-b-1}$} & Make/Model/Year & Chevrolet/Avalanche/2011 \\
\hline & EPA Class Size & Sports Utility Vehicle \\
\hline & Mission & Support \\
\hline \multirow[t]{8}{*}{ www.edmunds.com } & Contact & C. Sallinger/Motor Transport \\
\hline & Parking Location & Bldg 4074/Kaufman Ave \\
\hline & Fleet Vehicle ID & G62-1094L \\
\hline & Fuel Type & $\mathrm{Gas} / \mathrm{ETH}$ \\
\hline & EPA Label/MPG (City/Hwy/Combined)* & $15 / 21 / 17 \quad 11 / 16 / 13$ \\
\hline & EPA GHG Emissions (Grams $\left.\mathrm{CO}_{2} / \mathrm{Mi}\right)^{*}$ & $523 / 484$ \\
\hline & Study Logger ID & Logger 18 \\
\hline & Total Vehicle Days/Total Study Days & $30 / 63$ \\
\hline
\end{tabular}

\begin{tabular}{|l|c|c|c|c|}
\hline \multicolumn{5}{|c|}{ Vehicle G62-1094L travel Summary } \\
\hline & $\begin{array}{c}\text { Per Day } \\
\text { Average/Peak }\end{array}$ & $\begin{array}{c}\text { Per Outing } \\
\text { Average/Peak }\end{array}$ & $\begin{array}{c}\text { Per Trip } \\
\text { Average/Peak }\end{array}$ & Total \\
\hline Travel Distance (Miles) & $18.6 / 93.6$ & $15.1 / 91.3$ & $5.2 / 42.5$ & 559 \\
\hline Travel Time (Minutes) & $48 / 264$ & $38.9 / 259$ & $13.3 / 94$ & 1,438 \\
\hline Idle Time (Minutes) & $6.3 / \mathrm{NA}$ & $5.1 / \mathrm{NA}$ & $1.8 / \mathrm{NA}$ & 190 \\
\hline
\end{tabular}

\begin{tabular}{|c|c|c|c|c|}
\hline \multicolumn{2}{|c|}{ Total Stops } & \multicolumn{2}{c|}{ Stop Duration } \\
\hline $\begin{array}{c}\text { Distance From } \\
\text { Home Base (Miles) }\end{array}$ & Stops & Percentages & Stop Duration (Hours) & Stops \\
\hline Less than 10 & 90 & $95.7 \%$ & Less than 2 & 59 \\
\hline 10 to 20 & 4 & $4.3 \%$ & 2 to 4 & 4 \\
\hline 20 to 40 & 0 & $0 \%$ & 4 to 8 & 2 \\
\hline 40 to 60 & 0 & $0 \%$ & Greater than 8 & 29 \\
\hline
\end{tabular}

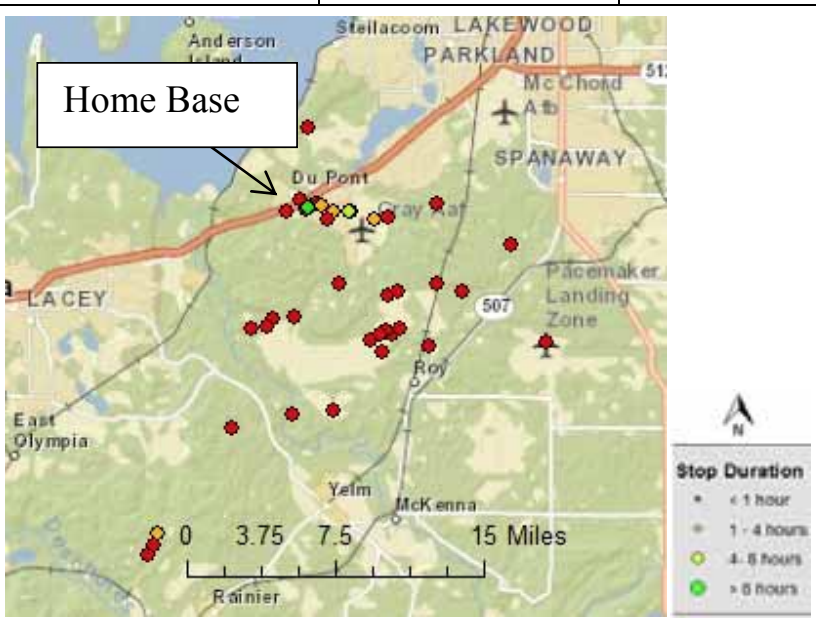

Figure E-34. Vehicle G62-1094L stops.

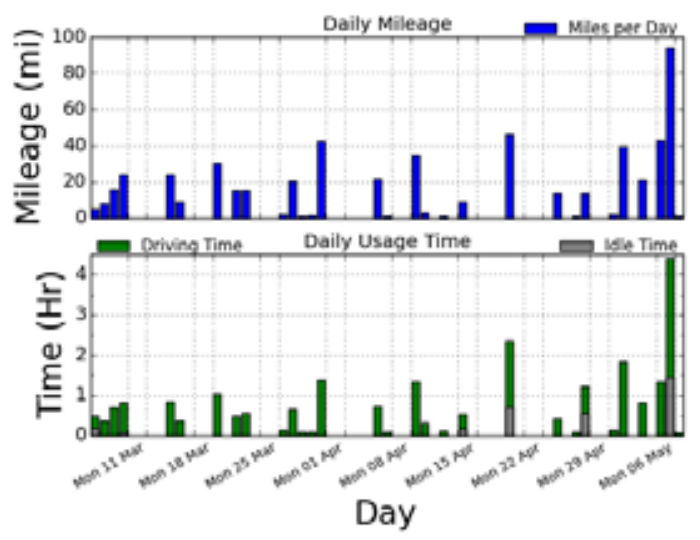

Figure E-35. Vehicle G62-1094L history. 

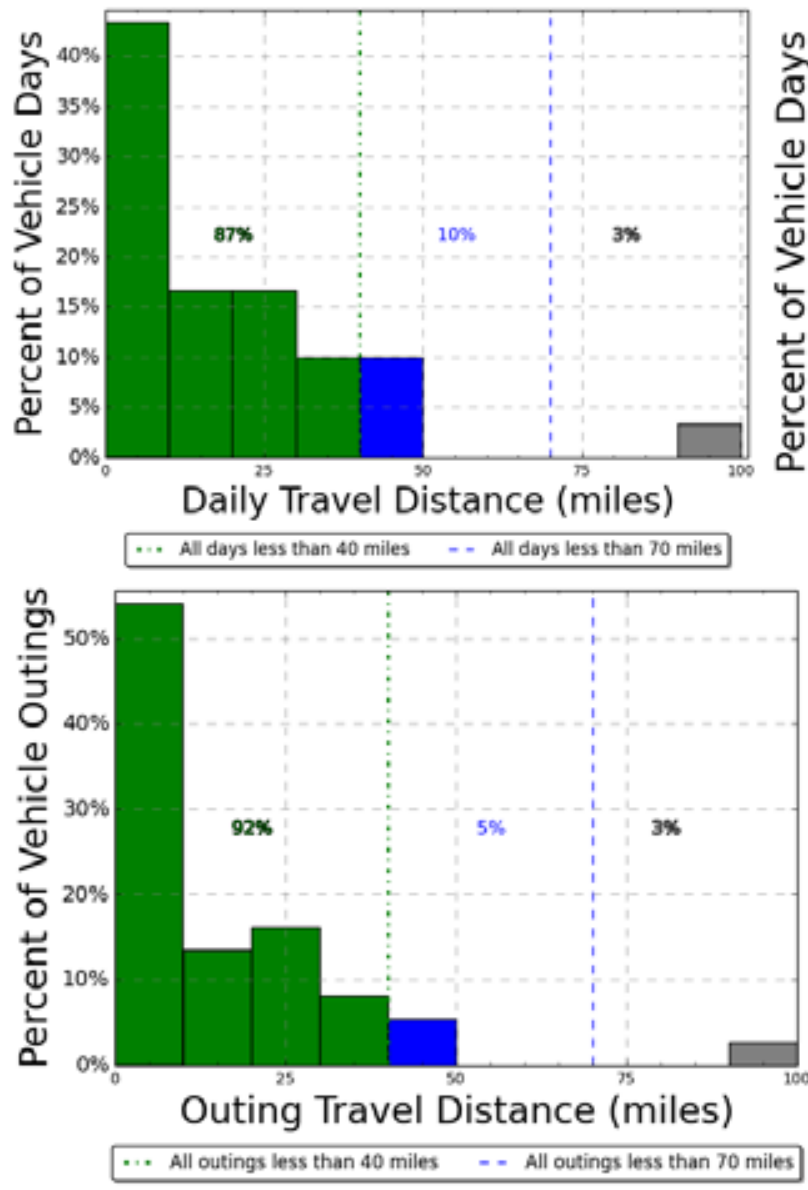

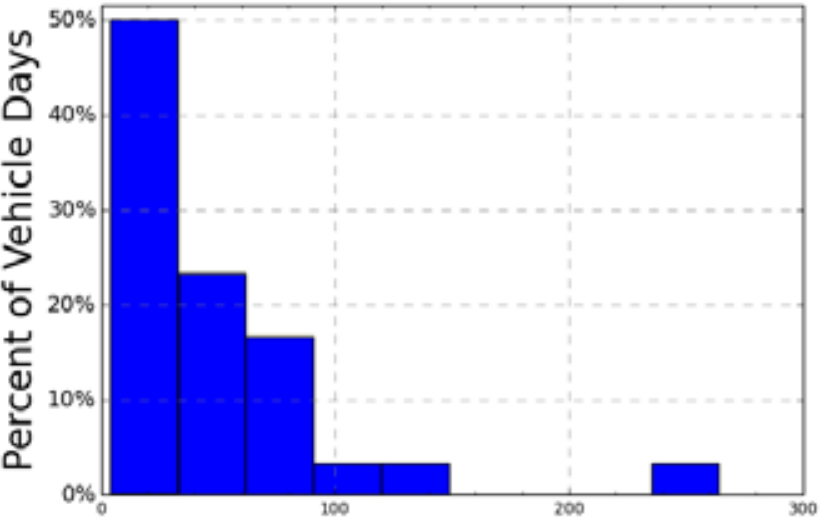

Daily Travel Time (minutes)

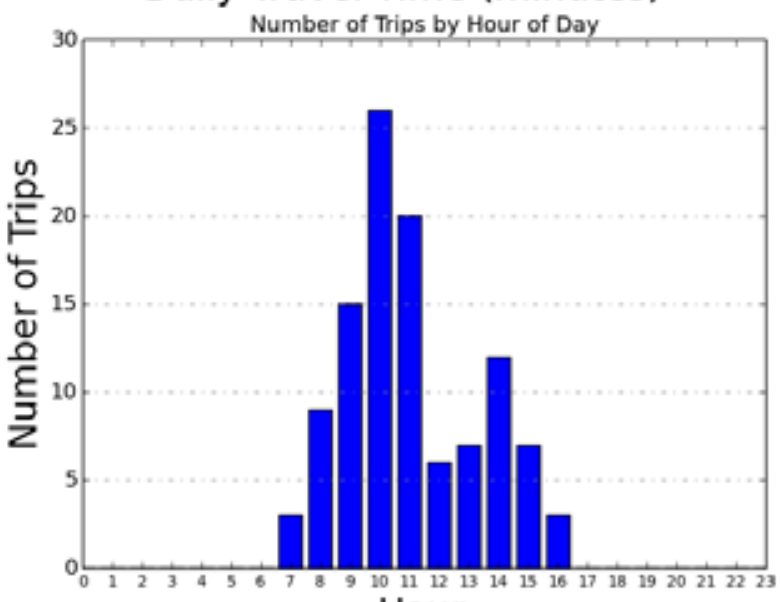

Hour

Figure E-42. Vehicle G62-1094L travel graphs.

\section{Vehicle G62-1094L Observations}

Logger 16 collected data on this vehicle for a period of 30 days of the 63-day study period. Validation occurred on $95.9 \%$ of the input data. The project survey response reports the Range Control Officer uses this vehicle to inspect ranges, visit units training in the range complex, and conducting VIP tours. It is accessible to between six and ten persons. It occasionally travels off base. While it typically operates during daytime hours, its availability at other times is necessary because Range Control is open and active 24 hours a day. It typically carries no particular cargo or equipment. It parks in the pool parking area near Bldg 4074.

Site data reports an odometer reading of 8,115 in May 2012 with an average of 624 miles per month. While the monthly mileage is not high, Motor Transport reports this vehicle has off road requirements. The expected retention of this vehicle is unknown.

Ninety-seven percent of all vehicle travel days were within the 70 -mile BEV safe range (green and blue bars on Figure E-36) and 97\% of all outings were within this range. One trip (3\%) of the vehicle travel days exceeded this range. The longest single outing of 91.3 miles occurred on May 5 th that was also the day with the longest daily travel involving a trip to Olympia and Olympia East. That outing took approximately 5 hours of the whole day.

These data indicate that choosing a BEV for this duty may require intermediate charging stations opportunities at either the home base or a frequent intermediate stop. Yet, the one travel day did not allow sufficient recharge opportunities. Thus, a PHEV is required for the days that involve extended trips. A combination of BEVs and PHEVs may be desirable for this fleet. 
Vehicle G41-1395G

\begin{tabular}{|l|l|c|}
\hline \multirow{4}{*}{ www.edmunds.com } & Make/Model/Year & Chevrolet/Uplander/2008 \\
\cline { 2 - 3 } & EPA Class Size & Minivan \\
\cline { 2 - 3 } & Mission & Pool \\
\cline { 2 - 3 } & Contact & Bldg R9641/Rainier Dr \\
\cline { 2 - 3 } & Parking Location & G41-1395G \\
\cline { 2 - 3 } & Fleet Vehicle ID & Gas/ETH \\
\cline { 2 - 3 } & Fuel Type & $16 / 23 / 1912 / 1714$ \\
\cline { 2 - 3 } & EPA Label/MPG (City/Hwy/Combined)* & $468 / 450$ \\
\cline { 2 - 3 } & EPA GHG Emissions (Grams CO CO $\left._{2} / \mathrm{Mi}\right)^{*}$ & Logger 19 \\
\cline { 2 - 3 } & Study Logger ID & $37 / 63$ \\
\cline { 2 - 3 } & Total Vehicle Days/Total Study Days & Cansport \\
\hline
\end{tabular}

\begin{tabular}{|l|c|c|c|c|}
\hline \multicolumn{5}{|c|}{ Vehicle G41-1395G Travel Summary } \\
\hline & $\begin{array}{c}\text { Per Day } \\
\text { Average/Peak }\end{array}$ & $\begin{array}{c}\text { Per Outing } \\
\text { Average/Peak }\end{array}$ & $\begin{array}{c}\text { Per Trip } \\
\text { Average/Peak }\end{array}$ & Total \\
\hline Travel Distance (Miles) & $6.0 / 31.3$ & $4.2 / 22.3$ & $1.9 / 18.3$ & 222 \\
\hline Travel Time (Minutes) & $22 / 86$ & $15.4 / 55$ & $7.1 / 46$ & 815 \\
\hline Idle Time (Minutes) & $2.0 / \mathrm{NA}$ & $1.4 / \mathrm{NA}$ & $0.7 / \mathrm{NA}$ & 75 \\
\hline
\end{tabular}

\begin{tabular}{|c|c|c|c|c|}
\hline \multicolumn{2}{|c|}{ Total Stops } & \multicolumn{2}{c|}{ Stop Duration } \\
\hline $\begin{array}{c}\text { Distance From } \\
\text { Home Base (Miles) }\end{array}$ & Stops & Percentages & Stop Duration (Hours) & Stops \\
\hline Less than 10 & 141 & $100 \%$ & Less than 2 & 98 \\
\hline 10 to 20 & 0 & $0 \%$ & 2 to 4 & 7 \\
\hline 20 to 40 & 0 & $0 \%$ & 4 to 8 & 2 \\
\hline 40 to 60 & 0 & $0 \%$ & Greater than 8 & 34 \\
\hline
\end{tabular}

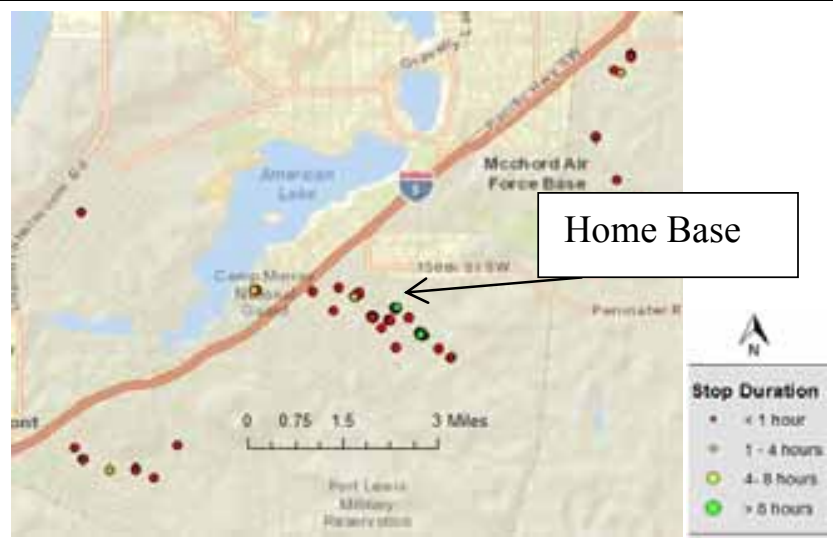

Figure E-37. Vehicle G41-1395G stops.

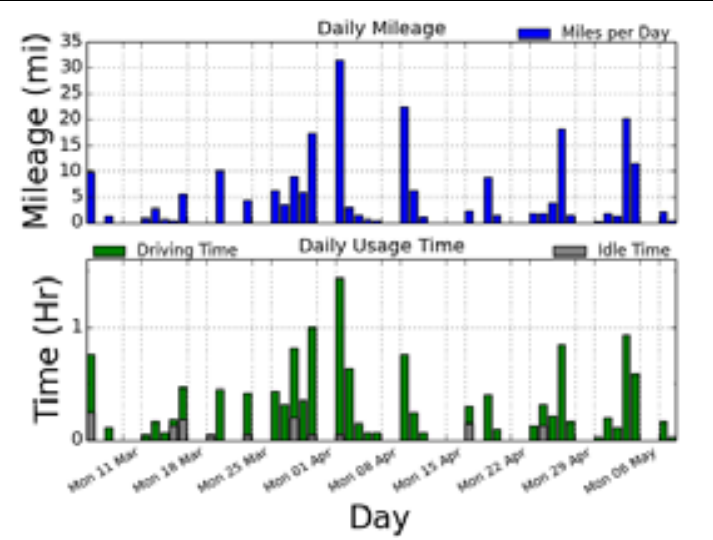

Figure E-38. Vehicle G41-1395G history. 

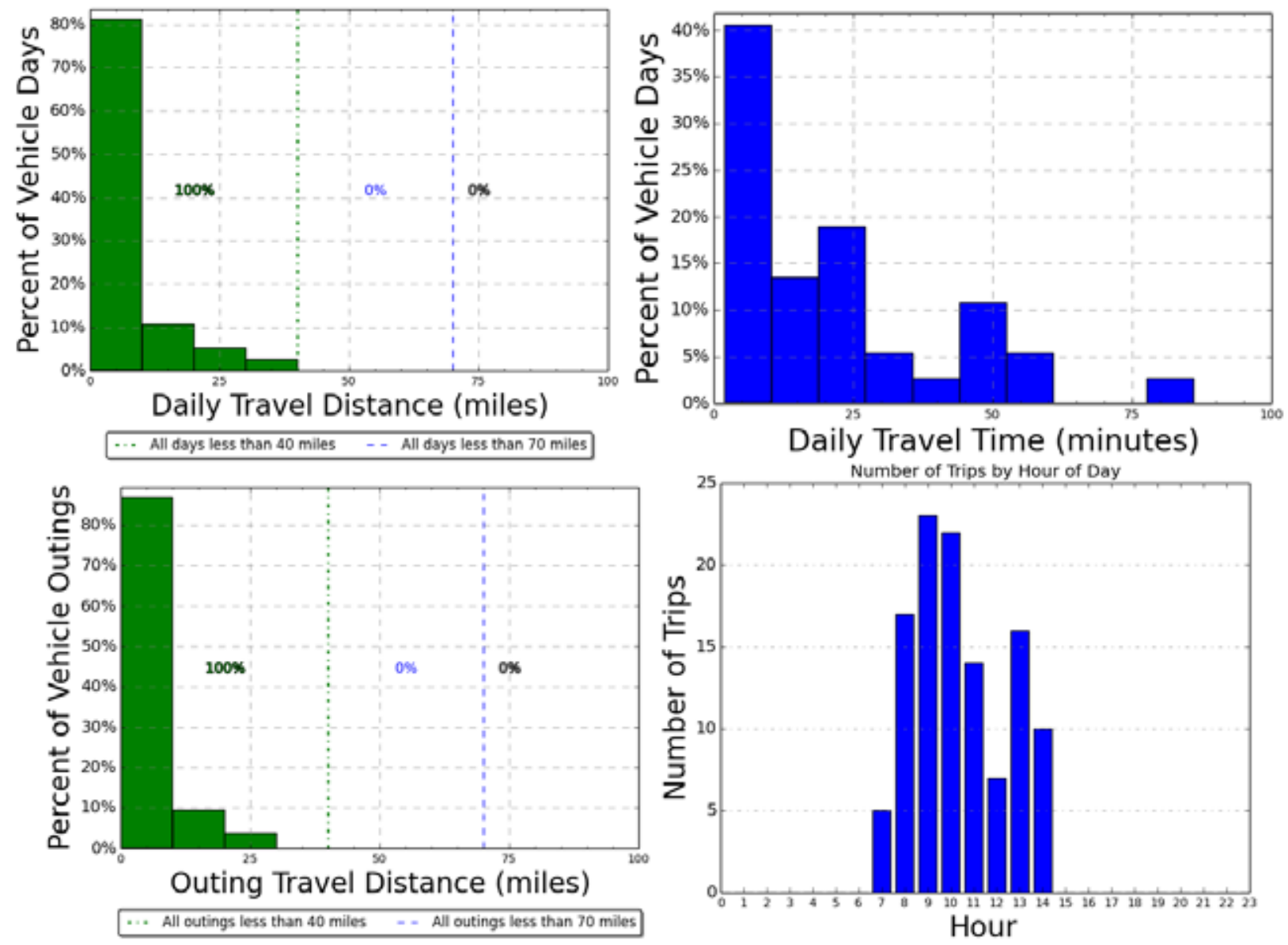

Figure E-43. Vehicle G41-1395G travel graphs.

\section{Vehicle G41-1395G Observations}

Logger 19 collected data on this vehicle for a period of 37 days of the 63-day study period. Validation occurred on $82.4 \%$ of the input data. The project survey response reports this vehicle is a pool vehicle used for IT service calls within JBLM to provide for computer troubleshooting, installations, and other preventive maintenance. It parks in the government vehicle parking area. No specific area was identified but the logger information suggests it is parked most frequently near Bldg 9614 on Rainier Dr. The expected retention of this vehicle is unknown. On a typical day, the vehicle travels between eleven and forty miles with each outing typically no more than ten miles. As a pool vehicle, more than twenty persons have access to this vehicle and it typically carries two persons. It typically operates only in the Fort Lewis and McChord Air Field areas. Normal operation is during daytime hours of 0700 to 1700 hours. The vehicle runs exclusively on gasoline. Equipment carried typically includes computer CPUs, monitors, printers and cables.

Site records report the vehicle travels approximately 319 miles per month and the odometer read 15,690 miles in May 2012.

All trips and outings were less than 70 miles and thus, were within the typically advertised range of a BEV of approximately 70 miles. In fact, all daily travel and outings are less than the 40-mile battery range of PHEVs.

This is a minivan and BEVs are available for replacement. The BEV would be expected to provide the acceptable performance of this vehicle. 


\begin{tabular}{|l|l|c|}
\hline & Make/Model/Year & Ford/Escape Hybrid/2006 \\
\cline { 1 - 2 } & EPA Class Size & Sports Utility Vehicle \\
\hline & Mission & Pool \\
\hline Contact & Bldg 4074/Kaufman Ave \\
\cline { 2 - 3 } & Parking Location & G61-1155D \\
\cline { 2 - 3 } & Fleet Vehicle ID & Gas \\
\cline { 2 - 3 } & Fuel Type & $28 / 26 / 27$ \\
\cline { 2 - 3 } & EPA Label/MPG (City/Hwy/Combined)* & 329 \\
\cline { 2 - 3 } & EPA GHG Emissions (Grams CO COMi) $^{*}$ & Logger 20 \\
\hline & Study Logger ID & $24 / 63$ \\
\hline
\end{tabular}

\begin{tabular}{|l|c|c|c|c|}
\hline \multicolumn{5}{|c|}{ Vehicle G61-1155D Travel Summary } \\
\hline & $\begin{array}{c}\text { Per Day } \\
\text { Average/Peak }\end{array}$ & $\begin{array}{c}\text { Per Outing } \\
\text { Average/Peak }\end{array}$ & $\begin{array}{c}\text { Per Trip } \\
\text { Average/Peak }\end{array}$ & Total \\
\hline Travel Distance (Miles) & $22.3 / 62.3$ & $17.2 / 64.1$ & $1.3 / 13.7$ & 534 \\
\hline Travel Time (Minutes) & $50 / 141$ & $38.5 / 141$ & $2.9 / 27$ & 1,193 \\
\hline Idle Time (Minutes) & $0.4 / \mathrm{NA}$ & $0.3 / \mathrm{NA}$ & $0 / \mathrm{NA}$ & 9 \\
\hline
\end{tabular}

\begin{tabular}{|c|c|c|c|c|}
\hline \multicolumn{3}{|c|}{ Total Stops } & \multicolumn{2}{c|}{ Stop Duration } \\
\hline $\begin{array}{l}\text { Distance From } \\
\text { Home Base (Miles) }\end{array}$ & Stops & Percentages & Stop Duration (Hours) & Stops \\
\hline Less than 10 & 104 & $95.4 \%$ & Less than 2 & 79 \\
\hline 10 to 20 & 5 & $4.6 \%$ & 2 to 4 & 4 \\
\hline 20 to 40 & 0 & $0 \%$ & 4 to 8 & 3 \\
\hline 40 to 60 & 0 & $0 \%$ & Greater than 8 & 23 \\
\hline
\end{tabular}

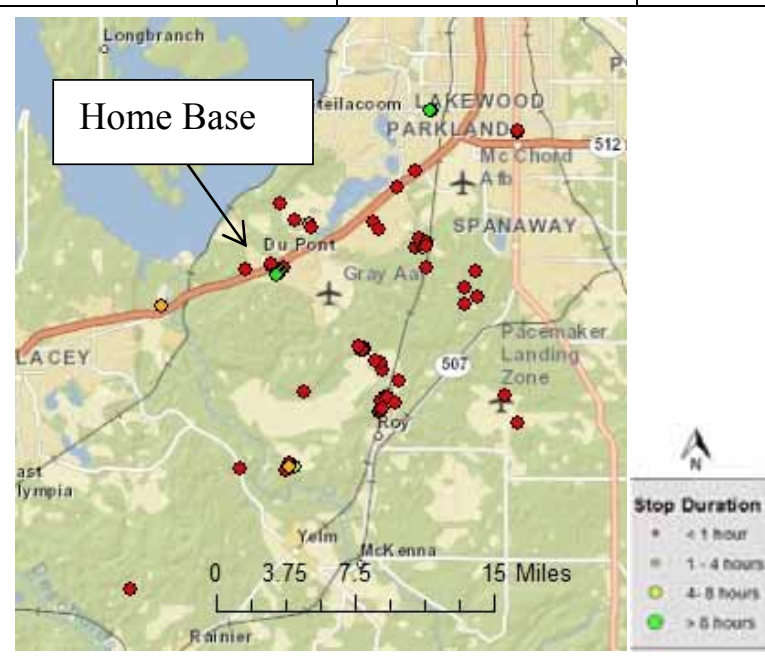

Figure E-40. Vehicle G61-1155D stops.
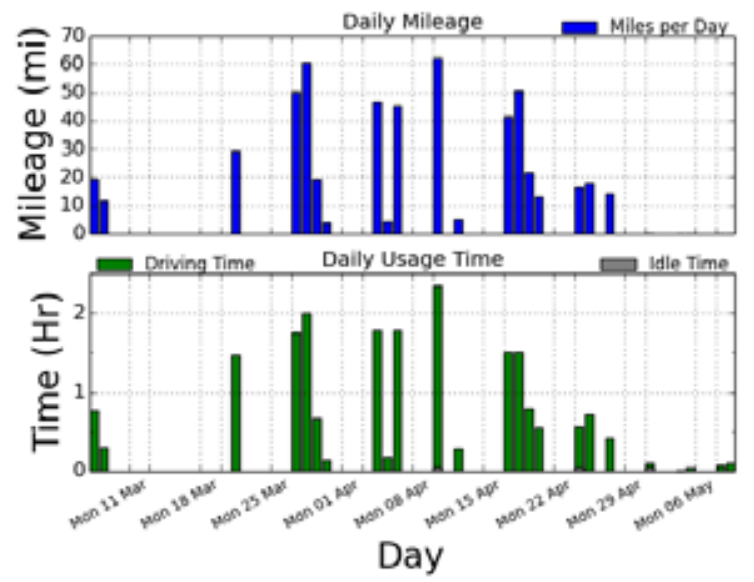

Figure E-41. Vehicle G61-1155D history. 

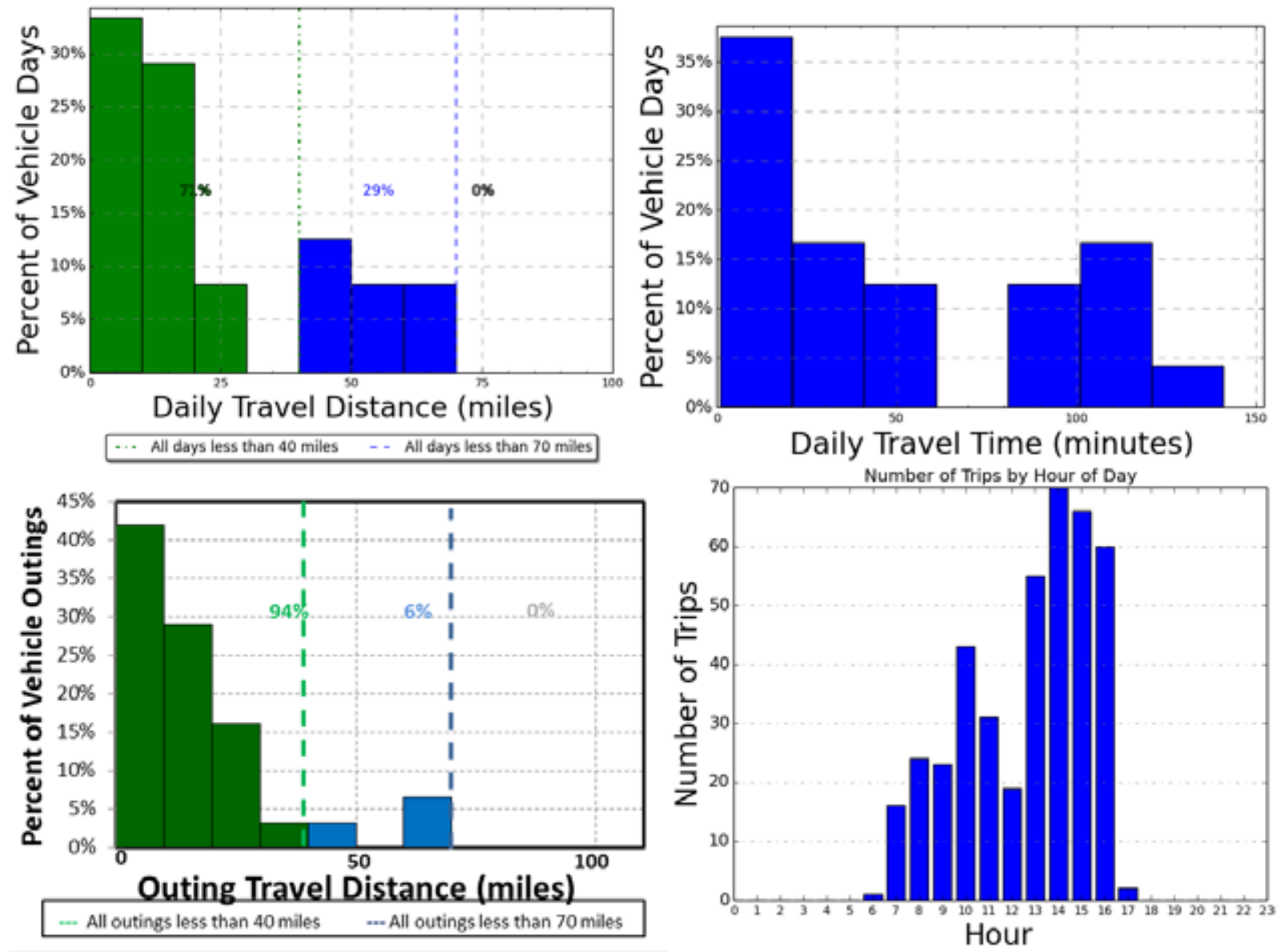

Figure E-44. Vehicle G61-1155D travel graphs.

\section{Vehicle G61-1155D Observations}

Logger 20 collected data on this vehicle for a period of 24 days of the 63-day study period. Validation occurred on $94.7 \%$ of the input data. The project survey response reports this is a pool vehicle used to transport equipment to field sites throughout all ranges and training areas of JBLM for the ITAM Program; transport personnel to other agencies on and off post for meetings, conferences, and general administration; and transport supplies and materials in support of ITAM and Range Control operations, maintenance, and administration. This vehicle regularly travels off pavement on improved and unimproved maintenance roads, firebreaks, forest tracks and cross-country. The vehicle parks in the motor pool area next to Range Control, Kaufman Ave Bldg 4074. DPTMS/Range Control/ITAM expects to retain this vehicle for less than two more years.

Expected daily travel is between forty and one hundred miles. Between six and ten persons have access to this vehicle that typically carries two persons. It travels off post once or twice per month with outings again between forth and one hundred miles. The vehicle daily usage is between 0630 and 1800 hours. It typically carries field equipment to include cameras, GPS equipment, marker flags, survey material, and personal gear for occupants. Site records report average travel to be 427 miles per month with an odometer reading of 31,200 in May 2012.The vehicle moved to the Lakewood, WA area on April 25 th and was involved in mostly local trips after this date. The vehicle analysis does not include this timeframe.

All trips and outings were less than 70 miles and thus, were within the typically advertised range of a BEV of approximately 70 miles. This is a hybrid SUV and BEVs are available for replacement. The BEV would be expected to provide the acceptable performance of this vehicle. 
Vehicle G10-2878L

\begin{tabular}{|c|c|c|}
\hline (8) & Make/Model/Year & Chevrolet / Malibu / 2011 \\
\hline 213 & EPA Class Size & Midsize Cars \\
\hline $6=$ & Mission & Pool \\
\hline www.edmunds.com & Contact & C. Sallinger/Motor Transport \\
\hline & Parking Location & Bldg R1407/West Way \\
\hline & Fleet Vehicle ID & G10-2878L \\
\hline & Fuel Type & Gas/E85 \\
\hline & EPA Label/MPG (City/Hwy/Combined)* & $22 / 33 / 26 \quad 15 / 23 / 18$ \\
\hline & EPA GHG Emissions (Grams $\left.\mathrm{CO}_{2} / \mathrm{Mi}\right)^{*}$ & $342 / 350$ \\
\hline & Study Logger ID & Logger 81 \\
\hline & Total Vehicle Days/Total Study Days & $37 / 63$ \\
\hline
\end{tabular}

\begin{tabular}{|l|c|c|c|c|}
\hline \multicolumn{5}{|c|}{ Vehicle G10-2878L Travel Summary } \\
\hline & $\begin{array}{c}\text { Per Day } \\
\text { Average/Peak }\end{array}$ & $\begin{array}{c}\text { Per Outing } \\
\text { Average/Peak }\end{array}$ & $\begin{array}{c}\text { Per Trip } \\
\text { Average/Peak }\end{array}$ & Total \\
\hline Travel Distance (Miles) & $20.2 / 80.7$ & $7.7 / 67.0$ & $2.9 / 31.1$ & 748 \\
\hline Travel Time (Minutes) & $115 / 443$ & $43.8 / 790$ & $16.5 / 225$ & 4,252 \\
\hline Idle Time (Minutes) & $53.2 / \mathrm{NA}$ & $20.3 / \mathrm{NA}$ & $7.6 / \mathrm{NA}$ & 1,969 \\
\hline
\end{tabular}

\begin{tabular}{|c|c|c|c|c|}
\hline \multicolumn{2}{|c|}{ Total Stops } & \multicolumn{2}{c|}{ Stop Duration } \\
\hline $\begin{array}{c}\text { Distance From } \\
\text { Home Base (Miles) }\end{array}$ & Stops & Percentages & Stop Duration (Hours) & Stops \\
\hline Less than 10 & 254 & $96.6 \%$ & Less than 2 & 208 \\
\hline 10 to 20 & 4 & $1.5 \%$ & 2 to 4 & 13 \\
\hline 20 to 40 & 5 & $1.9 \%$ & 4 to 8 & 6 \\
\hline 40 to 60 & 0 & $0 \%$ & Greater than 8 & 36 \\
\hline
\end{tabular}

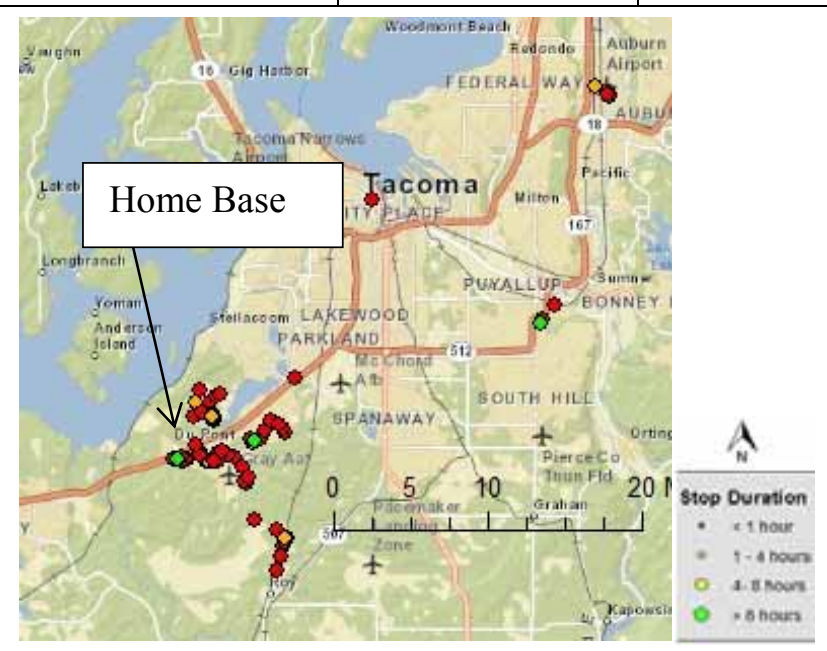

Figure E-43. Vehicle G10-2878L stops.

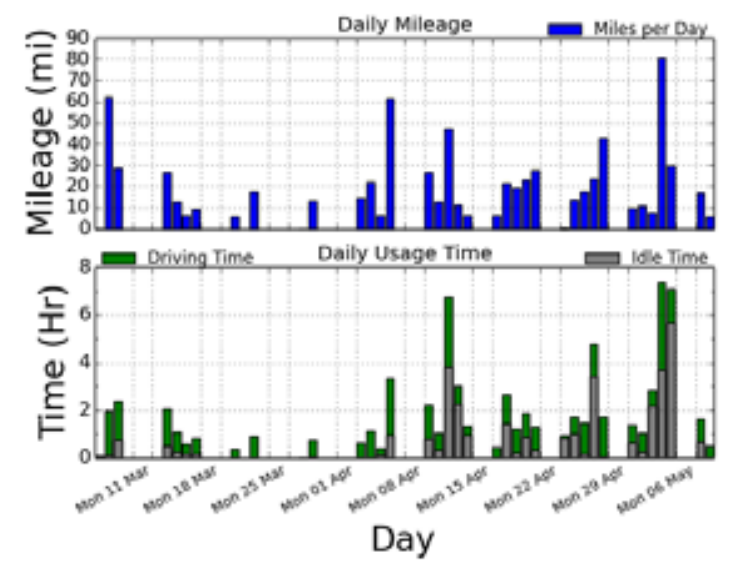

Figure E-44. Vehicle G10-2878L history. 

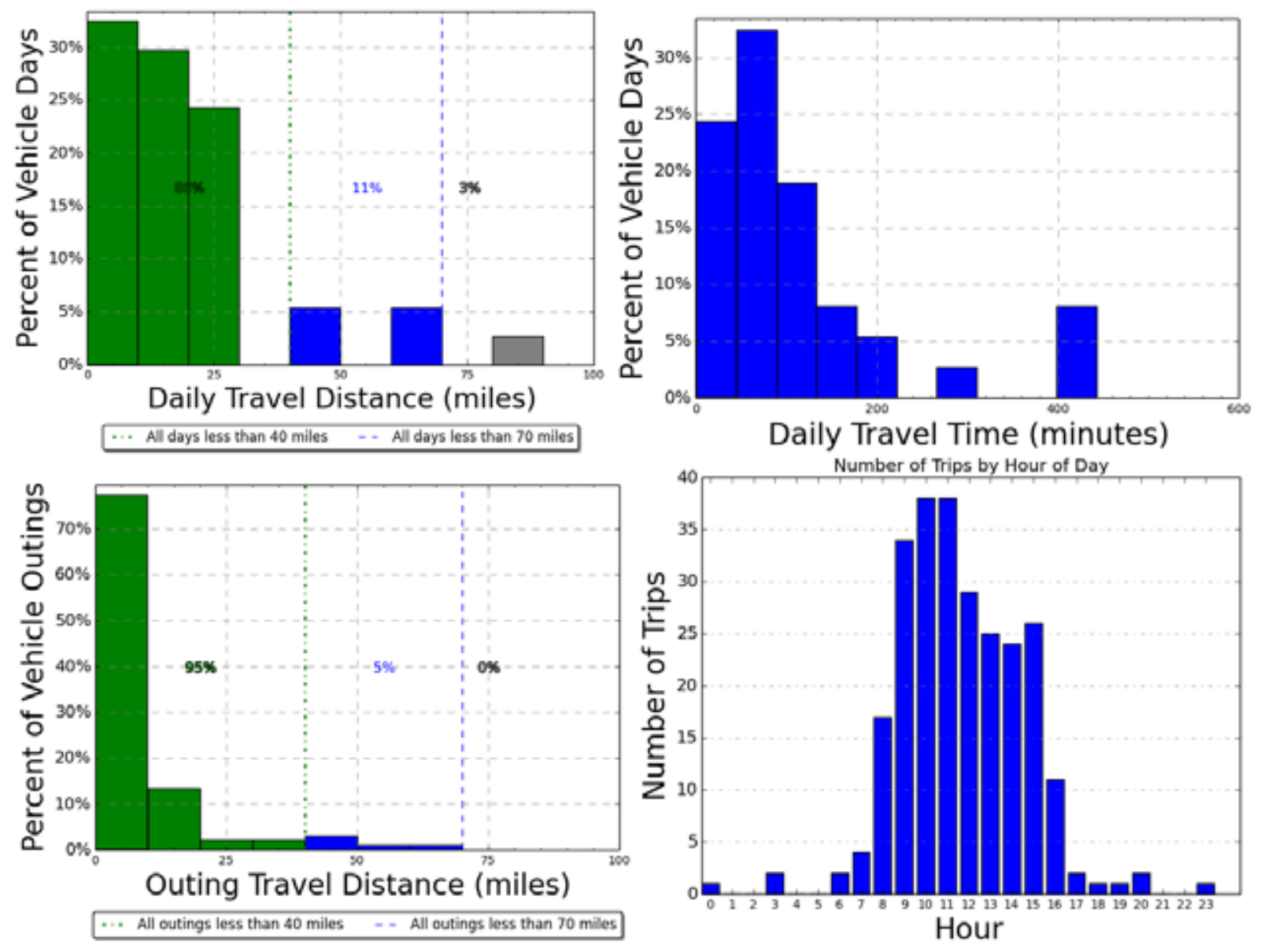

Figure E-45. Vehicle G10-2878L travel graphs.

\section{Vehicle G10-2878L Observations}

Logger 81 collected data on this vehicle for a period of 37 days of the 63-day study period. Validation occurred on $99.8 \%$ of the input data. Project survey response reports this vehicle is a pool vehicle typically parked in the gated lot near Bldg R1407. The vehicle supports the Warrior Training Academy. Primary usage is by the Commandant and Operations NCO to check on training at Combatives Training Area near R9651 and Combat Marksmanship Academy Training Areas (B3317 and Ranges). The vehicle is available to between two and five persons and usually travels between eleven and forty miles per day. It is occasionally used off base with outings less than 40 miles. Site records show average monthly travel to be 342 miles. The odometer read 4,887 miles in May 2012. G3 TREX, Warrior Training Academy operates the vehicle and expects to retain this vehicle more than 6 years. The vehicle typically operates from 0900 to 1700 hours daily. It frequently operates on the E-85 fuel. The response identified no specific cargo requirements.

Ninety-seven percent of all vehicle travel days were within the 70- mile BEV safe range (green and blue bars on Figure E-45) while all vehicle outings are within this range. The longest daily travel of 80.7 miles occurred on May 2 and consisted of several trips returning to the home base and allowing sufficient recharge opportunities to continue operation. The longest of the outings that day was 26.4 miles

This is a midsize car and BEVs are available for replacement. The BEV would be expected to provide the acceptable performance of this vehicle. 
Vehicle G41-1100K

\begin{tabular}{|l|l|c|}
\hline \multirow{4}{*}{ www.edmunds.com } & Make/Model/Year & Dodge/Grand Caravan/2010 \\
\cline { 1 - 2 } & EPA Class Size & Minivan \\
\cline { 2 - 3 } & Mission & Pool \\
\cline { 2 - 3 } & Contact & Bldg $2012 / 1210$ \\
\cline { 2 - 3 } & Parking Location & G41-1100K \\
\cline { 2 - 3 } & Fleet Vehicle ID & Gas/ETH \\
\cline { 2 - 3 } & Fuel Type & $17 / 24 / 1912 / 17 / 13$ \\
\cline { 2 - 3 } & EPA Label/MPG (City/Hwy/Combined)* & $468 / 484$ \\
\cline { 2 - 3 } & EPA GHG Emissions (Grams CO $\left.\mathrm{CO}_{2} / \mathrm{Mi}\right)^{*}$ & Logger 84 \\
\cline { 2 - 3 } & Study Logger ID & $28 / 63$ \\
\cline { 2 - 3 } & Total Vehicle Days/Total Study Days & \\
\hline
\end{tabular}

\begin{tabular}{|l|c|c|c|c|}
\hline \multicolumn{5}{|c|}{ Vehicle G41-1100K Travel Summary } \\
\hline & $\begin{array}{c}\text { Per Day } \\
\text { Average/Peak }\end{array}$ & $\begin{array}{c}\text { Per Outing } \\
\text { Average/Peak }\end{array}$ & $\begin{array}{c}\text { Per Trip } \\
\text { Average/Peak }\end{array}$ & Total \\
\hline Travel Distance (Miles) & $20.5 / 270.7$ & $19.1 / 168.6$ & $5.3 / 132$ & 573 \\
\hline Travel Time (Minutes) & $44 / 297$ & $40.7 / 223$ & $11.2 / 139$ & 1,221 \\
\hline Idle Time (Minutes) & $1.3 / \mathrm{NA}$ & $1.2 / \mathrm{NA}$ & $0.3 / \mathrm{NA}$ & 36 \\
\hline
\end{tabular}

\begin{tabular}{|c|c|c|c|c|}
\hline \multicolumn{2}{|c|}{ Total Stops } & \multicolumn{2}{c|}{ Stop Duration } \\
\hline $\begin{array}{c}\text { Distance From } \\
\text { Home Base (Miles) }\end{array}$ & Stops & Percentages & Stop Duration (Hours) & Stops \\
\hline Less than 10 & 103 & $96.3 \%$ & Less than 2 & 70 \\
\hline 10 to 20 & 0 & $0 \%$ & 2 to 4 & 7 \\
\hline 20 to 40 & 0 & $0 \%$ & 4 to 8 & 4 \\
\hline 40 to 60 & 4 & $3.7 \%$ & Greater than 8 & 26 \\
\hline
\end{tabular}

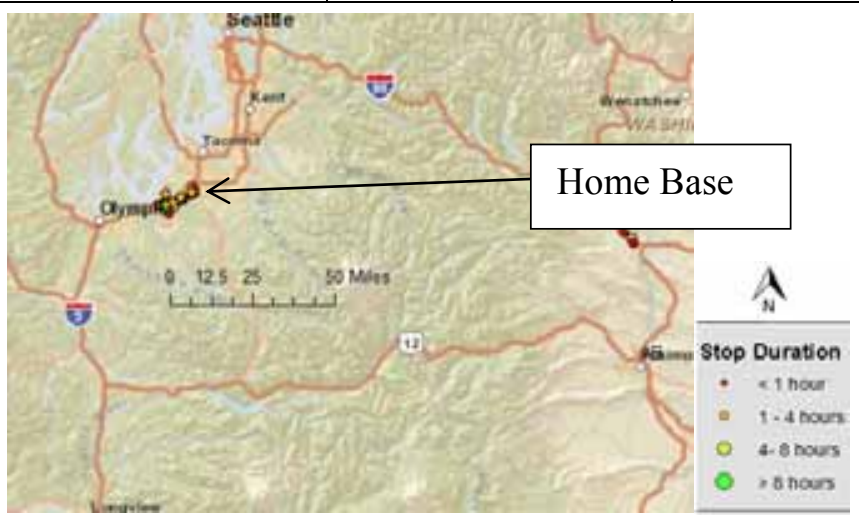

Figure E-46. Vehicle G41-1100K stops.

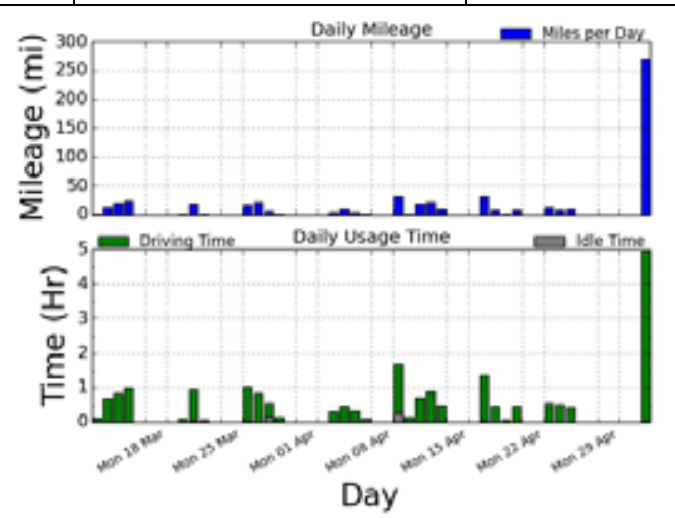

Figure E-47. Vehicle G41-1100K history. 

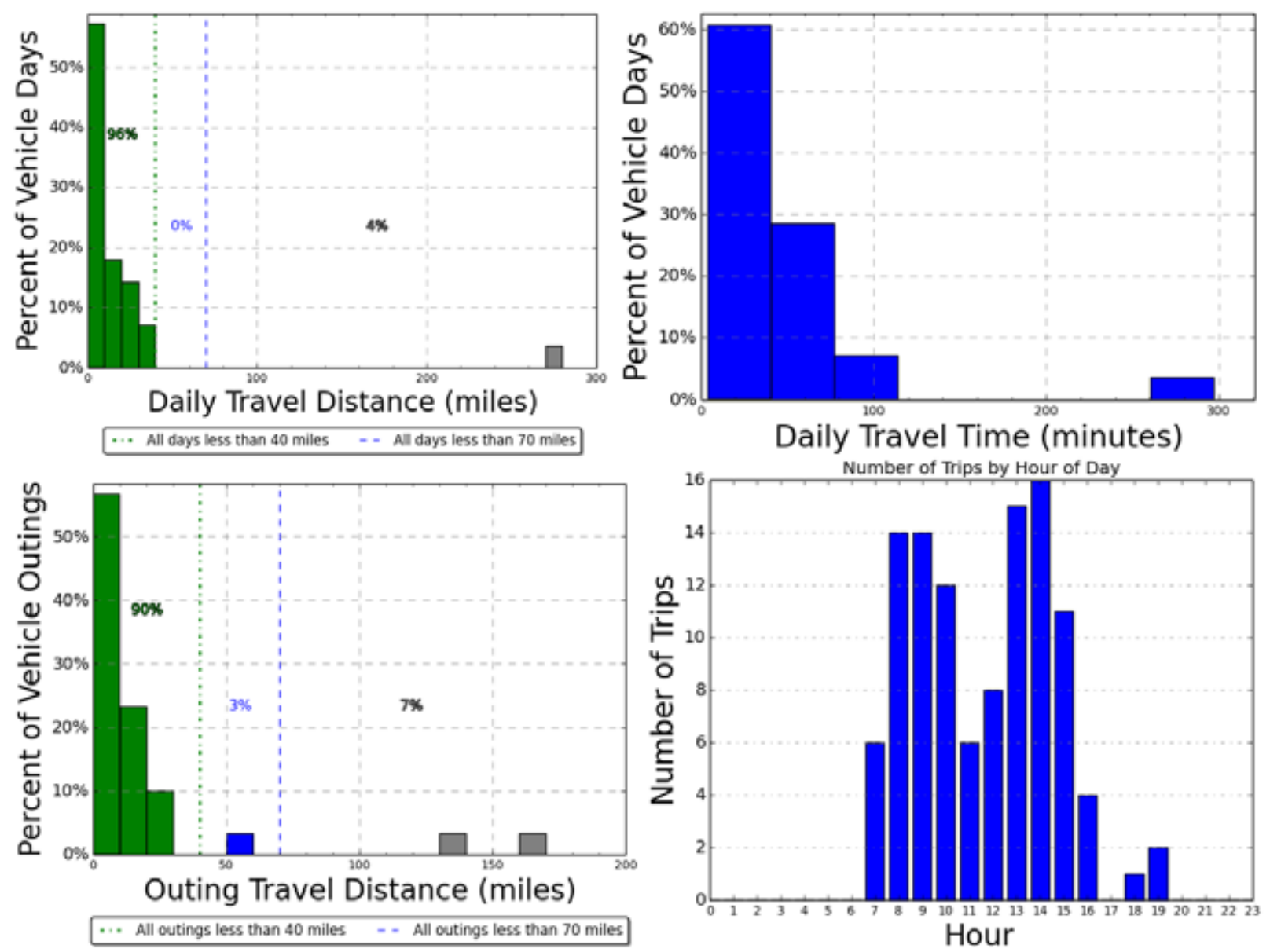

Figure E-46. Vehicle G41-1100K travel graphs.

\section{Vehicle G41-1100K Observations}

Logger 84 collected data on this vehicle for a period of 28 days of the 63-day study period. Validation occurred on $97.8 \%$ of the input data. The project survey response reports this vehicle is a pool vehicle available to 30 drivers located in Bldg 1210 and by 20 other drivers located in Bldg 2012. JBLM Public Works Environmental operates this vehicle and expects to retain it from three to six more years. On a typical day, this vehicle travels between eleven and forty miles. Site records report an average monthly travel of 83 miles with an odometer reading of 5,087 in May 2012. The vehicle provides tours for visiting VIPS and government officials. It occasionally travels off base for tours and training seminars but outings are typically less than 40 miles. The vehicle operates between 0700 and 1630 daily. There are no specific cargo requirements.

Ninety-six percent of all vehicle travel days were within the 70-mile BEV safe range (green and blue bars on Figure E-48) and 93\% of vehicle outings were within this range; $4 \%$ of the vehicle travel days exceed this range, which the history graph shows occurred on a single trip to Ellensburg, WA on May 1. The two outings shown in Figure E-48 exceeding the BEV range also occurred on this single trip.

This is a minivan and BEVs are available for replacement. The BEV would be expected to provide the acceptable performance of this vehicle with the exception of the single long trip. As a pool vehicle, the BEV could be used for $97 \%$ of the vehicle travel while other PHEVs in the pool could be used for longer trips. 
Vehicle G62-0979G

\begin{tabular}{|l|l|c|}
\hline \multirow{4}{*}{ www.edmunds.com } & Make/Model/Year & Dodge/1500/2008 \\
\cline { 2 - 3 } & EPA Class Size & Standard Pickup Truck \\
\cline { 2 - 3 } & Mission & Pool \\
\cline { 2 - 3 } & Contact & Bldg 1210/Mann Ave \\
\cline { 2 - 3 } & Parking Location & G62-0979G \\
\cline { 2 - 3 } & Fleet Vehicle ID & Gas/ETH \\
\cline { 2 - 3 } & Fuel Type & $13 / 18 / 159 / 12 / 10$ \\
\cline { 2 - 3 } & EPA Label/MPG (City/Hwy/Combined)* & $592 / 630$ \\
\cline { 2 - 3 } & EPA GHG Emissions (Grams $\left.\mathrm{CO}_{2} / \mathrm{Mi}\right)^{*}$ & Logger 85 \\
\cline { 2 - 3 } & Study Logger ID & $33 / 63$ \\
\cline { 2 - 3 } & Total Vehicle Days/Total Study Days & (3) \\
\hline
\end{tabular}

\begin{tabular}{|l|c|c|c|c|}
\hline \multicolumn{5}{|c|}{ Vehicle G62-0979G Travel Summary } \\
\hline & $\begin{array}{c}\text { Per Day } \\
\text { Average/Peak }\end{array}$ & $\begin{array}{c}\text { Per Outing } \\
\text { Average/Peak }\end{array}$ & $\begin{array}{c}\text { Per Trip } \\
\text { Average/Peak }\end{array}$ & Total \\
\hline Travel Distance (Miles) & $33.9 / 80.7$ & $19.3 / 80.7$ & $4.8 / 33.7$ & 1,117 \\
\hline Travel Time (Minutes) & $98 / 266$ & $55.7 / 203$ & $13.9 / 92.0$ & 3,229 \\
\hline Idle Time (Minutes) & $7.2 / \mathrm{NA}$ & $4.1 / \mathrm{NA}$ & $1.0 / \mathrm{NA}$ & 239 \\
\hline
\end{tabular}

\begin{tabular}{|c|c|c|c|c|}
\hline \multicolumn{2}{|c|}{ Total Stops } & \multicolumn{2}{c|}{ Stop Duration } \\
\hline $\begin{array}{c}\text { Distance From } \\
\text { Home Base (Miles) }\end{array}$ & Stops & Percentages & Stop Duration (Hours) & Stops \\
\hline Less than 10 & 192 & $86.1 \%$ & Less than 2 & 165 \\
\hline 10 to 20 & 29 & $13.0 \%$ & 2 to 4 & 14 \\
\hline 20 to 40 & 2 & $0.9 \%$ & 4 to 8 & 10 \\
\hline 40 to 60 & 0 & $0 \%$ & Greater than 8 & 34 \\
\hline
\end{tabular}

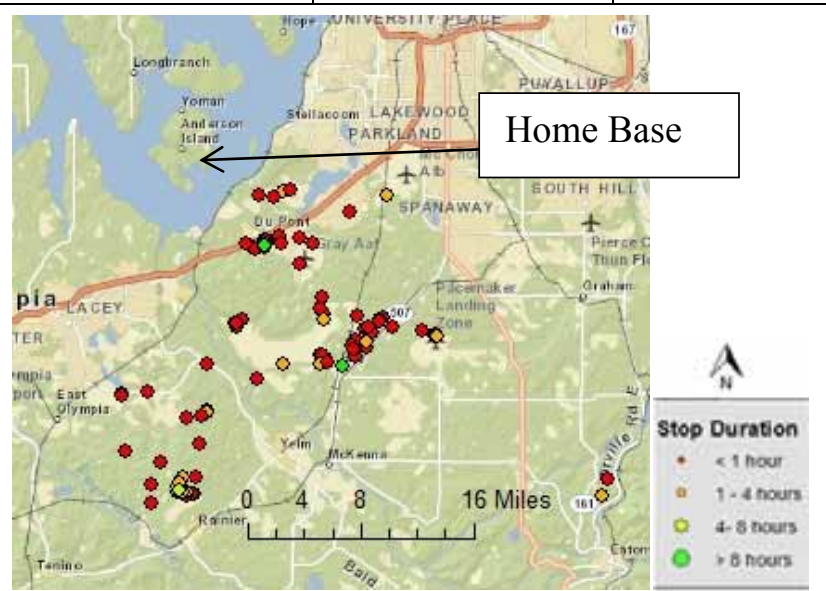

Figure E-49. Vehicle G62-0979G stops.

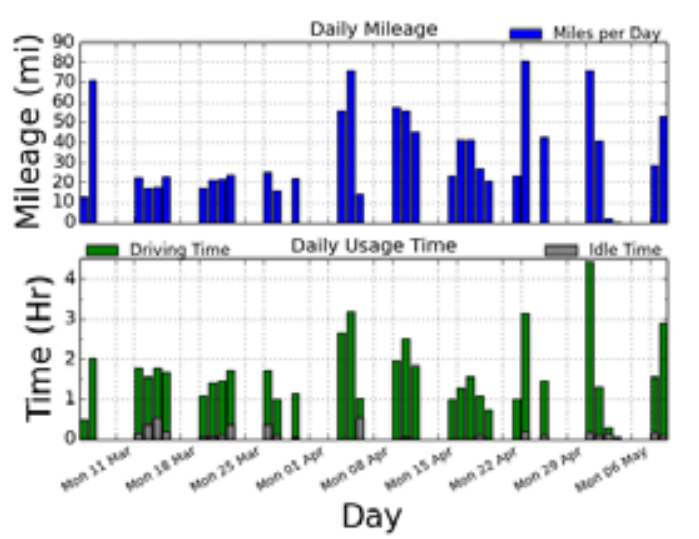

Figure E-50. Vehicle G62-0979G history. 

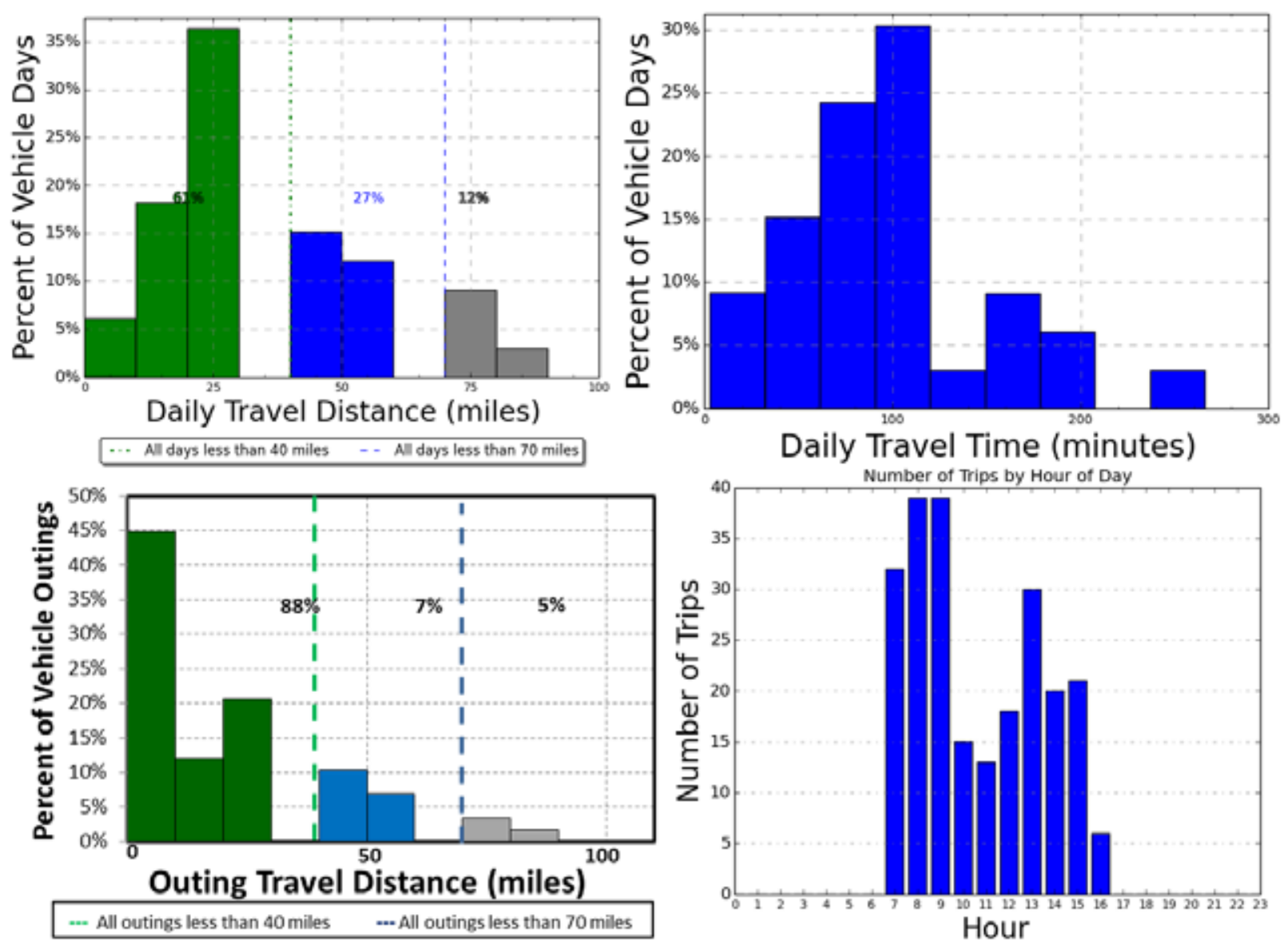

Figure E-47. Vehicle G62-0979G travel graphs.

\section{Vehicle G62-0979G Observations}

Logger 85 collected data on this vehicle for a period of 33 days of the 63-day study period. Validation occurred on $99.4 \%$ of the input data. The project survey response reports this vehicle assigned to Environmental is a pool vehicle typically parked in the pool parking area near Bldg 1210 on Mann or Kaufman Ave. They expect to retain this vehicle more than six years. It typically travels between eleven and forty miles per day and occasionally travels off base with outings of less than 40 miles. Site records report an average monthly travel of 135 miles with a recorded odometer reading of 30,654 in May 2012. Between six and ten people have access to this vehicle that typically carries two persons. The vehicle operates between 0700 and 1500 hours daily and occasionally later. It occasionally carries equipment and supplies.

Eighty-eight percent of all vehicle travel days were within the 70-mile BEV safe range (green and blue bars on Figure E-51) and 95\% of all outings were within this range; $12 \%$ of the vehicle travel days (4 days) exceed this range.

Sixty-one percent of all vehicle travel days were within the 40-mile PHEV safe range (green bars on Figure E-51) and $88 \%$ of all outings were within this range; $39 \%$ of the vehicle travel days (4 days) exceed this range.

This pickup truck occasionally carries equipment and supplies. Assuming that a PHEV or BEV could perform the load-carrying mission, a pool mix of BEVs and PHEVs could be expected to provide the acceptable performance of this vehicle. The BEV could be used for $61 \%$ of the vehicle travel while other PHEVs in the pool could be used for longer trips. 
Vehicle G71-0674A

\begin{tabular}{|l|l|c|}
\hline \multirow{4}{*}{ www.edmunds.com } & Make/Model/Year & Ford/F650 18'BO/2004 \\
\hline EPA Class Size & Delivery Van \\
\cline { 2 - 3 } & Mission & Transport \\
\cline { 2 - 3 } & Contact & C. Sallinger/Motor Transport \\
\cline { 2 - 3 } & Parking Location & Bldg R9641/Perry Ave \\
\cline { 2 - 3 } & Fleet Vehicle ID & G71-0674A \\
\cline { 2 - 3 } & Fuel Type & Diesel \\
\cline { 2 - 3 } & EPA Label/MPG (City/Hwy/Combined)* & Not available \\
\cline { 2 - 3 } & EPA GHG Emissions $\left(\mathrm{Grams} \mathrm{CO}_{2} / \mathrm{Mi}\right)^{*}$ & Not available \\
\cline { 2 - 3 } & Study Logger ID & Logger 89 \\
\cline { 2 - 3 } & Total Vehicle Days/Total Study Days & $28 / 63$ \\
\hline
\end{tabular}

\begin{tabular}{|l|c|c|c|c|}
\hline \multicolumn{5}{|c|}{ Vehicle G71-0674A Travel Summary } \\
\hline & $\begin{array}{c}\text { Per Day } \\
\text { Average/Peak }\end{array}$ & $\begin{array}{c}\text { Per Outing } \\
\text { Average/Peak }\end{array}$ & $\begin{array}{c}\text { Per Trip } \\
\text { Average/Peak }\end{array}$ & Total \\
\hline Travel Distance (Miles) & No data & No data & No data & No data \\
\hline Travel Time (Minutes) & No data & No data & No data & No data \\
\hline Idle Time (Minutes) & No data & No data & No data & No data \\
\hline
\end{tabular}

\begin{tabular}{|c|c|c|c|c|}
\hline \multicolumn{2}{|c|}{ Total Stops } & \multicolumn{2}{c|}{ Stop Duration } \\
\hline $\begin{array}{c}\text { Distance From } \\
\text { Home Base (Miles) }\end{array}$ & Stops & Percentages & Stop Duration (Hours) & Stops \\
\hline Less than 10 & No data & No data & Less than 2 & No data \\
\hline 10 to 20 & No data & No data & 2 to 4 & No data \\
\hline 20 to 40 & No data & No data & 4 to 8 & No data \\
\hline 40 to 60 & No data & No data & Greater than 8 & No data \\
\hline
\end{tabular}

\section{Vehicle G71-0674A Observations}

Survey information was not available for this vehicle. Site data reports an odometer reading of 37,210 in May 2012 with an average of 358 miles per month. Data transmittal occurred for only 6 days for unknown reasons. Trip data suggests it started parking near Bldg 9641 on Perry Ave but also spent considerable time in Yakima.

The data logger recorded only five vehicle trips during the first few days of the study period. The reason for the incomplete data is unknown but it is insufficient to provide a vehicle report. 
Vehicle G41-1373G

\begin{tabular}{|c|c|c|}
\hline \multirow{3}{*}{$\frac{17}{8-3}$} & Make/Model/Year & Dodge/Dakota/2008 \\
\hline & EPA Class Size & Standard Pickup Truck \\
\hline & Mission & Support \\
\hline \multirow[t]{8}{*}{ www.edmunds.com } & Contact & C. Sallinger/Motor Transport \\
\hline & Parking Location & Bldg R9654/Perry Ave \\
\hline & Fleet Vehicle ID & G41-1373G \\
\hline & Fuel Type & $\mathrm{Gas} / \mathrm{ETH}$ \\
\hline & EPA Label/MPG (City/Hwy/Combined)* & $14 / 19 / 159 / 12 / 10$ \\
\hline & EPA GHG Emissions (Grams $\left.\mathrm{CO}_{2} / \mathrm{Mi}\right)^{*}$ & $592 / 630$ \\
\hline & Study Logger ID & Logger 93 \\
\hline & Total Vehicle Days/Total Study Days & $63 / 63$ \\
\hline
\end{tabular}

\begin{tabular}{|l|c|c|c|c|}
\hline \multicolumn{5}{|c|}{ Vehicle G41-1373G Travel Summary } \\
\hline & $\begin{array}{c}\text { Per Day } \\
\text { Average/Peak }\end{array}$ & $\begin{array}{c}\text { Per Outing } \\
\text { Average/Peak }\end{array}$ & $\begin{array}{c}\text { Per Trip } \\
\text { Average/Peak }\end{array}$ & Total \\
\hline Travel Distance (Miles) & $61.7 / 113.3$ & $13.8 / 57.6$ & $9.5 / 39.8$ & 3,949 \\
\hline Travel Time (Minutes) & $177 / 311$ & $39.4 / 170$ & $27.2 / 111$ & 11,305 \\
\hline Idle Time (Minutes) & $20.6 / \mathrm{NA}$ & $4.6 / \mathrm{NA}$ & $3.2 / \mathrm{NA}$ & 1,319 \\
\hline
\end{tabular}

\begin{tabular}{|c|c|c|c|c|}
\hline \multicolumn{2}{|c|}{ Total Stops } & \multicolumn{2}{c|}{ Stop Duration } \\
\hline $\begin{array}{c}\text { Distance From } \\
\text { Home Base (Miles) }\end{array}$ & Stops & Percentages & Stop Duration (Hours) & Stops \\
\hline Less than 10 & 448 & $100 \%$ & Less than 2 & 271 \\
\hline 10 to 20 & 0 & $0 \%$ & 2 to 4 & 77 \\
\hline 20 to 40 & 0 & $0 \%$ & 4 to 8 & 51 \\
\hline 40 to 60 & 0 & $0 \%$ & Greater than 8 & 49 \\
\hline
\end{tabular}

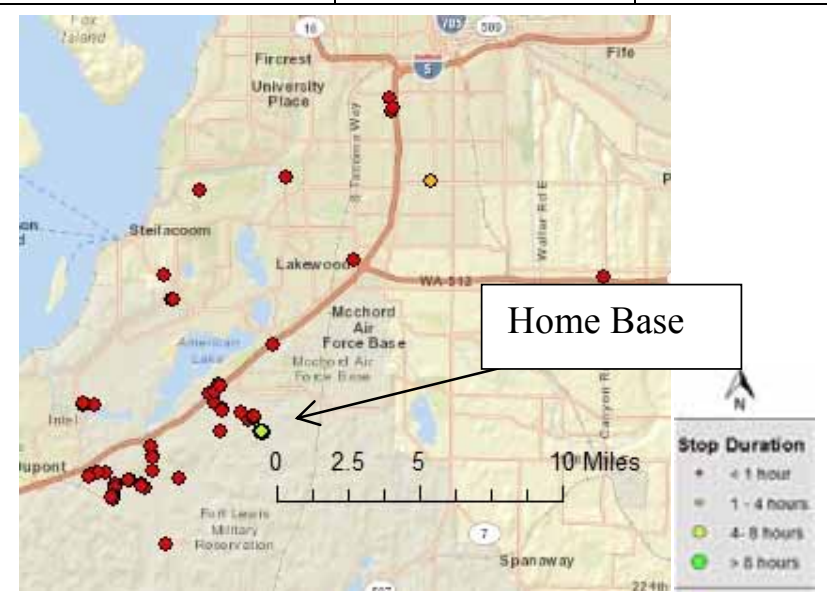

Figure E-52. Vehicle G41-1373G stops.

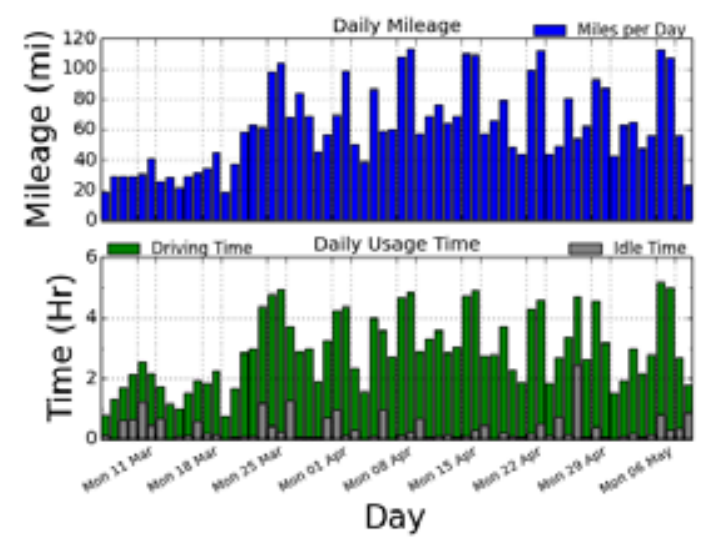

Figure E-53. Vehicle G41-1373G history. 

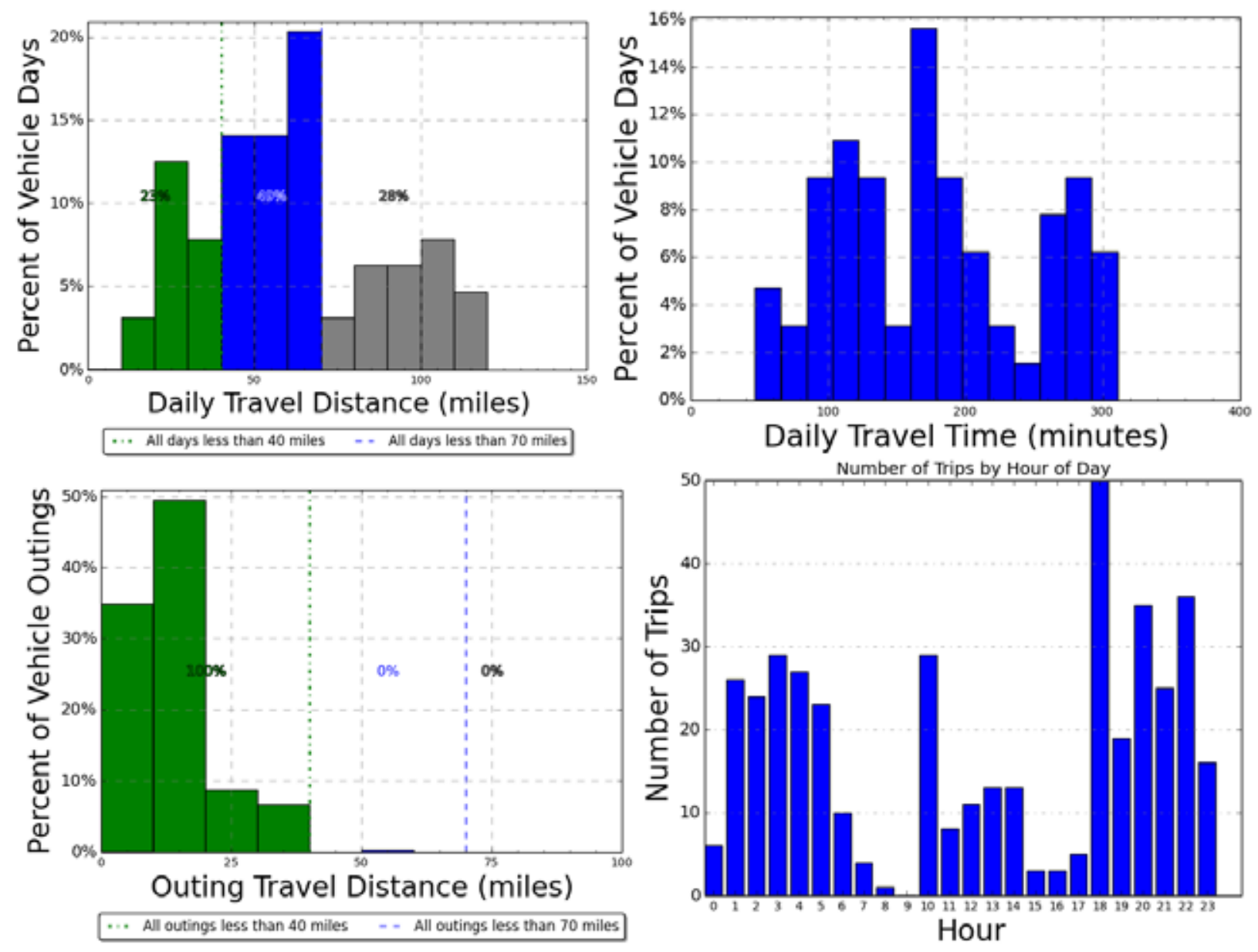

Figure E-48. Vehicle G41-1373G travel graphs.

\section{Vehicle G41-1373G Observations}

Logger 93 collected data on this vehicle for a period of 63 days of the 63-day study period. Validation occurred on $99.2 \%$ of the input data. The project survey response reports this vehicle assignment to Strategic Resources Inc Contractor to support the mission through a specific travel route in documenting transport security checks. It parks the office parking area near Bled R9654 on Perry or Cook Avenues. JMB HHC/S-1expects to retain this vehicle less than two years. It travels between 40 and 100 miles per day, rarely travels off base, and outings are typically less than 40 miles. Site records show an average monthly travel of 880 miles with an odometer reading of 45,361 in May 2012. Up to twenty persons have access to this vehicle and they typically travel alone. The response reports no specific cargo or equipment carry requirements.

The vehicle was used every day of the study period. During the study period, the vehicle traveled a total distance of 3,949 miles over 188 hours of travel. Seventy-two percent of all vehicle travel days were within the 70-mile BEV safe range (green and blue bars on Figure E-54) and all outings except one were within this range; $28 \%$ of the vehicle travel days exceed this range.

The daily use of this vehicle, high number of travel days exceeding a BEV range and the high mileage suggests that a PHEV would be the best choice for a replacement vehicle assuming it can handle the balance of mission responsibilities. This is a pickup, but no specific carry requirements were identified. 
Vehicle G41-1367G

\begin{tabular}{|c|c|c|}
\hline \multirow{11}{*}{ 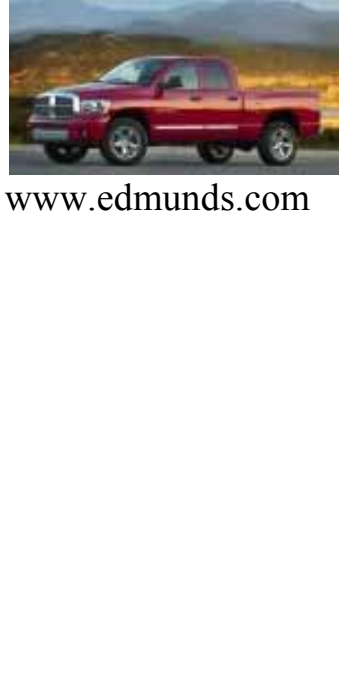 } & Make/Model/Year & Dodge/Dakota/2008 \\
\hline & EPA Class Size & Standard Pickup Truck \\
\hline & Mission & Pool \\
\hline & Contact & C. Sallinger/Motor Transport \\
\hline & Parking Location & Bldg R9641/Rainier Dr \\
\hline & Fleet Vehicle ID & G41-1367G \\
\hline & Fuel Type & $\mathrm{Gas} / \mathrm{ETH}$ \\
\hline & EPA Label/MPG (City/Hwy/Combined)* & $14 / 19 / 15 \quad 9 / 12 / 10$ \\
\hline & EPA GHG Emissions (Grams $\left.\mathrm{CO}_{2} / \mathrm{Mi}\right)^{*}$ & $592 / 630$ \\
\hline & Study Logger ID & Logger 97 \\
\hline & Total Vehicle Days/Total Study Days & $47 / 63$ \\
\hline
\end{tabular}

\begin{tabular}{|l|c|c|c|c|}
\hline \multicolumn{5}{|c|}{ Vehicle G41-1367G Travel Summary } \\
\hline & $\begin{array}{c}\text { Per Day } \\
\text { Average/Peak }\end{array}$ & $\begin{array}{c}\text { Per Outing } \\
\text { Average/Peak }\end{array}$ & $\begin{array}{c}\text { Per Trip } \\
\text { Average/Peak }\end{array}$ & Total \\
\hline Travel Distance (Miles) & $14.5 / 40$ & $4.9 / 29.7$ & $2.5 / 13.9$ & 682 \\
\hline Travel Time (Minutes) & $71 / 184$ & $24.0 / 120$ & $12.3 / 86$ & 3,314 \\
\hline Idle Time (Minutes) & $19.9 / \mathrm{NA}$ & $6.8 / \mathrm{NA}$ & $3.5 / \mathrm{NA}$ & 935 \\
\hline
\end{tabular}

\begin{tabular}{|c|c|c|c|c|}
\hline \multicolumn{2}{|c|}{ Total Stops } & \multicolumn{2}{c|}{ Stop Duration } \\
\hline $\begin{array}{c}\text { Distance From } \\
\text { Home Base (Miles) }\end{array}$ & Stops & Percentages & Stop Duration (Hours) & Stops \\
\hline Less than 10 & 322 & $100 \%$ & Less than 2 & 272 \\
\hline 10 to 20 & 0 & $0 \%$ & 2 to 4 & 14 \\
\hline 20 to 40 & 0 & $0 \%$ & 4 to 8 & 2 \\
\hline 40 to 60 & 0 & $0 \%$ & Greater than 8 & 44 \\
\hline
\end{tabular}

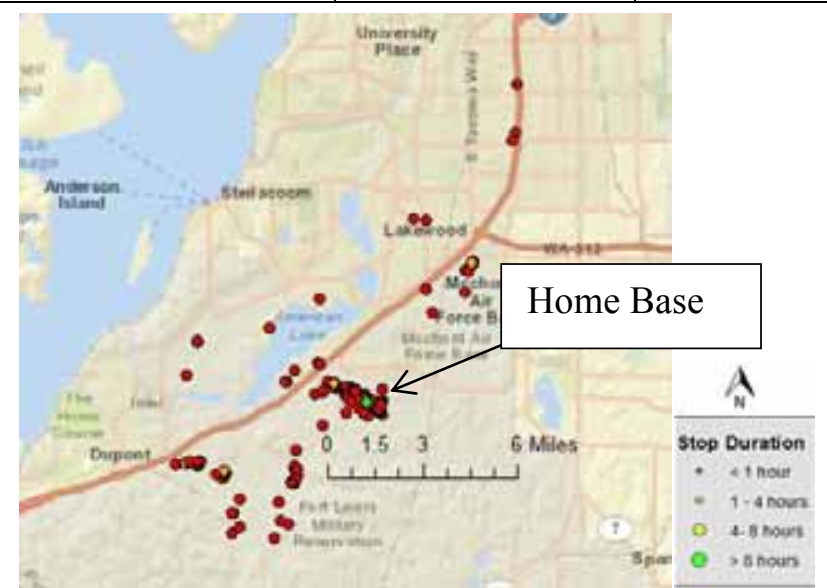

Figure E-55. Vehicle G41-1367G stops.

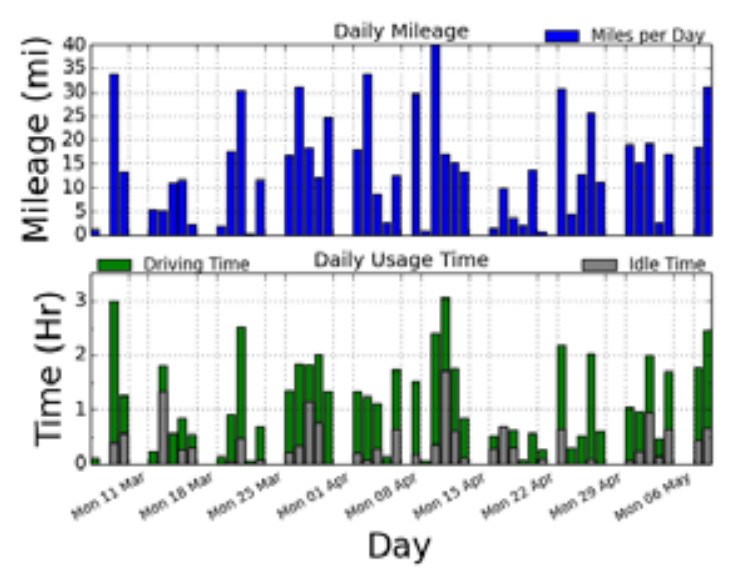

Figure E-56. Vehicle G41-1367G history. 


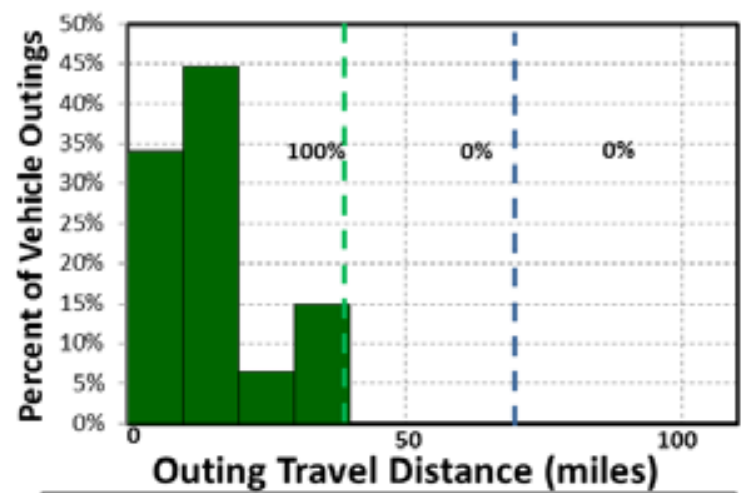

All outings less than 40 miles $\quad$... All outings less than 70 miles

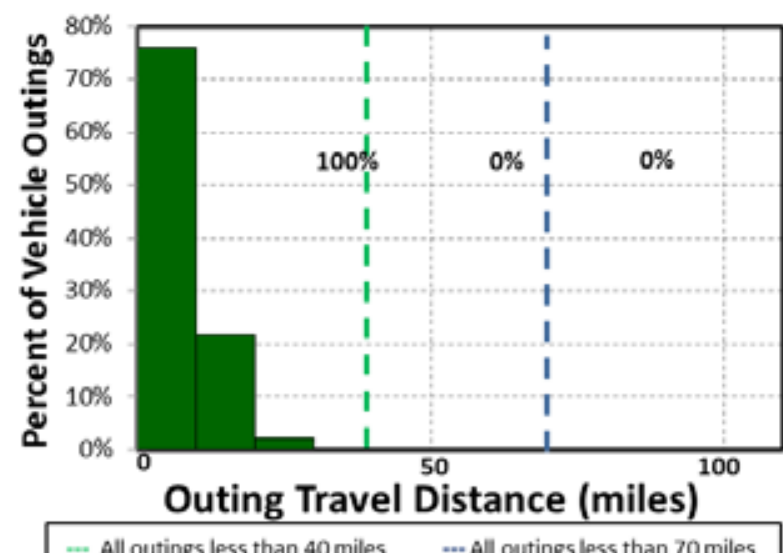

... All outings less than 70 miles

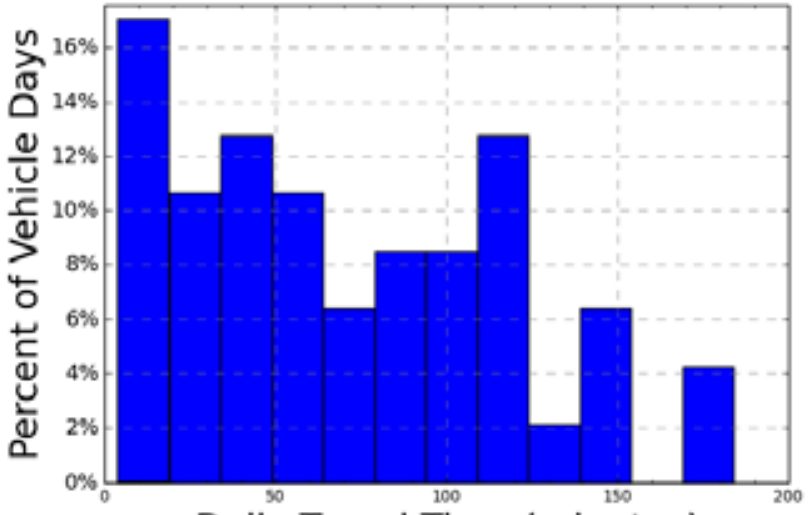

Daily Travel Time (minutes)

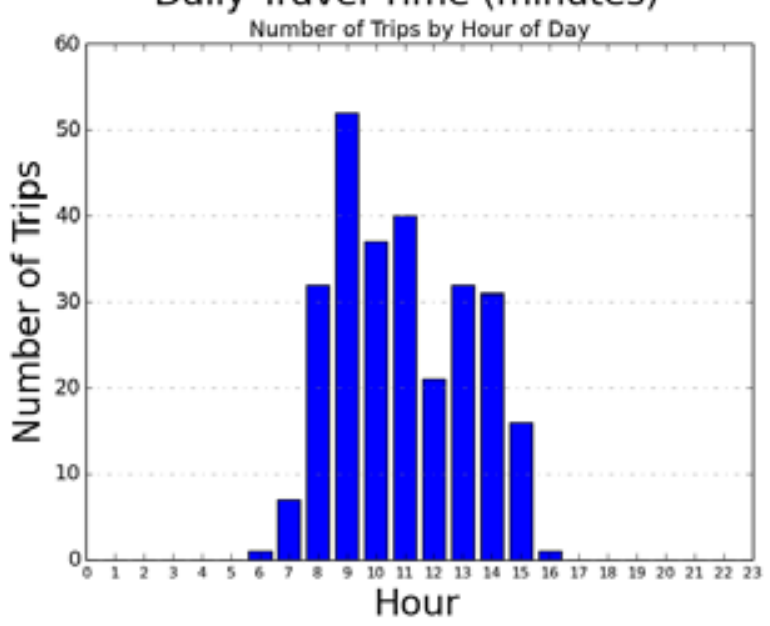

Figure E-49. Vehicle G41-1367G travel graphs.

\section{Vehicle G41-1367G Observations}

Logger 97 collected data on this vehicle for a period of 47 days of the 63-day study period. Validation occurred on $95.4 \%$ of the input data. The project survey response reports this is a pool vehicle assigned to ITD/TMP. It typically parks in the pool parking area but specific area was not identified. Data suggests the primary parking area is near Bldg 9641 on Perry Avenue or Rainier Dr. IDT/TMP suggests the vehicle travels between six and ten miles per day. Site records indicate average monthly travel is 316 miles and the vehicle's odometer read 21,670 in May 2012. More than twenty people have access to this vehicle. The response reports no particular cargo or equipment requirements.

All trips and outings were less than 70 miles and thus, were within the typically advertised range of a BEV of approximately 70 miles. Similarly, all trips and outings were less than 40 miles and thus, were within the typically advertised range of a PHEV. This is a standard pickup with no specific cargo or equipment requirements. Assuming available BEVs can support the balance of mission requirements, a BEV would be expected to provide the acceptable performance of this vehicle. 


\begin{tabular}{|c|c|c|}
\hline $\ln 5 \mathrm{~V} x$ & Make/Model/Year & $\begin{array}{c}\text { Chevrolet/CG3500 } \\
\text { Express/2010 }\end{array}$ \\
\hline & EPA Class Size & Passenger Van \\
\hline & Mission & Pool \\
\hline \multirow[t]{8}{*}{ www.edmunds.com } & Contact & C Sallinger/Motor Transport \\
\hline & Parking Location & Bldg R9640/Perry Ave \\
\hline & Fleet Vehicle ID & G43-0792K \\
\hline & Fuel Type & Gas/ETH \\
\hline & EPA Label/MPG (City/Hwy/Combined)* & $13 / 18 / 15 \quad 10 / 13 / 11$ \\
\hline & EPA GHG Emissions (Grams $\left.\mathrm{CO}_{2} / \mathrm{Mi}\right)^{*}$ & $592 / 572$ \\
\hline & Study Logger ID & Logger 101 \\
\hline & Total Vehicle Days/Total Study Days & $44 / 63$ \\
\hline
\end{tabular}

\begin{tabular}{|l|c|c|c|c|}
\hline \multicolumn{5}{|c|}{ Vehicle G43-0792K Travel Summary } \\
& $\begin{array}{c}\text { Per Day } \\
\text { Average/Peak }\end{array}$ & $\begin{array}{c}\text { Per Outing } \\
\text { Average/Peak }\end{array}$ & $\begin{array}{c}\text { Per Trip } \\
\text { Average/Peak }\end{array}$ & Total \\
\hline Travel Distance (Miles) & $36.0 / 308.7$ & $15.2 / 309.6$ & $5.0 / 149.5$ & 1,583 \\
\hline Travel Time (Minutes) & $127 / 581$ & $53.6 / 908$ & $17.7 / 182$ & 5,571 \\
\hline Idle Time (Minutes) & $38.6 / \mathrm{NA}$ & $16.3 / \mathrm{NA}$ & $5.4 / \mathrm{NA}$ & 1,697 \\
\hline
\end{tabular}

\begin{tabular}{|c|c|c|c|c|}
\hline \multicolumn{2}{|c|}{ Total Stops } & \multicolumn{2}{c|}{ Stop Duration } \\
\hline $\begin{array}{c}\text { Distance From } \\
\text { Home Base (Miles) }\end{array}$ & Stops & Percentages & Stop Duration (Hours) & Stops \\
\hline Less than 10 & 306 & $90.8 \%$ & Less than 2 & 255 \\
\hline 10 to 20 & 16 & $4.7 \%$ & 2 to 4 & 18 \\
\hline 20 to 40 & 5 & $1.5 \%$ & 4 to 8 & 16 \\
\hline 40 to 60 & 10 & $3.0 \%$ & Greater than 8 & 48 \\
\hline
\end{tabular}

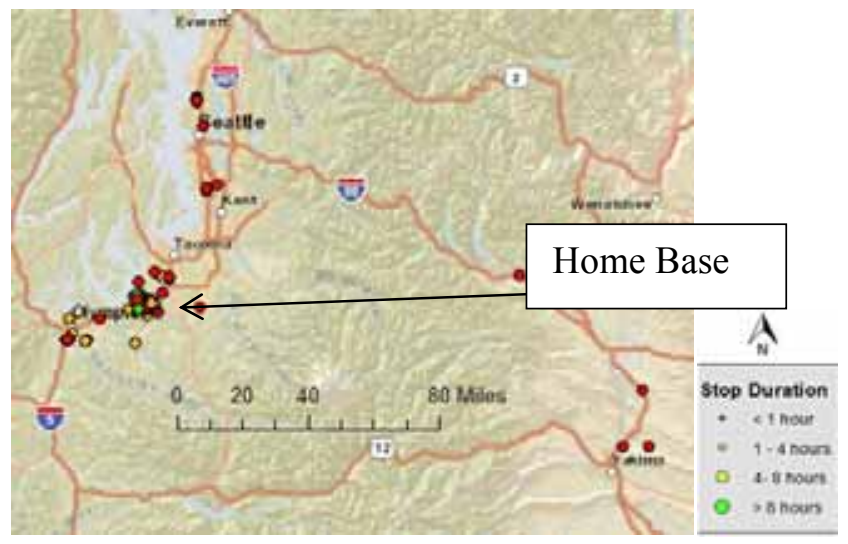

Figure E-58. Vehicle G43-0792K stops.

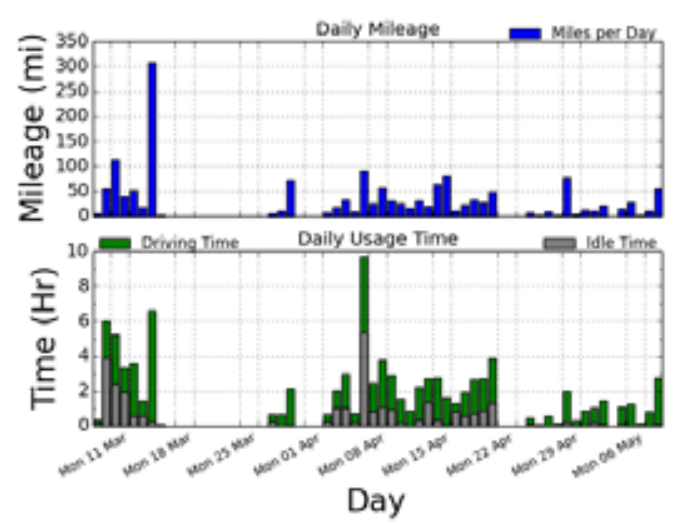

Figure E-59. Vehicle G43-0792K history.

*2010 Chevrolet Express 1500 information. EPA data for 2010 Chevrolet CG3500 Express not available. 

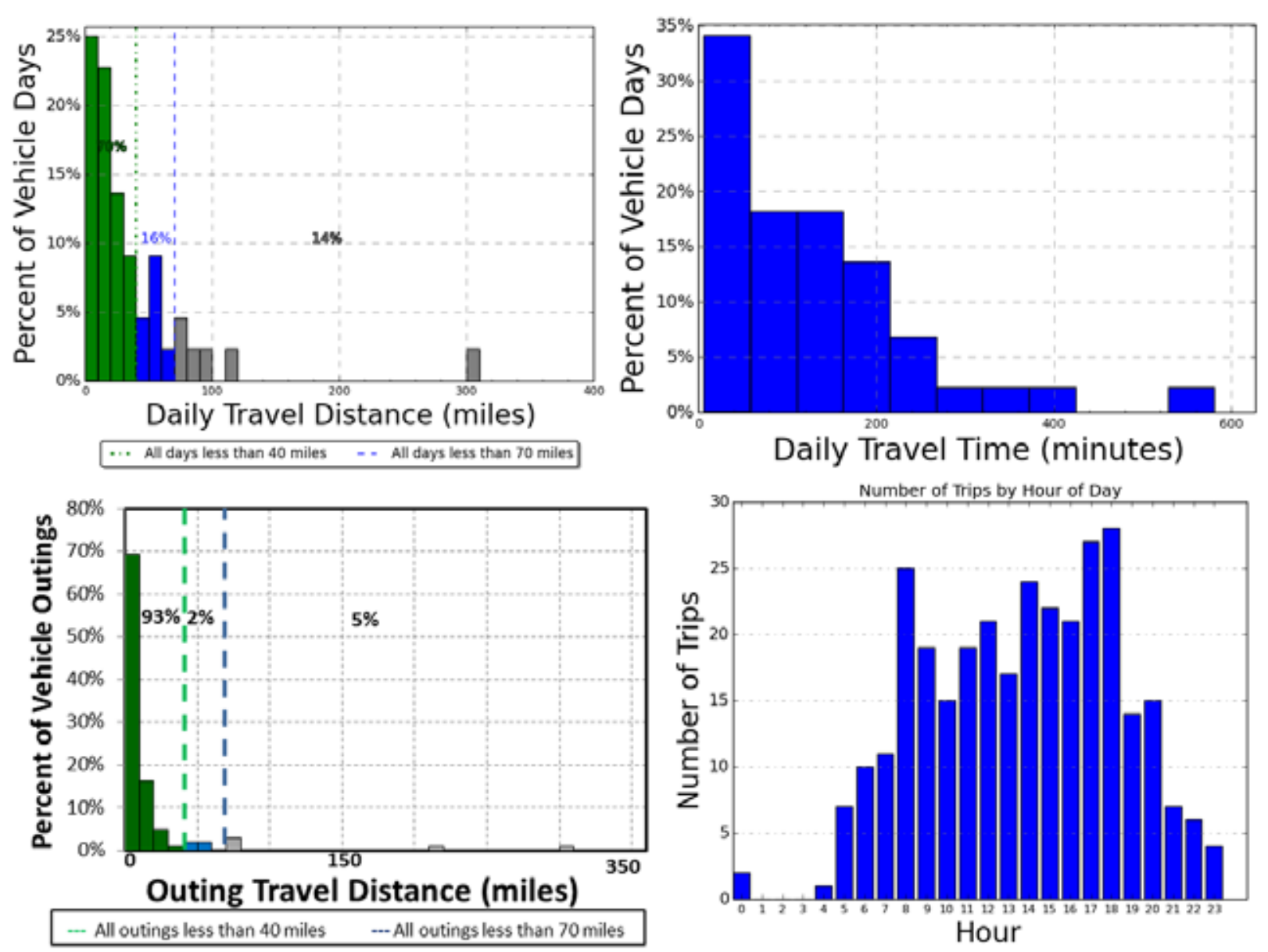

Figure E-50. Vehicle G43-0792K travel graphs.

\section{Vehicle G43-0792K Observations}

Logger 101 collected data on this vehicle for a period of 44 days of the 63-day study period. Validation occurred on $98.8 \%$ of the input data. Survey information was not available for this vehicle. Stop data suggests it typically parks near Bldg 9640 on Perry Ave or in the Eagle View Housing Area near $19^{\text {th }}$ Street and F Street. Frequent stops on Utah and other locations are also evident. Site data reports an odometer reading of 25,683 in May 2012 with an average of 1014 miles per month.

$86 \%$ of all vehicle travel days and $95 \%$ of all outings were within the 70 -mile BEV safe range (green and blue bars on Figure E-60), while 14\% of the vehicle travel days exceeds this range. The longest daily travel of 309 miles occurred on March 13 to Yakima and Tacoma that also included the longest single outing of 310 miles (the vehicle returned to the home base the next day). The next longest outing of 219 miles also occurred over a several day period involving a trip to Tumwater and Seattle, WA. Because this vehicle stops at many locations and does not return to a specific home base, outing information reported here may be overly conservative relative to a PEV, which would return to a home charging location. However, the longest outings shown are accurate depictions of vehicle travel.

While only 5 days of the 63 days in the study showed travel exceeding the 70-mile range, the occurrences were random suggesting that a BEV may not be a suitable replacement vehicle for this specific vehicle. However, a mix of BEVs and PHEVs may satisfy the necessary travel requirements of vehicles in this mission category depending upon the passenger carrying capabilities. 


\begin{tabular}{|c|c|c|}
\hline 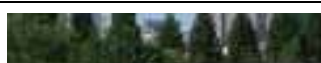 & Make/Model/Year & Chevrolet/Express CG3500/2010 \\
\hline & EPA Class Size & Passenger Van \\
\hline & Mission & Pool \\
\hline \multirow{8}{*}{ www.edmunds.com } & Contact & C. Sallinger/Motor Transport \\
\hline & Parking Location & Bldg R9641 \\
\hline & Fleet Vehicle ID & G43-0801K \\
\hline & Fuel Type & Gas/E85 \\
\hline & EPA Label/MPG (City/Hwy/Combined)* & $13 / 17 / 14 \quad 10 / 13 / 11$ \\
\hline & EPA GHG Emissions $\left(\mathrm{Grams} \mathrm{CO}_{2} / \mathrm{Mi}\right)^{*}$ & $635 / 572$ \\
\hline & Study Logger ID & Logger 102 \\
\hline & Total Vehicle Days/Total Study Days & $34 / 63$ \\
\hline
\end{tabular}

\begin{tabular}{|l|c|c|c|c|}
\hline \multicolumn{5}{|c|}{ Vehicle G43-0801K Travel Summary } \\
\hline & $\begin{array}{c}\text { Per Day } \\
\text { Average/Peak }\end{array}$ & $\begin{array}{c}\text { Per Outing } \\
\text { Average/Peak }\end{array}$ & $\begin{array}{c}\text { Per Trip } \\
\text { Average/Peak }\end{array}$ & Total \\
\hline Travel Distance (Miles) & $52.4 / 354.1$ & $46.9 / 995.0$ & $7.1 / 158.0$ & 1,782 \\
\hline Travel Time (Minutes) & $143 / 601.0$ & $128.1 / 1614$ & $19.5 / 169.0$ & 4,867 \\
\hline Idle Time (Minutes) & $52.8 / \mathrm{NA}$ & $47.3 / \mathrm{NA}$ & $7.2 / \mathrm{NA}$ & 1,796 \\
\hline
\end{tabular}

\begin{tabular}{|c|c|c|c|c|}
\hline \multicolumn{2}{|c|}{ Total Stops } & \multicolumn{2}{c|}{ Stop Duration } \\
\hline $\begin{array}{c}\text { Distance From } \\
\text { Home Base (Miles) }\end{array}$ & Stops & Percentages & Stop Duration (Hours) & Stops \\
\hline Less than 10 & 118 & $63.1 \%$ & Less than 2 & 140 \\
\hline 10 to 20 & 1 & $0.5 \%$ & 2 to 4 & 5 \\
\hline 20 to 40 & 9 & $4.8 \%$ & 4 to 8 & 9 \\
\hline 40 to 60 & 60 & $32.1 \%$ & Greater than 8 & 33 \\
\hline
\end{tabular}

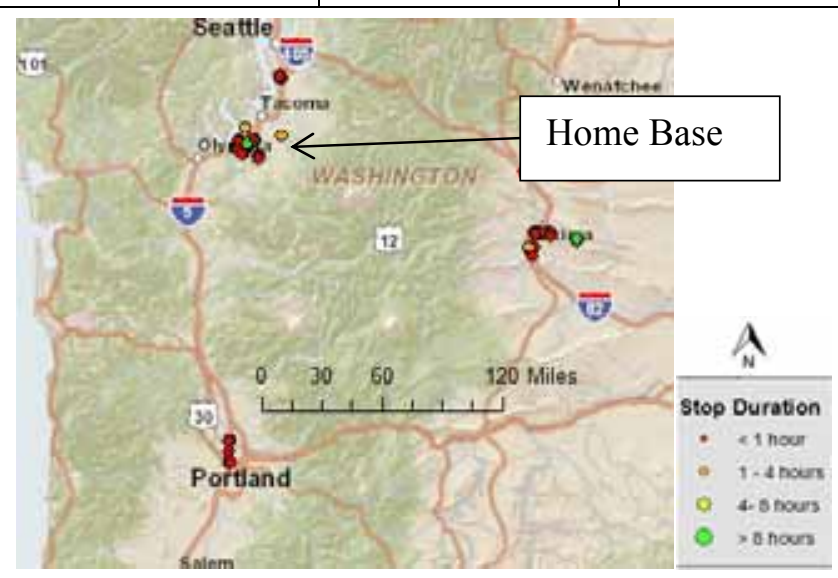

Figure E-61. Vehicle G43-0801K stops.

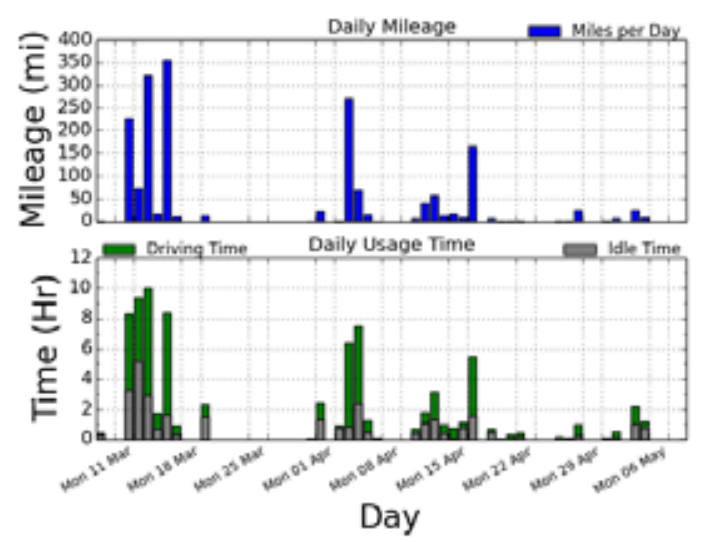

Figure E-62. Vehicle G43-0801K history. *2010 Chevrolet Express 1500 information. EPA data for CG3500 not available. 


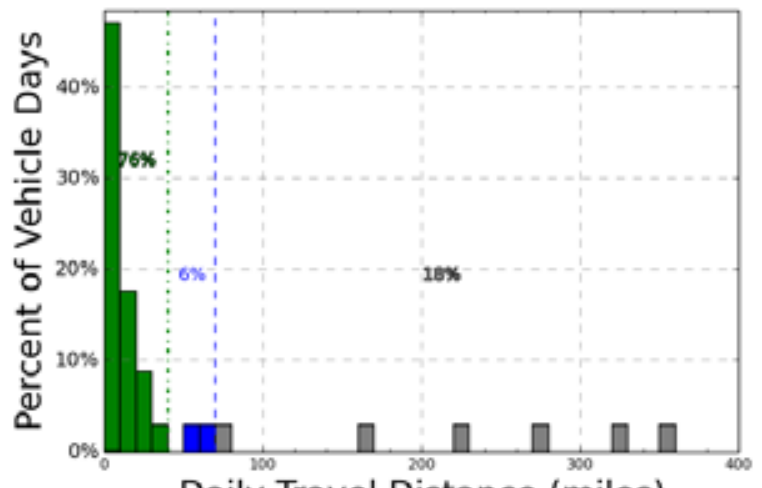

Daily Travel Distance (miles)

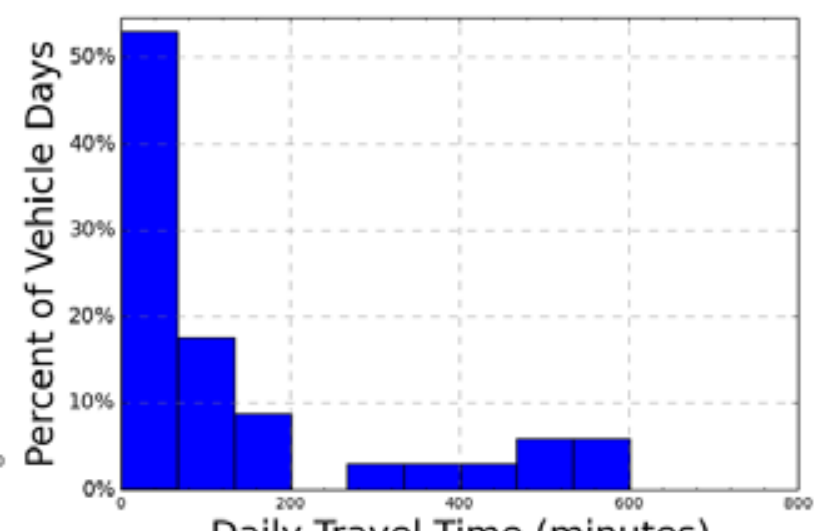

- All days less than 40 miles - - All days less than 70 miles
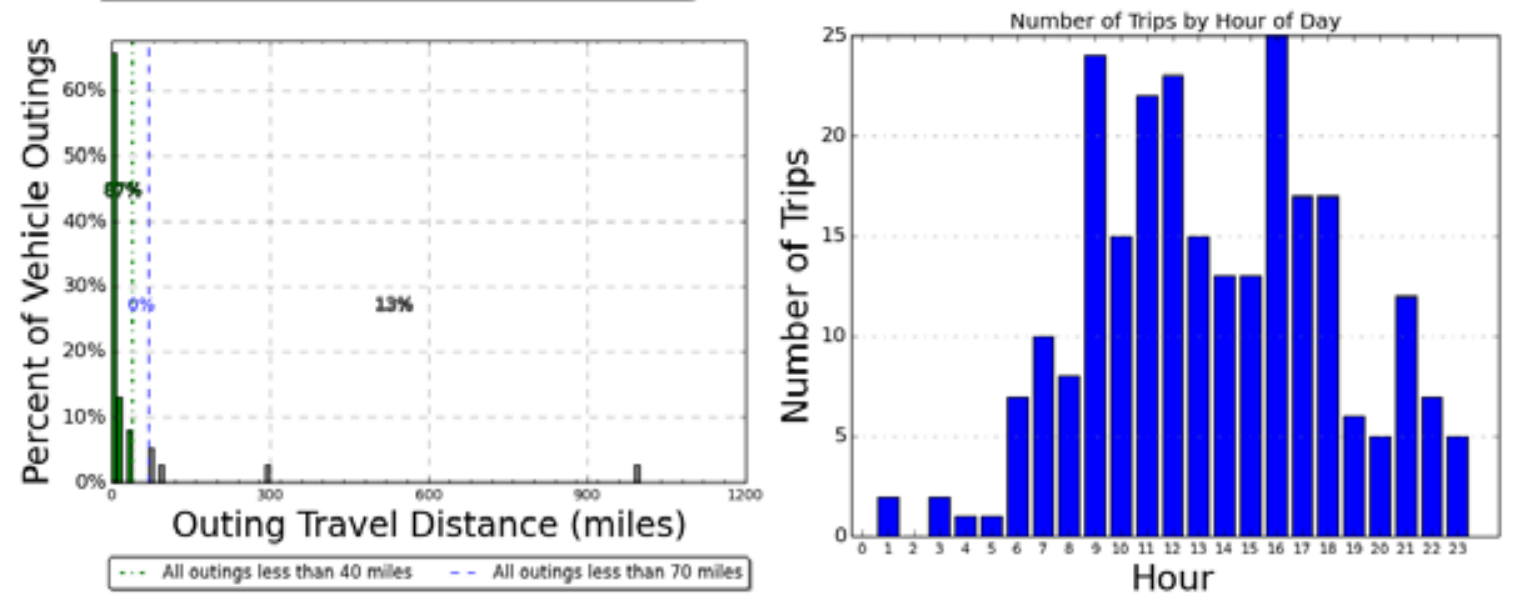

Figure E-51. Vehicle G43-0801K travel graphs.

\section{Vehicle G43-0801K Observations}

Logger 102 collected data on this vehicle for a period of 34 days of the 63-day study period. Validation occurred on $99.1 \%$ of the input data. Survey information was not available for this vehicle. Stop data suggests it typically parks near Bldg 9641 but is used extensively around the base. Site data reports an odometer reading of 17,820 in May 2012 with an average of 742 miles per month.

$82 \%$ of all vehicle travel days and $87 \%$ of all outings were within the 70 -mile BEV safe range (green and blue bars on Figure E-63), while 18\% of the vehicle travel days exceeds this range. An extended outing to Ellensburg, Yakima and SEATAC occurred on March 10 - March 18 of 995 miles. While the vehicle returned to Ft Lewis on March 12, it did not return to its home base on Perry Avenue until March 18. A similar outing occurred from April 9 to April 15 reflecting the outing of 300 miles.

Because this vehicle stops at many locations and does not return to a specific home base, outing information reported here may be overly conservative relative to a PEV, which would return to a home charging location. However, the longest outings shown are accurate depictions of vehicle travel.

While only 5 days of the 63 days in the study showed travel exceeding the 70-mile range, the occurrences were random suggesting that a BEV may not be a suitable replacement vehicle for this specific vehicle. However, a mix of BEVs and PHEVs may satisfy the necessary travel requirements of vehicles in this mission category depending upon the passenger carrying capabilities. 
Vehicle G42-0988F

\begin{tabular}{|c|c|c|}
\hline & Make/Model/Year & Chevrolet/Express 13/2007 \\
\hline & EPA Class Size & Cargo Van \\
\hline & Mission & Support \\
\hline www edmunds com & Contact & C. Sallinger/Motor Transport \\
\hline & Parking Location & Bldg 9040/Fitzsimmons \\
\hline & Fleet Vehicle ID & G42-0988F \\
\hline & Fuel Type & Gas \\
\hline & EPA Label/MPG (City/Hwy/Combined)* & $13 / 16 / 14$ \\
\hline & EPA GHG Emissions $\left(\text { Grams } \mathrm{CO}_{2} / \mathrm{Mi}\right)^{*}$ & 635 \\
\hline & Study Logger ID & Logger 104 \\
\hline & Total Vehicle Days/Total Study Days & $40 / 63$ \\
\hline
\end{tabular}

\begin{tabular}{|l|c|c|c|c|}
\hline \multicolumn{5}{|c|}{ Vehicle G42-0988F Travel Summary } \\
\hline & $\begin{array}{c}\text { Per Day } \\
\text { Average/Peak }\end{array}$ & $\begin{array}{c}\text { Per Outing } \\
\text { Average/Peak }\end{array}$ & $\begin{array}{c}\text { Per Trip } \\
\text { Average/Peak }\end{array}$ & Total \\
\hline Travel Distance (Miles) & $59.9 / 85.8$ & $11.3 / 52.7$ & $2.4 / 20.1$ & 2,394 \\
\hline Travel Time (Minutes) & $185 / 258.0$ & $35.0 / 127.0$ & $7.4 / 57.0$ & 7,410 \\
\hline Idle Time (Minutes) & $16.7 / \mathrm{NA}$ & $3.2 / \mathrm{NA}$ & $0.7 / \mathrm{NA}$ & 669 \\
\hline
\end{tabular}

\begin{tabular}{|c|c|c|c|c|}
\hline \multicolumn{2}{|c|}{ Total Stops } & \multicolumn{2}{c|}{ Stop Duration } \\
\hline $\begin{array}{c}\text { Distance From } \\
\text { Home Base (Miles) }\end{array}$ & Stops & Percentages & Stop Duration (Hours) & Stops \\
\hline Less than 10 & 907 & $97.5 \%$ & Less than 2 & 890 \\
\hline 10 to 20 & 23 & $2.5 \%$ & 2 to 4 & 0 \\
\hline 20 to 40 & 0 & $0 \%$ & 4 to 8 & 0 \\
\hline 40 to 60 & 0 & $0 \%$ & Greater than 8 & 40 \\
\hline
\end{tabular}

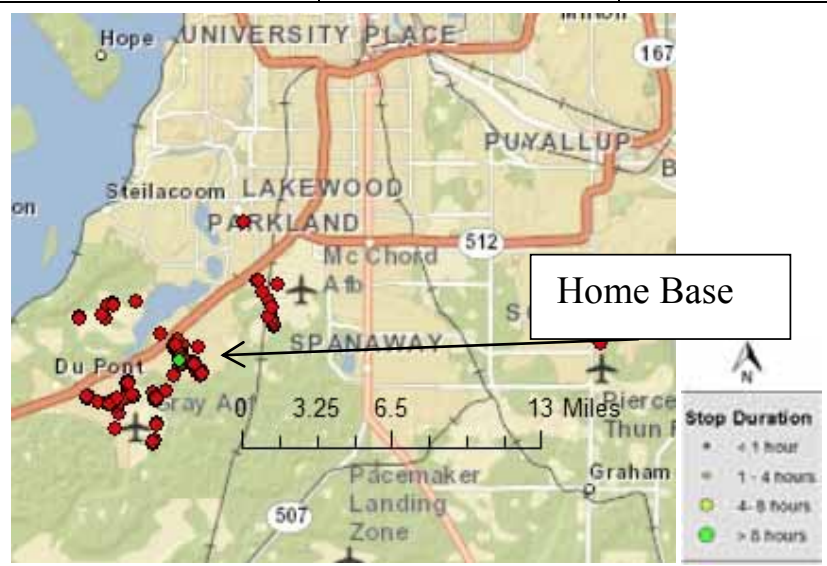

Figure E-64. Vehicle G42-0988F stops.

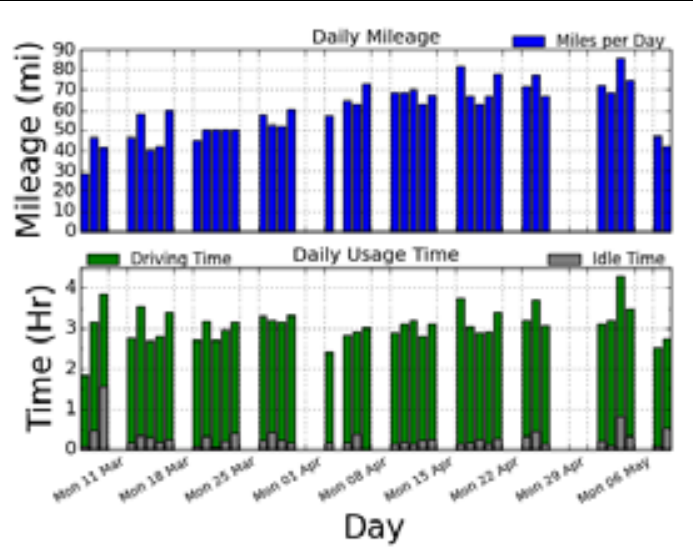

Figure E-65. Vehicle G42-0988F history. 

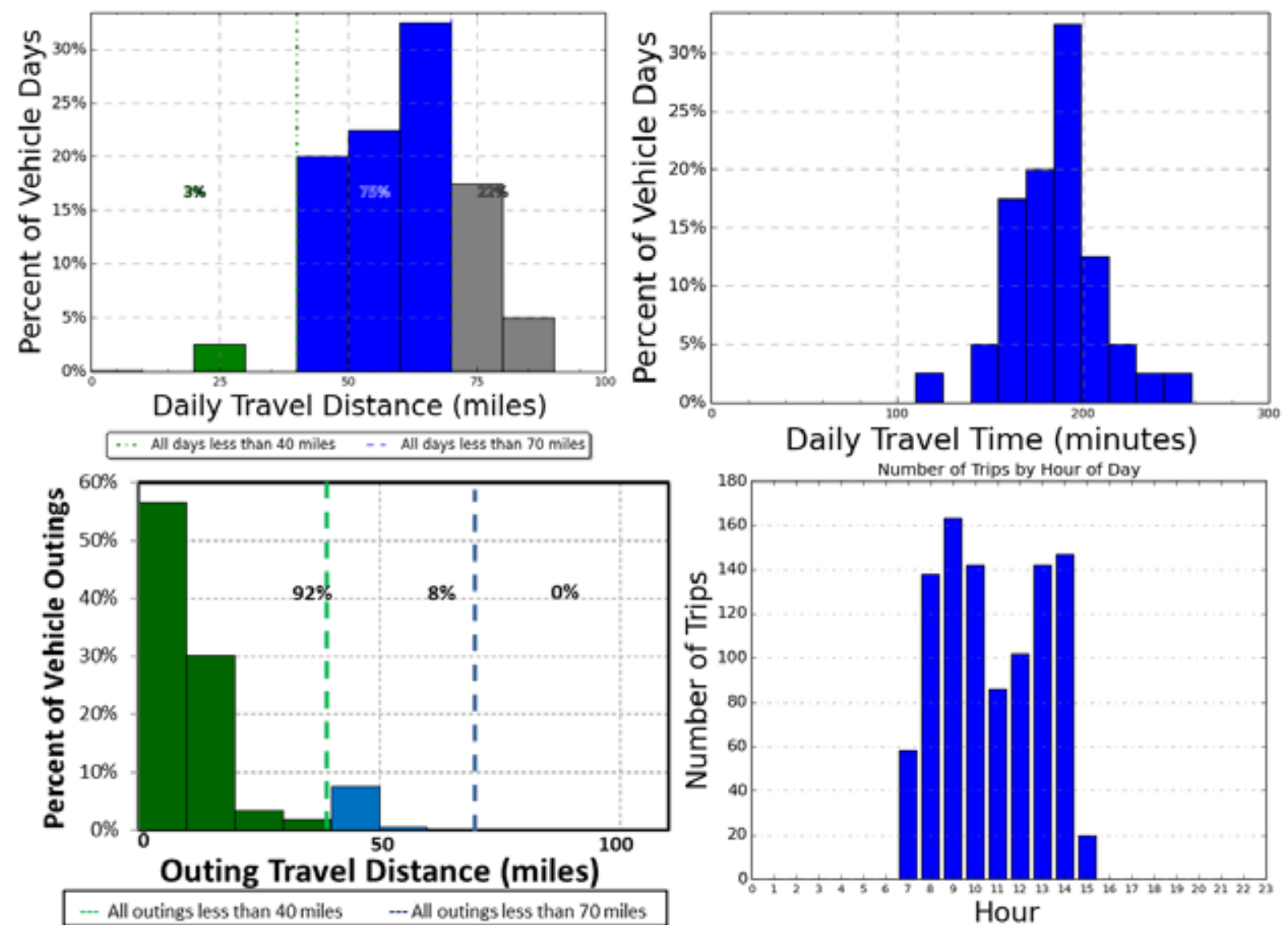

Daily Travel Time (minutes)

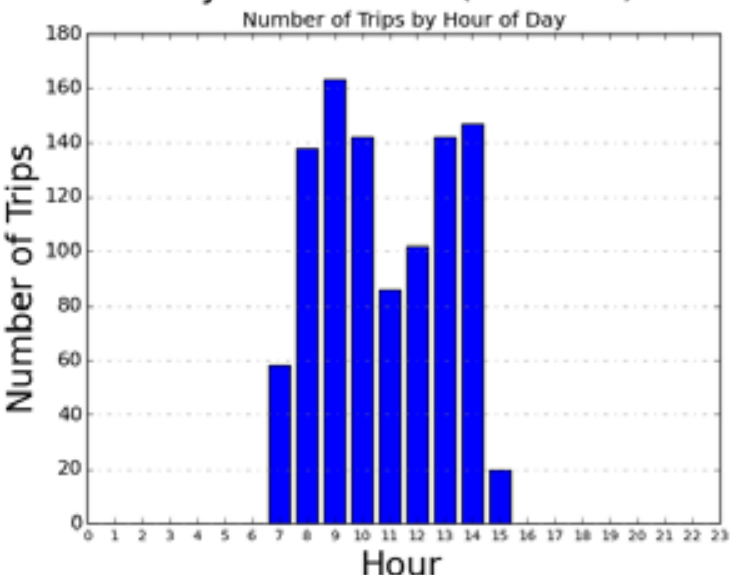

Figure E-52. Vehicle G42-0988F travel graphs.

\section{Vehicle G42-0988F Observations}

Logger 104 collected data on this vehicle for a period of 40 days of the 63-day study period.

Validation occurred on $99.9 \%$ of the input data. The project survey response reports this vehicle, assigned to MAMC/PAD/OPR, is a delivery vehicle that typically parks in the Madigan Army Medical lot on Fitzsimons, Madigan or Gardener Loop. It expects to retain this vehicle more than six years. Expected travel is between forty and one hundred miles per day. Site data reports an odometer reading of 32,172 in May 2012 with an average of 724 miles per month. Between two and five persons access this vehicle and it typically carries one person at a time. This vehicle travels off base frequently - twenty to twenty five times per week with outings expected to be up to one hundred miles. It operates generally between 0700 and 1500 hours daily. It typically carries office supplies, furniture, and medical records.

During the study period, the vehicle traveled a total distance of 2,394 miles over 123 hours. As seen on the history graph (Figure E-65), this vehicle is used extensively. Over 990 individual trips were recorded during the study period. Seventy-eight percent of all vehicle travel days were within the 70-mile BEV safe range (green and blue bars on Figure E-66), while $22 \%$ of the vehicle travel days exceeds this range.

Most of these daily travels consist of relatively short outings. The longest single outing of 52.7 miles occurred on April 9th that remains within the assumed range capability of a BEV. That outing took 1.8 hours of driving time. Total travel that day was 69 miles. There appeared to be insufficient time between trips for any opportunity charging that day. There are a sufficient number of days where the daily miles exceed the 70-mile range and it is suggested a PHEV would best be suited for this vehicle replacement should such meet the cargo carrying requirements. 
Vehicle G43-0860G

\begin{tabular}{|c|c|c|}
\hline \multirow{11}{*}{ www.edmunds.com } & Make/Model/Year & Chevrolet/CG3300/2008 \\
\hline & EPA Class Size & Passenger Van \\
\hline & Mission & Pool \\
\hline & Contact & C. Sallinger/Motor Transport \\
\hline & Parking Location & Bldg R9641or 19th St N \\
\hline & Fleet Vehicle ID & G43-0860G \\
\hline & Fuel Type & Gas \\
\hline & EPA Label/MPG (City/Hwy/Combined)* & $12 / 16 / 14$ \\
\hline & EPA GHG Emissions (Grams $\left.\mathrm{CO}_{2} / \mathrm{Mi}\right)^{*}$ & 635 \\
\hline & Study Logger ID & Logger 105 \\
\hline & Total Vehicle Days/Total Study Days & $41 / 63$ \\
\hline
\end{tabular}

\begin{tabular}{|l|c|c|c|c|}
\hline \multicolumn{5}{|c|}{ Vehicle G43-0860G Travel Summary } \\
\hline & $\begin{array}{c}\text { Per Day } \\
\text { Average/Peak }\end{array}$ & $\begin{array}{c}\text { Per Outing } \\
\text { Average/Peak }\end{array}$ & $\begin{array}{c}\text { Per Trip } \\
\text { Average/Peak }\end{array}$ & Total \\
\hline Travel Distance (Miles) & $33.6 / 164.9$ & $13.2 / 306.0$ & $4.6 / 45.5$ & 1,376 \\
\hline Travel Time (Minutes) & $139 / 433.0$ & $54.6 / 921$ & $18.9 / 139.0$ & 5,680 \\
\hline Idle Time (Minutes) & $45.8 / \mathrm{NA}$ & $18.0 / \mathrm{NA}$ & $6.3 / \mathrm{NA}$ & 1,876 \\
\hline
\end{tabular}

\begin{tabular}{|c|c|c|c|c|}
\hline \multicolumn{2}{|c|}{ Total Stops } & \multicolumn{2}{c|}{ Stop Duration } \\
\hline $\begin{array}{c}\text { Distance From } \\
\text { Home Base (Miles) }\end{array}$ & Stops & Percentages & Stop Duration (Hours) & Stops \\
\hline Less than 10 & 299 & $86.7 \%$ & Less than 2 & 267 \\
\hline 10 to 20 & 11 & $3.2 \%$ & 2 to 4 & 25 \\
\hline 20 to 40 & 35 & $10.1 \%$ & 4 to 8 & 8 \\
\hline 40 to 60 & 0 & $0 \%$ & Greater than 8 & 45 \\
\hline
\end{tabular}

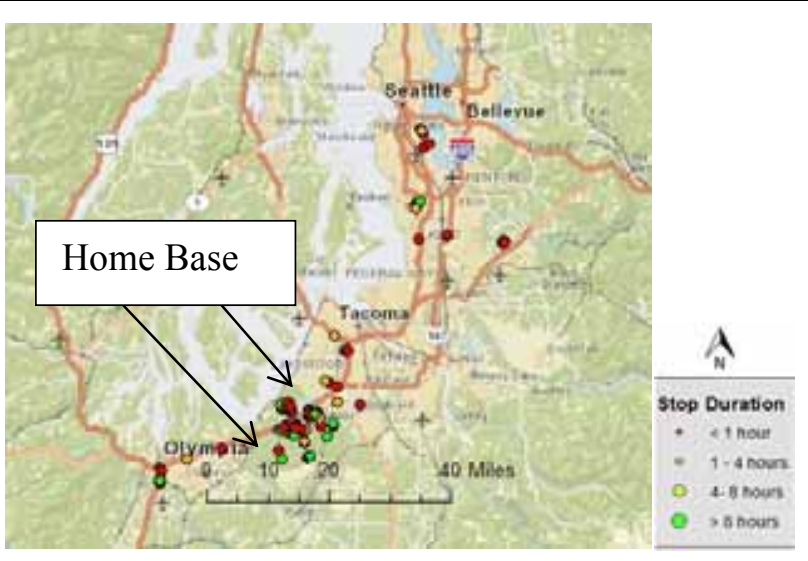

Figure E-67. Vehicle G43-0860G stops.

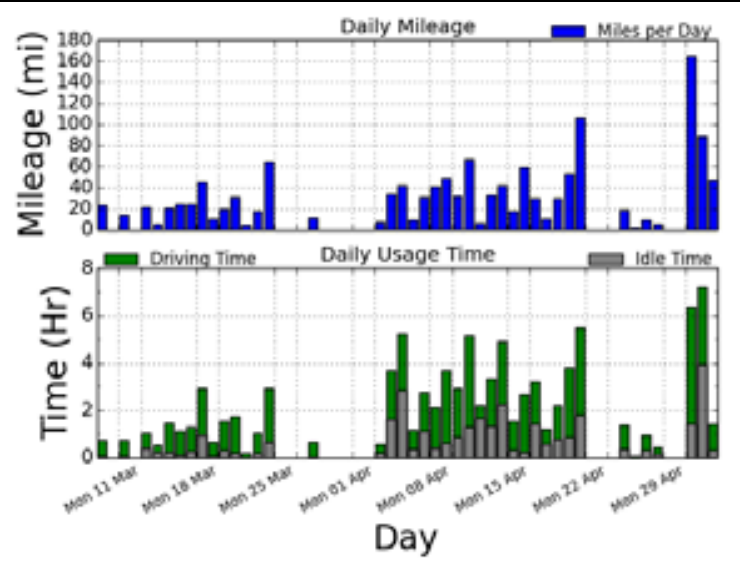

Figure E-68. Vehicle G43-0860G history.

*2008 Chevrolet Express 1500 information. EPA data for CG3300 not available. 


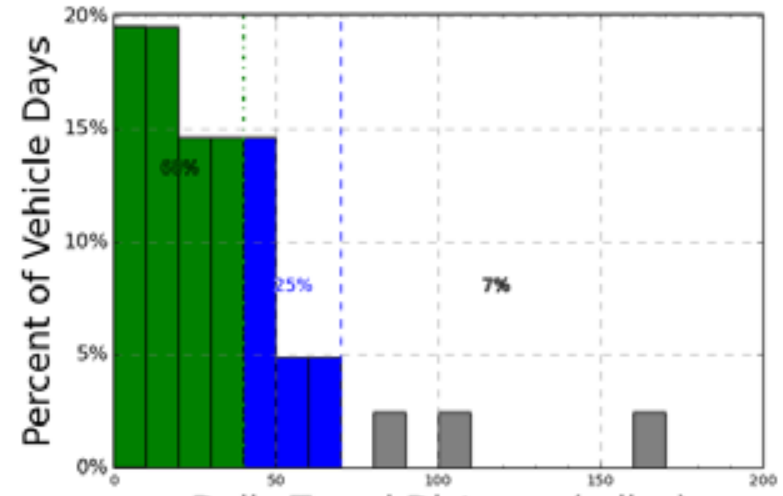

Daily Travel Distance (miles)

... All days less than 40 miles - - All days less than 70 miles

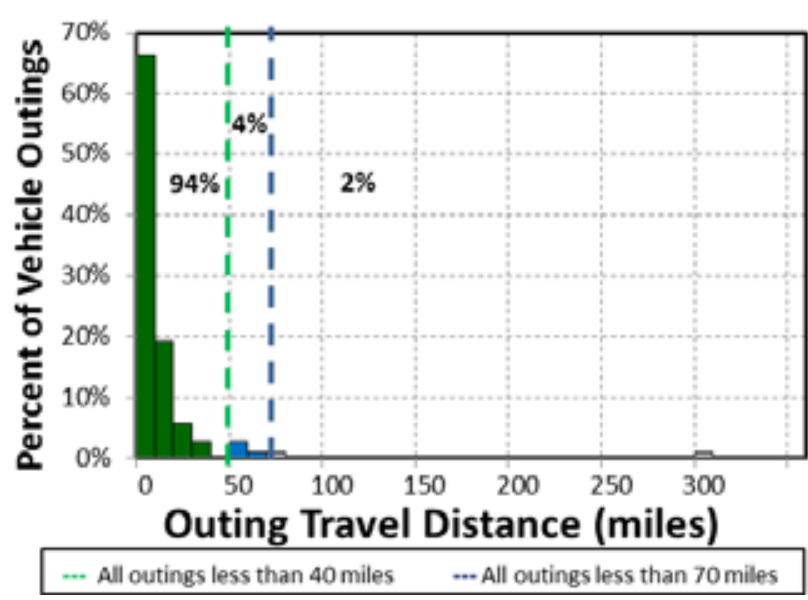

Figure E-53. Vehicle G43-0860G travel graphs.

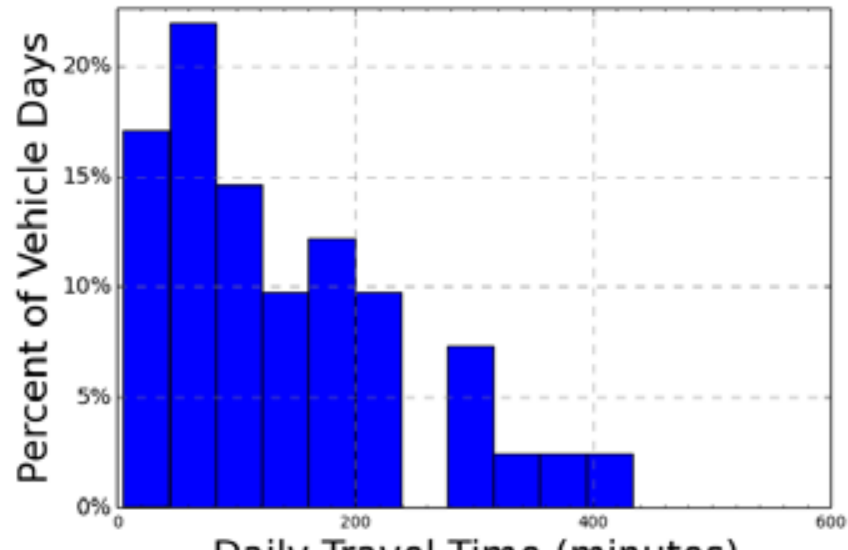

Daily Travel Time (minutes)

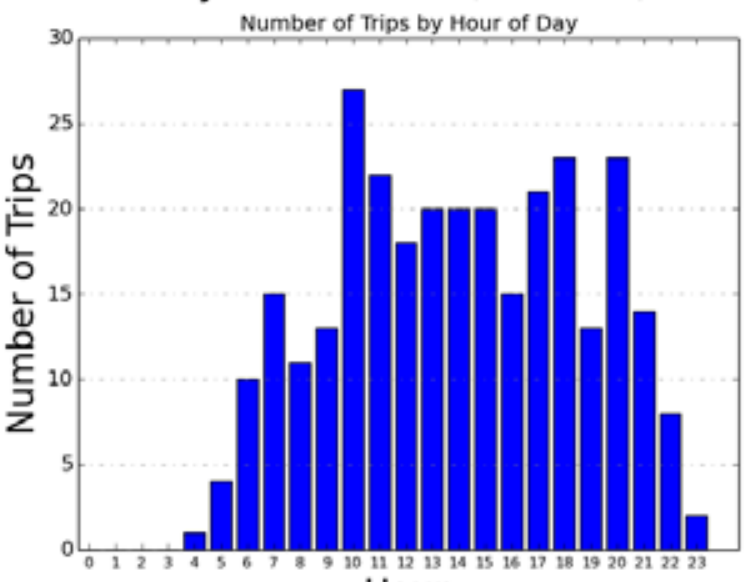

Hour

\section{Vehicle G43-0860G Observations}

Logger 105 collected data on this vehicle for a period of 41 days of the 63-day study period. Validation occurred on $99.8 \%$ of the input data. Survey information was not available for this vehicle. Stop data suggests it typically parks near Bldg 9641 on Perry Ave or on $19^{\text {th }}$ St N. near 12300 buildings area of Eagle View Housing Area. It is also used extensively around the base. Frequent trips to SEATAC were recorded. Site data reports an odometer reading of 39,267 in May 2012 with an average of 818 miles per month.

During the study period, the vehicle traveled a total distance of 1,376 miles over 94 hours. Ninety-three percent of all vehicle travel days were within the 70-mile BEV safe range (green and blue bars on Figure E-69) while 7\% of the vehicle travel days exceeds this range.

The longest single outing of 306 miles occurred over several days from April 29 through May 1 including travel to Shadow Lake, SEATAC, Kent, and Seattle. This outing also contained several of the longer daily travels. Most of the other travel consists of relatively short outings. There are a sufficient number of days where the daily miles exceed the 70-mile range and it is suggested a PHEV would best be suited for this vehicle replacement should such meet the typical passenger carrying requirements. 


\begin{tabular}{|c|c|c|}
\hline $\log 5$ & Make/Model/Year & Chevrolet/CG3300/2010 \\
\hline & EPA Class Size & Passenger Van \\
\hline & Mission & Pool \\
\hline \multirow{8}{*}{ www.edmunds.com } & Contact & C. Sallinger/Motor Transport \\
\hline & Parking Location & Various \\
\hline & Fleet Vehicle ID & G43-1389K \\
\hline & Fuel Type & Gas/ETH \\
\hline & EPA Label/MPG (City/Hwy/Combined)* & $13 / 17 / 14 \quad 10 / 13 / 11$ \\
\hline & EPA GHG Emissions (Grams $\left.\mathrm{CO}_{2} / \mathrm{Mi}\right)^{*}$ & $635 / 572$ \\
\hline & Study Logger ID & Logger 106 \\
\hline & Total Vehicle Days/Total Study Days & $34 / 63$ \\
\hline
\end{tabular}

\begin{tabular}{|l|c|c|c|c|}
\hline \multicolumn{5}{|c|}{ Vehicle G43-1389K Travel Summary } \\
\hline & $\begin{array}{c}\text { Per Day } \\
\text { Average/Peak }\end{array}$ & $\begin{array}{c}\text { Per Outing } \\
\text { Average/Peak }\end{array}$ & $\begin{array}{c}\text { Per Trip } \\
\text { Average/Peak }\end{array}$ & Total \\
\hline Travel Distance (Miles) & $94.7 / 378.4$ & $74.9 / 379.5$ & $19.5 / 160.4$ & 3,219 \\
\hline Travel Time (Minutes) & $181 / 535.0$ & $143.4 / 777.0$ & $37.4 / 184.0$ & 6,166 \\
\hline Idle Time (Minutes) & $39.4 / \mathrm{NA}$ & $31.1 / \mathrm{NA}$ & $8.1 / \mathrm{NA}$ & 1,338 \\
\hline
\end{tabular}

\begin{tabular}{|c|c|c|c|c|}
\hline \multicolumn{2}{|c|}{ Total Stops } & \multicolumn{2}{c|}{ Stop Duration } \\
\hline $\begin{array}{c}\text { Distance From } \\
\text { Home Base (Miles) }\end{array}$ & Stops & Percentages & Stop Duration (Hours) & Stops \\
\hline Less than 10 & 124 & $50.8 \%$ & Less than 2 & 191 \\
\hline 10 to 20 & 14 & $5.7 \%$ & 2 to 4 & 14 \\
\hline 20 to 40 & 41 & $16.8 \%$ & 4 to 8 & 3 \\
\hline 40 to 60 & 65 & $26.6 \%$ & Greater than 8 & 36 \\
\hline
\end{tabular}

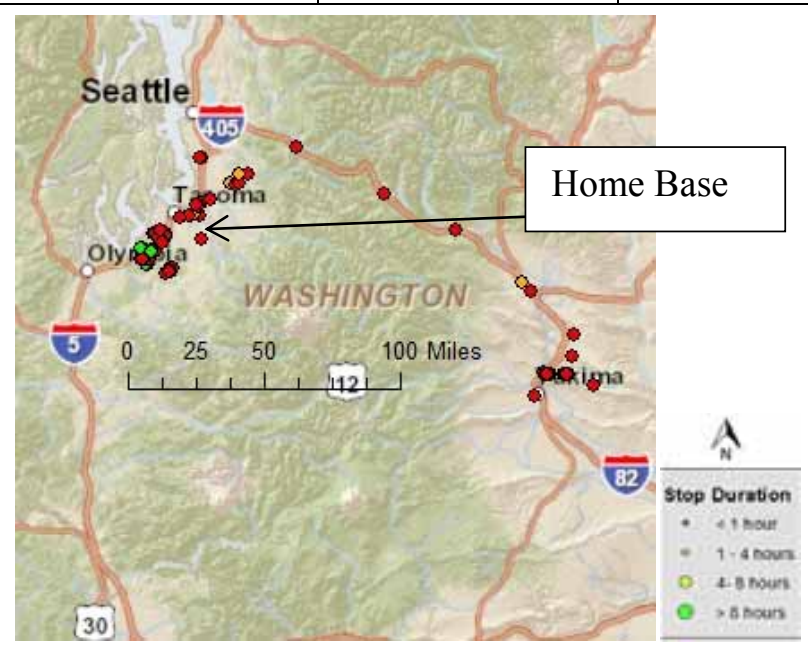

Figure E-70. Vehicle G43-1389K stops.

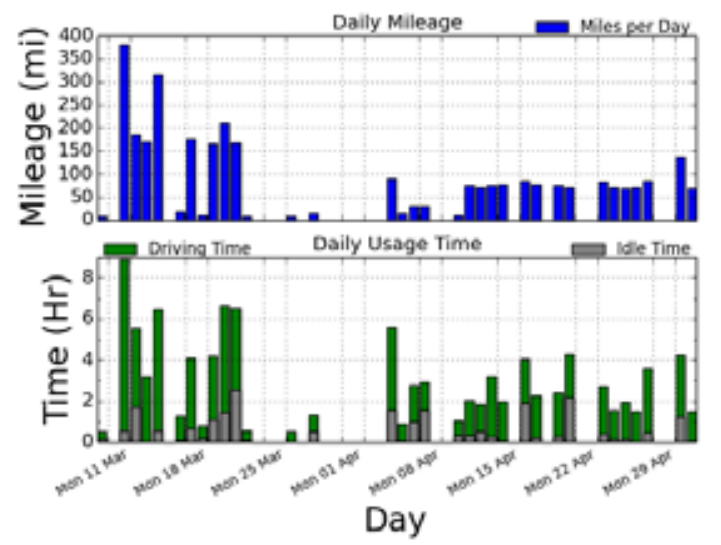

Figure E-71. Vehicle G43-1389K history.

*2010 Chevrolet Express 1500 information. EPA data for CG3300 not available. 

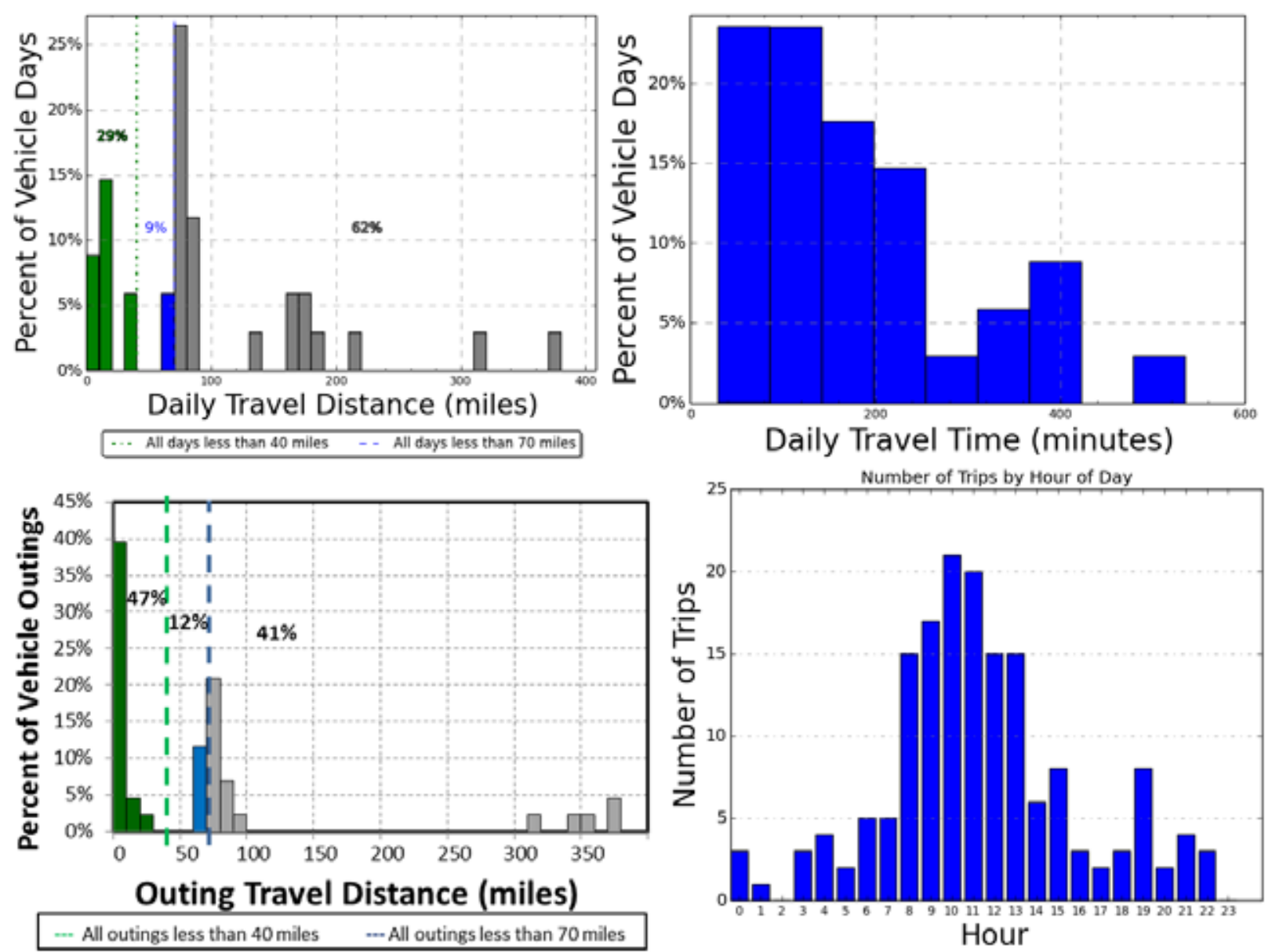

Figure E-54. Vehicle G43-1389K travel graphs.

\section{Vehicle G43-1389K Observations}

Logger 106 collected data on this vehicle for a period of 34 days of the 63-day study period.

Validation occurred on $98.9 \%$ of the input data. Survey information was not available for this vehicle. For the first part of the study period, trip data suggests it was involved in frequent trips to Northeast Yakima on $6^{\text {th }}$ Ave (approximately $300+$ miles round trip) as well as typically parked near $\mathrm{H} \mathrm{St} / \mathrm{I} \mathrm{St} / 12^{\text {th }}$ Street area in North Fort Lewis. It shifted parking areas to Perry Avenue near Bldg 9640. For the later part of the study period, the vehicle mostly parked on $41^{\text {st }}$ Division Way in Camp Murray. Here it was involved in frequent trips to Shadow Lake, WA (approximately 70 miles round trip). Site data reports an odometer reading of 15,291 in May 2012 with an average of 694 miles per month.

During the study period, the vehicle traveled a total distance of 3,219 miles over 100 hours. Thirty-eight percent of all vehicle travel days were within the 70-mile BEV safe range (green and blue bars on Figure E-72) while $62 \%$ of the vehicle travel days exceeds this range.

Because of the frequent long trips and frequent use, it is suggested a PHEV would best be suited for this vehicle replacement should such meet the typical passenger carrying requirements. 
Vehicle G41-1180G

\begin{tabular}{|l|l|c|}
\hline \multirow{4}{*}{ www.edmunds.com } & Make/Model/Year & Chevrolet/Uplander/2008 \\
\cline { 2 - 3 } & EPA Class Size & Minivan \\
\cline { 2 - 3 } & Mission & Support \\
\cline { 2 - 3 } & Contact & Jldg $9040 /$ Fitzsimmons \\
\cline { 2 - 3 } & Parking Location & G41-1180G \\
\cline { 2 - 3 } & Fleet Vehicle ID & Gas/ETH \\
\cline { 2 - 3 } & Fuel Type & $16 / 23 / 1912 / 17 / 14$ \\
\cline { 2 - 3 } & EPA Label/MPG (City/Hwy/Combined)* & $468 / 450$ \\
\cline { 2 - 3 } & EPA GHG Emissions (Grams CO $\left.\mathrm{CO}_{2} / \mathrm{Mi}\right)^{*}$ & Logger 107 \\
\cline { 2 - 3 } & Study Logger ID & $16 / 63$ \\
\hline & Total Vehicle Days/Total Study Days & . \\
\hline
\end{tabular}

\begin{tabular}{|l|c|c|c|c|}
\hline \multicolumn{5}{|c|}{ Vehicle G42-0698K Travel Summary } \\
\hline & $\begin{array}{c}\text { Per Day } \\
\text { Average/Peak }\end{array}$ & $\begin{array}{c}\text { Per Outing } \\
\text { Average/Peak }\end{array}$ & $\begin{array}{c}\text { Per Trip } \\
\text { Average/Peak }\end{array}$ & Total \\
\hline Travel Distance (Miles) & $18.3 / 79.1$ & $17.2 / 79.1$ & $6.0 / 36.5$ & 293 \\
\hline Travel Time (Minutes) & $44 / 120.0$ & $41.0 / 120$ & $14.3 / 43.0$ & 697 \\
\hline Idle Time (Minutes) & $5.9 / \mathrm{NA}$ & $5.5 / \mathrm{NA}$ & $1.9 / \mathrm{NA}$ & 94 \\
\hline
\end{tabular}

\begin{tabular}{|c|c|c|c|c|}
\hline \multicolumn{2}{|c|}{ Total Stops } & \multicolumn{2}{c|}{ Stop Duration } \\
\hline $\begin{array}{c}\text { Distance From } \\
\text { Home Base (Miles) }\end{array}$ & Stops & Percentages & Stop Duration (Hours) & Stops \\
\hline Less than 10 & 51 & $94.4 \%$ & Less than 2 & 38 \\
\hline 10 to 20 & 1 & $1.9 \%$ & 2 to 4 & 2 \\
\hline 20 to 40 & 2 & $3.7 \%$ & 4 to 8 & 0 \\
\hline 40 to 60 & 0 & $0 \%$ & Greater than 8 & 14 \\
\hline
\end{tabular}

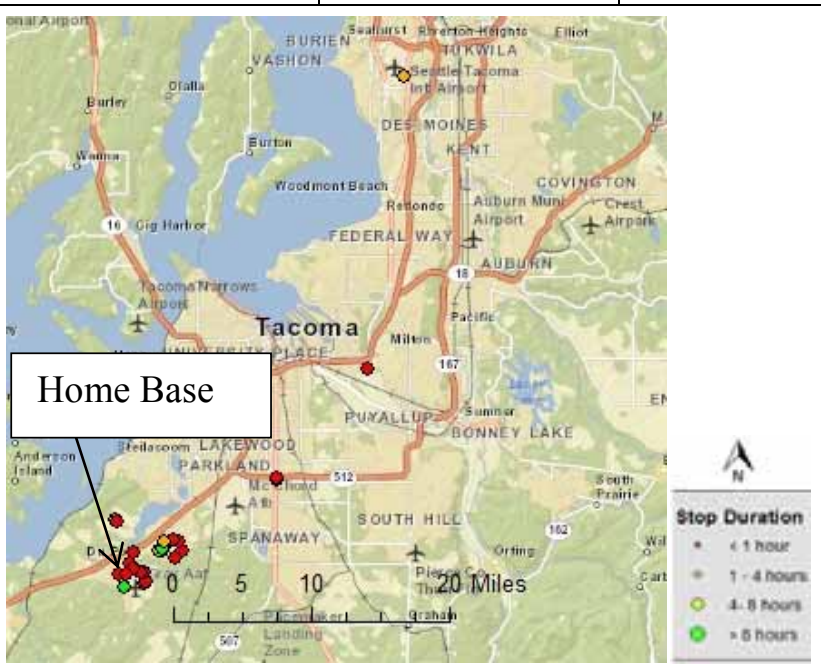

Figure E-73. Vehicle G41-1180G stops.

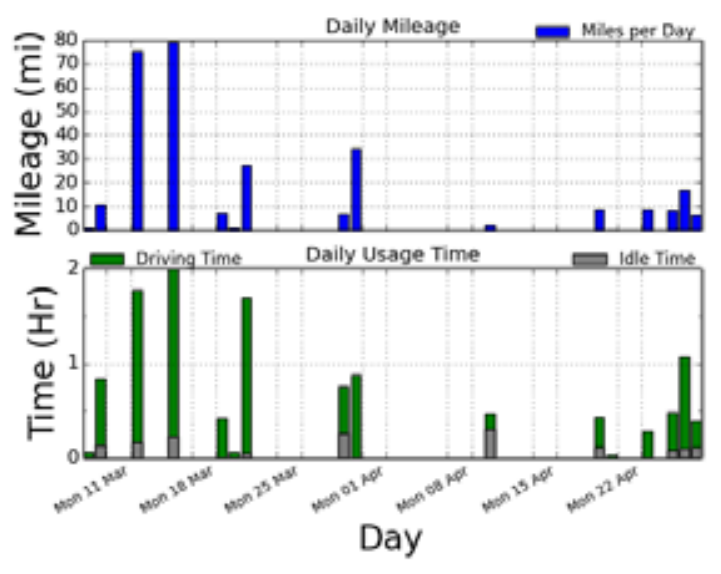

Figure E-74. Vehicle G41-1180G history. 

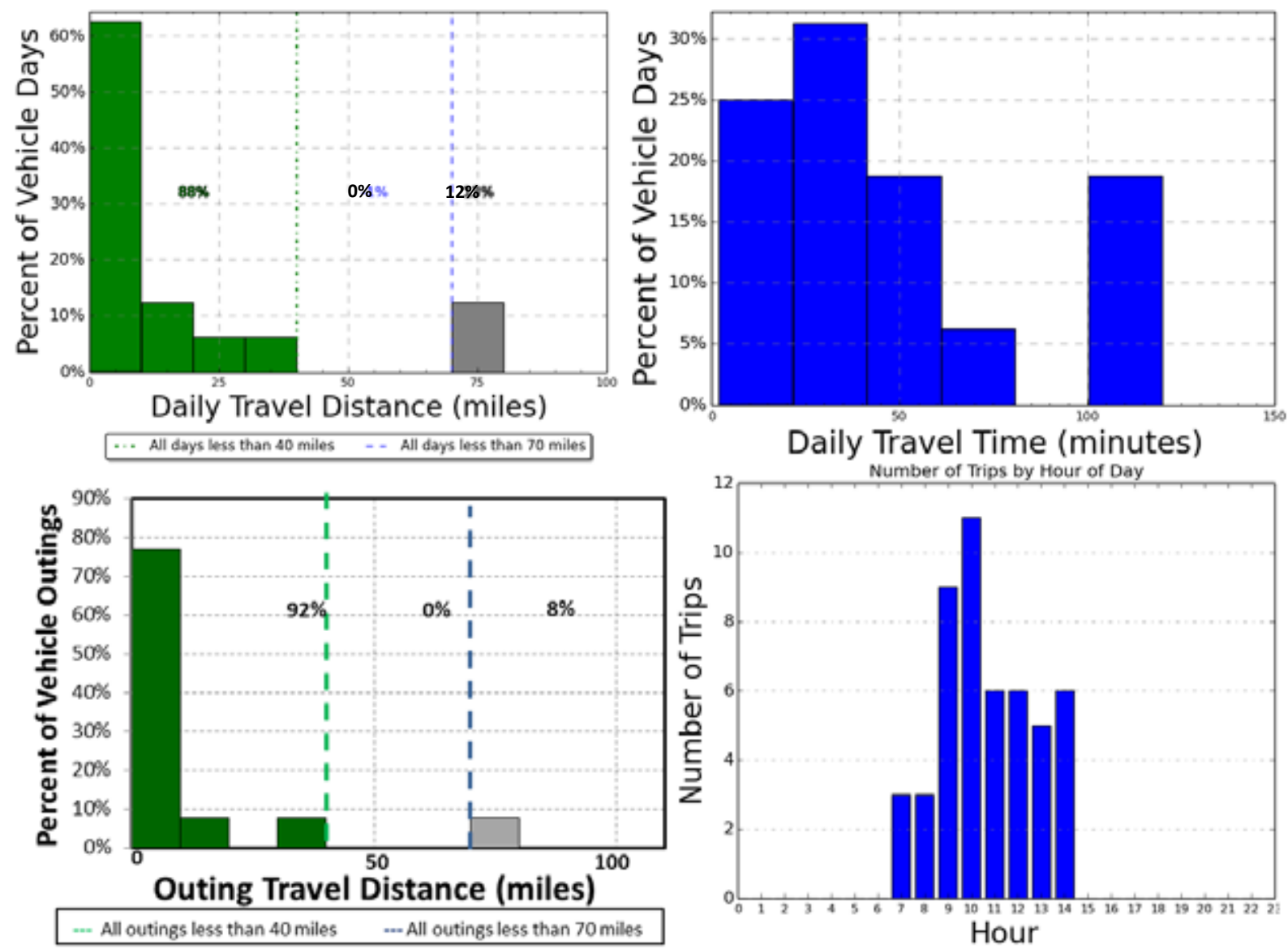

Figure E-55. Vehicle G41-1180G travel graphs.

\section{Vehicle G41-1180G Observations}

Logger 107 collected data on this vehicle for a period of 16 days of the 63-day study period. Validation occurred on $94.4 \%$ of the input data. Survey information was not available for this vehicle. Stop data suggests it typically parks near Bldg 9040, Madigan Army Medical Center, on Fitzsimmons or Gardner Lop Road. Site data reports an odometer reading of 17,820 in May 2012 with an average of 742 miles per month.

During the study period, the vehicle traveled a total distance of 293 miles over 11 hours. Eighty-eight percent of all vehicle travel days were within the 70-mile BEV safe range (green and blue bars on Figure E-75) while $12 \%$ of the vehicle travel days exceeds this range.

Two outings of 71.2 and 79.1 miles occurred on March 11 and March 14 during travel to SEATAC. That outing took less than 2 hours of driving time but unless charging stations are located at SEATAC that are convenient, the outing exceeds the BEV safe range. It is suggested a PHEV would best be suited for this vehicle. 
Vehicle G11-2675G

\begin{tabular}{|l|l|c|}
\hline \multirow{4}{*}{ www.edmunds.com } & Make/Model/Year & Chevrolet/Impala/2008 \\
\cline { 2 - 3 } & EPA Class Size & Large Cars \\
\cline { 2 - 3 } & Mission & Pool \\
\cline { 2 - 3 } & Contact & Bldg $9040 / 9900$ \\
\cline { 2 - 3 } & Parking Location & G11-2675G \\
\cline { 2 - 3 } & Fleet Vehicle ID & Gas/ETH \\
\cline { 2 - 3 } & Fuel Type & $18 / 29 / 2214 / 21 / 16$ \\
\cline { 2 - 3 } & EPA Label/MPG (City/Hwy/Combined)* & $404 / 393$ \\
\cline { 2 - 3 } & EPA GHG Emissions (Grams CO $/$ Mi)* & Logger 108 \\
\cline { 2 - 3 } & Study Logger ID & $8 / 63$ \\
\hline & Total Vehicle Days/Total Study Days & . \\
\hline
\end{tabular}

\begin{tabular}{|l|c|c|c|c|}
\hline \multicolumn{5}{|c|}{ Vehicle G11-2675G Travel Summary } \\
\hline & $\begin{array}{c}\text { Per Day } \\
\text { Average/Peak }\end{array}$ & $\begin{array}{c}\text { Per Outing } \\
\text { Average/Peak }\end{array}$ & $\begin{array}{c}\text { Per Trip } \\
\text { Average/Peak }\end{array}$ & Total \\
\hline Travel Distance (Miles) & $20.0 / 85.4$ & $16.0 / 85.4$ & $7.3 / 40.3$ & 160 \\
\hline Travel Time (Minutes) & $51 / 117.0$ & $40.6 / 117.0$ & $18.5 / 53.0$ & 406 \\
\hline Idle Time (Minutes) & $5.4 / \mathrm{NA}$ & $4.3 / \mathrm{NA}$ & $2.0 / \mathrm{NA}$ & 43 \\
\hline
\end{tabular}

\begin{tabular}{|c|c|c|c|c|}
\hline \multicolumn{2}{|c|}{ Total Stops } & \multicolumn{2}{c|}{ Stop Duration } \\
\hline $\begin{array}{c}\text { Distance From } \\
\text { Home Base (Miles) }\end{array}$ & Stops & Percentages & Stop Duration (Hours) & Stops \\
\hline Less than 10 & 28 & $93.3 \%$ & Less than 2 & 19 \\
\hline 10 to 20 & 0 & $0 \%$ & 2 to 4 & 2 \\
\hline 20 to 40 & 2 & $6.7 \%$ & 4 to 8 & 1 \\
\hline 40 to 60 & 0 & $0 \%$ & Greater than 8 & 8 \\
\hline
\end{tabular}

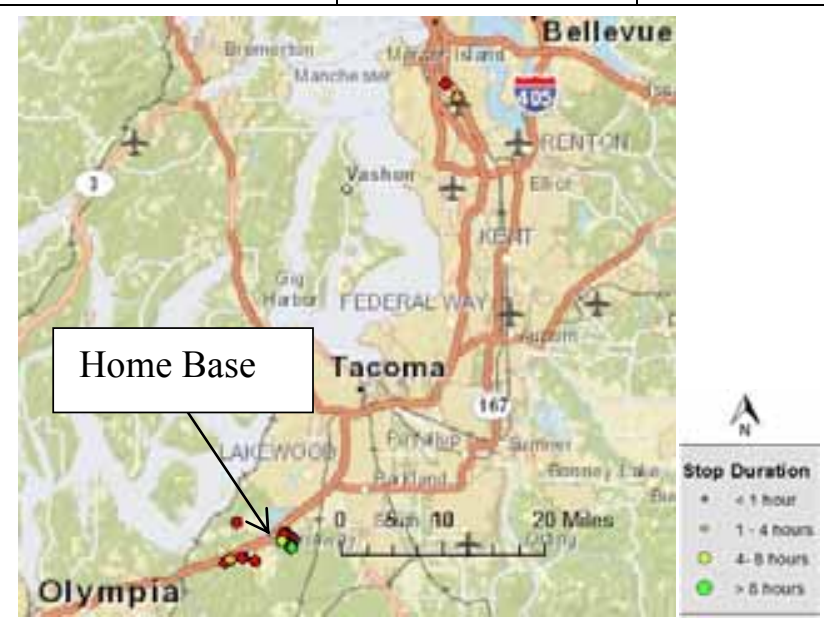

Figure E-76. Vehicle G11-2675G stops.

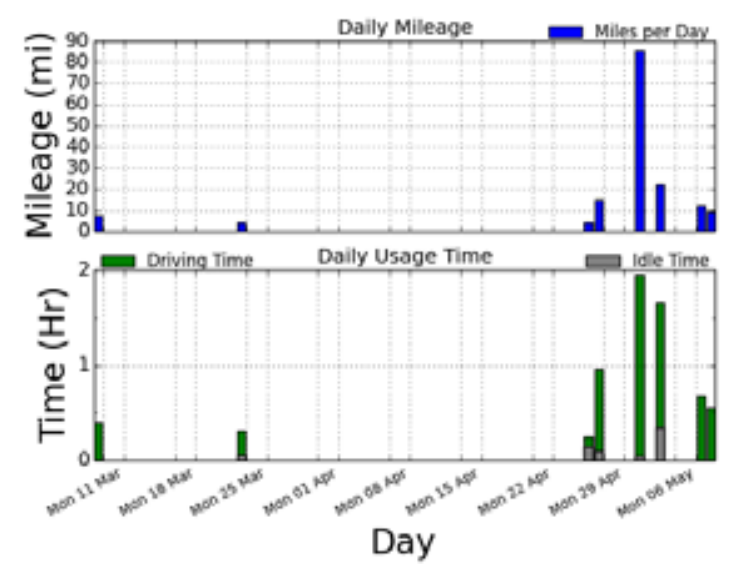

Figure E-77. Vehicle G11-2675G history. 


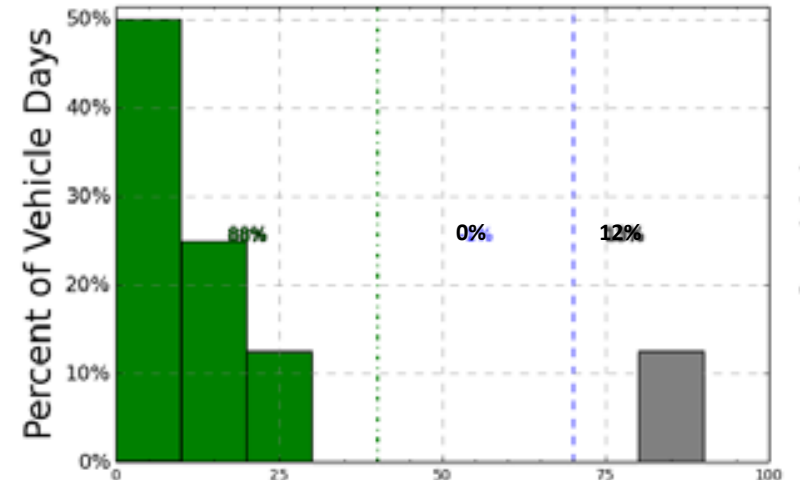

Daily Travel Distance (miles)

- All days less than 40 miles _ - All days less than 70 miles

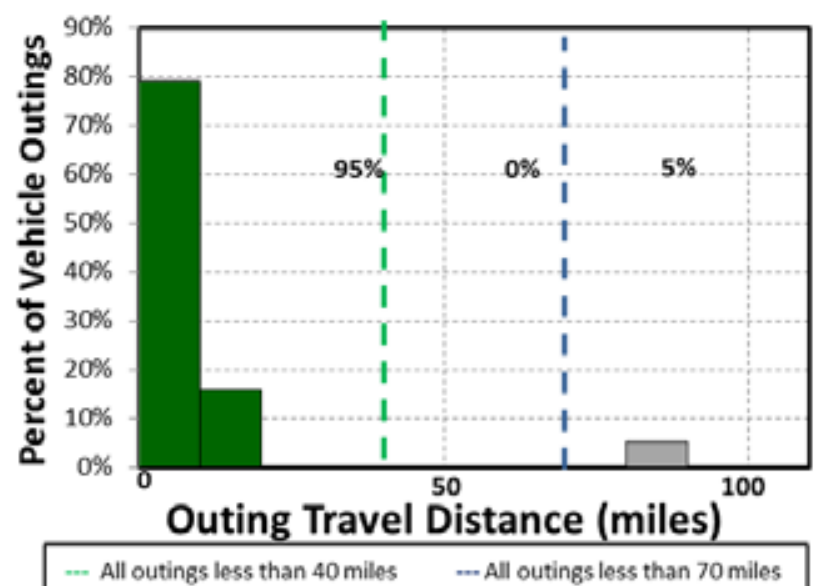

All outings less than 40 miles $\quad$.... All outings less than 70 miles

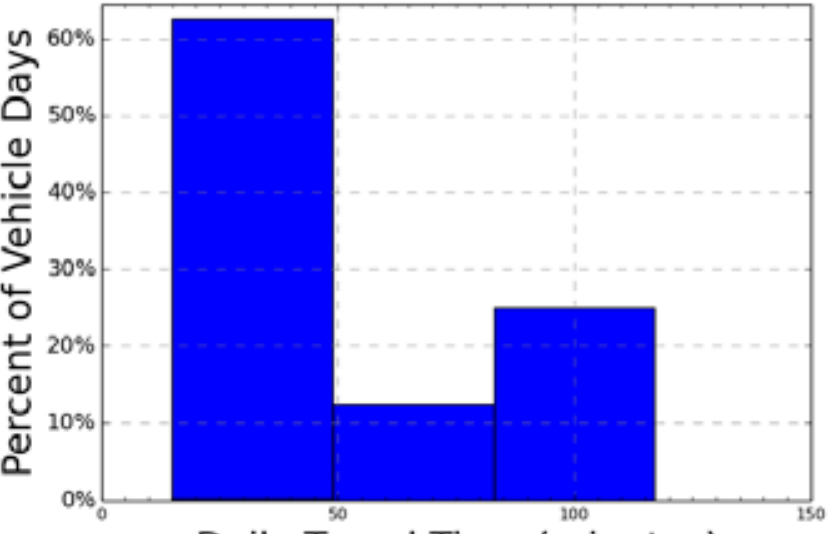

Daily Travel Time (minutes)

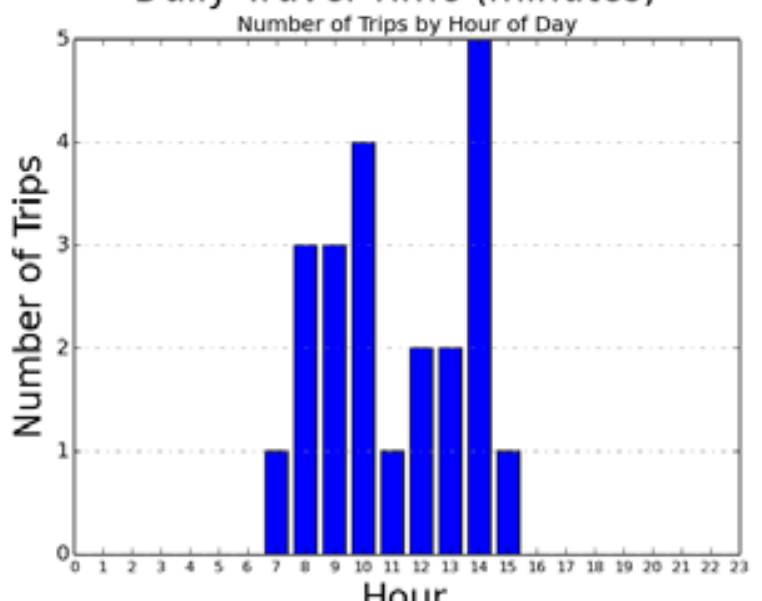

Figure E-56. Vehicle G11-2675G travel graphs.

\section{Vehicle G11-2675G Observations}

Logger 108 collected data on this vehicle for a period of 8 days of the 63-day study period. Validation occurred on $89.9 \%$ of the input data. Project survey response reports this pool vehicle, assigned to Military Personnel Division performs courier type tasks. This vehicle is used to transport documents and personnel to and from Western Regional Medical Command, finance and Waller Hall as well as the hospital. It parks in the office parking lot on Johnson St near Bldg 9900 or on Fitzsimmons near the Medical Center, Bldg 9040. Expected retention of this vehicle is unknown. It typically travels between six and ten miles per day. Between six and ten persons regularly access this vehicle and it typically carries up to three persons. It occasionally operates off base - typically twice per month. Off base outings are typically less than ten miles. Site data reports an odometer reading of 5,642 in May 2012 with an average of 107 miles per month. It frequently operates on the E-85 fuel.

Eighty-eight percent of all vehicle travel days were within the 70-mile BEV safe range (green bars on Figure E-78) while $12 \%$ of the vehicle travel days exceeds this range. This was one day's travel to Seattle, which also was the longest single outing. All other trips were of short distances.

This one outing exceeds the 70-mile range for a replacement BEV so strictly, the recommended replacement would be a PHEV. However, as a pool vehicle, a mix of BEVs and PHEVs may support the mission if vehicle are selected carefully. 
Vehicle G43-1191L

\begin{tabular}{|l|l|c|}
\hline & Make/Model/Year & Chevrolet/CG3300/2011 \\
\hline EPA Class Size & Passenger Van \\
\hline \multirow{5}{*}{ www.edmunds.com } & Pission & C. Sallinger/Motor Transport \\
\hline & Contact & Bldg R9641/Yakima \\
\cline { 2 - 3 } & Parking Location & G43-1191L \\
\hline & Fleet Vehicle ID & Gas/ETH \\
\hline & Fuel Type & $11 / 16 / 128 / 12 / 9$ \\
\hline & EPA Label/MPG (City/Hwy/Combined)* & $741 / 699$ \\
\hline & EPA GHG Emissions (Grams CO $/$ Mi)* & Logger 109 \\
\hline & Study Logger ID & $37 / 63$ \\
\hline
\end{tabular}

\begin{tabular}{|l|c|c|c|c|}
\hline \multicolumn{5}{|c|}{ Vehicle G43-1191L Travel Summary } \\
\hline & $\begin{array}{c}\text { Per Day } \\
\text { Average/Peak }\end{array}$ & $\begin{array}{c}\text { Per Outing } \\
\text { Average/Peak }\end{array}$ & $\begin{array}{c}\text { Per Trip } \\
\text { Average/Peak }\end{array}$ & Total \\
\hline Travel Distance (Miles) & $40.4 / 186.1$ & $17.0 / 374.4$ & $4.8 / 104.8$ & 1,493 \\
\hline Travel Time (Minutes) & $121 / 332.0$ & $50.8 / 754.0$ & $14.2 / 116.0$ & 4,469 \\
\hline Idle Time (Minutes) & $24.9 / \mathrm{NA}$ & $10.5 / \mathrm{NA}$ & $2.9 / \mathrm{NA}$ & 920 \\
\hline
\end{tabular}

\begin{tabular}{|c|c|c|c|c|}
\hline \multicolumn{2}{|c|}{ Total Stops } & \multicolumn{2}{c|}{ Stop Duration } \\
\hline $\begin{array}{c}\text { Distance From } \\
\text { Home Base (Miles) }\end{array}$ & Stops & Percentages & Stop Duration (Hours) & Stops \\
\hline Less than 10 & 249 & $76.4 \%$ & Less than 2 & 249 \\
\hline 10 to 20 & 20 & $6.1 \%$ & 2 to 4 & 26 \\
\hline 20 to 40 & 0 & $0 \%$ & 4 to 8 & 12 \\
\hline Greater than 40 & 57 & $17.5 \%$ & Greater than 8 & 39 \\
\hline
\end{tabular}

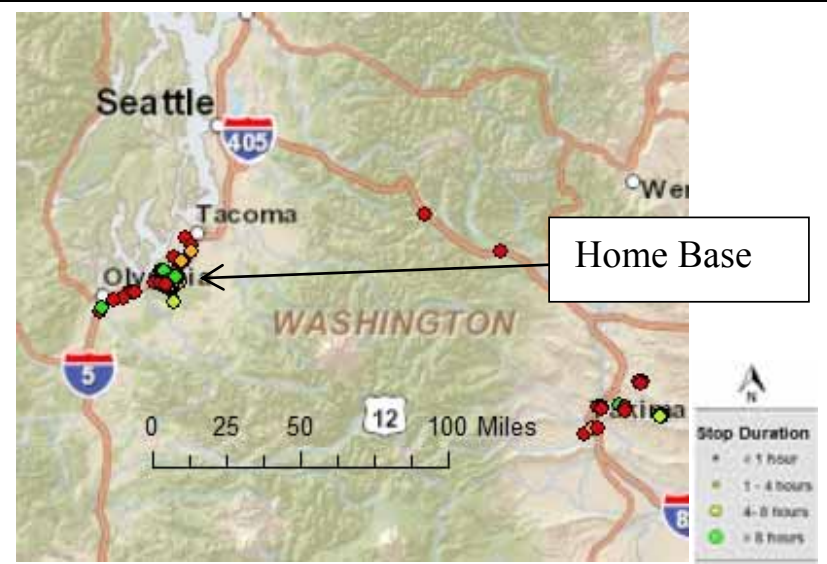

Figure E-79. Vehicle G43-1191L stops.

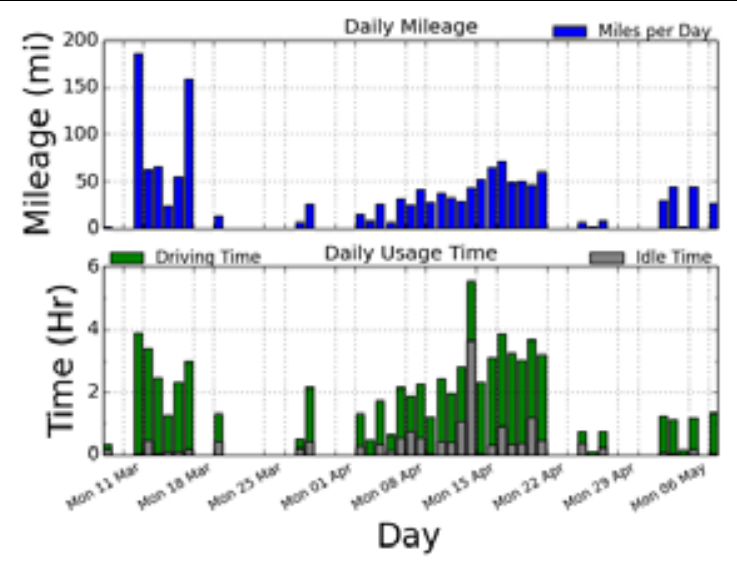

Figure E-80. Vehicle G43-1191L history. 


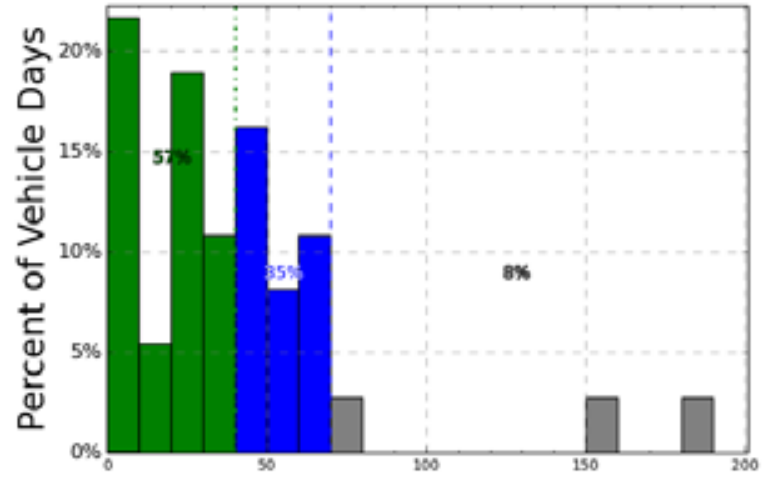

Daily Travel Distance (miles)

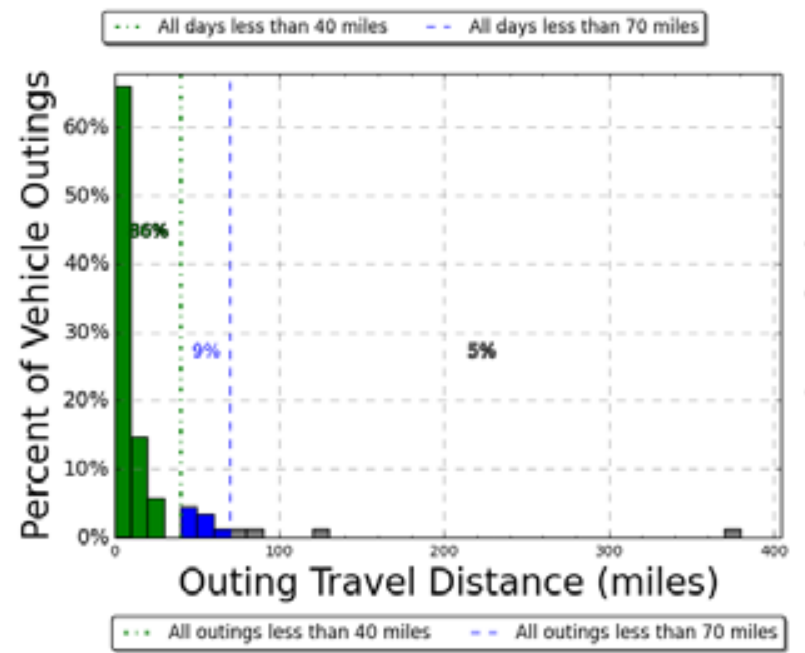

All outings less than 40 miles $\quad$ - All outings less than 70 miles

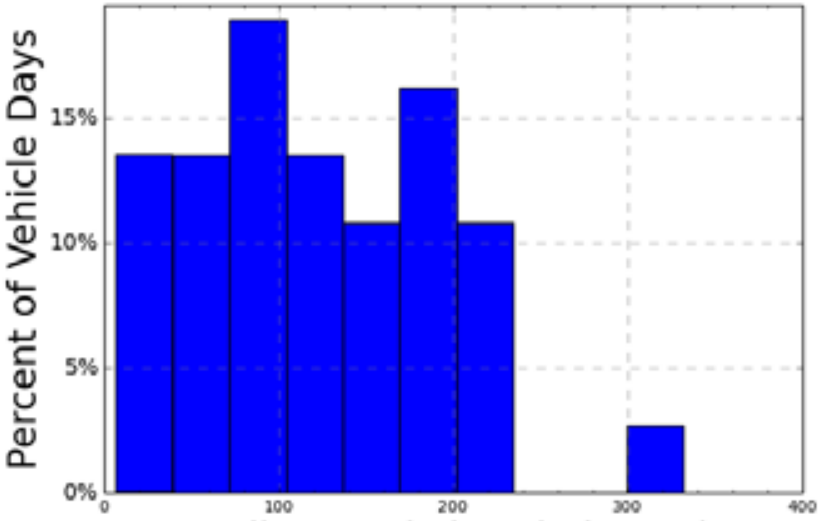

Daily Travel Time (minutes)

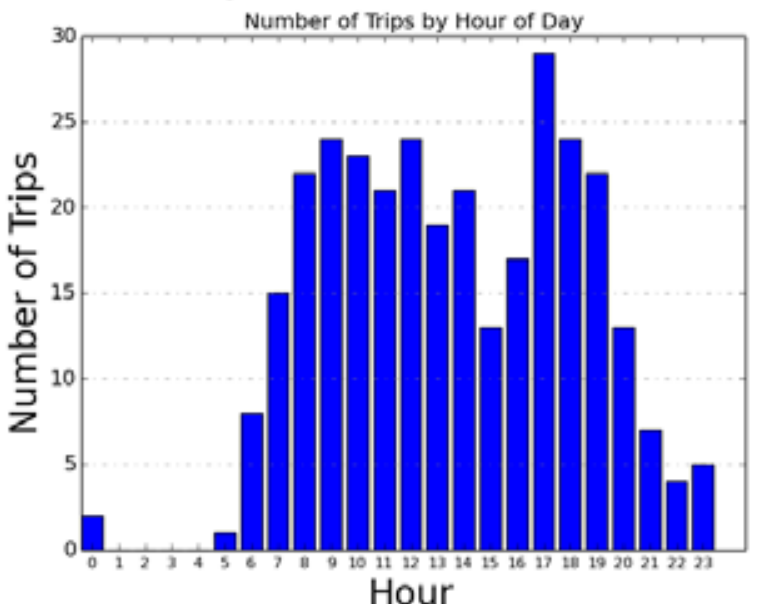

Figure E-57. Vehicle G43-1191L travel graphs.

\section{Vehicle G43-1191L Observations}

Logger 109 collected data on this vehicle for a period of 37 days of the 63-day study period. Validation occurred on $99.5 \%$ of the input data. Survey information was not available for this vehicle. Stop data suggests it typically parks near Bldg 9641 on Perry but frequently parked in the Eagle View Housing Area and in Yakima. Site data reports an odometer reading of 6,695 in May 2012 with an average of 514 miles per month.

During the study period, the vehicle traveled a total distance of 1,493 miles over 74 hours. Ninety-two percent of all vehicle travel days were within the 70-mile BEV safe range (green and blue bars on Figure E-81), while $8 \%$ of the vehicle travel days exceeds this range.

Ninety-five percent of all outings were within the 70-mile BEV safe range, while 5\% exceed this range. The longest single outing occurred on a several day travel to Yakima so the vehicle did not return to the home base during this time. The trip data also show frequent trips to the Olympia area.

Because there are several outings exceeding the BEV safe range, a BEV would not be recommended as a replacement vehicle for this particular vehicle. A PHEV would be recommended provided it can meet the passenger carrying requirements of this vehicle. 


\begin{tabular}{|c|c|c|}
\hline & Make/Model/Year & Ford/Fusion HEV/2010 \\
\hline & EPA Class Size & Midsize Car \\
\hline 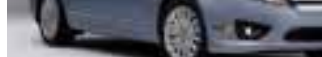 & Mission & Pool \\
\hline \multirow{8}{*}{ www.edmunds.com } & Contact & J. Lamantia/Motor Transport \\
\hline & Parking Location & Bldg R9641/3674 \\
\hline & Fleet Vehicle ID & G12-0662H \\
\hline & Fuel Type & Gas \\
\hline & EPA Label/MPG (City/Hwy/Combined)* & $41 / 36 / 39$ \\
\hline & EPA GHG Emissions (Grams $\left.\mathrm{CO}_{2} / \mathrm{Mi}\right)^{*}$ & 228 \\
\hline & Study Logger ID & Logger 110 \\
\hline & Total Vehicle Days/Total Study Days & $27 / 63$ \\
\hline
\end{tabular}

\begin{tabular}{|l|c|c|c|c|}
\hline \multicolumn{5}{|c|}{ Vehicle G12-0662H Travel Summary } \\
\hline & $\begin{array}{c}\text { Per Day } \\
\text { Average/Peak }\end{array}$ & $\begin{array}{c}\text { Per Outing } \\
\text { Average/Peak }\end{array}$ & $\begin{array}{c}\text { Per Trip } \\
\text { Average/Peak }\end{array}$ & Total \\
\hline Travel Distance (Miles) & $68.4 / 274.7$ & $35.5 / 274.7$ & $4.1 / 106.4$ & 1,847 \\
\hline Travel Time (Minutes) & $96 / 325.0$ & $50.1 / 319.0$ & $5.8 / 128.0$ & 2,605 \\
\hline Idle Time (Minutes) & $1.4 / \mathrm{NA}$ & $0.7 / \mathrm{NA}$ & $0.1 / \mathrm{NA}$ & 37 \\
\hline
\end{tabular}

\begin{tabular}{|c|c|c|c|c|}
\hline \multicolumn{2}{|c|}{ Total Stops } & \multicolumn{2}{c|}{ Stop Duration } \\
\hline $\begin{array}{c}\text { Distance From } \\
\text { Home Base (Miles) }\end{array}$ & Stops & Percentages & Stop Duration (Hours) & Stops \\
\hline Less than 10 & 93 & $66.9 \%$ & Less than 2 & 104 \\
\hline 10 to 20 & 14 & $10.1 \%$ & 2 to 4 & 6 \\
\hline 20 to 40 & 16 & $11.5 \%$ & 4 to 8 & 5 \\
\hline Greater than 40 & 16 & $11.5 \%$ & Greater than 8 & 24 \\
\hline
\end{tabular}

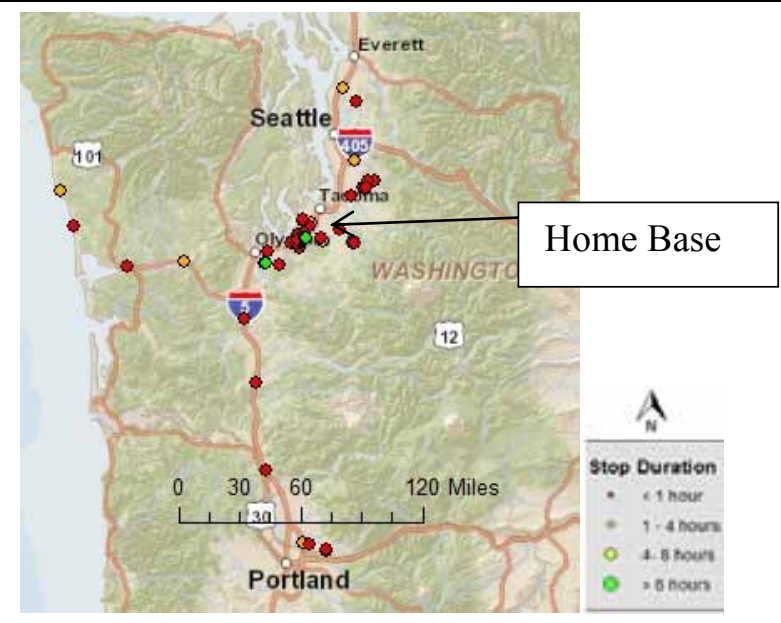

Figure E-82. Vehicle G12-0662H stops.

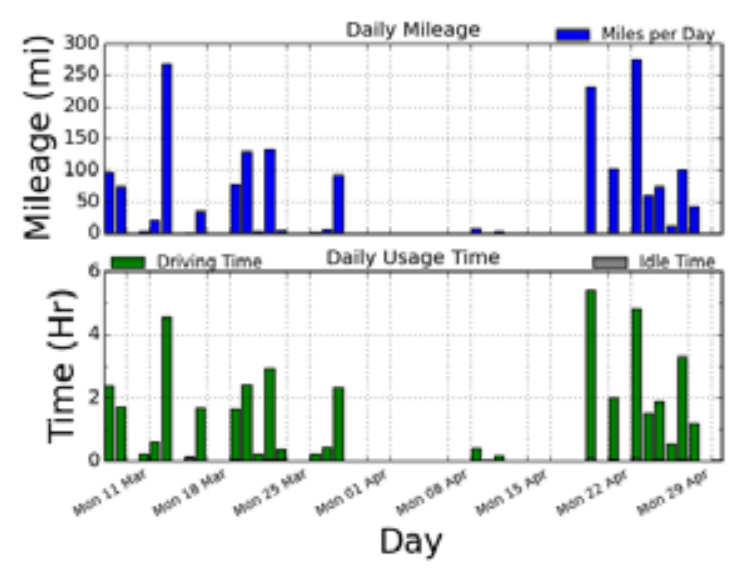

Figure E-83. Vehicle G12-0662H history. 


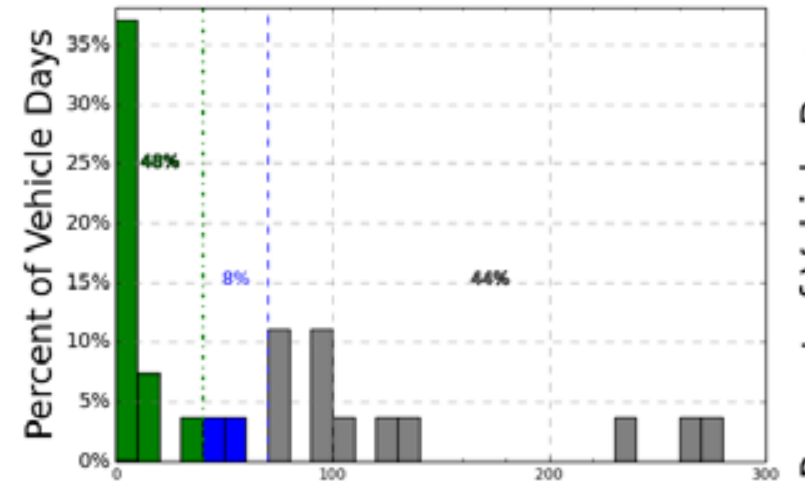

Daily Travel Distance (miles)
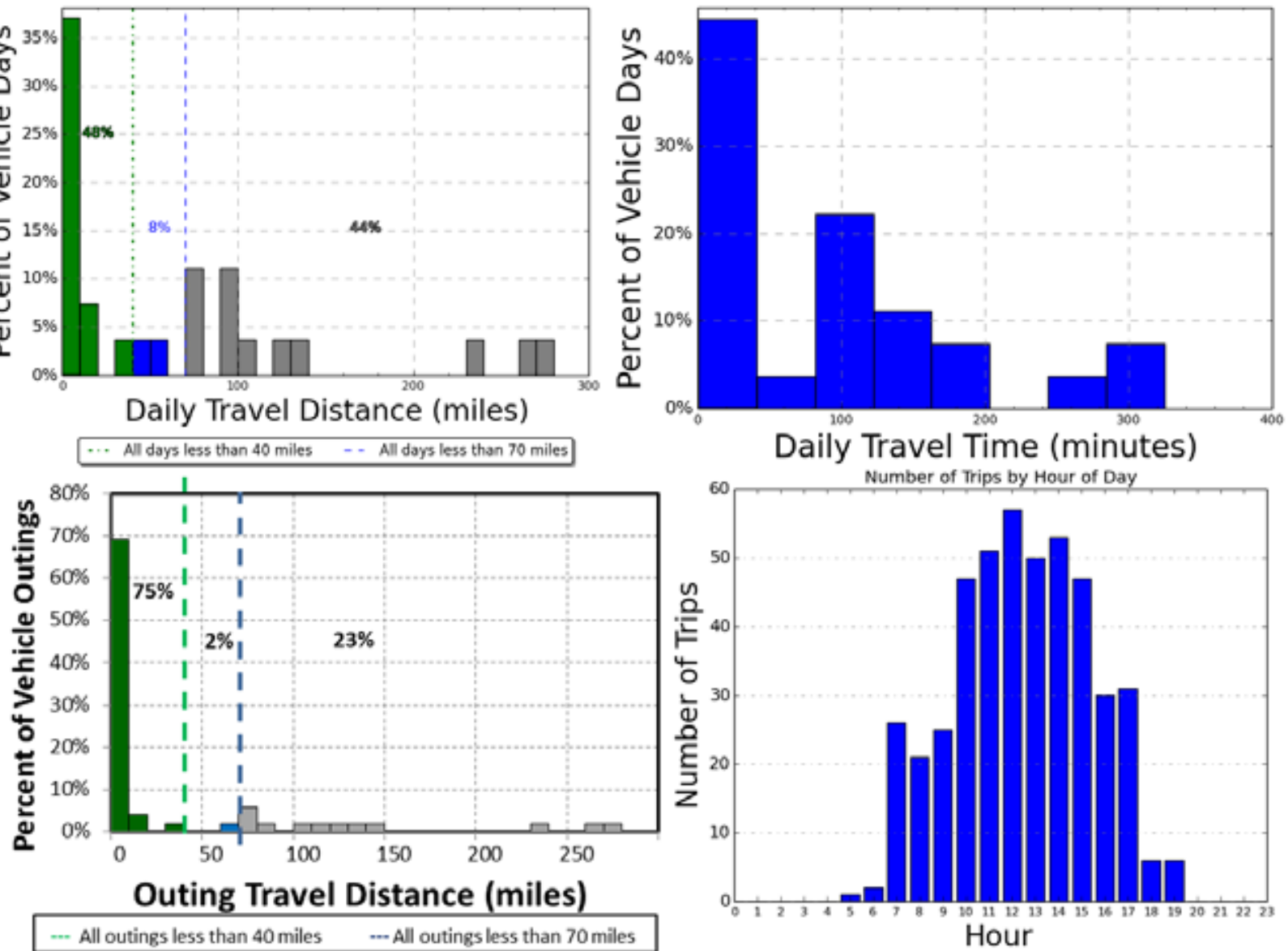

Figure E-58. Vehicle G12-0662H travel graphs.

\section{Vehicle G12-0662H Observations}

Logger 110 collected data on this vehicle for a period of 27 days of the 63-day study period. Validation occurred on $99.0 \%$ of the input data. Survey information was not available for this vehicle. Stop data suggests it typically parks near Bldg 9641 on Perry or Bldg 3674 on Railroad Avenue. Site data reports on odometer and mileage is unavailable.

This vehicle is used rather infrequently but selected for longer excursions. Fifty-six percent of all vehicle travel days were within the 70-mile BEV safe range (green and blue bars on Figure E-84), while $44 \%$ of the vehicle travel days exceeds this range. Several excursions were made to several locations offbase in Washington State during the study period.

The longest single outing of 275 miles occurred on March 22 on an excursion to several locations in Washington State. Several other outings (23\%) exceeded the 70 -mile BEV safe range while $77 \%$ of outings were within this range. While a BEV cannot meet the travel requirements of this vehicle, a PHEV would provide significant benefit. $48 \%$ of daily travel and $75 \%$ of the outings are within the 40 -mile battery only range of typical PHEVs. As this vehicle is a sedan, PHEVs are currently available to meet this mission. 
Vehicle G63-0271A

\begin{tabular}{|l|l|c|}
\hline \multirow{4}{*}{$\begin{array}{l}\text { www.commercialtruckt } \\
\text { rade.com }\end{array}$} & Make/Model/Year & Ford/F350 Stake/2004 \\
\cline { 2 - 3 } & EPA Class Size & Stake Truck \\
\cline { 2 - 3 } & Mission & Transport \\
\cline { 2 - 3 } & Contact & Callinger/Motor Transport \\
\cline { 2 - 3 } & Fleet Vehicle ID & G63-0271A \\
\cline { 2 - 3 } & Fuel Type & Gas \\
\cline { 2 - 3 } & EPA Label/MPG (City/Hwy/Combined)* & $11 / 15 / 13$ \\
\cline { 2 - 3 } & EPA GHG Emissions (Grams CO $\left.\mathrm{CO}_{2} / \mathrm{Mi}\right)^{*}$ & 635 \\
\cline { 2 - 3 } & Study Logger ID & Logger 111 \\
\hline & Total Vehicle Days/Total Study Days & $22 / 63$ \\
\hline
\end{tabular}

\begin{tabular}{|l|c|c|c|c|}
\hline \multicolumn{5}{|c|}{ Vehicle G63-0271A Travel Summary } \\
\hline & $\begin{array}{c}\text { Per Day } \\
\text { Average/Peak }\end{array}$ & $\begin{array}{c}\text { Per Outing } \\
\text { Average/Peak }\end{array}$ & $\begin{array}{c}\text { Per Trip } \\
\text { Average/Peak }\end{array}$ & Total \\
\hline Travel Distance (Miles) & $71.9 / 393.8$ & $26.8 / 393.8$ & $7.7 / 142.5$ & 1,582 \\
\hline Travel Time (Minutes) & $311 / 669.0$ & $116.1 / 673.0$ & $33.2 / 218.0$ & 6,847 \\
\hline Idle Time (Minutes) & $178.6 / \mathrm{NA}$ & $66.6 / \mathrm{NA}$ & $19.1 / \mathrm{NA}$ & 3,930 \\
\hline
\end{tabular}

\begin{tabular}{|c|c|c|c|c|}
\hline \multicolumn{2}{|c|}{ Total Stops } & \multicolumn{2}{c|}{ Stop Duration } \\
\hline $\begin{array}{c}\text { Distance From } \\
\text { Home Base (Miles) }\end{array}$ & Stops & Percentages & Stop Duration (Hours) & Stops \\
\hline Less than 10 & 115 & $52.8 \%$ & Less than 2 & 177 \\
\hline 10 to 20 & 1 & $0.5 \%$ & 2 to 4 & 11 \\
\hline 20 to 40 & 0 & $0 \%$ & 4 to 8 & 9 \\
\hline 40 to 60 & 102 & $46.8 \%$ & Greater than 8 & 21 \\
\hline
\end{tabular}

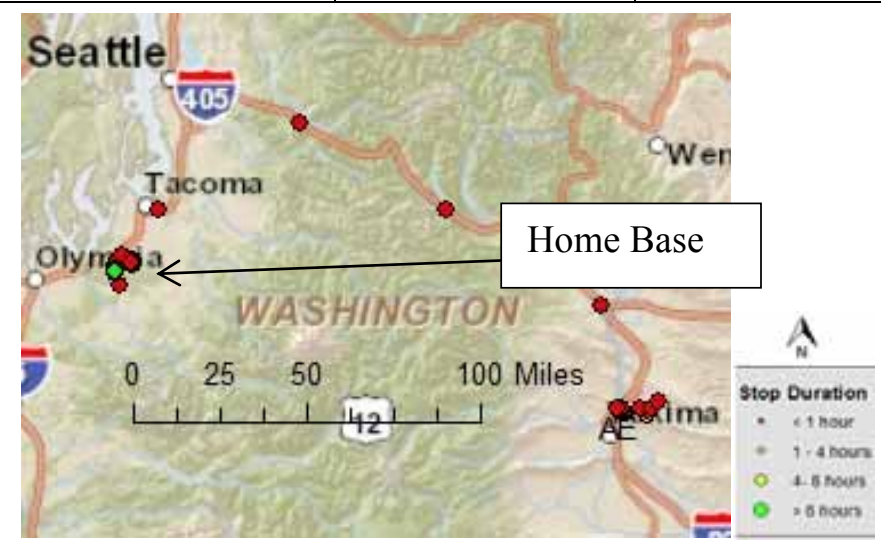

Figure E-85. Vehicle G63-0271A stops.

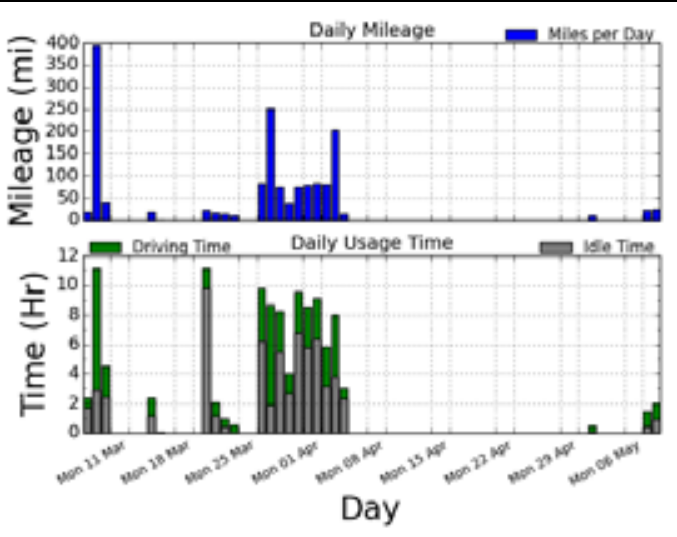

Figure E-86. Vehicle G63-0271A history.

*2004 Ford F150 information. EPA data for 2004 Ford 350 stake not available. 

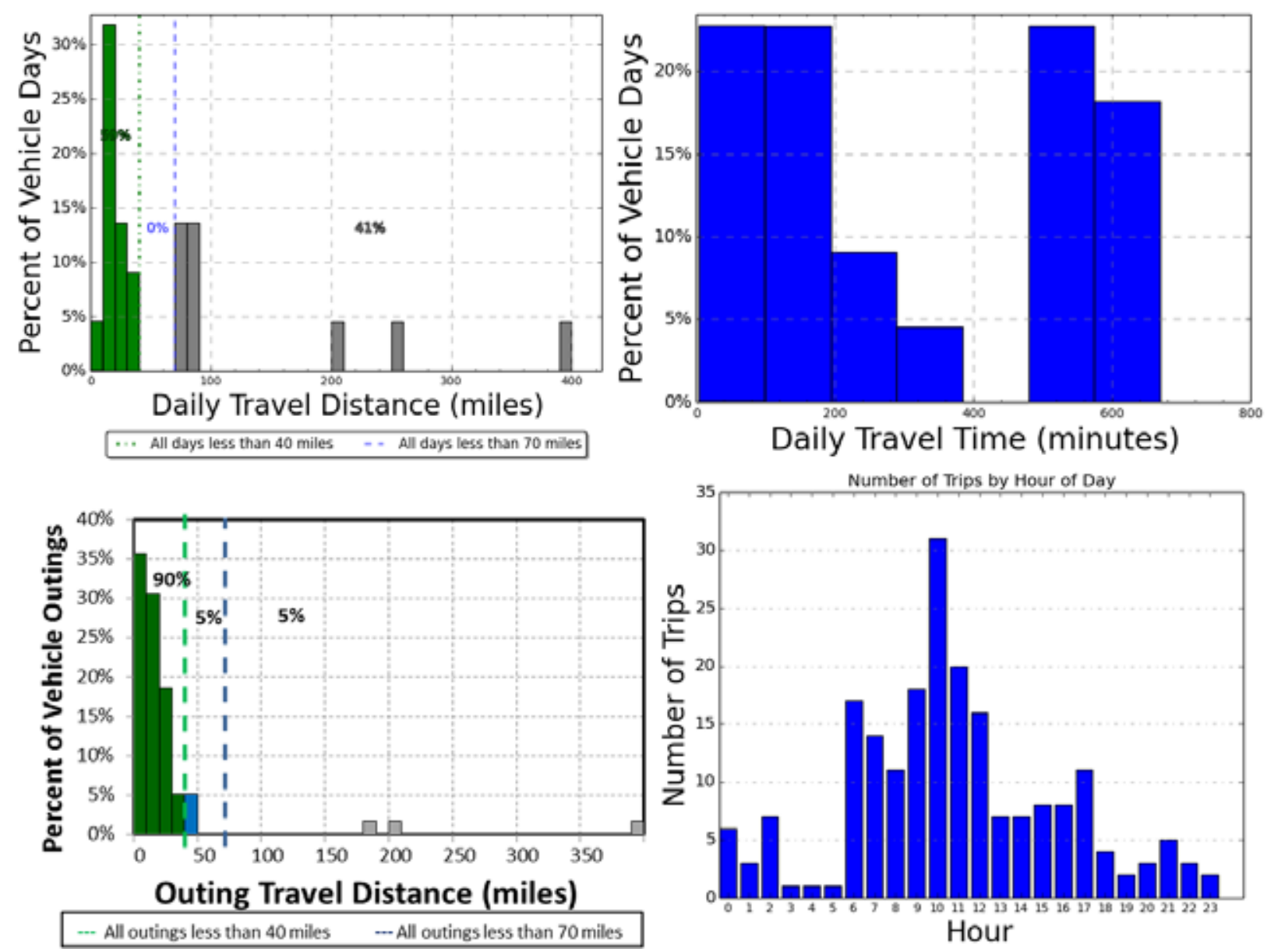

Figure E-59. Vehicle G63-0271A travel graphs.

\section{Vehicle G63-0271A Observations}

Logger 111 collected data on this vehicle for a period of 22 days of the 63-day study period. Validation occurred on $99.1 \%$ of the input data. Survey information was not available for this vehicle. Stop data suggests it typically parks in Camp Murray on 41st Division Way but spent a considerable amount of time in Yakima apparently home based on $5^{\text {th }}$ Avenue. Site data reports an odometer reading of 49,748 in May 2012 with an average of 360 miles per month.

A large percentage (41\%) of all vehicle travel days exceeded the 70-mile BEV safe range (gray bars on Figure E-87). Several of the outings also exceeded this safe range. Thus, a BEV would not be recommended as a replacement. A PHEV could be utilized and there would be potential for significant savings with $59 \%$ of daily travel within the 40 -mile battery only range and $90 \%$ of outings in this range. However, there are currently no PHEVs as suitable replacements for heavy-duty trucks. 
Vehicle G41-1392G

\begin{tabular}{|l|l|c|}
\hline \multirow{4}{*}{ www.edmunds.com } & Make/Model/Year & Chevrolet/Uplander/2008 \\
\cline { 2 - 3 } & EPA Class Size & Minivan \\
\hline & Mission & Support \\
\cline { 2 - 3 } & Contact & C. Sallinger/Motor Transport \\
\cline { 2 - 3 } & Parking Location & Bldg R9641/Bldg 3017 \\
\hline & Fleet Vehicle ID & G41-1392G \\
\cline { 2 - 3 } & Fuel Type & Gas/ETH \\
\cline { 2 - 3 } & EPA Label/MPG (City/Hwy/Combined)* & $16 / 23 / 1912 / 17 / 14$ \\
\cline { 2 - 3 } & EPA GHG Emissions (Grams CO $/$ Mi)* & $468 / 450$ \\
\cline { 2 - 3 } & Study Logger ID & Logger 112 \\
\hline & Total Vehicle Days/Total Study Days & $20 / 63$ \\
\hline
\end{tabular}

\begin{tabular}{|l|c|c|c|c|}
\hline \multicolumn{5}{|c|}{ Vehicle G41-1392G Travel Summary } \\
\hline & $\begin{array}{c}\text { Per Day } \\
\text { Average/Peak }\end{array}$ & $\begin{array}{c}\text { Per Outing } \\
\text { Average/Peak }\end{array}$ & $\begin{array}{c}\text { Per Trip } \\
\text { Average/Peak }\end{array}$ & Total \\
\hline Travel Distance (Miles) & $42.1 / 251.9$ & $40.1 / 253.8$ & $7.4 / 125.1$ & 842 \\
\hline Travel Time (Minutes) & $108 / 306.0$ & $102.5 / 715.0$ & $19.1 / 120.0$ & 2,153 \\
\hline Idle Time (Minutes) & $28.4 / \mathrm{NA}$ & $27.0 / \mathrm{NA}$ & $5.0 / \mathrm{NA}$ & 568 \\
\hline
\end{tabular}

\begin{tabular}{|c|c|c|c|c|}
\hline \multicolumn{2}{|c|}{ Total Stops } & \multicolumn{2}{c|}{ Stop Duration } \\
\hline $\begin{array}{c}\text { Distance From } \\
\text { Home Base (Miles) }\end{array}$ & Stops & Percentages & Stop Duration (Hours) & Stops \\
\hline Less than 10 & 102 & $81.0 \%$ & Less than 2 & 97 \\
\hline 10 to 20 & 10 & $7.9 \%$ & 2 to 4 & 8 \\
\hline 20 to 40 & 2 & $1.6 \%$ & 4 to 8 & 2 \\
\hline Greater than 40 & 12 & $9.5 \%$ & Greater than 8 & 19 \\
\hline
\end{tabular}

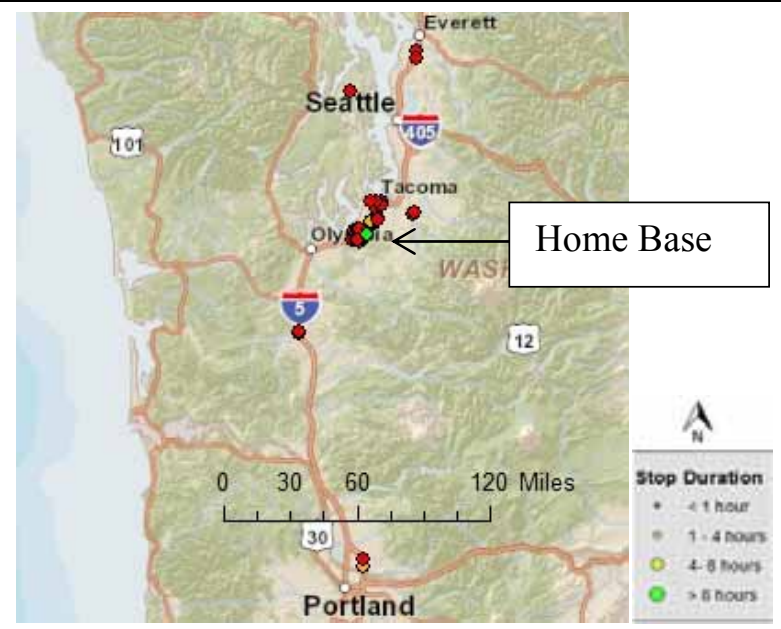

Figure E-88. Vehicle G41-1392G stops.

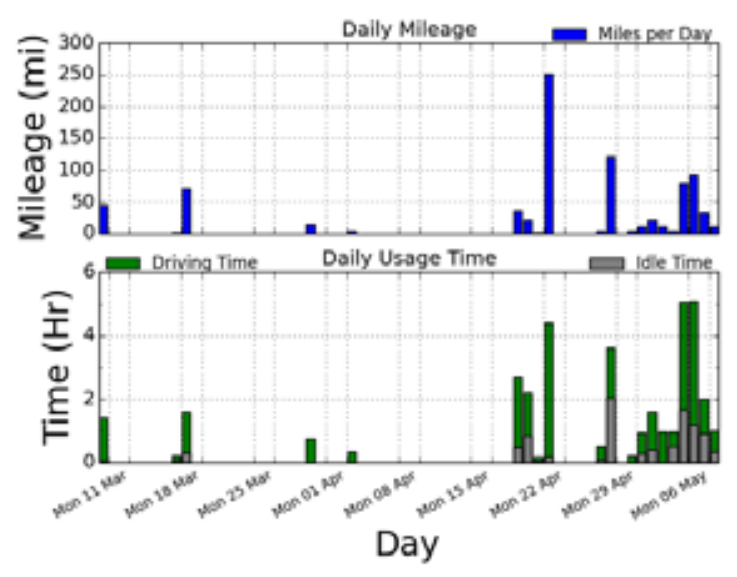

Figure E-89. Vehicle G41-1392G history. 

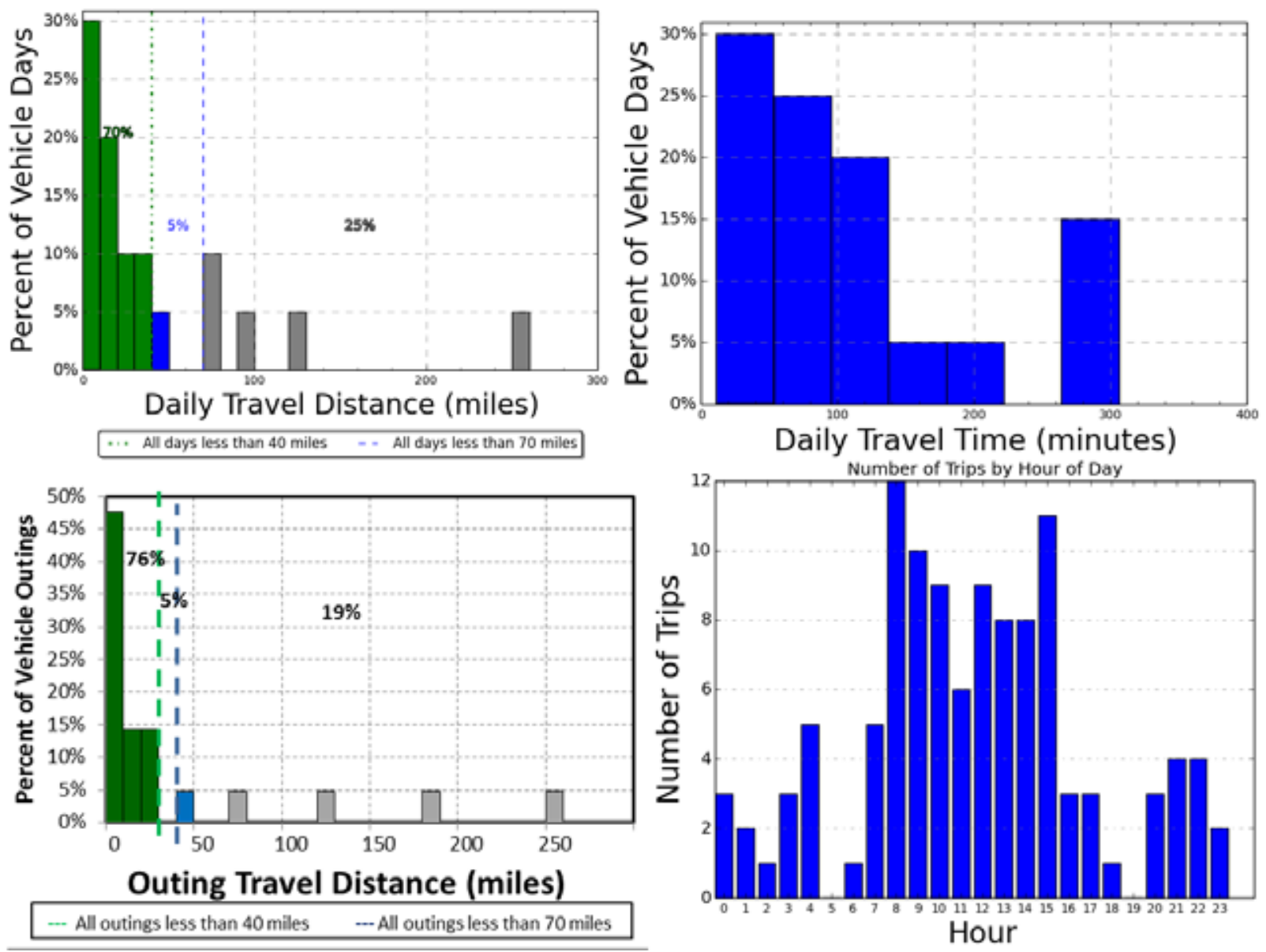

Figure E-60. Vehicle G41-1392G travel graphs.

\section{Vehicle G41-1392G Observations}

Logger 112 collected data on this vehicle for a period of 20 days of the 63-day study period. Validation occurred on $97.1 \%$ of the input data. Survey information was not available for this vehicle. Stop data suggests it typically parks near Bldg 9641 on Perry Avenue but from April 29 to May 3rd parked frequently at S $17^{\text {th }}$ St and Stryker Rd near Bldg 3017. Starting May $3^{\text {rd }}$ the vehicle spent several days in Tacoma. Site data reports an odometer reading of 28,122 in May 2012 with an average of 548 miles per month

This vehicle experienced light usage during the study period being unused for $68 \%$ of the period days. When driven, this vehicle had four travel days $(25 \%)$ where the 70 -mile BEV safe range (green and blue bars on Figure E-90) was exceeded. Conversely, $75 \%$ of the days were within this range.

These same days showed outings that also exceeded the assumed range capability of a BEV. However, $81 \%$ of the outings were within this BEV range. Aside from the longer trips, a BEV could be a replacement for this vehicle, especially if there are other vehicles that may be used for the longer trips. 
Vehicle G43-3881H

\begin{tabular}{|l|l|c|}
\hline & Make/Model/Year & Ford/E350/2009 \\
\hline EPA Class Size & Passenger Van \\
\hline & Pission & C. Sallinger/Motor Transport \\
\hline Contact & Bldg R9641/Perry Ave \\
\hline Parking Location & G43-3881H \\
\hline Fleet Vehicle ID & Gas/ETH \\
\hline Fuel Type & $14 / 18 / 15$ 10/13/11 \\
\cline { 2 - 3 } & EPA Label/MPG (City/Hwy/Combined)* & $592 / 572$ \\
\hline & EPA GHG Emissions (Grams CO $/$ Mi)* & Logger 113 \\
\cline { 2 - 3 } & Study Logger ID & $34 / 63$ \\
\hline & Total Vehicle Days/Total Study Days & \\
\hline
\end{tabular}

\begin{tabular}{|l|c|c|c|c|}
\hline \multicolumn{5}{|c|}{ Vehicle G43-3881H Travel Summary } \\
\hline & $\begin{array}{c}\text { Per Day } \\
\text { Average/Peak }\end{array}$ & $\begin{array}{c}\text { Per Outing } \\
\text { Average/Peak }\end{array}$ & $\begin{array}{c}\text { Per Trip } \\
\text { Average/Peak }\end{array}$ & Total \\
\hline Travel Distance (Miles) & $105.0 / 571.2$ & $56.7 / 1,566.9$ & $10.2 / 202.5$ & 3,570 \\
\hline Travel Time (Minutes) & $257 / 639.0$ & $139.0 / 1,897.0$ & $24.9 / 257.0$ & 8,754 \\
\hline Idle Time (Minutes) & $82.7 / \mathrm{NA}$ & $44.6 / \mathrm{NA}$ & $8.0 / \mathrm{NA}$ & 2,812 \\
\hline
\end{tabular}

\begin{tabular}{|c|c|c|c|c|}
\hline \multicolumn{2}{|c|}{ Total Stops } & \multicolumn{2}{c|}{ Stop Duration } \\
\hline $\begin{array}{c}\text { Distance From } \\
\text { Home Base (Miles) }\end{array}$ & Stops & Percentages & Stop Duration (Hours) & Stops \\
\hline Less than 10 & 84 & $22.3 \%$ & Less than 2 & 307 \\
\hline 10 to 20 & 3 & $0.8 \%$ & 2 to 4 & 24 \\
\hline 20 to 40 & 1 & $0.3 \%$ & 4 to 8 & 15 \\
\hline Greater than 40 & 288 & $76.6 \%$ & Greater than 8 & 30 \\
\hline
\end{tabular}

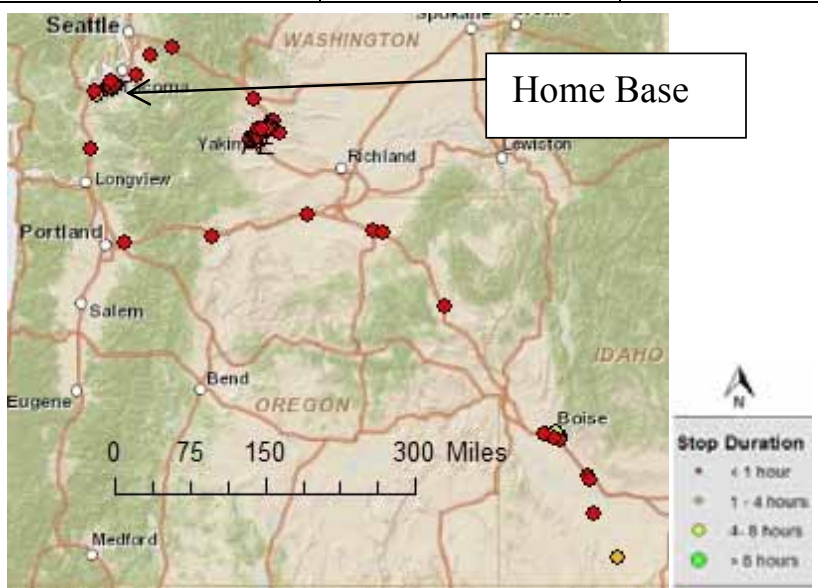

Figure E-91. Vehicle G43-3881H stops.

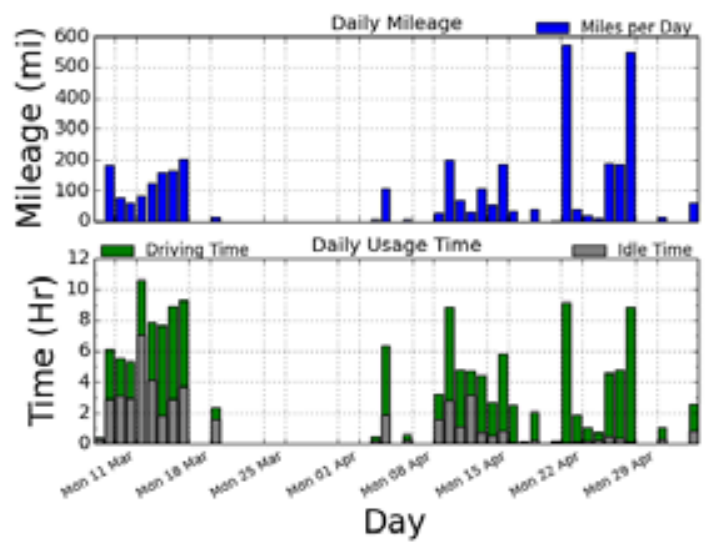

Figure E-92. Vehicle G43-3881H history. *2009 Ford F150 pickup information. EPA data for 2009 Ford E350 not available. 

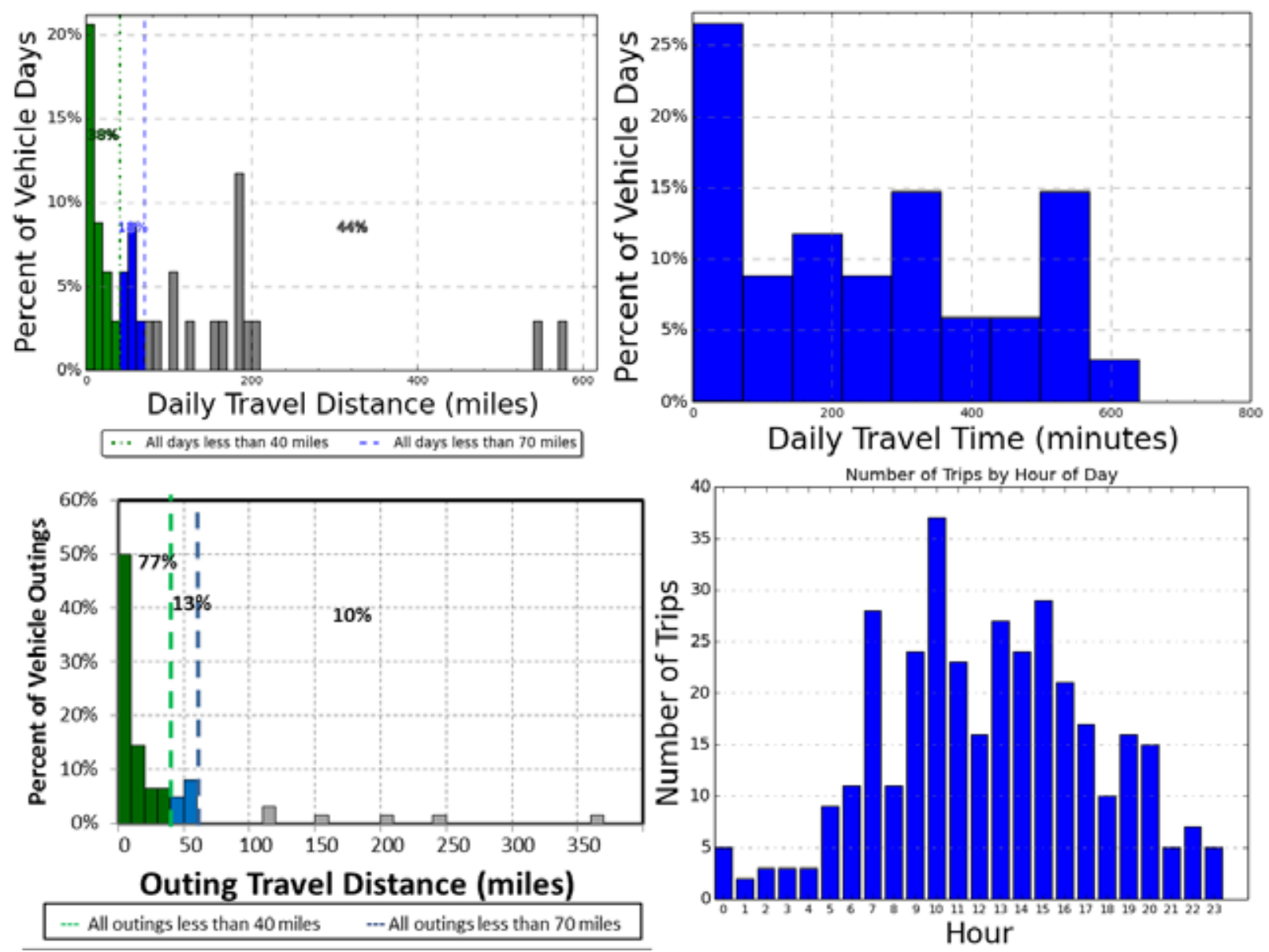

Figure E-61. Vehicle G43-3881H travel graphs.

\section{Vehicle G43-3881H Observations}

Logger 113 collected data on this vehicle for a period of 34 days of the 63-day study period. Validation occurred on $99.5 \%$ of the input data. Survey information was not available for this vehicle. Stop data suggests it typically parks near Bldg 9641 on Perry Avenue. However, this vehicle spent a considerable amount of test period time in Yakima and traveled to Boise, ID and Washington State from April 20 to 26. Site data reports an odometer reading of 22,613 in May 2012 with an average of 574 miles per month.

This vehicle was used for extended travel on many of the travel days. Forty-four percent of all vehicle travel days exceeded the 70-mile BEV safe range (gray bars on Figure E-93), while $56 \%$ of the vehicle travel days were within this range.

The longest single outing of 1,567 miles occurred on the April excursion to Idaho and Washington. (This several day outing is not shown in Figure E-93). Because several of the outings were also beyond the BEV safe range, a PHEV would be recommended as a replacement should one provide the rest of the mission requirements for this pool passenger van. A PHEV in this role would be of benefit for $38 \%$ of the travel days and $77 \%$ of the vehicle outings. 


\begin{tabular}{|c|c|c|}
\hline \multirow{11}{*}{ 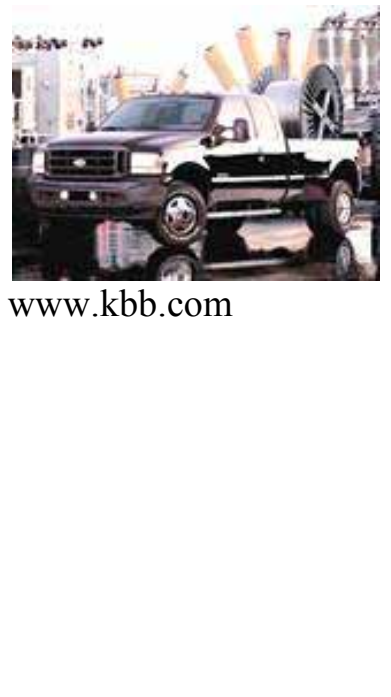 } & Make/Model/Year & Ford /F350/2003 \\
\hline & EPA Class Size & Pickup Truck \\
\hline & Mission & Transport \\
\hline & Contact & J. Lamantia/Motor Transport \\
\hline & Parking Location & Bldg R9641 \\
\hline & Fleet Vehicle ID & G43-25839 \\
\hline & Fuel Type & Diesel \\
\hline & EPA Label/MPG (City/Hwy/Combined)* & Not available \\
\hline & EPA GHG Emissions (Grams $\left.\mathrm{CO}_{2} / \mathrm{Mi}\right)^{*}$ & Not available \\
\hline & Study Logger ID & Logger 114 \\
\hline & Total Vehicle Days/Total Study Days & No data \\
\hline
\end{tabular}

\begin{tabular}{|l|c|c|c|c|}
\hline \multicolumn{5}{|c|}{ Vehicle G43-25839Travel Summary } \\
\hline & $\begin{array}{c}\text { Per Day } \\
\text { Average/Peak }\end{array}$ & $\begin{array}{c}\text { Per Outing } \\
\text { Average/Peak }\end{array}$ & $\begin{array}{c}\text { Per Trip } \\
\text { Average/Peak }\end{array}$ & Total \\
\hline Travel Distance (Miles) & No data & No data & No data & No data \\
\hline Travel Time (Minutes) & No data & No data & No data & No data \\
\hline Idle Time (Minutes) & No data & No data & No data & No data \\
\hline
\end{tabular}

\begin{tabular}{|c|c|c|c|c|}
\hline \multicolumn{2}{|c|}{ Total Stops } & \multicolumn{2}{c|}{ Stop Duration } \\
\hline $\begin{array}{c}\text { Distance From } \\
\text { Home Base (Miles) }\end{array}$ & Stops & Percentages & Stop Duration (Hours) & Stops \\
\hline Less than 10 & No data & No data & Less than 2 & No data \\
\hline 10 to 20 & No data & No data & 2 to 4 & No data \\
\hline 20 to 40 & No data & No data & 4 to 8 & No data \\
\hline 40 to 60 & No data & No data & Greater than 8 & No data \\
\hline
\end{tabular}

\section{Vehicle G43-25839 Observations}

Survey information was not available for this vehicle. Site data reports an odometer reading of 21,897 in May 2012 with an average of 332 miles per month. The Logger reported no data on this vehicle for the duration of the test period. No further information is available. 
Vehicle G41-1376G

\begin{tabular}{|l|l|c|}
\hline \multirow{4}{*}{ www.edmunds.com } & Make/Model/Year & Dodge/Dakota/2008 \\
\cline { 2 - 3 } & EPA Class Size & Standard Pickup Truck \\
\cline { 2 - 3 } & Mission & Cupport \\
\cline { 2 - 3 } & Contact & Bldg R9640/Perry Ave \\
\cline { 2 - 3 } & Parking Location & G41-1376G \\
\cline { 2 - 3 } & Fleet Vehicle ID & Gas/ETH \\
\cline { 2 - 3 } & Fuel Type & $14 / 19 / 159 / 12 / 10$ \\
\cline { 2 - 3 } & EPA Label/MPG (City/Hwy/Combined)* & $592 / 630$ \\
\cline { 2 - 3 } & EPA GHG Emissions (Grams CO $\left.\mathrm{CO}_{2} / \mathrm{Mi}\right)^{*}$ & Logger 115 \\
\cline { 2 - 3 } & Study Logger ID & $30 / 63$ \\
\hline & Total Vehicle Days/Total Study Days & . \\
\hline
\end{tabular}

\begin{tabular}{|l|c|c|c|c|}
\hline \multicolumn{5}{|c|}{ Vehicle G41-1376G Travel Summary } \\
\hline & $\begin{array}{c}\text { Per Day } \\
\text { Average/Peak }\end{array}$ & $\begin{array}{c}\text { Per Outing } \\
\text { Average/Peak }\end{array}$ & $\begin{array}{c}\text { Per Trip } \\
\text { Average/Peak }\end{array}$ & Total \\
\hline Travel Distance (Miles) & $8.3 / 35.8$ & $5.1 / 50.7$ & $2.4 / 29.8$ & 248 \\
\hline Travel Time (Minutes) & $29 / 111.0$ & $17.7 / 170.0$ & $8.3 / 83.0$ & 867 \\
\hline Idle Time (Minutes) & $2.5 / \mathrm{NA}$ & $1.6 / \mathrm{NA}$ & $0.7 / \mathrm{NA}$ & 76 \\
\hline
\end{tabular}

\begin{tabular}{|c|c|c|c|c|}
\hline \multicolumn{2}{|c|}{ Total Stops } & \multicolumn{2}{c|}{ Stop Duration } \\
\hline $\begin{array}{c}\text { Distance From } \\
\text { Home Base (Miles) }\end{array}$ & Stops & Percentages & Stop Duration (Hours) & Stops \\
\hline Less than 10 & 114 & $100 \%$ & Less than 2 & 79 \\
\hline 10 to 20 & 0 & $0 \%$ & 2 to 4 & 5 \\
\hline 20 to 40 & 0 & $0 \%$ & 4 to 8 & 0 \\
\hline 40 to 60 & 0 & $0 \%$ & Greater than 8 & 30 \\
\hline
\end{tabular}

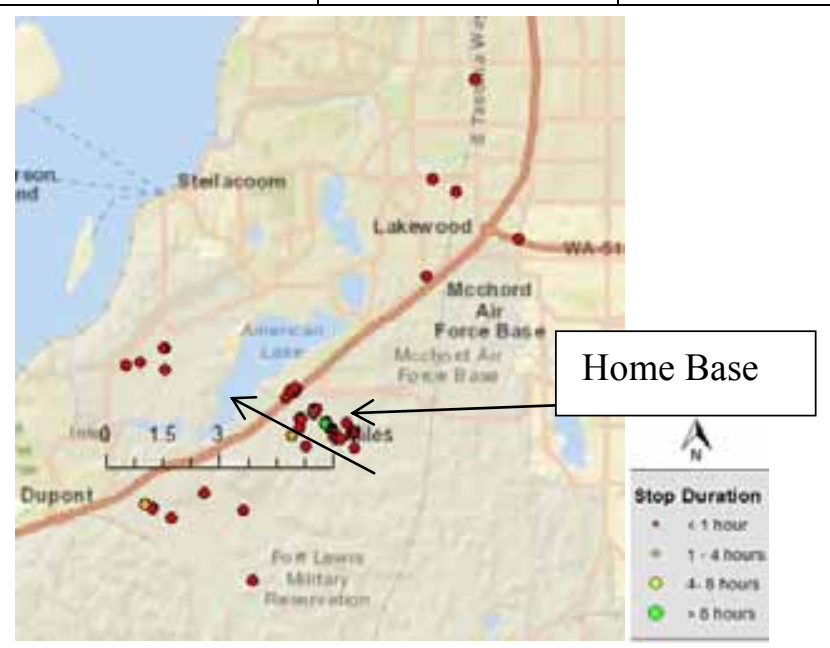

Figure E-94. Vehicle G41-1376G stops.

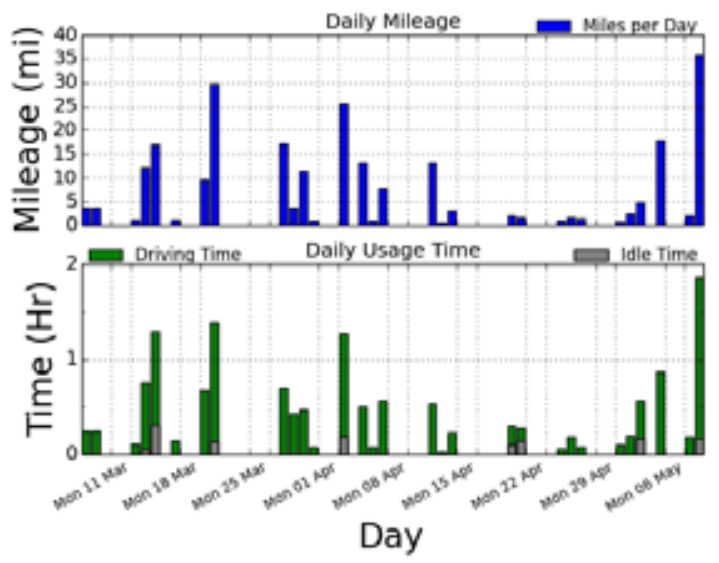

Figure E-95. Vehicle G41-1376G history. 

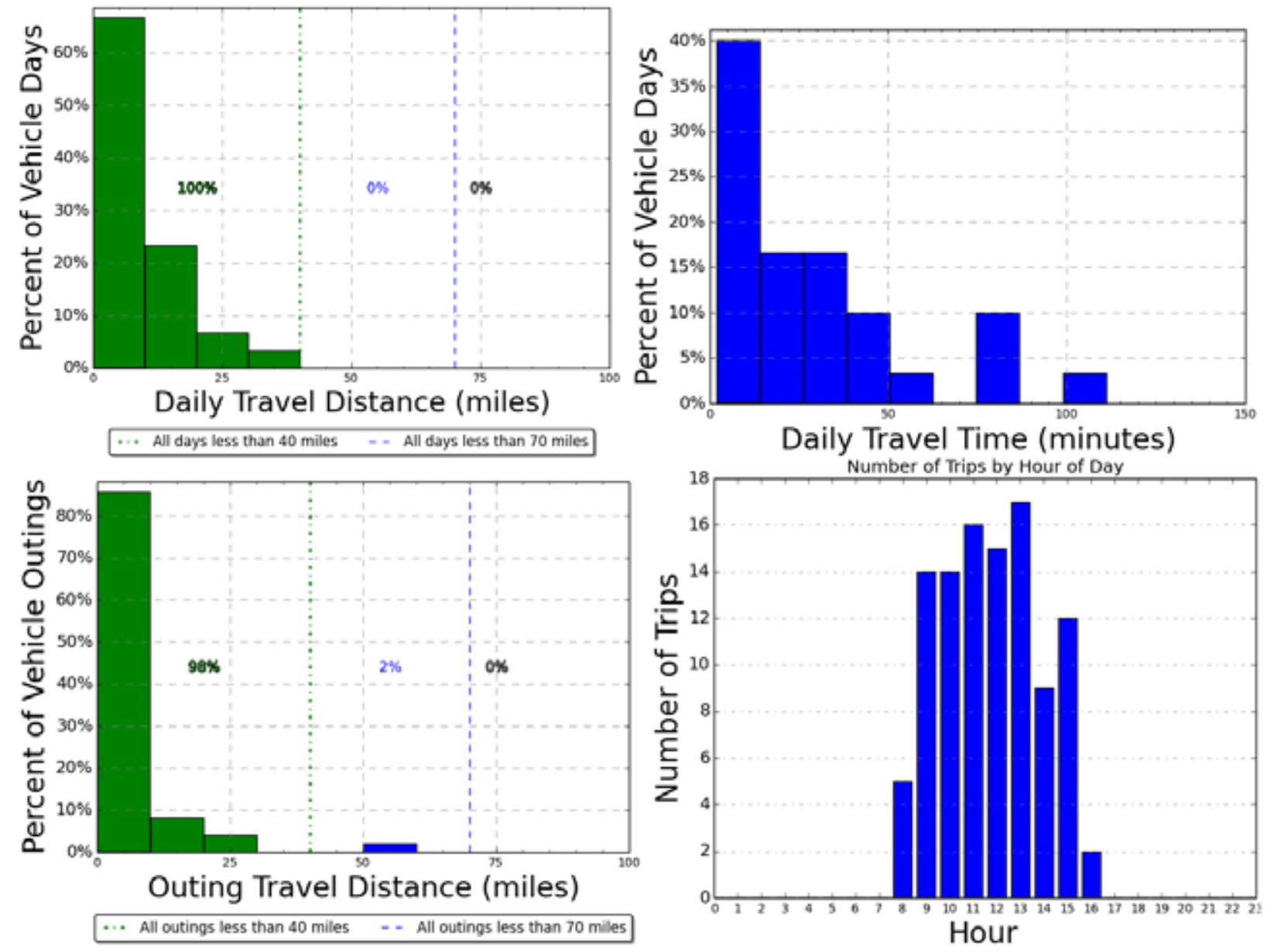

Figure E-62. Vehicle G41-1376G travel graphs.

\section{Vehicle G41-1376G Observations}

Logger 115 collected data on this vehicle for a period of 30 days of the 63-day study period. Validation occurred on $99.1 \%$ of the input data. Survey information was not available for this vehicle. Overnight parking typically occurs on Perry Ave or S I St near Bldg 9640. Site data reports an odometer reading of 10,921 in May 2012 with an average of 218 miles per month.

All of the vehicle travel days were within the 70-mile BEV safe range (green bars on Figure E-96).

The longest single outing of 50.7 miles occurred on March 26 and 27 when the vehicle returned to Perry Avenue instead of S I St. However, it remains within the assumed range capability of a BEV. These data suggest that a BEV could be a suitable replacement if the BEV meets the other mission requirements of this support vehicle. Survey information was not available to identify any such requirements. 
Vehicle G41-1161G

\begin{tabular}{|l|l|c|}
\hline \multirow{4}{*}{ www.edmunds.com } & Make/Model/Year & Chevrolet/Uplander/2008 \\
\cline { 2 - 3 } & EPA Class Size & Minivan \\
\cline { 2 - 3 } & Mission & Pool \\
\cline { 2 - 3 } & Contact & Bldg $9040 \mathrm{~A} /$ Fitzsimmons \\
\cline { 2 - 3 } & Parking Location & G41-1161G \\
\hline & Fleet Vehicle ID & Gas/ETH \\
\cline { 2 - 3 } & Fuel Type & $16 / 23 / 1912 / 17 / 14$ \\
\hline & EPA Label/MPG (City/Hwy/Combined)* & $468 / 450$ \\
\cline { 2 - 3 } & EPA GHG Emissions (Grams CO $/$ Mi)* & Logger 116 \\
\cline { 2 - 3 } & Study Logger ID & $29 / 63$ \\
\hline & Total Vehicle Days/Total Study Days & \\
\hline
\end{tabular}

\begin{tabular}{|l|c|c|c|c|}
\hline \multicolumn{5}{|c|}{ Vehicle G41-1161G Travel Summary } \\
\hline & $\begin{array}{c}\text { Per Day } \\
\text { Average/Peak }\end{array}$ & $\begin{array}{c}\text { Per Outing } \\
\text { Average/Peak }\end{array}$ & $\begin{array}{c}\text { Per Trip } \\
\text { Average/Peak }\end{array}$ & Total \\
\hline Travel Distance (Miles) & $11.2 / 31.6$ & $12.5 / 45.1$ & $2.0 / 8.1$ & 324 \\
\hline Travel Time (Minutes) & $43 / 109.0$ & $48.1 / 168.0$ & $7.7 / 29.0$ & 1,251 \\
\hline Idle Time (Minutes) & $1.6 / \mathrm{NA}$ & $1.7 / \mathrm{NA}$ & $0.3 / \mathrm{NA}$ & 45 \\
\hline
\end{tabular}

\begin{tabular}{|c|c|c|c|c|}
\hline \multicolumn{2}{|c|}{ Total Stops } & \multicolumn{2}{c|}{ Stop Duration } \\
\hline $\begin{array}{c}\text { Distance From } \\
\text { Home Base (Miles) }\end{array}$ & Stops & Percentages & Stop Duration (Hours) & Stops \\
\hline Less than 10 & 168 & $100 \%$ & Less than 2 & 129 \\
\hline 10 to 20 & 0 & $0 \%$ & 2 to 4 & 9 \\
\hline 20 to 40 & 0 & $0 \%$ & 4 to 8 & 0 \\
\hline 40 to 60 & 0 & $0 \%$ & Greater than 8 & 30 \\
\hline
\end{tabular}

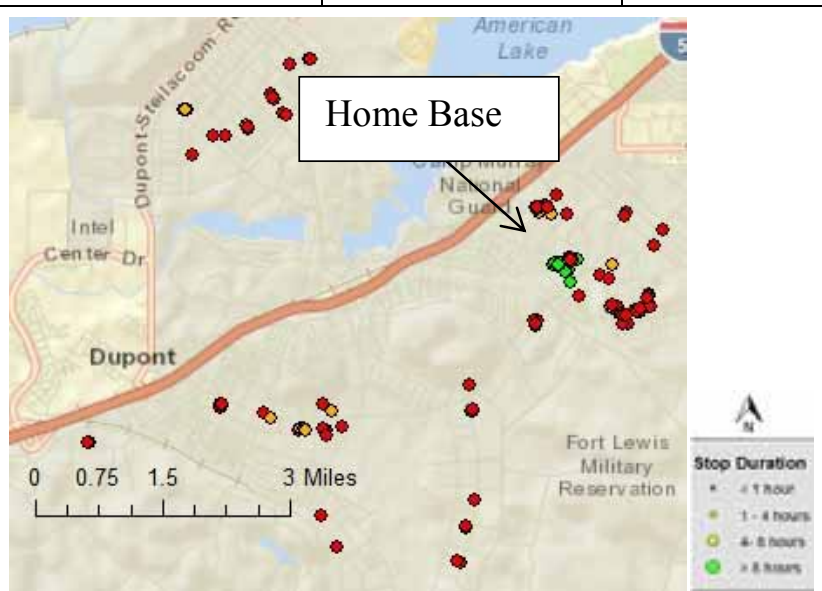

Figure E-97. Vehicle G41-1161G stops.

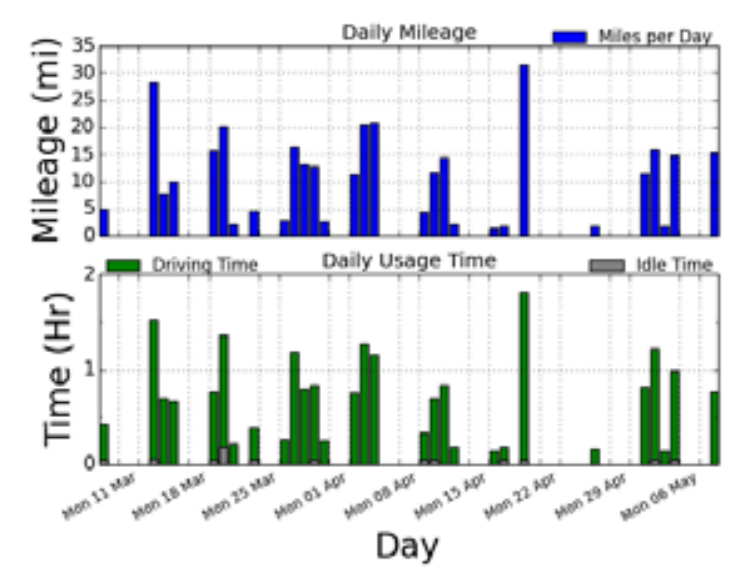

Figure E-98. Vehicle G41-1161G history. 


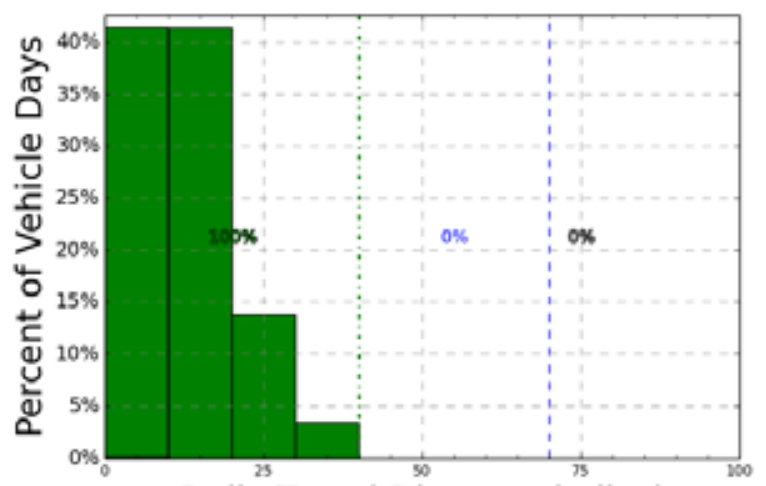

Daily Travel Distance (miles)

All days less than 40 miles $\ldots$ All days less than 70 miles
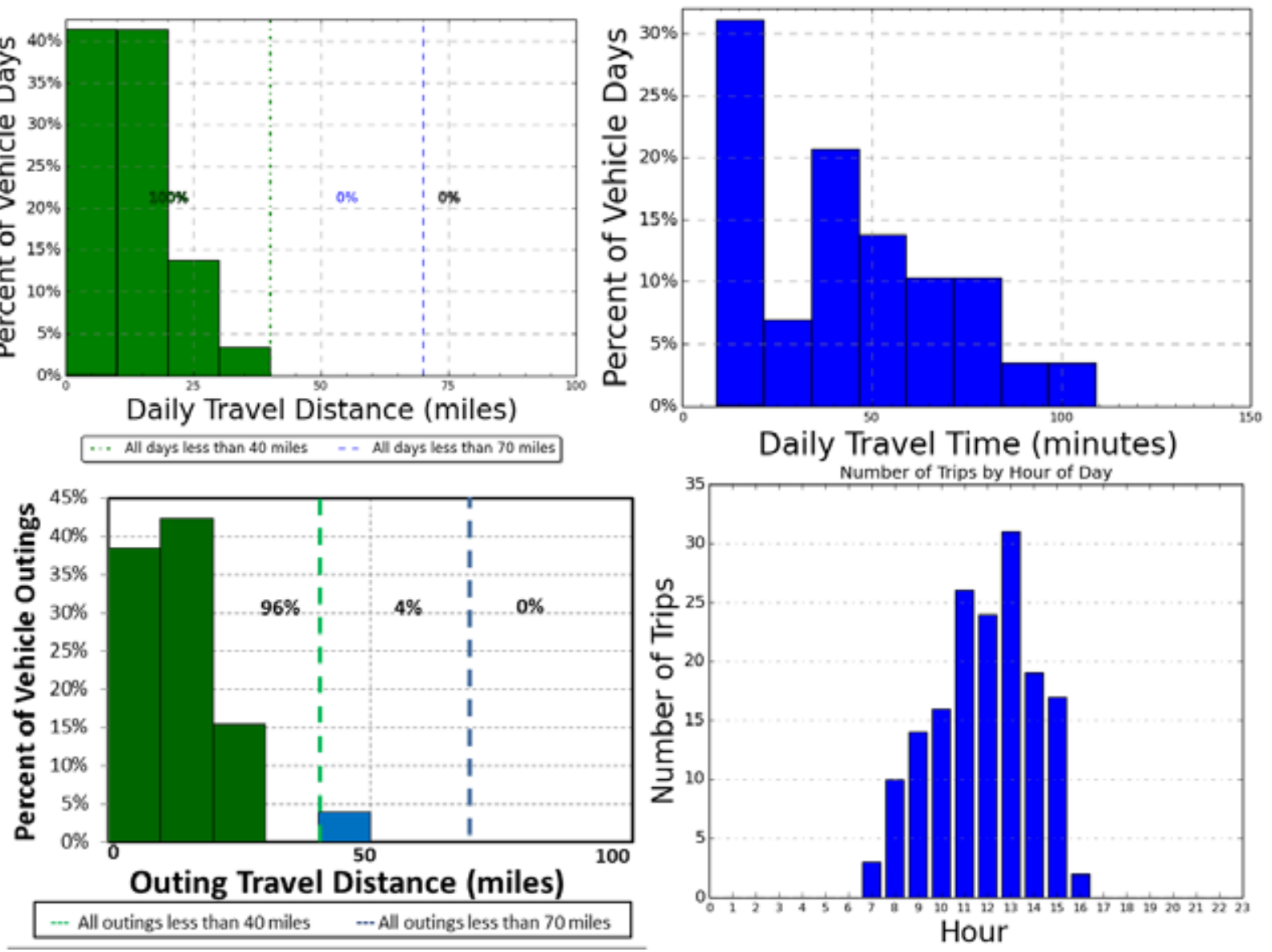

Daily Travel Time (minutes)

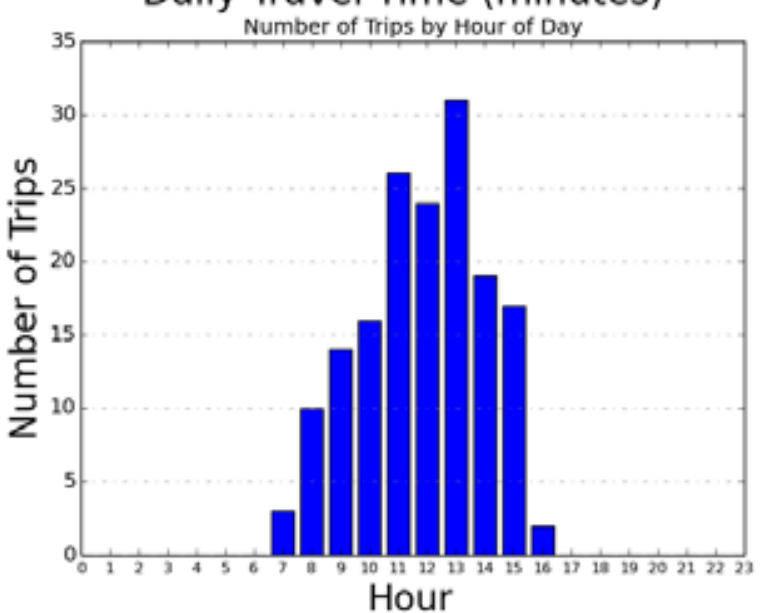

Figure E-63. Vehicle G41-1161G travel graphs.

\section{Vehicle G41-1161G Observations}

Logger 116 collected data on this vehicle for a period of 29 days of the 63-day study period.

Validation occurred on $98.6 \%$ of the input data. The project survey response reports this vehicle is a pool vehicle used to provide transportation for IMD Techs to travel to user locations throughout the base, Camp Murray, and McChord. Device is also used by other branches of IMD, and available for use by other departments who are authorized drivers. It parks in the pool parking area on Fitzsimmons near Bldg 9040A: Logistics Loading Dock. The expected retention of this vehicle is unknown. It typically travels between six and ten miles daily but does travel off base to Camp Murray, McChord, Umatilla and Sacramento frequently. Such outings are typically between eleven and forty miles. Site data reports an odometer reading of 7,222 in May 2012 with an average of 141 miles per month. Between 11 and 20 people have access to this vehicle. It typically operates during regular hours of 0700 to 1600 . The fuel used is typically E-85. It regularly carries recording, computers and network equipment for installation or repair. Vans are generally used by Customer Support, Visual Information, Networking, to setup at remote locations to include North Fort, Camp Murray and McChord.

All of the vehicle travel days were within the 70-mile BEV safe range (green bars on Figure E-99).

The longest single outing of 45 miles remains within the assumed range capability of a BEV. These data suggest that a BEV could be a suitable replacement if the BEV meets the other mission requirements of this pool vehicle. The survey information reports these requirements appear well within BEV capabilities. 
Vehicle G43-0790K

\begin{tabular}{|l|l|c|}
\hline \multirow{4}{*}{ www.edmunds.com } & Make/Model/Year & Chevrolet/CG3300/2010 \\
\cline { 2 - 3 } & EPA Class Size & Passenger Van \\
\cline { 2 - 3 } & Mission & Pool \\
\cline { 2 - 3 } & Contact & C. Sallinger/Motor Transport \\
\cline { 2 - 3 } & Parking Location & Bldg R9641 \\
\cline { 2 - 3 } & Fleet Vehicle ID & G43-0790K \\
\cline { 2 - 3 } & Fuel Type & Gas/ETH \\
\cline { 2 - 3 } & EPA Label/MPG (City/Hwy/Combined)* & $13 / 17 / 1410 / 13 / 11$ \\
\cline { 2 - 3 } & EPA GHG Emissions $($ Grams CO$/$ Mi)* & $635 / 572$ \\
\cline { 2 - 3 } & Study Logger ID & Logger 117 \\
\cline { 2 - 3 } & Total Vehicle Days/Total Study Days & No data \\
\hline
\end{tabular}

\begin{tabular}{|l|c|c|c|c|}
\hline \multicolumn{5}{|c|}{ Vehicle G43-0790K Travel Summary } \\
\hline & $\begin{array}{c}\text { Per Day } \\
\text { Average/Peak }\end{array}$ & $\begin{array}{c}\text { Per Outing } \\
\text { Average/Peak }\end{array}$ & $\begin{array}{c}\text { Per Trip } \\
\text { Average/Peak }\end{array}$ & Total \\
\hline Travel Distance (Miles) & No data & No data & No data & No data \\
\hline Travel Time (Minutes) & No data & No data & No data & No data \\
\hline Idle Time (Minutes) & No data & No data & No data & No data \\
\hline
\end{tabular}

\begin{tabular}{|c|c|c|c|c|}
\hline \multicolumn{2}{|c|}{ Total Stops } & \multicolumn{2}{c|}{ Stop Duration } \\
\hline $\begin{array}{c}\text { Distance From } \\
\text { Home Base (Miles) }\end{array}$ & Stops & Percentages & Stop Duration (Hours) & Stops \\
\hline Less than 10 & No data & No data & Less than 2 & No data \\
\hline 10 to 20 & No data & No data & 2 to 4 & No data \\
\hline 20 to 40 & No data & No data & 4 to 8 & No data \\
\hline 40 to 60 & No data & No data & Greater than 8 & No data \\
\hline
\end{tabular}

*2010 Chevrolet Express 1500 information. EPA data for CG3300 not available.

\section{Vehicle G43-0790K Observations}

Survey information was not available for this vehicle. Site data reports an odometer reading of 16,287 in May 2012 with an average of 678 miles per month. Logger reported no data for the duration of the test period for unknown reasons. No further information is available. 
Vehicle G82-0509A

\begin{tabular}{|l|l|c|}
\hline & Make/Model/Year & Ford/F350/2004 \\
\cline { 2 - 3 } & EPA Class Size & Stake Truck \\
\hline Mission & Transport \\
\hline \multirow{4}{*}{ www.edmunds.com } & Contact & C. Sallinger/Motor Transport \\
\cline { 2 - 3 } & Parking Location & Bldg R9641/Perry Ave \\
\cline { 2 - 3 } & Fleet Vehicle ID & G82-0509A \\
\cline { 2 - 3 } & Fuel Type & Diesel \\
\cline { 2 - 3 } & EPA Label/MPG (City/Hwy/Combined)* & Not available \\
\cline { 2 - 3 } & EPA GHG Emissions (Grams CO $/$ Mi)* & Not available \\
\cline { 2 - 3 } & Study Logger ID & Logger 118 \\
\cline { 2 - 3 } & Total Vehicle Days/Total Study Days & Insufficient data \\
\hline
\end{tabular}

\begin{tabular}{|l|c|c|c|c|}
\hline \multicolumn{7}{|c|}{ Vehicle G82-0509A Travel Summary } \\
\hline & $\begin{array}{c}\text { Per Day } \\
\text { Average/Peak }\end{array}$ & $\begin{array}{c}\text { Per Outing } \\
\text { Average/Peak }\end{array}$ & $\begin{array}{c}\text { Per Trip } \\
\text { Average/Peak }\end{array}$ & Total \\
\hline Travel Distance (Miles) & Insufficient data & Insufficient data & Insufficient data & Insufficient data \\
\hline Travel Time (Minutes) & Insufficient data & Insufficient data & Insufficient data & Insufficient data \\
\hline Idle Time (Minutes) & Insufficient data & Insufficient data & Insufficient data & Insufficient data \\
\hline
\end{tabular}

\begin{tabular}{|c|c|c|c|c|}
\hline \multicolumn{2}{|c|}{ Total Stops } & \multicolumn{2}{c|}{ Stop Duration } \\
\hline $\begin{array}{c}\text { Distance From } \\
\text { Home Base (Miles) }\end{array}$ & Stops & Percentages & $\begin{array}{c}\text { Stop Duration } \\
\text { (Hours) }\end{array}$ & Stops \\
\hline Less than 10 & Insufficient data & Insufficient data & Less than 2 & Insufficient data \\
\hline 10 to 20 & Insufficient data & Insufficient data & 2 to 4 & Insufficient data \\
\hline 20 to 40 & Insufficient data & Insufficient data & 4 to 8 & Insufficient data \\
\hline 40 to 60 & Insufficient data & Insufficient data & Greater than 8 & Insufficient data \\
\hline
\end{tabular}

\section{Vehicle G82-0509A Observations}

Survey information was not available for this vehicle. The limited stop data suggests it typically parks near Bldg 9641 on Perry Avenue. Site data reports an odometer reading of 6,292 in May 2012 with an average of 13 miles per month.

Logger 118 collected data on the vehicle for only 2 days of the 63-day study period. This is insufficient for analysis. 
Vehicle G10-6379L

\begin{tabular}{|l|l|c|}
\hline & Make/Model/Year & Dodge/Avenger/2011 \\
\cline { 2 - 3 } & EPA Class Size & Midsize Car \\
\hline \multirow{4}{*}{ www.edmunds.com } & Mission & Support \\
\cline { 2 - 3 } & Contact & Bldg $9040 /$ Gardner Loop RD \\
\cline { 2 - 3 } & Parking Location & G10-6379L \\
\hline & Fleet Vehicle ID & Gas/ETH \\
\cline { 2 - 3 } & Fuel Type & $19 / 29 / 2214 / 21 / 16$ \\
\cline { 2 - 3 } & EPA Label/MPG (City/Hwy/Combined)* & $404 / 393$ \\
\cline { 2 - 3 } & EPA GHG Emissions (Grams CO $/$ Mi)* & Logger 119 \\
\cline { 2 - 3 } & Study Logger ID & $19 / 63$ \\
\hline & Total Vehicle Days/Total Study Days & \\
\hline
\end{tabular}

\begin{tabular}{|l|c|c|c|c|}
\hline \multicolumn{5}{|c|}{ Vehicle G10-6379L Travel Summary } \\
\hline & $\begin{array}{c}\text { Per Day } \\
\text { Average/Peak }\end{array}$ & $\begin{array}{c}\text { Per Outing } \\
\text { Average/Peak }\end{array}$ & $\begin{array}{c}\text { Per Trip } \\
\text { Average/Peak }\end{array}$ & Total \\
\hline Travel Distance (Miles) & $88.5 / 555.0$ & $105.1 / 1,236.1$ & $18.5 / 245.6$ & 1,682 \\
\hline Travel Time (Minutes) & $125 / 555.0$ & $148.2 / 1,353.0$ & $26.1 / 223.0$ & 2,371 \\
\hline Idle Time (Minutes) & $11.9 / \mathrm{NA}$ & $14.2 / \mathrm{NA}$ & $2.5 / \mathrm{NA}$ & 227 \\
\hline
\end{tabular}

\begin{tabular}{|c|c|c|c|c|}
\hline \multicolumn{2}{|c|}{ Total Stops } & \multicolumn{2}{c|}{ Stop Duration } \\
\hline $\begin{array}{c}\text { Distance From } \\
\text { Home Base (Miles) }\end{array}$ & Stops & Percentages & Stop Duration (Hours) & Stops \\
\hline Less than 10 & 45 & $43.7 \%$ & Less than 2 & 80 \\
\hline 10 to 20 & 5 & $4.9 \%$ & 2 to 4 & 1 \\
\hline 20 to 40 & 6 & $5.8 \%$ & 4 to 8 & 4 \\
\hline Greater than 40 & 47 & $45.6 \%$ & Greater than 8 & 18 \\
\hline
\end{tabular}

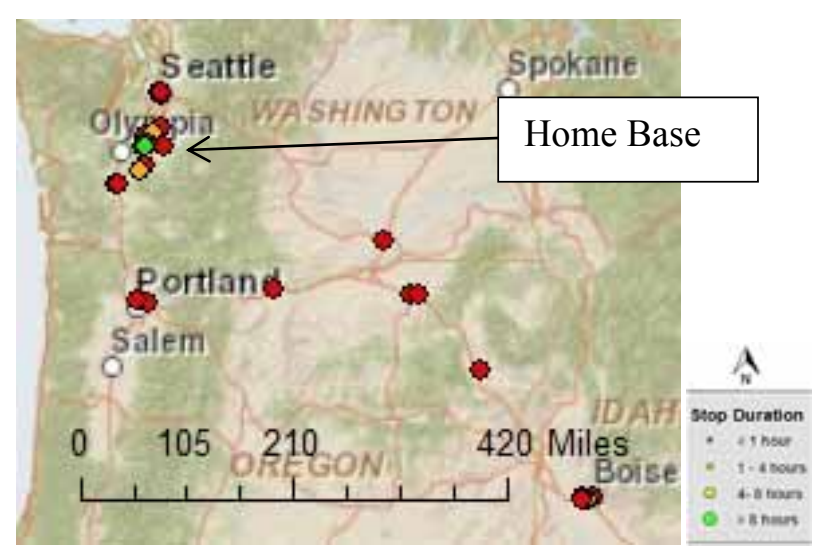

Figure E-100. Vehicle G10-6379L stops.

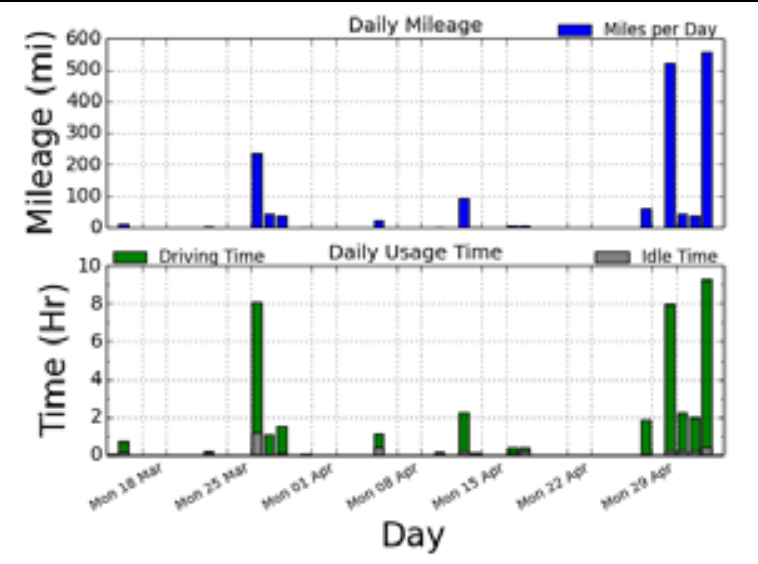

Figure E-101. Vehicle G10-6379L history. 

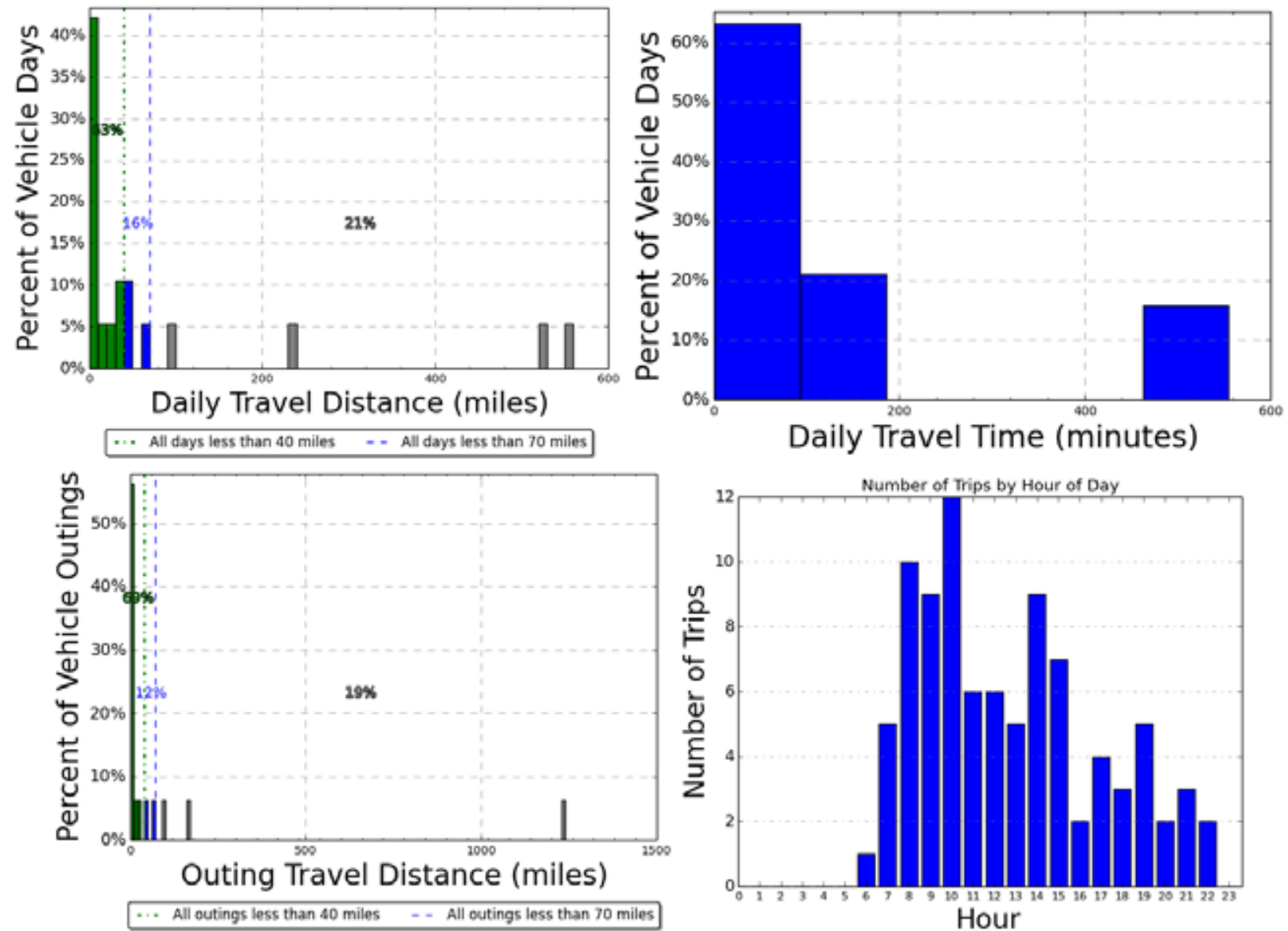

Daily Travel Time (minutes)

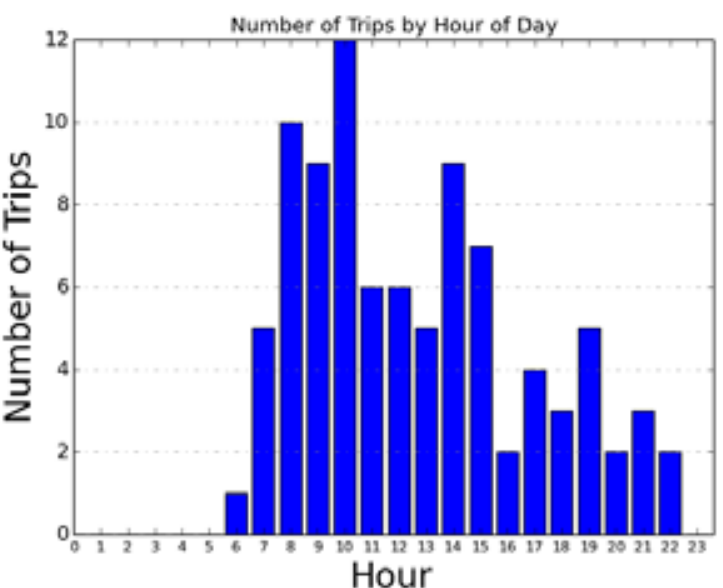

Figure E-64. Vehicle G10-6379L travel graphs.

\section{Vehicle G10-6379L Observations}

Logger 119 collected data on this vehicle for a period of 19 days of the 63-day study period. Validation occurred on $95.4 \%$ of the input data. Survey information was not available for this vehicle. Stop data suggests it typically parks near Bldg 9040 Medical Center on Fitzsimmons or Gardner Loop Rd. This vehicle took an extended excursion to Idaho and Oregon from April 28 through May 1. Site data reports an odometer reading of 9,478 in May 2012 with an average of 728 miles per month.

Seventy-nine percent of all vehicle travel days were within the 70-mile BEV safe range (green and blue bars on Figure E-102), while $21 \%$ of the vehicle travel days exceeds this range. This vehicle was used rather infrequently but when used, was utilized for these longer excursions.

The longest single outing of 1236 miles occurred on the excursion to Idaho and Oregon from April 28 to May 1. Several other outings (19\%) exceeded the 70 -mile BEV safe range while $81 \%$ of outings were within this range. While a BEV cannot meet the travel requirements of this vehicle, a PHEV would provide significant benefit. $63 \%$ of daily travel and $69 \%$ of the outings are within the 40 -mile battery only range of typical PHEVs. As this vehicle is a sedan, PHEVs are currently available to meet this mission. 
Vehicle G42-3471A

\begin{tabular}{|l|l|c|}
\hline & Make/Model/Year & Chevrolet/G2300/2005 \\
\hline \multirow{5}{*}{ www.edmunds.com } & EPA Class Size & Cargo Van \\
\hline & Mission & Transport \\
\cline { 2 - 3 } & Contact & C. Sallinger/Motor Transport \\
\hline & Farking Location & Bldg 690 \\
\hline & Fleet Vehicle ID & G42-3471A \\
\cline { 2 - 3 } & Fuel Type & Gas \\
\cline { 2 - 3 } & EPA Label/MPG (City/Hwy/Combined)* & $14 / 19 / 15$ \\
\hline & EPA GHG Emissions (Grams CO $/$ Mi)* & 592 \\
\hline & Study Logger ID & Logger 120 \\
\hline & Total Vehicle Days/Total Study Days & $10 / 63$ \\
\hline
\end{tabular}

\begin{tabular}{|l|c|c|c|c|}
\hline \multicolumn{5}{|c|}{ Vehicle G42-3471A Travel Summary } \\
\hline & $\begin{array}{c}\text { Per Day } \\
\text { Average/Peak }\end{array}$ & $\begin{array}{c}\text { Per Outing } \\
\text { Average/Peak }\end{array}$ & $\begin{array}{c}\text { Per Trip } \\
\text { Average/Peak }\end{array}$ & Total \\
\hline Travel Distance (Miles) & $20.2 / 44.6$ & $14.4 / 83.5$ & $3.6 / 38.9$ & 202 \\
\hline Travel Time (Minutes) & $102 / 241.0$ & $73.1 / 241.0$ & $18.3 / 65.0$ & 1,023 \\
\hline Idle Time (Minutes) & $50.0 / \mathrm{NA}$ & $35.7 / \mathrm{NA}$ & $8.9 / \mathrm{NA}$ & 500 \\
\hline
\end{tabular}

\begin{tabular}{|c|c|c|c|c|}
\hline \multicolumn{2}{|c|}{ Total Stops } & \multicolumn{2}{c|}{ Stop Duration } \\
\hline $\begin{array}{c}\text { Distance From } \\
\text { Home Base (Miles) }\end{array}$ & Stops & Percentages & Stop Duration (Hours) & Stops \\
\hline Less than 10 & 40 & $90.9 \%$ & Less than 2 & 28 \\
\hline 10 to 20 & 0 & $0 \%$ & 2 to 4 & 7 \\
\hline 20 to 40 & 4 & $9.1 \%$ & 4 to 8 & 0 \\
\hline 40 to 60 & 0 & $0 \%$ & Greater than 8 & 9 \\
\hline
\end{tabular}

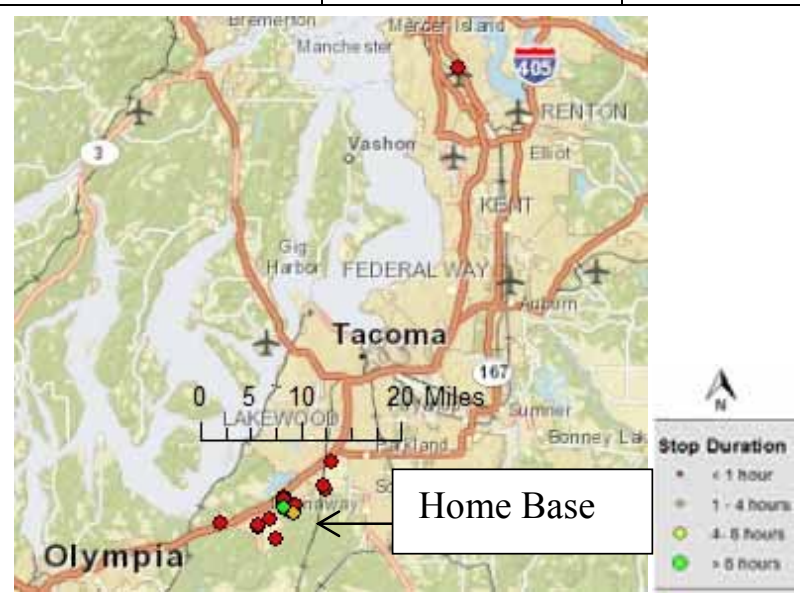

Figure E-103. Vehicle G42-3471A stops.

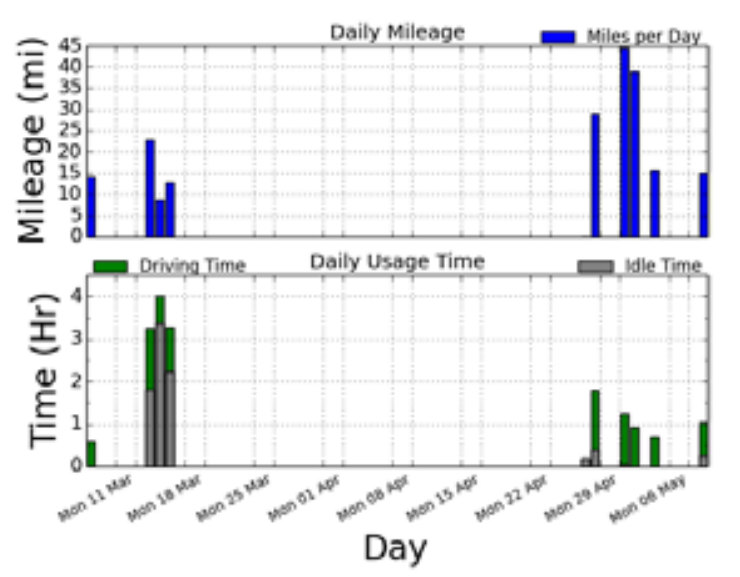

Figure E-104. Vehicle G42-3471A history. 


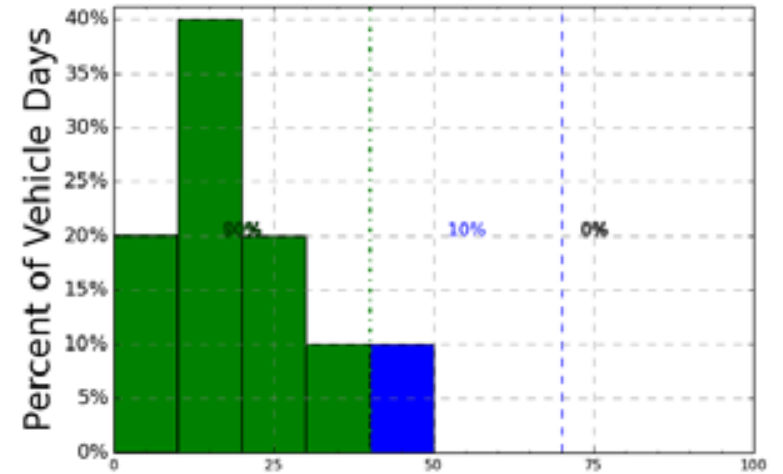

Daily Travel Distance (miles)
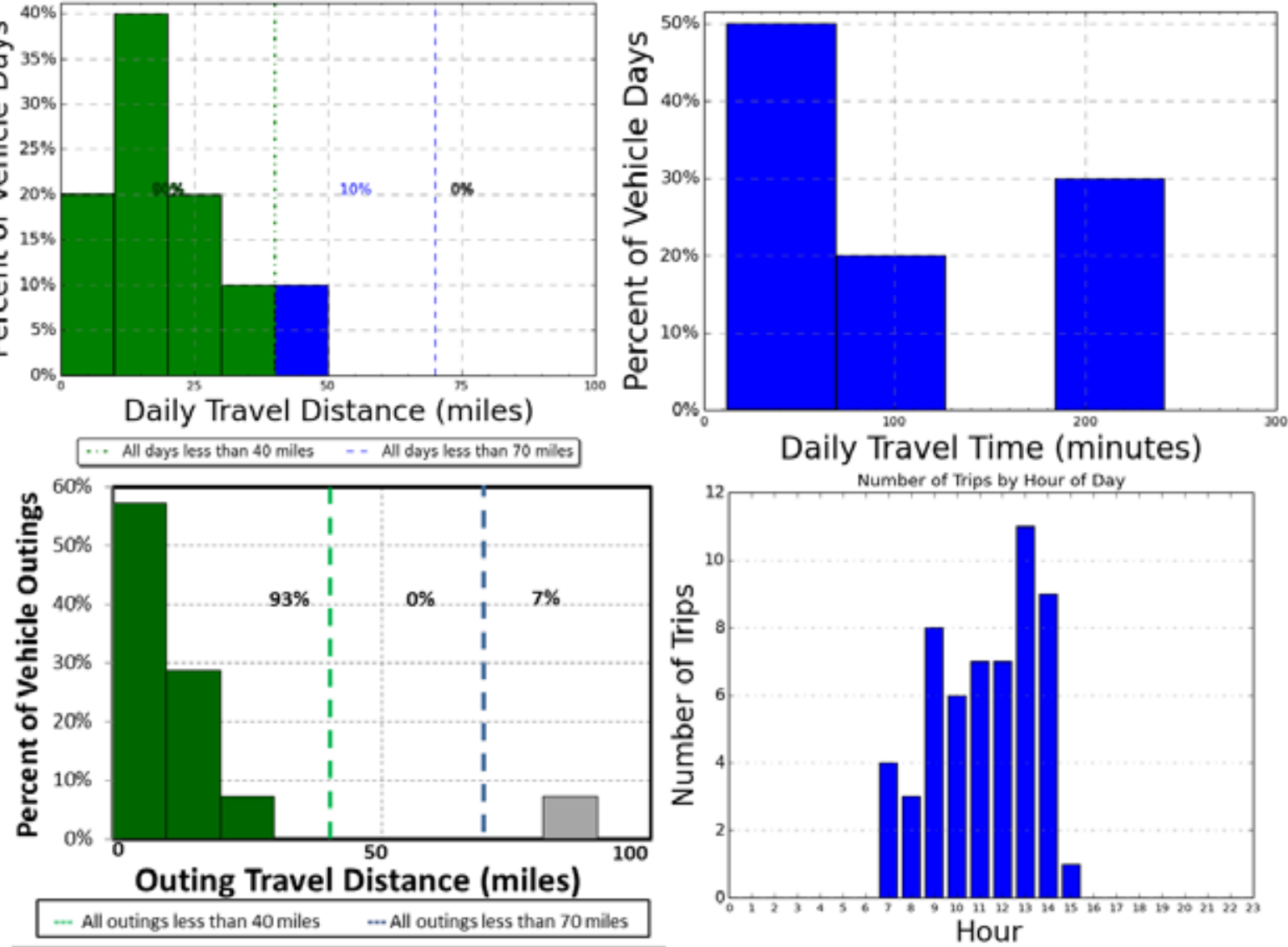

Daily Travel Time (minutes)

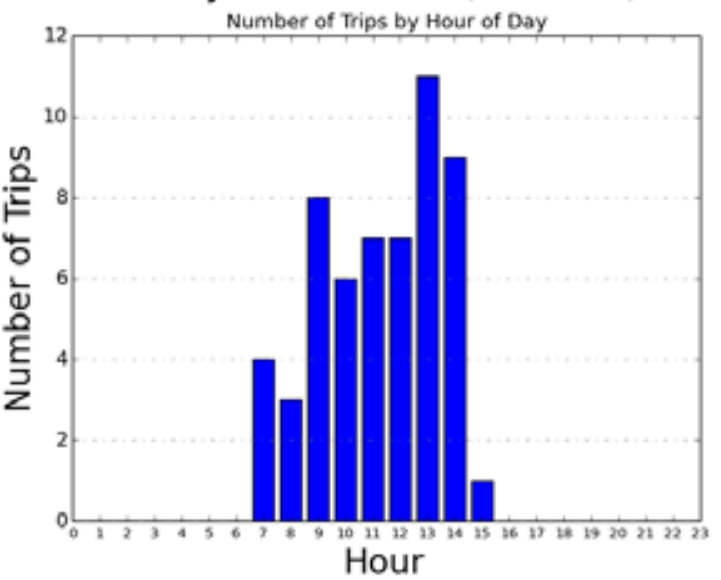

Figure E-65. Vehicle G42-3471A travel graphs.

\section{Vehicle G42-3471A Observations}

Logger 120 collected data on this vehicle for a period of 10 days of the 63-day study period. Validation occurred on $97.1 \%$ of the input data. The project survey response reports this vehicle, assigned to McChord Medical Clinic is a delivery vehicle used to transport all Class VIII items from Madigan to multiple clinic and squadron located on McChord Field. While the survey reported it parks in the office parking lot near Bldg 690 at the McChord Medical Clinic, the data report it parked most frequently near Bldg 9040, Medical Center on Fitzsimmons or Gardner Loop Road. From April 26 to May 2 it was parked overnight on Lincoln Street near Bldg 9993/9999. It typically travels between 11 and 40 miles per day. Site data reports an odometer reading of 9,478 in May 2012 with an average of 728 miles per month. Between two and five people have access to this vehicle and it carries one person per trip. It may be used at any time but typically operates from 0630 to 1730 hours daily.

This vehicle is the main support for transporting medical supplies and picking up supplies for the McChord Clinic, 62d Medical Squadron, McChord VET Clinic, McChord Dental Clinic and Multiple Air Force Squadrons located on McChord Field. This vehicle is the main logistic transportation for these multiple organization on McChord Air Field.

All vehicle travel days were within the 70-mile BEV safe range (green and blue bars on Figure E-105). All outings were within this range except for the single outing to King County Airport in Seattle on April 29/30. This single outing precludes the replacement by a BEV but a PHEV would provide significant benefit, if one can meet the other mission and carry requirements. $90 \%$ of daily travel and $93 \%$ of outings are within the battery-only range of typical PHEVs. 


\section{Appendix F}

\section{6th MP Group Vehicle Analysis}

\section{F.1 6th MP Group Vehicle Summary}

This section summarizes and aggregates the data collection for the $6^{\text {th }}$ MP Group. The details of each vehicle monitored are included in Appendix B.

The $6^{\text {th }}$ MP Group fleet contains twenty vehicles. Table 9 provides a summary of all vehicles in the $6^{\text {th }}$ MP Group fleet.

Table F-1. $6^{\text {th }}$ MP Group total fleet summary.

\begin{tabular}{ccccccccccc} 
& & & & & & \multicolumn{4}{c}{ Pickup } & MD or \\
Mission & $\begin{array}{c}\text { Sedan } \\
\text { Compact }\end{array}$ & $\begin{array}{c}\text { Sedan } \\
\text { Midsize }\end{array}$ & $\begin{array}{c}\text { Sedan } \\
\text { Large }\end{array}$ & SUV & $\begin{array}{c}\text { Mini } \\
\text {-van }\end{array}$ & $\begin{array}{c}\text { Cargo } \\
\text { Van }\end{array}$ & $\begin{array}{c}\text { Pass. } \\
\text { Van }\end{array}$ & $\begin{array}{c}\text { or LD } \\
\text { Truck }\end{array}$ & $\begin{array}{c}\text { Truck } \\
\text { Trual }\end{array}$ \\
\hline $\begin{array}{c}\text { Pool } \\
\text { Other }\end{array}$ & 3 & 3 & 5 & 2 & 2 & & 1 & 4 & & 20 \\
Total & 3 & 3 & 5 & 2 & 2 & & 1 & 4 & 0 \\
\hline
\end{tabular}

Error! Reference source not found. provides a summary of the vehicles monitored for this report. Table F-2. $6^{\text {th }}$ MP Group vehicle logger summary.

\begin{tabular}{ccccccc}
$\begin{array}{c}\text { Logger } \\
\text { No. }\end{array}$ & Fleet Vehicle Id & Make & Model & Year & EPA Class & Mission \\
\hline 82 & G61-0546L & GMC & Terrain & 2011 & SUV & Pool \\
86 & G61-0689A & Ford & Ranger & 2004 & Pickup Truck & Pool \\
103 & G41-5433B & Dodge & Grand Caravan & 2006 & Minivan & Pool \\
\hline
\end{tabular}

In the following analysis, vehicles may be referenced by logger number or fleet vehicle ID.

JBLM data collection occurred from March 5, 2013 through May 7, 2013. Vehicle data sheets (presented in Appendix B) detail the collected data for each vehicle.

Of the data collected, validation occurred for $99.7 \%$ of the data, while null values exist for the balance. Error! Reference source not found. shows this information by mission type.

Table F-3. $6^{\text {th }}$ MP Group vehicle data logger reporting summary.

\begin{tabular}{lccc}
\multicolumn{4}{c}{ Vehicle Data Logger Reporting Summary } \\
\multicolumn{1}{c}{ Mission } & $\%$ Valid & \% Null Values & Total \\
\hline $\begin{array}{l}\text { Pool } \\
\text { Other }\end{array}$ & 99.7 & 0.3 & $100 \%$ \\
All Vehicles & 99.7 & 0.3 & $100 \%$ \\
\hline
\end{tabular}

\section{F.2 6th MP Group Pool Vehicles Evaluation}

Grouping the vehicles by mission creates an aggregated view of mission requirements to provide observations related to PEV replacement. All these vehicles assigned to the 6th MP Group are pool vehicles.

Pool vehicles are typically light-duty motor vehicles for use in passenger transportation, with not more than ten passengers. Pool missions can vary by agency, location, and jurisdiction; however, they 
typically utilize sedans, minivans, vans, or small pickup trucks and typically do not carry specific cargo or equipment.

Incorporation of BEVs and/or PHEVs into the pool mission is a definite possibility. Pool vehicles used for shorter trips or outings qualify for BEV or PHEV replacement, while other pool vehicle activities that are associated with longer trips may require PHEV capabilities.

\section{F.2.1 Summary for $6^{\text {th }}$ MP Group Pool Vehicles}

Appendix B provides the vehicle data sheets for each of the three pool vehicles monitored. This section aggregates data for all pool vehicles. Table summarizes pool travel during the study period for those days in which the vehicle was driven. Vehicle use occurred primarily between 0900 and 1900 hours daily. They traveled 2,052 miles, logged 108 hours, and idled for 21 hours during the 63-day study period.

Table F-4. Pool vehicles travel summary.

\begin{tabular}{lcccc}
\hline \multicolumn{4}{c}{ Pool Vehicles Travel Summary } & \\
& $\begin{array}{c}\text { Per Day } \\
\text { Average/Peak }\end{array}$ & $\begin{array}{c}\text { Per Outing } \\
\text { Average/Peak }\end{array}$ & $\begin{array}{c}\text { Per Trip } \\
\text { Average/Peak }\end{array}$ & Total \\
\hline Travel Distance (Miles) & $22.1 / 224$ & $11.3 / 156$ & $4.5 / 83$ & 2,050 \\
Travel Time (Minutes) & $69.6 / 361$ & $35.6 / 443$ & $14.2 / 181$ & 6,477 \\
Idle Time (Minutes) & $13.6 / \mathrm{NA}$ & $7.0 / \mathrm{NA}$ & $2.8 / \mathrm{NA}$ & 1,269 \\
\hline
\end{tabular}

Figure F-1 shows the travel summary for pool vehicles: by vehicle, by daily mileage, and daily usage time. Figure F-2 shows the composite history for all pool vehicles. In the stacked bar charts of Error! Reference source not found., the contribution of each vehicle is indicated by a different color.
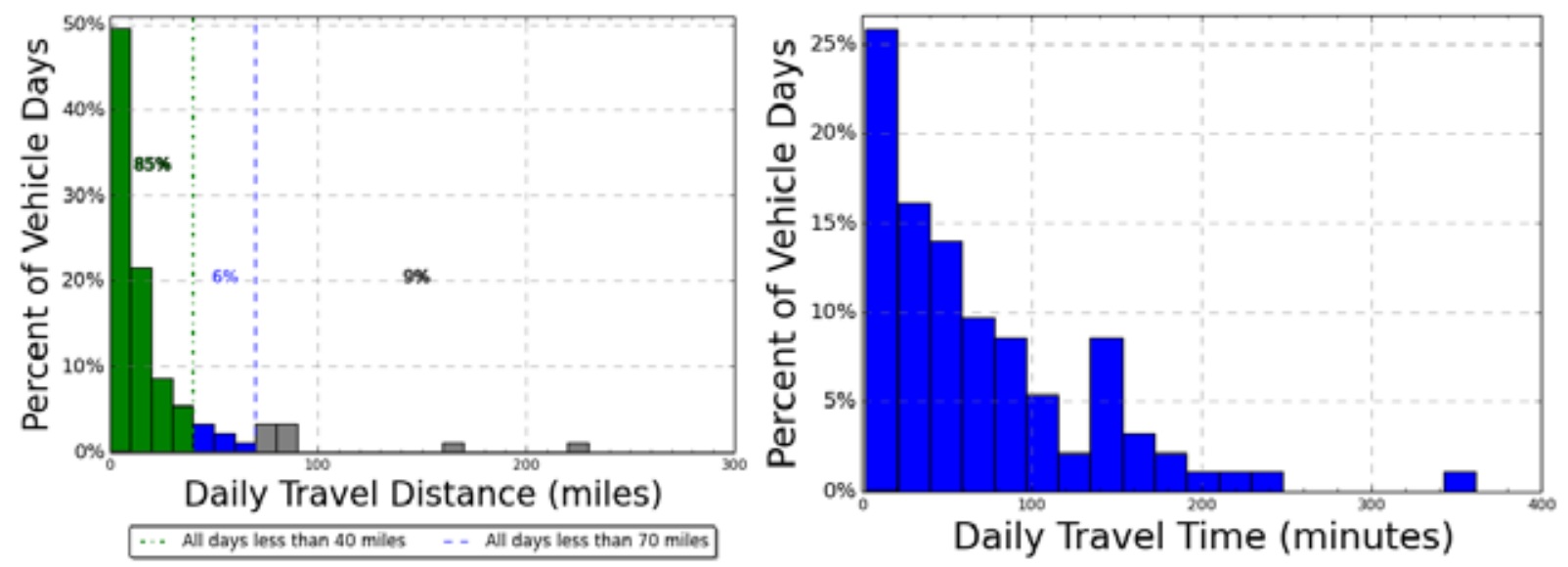

Figure F-1. Pool vehicle daily travel miles and time (all vehicles) 


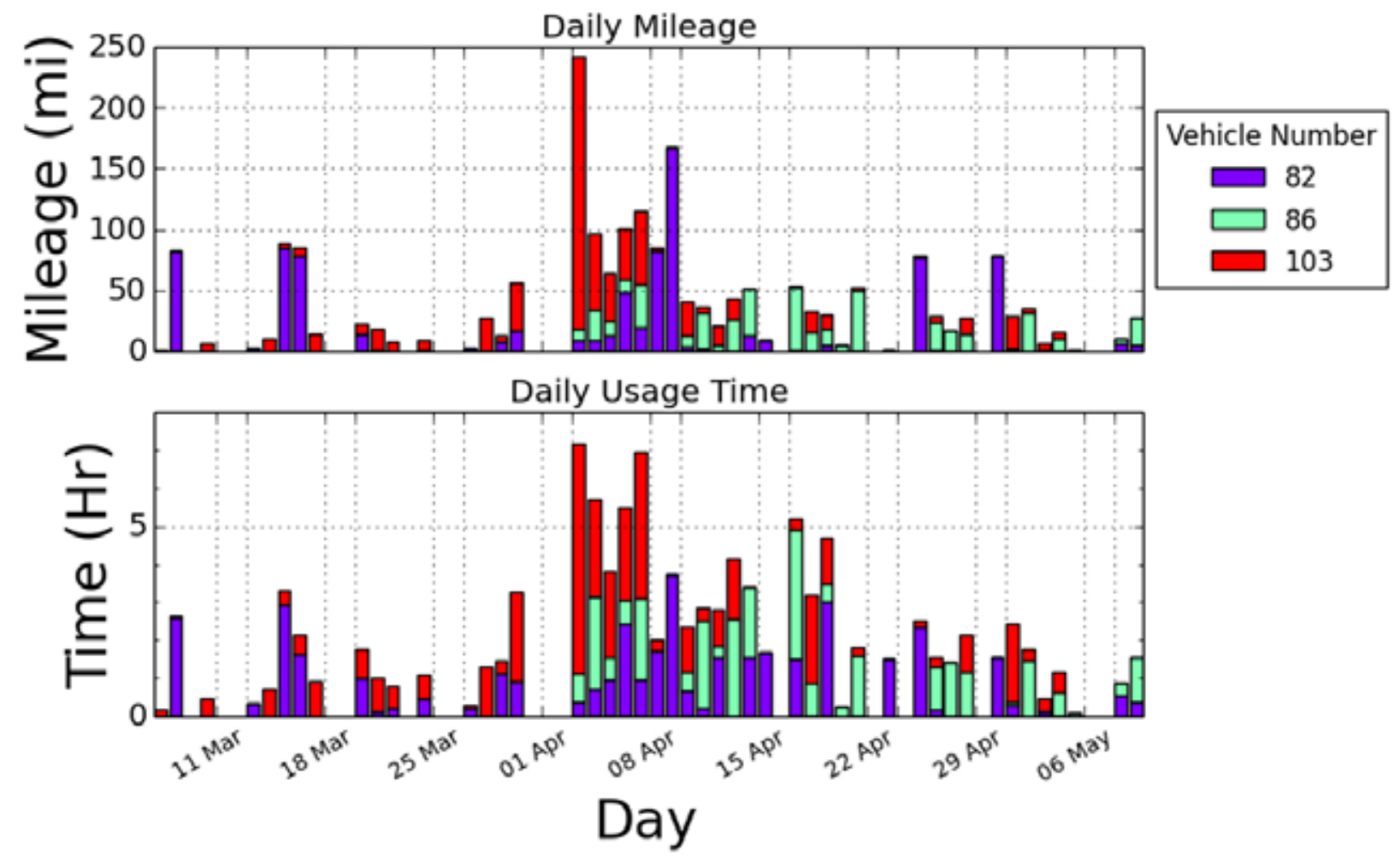

Figure F-2. Pool vehicles travel history (all vehicles)

\section{F.2.2 Pool Vehicles Daily Summary}

The average travel distance per day when driven for pool vehicles is 22.1 miles. On $91 \%$ of these vehicle days, the daily travel is less than the 70 miles considered to be within the BEV safe range (blue and green bars in Figure F-1). That is, while BEV range can vary based on several factors; most BEVs provide at least 70 miles of vehicle range on a single battery charge. Meanwhile, $9 \%$ percent of pool daily travel is greater than 70 miles. Eighty-five percent of vehicle travel days are less than 40 miles considered to be within the CD range of a PHEV (green bars of Figure F-1).

Figure F-2 shows that vehicles are used frequently. Vehicle G61-0546L traveled 52\% of the days monitored, Vehicle G61-0689A traveled 38\% of the days and Vehicle G41-5433B traveled 57\% of the days. However, there are periods where each vehicle operated several days in a row and days that all vehicles are in use.

Figure F-3 displays the summary of use by time of day for all pool vehicles.

Figure F-4 shows the outings for all vehicles.

Appendix B provides the details of each of the pool vehicle's outings. At some point during the evaluation period, both vehicles G61-0546L and G61-0689A exceeded 70 miles in an outing.

The average travel outing when driven for pool vehicles is 11.3 miles. On $95 \%$ of these vehicle outings, the distance traveled is less than the 70 miles considered to be within the BEV safe range. Meanwhile, $5 \%$ percent of pool outing travel is greater than 70 miles. Ninety-three percent of vehicle travel outings are less than 40 miles considered to be within the CD range of a PHEV. 


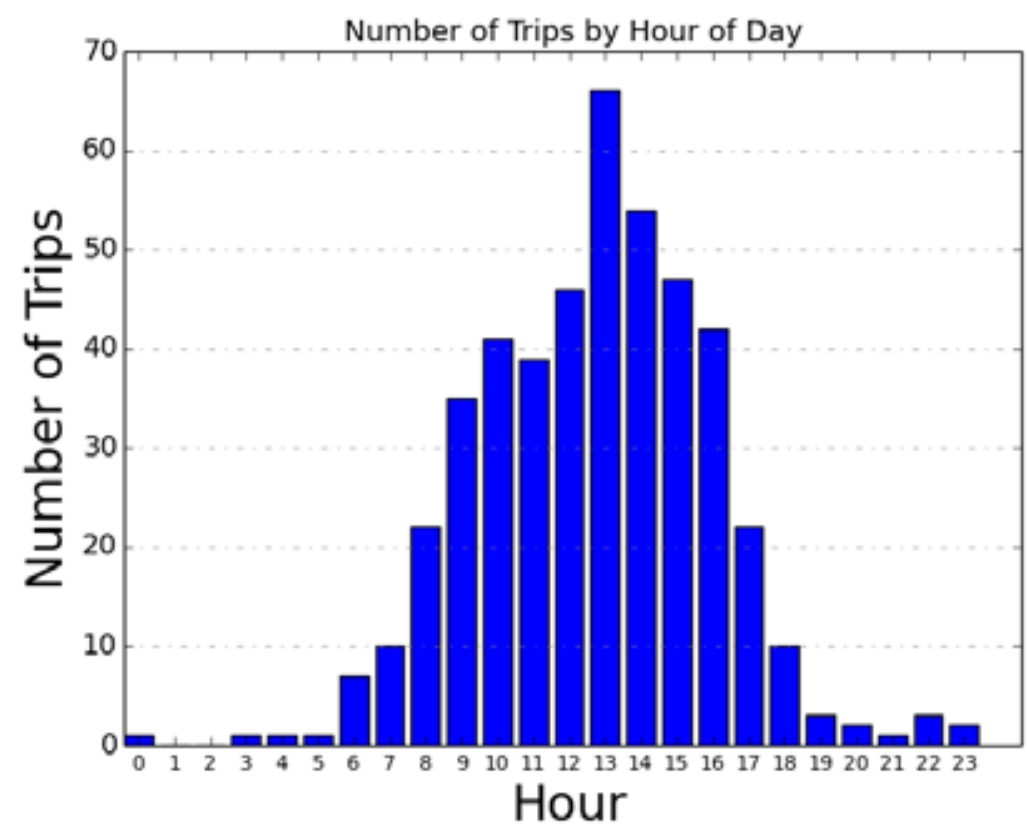

Figure F-3. Pool vehicles hourly usage

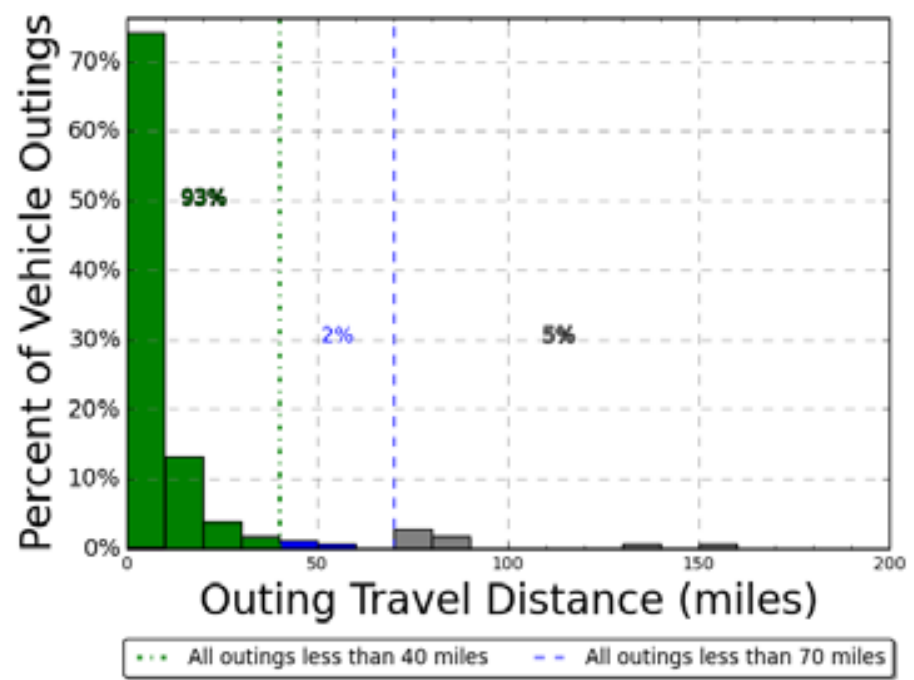

Figure F-4. Pool vehicle combined outings

\section{F.2.3 Pool Vehicle Observations/Summary}

There appear to be three choices for JBLM in implementing PEVs into the 6th MP Group pool fleet. It should be noted that the optimum goal would be to incorporate as many BEVs as possible to realize the advantages of reduced petroleum usage and reduced emissions of GHG.

1. All BEV fleet: While some BEV manufacturers report vehicle range exceeding 70 miles, Intertek recommends careful evaluation of experienced range to ensure vehicle missions are accomplished. Nevertheless, assuming the 70-mile safe range for a BEV, an all-BEV fleet does not appear to be possible due to the length of the daily outings.

2. Mixed BEV/PHEV fleet: Certainly, PHEVs can accomplish the same mission as the current fleet when only considering travel times and distances because the PHEV's gasoline engine can provide motive power when the battery has been depleted. The data reveal that on $85 \%$ of all vehicle travel days, the total daily travel is less than 40 miles, which typically is the maximum distance a PHEV will travel in CD mode. This represents a significant operating cost savings opportunity while 
retaining the ability to go longer distances when needed. Furthermore, $93 \%$ of the outings are less than 40 miles and could be completed in CD mode for certain PHEVs if the battery is fully charged prior to the outing.

Fully $95 \%$ of the outings are within the typical capability of a BEV, and so the EVSE at the home base could provide recharge energy for another outing. A mixed fleet requires fleet manager attention to assign vehicles appropriately for the anticipated use on that day.

3. All PHEV fleet: As noted above, PHEVs can accomplish the same mission as the current fleet when only considering travel times and distances. Replacing all current vehicles with PHEVs only requires an evaluation of the individual vehicle capabilities of currently available PHEVs to meet current pool requirements. Data show that for a significant number of days, the PHEV will operate in CD mode.

As above, this represents a significant operating cost savings opportunity while retaining the ability to go longer distances when needed. Intermediate charging opportunities provide additional benefit, enhancing the CD mode. Data show significant charging opportunities throughout the day during stop times.

While it would appear that PEVs are suitable replacements for these pool vehicles, additional mission analysis and management input is required. The missions of these vehicles likely include considerations other than mileage, such as cargo demands placed on the vehicle. Pool vehicles typically do not have such regular demands, nor were such identified on the vehicle surveys.

The vehicle summary shows sufficient time for charging at the base location during the course of the day and additional opportunities at intermediate charging stations. These stations also provide charging opportunities for the visiting public, whose fees may assist in offsetting capital and operating costs.

Intertek suggests further mission evaluation be given to pool vehicles when considering the adoption of BEVs and PHEVs. The fleet of pool vehicles in this study included one SUV, one minivan, and one pickup truck. Section 4.4 provides information on PEV currently or soon to be available in the automotive market. Without specific cargo requirements, replacement PEVs currently exist for all these vehicles. Based on the travel data, Intertek suggests that replacing these three vehicles with one PHEV and two BEVs would meet current mission requirements.

Considering a full complement of 20 pool vehicles in the 6th MP Group fleet, Intertek suggests that a mixed fleet may be possible. While one of the vehicles is a passenger van and there are currently no PEVs in this class, the remaining vehicles may be replaced. These remaining vehicles were not monitored, but using the data collected for the three that were, Intertek suggests a fleet of 12 BEVs and 7 PHEVs conservatively meets vehicle travel requirements.

\section{F.2.4 Pool Vehicle Charging Needs}

Upon review of these data, Intertek suggests replacement of the $6^{\text {th }}$ MP Group pool fleet with two BEVs and one PHEV. No available PHEVs at this writing provide for DC fast charging nor do the data suggest that this would be a significant benefit for PHEVs in the pool fleet. A DCFC at the home base will provide a more rapid recharge for BEVs but appears to be unnecessary if the fleet manager carefully assigns pool vehicles based upon anticipated outing lengths.

As noted previously, AC Level 2 overnight charging of BEVs is typical, whereas overnight charging of PHEVs can usually be accomplished with AC Level 1 charging.

Intertek's experience suggests that each vehicle should have an assigned charging location at its home base. Assigned stations require less management attention to ensure completion of overnight charging. BEVs and PHEVs not assigned to these locations also benefit during visits to the location as part of their normal operation. For the entire fleet of pool vehicles, two BEVs require two AC Level 2 EVSE units for overnight charging and one PHEV require one AC Level 1 outlets for home base. Intertek recommends a minimum of two EVSE at each location to maximize charge capability without a significant increase in installation costs. The PHEVs can utilize the AC Level 2 EVSE at the home base during the day to increase the amount of vehicle miles traveled in CD Mode. 
At times, fleet vehicles obtain benefit from using public charging infrastructure. Figure F-5 displays the availability of public charging at the time of this writing for the JBLM area. The green-colored sites are AC sites indicating either AC Level 1 and Level 2 public locations and the orange-colored sites are DCFCs.

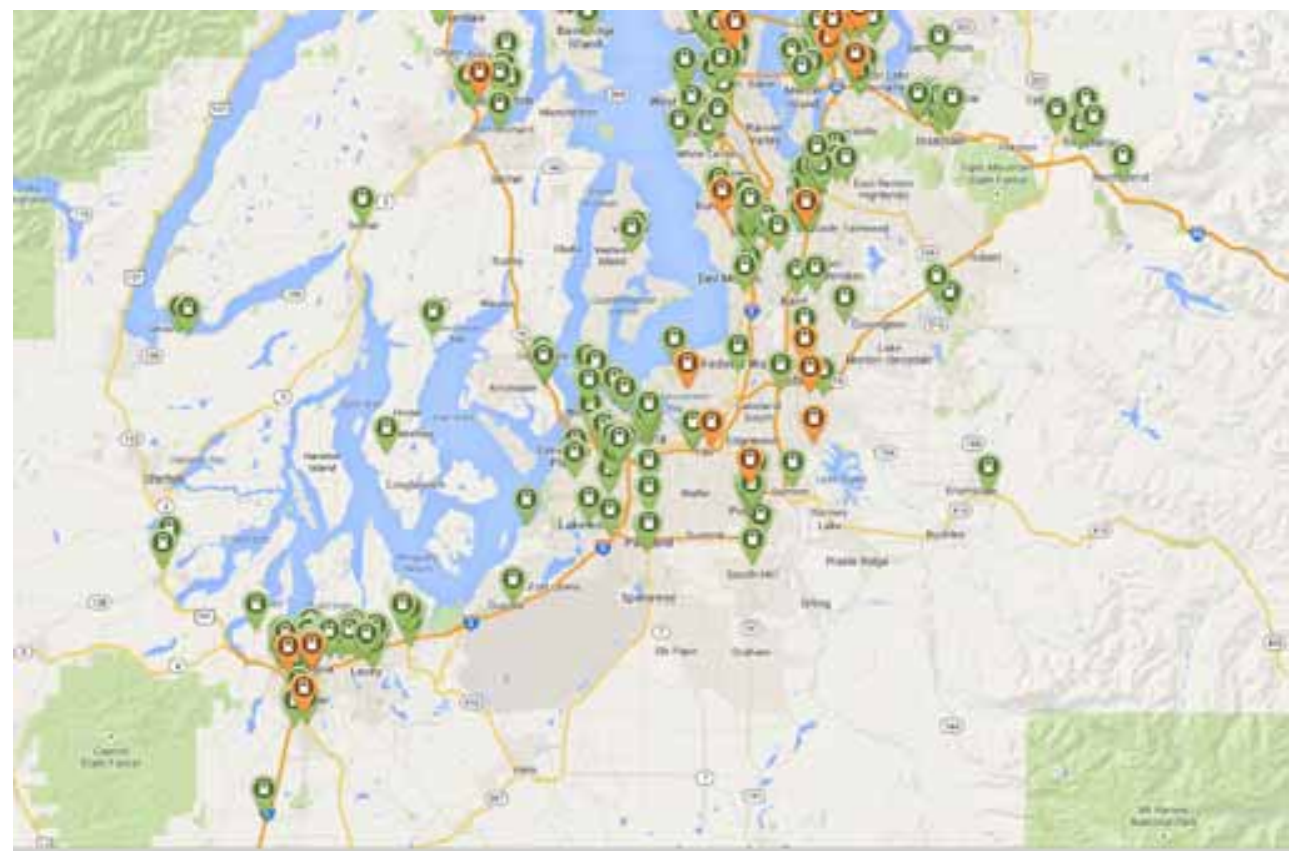

Figure F-5. Public EVSE in JBLM Region ${ }^{26}$

There is significant development in public charging infrastructure in the JBLM area due to the great public interest in PEV adoption and earlier emphasis on infrastructure through DOE granted programs and EVSE supplier interests. For the $6^{\text {th }}$ MP Group fleet monitored, all travel was within the JBLM base but this may not be the case for all MP Group vehicles.

\section{F.3 6th MP Group Vehicles Mileage}

The vehicle annual miles factor into the calculations for replacement of vehicles as noted in Section 5 and Appendix F. The actual miles measured during the study are extrapolated to identify calculated annual miles in the study. JBLM has also provided vehicle information that identifies the average monthly miles and vehicle mileage in April 2012. Table F-5 shows these values and calculations with the study-extrapolated miles in the far right column.

Table F-5. $6^{\text {th }}$ MP Group Vehicle Mileage.

\begin{tabular}{ccccccc}
$\begin{array}{c}\text { Logger } \\
\text { No. }\end{array}$ & Fleet Vehicle Id & Year & Odometer & $\begin{array}{c}\text { Monthly } \\
\text { Miles }\end{array}$ & $\begin{array}{c}\text { Calculated } \\
\text { Annual Miles }\end{array}$ & $\begin{array}{c}\text { Study-Extrapolated } \\
\text { Miles }\end{array}$ \\
\hline 82 & G61-0546L & 2011 & 8,632 & 616 & 7,392 & 4,921 \\
86 & G61-0689A & 2004 & 23,062 & 199 & 2,388 & 2,651 \\
103 & G41-5433B & 2006 & 46,154 & 623 & 7,476 & 4,314 \\
\hline
\end{tabular}

For the entire 6th MP Group fleet, the average monthly miles traveled as provided by JBLM are 509 miles for an average annual travel total of 6,114 miles. The JBLM-provided mileage information will be used in the fuel cost and GHG emissions calculations.

\footnotetext{
${ }^{26}$ http://www.plugshare.com/ [accessed June 19, 2014]
} 


\section{F.4 $6^{\text {th }}$ MP Group Vehicle Utilization}

Vehicle utilization is an important factor in the evaluation of vehicles both from an inventory perspective and for charging availability. Table F-6 identifies the percent utilization of the vehicle considering all days used during the study period. Since most travel occurred during weekdays, only the 45 weekdays in the 63-day study period are considered. In the event that the vehicle was used for more than these 45 days, the percent utilization is considered $100 \%$.

The average daily usage of each vehicle is identified in the Appendix B data sheets. It is also shown here for completeness.

Table F-6. Vehicle utilization.

\begin{tabular}{|c|c|c|c|c|c|}
\hline Logger & Vehicle & Mission & Vehicle Class & $\begin{array}{c}\text { Percent } \\
\text { Days Used }\end{array}$ & $\begin{array}{c}\text { Avg Daily Travel } \\
\text { Time (Hrs) }\end{array}$ \\
\hline 82 & G61-0546L & $\mathrm{PL}$ & SUV & $73 \%$ & 1.2 \\
\hline 86 & G61-0689A & PL & Pickup & $53 \%$ & 1.2 \\
\hline 103 & G41-5433B & PL & Minivan & $80 \%$ & 1.1 \\
\hline & & & Average & $69 \%$ & 1.2 \\
\hline
\end{tabular}

In general, the vehicles are used on frequent days but average usage per day is quite low.

\section{F.5 $6^{\text {th }}$ MP Group Summary}

This study provides observations for both the vehicles monitored and for the entire non-tactical fleet of vehicles identified with the 6th MP Group. The study indicates that PEVs offer alternatives to vehicles in the existing fleet provided that any specific cargo requirements may be met by the PEV. In general, a mixed fleet of BEVs and PHEVs is suggested.

The vehicles in this study included one SUV, one minivan, and one pickup truck. Based on the travel data, Intertek suggests that replacing these three vehicles with one PHEV and two BEVs would meet current mission requirements. Section 5 identifies potential replacement PEVs and Appendix J provides specific recommendations. While daily usage is quite low, the vehicles are used on frequent days so a reduction in the number of these vehicles is not recommended.

The 6th MP Group fleet of vehicles contains 20 vehicles, all but one of which have possible PEV replacement opportunities. Intertek suggests retaining the passenger van for now and also suggests a fleet of 12 BEVs and seven PHEVs conservatively meet the balance of vehicle travel requirements.

With the potential replacement by PEVs established, Section 5 and Appendix J provide further evaluation of the benefits of such replacements. This will be factored into further observations and suggestions related to the business case and schedule for any replacements for the 6th MP Group. Those observations will be addressed in Task 4 of this project. 


\section{Appendix G}

\section{DCA Support Group Vehicle Analysis}

\section{G.1 DCA Support Group Vehicle Summary}

The Directorate of Community Activities (DCA) support group fleet contains 52 vehicles. Table G-1 provides a summary of the all vehicles in the DCA Support Group fleet. Table G-2 provides a summary of all vehicles monitored for this report. Table G-3 provides the details of each of the vehicles monitored.

Table G-1. DCA Group total fleet summary.

\begin{tabular}{cccccccccccc} 
& $\begin{array}{c}\text { Sedan } \\
\text { Compact/ }\end{array}$ & $\begin{array}{c}\text { Sedan } \\
\text { Mission }\end{array}$ & Sub Com & Sidsize & Large & SUV & Mini & Cargo & Cass. & Pickup & MD or \\
or LD & HD & Van \\
Truck & Truck & Bus & Total \\
\hline Pool & & & & & 1 & 2 & 2 & 3 & 3 & 1 & 12 \\
Support & 8 & 2 & & & & 6 & 6 & 16 & 2 & 40 \\
\hline Total & 8 & 2 & & & 1 & 8 & 8 & 19 & 5 & 1 & 52 \\
\hline
\end{tabular}

Table G-2. DCA Group vehicle logger summary.

\begin{tabular}{|c|c|c|c|c|c|c|c|c|c|c|c|}
\hline Mission & $\begin{array}{c}\text { Sedan } \\
\text { Compact }\end{array}$ & $\begin{array}{l}\text { Sedan } \\
\text { Midsize }\end{array}$ & $\begin{array}{l}\text { Sedan } \\
\text { Large }\end{array}$ & SUV & $\begin{array}{l}\text { Mini } \\
\text {-van }\end{array}$ & $\begin{array}{c}\text { Cargo } \\
\text { Van }\end{array}$ & $\begin{array}{c}\text { Pass. } \\
\text { Van }\end{array}$ & $\begin{array}{l}\text { Pickup } \\
\text { or LD } \\
\text { Truck }\end{array}$ & $\begin{array}{l}\text { MD or } \\
\text { HD } \\
\text { Truck }\end{array}$ & Bus & Total \\
\hline Pool & & & & & & 1 & & & 1 & & 2 \\
\hline Support & & & & & & & 1 & 1 & & & 2 \\
\hline Total & & & & & & 1 & 1 & 1 & 1 & & 4 \\
\hline
\end{tabular}

Table G-3. DCA Group monitored vehicle details.

\begin{tabular}{ccccccc}
\hline Log & Fleet Vehicle Id & Make & Model & Year & EPA Class & Mission \\
\hline 83 & G41-74299 & Ford & Ranger & 2004 & Pickup Truck & Support \\
94 & G71-0684A & Chevrolet & C6500 Stake & 2005 & Stake Truck & Pool \\
96 & G43-1195H & Chevrolet & 15 Pas Van & 2011 & Passenger Van & Support \\
99 & G42-0289G & Chevrolet & G1300 & 2008 & Cargo Van & Pool \\
\hline
\end{tabular}

These vehicles are referenced by Logger number or Fleet Vehicle ID in the following analyses.

JBLM DCA Group data collection took place from March 5, 2013 through May 7, 2013. Vehicle data sheets (presented in Appendix C) detail the collected data for each vehicle.

Of the data collected, validation occurred for $99.5 \%$ of the data, while null values exist for the balance. Table G-4 shows this information by mission type.

Table G-4. Vehicle data logger reporting summary.

\begin{tabular}{lccc}
\multicolumn{4}{c}{ Vehicle Data Logger Reporting Summary } \\
\multicolumn{1}{r}{ Mission } & $\%$ Valid & \% Null Values & Total \\
\hline Pool & $100 \%$ & $0 \%$ & $100 \%$ \\
Support & $98.6 \%$ & $1.4 \%$ & $100 \%$ \\
All Vehicles & $99.5 \%$ & $0.5 \%$ & $100 \%$ \\
\hline
\end{tabular}


Grouping the vehicles by mission creates an aggregated view of mission requirements to provide observations related to PEV replacement. Analysis by mission type follows.

\section{G.2 DCA Pool Vehicles Analysis}

Pool vehicles are typically light-duty motor vehicles for use in passenger transportation, with not more than 10 passengers. Pool missions can vary by agency, location, and jurisdiction and for DCA Support Group, the pool vehicles are a cargo van and a heavy-duty truck. Although there are currently no PEVs available to replace the heavy-duty truck, it is assumed that the usage of these pool vehicles can be of value in considering the remaining pool vehicles in the larger DCA fleet. PEVs are currently available to replace the balance of vehicles.

Incorporation of BEVs and/or PHEVs into the pool mission is a definite possibility. Pool vehicles used for shorter trips or outings qualify for BEV or PHEV replacement, while other pool vehicle activities that are associated with longer trips may require PHEV capabilities.

\section{G.2.1 Summary for DCA Pool Vehicles}

Appendix $C$ provides the vehicle data sheets for each of the pool vehicles monitored. This section aggregates data for both pool vehicles. Table G-5 summarizes pool travel during the study period for those days in which the vehicle was driven. Vehicle use occurred primarily between 0800 and 1500 hours daily. The vehicles traveled 409 miles, logged 32 hours, and idled for 7 hours during the 63 -day study period.

Table G-5. Pool vehicles travel summary.

\begin{tabular}{lcccc}
\hline & Pool Vehicles Travel Summary & & \\
& $\begin{array}{c}\text { Per Day } \\
\text { Average/Peak }\end{array}$ & $\begin{array}{c}\text { Per Outing } \\
\text { Average/Peak }\end{array}$ & $\begin{array}{c}\text { Per Trip } \\
\text { Average/Peak }\end{array}$ & Total \\
\hline Travel Distance (Miles) & $8.5 / 53.5$ & $6.1 / 53.5$ & $1.8 / 20.2$ & 408.7 \\
Travel Time (Minutes) & $40.1 / 123.0$ & $28.7 / 133.0$ & $8.3 / 55.0$ & $1,926.0$ \\
Idle Time (Minutes) & $9.1 / \mathrm{NA}$ & $6.5 / \mathrm{NA}$ & $1.9 / \mathrm{NA}$ & 435.0 \\
\hline
\end{tabular}

Figure G-1 shows the travel summary for pool vehicles: by vehicle, by daily mileage, and daily usage time. Figure G-2 shows the composite history for all pool vehicles. In the stacked bar charts of Figure G2 , the contribution of each vehicle is indicated by a different color.
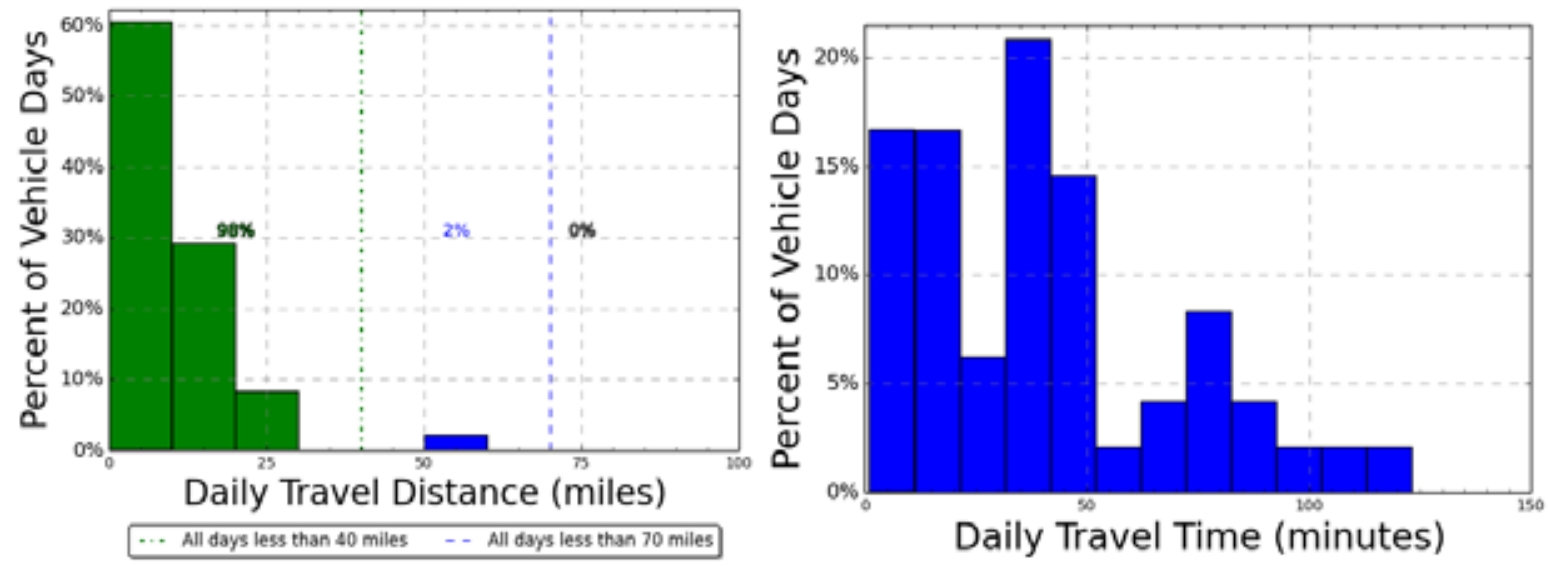

Figure G-1. Pool vehicle daily travel miles and time (all vehicles). 

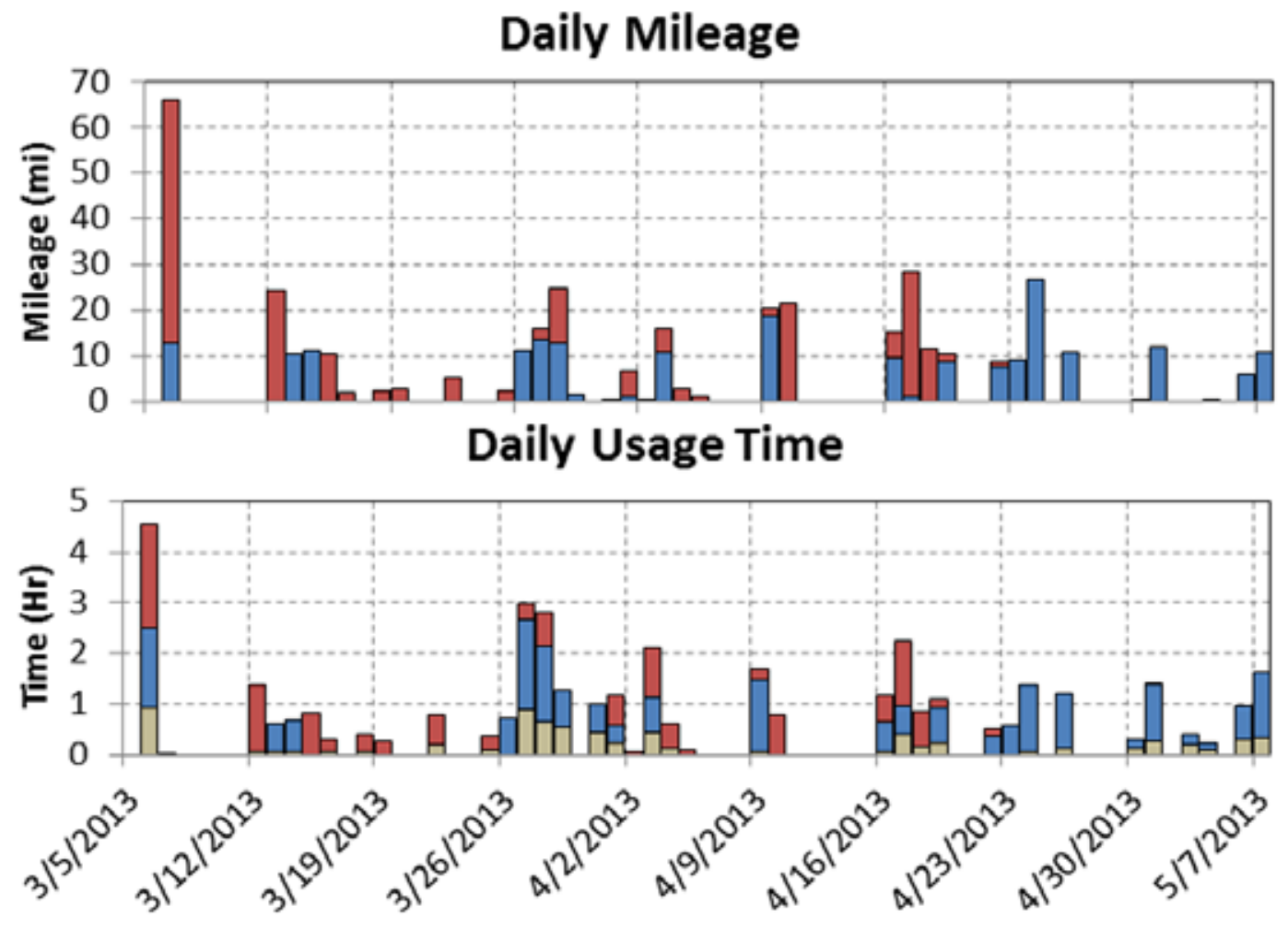

Total Idle $\square \log 94 \quad \square \log 99$

Figure G-2. Pool vehicles travel history (all vehicles).

\section{G.2.2 Pool Vehicles Daily Summary}

The average travel distance per day when driven for pool vehicles is 8.5 miles. On all vehicle travel days, the daily travel is less than the 70 miles considered to be within the BEV safe range (blue and green bars in Figure G-1). That is, while BEV range can vary based on several factors; most BEVs provide at least 70 miles of vehicle range on a single battery charge. Meanwhile, $98 \%$ of vehicle travel days are less than 40 miles considered to be within the battery only range of a PHEV (green bars of Figure G-1).

Figure G-2 shows that vehicles are used rather infrequently. Vehicle G71-0684A traveled $40 \%$ of the days monitored and G42-0289G traveled $36 \%$ of the days. However, there are periods where each vehicle operated several days in a row and days that both vehicles are in use.

Figure G-3 displays the summary of use by time of day for all pool vehicles. Figure G-4 shows the outings for all vehicles.

Appendix C provides the details of each of the pool vehicle's outings. Neither vehicle exceeded 70 miles in a single outing.

The average travel outing when driven for pool vehicles is 6.1 miles. All outings were less than the 70 miles considered to be within the BEV safe range. Furthermore, $99 \%$ percent of pool outings are less than 40 miles considered to be within the CD range of a PHEV. 


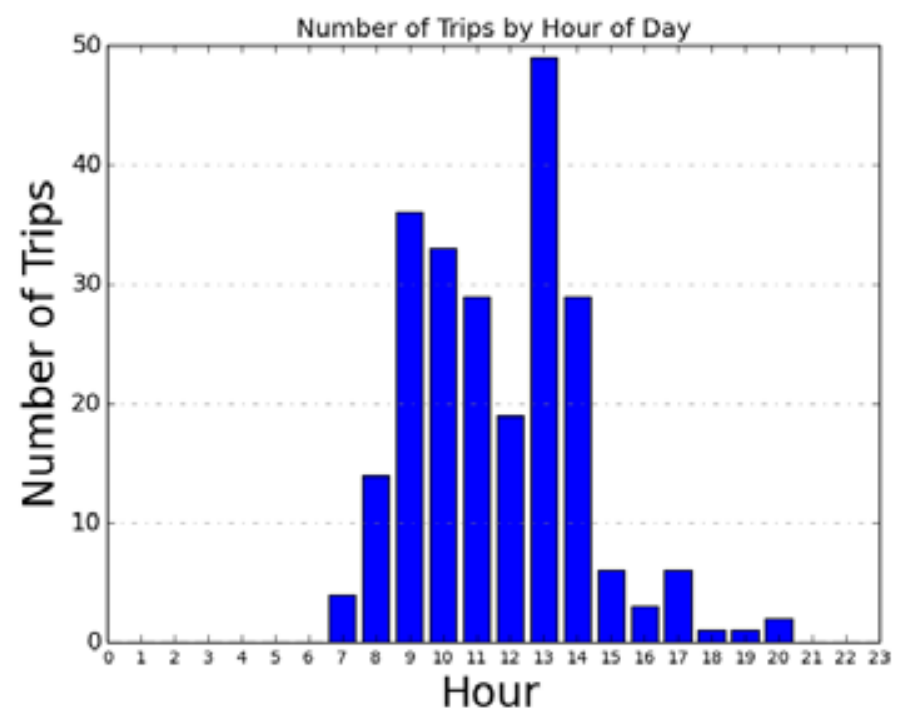

Figure G-3. Pool vehicles hourly usage.

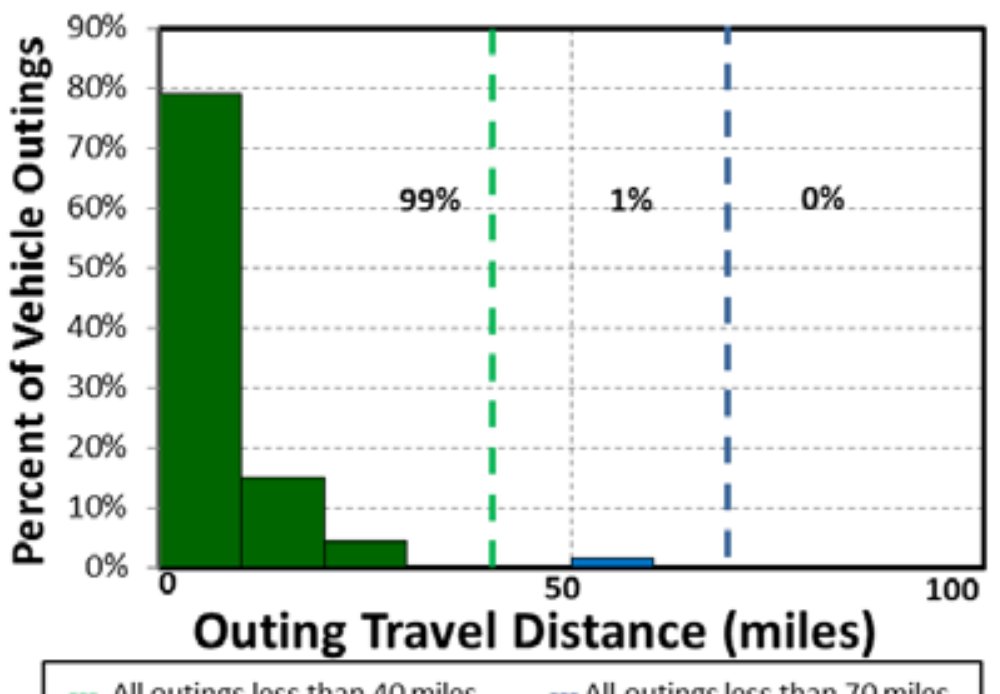

Figure G-4. Pool vehicle combined outings.

\section{G.2.3 Pool Vehicle Observations/Summary}

There appear to be three choices for JBLM in implementing PEVs into the DCA Support Group pool fleet. There are no current PEV replacements for heavy-duty trucks. However, the full DCA fleet does contain one minivan, two cargo vans, and three pickup trucks for which suitable PEVs may be found. The observations here relate to these six vehicles assuming the travel of the monitored vehicles is typical.

As noted before, the optimum goal would be to incorporate as many BEVs as possible to realize the advantages of reduced petroleum usage and reduced emissions of GHG.

1. All BEV fleet: While some BEV manufacturers report vehicle range exceeding 70 miles, Intertek recommends careful evaluation of experienced range to ensure vehicle missions are accomplished. Nevertheless, assuming the 70-mile safe range for a BEV, all daily travel and outings were within the capabilities of a BEV and consideration of cargo carrying capabilities may be the only deterrent.

2. Mixed BEV/PHEV fleet: Certainly, PHEVs can accomplish the same mission as the current fleet when only considering travel times and distances because the PHEV's gasoline engine can provide motive power when the battery has been depleted. The data reveal that on $98 \%$ of all vehicle travel 
days, the total daily travel is less than 40 miles, which typically is the maximum distance a PHEV will travel in CD mode. This represents a significant operating cost savings opportunity while retaining the ability to go longer distances when needed. Furthermore, $99 \%$ of the outings are less than 40 miles and could be completed in CD mode with certain PHEVs if the battery is fully charged prior to the outing.

A mixed fleet requires fleet manager attention to assign vehicles appropriately for the anticipated use on that day.

3. All PHEV fleet: As noted above, PHEVs can accomplish the same mission as the current fleet when only considering travel times and distances. Replacing all current vehicles with PHEVs only requires an evaluation of the individual vehicle capabilities of currently available PHEVs to meet current pool requirements. Data show that for up to $98 \%$ of all travel days, the PHEV will operate in a CD mode.

As above, this represents a significant operating cost savings opportunity while retaining the ability to go longer distances when needed. Intermediate charging opportunities provide additional benefit, enhancing the CD mode. Data show significant charging opportunities throughout the day during stop times.

While it would appear that PEVs are suitable replacements for these six pool vehicles, additional mission analysis and management input is required. The missions of these vehicles likely include considerations other than mileage, such as cargo demands placed on the vehicle. Fleet managers typically desire greater conservatism in maintaining vehicle capabilities. Thus, it is assumed that one monitored vehicle may be replaced by a suitable style BEV and the other by a PHEV. A less conservative approach for the full pool fleet would be to use 75\% BEV and 25\% PHEV. See Section 5 for these suggestions.

The total DCA Support pool fleet of 12 vehicles then could consist of 4BEVs, two PHEVs, two conventional passenger vans, three conventional heavy-duty trucks, and one conventional bus.

The vehicle summary shows sufficient time for charging at the base location during the course of the day and additional opportunities at intermediate charging stations. These stations also provide charging opportunities for the visiting public, whose fees may assist in offsetting operating costs.

\section{G.2.4 Pool Vehicle Charging Needs}

Upon review of these data, Intertek suggests replacement of the full DCA Support Group pool fleet with four BEVs and two PHEVs while retaining the conventional heavy-duty truck, passenger vans, and bus for now.

As noted previously, AC Level 2 overnight charging of BEVs is typical, whereas overnight charging of PHEVs can be accomplished using AC Level 1 charging.

Intertek's experience suggests that each vehicle should have an assigned charging location at their home base. Assigned stations require less management attention to ensure completion of overnight charging. BEVs and PHEVs not assigned to these locations also benefit during visits to the location as part of their normal operation. For the entire fleet of pool vehicles, four BEVs require four AC Level 2 EVSE units for overnight charging and two PHEVs require two AC Level 1 outlets for home base. Intertek recommends a minimum of two EVSE at each location to maximize charge capability without a significant increase in installation costs. The PHEVs can utilize the AC Level 2 EVSE at the home base during the day to increase the amount of vehicle miles traveled in CD Mode.

At times, fleet vehicles obtain benefit from using public charging infrastructure. Figure 18 displays the availability of public charging at the time of this writing for the JBLM area. Since all travel was within the JBLM base there may be little benefit in using public charging for the DCA Support Group pool vehicles.

\section{G.3 DCA Support Group Support Vehicles Analysis}

Support vehicles provide a specific work function, facilitating the mission of a particular group. The vehicles are generally passenger or light-duty pickup trucks and may contain after-market modifications 
to support the mission. While assigned to maintenance and service areas, missions may vary depending on agency needs.

As shown above, vehicles G41-74299 (logger 83) and G43-1195H (logger 96) were the support vehicles monitored.

\section{G.3.1 Summary for DCA Support Group Support Vehicles}

Appendix $\mathrm{C}$ provides the vehicle data sheets for each of the two support vehicles monitored. This section aggregates the data for both support vehicles.

Table G-6 summarizes support vehicle travel during the study period. Vehicle use occurred primarily between 0800 and 1600 hours daily. Support vehicles traveled 4,677 miles, logged 136 hours, and idled for 14 hours during the study period.

Table G-6. Support vehicle travel summary.

\begin{tabular}{lcccc}
\hline \multicolumn{4}{c}{ Support Vehicle Travel Summary } & \\
& Per Day & Per Outing & Per Trip & \\
& Average/Peak & Average/Peak & Average/Peak & Total \\
\hline Travel Distance (Miles) & $61.5 / 354.1$ & $30.6 / 354.1$ & $12.3 / 129.4$ & 4,677 \\
Travel Time (Minutes) & $108.0 / 544.0$ & $53.6 / 544.0$ & $21.7 / 222.0$ & 8,208 \\
Idle Time (Minutes) & $11.5 / \mathrm{NA}$ & $2.3 / \mathrm{NA}$ & $2.3 / \mathrm{NA}$ & 872 \\
\hline
\end{tabular}

Figure G-5 shows the travel summary for support vehicles by vehicle, by daily mileage and daily usage time. Figure G-6 shows the composite history for both support vehicles.

The history graphs identify when several support vehicles may be in use at the same time as well as the total miles driven on a daily basis.

\section{G.3.2 DCA Support Group Support Vehicle Daily Summary}

The average travel distance per day when driven for support vehicles is 61.5 miles. On $76 \%$ of these vehicle days, the daily travel is less than the 70 miles considered to be within the BEV safe range. Meanwhile, 24\% percent of support vehicle daily travel is greater than 70 miles. Furthermore, $75 \%$ of vehicle travel days are less than 40 miles considered to be within the CD range of a PHEV.

Figure G-6 shows that the vehicles are not used every day. Vehicle G41-74299 is unused 30\% of the days and vehicle G43-1195H is unused $49 \%$ of the days monitored. However, there are periods where both vehicles operated several days in a row and days that both vehicles are in use at the same time. Figure G-7 displays the summary of use by time of day for all support vehicles combined. Figure G-8 shows the outings for all support vehicles combined.
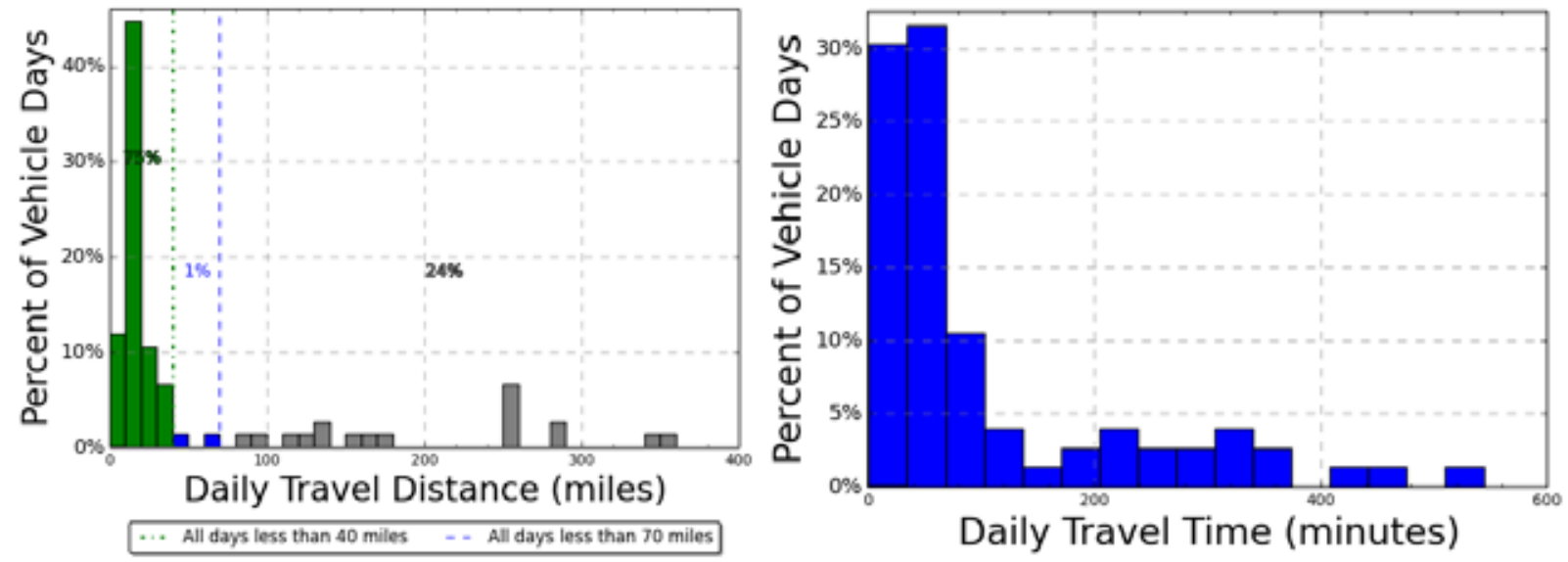

Figure G-5. Support vehicle daily travel miles and usage time (all vehicles). 

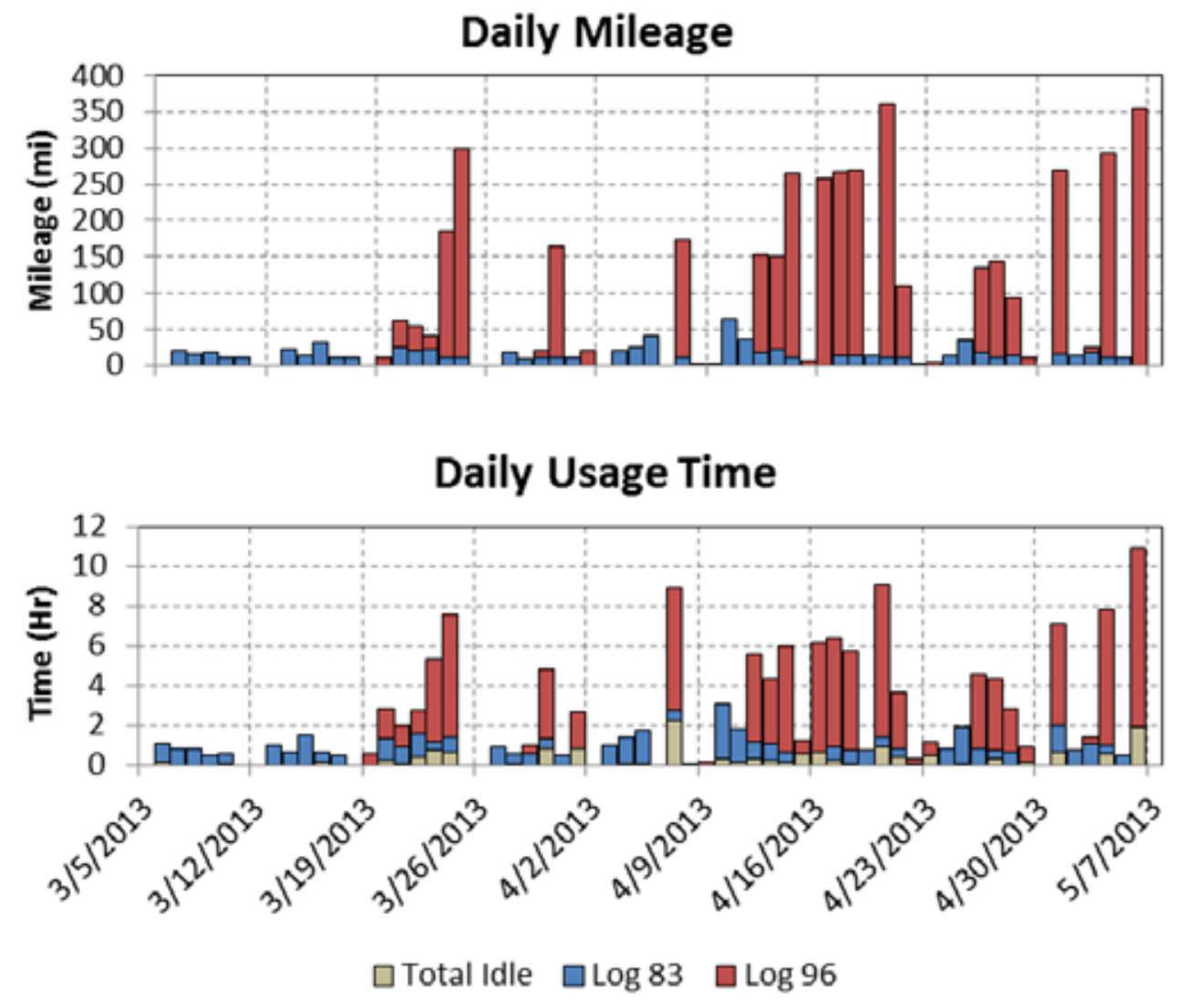

Figure G-6. Support vehicle history (all vehicles).

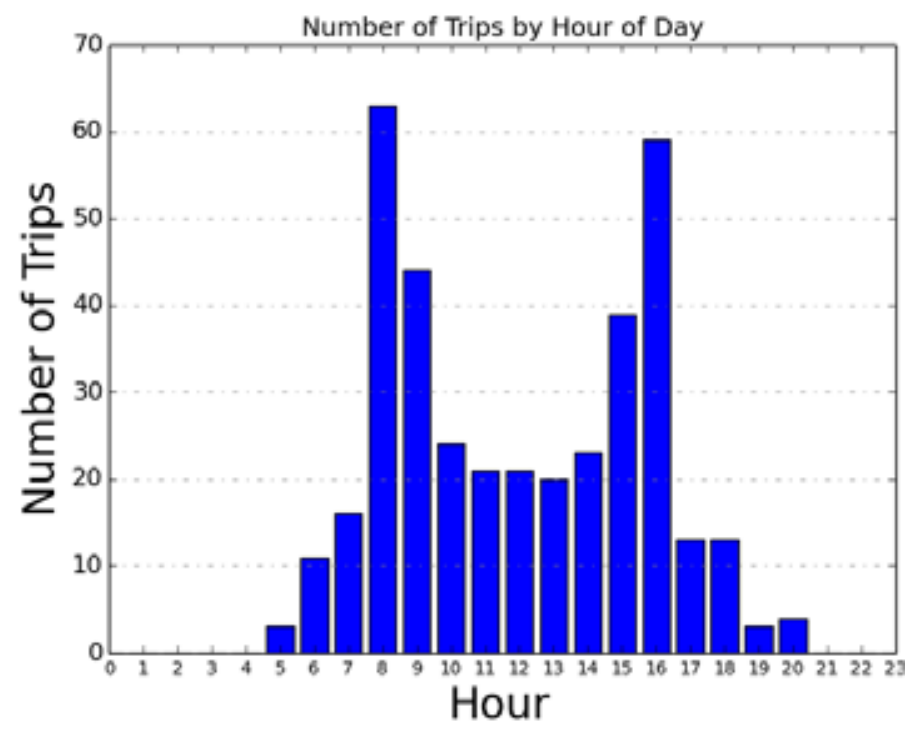

Figure G-7. Support vehicles hourly usage. 


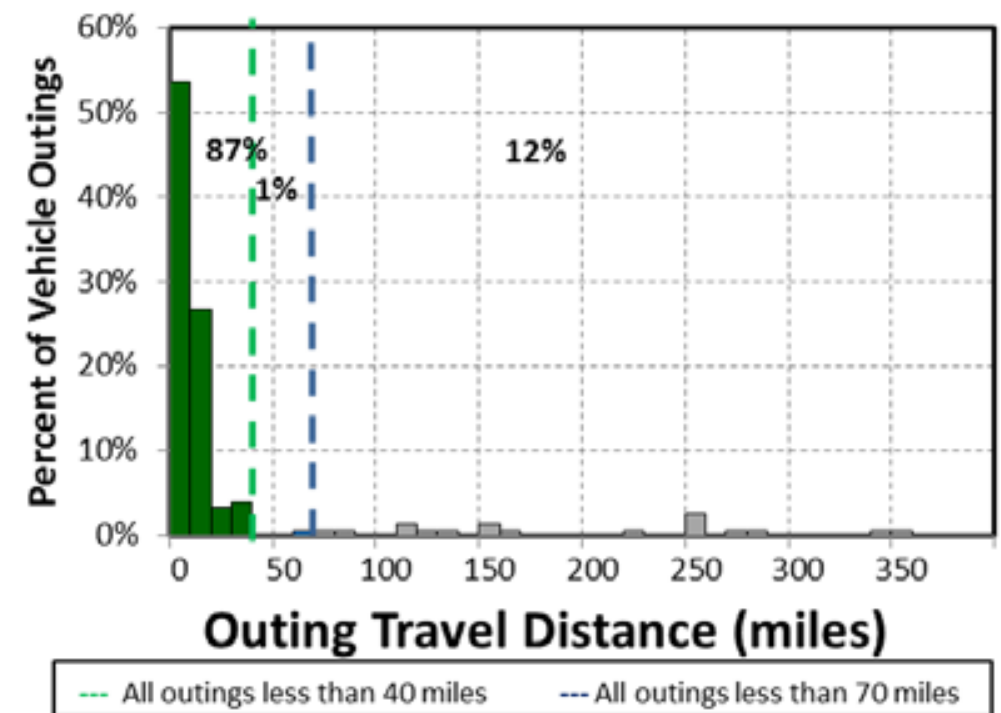

Figure G-8. Support vehicle combined outings.

Appendix C provides the details of each of the support vehicle's daily travel. While vehicle G4174299 remained below the 70-mile range on all vehicle days and outings, vehicle G43-1195L exceeded this range on $56 \%$ of the travel days.

The average travel outing when driven for support vehicles is 30.6 miles. On $88 \%$ of these vehicle outings, the distance traveled is less than the 70 miles considered to be within the BEV safe range. Meanwhile, $12 \%$ of support outing travel is greater than 70 miles. All of this travel was by vehicle G43$1195 \mathrm{~L}$ which exceeded this range on $13 \%$ of its outings. Some of these outings are significantly longer than this range however, with the longest outing 354 miles. Furthermore, $87 \%$ of vehicle travel outings are less than 40 miles considered to be within the CD range of a PHEV.

\section{G.3.3 DCA Support Group Support Vehicle Observations/Summary}

There appear to be three choices for JBLM in implementing PEVs into the DCA Support Group support mission fleet. There are no current PEV replacements for heavy-duty trucks or passenger vans.

However, the DCA fleet does contain 10 sedans, six cargo vans, and 16 pickups for which suitable PEVs may be found. While a closer evaluation of the use of the vans may also reveal suitable PEV replacements, the observations here relate to these 32 vehicles assuming the travel of the monitored vehicles are typical.

Pickup trucks are a popular choice for support vehicle because they are versatile to support various types of support needed, i.e. special cargo or equipment transport. In some cases, as seen here, SUVs or mini-vans can perform the same mission. Section 4.4 provides information on PEV trucks and vans currently or soon to be available.

As noted before, the optimum goal would be to incorporate as many BEVs as possible to realize the advantages of reduced petroleum usage and reduced emissions of GHG.

1. All BEV fleet: While some BEV manufacturers report vehicle range exceeding 70 miles, Intertek recommends careful evaluation of experienced range to ensure vehicle missions are accomplished. Nevertheless, assuming the 70-mile safe range for a BEV, an all-BEV fleet is not possible for support vehicles due to the long distances experienced by at least one of these vehicles.

2. Mixed BEV/PHEV fleet: Certainly, PHEVs can accomplish the same mission as the current fleet when only considering travel times and distances because the PEV's gasoline engine can provide motive power when the battery has been depleted. The data reveal that on $75 \%$ of all vehicle travel days the total travel is less than 40 miles, which typically is the maximum distance a PHEV will travel in CD mode. Thus, the PHEV would be of benefit for this travel. 
3. It is noted that $76 \%$ of all travel days and $88 \%$ of all outings are less than 70 miles. This would support travel by BEVs. For the days where the 70 miles are exceeded, intermediate charging locations typically provide the recharge necessary to increase the all-electric drive. There are significant quantities of public charging stations locally but they cannot be assured to be available when needed. Thus, consideration should be given to home base charging only. Additional charging during the day at the home base between outings would add daily range. Incorporation of BEVs into the fleet will require management attention to ensure appropriate deployment based upon the need and expected distance to be driven.

4. All PHEV fleet: As noted above, PHEVs can accomplish the same mission as the current fleet when only considering travel times and distances. Replacing all current vehicles with PHEVs only requires an evaluation of the individual vehicle capabilities of currently available PHEVs to meet current support vehicle requirements.

While it would appear that PEVs may be suitable replacements for these 32 support vehicles, additional mission analysis and management input is required. The missions of these vehicles likely include considerations other than mileage, such as cargo demands placed on the vehicle. Fleet managers typically desire greater conservatism in maintaining vehicle capabilities. Thus, it is assumed that the 10 sedans, six cargo vans, and 16 pickups may be replaced by 20 suitable style BEVs and 12 suitable style PHEVs. See Section 5 for these suggestions.

The total DCA Support pool fleet of 40 vehicles then could consist of 20 BEVs, 12 PHEVs, 6 conventional passenger vans, and 2 conventional heavy-duty trucks. The vehicle summary shows sufficient time for charging at the base location during the course of the day. These stations also provide charging opportunities for the visiting public, whose fees may assist in offsetting operating costs.

Intertek suggests further mission evaluation be given to the balance of the support vehicles when considering the adoption of BEVs and PHEVs. Additional BEVs may be possible with further management or fleet software attention; however, fleet managers typically desire vehicles that support longer trips.

\section{G.3.4 DCA Support Group Support Vehicle Charging Needs}

Upon review of these data, Intertek suggests replacement of most of the support vehicle fleet with 20 BEVs and 12 PHEVs. No available PHEVs at the time of this writing provide for DC fast charging nor do the data suggest that this would be a significant benefit for PHEVs in the support vehicle fleet. Additional charging of BEVs during the day is not a requirement nor would DCFCs be required. The majority of the support vehicle activity occurs during daytime hours, which leaves significant time during the nighttime hours for recharging.

As noted above, AC Level 2 overnight charging of BEVs is typical, whereas overnight charging of PHEVs can be accomplished with AC Level 1 charging. Opportunity charging at intermediate stops obtains the greater benefits from AC Level 2 EVSE. Most vehicles returned to their home base daily with the exception of long trips lasting several days.

For the entire fleet of support vehicles, 20 BEVs require 20 AC Level 2 EVSE for overnight charging and 12 PHEVs require $12 \mathrm{AC}$ Level 1 outlets for home base charging. Intertek recommends a minimum of two EVSE units at each location to maximize charge capability without a significant increase in installation costs.

Greater management attention provides the possibility of reducing the overall number of AC Level 2 EVSE. A ratio of two AC Level 2 charging stations to three vehicles typically sustains a normal fleet operation. Fleet managers rotate vehicles on the charger to complete charging of all vehicles in the allotted time. This analysis does assume a fully recharged battery at the start of each day. JBLM will gain experience in this management as the PEV fleet grows. 


\section{G.4 DCA Support Group Vehicles Mileage}

The vehicle annual miles factor into the calculations for replacement of vehicles as noted in Section 5 and Appendix G. The actual miles measured during the study are extrapolated to identify calculated annual miles in the study. JBLM has also provided vehicle information that identifies the average monthly miles and vehicle mileage in April 2012. Table G-7 shows these values and calculations with the study-extrapolated miles in the far right column.

Table G-7. DCA Support Group vehicle mileage.

\begin{tabular}{ccccccc}
$\begin{array}{c}\text { Logger } \\
\text { No. }\end{array}$ & $\begin{array}{c}\text { Fleet Vehicle } \\
\text { Id }\end{array}$ & Year & Odometer & $\begin{array}{c}\text { Monthly } \\
\text { Miles }\end{array}$ & $\begin{array}{c}\text { Calculated } \\
\text { Annual Miles }\end{array}$ & $\begin{array}{c}\text { Study-Extrapolated } \\
\text { Miles }\end{array}$ \\
\hline 83 & G41-74299 & 2004 & 20654 & 250 & 3,000 & 4,576 \\
94 & G71-0684A & 2005 & 10921 & 120 & 1,440 & 1,193 \\
96 & G43-1195H & 2011 & Not avail. & Not Avail. & Not avail. & 22,522 \\
99 & G42-0289G & 2008 & 7347 & 153 & 1,836 & 1,175 \\
\hline
\end{tabular}

For the entire DCA Support Group fleet, the average monthly miles traveled are 274 miles for an average annual travel of 3,291 miles. The JBLM-provided mileage information will be used in the fuel cost and GHG emissions calculations, if available.

\section{G.5 DCA Support Group Vehicle Utilization}

Vehicle utilization is an important factor in the evaluation of vehicles both from an inventory perspective and for charging availability. Table G-8 identifies the percent utilization of the vehicle considering all days used during the study period. Since most travel occurred during weekdays, only the 45 weekdays in the 63-day study period are considered. In the event that the vehicle was used for more than these 45 days, the percent utilization is considered $100 \%$.

The average daily usage of each vehicle is identified in the Appendix $\mathrm{C}$ data sheets. It is also shown here for completeness.

Table G-8. Vehicle utilization.

\begin{tabular}{|c|c|c|c|c|c|}
\hline Logger & Vehicle & Mission & Vehicle Class & $\begin{array}{c}\text { Percent } \\
\text { Days Used }\end{array}$ & $\begin{array}{c}\text { Avg Daily Travel } \\
\text { Time (Hrs) } \\
\end{array}$ \\
\hline 83 & G41-74299 & SU & Pickup & $98 \%$ & 0.8 \\
\hline 94 & G71-0684A & PL & Truck HD & $56 \%$ & 0.8 \\
\hline 96 & G43-1195H & SU & Van - Pass & $71 \%$ & 3.1 \\
\hline 99 & G42-0289G & PL & Van - Cargo & $51 \%$ & 0.6 \\
\hline & & & Average & $69 \%$ & 1.3 \\
\hline
\end{tabular}

In general, the vehicles are used on frequent days but average usage per day is quite low. For example, the pickup truck is used almost every day but for less than an hour each day.

\section{G.6 DCA Support Group Summary}

This study provides observations for both the vehicles monitored and for the entire non-tactical fleet of vehicles identified with the DCA Support Group. The study indicates that PEVs offer alternatives to vehicles in the existing fleet provided that any specific cargo requirements may be met by the PEV. In general, a mixed fleet of BEVs and PHEVs is suggested.

The vehicles monitored in this study included one cargo van, one passenger van, one pickup truck, and one heavy-duty truck. Based on the travel data, Intertek suggests that retaining the conventional 
passenger van and replacing three vehicles with two PHEVs and one BEV would meet current mission requirements. Section 5 identifies potential replacement PEVs and Appendix G provides specific recommendations.

The DCA Support Group full fleet of vehicles contains 52 vehicles. Intertek suggests retaining the conventional bus, eight passenger vans, and five heavy-duty trucks for now and also suggests a fleet of 24 BEVs and 14 PHEVs conservatively meet the balance of vehicle travel requirements.

With the potential replacement by PEVs established, Section 5 and Appendix K provide further evaluation of the benefits of such replacements. This will be factored into further observations and suggestions related to the business case and schedule for any replacements for the DCA Support Group. Those observations will be addressed in Task 4 of this project. 


\section{Appendix $\mathrm{H}$}

\section{Public Works Group Vehicle Analysis}

\section{H.1 Public Works Group Vehicle Summary}

The Public Works Group fleet contains 250 vehicles. Table H-1 identifies these vehicles by vehicle type according to site records. The mission assignments identified in Table $\mathrm{H}-1$ are based upon survey responses received and extrapolation to the balance of the fleet. Survey responses received included 32 of these vehicles, or $12.8 \%$ of the total. Table $\mathrm{H}-2$ provides a summary of mission types for these survey responses.

Table H-1. Public Works Group total fleet characterization.

\begin{tabular}{|c|c|c|c|c|c|c|c|c|c|c|c|}
\hline Mission & $\begin{array}{c}\text { Sedan } \\
\text { Compact/ } \\
\text { Sub Com }\end{array}$ & $\begin{array}{c}\text { Sedan } \\
\text { Midsize/ } \\
\text { Large }\end{array}$ & $\begin{array}{l}\text { Mini- } \\
\text { van }\end{array}$ & SUV & $\begin{array}{l}\text { Spec } \\
\text { ialty }\end{array}$ & $\begin{array}{c}\text { Cargo } \\
\text { Van }\end{array}$ & $\begin{array}{l}\text { Pass. } \\
\text { Van }\end{array}$ & $\begin{array}{l}\text { Pickup } \\
\text { or LD } \\
\text { Truck }\end{array}$ & $\begin{array}{l}\text { MD or } \\
\text { HD } \\
\text { Truck }\end{array}$ & Bus & Total \\
\hline Pool & 5 & 2 & 2 & 7 & & 8 & 35 & 48 & & & 107 \\
\hline Support & & & 1 & 4 & & 14 & 17 & 65 & 16 & & 117 \\
\hline Transport & & & & & & & & 8 & 17 & & 25 \\
\hline Specialty & & & & & 1 & & & & & & 1 \\
\hline Total & 5 & 2 & 3 & 11 & 1 & 22 & 52 & 121 & 33 & & 250 \\
\hline
\end{tabular}

Table H-2. Public Works Group survey responses.

\begin{tabular}{|c|c|c|c|c|c|c|c|c|c|c|c|}
\hline Mission & $\begin{array}{c}\text { Sedan } \\
\text { Compact/ } \\
\text { Sub Com }\end{array}$ & $\begin{array}{c}\text { Sedan } \\
\text { Midsize/ } \\
\text { Large }\end{array}$ & $\begin{array}{l}\text { Mini } \\
\text {-van }\end{array}$ & SUV & $\begin{array}{l}\text { Speci } \\
\text { alty }\end{array}$ & $\begin{array}{c}\text { Cargo } \\
\text { Van }\end{array}$ & $\begin{array}{c}\text { Pass. } \\
\text { Van }\end{array}$ & $\begin{array}{l}\text { Pickup } \\
\text { or LD } \\
\text { Truck }\end{array}$ & $\begin{array}{c}\text { MD or } \\
\text { HD } \\
\text { Truck }\end{array}$ & Bus & Total \\
\hline Pool & 3 & 1 & 1 & 3 & & 2 & & 6 & & & 18 \\
\hline Support & & & 1 & 1 & & 3 & 2 & 8 & & & 13 \\
\hline Transport & & & & & & & & 1 & & & 1 \\
\hline Total & 3 & 1 & 2 & 4 & 0 & 5 & 2 & 15 & 0 & 0 & 32 \\
\hline
\end{tabular}

Table H-3 provides a summary of the vehicles monitored for this report. Survey responses were not received for all vehicles so missions are assumed based upon total survey response percentages.

Table H-3. Public Works Group vehicle logger summary.

\begin{tabular}{lcccccccccc} 
& Sedan & Sedan & & \multicolumn{5}{c}{ Pickup } & MD or \\
Mission & Compact/ & Midsize/ & Mini & & Speci & Cargo & Pass. & or LD & HD & \\
Sub com & Large & -van & SUV & alty & Van & Van & Truck & Truck & Bus & Total \\
\hline Pool & & & 2 & & & & 2 & 4 & & 8 \\
Support & & & & & & 1 & 5 & & 6 \\
\hline Total & & & & & & 3 & 9 & & 14 \\
\hline
\end{tabular}

Table H-4 provides the full characterization of the fleet of vehicles monitored in this survey. 
Table H-4. Public Works vehicle characterization index.

\begin{tabular}{ccccccc} 
Logger & Fleet & \multicolumn{5}{c}{ Vehicle Index } \\
No. & Vehicle Id & Make & Model & Year & EPA Class & Mission \\
\hline 1 & G42-0658K & Ford & F150 & 2010 & Pickup Truck & Pool \\
2 & G42-1054F & Ford & F150 & 2008 & Pickup Truck & Pool \\
3 & G71-0133L & Ford & E450 & 2011 & Passenger van & Pool \\
4 & G43-0944G & Chevrolet & G3500 & 2008 & Passenger van & Pool \\
5 & G43-0822G & Ford & F350 & 2008 & Pickup Truck & Support \\
84 & G41-1100K & Dodge & Gr Caravan & 2010 & Minivan & Pool \\
87 & G42-0619K & Chevrolet & C1500 & 2010 & Pickup Truck & Pool \\
88 & G41-1180K & Dodge & Gr Caravan & 2010 & Minivan & Pool \\
90 & G43-1892H & Chevrolet & C2500HD & 2009 & Pickup Truck & Support \\
91 & G43-1961H & Chevrolet & C3500 & 2009 & Pickup Truck & Support \\
92 & G42-0505A & Chevrolet & G1300 & 2004 & Passenger van & Support \\
95 & G43-1155L & Ford & F350 & 2011 & Pickup Truck & Support \\
98 & G41-1605L & Dodge & Dakota & 2011 & Pickup Truck & Support \\
100 & G42-0610K & Chevrolet & C1500 & 2010 & Pickup Truck & Pool \\
\hline
\end{tabular}

Reference to these vehicles may be by logger number or fleet vehicle ID.

JBLM data collection took place from March 5, 2013 through May 7, 2013. Vehicle data sheets (presented in Appendix D) detail the collected data for each vehicle.

Of the data collected, validation occurred for $98.1 \%$ of the data, while null values exist for the balance. Table H-5 shows this information by mission type.

Table H-5. Vehicle data logger reporting summary.

\begin{tabular}{lccc}
\hline & \multicolumn{4}{c}{ Vehicle Data Logger Reporting Summary } & \\
Mission & \% Collected & \% Null Values & Total \\
\hline Pool & $98.8 \%$ & $1.2 \%$ & $100 \%$ \\
Support & $97.1 \%$ & $2.9 \%$ & $100 \%$ \\
All Vehicles & $98.1 \%$ & $1.9 \%$ & $100 \%$ \\
\hline
\end{tabular}

\section{H.2 Public Works Pool Vehicles Analysis}

Pool vehicles are typically light-duty motor vehicles for use in passenger transportation, with not more than 10 passengers. Pool missions can vary by agency, location, and jurisdiction and for Public Works, they are four pickups, two passenger vans, and two minivans. Although there are currently no PEVs available to replace passenger vans, it is assumed that the usage of these pool vehicles can be of value in considering the remaining pool vehicles in the Public Works fleet. Pickups and minivans may be replaced by currently available PEVs.

Incorporation of BEVs and/or PHEVs into the pool mission is a definite possibility. Pool vehicles used for shorter trips or outings qualify for BEV or PHEV replacement, while other pool vehicle activities that are associated with longer trips may require PHEV capabilities. 


\section{H.2.1 Summary for Public Works Pool Vehicles}

Appendix D provides the vehicle data sheets for each of the pool vehicles monitored. This section aggregates data for all pool vehicles. Table H-6 summarizes pool travel during the study period for those days in which the vehicle was driven. Vehicle use occurred primarily between 0700 and 1500 hours daily. They traveled 3,620 miles, logged 259 hours, and idled for 76 hours during the 63-day study period.

Table H-6. Pool vehicles travel summary.

\begin{tabular}{lcccc}
\hline & Pool Vehicles Travel Summary & & \\
& Per Day & Per Outing & Per Trip & \\
& Average/Peak & Average/Peak & Average/Peak & Total \\
\hline Travel Distance (Miles) & $13.8 / 270.7$ & $5.3 / 168.6$ & $2.2 / 132.0$ & $3,621.3$ \\
Travel Time (Minutes) & $59.2 / 297.0$ & $23.0 / 247.0$ & $9.3 / 139.0$ & 15,563 \\
Idle Time (Minutes) & $17.5 / \mathrm{NA}$ & $6.9 / \mathrm{NA}$ & $2.7 / \mathrm{NA}$ & 4,595 \\
\hline
\end{tabular}

Figure $\mathrm{H}-1$ shows the travel summary for pool vehicles: by vehicle, by daily mileage, and daily usage time. Figure H-2 shows the composite history for all pool vehicles. In the stacked bar charts of Figure $\mathrm{H}-$ 2 , the contribution of each vehicle is indicated by a different color.

\section{H.2.2 Pool Vehicles Daily Summary}

The average travel distance per day when driven for pool vehicles is 13.8 miles. On $99 \%$ of the vehicle travel days, the daily travel is less than the 70 miles considered to be within the BEV safe range (blue and green bars in Figure H-1). That is, while BEV range can vary based on several factors; most BEVs provide at least 70 miles of vehicle range on a single battery charge. Meanwhile, $95 \%$ of vehicle travel days are less than 40 miles considered to be within the CD range of a PHEV (green bars of Figure $\mathrm{H}-1)$.

The pool vehicles were used on average $52 \%$ of the study days. However, there are periods where each vehicle operated several days in a row and days that several vehicles are in use. Figure H-3 displays the summary of use by time of day for all pool vehicles. Figure H-4 shows the outings for all vehicles.
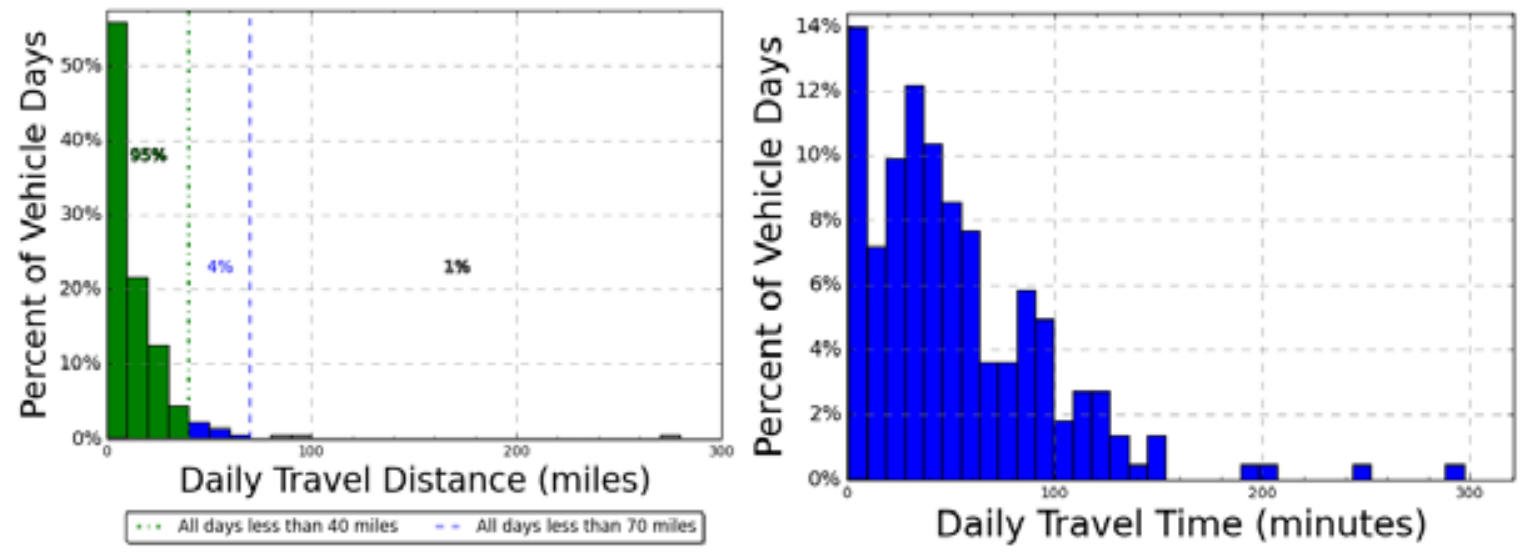

Figure H-1. Pool vehicle daily travel miles and time (all vehicles). 

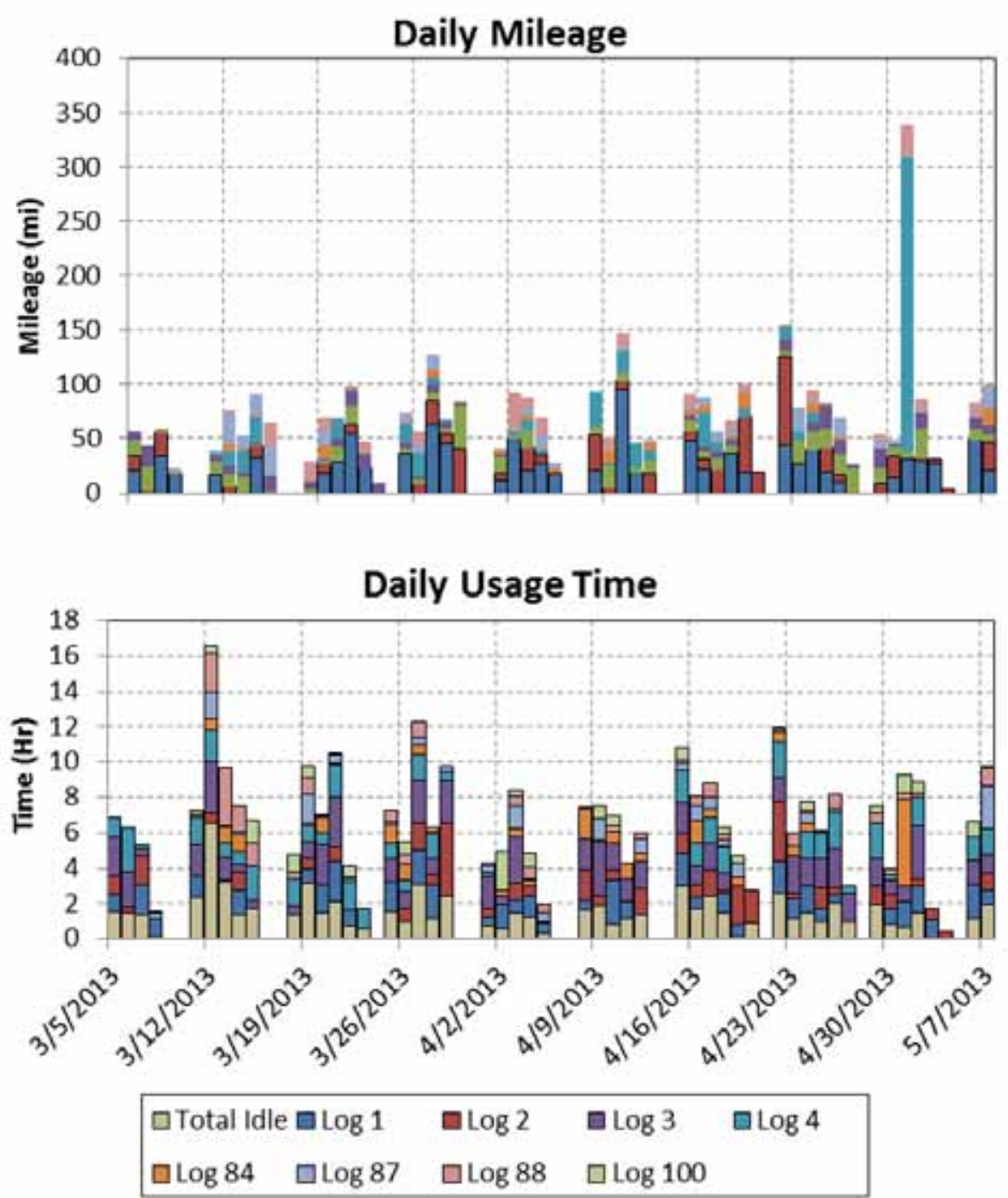

Figure H-2. Pool vehicles travel history (all vehicles).

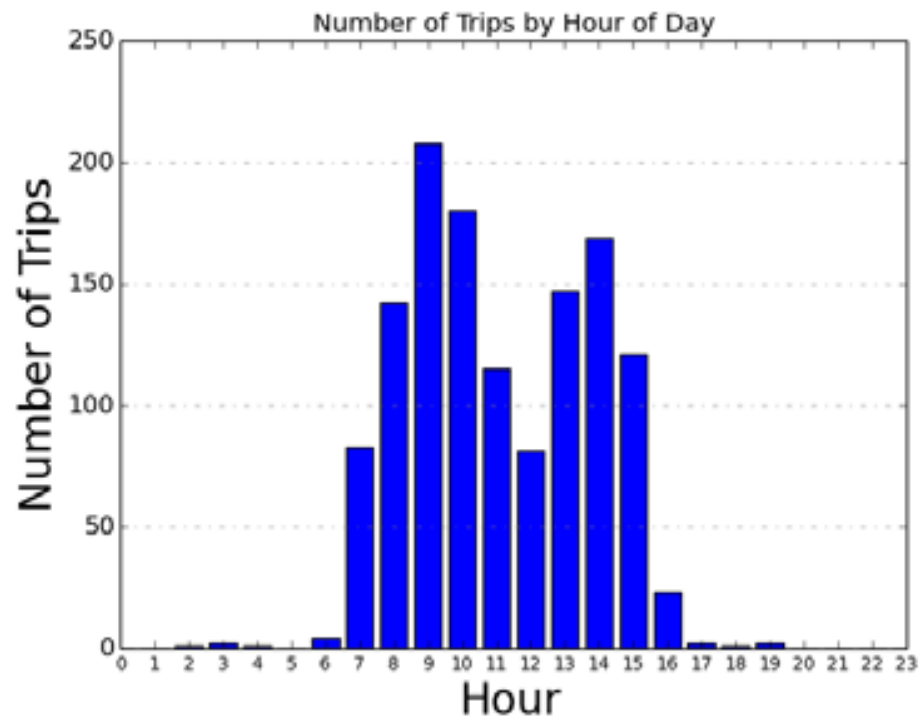

Figure H-3. Pool vehicles hourly usage. 


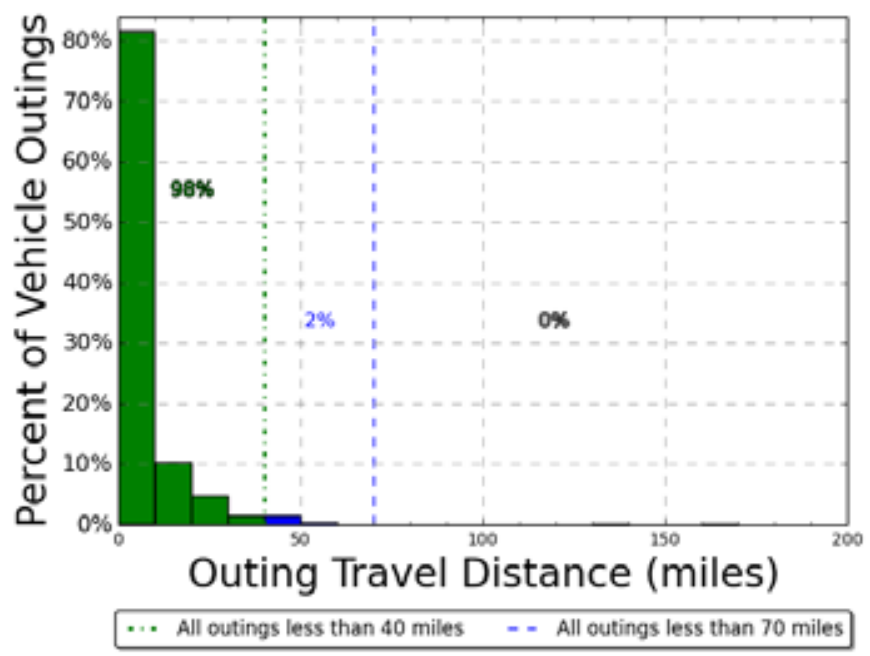

Figure H-4. Pool vehicle combined outings

Appendix D provides the details of each of the pool vehicle's outings. Vehicle 84 exceeded 70 miles in a single outing twice during the study period, which was still less than $0.5 \%$ of all pool outings.

The average travel outing when driven for pool vehicles is 5.2 miles. All outings (except 2) or 100\% were less than the 70 miles considered to be within the BEV safe range. Furthermore, $98 \%$ percent of pool outings are less than 40 miles considered to be within the CD range of a PHEV.

\section{H.2.3 Pool Vehicle Observations/Summary}

There appears to be three choices for JBLM in implementing PEVs into the Public Works pool fleet. There are no current PEV replacements for the two conventional passenger vans. However, the monitored Public Works pool fleet also contains two conventional minivans and four conventional pickups for which suitable PEVs may be found. The observations here relate to these six vehicles, assuming the travel of the monitored vehicles is typical.

As noted before the optimum goal would be to incorporate as many BEVs as possible to realize the advantages of reduced petroleum usage and reduced emissions of GHG.

1. All BEV fleet: While some BEV manufacturers report vehicle range exceeding 70 miles, Intertek recommends careful evaluation of experienced range to ensure vehicle missions are accomplished. Nevertheless, assuming the 70-mile safe range for a BEV, a small percentage of daily travel and outings exceeded the capabilities of a BEV and an all-BEV fleet is not possible.

2. Mixed BEV/PHEV fleet: Certainly, PHEVs can accomplish the same mission as the current fleet when only considering travel times and distances. The data reveal that on $95 \%$ of all vehicle travel days, the total daily travel is less than 40 miles, which typically is the maximum distance a PHEV will travel in CD mode. This represents a significant operating cost savings opportunity while retaining the ability to go longer distances when needed. Furthermore, $98 \%$ of the outings are less than 40 miles and could be completed in CD mode with certain PHEVs if the battery is fully charged prior to the outing.

At the same time, $99 \%$ of daily travel and virtually $100 \%$ of all outings are within the capabilities of BEVs thus making a mixed fleet a possibility. A mixed fleet requires fleet manager attention to assign vehicles appropriately for the anticipated use on that day.

3. All PHEV fleet: As noted above, PHEVs can accomplish the same mission as the current fleet when only considering travel times and distances. Replacing all current vehicles with PHEVs only requires an evaluation of the individual vehicle capabilities of currently available PHEVs to meet current pool requirements. Data show that for $95 \%$ of all travel days, the PHEV will operate in a CD mode. As above, this represents a significant operating cost savings opportunity while retaining the ability to go 
longer distances when needed. Intermediate charging opportunities provide additional benefit, enhancing the CD mode. Data show significant charging opportunities throughout the day during stop times.

While it would appear that PEVs are suitable replacements for these six pool vehicles, additional mission analysis and management input is required. The missions of these vehicles likely include considerations other than mileage, such as cargo demands placed on the vehicle. Fleet managers typically desire greater conservatism in maintaining vehicle capabilities. Thus, it is assumed that the two minivans and four pickups may be replaced by four suitable styled BEV and two PHEV. See Section 5 for these suggestions.

With no PEV available for passenger vans, the balance of 72 vehicles may have suitable PEVs for replacement. Assuming these 72 vehicles operate in a manner similar to the monitored vehicles, the 72 vehicles could consist of 57 BEVs and 15 PHEVs.

The vehicle summary shows sufficient time for charging at the base location during the course of the day and additional opportunities at intermediate charging stations. These stations also provide charging opportunities for the visiting public, whose fees may assist in offsetting operating costs.

\section{H.2.4 Pool Vehicle Charging Needs}

Upon review of these data, Intertek suggests replacement of the Public Works pool fleet with 57 BEVs and 15 PHEVs while retaining the 35 passenger vans for now.

As noted previously, AC Level 2 overnight charging of BEVs is typical, whereas overnight charging of PHEVs can be accomplished with AC Level 1 charging.

Intertek's experience suggests that each vehicle have an assigned charging location at their home base. Assigned stations require less management attention to ensure completion of overnight charging. BEVs and PHEVs not assigned to these locations also benefit during visits to the location as part of their normal operation. For the entire fleet of pool vehicles, 57 AC Level 2 EVSE units for overnight charging and 15 AC Level 1 outlets for home base are required. Intertek recommends a minimum of two EVSE at each location to maximize charge capability without a significant increase in installation costs. The PHEVs can utilize the AC Level 2 EVSE at the home base during the day to increase the amount of vehicle miles traveled in EV Mode.

At times, fleet vehicles obtain benefit from using public charging infrastructure. Figure 18 displays the availability of public charging at the time of this writing for the JBLM area. Since all travel was within the JBLM base there may be little benefit in using public charging for the DCA Support Group pool vehicles.

\section{H.3 Public Works Support Vehicles Analysis}

Support vehicles provide a specific work function, facilitating the mission of a particular group. The vehicles are generally passenger or light-duty pickup trucks and may contain after-market modifications to support the mission. While assigned to maintenance and service areas, missions may vary depending on agency needs.

As shown above, Public Works support vehicles monitored included five conventional pickup trucks and one conventional passenger van.

\section{H.3.1 Summary for Public Works Support Vehicles}

Appendix D provides the vehicle data sheets for each of the six support vehicles monitored. This section aggregates the data for all support vehicles.

Table H-7 summarizes support vehicle travel during the study period. Vehicle use occurred primarily between 0700 and 1500 hours daily. The six support vehicles traveled 5,244 miles, logged 300 hours, and idled for 62 hours during the study period. 
Table H-7. Support vehicle travel summary.

\begin{tabular}{lcccc}
\hline \multicolumn{4}{c}{ Support Vehicle Travel Summary } & \\
& $\begin{array}{c}\text { Per Day } \\
\text { Average/Peak }\end{array}$ & $\begin{array}{c}\text { Per Outing } \\
\text { Average/Peak }\end{array}$ & $\begin{array}{c}\text { Per Trip } \\
\text { Average/Peak }\end{array}$ & Total \\
\hline Travel Distance (Miles) & $25.6 / 598.5$ & $7.6 / 608.8$ & $3.4 / 236.9$ & 5,244 \\
Travel Time (Minutes) & $88.1 / 585$ & $26.2 / 628$ & $11.6 / 215$ & 18,053 \\
Idle Time (Minutes) & $18.2 / \mathrm{NA}$ & $5.4 / \mathrm{NA}$ & $2.4 / \mathrm{NA}$ & 3,722 \\
\hline
\end{tabular}

Figure H-5 shows the travel summary for support vehicles by vehicle, by daily mileage and daily usage time. Figure H-6 shows the composite history for both support vehicles. In the stacked bar charts of Figure H-6, the contribution of each vehicle is indicated by a different color.

The history graphs identify when several support vehicles may be in use at the same time as well as the total miles driven on a daily basis. The single multiple-day outing by vehicle G43-1892H (logger 90) is evident by its unusual distance.

\section{H.3.2 Public Works Support Vehicle Daily Summary}

The average travel distance per day when driven for support vehicles is 25.6 miles. On $96 \%$ of these vehicle days, the daily travel is less than the 70 miles considered to be within the BEV safe range. Meanwhile, $4 \%$ percent of support vehicle daily travel is greater than 70 miles. Furthermore, $88 \%$ of vehicle travel days are less than 40 miles considered to be within the CD range of a PHEV.

Figure H-6 shows that the vehicles are used nearly every day. There are periods where several vehicles operated several days in a row and days that several vehicles are in use at the same time. Figure $\mathrm{H}-7$ displays the summary of use by time of day for all support vehicles combined. Figure H-8 shows the outings for all support vehicles combined.

Appendix D provides the details of each of the support vehicle's daily travel. Again, the extended outage of vehicle G43-1892H dominates the highest distance with the single outing of 608 miles. All other outings remained below the 70-mile range on all vehicle days and outings.

The average travel outing when driven for support vehicles is 7.6 miles. On $99 \%$ of these vehicle outings, the distance traveled is less than the 70 miles considered to be within the BEV safe range. Furthermore, $98 \%$ of vehicle travel outings are less than 40 miles considered to be within the CD range of a PHEV.
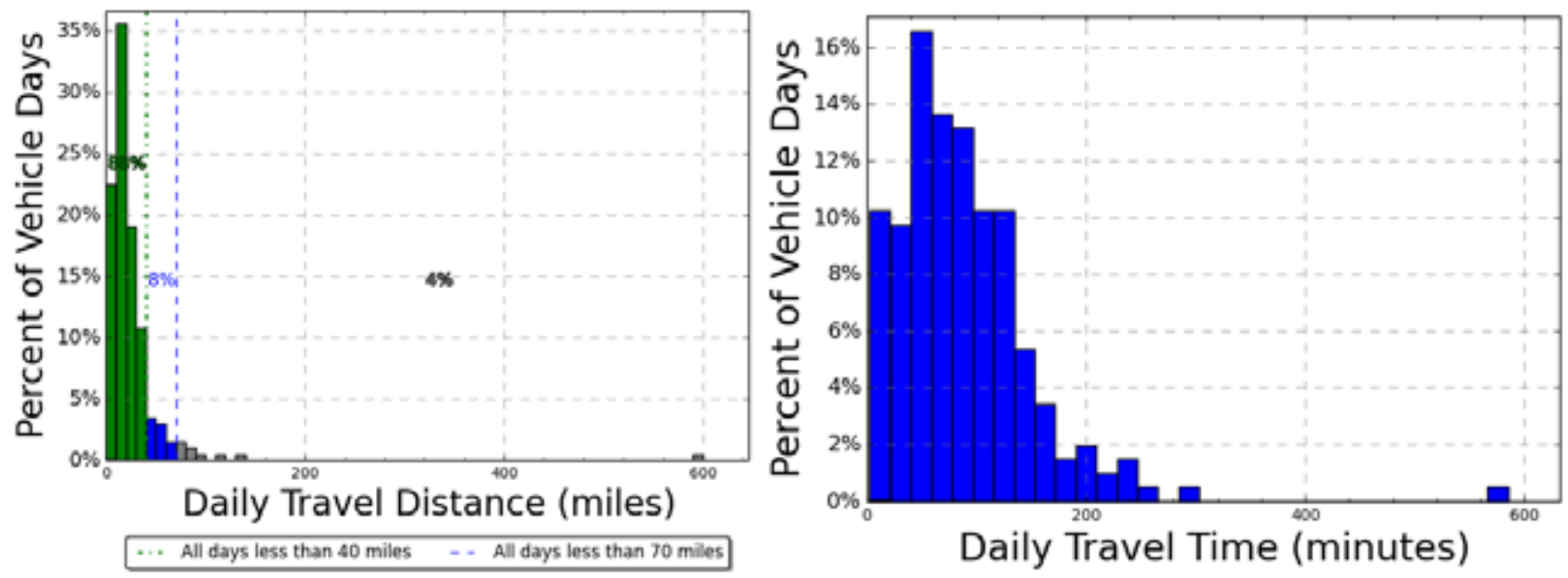

Figure H-5. Support vehicle daily travel miles and usage time (all vehicles). 

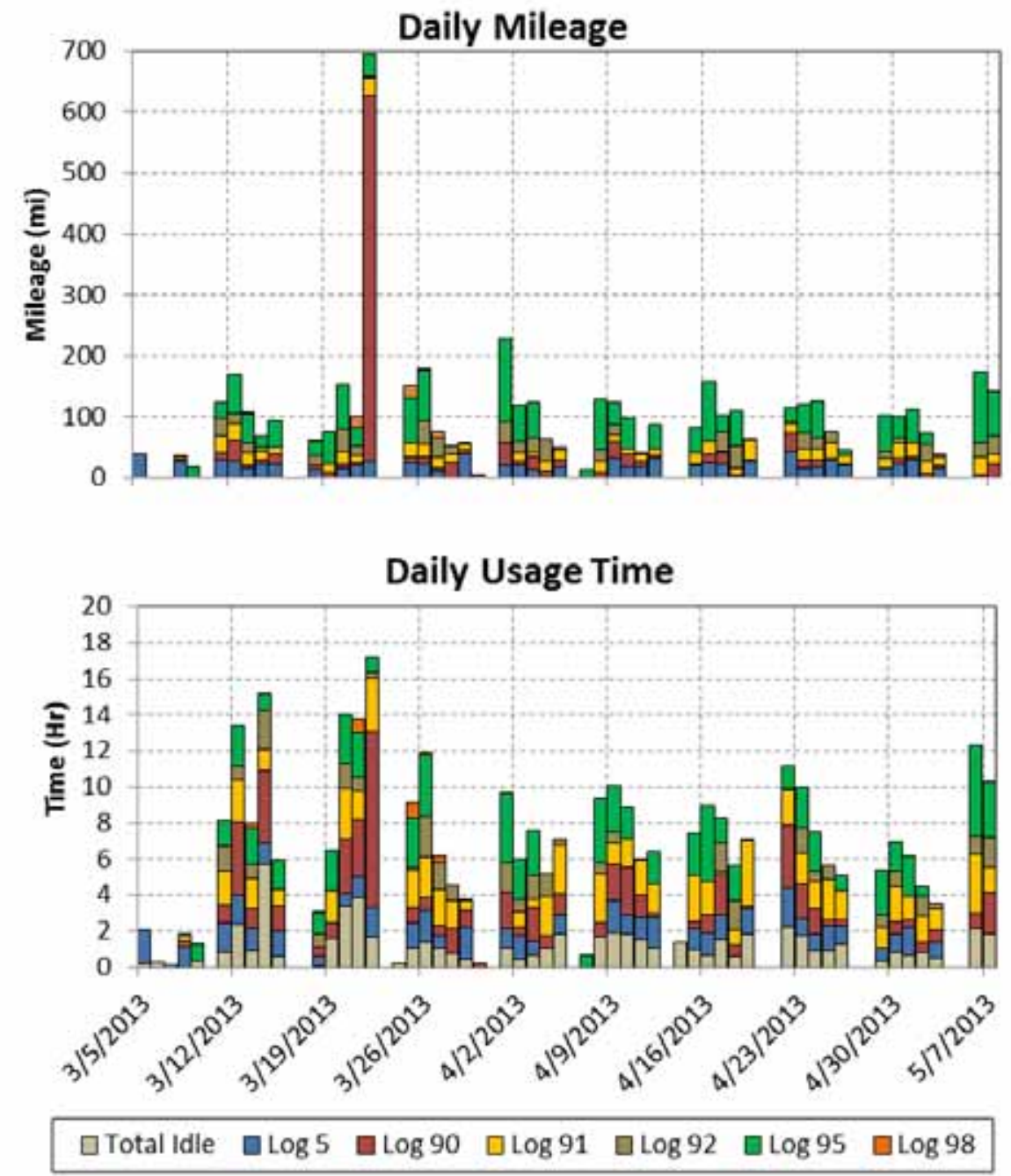

Figure H-6. Support vehicle history (all vehicles).

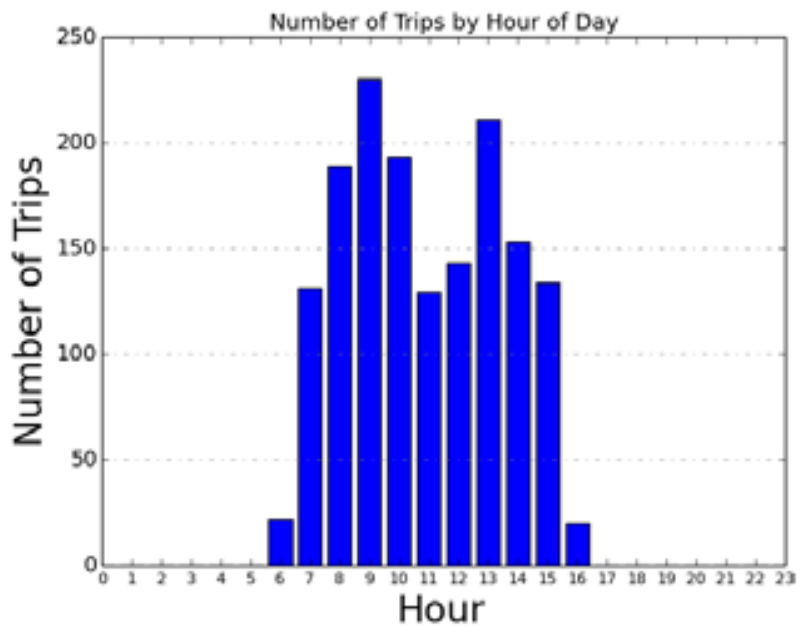

Figure H-7. Support vehicle hourly usage. 


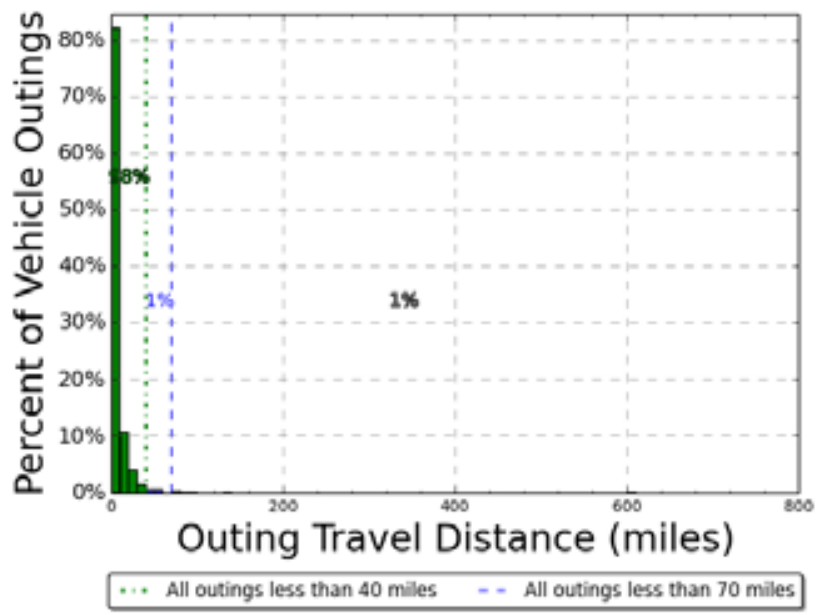

Figure H-8. Support vehicle combined outings.

\section{H.3.3 Public Works Support Vehicle Observations/Summary}

There appears to be three choices for JBLM in implementing PEVs into the Public Works support mission fleet. There are no current PEV replacements for the passenger van. However, the Public Works fleet does contain 5conventinoal pickup trucks for which suitable PEVs may be found. While a closer evaluation of the use of the van may also reveal suitable PEV replacements (such as a SUV), the observations here relate to these five pickup trucks assuming the travel of the monitored vehicles are typical.

Pickup trucks are a popular choice for support vehicle because they are versatile to support various types of support needed, i.e. special cargo or equipment transport. In some cases, as seen here, SUVs or mini-vans can perform the same mission. Section 4.4 provides information on PEV trucks and vans currently or soon to be available.

As before, there appears to be three choices for JBLM in implementing PEVs into the Public Works' support vehicle fleet. Keep in mind that the optimum goal would be to incorporate as many BEVs as possible to realize the advantages of reduced petroleum usage and reduced emissions of GHG.

1. All BEV fleet: While some BEV manufacturers report vehicle range exceeding 70 miles, Intertek recommends careful evaluation of experienced range to ensure vehicle missions are accomplished. Nevertheless, assuming the 70-mile safe range for a BEV, an all-BEV fleet is not possible for support vehicles due to the long distances experienced by at least one of these vehicles.

2. Mixed BEV/PHEV fleet: Certainly, PHEVs can accomplish the same mission as the current fleet when only considering travel times and distances. The data reveal that on $88 \%$ of all vehicle travel days the total travel is less than 40 miles, which typically is the maximum distance a PHEV will travel in CD mode. Thus, the PHEV would be of benefit for this travel.

It is noted that $96 \%$ of all travel days and $99 \%$ of all outings are less than 70 miles. This would support travel by BEVs. For the days where the 70 miles are exceeded, intermediate charging locations typically provide the recharge necessary to increase the all-electric drive. There are significant quantities of public charging stations locally but they cannot be assured to be available when needed. Thus, consideration should be given to home base charging only. Additional charging during the day at the home base between outings would add daily range. Incorporation of BEVs into the fleet will require management attention to ensure appropriate deployment based upon the need and expected distance to be driven.

3. All PHEV fleet: As noted above, PHEVs can accomplish the same mission as the current fleet when only considering travel times and distances. Replacing all current vehicles with PHEVs only requires an evaluation of the individual vehicle capabilities of currently available PHEVs to meet current support vehicle requirements. 
While it would appear that PEVs may be suitable replacements for these five support vehicles, additional mission analysis and management input is required. The missions of these vehicles likely include considerations other than mileage, such as cargo demands placed on the vehicle. Fleet managers typically desire greater conservatism in maintaining vehicle capabilities. Thus, it is assumed that the five pickup may be replaced by four suitable style BEVs and one suitable style PHEVs. See Section 5 for these suggestions.

The total Public Works support fleet of 117 vehicles then could consist of 67 BEVs, 17 PHEVs, 17 conventional passenger vans, and 16 conventional heavy-duty trucks. The vehicle summary shows sufficient time for charging at the base location during the course of the day. These stations also provide charging opportunities for the visiting public, whose fees may assist in offsetting operating costs.

Intertek suggests further mission evaluation be given to the balance of the support vehicles when considering the adoption of BEVs and PHEVs. Additional BEVs may be possible with further management or fleet software attention; however, fleet managers typically desire vehicles that support longer trips. Some of the vans may find suitable replacements in PEVs as well.

\section{H.3.4 Public Works Support Vehicle Charging Needs}

Upon review of these data, Intertek suggests replacement of most of the support vehicle fleet with 67 BEVs and 17 PHEVs. No available PHEVs at the time of this writing provide for DC fast charging nor do the data suggest that this would be a significant benefit for PHEVs in the support vehicle fleet. Additional charging of BEVs during the day is not a requirement nor would DCFCs be required. The majority of the support vehicle activity occurs during daytime hours, which leaves significant time during the nighttime hours for recharging.

As noted above, AC Level 2 overnight charging of BEVs is typical, whereas overnight charging of PHEVs can be accomplished with AC Level 1 charging. Opportunity charging at intermediate stops obtains the greater benefits from AC Level 2 EVSE. Most vehicles returned to their home base daily with the exception of long trips lasting several days.

For the entire fleet of support vehicles, 67 BEVs require 67 AC Level 2 EVSE for overnight charging and 17 PHEVs require $17 \mathrm{AC}$ Level 1 outlets for home base charging. Intertek recommends a minimum of two EVSE at each location to maximize charge capability without a significant increase in installation costs.

Greater management attention provides the possibility of reducing the overall number of AC Level 2 EVSE units. A ratio of two AC Level 2 charging stations to three vehicles typically sustains a normal fleet operation. Fleet managers rotate vehicles on the charger to complete charging of all vehicles in the allotted time. This analysis does assume a fully recharged battery at the start of each day. JBLM will gain experience in this management as the PEV fleet grows.

\section{H.4 Public Works Group Vehicles Mileage}

The vehicle annual miles factor into the calculations for replacement of vehicles as noted in Section 5 and Appendix $\mathrm{H}$. The actual miles measured during the study are extrapolated to identify calculated annual miles in the study. JBLM has also provided vehicle information thFigure $\mathrm{H}-1$ at identifies the average monthly miles and vehicle mileage in April 2012. Table H-8 shows these values and calculations with the study-extrapolated miles in the far right column.

Table H-8. Public Works Group vehicle mileage.

\begin{tabular}{ccccccc}
$\begin{array}{c}\text { Logger } \\
\text { No. }\end{array}$ & $\begin{array}{c}\text { Fleet Vehicle } \\
\text { Id }\end{array}$ & Year & Odometer & $\begin{array}{c}\text { Monthly } \\
\text { Miles }\end{array}$ & $\begin{array}{c}\text { Calculated } \\
\text { Annual Miles }\end{array}$ & $\begin{array}{c}\text { Study-Extrapolated } \\
\text { Miles }\end{array}$ \\
\hline 1 & G42-0658K & 2010 & 11,073 & 389 & 4,668 & $6,276.84$ \\
2 & G42-1054F & 2008 & 34,940 & Not avail. & Not avail. & $3,130.31$ \\
3 & G71-0133L & 2011 & 8,720 & 347 & 4,164 & $2,725.33$ \\
\hline
\end{tabular}




\begin{tabular}{ccccccc}
\hline $\begin{array}{c}\text { Logger } \\
\text { No. }\end{array}$ & $\begin{array}{c}\text { Fleet Vehicle } \\
\text { Id }\end{array}$ & Year & Odometer & $\begin{array}{c}\text { Monthly } \\
\text { Miles }\end{array}$ & $\begin{array}{c}\text { Calculated } \\
\text { Annual Miles }\end{array}$ & $\begin{array}{c}\text { Study-Extrapolated } \\
\text { Miles }\end{array}$ \\
\hline 4 & G43-0944G & 2008 & 7,992 & 148 & 1,776 & $1,573.56$ \\
5 & G43-0822G & 2008 & 26,318 & 477 & 5,724 & $5,824.36$ \\
84 & G41-1100K & 2010 & Not avail. & Not avail. & Not avail. & $3,320.34$ \\
87 & G42-0619K & 2010 & 5,217 & 163 & 1,956 & 762.44 \\
88 & G41-1180K & 2010 & 7,120 & 215 & 2,580 & $1,635.55$ \\
90 & G43-1892H & 2009 & 11,362 & 306 & 3,672 & $6,175.45$ \\
91 & G43-1961H & 2009 & 15,649 & 410 & 4,920 & $4,059.61$ \\
92 & G42-0505A & 2004 & 28,838 & 391 & 4,692 & $3,605.97$ \\
95 & G43-1155L & 2011 & 10,153 & 517 & 6,204 & $10,418.14$ \\
98 & G41-1605L & 2011 & 3,175 & 148 & 1,776 & 300.11 \\
100 & G42-0610K & 2010 & 8,255 & 262 & 3,144 & $1,556.17$ \\
\hline
\end{tabular}

For the entire Public Works Group fleet, the average monthly miles traveled are 335 miles for an average annual travel of 4,024 miles. In general, there is good correlation between the JBLM provided averages and the study calculated annual mileage. The JBLM provided mileage information will be used in the calculations when available.

\section{H.5 Public Works Group Vehicle Utilization}

Vehicle utilization is an important factor in the evaluation of vehicles both from an inventory perspective and for charging availability. Table H-9 identifies the percent utilization of the vehicle considering all days used during the study period. Since most travel occurred during weekdays, only the 45 weekdays in the 63-day study period are considered. In the event that the vehicle was used for more than these 45 days, the percent utilization is considered $100 \%$.

The average daily usage of each vehicle is identified in the Appendix D data sheets. It is also shown here for completeness.

Table H-9. Vehicle utilization.

\begin{tabular}{|c|c|ccrr|}
\hline Logger & Vehicle & Mission & Vehicle Class & $\begin{array}{c}\text { Percent } \\
\text { Days Used }\end{array}$ & $\begin{array}{c}\text { Avg Daily Travel } \\
\text { Time (Hrs) }\end{array}$ \\
\hline 1 & G42-0658K & PL & Pickup & $82 \%$ & 1.2 \\
2 & G42-1054F & PL & Pickup & $78 \%$ & 1.0 \\
3 & G71-0133L & PL & Van - Pass & $91 \%$ & 1.6 \\
4 & G43-0944G & PL & Van - Pass & $76 \%$ & 1.3 \\
5 & G43-0822G & SU & Pickup & $100 \%$ & 1.3 \\
84 & G41-1100K & PL & Minivan & $62 \%$ & 0.7 \\
87 & G42-0619K & PL & Pickup & $67 \%$ & 0.5 \\
88 & G41-1180K & PL & Minivan & $84 \%$ & 0.6 \\
90 & G43-1892H & SU & Pickup & $96 \%$ & 1.5 \\
91 & G43-1961H & SU & Pickup & $91 \%$ & 1.7 \\
92 & G42-0505A & SU & Van - Pass & $78 \%$ & 0.9 \\
95 & G43-1155L & SU & Pickup & $78 \%$ & 2.2 \\
98 & G41-1605L & SU & Pickup & $13 \%$ & 0.4 \\
100 & G42-0610K & PL & Pickup & $44 \%$ & 0.7 \\
\hline \multicolumn{7}{l}{} & Average & $74 \%$ & 1.1 \\
\hline
\end{tabular}


In general, the vehicles are used on frequent days but average usage per day is quite low. For example, the average vehicle is used on three out of four days but just over an hour each day.

\section{H.6 Public Works Group Summary}

This study provides observations for both the vehicles monitored and for the entire non-tactical fleet of vehicles identified with the Public Works Group. The study indicates that PEVs offer alternatives to vehicles in the existing provided that any specific cargo requirements may be met by the PEV. In general, a mixed fleet of BEVs and PHEVs is suggested.

The vehicles monitored in this study included three conventional passenger vans, nine conventional pickup trucks, and two conventional minivans. Based on the travel data, Intertek suggests that retaining the passenger vans and replacing the remaining vehicles with three PHEVs and eight BEVs would meet current mission requirements. Section 5 identifies potential replacement PEVs and Appendix H provides specific recommendations.

The Public Works Group full fleet of vehicles contains 250 vehicles. Intertek suggests retaining the conventional specialty vehicle, 52 conventional passenger vans, and 33 conventional heavy-duty trucks for now, and suggests a fleet of $128 \mathrm{BEVs}$ and 36 PHEVs conservatively meet the balance of vehicle travel requirements.

With the potential replacement by PEVs established, Section 5 and Appendix L provide further evaluation of the benefits of such replacements. This will be factored into further observations and suggestions related to the business case and schedule for any replacements for the Public Works Group. Those observations will be addressed in Task 4 of this project 


\section{Appendix I}

\section{Motor Transport Branch Vehicle Analysis}

\section{l.1 Motor Transport Branch Vehicle Summary}

The Motor Transport Branch fleet contains 1060 vehicles, not including the LSVs and non-powered vehicles. Table I-1 identifies these vehicles by vehicle type according to site records. The mission assignments identified in this table are based upon survey responses received and extrapolation to the entire fleet. Table I-2 provides a summary of mission types for these survey responses. Survey responses received included 76 of these vehicles or $7 \%$ of the total.

Table I-1. Motor Transport Branch fleet vehicles by type and mission.

\begin{tabular}{|c|c|c|c|c|c|c|c|c|c|c|c|}
\hline Mission & $\begin{array}{c}\text { Sedan } \\
\text { Compact/ } \\
\text { Sub Com }\end{array}$ & $\begin{array}{c}\text { Sedan } \\
\text { Midsize/ } \\
\text { Large }\end{array}$ & $\begin{array}{l}\text { Mini } \\
\text {-van }\end{array}$ & SUV & $\begin{array}{c}\text { Speci } \\
\text { alty }\end{array}$ & $\begin{array}{c}\text { Cargo } \\
\text { Van }\end{array}$ & $\begin{array}{c}\text { Pass. } \\
\text { Van }\end{array}$ & $\begin{array}{l}\text { Pickup } \\
\text { or LD } \\
\text { Truck } \\
\end{array}$ & $\begin{array}{c}\text { MD or } \\
\text { HD } \\
\text { Truck }\end{array}$ & Bus & Total \\
\hline Pool & 20 & 36 & 59 & 23 & & 72 & 168 & 117 & & & 495 \\
\hline Support & 3 & 60 & 29 & 92 & & 6 & 18 & 93 & & & 301 \\
\hline Transport & 3 & & 10 & & & 32 & 16 & 70 & 73 & & 204 \\
\hline Specialty & & & & & 4 & & & & & & 4 \\
\hline Bus & & & & & & & & & & 56 & 56 \\
\hline Total & 26 & 96 & 98 & 115 & 4 & 110 & 202 & 280 & 73 & 56 & 1060 \\
\hline
\end{tabular}

Table I-2. Motor Transport Branch survey responses.

\begin{tabular}{|c|c|c|c|c|c|c|c|c|c|c|c|}
\hline Mission & $\begin{array}{c}\text { Sedan } \\
\text { Compact/ } \\
\text { Sub Com }\end{array}$ & $\begin{array}{c}\text { Sedan } \\
\text { Midsize/ } \\
\text { Large }\end{array}$ & $\begin{array}{l}\text { Mini } \\
\text {-van }\end{array}$ & SUV & $\begin{array}{l}\text { Speci } \\
\text { alty }\end{array}$ & $\begin{array}{c}\text { Cargo } \\
\text { Van }\end{array}$ & $\begin{array}{l}\text { Pass. } \\
\text { Van }\end{array}$ & $\begin{array}{l}\text { Pickup } \\
\text { or LD } \\
\text { Truck }\end{array}$ & $\begin{array}{l}\text { MD or } \\
\text { HD } \\
\text { Truck }\end{array}$ & Bus & Total \\
\hline Pool & 6 & 6 & 12 & 2 & & 3 & 5 & 5 & & & 39 \\
\hline Support & 1 & 10 & 6 & 8 & & & & 4 & & & 29 \\
\hline Transport & 1 & & 2 & & & 1 & 1 & 3 & & & 8 \\
\hline Total & 8 & 16 & 20 & 10 & & 4 & 6 & 12 & & & 76 \\
\hline
\end{tabular}

Table I-3 provides a summary of the vehicles monitored for this report. Survey responses were not received for all vehicles so missions are assumed based upon total survey response percentages.

Table I-3. Motor Transport Branch fleet vehicle logger summary.

\begin{tabular}{|c|c|c|c|c|c|c|c|c|c|c|c|}
\hline Mission & $\begin{array}{c}\text { Sedan } \\
\text { Compact/ } \\
\text { Sub Com }\end{array}$ & $\begin{array}{c}\text { Sedan } \\
\text { Midsize/ } \\
\text { Large }\end{array}$ & $\begin{array}{l}\text { Mini } \\
\text {-van }\end{array}$ & SUV & $\begin{array}{c}\text { Speci } \\
\text { alty }\end{array}$ & $\begin{array}{c}\text { Cargo } \\
\text { Van }\end{array}$ & $\begin{array}{l}\text { Pass. } \\
\text { Van }\end{array}$ & $\begin{array}{l}\text { Pickup } \\
\text { or LD } \\
\text { Truck }\end{array}$ & $\begin{array}{l}\text { MD or } \\
\text { HD } \\
\text { Truck }\end{array}$ & Bus & Total \\
\hline Pool & 3 & 2 & 3 & 1 & & 3 & 7 & 4 & & & 23 \\
\hline Support & 1 & 2 & 2 & 2 & & 1 & & 3 & & & 11 \\
\hline Transport & & & & & & 2 & & 2 & 2 & & 6 \\
\hline Total & 4 & 4 & 5 & 3 & & 6 & 7 & 9 & 2 & & 40 \\
\hline
\end{tabular}

Table I-4 provides the full characterization of the fleet of vehicles monitored in this survey. 
Table I-4. Motor Transport Branch vehicle characterization index.

\begin{tabular}{|c|c|c|c|c|c|c|}
\hline \multicolumn{7}{|c|}{ Vehicle Index } \\
\hline $\begin{array}{l}\text { Logger } \\
\text { No. }\end{array}$ & Fleet Vehicle Id & Make & Model & Year & EPA Class & Mission \\
\hline 6 & G43-0875K & Ford & E350 & 2010 & Cargo Van & Pool \\
\hline 7 & G41-1288A & Ford & Sport Trac & 2004 & Pickup Truck & Pool \\
\hline 8 & G43-4937A & Ford & E350 & 2004 & Cargo Van & Pool \\
\hline 9 & G10-7664F & Dodge & Avenger & 2008 & Compact Sedan & Pool \\
\hline 10 & G41-65991 & Dodge & Dakota & 2002 & Pickup Truck & Pool \\
\hline 11 & G11-2676G & Chevrolet & Impala & 2008 & Large Car & Pool \\
\hline 12 & G43-3717A & Ford & E350 & 2004 & Cargo Van & Pool \\
\hline 13 & G11-0678K & Chevrolet & Impala & 2010 & Large Car & Support \\
\hline 14 & G62-4526H & Chevrolet & Tahoe & 2009 & SUV & Support \\
\hline 15 & G42-0698K & Chevrolet & $\mathrm{C} 1500$ & 2011 & Pickup Truck & Support \\
\hline 16 & G11-0493L & Chevrolet & Impala & 2012 & Large Car & Support \\
\hline 17 & G71-0062G & Ford & F750 & 2008 & Stake Truck & Transport \\
\hline 18 & G62-1094L & Chevrolet & Avalanche & 2011 & SUV & Support \\
\hline 19 & G41-1395G & Chevrolet & Uplander & 2008 & Minivan & Pool \\
\hline 20 & G61-1155D & Ford & Escape HYB & 2006 & SUV & Pool \\
\hline 81 & G10-2878L & Chevrolet & Malibu & 2011 & Midsize Sedan & Pool \\
\hline 84 & G41-1100K & Dodge & Gr Caravan & 2010 & Minivan & Pool \\
\hline 85 & G62-0979G & Dodge & 1500 & 2008 & Pickup Truck & Pool \\
\hline 89 & G71-0674A & Ford & F650 18'BO & 2004 & Delivery Van & Transport \\
\hline 93 & G41-1373G & Dodge & Dakota & 2008 & Pickup Truck & Support \\
\hline 97 & G41-1367G & Dodge & Dakota & 2008 & Pickup Truck & Pool \\
\hline 101 & G43-0792K & Chevrolet & CG3300 & 2010 & Passenger Van & Pool \\
\hline 102 & G43-0801K & Chevrolet & CG3300 & 2010 & Passenger Van & Pool \\
\hline 104 & G42-0988F & Chevrolet & Express 13 & 2007 & Cargo Van & Support \\
\hline 105 & G43-0860G & Chevrolet & CG3300 & 2008 & Passenger Van & Pool \\
\hline 106 & G43-1389K & Chevrolet & CG3300 & 2010 & Passenger Van & Pool \\
\hline 107 & G41-1180G & Chevrolet & Uplander & 2008 & Minivan & Support \\
\hline 108 & G11-2675G & Chevrolet & Impala & 2008 & Large Sedan & Pool \\
\hline 109 & G43-1191L & Chevrolet & CG3300 & 2011 & Passenger Van & Pool \\
\hline 110 & G12-0662H & Ford & Fusion HEV & 2010 & Midsize Sedan & Pool \\
\hline 111 & G63-0271A & Ford & F350 Stake & 2004 & Stake Truck & Transport \\
\hline 112 & G41-1392G & Chevrolet & Uplander & 2008 & Minivan & Support \\
\hline 113 & G43-3881H & Ford & E350 & 2009 & Passenger Van & Pool \\
\hline 114 & G43-25839 & Ford & F350 & 2003 & Pickup Truck & Transport \\
\hline 115 & G41-1376G & Dodge & Dakota & 2008 & Pickup Truck & Support \\
\hline 116 & G41-1161G & Chevrolet & Uplander & 2008 & Minivan & Pool \\
\hline
\end{tabular}




\begin{tabular}{|l|c|c|c|c|c|c|}
\hline \multicolumn{7}{|c|}{ Vehicle Index } \\
\hline $\begin{array}{l}\text { Logger } \\
\text { No. }\end{array}$ & Fleet Vehicle Id & Make & Model & Year & EPA Class & Mission \\
\hline 117 & G43-0790K & Chevrolet & CG3300 & 2010 & Passenger Van & Pool \\
\hline 118 & G82-0509A & Ford & F650 Stake & 2004 & Stake Truck & Transport \\
\hline 119 & G10-6379L & Dodge & Avenger & 2011 & Midsize Sedan & Support \\
\hline 120 & G42-3471A & Chevrolet & G2300 & 2005 & Cargo Van & Transport \\
\hline
\end{tabular}

The following may reference specific vehicles by logger number or Fleet Vehicle ID.

JBLM data collection took place from March 5, 2013 through May 7, 2013. Vehicle data sheets (presented in Appendix E) detail the collected data for each vehicle.

Of the data collected, validation occurred for $99.7 \%$ of the data, while null values exist for the balance. Table I-5 shows this information by mission type.

Table I-5. Vehicle data logger reporting summary.

\begin{tabular}{cccc}
\hline \multicolumn{4}{c}{ Vehicle Data Logger Reporting Summary } \\
Mission & \% Collected & \% Null Values & Total \\
\hline Pool & 96.5 & 3.4 & $100 \%$ \\
Support & 95.8 & 4.2 & $100 \%$ \\
Transport & 98.7 & 1.3 & $100 \%$ \\
\hline All Vehicles & 97.4 & 2.6 & $100 \%$ \\
\hline
\end{tabular}

Grouping the vehicles by mission creates an aggregated view of mission requirements to provide observations related to PEV replacement. Analysis by mission type follows.

\section{I.2 Motor Transport Branch Pool Vehicles Analysis}

Pool vehicles are typically light-duty motor vehicles for use in passenger transportation, with not more than 10 passengers. Pool missions can vary by agency, location, and jurisdiction, and for Motor Transport Branch, the pool vehicles include minivans, sedans, pickup trucks, cargo and passenger vans, and a SUV. Although there are currently no PEVs available to replace the passenger van vehicle, it is assumed that the usage of all these pool vehicles can be of value in considering the remaining pool vehicles in the Motor Transport fleet. The other vehicles may be replaced by currently available PEVs.

Incorporation of BEVs and/or PHEVs into the pool mission is a definite possibility. Pool vehicles used for shorter trips or outings qualify for BEV or PHEV replacement, while other pool vehicle activities that are associated with longer trips may require PHEV capabilities.

\section{I.2.1 Summary for Motor Transport Branch Pool Vehicles}

Appendix E provides the vehicle data sheets for each of the 23 pool vehicles monitored. This section aggregates data for all pool vehicles. Table I-6 summarizes pool travel during the study period for those days in which the vehicle was driven. Vehicle use occurred at all hours of the day but primarily between 0700 and 1800 hours. They traveled 23,746 miles, logged1,158 hours, and idled for 312 hours during the 63-day study period.

Figure I-1 shows the travel summary for pool vehicles: by vehicle, by daily mileage, and daily usage time. Figure I-2 shows the composite history for all pool vehicles. In these stacked bar charts of Figure I2 , the contribution of each vehicle is indicated by a different color. 
Table I-6. Pool vehicles travel summary.

\begin{tabular}{|c|c|c|c|c|}
\hline \multicolumn{5}{|c|}{ Pool Vehicles Travel Summary } \\
\hline & $\begin{array}{c}\text { Per Day } \\
\text { Average/Peak }\end{array}$ & $\begin{array}{c}\text { Per Outing } \\
\text { Average/Peak }\end{array}$ & $\begin{array}{c}\text { Per Trip } \\
\text { Average/Peak }\end{array}$ & Total \\
\hline Travel Distance (Miles) & $35.2 / 571.2$ & $11.9 / 1566.9$ & $4.4 / 202.5$ & 23,746 \\
\hline Travel Time (Minutes) & 103.1/777.0 & $34.8 / 1897$ & $12.7 / 257.0$ & 69,499 \\
\hline Idle Time (Minutes) & 27.8/NA & 9.4/NA & $3.4 / \mathrm{NA}$ & 18,748 \\
\hline
\end{tabular}
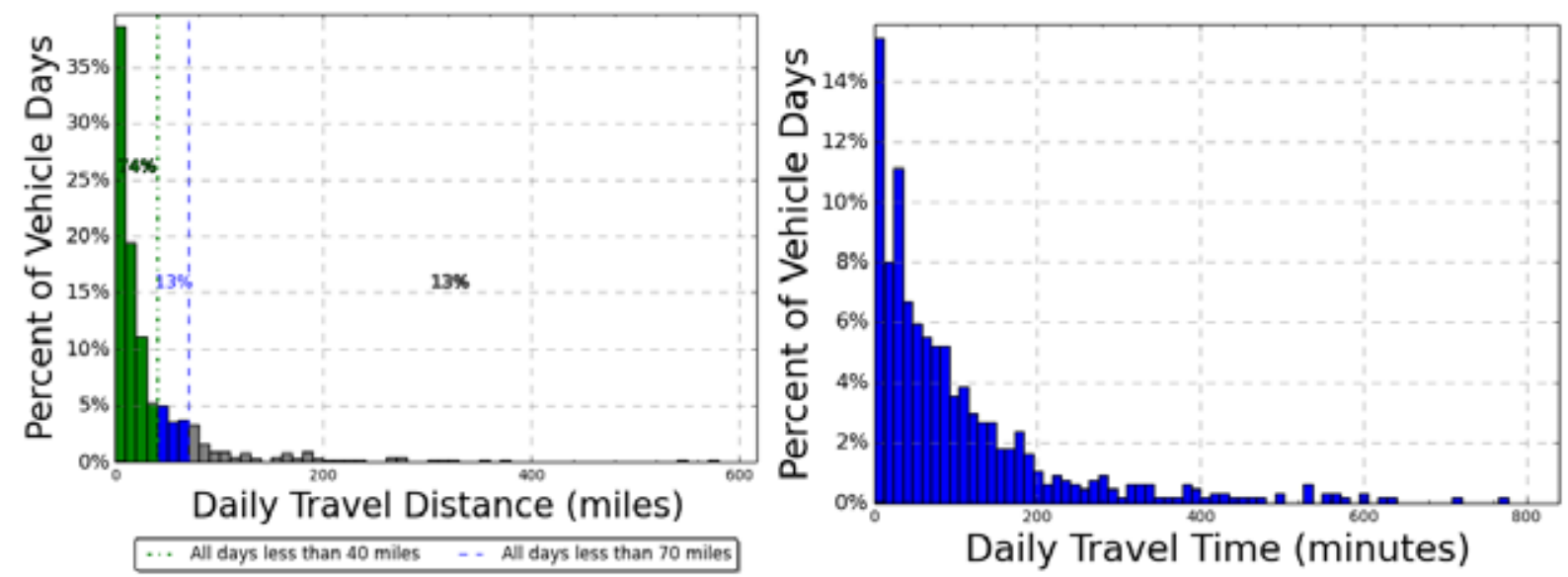

Figure I-1. Motor Transport Branch pool vehicle daily travel miles and time (all vehicles).

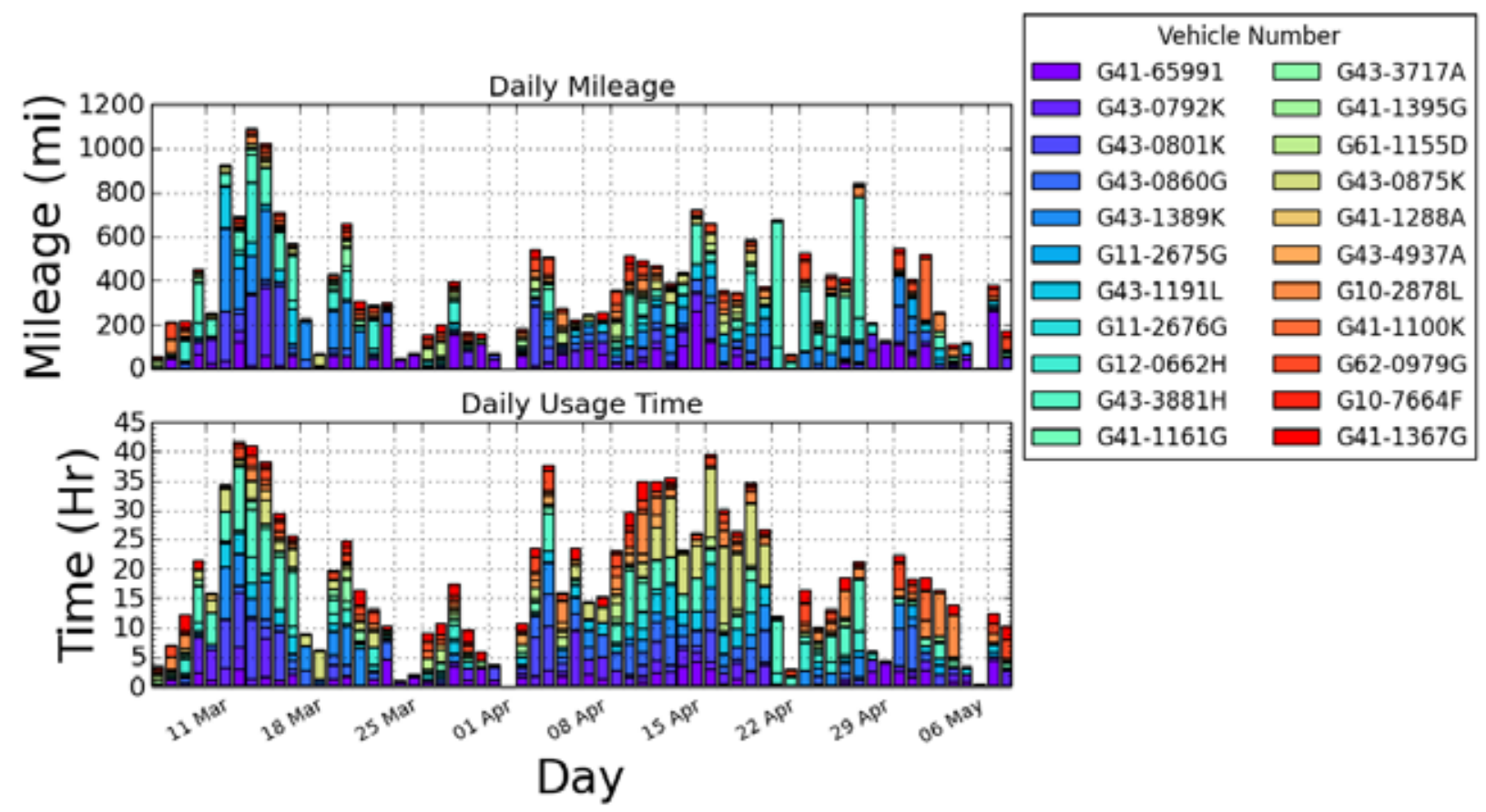

Figure I-2. Motor Transport Branch pool vehicles travel history (all vehicles). 


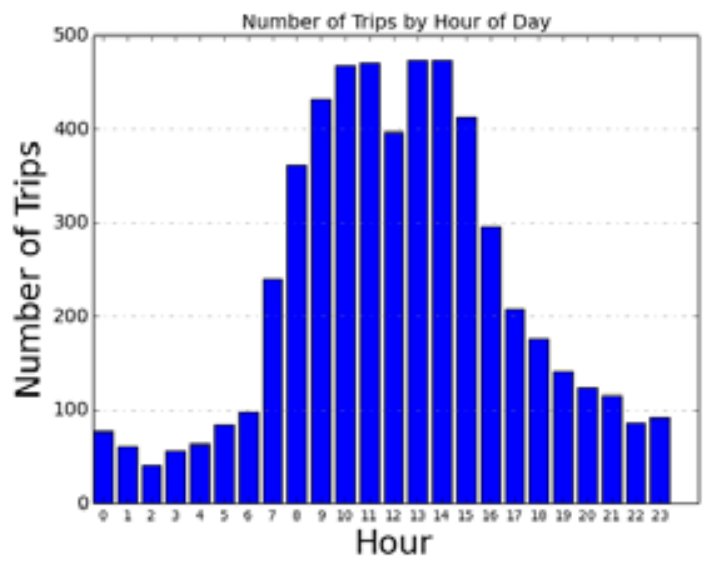

Figure I-3. Motor Transport Branch pool vehicles hourly usage.

Because there were 23 vehicles in this pool mission for Motor Transport Branch, the vehicles are split into three groups for clarity of daily use. These groups are sedans and minivans, pickup trucks and cargo vans and passenger vans. Figure I-4 shows the outings for all sedans and minivans.
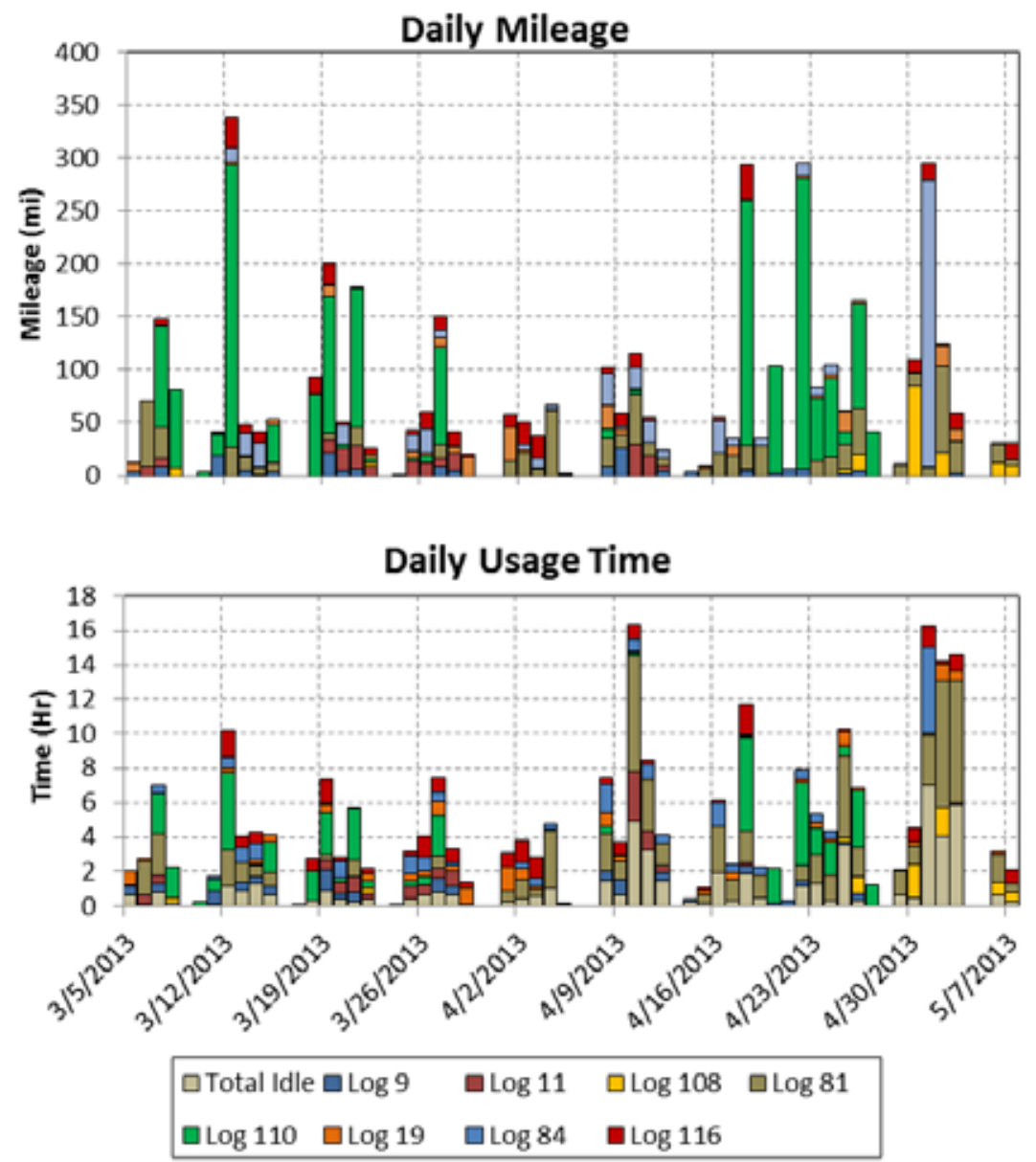

Figure I-4. Motor Transport Branch pool sedan and minivan combined daily travel.

Within this group, two vehicles stand out for exceptional travel distances compared to the others in their vehicle class. Sedan 110 (Vehicle G12-0662H) had a maximum daily travel of 275 miles while all other sedans had a maximum daily travel less than 85 miles. Minivan 84 (Vehicle G41-1100K) had a maximum daily travel of 271 miles while the other two maximum daily travels were less than 32 miles. 
Figure I-5 shows the daily travel for all pickup trucks, the SUV, and cargo vans.
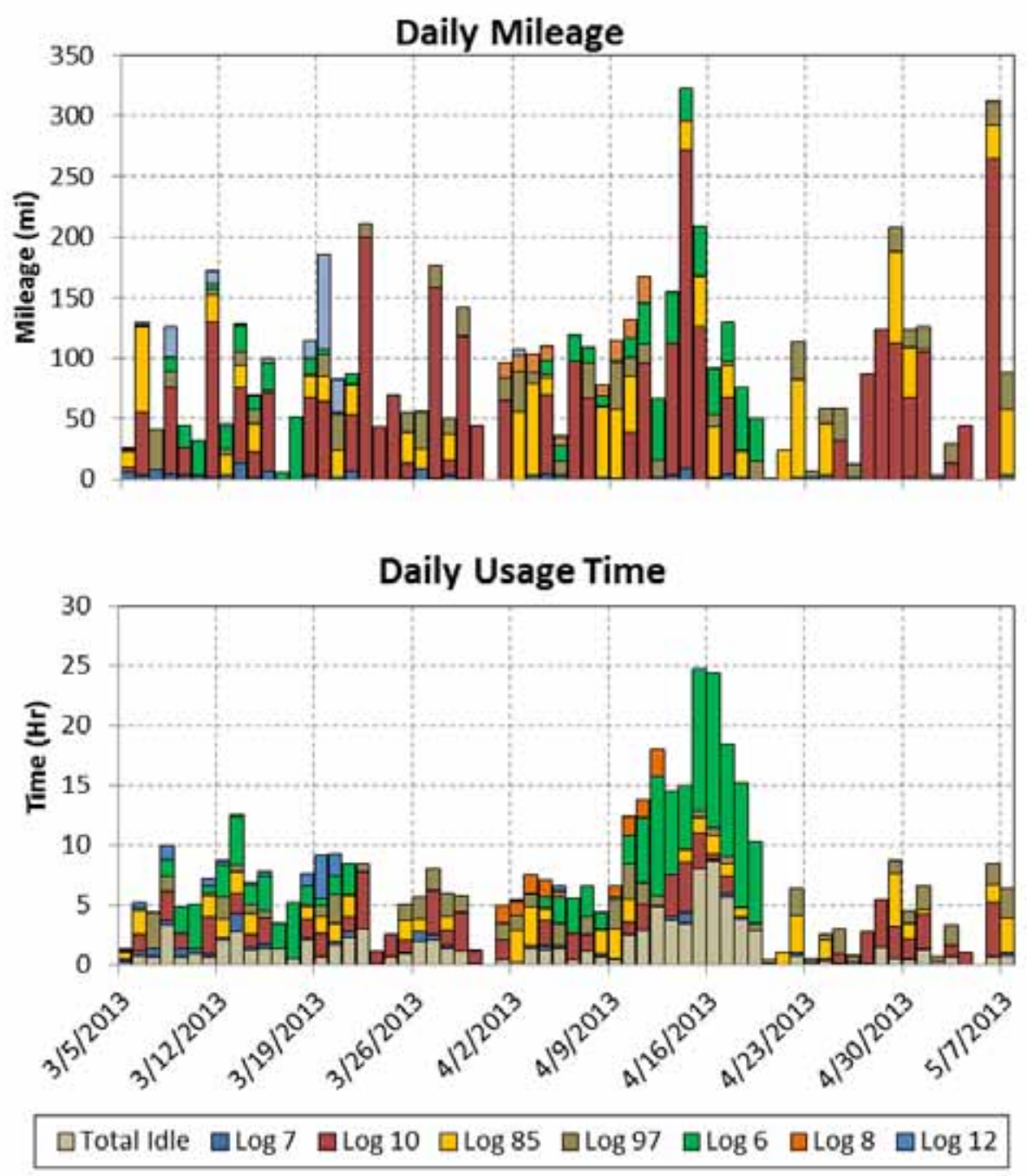

Figure I-5. Motor Transport Branch pool pickup truck, SUV, and cargo van combined daily travel.

Within this group, pickup truck \#10 (Vehicle G41-65991) had significantly higher daily miles than the other vehicles with 264 miles compared to 85 miles or less for all the other vehicles in this group. Vehicle 6 (cargo van) had significantly more travel time but such travel was of shorter distances. Cargo van \#6 (Vehicle G43-0875K) contributed most of the idle time seen around April 16. For the study period, this van averaged more than one hour per day idling on those days driven. For the days from April 12 to 18 , the vehicle averaged approximately 5 hours per day idling although no significant travel offbase was recorded.

Figure I-6 shows the combined daily travel for passenger vans.

Within this group, passenger van \#113 (Vehicle G43-3881H) had the highest travel day although all vehicles in this category exhibited significant travel. It is noted that passenger van \#117 (Vehicle G430790K) provided insufficient data to evaluate.

All these graphs reveal the extensive use that the Motor Transport Group pool vehicles experience. They are used nearly every day and many vehicles at the same time. 

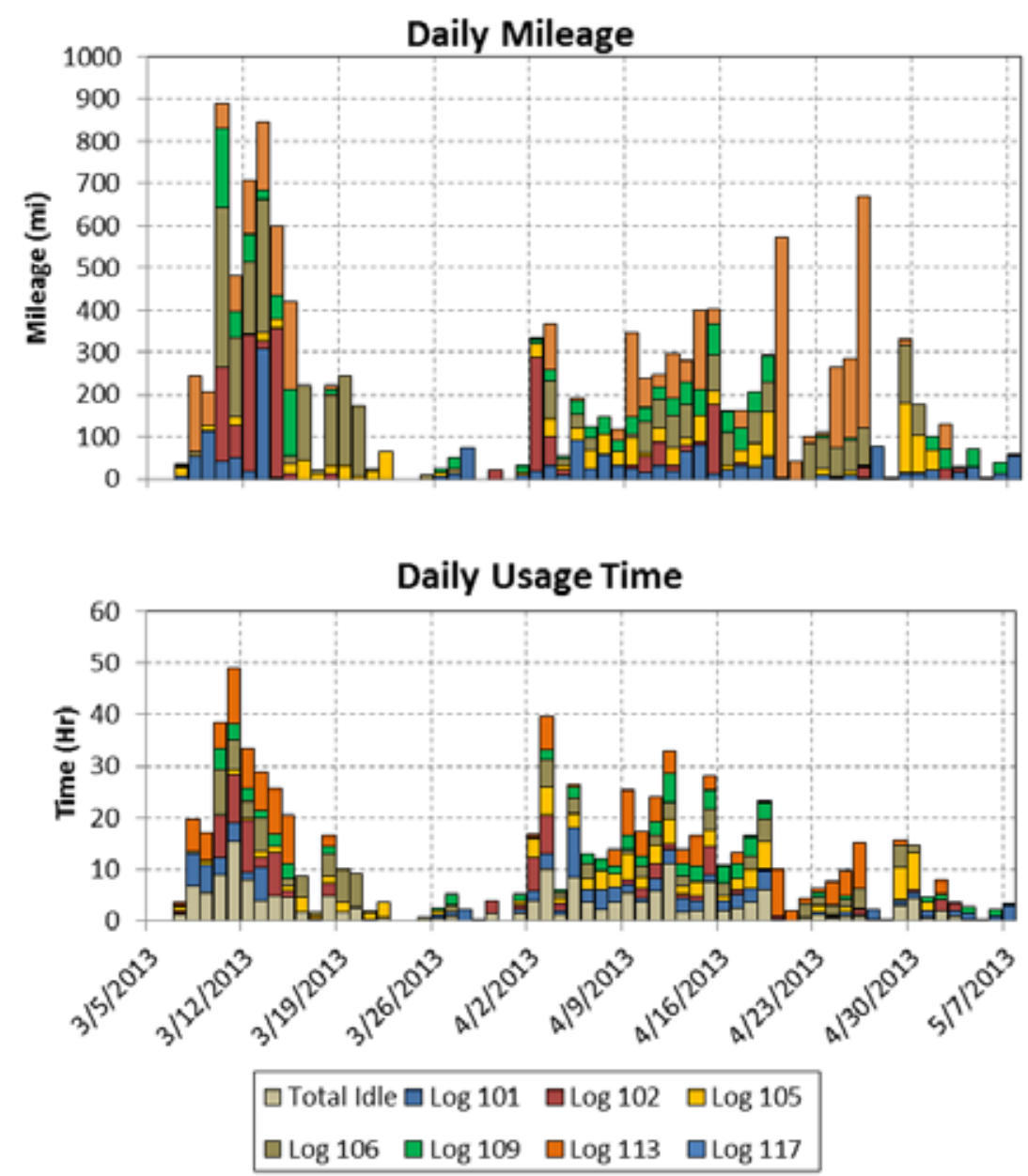

Figure I-6. Motor Transport Branch pool passenger van combined daily travel.

\section{I.2.2 Motor Transport Branch Pool Vehicles Daily Summary}

The average travel distance per day when driven for pool vehicles is 35.2 miles. On $87 \%$ of the vehicle travel days, the daily travel is less than the 70 miles considered to be within the BEV safe range (blue and green bars in Figure I-1). That is, while BEV range can vary based on several factors; most BEVs provide at least 70 miles of vehicle range on a single battery charge. Meanwhile, $74 \%$ of vehicle travel days are less than 40 miles considered to be within the CD range of a PHEV (green bars of Figure I-1). However, $13 \%$ of daily travel exceeds the 70-mile range. As noted above, most of this higher travel was by vehicles 110,10 and 84 as well as most of the passenger vans.

Figure I-4, I-5, and I-6 show that vehicles are used extensively. As a group, the vehicles were used approximately half the days of the study period.

Figure I-7 displays the summary of outings for all pool vehicles. 


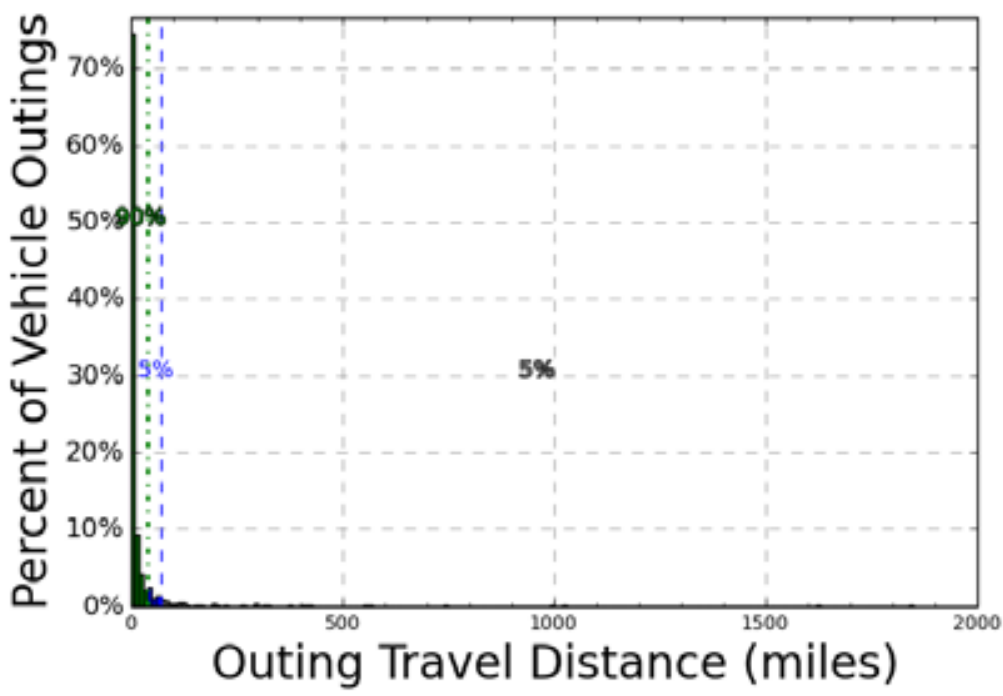

-.. All outings less than 40 miles - - All outings less than 70 miles

Figure I-7. Motor Transport Branch pool vehicle outings (all vehicles).

The outings graph is dominated by the highest outing recorded of 1599.9 miles by passenger van \#113 (vehicle G43-3881H) during an April excursion to Idaho and Washington. Appendix E shows this vehicle having several of the outings exceeding 70 miles. The majority of high-distance outings were experienced by minivan $\# 84$, sedan $\# 110$, pickup $\# 10$, and most of the passenger vans in a manner similar to the daily travel maximums noted above. The other pool vehicles experienced 85 miles or less in their maximum outings. Truncating the graph at 150 miles provides a clearer view of the left side of the above graph. Figure I-8 provides this graph.

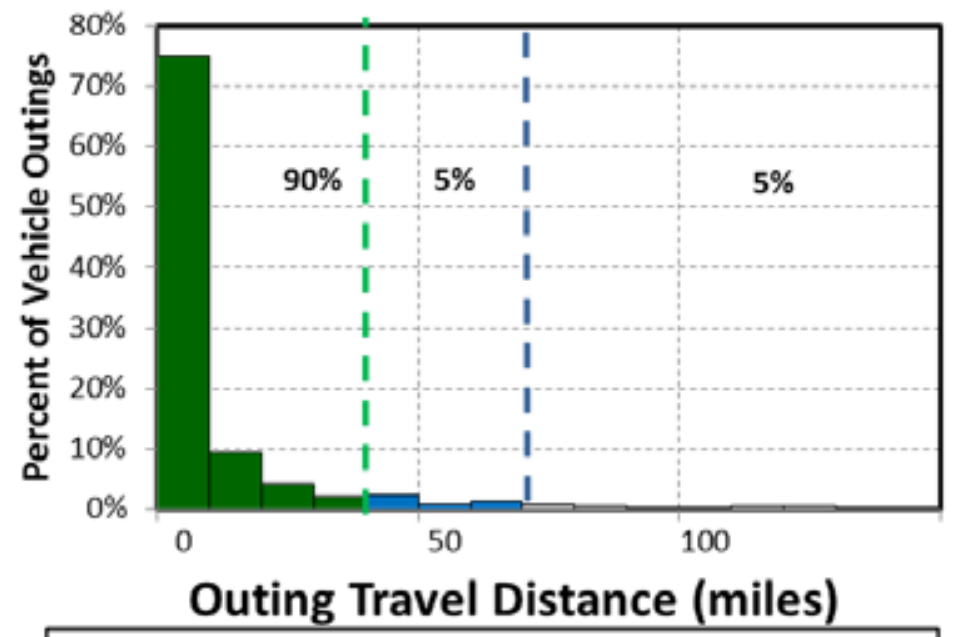

-..-All outings less than 40 miles _..-All outings less than 70 miles

Figure I-8. Motor Transport Branch pool vehicle outings (all vehicles) truncated at 150 miles.

Appendix E provides the details of each of the pool vehicle's outings.

The average travel outing when driven for pool vehicles is 11.9 miles. Meanwhile, $75 \%$ of all outings for all 23 vehicles in the pool mission are less than 10 miles. Furthermore, $95 \%$ of all outings were less than the 70 miles considered to be within the BEV safe range. However, $90 \%$ percent of pool vehicle outings are less than 40 miles considered to be within the CD range of a PHEV. 


\section{I.2.3 Motor Transport Branch Pool Vehicle Observations/Summary}

There appear to be three choices for JBLM in implementing PEVs into the Motor Transport Branch pool fleet. There are no current PEV replacements for passenger vans. However, the Motor Transport fleet with the pool mission does contain three minivans, four pickups, five sedans, one SUV, and three cargo vans for which suitable PEVs may be found. The observations here relate to these 16 vehicles assuming the travel of the monitored vehicles is typical.

As noted before, the optimum goal would be to incorporate as many BEVs as possible to realize the advantages of reduced petroleum usage and reduced emissions of GHG.

1. All BEV fleet: While some BEV manufacturers report vehicle range exceeding 70 miles, Intertek recommends careful evaluation of experienced range to ensure vehicle missions are accomplished. Nevertheless, assuming the 70-mile safe range for a BEV, an all-BEV fleet is not possible for support vehicles due to the long distances experienced by some of these vehicles.

2. Mixed BEV/PHEV fleet: Certainly, PHEVs can accomplish the same mission as the current fleet when only considering travel times and distances. The data reveal that on $74 \%$ of all vehicle travel days, the total daily travel is less than 40 miles, which typically is the maximum distance a PHEV will travel in CD mode. This represents a significant operating cost savings opportunity while retaining the ability to go longer distances when needed. Furthermore, $90 \%$ of the outings are less than 40 miles and could be completed in CD mode with certain PHEVs if the battery is fully charged prior to the outing.

It is noteworthy that $87 \%$ of the travel days are less than 70 miles and $95 \%$ of the vehicle outings are less than 70 miles indicating a BEV may be advantageous in the fleet. A mixed fleet requires fleet manager attention to assign vehicles appropriately for the anticipated use on that day.

3. All PHEV fleet: As noted above, PHEVs can accomplish the same mission as the current fleet when only considering travel times and distances. Replacing all current vehicles with PHEVs only requires an evaluation of the individual vehicle capabilities of currently available PHEVs to meet current pool requirements. Data show that for $74 \%$ of all travel days, the PHEV will operate in a CD mode. As above, this represents a significant operating cost savings opportunity while retaining the ability to go longer distances when needed. Intermediate charging opportunities provide additional benefit, enhancing the CD mode. Data show significant charging opportunities throughout the day during stop times.

While it would appear that PEVs are suitable replacements for these 16 conventional pool vehicles, additional mission analysis and management input is required. The missions of these vehicles likely include considerations other than mileage, such as cargo demands placed on the vehicle. Fleet managers typically desire greater conservatism in maintaining vehicle capabilities. While strict percentages might suggest $13 \%$ of the fleet requires PHEV because of the travel greater than 70 miles, a conservative approach for these 16 vehicles would be to suggest $40 \%$ PHEV and $60 \%$ BEV. See Section 5 for these suggestions.

The Motor Transport pool fleet of 23 vehicles monitored then could consist of 7 conventional passenger vans, $10 \mathrm{BEVs}$, and 6 PHEVs. There are 168 conventional passenger vans in the entire Motor Transport Branch fleet identified in Table I-1 for which no PEV currently exists as a replacement vehicle. Thus, the resulting fleet could consist of 168 conventional passenger vans, 196 BEVs and 131 PHEVs.

The vehicle summary shows sufficient time for charging at the base location during the course of the day and additional opportunities at intermediate charging stations. These stations also provide charging opportunities for the visiting public, whose fees may assist in offsetting operating costs.

\section{I.2.4 Motor Transport Branch Pool Vehicle Charging Needs}

Upon review of these data, Intertek suggests replacement of the Motor Transport Branch pool fleet monitored in this study with $10 \mathrm{BEVs}$ and $6 \mathrm{PHEV}$ while retaining the conventional passenger vans unchanged for now. The entire fleet could consist of 196 BEVs and 131 PHEVs. 
As noted previously, AC Level 2 overnight charging of BEVs is typical, whereas overnight charging of PHEVs can be accomplished with AC Level 1 charging.

Intertek's experience suggests that each vehicle have an assigned charging location at their home base. Assigned stations require less management attention to ensure completion of overnight charging. BEVs and PHEVs not assigned to these locations also benefit during visits to the location as part of their normal operation. For the monitored fleet of pool vehicles, $10 \mathrm{BEVs}$ require $10 \mathrm{AC}$ Level $2 \mathrm{EVSE}$ units for overnight charging and six PHEVs require 6AC Level 1 outlets for home base. Intertek recommends a minimum of two EVSE at each location to maximize charge capability without a significant increase in installation costs. The PHEVs can utilize the AC Level 2 EVSE at the home base during the day to increase the amount of vehicle miles traveled in CD Mode.

At times, fleet vehicles obtain benefit from using public charging infrastructure. Figure 18 displays the availability of public charging at the time of this writing for the JBLM area. Significant travel occurs off base by several vehicles that may find benefit in increased range for these vehicles.

\section{I.3 Motor Transport Branch Support Vehicles Analysis}

Support vehicles provide a specific work function, facilitating the mission of a particular group. The vehicles are generally passenger or light-duty pickup trucks and may contain after-market modifications to support the mission. While assigned to maintenance and service areas, missions may vary depending on agency needs.

As shown above, vehicles G41-74299 (logger 83) and G43-1195H (logger 96) were support vehicles monitored.

\section{I.3.1. Summary for Motor Transport Branch Support Vehicles}

Appendix E provides the vehicle data sheets for each of the eleven support vehicles monitored. This section aggregates the data for all support vehicles.

Table I-7 summarizes support vehicle travel during the study period. Vehicle use may occur at any hour but primarily occurred between 0700 and 1500 hours daily. Support vehicles traveled 19,336 miles, logged 1,886 hours, and idled for 989 hours during the study period.

Table I-7. Support vehicle travel summary.

\begin{tabular}{lcccc}
\hline \multicolumn{4}{c}{ Support Vehicle Travel Summary } & \\
& $\begin{array}{c}\text { Per Day } \\
\text { Average/Peak }\end{array}$ & $\begin{array}{c}\text { Per Outing } \\
\text { Average/Peak }\end{array}$ & $\begin{array}{c}\text { Per Trip } \\
\text { Average/Peak }\end{array}$ & Total \\
\hline Travel Distance (Miles) & $46.9 / 555.0$ & $13.3 / 1236$ & $5.3 / 245.6$ & 19,336 \\
Travel Time (Minutes) & $274.8 / 1502$ & $78.0 / 1440$ & $30.8 / 512.0$ & 113,202 \\
Idle Time (Minutes) & $58.2 / \mathrm{NA}$ & $16.5 / \mathrm{NA}$ & $6.5 / \mathrm{NA}$ & 59,355 \\
\hline
\end{tabular}

Figure I-9 shows the travel summary for support vehicles by vehicle, by daily mileage and daily usage time. Figure I-10 shows the composite history for all support vehicles.

Sedans \#119 and \#16 (Vehicles G10-6379 L and G11-0493 L) and minivan \#112 (Vehicle G41$1392 \mathrm{G}$ ) dominate the maximum daily travel with maximums of 1,236 miles, 237 miles and 253 miles respectively. All other vehicles in this group had maximum daily travel less than 92 miles. Pickup \#15 (Vehicle G42-0698K) was used most frequently, experiencing travel 92\% of the study days.

The history graphs identify when several support vehicles may be in use at the same time as well as the total miles driven on a daily basis. 

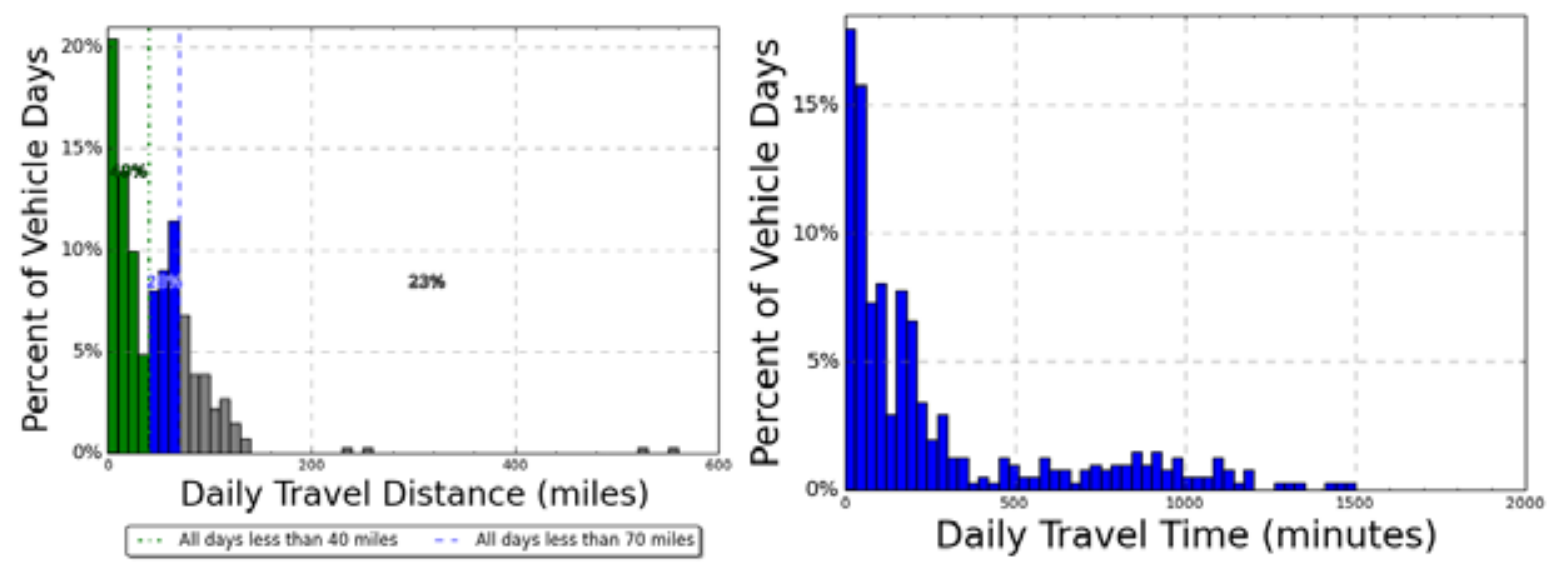

Figure I-9. Motor Transport Branch support vehicle daily travel miles and usage time (all vehicles).
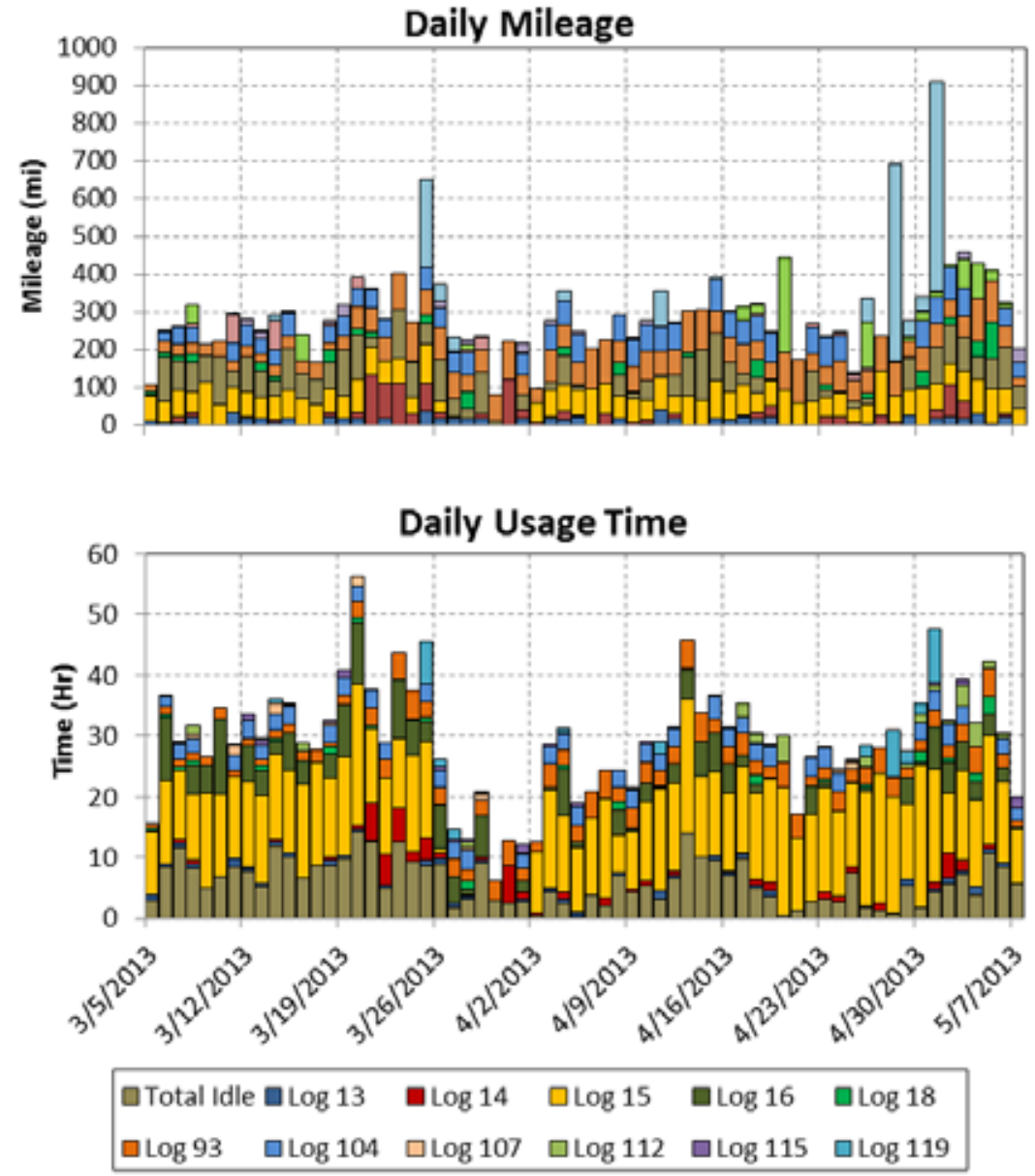

Figure I-10. Motor Transport Branch support vehicle history (all vehicles).

\section{I.3.2 Motor Transport Branch Support Vehicle Daily Summary}

The average travel distance per day when driven for support vehicles is 46.9 miles. On $77 \%$ of these vehicle days, the daily travel is less than the 70 miles considered to be within the BEV safe range. Meanwhile, 23\% percent of support vehicle daily travel is greater than 70 miles. Furthermore, $49 \%$ of vehicle travel days are less than 40 miles considered to be within the CD range of a PHEV.

Figure I-11 displays the summary of use by time of day for all support vehicles combined. 


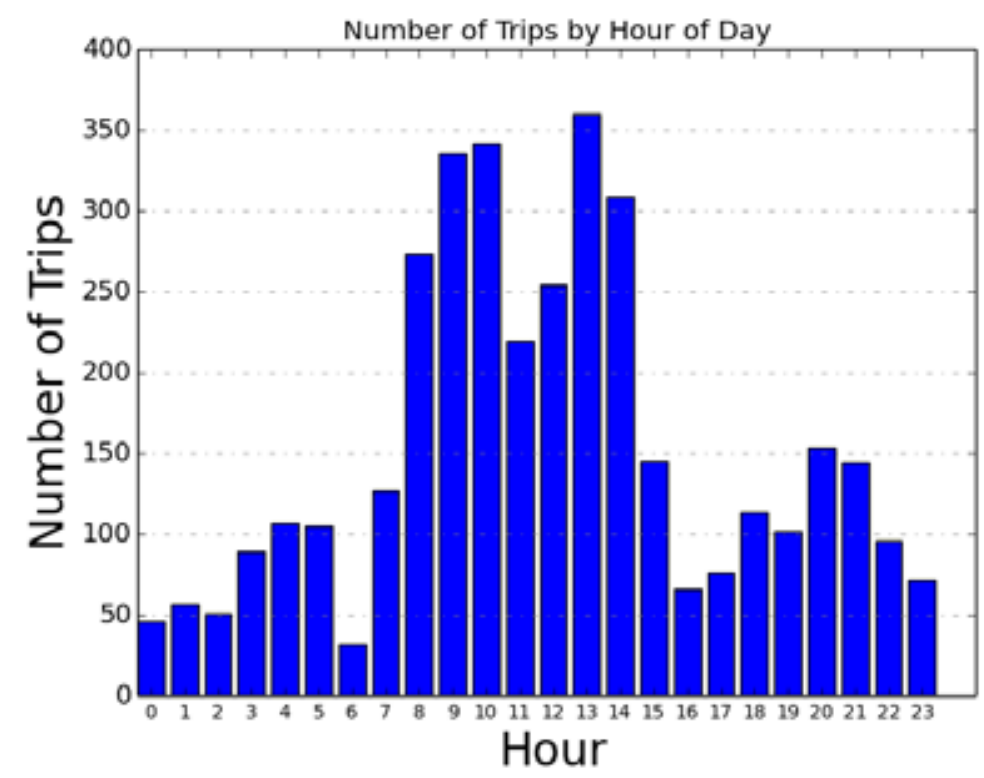

Figure I-11. Motor Transport Branch support vehicles hourly usage.

Figure I-12 shows the outings for all support vehicles combined.

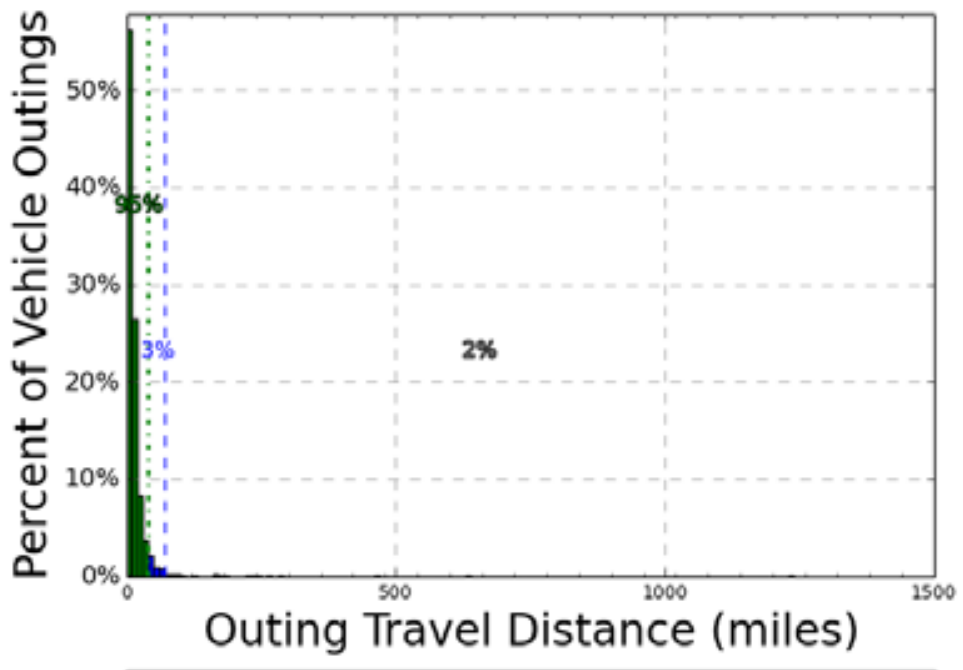

-.. All outings less than 40 miles _- All outings less than 70 miles

Figure I-12. Motor Transport Branch support vehicle combined outings.

As above, sedans \#119 and \#16 (Vehicles G10-6379 L and G11-0493 L) and minivan \#112 (Vehicle G41-1392G) dominate the maximum outings traveled with maximums of 1,236 miles, 237 miles and 253 miles respectively. All other vehicles in this group had maximum outings less than 92 miles. Although used extensively, pickup \#15 (Vehicle G42-0698K) traveled a maximum of 71.5 miles in an outing. Because the single highest travel of sedan \#119 sets the upper limit of distance in Figure I-13, the figure is duplicated below but truncated at 200 miles to more clearly show the lower outing distances.

The average travel outing when driven for support vehicles is 13.3 miles. On $98 \%$ of these vehicle outings, the distance traveled is less than the 70 miles considered to be within the BEV safe range. Meanwhile, $2 \%$ of support outing travel is greater than 70 miles. Furthermore, $95 \%$ of vehicle travel outings are less than 40 miles considered to be within the CD range of a PHEV. 


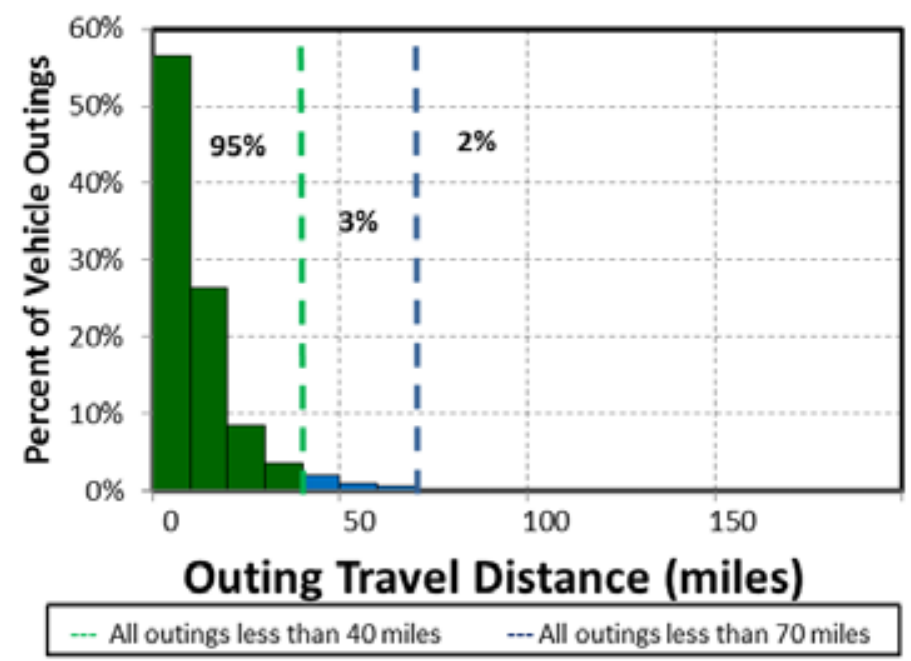

Figure I-13. Motor Transport Branch support vehicle outings (all vehicles) truncated to 200 miles.

\section{I.3.3 Motor Transport Branch Support Vehicle Observations/Summary}

There appear to be three choices for JBLM in implementing PEVs into the Motor Transport Branch support mission fleet. The vehicles monitored in the study include two minivans, three pickup trucks, three sedans, two SUVs, and one cargo van for which suitable PEVs may be found. The observations here relate to these 11 vehicles and to the full fleet of vehicles identified in Table I-1 assuming the travel of the monitored vehicles are typical.

Pickup trucks are a popular choice for support vehicle because they are versatile to support various types of support needed, i.e. special cargo or equipment transport. In some cases, SUVs or mini-vans can perform the same mission. Section 4.4 provides information on PEV trucks and vans currently or soon to be available.

As before, it should be noted that the optimum goal would be to incorporate as many BEVs as possible to realize the advantages of reduced petroleum usage and reduced emissions of GHG.

1. All BEV fleet: While some BEV manufacturers report vehicle range exceeding 70 miles, Intertek recommends careful evaluation of experienced range to ensure vehicle missions are accomplished. Nevertheless, assuming the 70-mile safe range for a BEV, an all-BEV fleet is not possible for support vehicles due to the long distances experienced by some of these vehicles.

2. Mixed BEV/PHEV fleet: Certainly, PHEVs can accomplish the same mission as the current fleet when only considering travel times and distances. The data reveal that on $49 \%$ of all vehicle travel days the total travel is less than 40 miles, which typically is the maximum distance a PHEV will travel in CD mode. Thus, the PHEV would be of benefit for this travel.

It is noted that $77 \%$ of all travel days and $98 \%$ of all outings are less than 70 miles. This would support travel by BEVs. For the days where the 70 miles are exceeded, intermediate charging locations typically provide the recharge necessary to increase the all-electric drive. There are significant quantities of public charging stations locally but they cannot be assured to be available when needed. Thus, consideration should be given to home base charging only. Additional charging during the day at the home base between outings would add daily range. Incorporation of BEVs into the fleet will require management attention to ensure appropriate deployment based upon the need and expected distance to be driven.

3. All PHEV fleet: As noted above, PHEVs can accomplish the same mission as the current fleet when only considering travel times and distances. Replacing all current vehicles with PHEVs only requires an evaluation of the individual vehicle capabilities of currently available PHEVs to meet current support vehicle requirements. 
While it would appear that PEVs may be suitable replacements for these 11 conventional support vehicles, additional mission analysis and management input is required. The missions of these vehicles likely include considerations other than mileage, such as cargo demands placed on the vehicle. Fleet managers typically desire greater conservatism in maintaining vehicle capabilities. Because a PHEV is required for only $23 \%$ of daily travel, the 11 vehicles monitored may be replaced by eight suitable style BEVs and three suitable style PHEVs. Because fleet managers may desire a more conservative approach with more PHEVs, it is suggested that these 11 vehicles be replaced by six BEVs and five PHEVs. See Section 5 for these suggestions.

The total Motor Transport Branch support fleet of 301 vehicles (Table I-1) then could consist of 18 conventional passenger vans, $155 \mathrm{BEVs}$, and 128 PHEVs. The vehicle summary shows sufficient time for charging at the base location during the course of the day. These stations also provide charging opportunities for the visiting public, whose fees may assist in offsetting operating costs.

Intertek suggests further mission evaluation be given to the balance of the support vehicles when considering the adoption of BEVs and PHEVs. Additional BEVs may be possible with further management or fleet software attention; however, fleet managers typically desire vehicles that support longer trips.

\section{I.3.4 Motor Transport Branch Support Vehicle Charging Needs}

Upon review of these data, Intertek suggests replacement of the Motor Transport Branch support vehicle fleet with 155 BEVs and 128 PHEVs. No available PHEVs at the time of this writing provide for DC fast charging nor do the data suggest that this would be a significant benefit for PHEVs in the support vehicle fleet. Additional charging of BEVs during the day is not a requirement nor would DCFCs be required. The majority of the support vehicle activity occurs during daytime hours, which leaves significant time during the nighttime hours for recharging.

As noted above, AC Level 2 overnight charging of BEVs is typical, whereas overnight charging of PHEVs can be accomplished using AC Level 1 charging. Opportunity charging at intermediate stops obtains the greater benefits from AC Level 2 EVSE. Most vehicles returned to their home base daily with the exception of long trips lasting several days.

Greater management attention provides the possibility of reducing the overall number of AC Level 2 EVSE. A ratio of two AC Level 2 charging stations to three vehicles typically sustains a normal fleet operation. Fleet managers rotate vehicles on the charger to complete charging of all vehicles in the allotted time. This analysis does assume a fully recharged battery at the start of each day. JBLM will gain experience in this management as the PEV fleet grows.

\section{I.4 Motor Transport Branch Transport Vehicles Analysis}

Transport vehicles are typically light- or heavy-duty motor vehicles for use in cargo transportation and typically not for personnel transport. Transport missions can vary by agency, location, and jurisdiction and for Motor Transport Branch, the transport vehicles include pickup trucks, heavy-duty trucks, passenger vans, and cargo vans. Although there are currently no PEVs available to replace heavyduty trucks and passenger vans, it is assumed that the usage of all these transport vehicles can be of value in considering the remaining transport vehicles in the Motor Transport Branch fleet. The other vehicles may be replaced by currently available PEVs.

Incorporation of BEVs and/or PHEVs into the transport mission is a definite possibility. Transport vehicles used for shorter trips or outings qualify for BEV or PHEV replacement, while other transport vehicle activities that are associated with longer trips may require PHEV capabilities.

\section{I.4.1 Summary for Motor Transport Branch Transport Vehicles}

Appendix E provides the vehicle data sheets for each of the transport vehicles monitored. This section aggregates data for all transport vehicles. Table I-8 summarizes pool travel during the study period for those days in which the vehicle was driven. Vehicle use occurred primarily between 0600 and 1700 hours 
daily. They traveled 1,803 miles, logged 148 hours, and idled for 77 hours during the 63-day study period.

Table I-8. Pool vehicles travel summary.

\begin{tabular}{lcccc}
\hline \multicolumn{4}{c}{ Transport Vehicles Travel Summary } & \\
& $\begin{array}{c}\text { Per Day } \\
\text { Average/Peak }\end{array}$ & $\begin{array}{c}\text { Per Outing } \\
\text { Average/Peak }\end{array}$ & $\begin{array}{c}\text { Per Trip } \\
\text { Average/Peak }\end{array}$ & Total \\
\hline Travel Distance (Miles) & $53.0 / 393.8$ & $22.9 / 393.8$ & $6.5 / 142.5$ & 1,803 \\
Travel Time (Minutes) & $237.9 / 669.0$ & $102.5 / 673.0$ & $29.2 / 218.0$ & 8,090 \\
Idle Time (Minutes) & $136.6 / \mathrm{NA}$ & $58.8 / \mathrm{NA}$ & $16.8 / \mathrm{NA}$ & 4,643 \\
\hline
\end{tabular}

Figure I-14 shows the travel summary for transport vehicles: by vehicle, by daily mileage, and daily usage time. Figure I-15 shows the composite history for all transport vehicles. In these stacked bar charts, the contribution of each vehicle is indicated by a different color. Note that vehicles G71-0062G (logger 17), G71-0674A (logger 89), G43-25839 (logger 114), and G82-0509A (logger 118) failed to report sufficient data for analysis.

\section{I.4.2 Transport Vehicles Daily Summary}

The average travel distance per day when driven for transport vehicles is 53.0 miles. On $72 \%$ of vehicle travel days, the daily travel is less than the 70 miles considered to be within the BEV safe range (blue and green bars in Figure 31). That is, while BEV range can vary based on several factors; most BEVs provide at least 70 miles of vehicle range on a single battery charge. Meanwhile, $69 \%$ of vehicle travel days are less than 40 miles considered to be within the CD range of a PHEV (green bars of Figure $31)$.

Figure I-15 suggests that vehicles are used rather infrequently but it is noted that four of the six transport vehicles failed to provide sufficient data for analysis. This is most likely due to infrequent use because there were a few data points logged.

Figure I-16 displays the summary of use by time of day for all transport vehicles. Figure I-17 shows the outings for all vehicles.
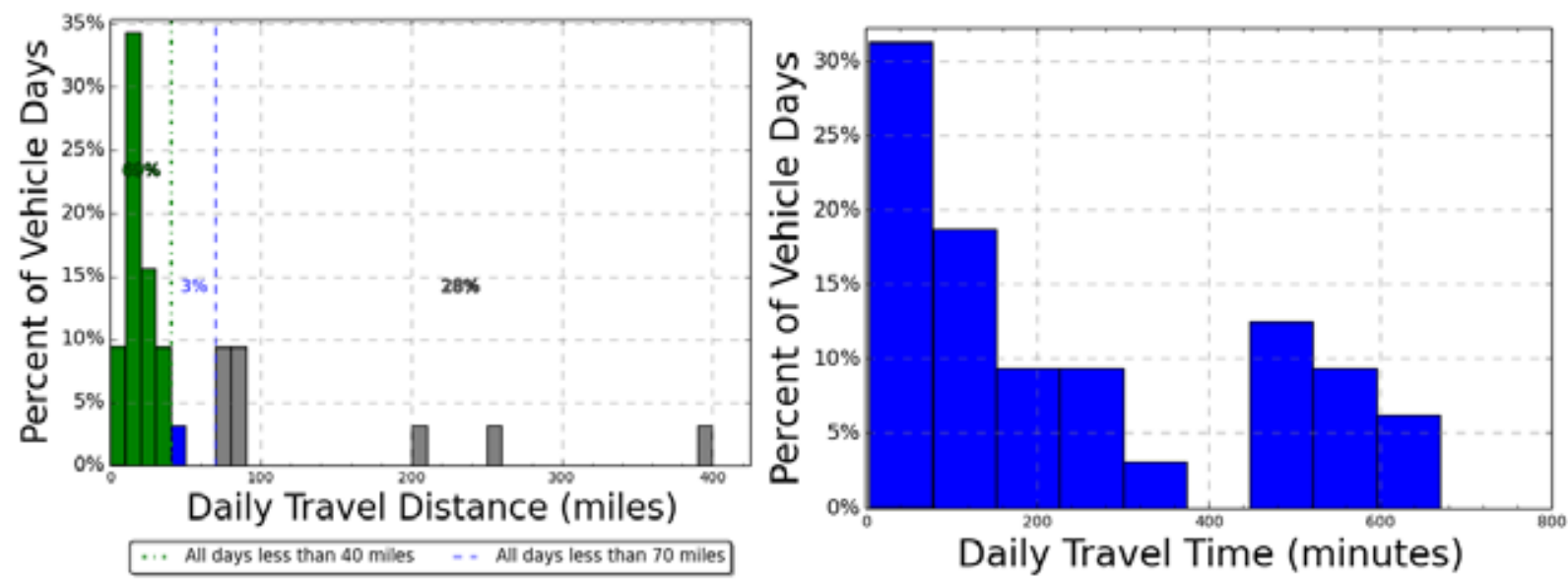

Figure I-14. Motor Transport Branch transport vehicle daily travel miles and time (all vehicles). 

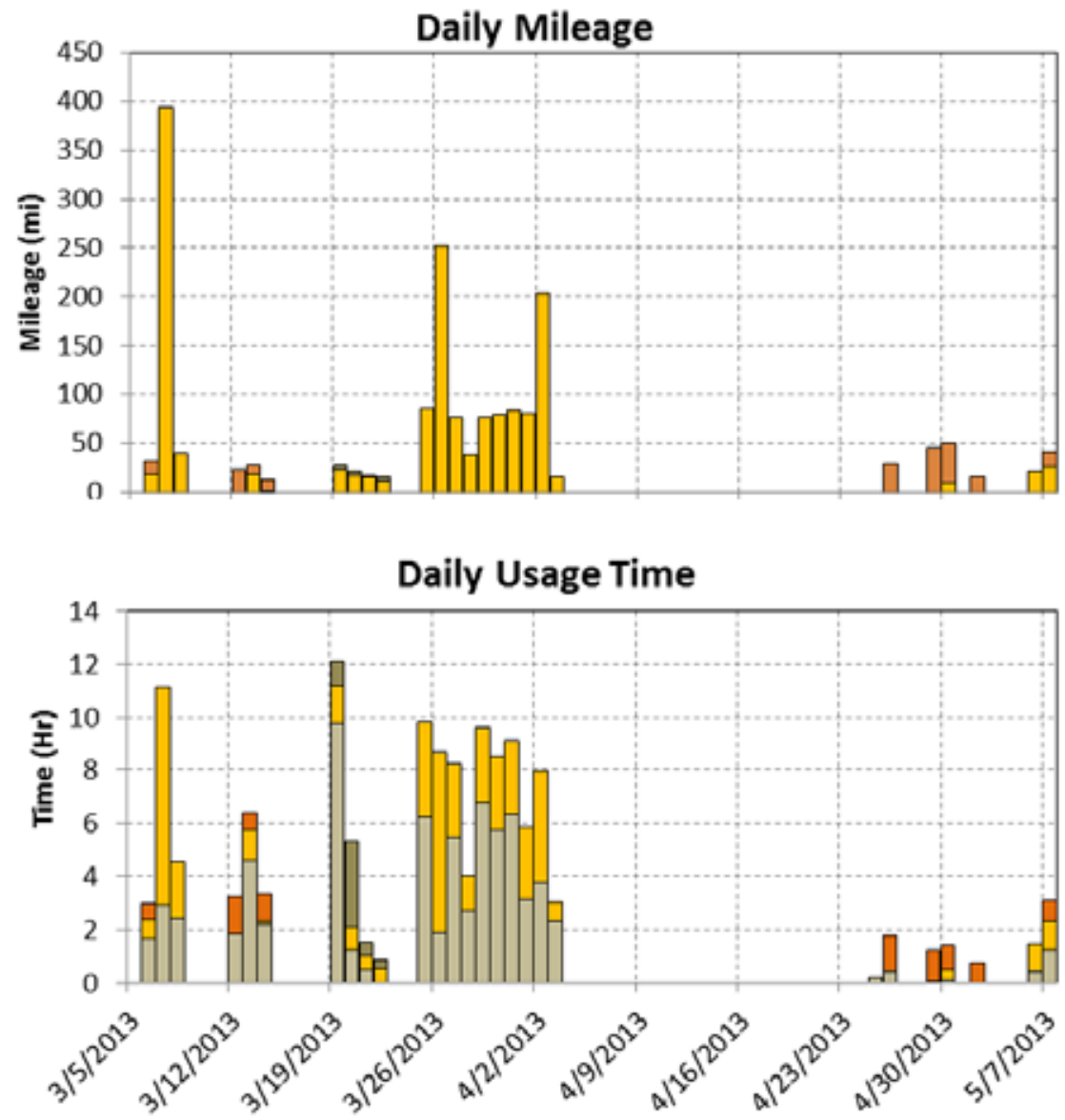

\section{口Total Idle घLog $17 \quad$ a Log $89 \square \log 111 \quad \square \log 114 \quad \square \log 118 \square \log 120$}

Figure I-15. Motor Transport Branch transport vehicles travel history (all vehicles).

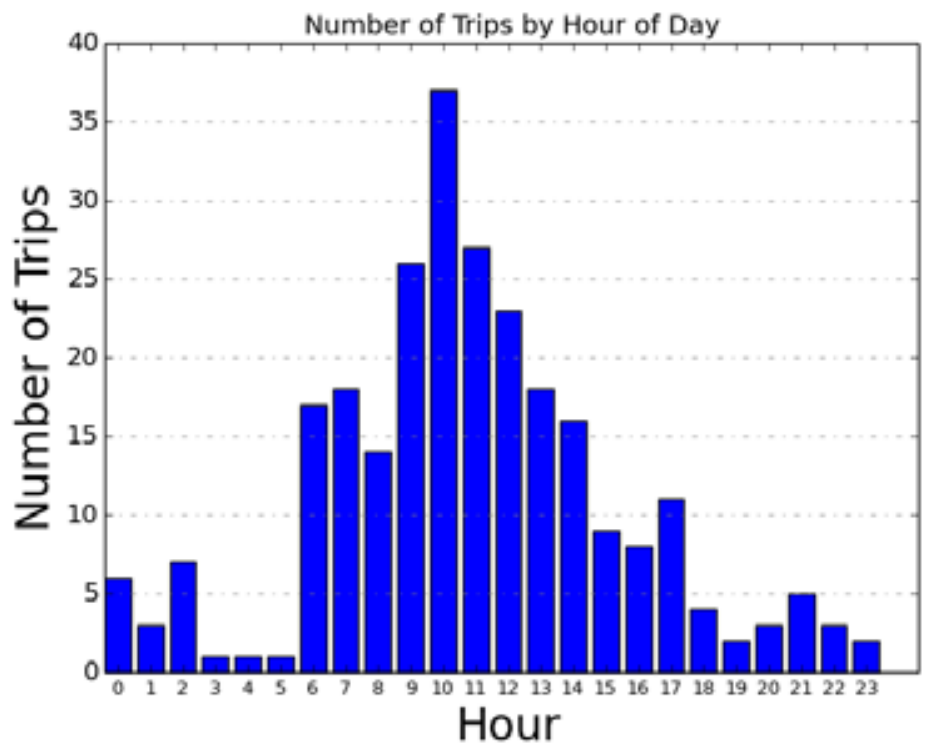

Figure I-16. Motor Transport Branch transport vehicles hourly usage. 


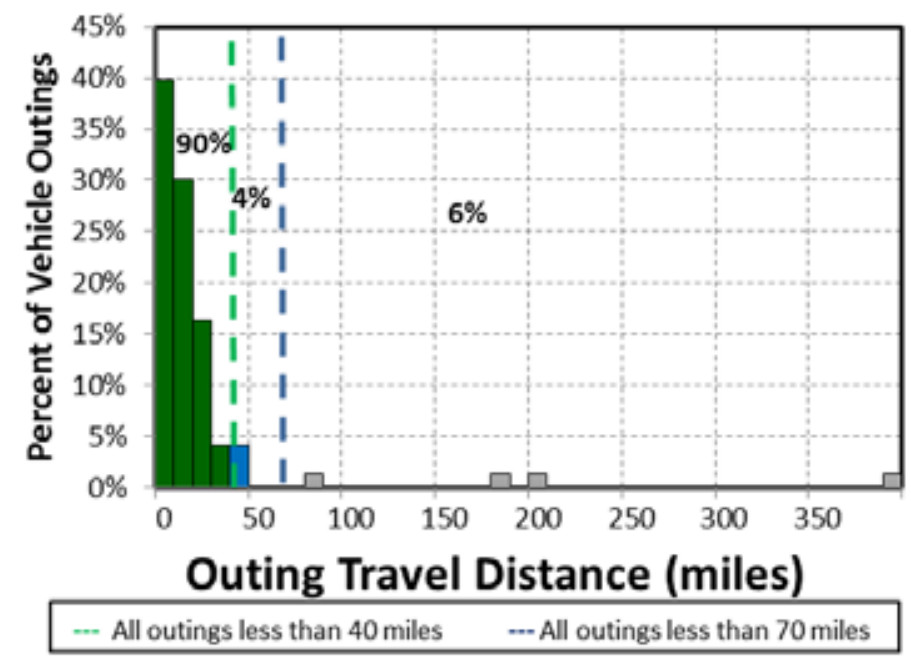

Figure I-17. Motor Transport Branch transport vehicle combined outings.

Appendix E provides the details of each of the transport vehicle's outings. Pickup truck \#111 (Vehicle G63-3881H) was used on the three longest outings noted above.

The average travel outing when driven for transport vehicles is 22.9 miles. Meanwhile, $90 \%$ percent of transport outings are less than 40 miles considered to be within the CD range of a PHEV.

\section{I.4.3. Motor Transport Branch Transport Vehicle Observations/Summary}

There appear to be three choices for JBLM in implementing PEVs into the Motor Transport Branch transport fleet. There are no current PEV replacements for heavy-duty trucks. However, the monitored Motor Transport Branch transport fleet does contain two conventional pickup trucks and two conventional cargo-vans for which suitable PEVs may be found. The observations here relate to these four vehicles monitored and to the balance of the transport fleet (Table I-1) assuming the travel of the monitored vehicles is typical.

As noted before, the optimum goal would be to incorporate as many BEVs as possible to realize the advantages of reduced petroleum usage and reduced emissions of GHG.

1. All BEV fleet: While some BEV manufacturers report vehicle range exceeding 70 miles, Intertek recommends careful evaluation of experienced range to ensure vehicle missions are accomplished. Nevertheless, assuming the 70-mile safe range for a BEV, an all-BEV fleet is not possible for transport vehicles due to the long distances experienced by some of these vehicles.

2. Mixed BEV/PHEV fleet: Certainly, PHEVs can accomplish the same mission as the current fleet when only considering travel times and distances. The data reveal that on $69 \%$ of all vehicle travel days, the total daily travel is less than 40 miles, which typically is the maximum distance a PHEV will travel in CD mode. This represents a significant operating cost savings opportunity while retaining the ability to go longer distances when needed. Furthermore, $90 \%$ of the outings are less than 40 miles and could be completed in CD mode if the battery is fully charged prior to the outing.

It is noted that $72 \%$ of all travel days and $94 \%$ of all outings are less than 70 miles. This would support travel by BEVs. For the days where the 70 miles are exceeded, intermediate charging locations typically provide the recharge necessary to increase the all-electric drive. There are significant quantities of public charging stations locally but they cannot be assured to be available when needed. Thus, consideration should be given to home base charging only. Additional charging during the day at the home base between outings would add daily range. Incorporation of BEVs into the fleet will require management attention to ensure appropriate deployment based upon the need and expected distance to be driven. 
3. All PHEV fleet: As noted above, PHEVs can accomplish the same mission as the current fleet when only considering travel times and distances. Replacing all current vehicles with PHEVs only requires an evaluation of the individual vehicle capabilities of currently available PHEVs to meet current transport requirements. Data show that for up to $69 \%$ of all travel days, the PHEV will operate in CD mode. As above, this represents a significant operating cost savings opportunity while retaining the ability to go longer distances when needed. Intermediate charging opportunities provide additional benefit, enhancing the pure-electric mode. Data show significant charging opportunities throughout the day during stop times.

While it would appear that PEVs are suitable replacements for these four transport vehicles, additional mission analysis and management input is required. The missions of these vehicles likely include considerations other than mileage, such as cargo demands placed on the vehicle. While the data show only $28 \%$ of daily travel requires the longer-range capabilities of a PHEV, fleet managers typically desire greater conservatism in maintaining vehicle capabilities. Thus, it is assumed that of the vehicles monitored, the two heavy-duty trucks remain ICE vehicles and the remaining 4conventional vehicles be replaced by two suitable styled BEV and two PHEVs. See Section 5 for these suggestions.

The total Motor Transport Branch transport fleet of 204 vehicles (Table I-1) then would retain the 73 conventional heavy-duty trucks and 16 conventional passenger vans with the balance consisting of 58 BEVs and 57 PHEVs.

The vehicle summary shows sufficient time for charging at the base location during the course of the day and additional opportunities at intermediate charging stations. These stations also provide charging opportunities for the visiting public, whose fees may assist in offsetting operating costs.

\section{I.4.4 Motor Transport Branch Transport Vehicle Charging Needs}

Upon review of these data, Intertek suggests replacement of the Motor Transport Branch transport fleet with 58 BEVs and 57 PHEVs is possible while retaining the heavy-duty trucks and passenger vans unchanged for now.

As noted previously, AC Level 2 overnight charging of BEVs is typical, whereas overnight charging of PHEVs uses the AC Level 1 outlet.

Intertek's experience suggests that each vehicle have an assigned charging location at their home base. Assigned stations require less management attention to ensure completion of overnight charging. BEVs and PHEV not assigned to these locations also benefit during visits to the location as part of their normal operation. The PHEVs can utilize the AC Level 2 EVSE at the home base during the day to increase the amount of vehicle miles traveled in EV Mode.

At times, fleet vehicles obtain benefit from using public charging infrastructure. Figure 18 displays the availability of public charging at the time of this writing for the JBLM area. This may be of benefit for local travel but availability of public EVSE cannot be assured and is not considered as part of this evaluation.

\section{I.5 Motor Transport Branch Vehicles Mileage}

The vehicle annual miles factor into the calculations for replacement of vehicles as noted in Section 5 and Appendix I. The actual miles measured during the study are extrapolated to identify calculated annual miles in the study. JBLM has also provided vehicle information that identifies the average monthly miles and vehicle mileage in April 2012. Table I-9 shows these values and calculations with the studyextrapolated miles in the far right column. 
Table I-9. Motor Transport Branch vehicle mileage.

\begin{tabular}{|c|c|c|c|c|c|c|}
\hline \multicolumn{7}{|c|}{ Vehicle Mileage } \\
\hline $\begin{array}{l}\text { Logger } \\
\text { No. }\end{array}$ & $\begin{array}{c}\text { Fleet Vehicle } \\
\text { Id }\end{array}$ & Year & Odometer & $\begin{array}{l}\text { Monthly } \\
\text { Miles }\end{array}$ & $\begin{array}{c}\text { Calculated } \\
\text { Annual Miles }\end{array}$ & $\begin{array}{c}\text { Study-Extrapolated } \\
\text { Miles }\end{array}$ \\
\hline 6 & G43-0875K & 2010 & 22,120 & 1,271 & 15,252 & 3,848 \\
\hline 7 & G41-1288A & 2004 & 14,988 & 57 & 684 & 699 \\
\hline 8 & G43-4937A & 2004 & 32,153 & 320 & 3,840 & 682 \\
\hline 9 & G10-7664F & 2008 & 13,532 & 118 & 1,416 & 904 \\
\hline 10 & G41-65991 & 2002 & 25,797 & 618 & 7,416 & 17,935 \\
\hline 11 & G11-2676G & 2008 & 36,779 & 641 & 7,692 & 1,092 \\
\hline 12 & G43-3717A & 2004 & 42,046 & 633 & 7,596 & 1,009 \\
\hline 13 & G11-0678K & 2010 & 6,142 & 511 & 6,132 & 4,129 \\
\hline 14 & G62-4526H & 2009 & 42,820 & 1,002 & 12,024 & 6,246 \\
\hline 15 & G42-0698K & 2011 & 24,958 & 8 & 96 & 23,110 \\
\hline 16 & G11-0493L & 2012 & 16,394 & 1,168 & 14,016 & 20,806 \\
\hline 17 & G71-0062G & 2008 & 8,825 & 157 & 1,884 & 9,160 \\
\hline 18 & G62-1094L & 2011 & 10,898 & 544 & 6,528 & 3,237 \\
\hline 19 & G41-1395G & 2008 & 17,133 & 304 & 3,648 & 1,287 \\
\hline 20 & G61-1155D & 2006 & 35,868 & 436 & 5,232 & 3,094 \\
\hline 81 & G10-2878L & 2011 & 8,387 & 484 & 5,808 & 4,331 \\
\hline 84 & G41-1100K & 2010 & 6,618 & 161 & 1,932 & 3,320 \\
\hline 85 & G62-0979G & 2008 & 33,544 & 329 & 3,948 & 6,474 \\
\hline 89 & G71-0674A & 2004 & 39,319 & 358 & 4,296 & 9,160 \\
\hline 93 & G41-1373G & 2008 & 53,689 & 917 & 11,004 & 22,879 \\
\hline 97 & G41-1367G & 2008 & 24,556 & 337 & 4,044 & 3,951 \\
\hline 101 & G43-0792K & 2010 & 30,768 & 963 & 11,556 & 9,173 \\
\hline 102 & G43-0801K & 2010 & 29,320 & 898 & 10,776 & 10,323 \\
\hline 104 & G42-0988F & 2007 & 39,860 & 758 & 9,096 & 13,870 \\
\hline 105 & G43-0860G & 2008 & 44,561 & 810 & 9,720 & 7,970 \\
\hline 106 & G43-1389K & 2010 & 21,661 & 730 & 8,760 & 18,648 \\
\hline 107 & G41-1180G & 2008 & 54,615 & 947 & 11,364 & 1,696 \\
\hline 108 & G11-2675G & 2008 & 6,079 & 106 & 1,272 & 926 \\
\hline 109 & G43-1191L & 2011 & 14,450 & 682 & 8,184 & 8,652 \\
\hline 110 & G12-0662H & 2010 & Not avail. & Not avail. & Not avail. & 10,701 \\
\hline 111 & G63-0271A & 2004 & 50,997 & 318 & 3,816 & 9,164 \\
\hline 112 & G41-1392G & 2008 & 33,655 & 556 & 6,672 & 4,876 \\
\hline 113 & G43-3881H & 2009 & 27,665 & 595 & 7,140 & 20,682 \\
\hline 114 & G43-25839 & 2003 & 25,189 & 401 & 4,812 & 9,160 \\
\hline 115 & G41-1376G & 2008 & 24,197 & 257 & 3,084 & 1,437 \\
\hline 116 & G41-1161G & 2008 & 8,333 & 143 & 1,716 & 1,877 \\
\hline 117 & G43-0790K & 2010 & 25,231 & 813 & 9,756 & NA \\
\hline 118 & G82-0509A & 2004 & 6,416 & 15 & 180 & NA \\
\hline 119 & G10-6379L & 2011 & 12,953 & 632 & 7,584 & 9,743 \\
\hline 120 & G42-3471A & 2005 & 27,858 & 269 & 3,228 & 1,170 \\
\hline
\end{tabular}


For the entire Motor Transport Branch fleet, the average monthly miles traveled are 527 miles for average annual travel of 6,328 miles. In general, there is good correlation between the JBLM provided averages and the study calculated annual mileage. The JBLM provided mileage information will be used in the calculations when available except for logger \#15 where the study information appears more reasonable. JBLM information shows extremely low utilization but this vehicle logged more time and miles than any other vehicle in the study. The vehicle data sheet for this vehicle in Appendix E identifies some data issues with respect to travel and idle time but miles recorded appear to be accurate.

\section{I.6 Public Works Group Vehicle Utilization}

Vehicle utilization is an important factor in the evaluation of vehicles both from an inventory perspective and for charging availability. Table I-10 identifies the percent utilization of the vehicle considering all days used during the study period. Since most travel occurred during weekdays, only the 45 weekdays in the 63-day study period are considered. In the event that the vehicle was used for more than these 45 days, the percent utilization is considered $100 \%$.

The average daily usage of each vehicle is identified in the Appendix E data sheets. It is also shown here for completeness.

In general, the vehicles are used on frequent days but average usage per day is quite low. For example, the average vehicle is used on two out of three days but only two hours, 20 minutes each day. As above, the pickup truck with logger 15 showed very high utilization. The vehicle data sheet in Appendix E identifies potential issues with the time data but mileage appeared to be correct.

\section{I.7 Motor Transport Branch Summary}

This study provides observations for both the vehicles monitored and for the entire non-tactical fleet of vehicles identified with the Motor Transport Branch. The study indicates that PEVs offer alternatives to vehicles in the existing provided that any specific cargo requirements may be met by the PEV. In general, a mixed fleet of BEVs and PHEVs is suggested.

The vehicles monitored in this study included eight sedans, five minivans, Three SUVs, six cargo vans, seven passenger vans, nine pickup trucks, and two heavy-duty trucks, all conventional ICE based. Based on the travel data, Intertek suggests that retaining the passenger vans and heavy-duty trucks and that replacing the remaining vehicles with 13 PHEVs and 18 BEVs would meet current mission requirements. Section 5 identifies potential replacement PEVs and Appendix M provides specific recommendations.

The Motor Transport Branch full fleet of vehicles contains 1060 vehicles. Intertek suggests retaining the 4 conventional specialty vehicles, 202 conventional passenger vans, 56 conventional buses, and 73 conventional heavy-duty trucks for now and also suggests a fleet of 409 BEVs and 316 PHEVs conservatively meets the balance of vehicle travel requirements.

With the potential replacement by PEVs established, Section 5 and Appendix I provide further evaluation of the benefits of such replacements. This will be factored into further observations and suggestions related to the business case and schedule for any replacements for the Motor Transport Branch. Those observations will be addressed in Task 4 of this project. 
Table I-10. Vehicle utilization.

\begin{tabular}{|c|c|c|c|c|c|}
\hline Logger & Vehicle & Mission & Vehicle Class & $\begin{array}{c}\text { Percent } \\
\text { Days Used }\end{array}$ & $\begin{array}{c}\text { Avg Daily Travel } \\
\text { Time (Hrs) }\end{array}$ \\
\hline 6 & G43-0875K & PL & Van-Cargo & $76 \%$ & 3.7 \\
\hline 7 & G41-1288A & PL & Pickup & $98 \%$ & 0.3 \\
\hline 8 & G43-4937A & $\mathrm{PL}$ & Van - Cargo & $20 \%$ & 1.4 \\
\hline 9 & G10-7664F & $\mathrm{PL}$ & jedan - Compac1 & $56 \%$ & 0.4 \\
\hline 10 & G41-65991 & PL & Pickup & $89 \%$ & 2.0 \\
\hline 11 & G11-2676G & PL & Sedan - Large & $33 \%$ & 0.7 \\
\hline 12 & G43-3717A & PL & Van - Cargo & $29 \%$ & 0.8 \\
\hline 13 & G11-0678K & SU & Sedan - Large & $87 \%$ & 1.0 \\
\hline 14 & G62-4526H & SU & SUV & $91 \%$ & 1.8 \\
\hline 15 & G42-0698K & SU & Pickup & $100 \%$ & 15.5 \\
\hline 16 & G11-0493L & SU & Sedan - Large & $100 \%$ & 7.9 \\
\hline 17 & G71-0062G & TR & Truck HD & No Data & No Data \\
\hline 18 & G62-1094L & SU & SUV & $67 \%$ & 0.8 \\
\hline 19 & G41-1395G & $\mathrm{PL}$ & Minivan & $82 \%$ & 0.4 \\
\hline 20 & G61-1155D & PL & SUV & $53 \%$ & 0.8 \\
\hline 81 & G10-2878L & PL & Sedan - Midsize & $82 \%$ & 1.9 \\
\hline 84 & G41-1100K & PL & Minivan & $62 \%$ & 0.7 \\
\hline 85 & G62-0979G & $\mathrm{PL}$ & Pickup & $73 \%$ & 1.6 \\
\hline 89 & G71-0674A & TR & Van-Cargo & No Data & No Data \\
\hline 93 & G41-1373G & SU & Pickup & $100 \%$ & 2.9 \\
\hline 97 & G41-1367G & $\mathrm{PL}$ & Pickup & $100 \%$ & 1.2 \\
\hline 101 & G43-0792K & $\mathrm{PL}$ & Van - Pass & $98 \%$ & 2.1 \\
\hline 102 & G43-0801K & $\mathrm{PL}$ & Van - Pass & $76 \%$ & 2.4 \\
\hline 104 & G42-0988F & SU & Van-Cargo & $89 \%$ & 3.1 \\
\hline 105 & G43-0860G & PL & Van - Pass & $91 \%$ & 2.3 \\
\hline 106 & G43-1389K & $\mathrm{PL}$ & Van - Pass & $76 \%$ & 3.0 \\
\hline 107 & G41-1180G & SU & Minivan & $36 \%$ & 0.7 \\
\hline 108 & G11-2675G & $\mathrm{PL}$ & Sedan - Large & $18 \%$ & 0.8 \\
\hline 109 & G43-1191L & PL & Van - Pass & $82 \%$ & 2.0 \\
\hline 110 & G12-0662H & PL & Sedan - Midsize & $60 \%$ & 1.6 \\
\hline 111 & G63-0271A & TR & Pickup & $49 \%$ & 5.2 \\
\hline 112 & G41-1392G & SU & Minivan & $44 \%$ & 1.8 \\
\hline 113 & G43-3881H & $\mathrm{PL}$ & Van - Pass & $76 \%$ & 4.3 \\
\hline 114 & G43-25839 & TR & Pickup & No Data & No Data \\
\hline 115 & G41-1376G & SU & Pickup & $67 \%$ & 0.5 \\
\hline 116 & G41-1161G & $\mathrm{PL}$ & Minivan & $64 \%$ & 0.7 \\
\hline 117 & G43-0790K & PL & Van - Pass & No Data & No Data \\
\hline 118 & G82-0509A & TR & Truck HD & No Data & No Data \\
\hline 119 & G10-6379L & SU & Sedan - Midsize & $42 \%$ & 2.1 \\
\hline 120 & G42-3471A & TR & Van - Cargo & $22 \%$ & 1.7 \\
\hline & & & Average & $68 \%$ & 2.3 \\
\hline
\end{tabular}




\section{Appendix J}

\section{Greenhouse Gas Emissions Avoided and fuel Cost Reduction Analysis $-6^{\text {th }}$ MP Group}

\section{J.1 Replacement PEVs for $6^{\text {th }}$ MP Group}

Section 4.1 provided the analysis results for the $6^{\text {th }}$ MP Group vehicles monitored during the study period based upon the data recorded and reported in the vehicle data sheets found in Appendix B. The pool vehicles in this study included one SUV, one minivan, and one pickup truck. Section 3 identifies PEVs currently or soon to be available as potential replacements. For the study, PEV replacements are based upon vehicle class. The observations of Section 4.1.2.3 suggest that replacing these three vehicles with one PHEV and two BEVs would meet current mission requirements. Specific vehicle cargo requirements have not been specified and thus were not considered in these replacement suggestions.

Table J-3. JBLM $6^{\text {th }}$ MP Group PEV replacements.

\begin{tabular}{ccccccc} 
& \multicolumn{5}{c}{ Vehicle Replacements } \\
Logger No. & Make & Model & EPA Class & PEV Make & PEV Model & Mission \\
\hline 82 & GMC & Terrain & SUV & Toyota & RAV4 EV & Pool \\
86 & Ford & Ranger & Pickup Truck & Via Motors & VTRUX PU & Pool \\
103 & Dodge & Grand Caravan & Minivan & Nissan & Leaf & Pool \\
\hline
\end{tabular}

Section 5 provides the methodology and assumptions for the calculations for the reduction in GHG and fuel costs. The miles recorded by vehicles during the 63-day study are extrapolated into annual miles. If the PEV replacing the monitored vehicle is a BEV, all annual miles can potentially occur in CD mode. If the PEV is a PHEV, the percentage of miles that are less than 40 miles per day recorded by the monitored vehicles (Appendix B) is multiplied by the annual miles to identify miles in CD mode. Only these miles are used in the reduction calculations. This is conservative because the replacement PHEV is likely more fuel efficient than the monitored vehicle when powered by the ICE.

\section{J.2 Monitored Vehicle Fuel Cost Reduction}

Table J-2 identifies the calculated miles in CD mode for each replacement vehicle as well as the projected fuel cost reductions. As noted in Section 5, both the local cost of fuel and the national average are used for comparisons.

Because Washington State fuel costs are higher than the national average, gasoline costs locally are greater than national figures. Also, because Tacoma Power relies more on cheaper hydroelectric power than the average of all national power providers, electrical fuel costs in Washington State are lower.

Section 5 summarizes these values.

An example calculation for logger 86 follows: The JBLM reported annual miles for this vehicle is 2,388 miles. The suggested replacement PEV is a PHEV. The Appendix B daily travel percentage for this vehicle less than 40 miles is $92 \%$ so annual miles CD mode is 2,197 miles. EPA fuel economy for this vehicle is 23 MPG implying 96 gallons of gasoline are unused. Washington State cost for gasoline is $\$ 4.009 /$ gallon for an annual cost of $\$ 383$. The replacement PEV requires $475 \mathrm{Wh} / \mathrm{mi}$ so $1,044 \mathrm{kWh}$ are required for recharging the battery. Local power cost is $\$ 0.02783 / \mathrm{kWh}$, resulting in annual electric cost of $\$ 29$. The savings are $\$ 354$ for a $92 \%$ reduction in fuel cost. 
Table J-4. Monitored vehicle replacement fuel cost reduction (Washington State and nationally).

\begin{tabular}{|c|c|c|c|c|c|c|c|c|c|c|c|c|}
\hline Logger & Vehicle & $\begin{array}{c}\text { Replaceme } \\
\text { nt PEV }\end{array}$ & $\begin{array}{c}\% \text { of } \\
\text { Travel CD } \\
\text { Mode }\end{array}$ & $\begin{array}{l}\text { Annual } \\
\text { Miles CD }\end{array}$ & $\begin{array}{c}\text { Gas } \\
\text { Gallons } \\
\text { Saved }\end{array}$ & $\begin{array}{r}\text { Ann } \\
\text { Co }\end{array}$ & $\begin{array}{l}\text { ual Gas } \\
\text { st WA }\end{array}$ & & $\begin{array}{l}\text { ual } \\
\text { Fuel } \\
\text { WA }\end{array}$ & & $\begin{array}{l}\text { nual } \\
\text { uel } \\
\text { ng WA }\end{array}$ & $\begin{array}{c}\text { Annual Fuel } \\
\text { Red WA \% }\end{array}$ \\
\hline 82 & G61-0546L & Rav4 & $100 \%$ & 7,392 & 389 & $\$$ & 1,560 & $\$$ & 91 & $\$$ & 1,469 & $94 \%$ \\
\hline 86 & G61-0689A & VTRUX PU & $92 \%$ & 2,197 & 96 & $\$$ & 383 & $\$$ & 29 & $\$$ & 354 & $92 \%$ \\
\hline 103 & G41-5433B & Leaf & $100 \%$ & 7,476 & 374 & $\$$ & 1,499 & $\$$ & 62 & $\$$ & 1,436 & $96 \%$ \\
\hline \multicolumn{4}{|l|}{ Total } & 17,065 & 859 & $\$$ & 3,442 & $\$$ & 182 & $\$$ & 3,259 & $95 \%$ \\
\hline
\end{tabular}

\begin{tabular}{|c|c|c|c|c|c|c|c|c|c|c|c|c|}
\hline Logger & Vehicle & $\begin{array}{c}\text { Replaceme } \\
\text { nt PEV }\end{array}$ & $\begin{array}{c}\% \text { of } \\
\text { Travel CD } \\
\text { Mode }\end{array}$ & $\begin{array}{c}\text { Annual } \\
\text { Miles CD }\end{array}$ & $\begin{array}{c}\text { Gas } \\
\text { Gallons } \\
\text { Saved }\end{array}$ & & $\begin{array}{l}\text { inual } \\
\text { Cost } \\
\text { ional }\end{array}$ & & $\begin{array}{l}\text { ual } \\
\text { Fuel } \\
\text { Nat }\end{array}$ & & $\begin{array}{l}\text { inual } \\
\text { uel } \\
\text { igs Nat }\end{array}$ & $\begin{array}{c}\text { Annual Fuel } \\
\text { Red Nat \% }\end{array}$ \\
\hline 82 & G61-0546L & Rav4 & $100 \%$ & 7392 & 389 & $\$$ & 1,431 & $\$$ & 423 & $\$$ & 1,008 & $70 \%$ \\
\hline 86 & G61-0689A & VTRUX PU & $92 \%$ & 2197 & 96 & $\$$ & 351 & $\$$ & 136 & $\$$ & 216 & $61 \%$ \\
\hline 103 & G41-5433B & Leaf & $100 \%$ & 7476 & 374 & $\$$ & 1,375 & $\$$ & 292 & $\$$ & 1,084 & $79 \%$ \\
\hline \multicolumn{4}{|l|}{ Total } & 17,065 & 859 & $\$$ & 3,157 & $\$$ & 851 & $\$$ & 2,308 & $73 \%$ \\
\hline
\end{tabular}

\section{J.3 Monitored Vehicle GHG Reduction}

Table J-3 identifies the reduction in GHG projected when replacing the current vehicles with PEVs. The calculated miles in CD mode are also used in the calculation of GHG reduction. As noted in Section 5 , the emissions from burning gasoline is known and the emissions from the use of electricity is dependent upon the power generation mix that is used to recharge the PEV battery. As before, both the local power production emission figures and the national average are used for comparisons.

Because Tacoma Power relies more on cleaner hydroelectric power than the average of all national power providers, electrical emissions in Washington State are lower. Electrical emissions are significantly lower than gasoline emissions.

Table J-5. Monitored vehicle replacement GHG reduction (Washington State and nationally).

\begin{tabular}{|c|c|c|l|r|r|r|r|}
\hline Logger & Vehicle & Vehicle Class & $\begin{array}{c}\text { Replaceme } \\
\text { nt PEV }\end{array}$ & $\begin{array}{c}\text { Annual GHG } \\
\text { Emission ICE } \\
\text { Ib-CO2e }\end{array}$ & $\begin{array}{c}\text { Annual PEV } \\
\text { GHG WA } \\
\text { Ib-CO2e }\end{array}$ & $\begin{array}{c}\text { Annual PEV } \\
\text { GHG Sav WA } \\
\text { lb-CO2e }\end{array}$ & $\begin{array}{c}\text { Annual GHG } \\
\text { Reduction } \\
\text { WA \% }\end{array}$ \\
\hline 82 & G61-0546L & SUV & Rav4 & 7,820 & 567 & 7,253 & $93 \%$ \\
86 & G61-0689A & Pickup & VTRUX PU & 1,920 & 182 & 1,738 & $91 \%$ \\
103 & G41-5433B & Minivan & Leaf & 7,513 & 391 & 7,122 & $95 \%$ \\
\hline \multicolumn{1}{l|}{ Total } & 17,253 & 1,140 & 16,113 & $93 \%$ \\
\hline
\end{tabular}

\begin{tabular}{|c|c|c|l|r|r|r|r|}
\hline Logger & Vehicle & Vehicle Class & $\begin{array}{c}\text { Replaceme } \\
\text { nt PEV }\end{array}$ & $\begin{array}{c}\text { Annual GHG } \\
\text { Emission ICE } \\
\text { lb-CO2e }\end{array}$ & $\begin{array}{c}\text { Annual PEV } \\
\text { GHG Nat } \\
\text { lb-CO2e }\end{array}$ & $\begin{array}{c}\text { Annual PEV } \\
\text { GHG Sav Nat } \\
\text { lb-CO2e }\end{array}$ & $\begin{array}{c}\text { Annual GHG } \\
\text { Reduction } \\
\text { National \% }\end{array}$ \\
\hline 82 & G61-0546L & SUV & Rav4 & 7,820 & 4,976 & 2,844 & $36 \%$ \\
86 & G61-0689A & Pickup & VTRUX PU & 1,920 & 1,597 & 323 & $17 \%$ \\
103 & G41-5433B & Minivan & Leaf & 7,513 & 3,432 & 4,082 & $54 \%$ \\
\hline \multicolumn{7}{|l|}{ Total }
\end{tabular}

An example calculation for logger 86 follows: As shown above, the annual miles CD mode is 2,388 miles and 95.5 gallons of gasoline are unused. Internal combustion vehicles produce $20.1 \mathrm{lb}-\mathrm{CO} 2 \mathrm{e} /$ gallon so the annual emissions for the monitored vehicle are 1,920 lb-CO2e. Tacoma Power produces $0.1743 \mathrm{lb}-$ $\mathrm{CO} 2 \mathrm{e} / \mathrm{kWh}$. As above, $1,044 \mathrm{kWh}$ are required for recharging the battery, resulting in $182 \mathrm{lb}-\mathrm{CO} 2 \mathrm{e}$. The savings are 1,738 lb-CO2e for a 91\% reduction in GHG emission. 


\section{J.4 $6^{\text {th }}$ MP Group full Fleet Evaluation}

Table 8 in Section 4.1.1 identifies 20 vehicles in the $6^{\text {th }}$ MP Group fleet. Aside from the passenger van for which no PEV replacement is currently available, Intertek suggests a fleet of 12 BEVs and seven PHEVs conservatively meet vehicle travel requirements.

4 Nissan Leafs, 4 RAV4 EVs and 4 Ford Focus Electric vehicles are assumed to be appropriate BEVs and 2 Mitsubishi Outlander PHEVs, 1 Chevrolet Volt and 4 Via Motors VTRUX pickups are assumed to be appropriate PHEV replacements.

Using averages for these vehicles, the potential replacements offer the fuel cost reductions and GHG reductions shown in Table J-4 below and summarized in Section 5.

Table J-6. $6^{\text {th }}$ MP Group full fleet PEV replacement reductions (fuel cost and GHG emissions).

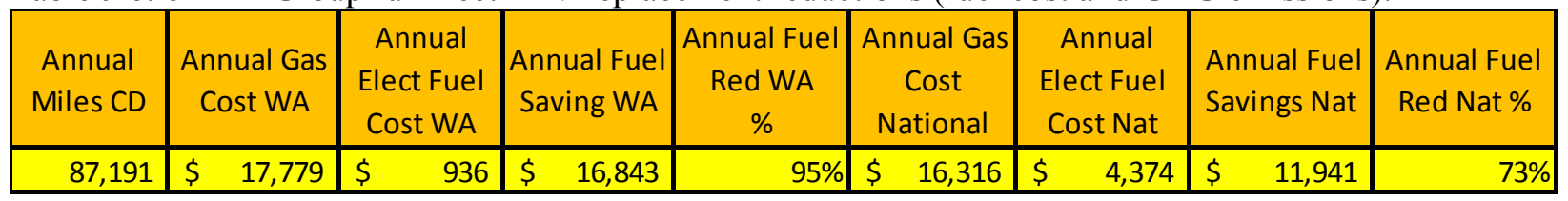

\begin{tabular}{|r|r|r|r|r|r|r|r|}
\hline $\begin{array}{c}\text { Annual } \\
\text { Miles CD }\end{array}$ & $\begin{array}{c}\text { Annual GHG } \\
\text { Emission } \\
\text { ICE Ib-CO2e }\end{array}$ & $\begin{array}{c}\text { Annual PEV } \\
\text { GHG WA } \\
\text { Ib-CO2e }\end{array}$ & $\begin{array}{c}\text { Annual PEV } \\
\text { GHG Sav } \\
\text { WA Ib-CO2e }\end{array}$ & $\begin{array}{c}\text { Annual GHG } \\
\text { Reduction } \\
\text { WA \% }\end{array}$ & $\begin{array}{c}\text { Annual PEV } \\
\text { GHG Nat } \\
\text { lb-CO2e }\end{array}$ & $\begin{array}{c}\text { Annual PEV } \\
\text { GHG Sav Nat } \\
\text { Ib-CO2e }\end{array}$ & $\begin{array}{c}\text { Annual GHG } \\
\text { Reduction } \\
\text { Nat \% }\end{array}$ \\
\hline 87,191 & 58,658 & 3,995 & 54,663 & $93 \%$ & 35,065 & 23,593 & $40 \%$ \\
\hline
\end{tabular}

\section{J.5 $6^{\text {th }}$ MP Group Summary}

Table J-5 provides the average values for all monitored vehicles belonging to the 6th MP Group.

Table J-7. $6^{\text {th }}$ MP Group monitored vehicles average values.

\begin{tabular}{|c|c|c|c|c|c|c|c|c|c|c|}
\hline $\begin{array}{c}\text { Average } \\
\text { Logged } \\
\text { Vehicles }\end{array}$ & $\begin{array}{l}\text { Annual } \\
\text { Miles CD }\end{array}$ & $\begin{array}{c}\text { Gas } \\
\text { Gallons } \\
\text { Saved }\end{array}$ & \multicolumn{2}{|c|}{$\begin{array}{c}\text { Annual Gas } \\
\text { Cost WA }\end{array}$} & \multicolumn{2}{|c|}{$\begin{array}{c}\text { Annual } \\
\text { Elect Fuel } \\
\text { Cost WA }\end{array}$} & \multicolumn{2}{|c|}{$\begin{array}{c}\text { Annual } \\
\text { Fuel } \\
\text { Saving WA }\end{array}$} & \multicolumn{2}{|c|}{$\begin{array}{c}\text { Annual Fuel } \\
\text { Red WA \% }\end{array}$} \\
\hline & 5,688 & 286 & $\$$ & 1,147 & $\$$ & 61 & $\$$ & 1,086 & & $95 \%$ \\
\hline & $\begin{array}{l}\text { verage } \\
\text { ogged } \\
\text { ehicles }\end{array}$ & $\begin{array}{c}\text { Annual G } \\
\text { Emission } \\
\text { lb-CO2 }\end{array}$ & & $\begin{array}{r}\text { Annual } \\
\text { GHG V } \\
\text { lb-CO }\end{array}$ & & $\begin{array}{r}\text { Annua } \\
\text { GHG Sa } \\
\text { lb-CC }\end{array}$ & $\begin{array}{l}\text { I PEV } \\
\text { v WA } \\
2 \mathrm{e}\end{array}$ & $\begin{array}{r}\text { Ann } \\
\text { Red } \\
W\end{array}$ & $\begin{array}{l}\text { GHG } \\
\text { ction } \\
\%\end{array}$ & \\
\hline & & 5, & 751 & & 380 & & 5,371 & & $93 \%$ & \\
\hline
\end{tabular}

Table J-5 shows that there is a significant opportunity for savings not only in fuel costs but also in GHG emissions with the deployment of PEVs in this fleet. 


\section{Appendix K}

\section{Greenhouse Gas Emissions Avoided and fuel Cost Reduction Analysis - DCA Support Group}

\section{K.1 Replacement PEVs for DCA Support Group}

Section 4.2 provided the analysis results for the DCA Support Group vehicles monitored during the study period based upon the data recorded and reported in the vehicle data sheets found in Appendix C. Both pool and support missions are identified for these vehicles.

The vehicles in this study included one pickup truck, one heavy-duty pickup truck, one passenger van and one cargo van. Section 3 identifies PEVs currently or soon to be available as potential replacements. There are currently no PEV replacement suggestions for heavy-duty pickup trucks or passenger vans. However, as noted in Section 4.2.1.3, the results for the HD truck can apply for other vehicles in the fleet so a replacement PHEV cargo van is suggested. For the study, PEV replacements are based upon vehicle class. The observations of Section 4.2.1.3 suggest that replacing these three vehicles with two PHEVs and one BEV would meet current mission requirements. Specific vehicle cargo requirements have not been specified and thus were not considered in these replacement suggestions.

Section 5 provides the methodology and assumptions for the calculations for the reduction in GHG and fuel costs. The miles recorded by vehicles during the 63-day study are extrapolated into annual miles. If the PEV replacing the monitored vehicle is a BEV, all annual miles are powered from the battery. If the $\mathrm{PEV}$ is a PHEV, the percentage of miles that are less than 40 miles per day recorded by the monitored vehicles (Appendix C) is multiplied by the annual miles to identify miles in CD mode. Only these miles are used in the reduction calculations. This is conservative because the replacement PHEV is likely more fuel efficient than the monitored vehicle when powered by the ICE.

Table K-8. JBLM DCA Support Group PEV replacements.

\begin{tabular}{ccccccc}
\multicolumn{7}{c}{ Current Vehicle } \\
$\begin{array}{c}\text { Logger } \\
\text { No. }\end{array}$ & Make & Model & EPA Class & PEV Make & PEV Model & Mission \\
\hline 83 & Ford & Ranger & Pickup Truck & Via Motors & VTRUX PU & Support \\
94 & Chevrolet & C6500 Stake & Pickup HD & Via Motors & VTRUX Van & Pool \\
96 & Chevrolet & 15 Pas Van & Passenger Van & NA & NA & Support \\
99 & Chevrolet & G1300 & Cargo Van & Nissan & eNV200 & Pool \\
\hline
\end{tabular}

\section{K.2 Monitored Pool Mission Vehicle Reductions}

\section{K.2.1 Monitored Pool Mission Vehicle Fuel Cost Reduction}

Table K-2 identifies the calculated miles in CD mode for each replacement vehicle as well as the projected fuel cost reductions for the pool vehicles. As noted in Section 5, both the local cost of fuel and the national average are used for comparisons.

Because Washington State fuel costs are higher than the national average, gasoline costs locally are greater than national figures. Also, because Tacoma Power relies more on cheaper hydroelectric power than the average of all national power providers, electrical fuel costs in Washington State are lower. 
Table K-9. Monitored pool vehicle replacement fuel cost reduction (Washington State and nationally).

\begin{tabular}{|c|c|c|c|c|c|c|c|c|c|}
\hline Logger & Vehicle & $\begin{array}{c}\text { Replaceme } \\
\text { nt PEV }\end{array}$ & $\begin{array}{c}\% \text { of } \\
\text { Travel CD } \\
\text { Mode }\end{array}$ & $\begin{array}{l}\text { Annual } \\
\text { Miles CD }\end{array}$ & $\begin{array}{c}\text { Gas } \\
\text { Gallons } \\
\text { Saved }\end{array}$ & $\begin{array}{c}\text { Annual Gas } \\
\text { Cost WA }\end{array}$ & $\begin{array}{c}\text { Annual } \\
\text { Elect Fuel } \\
\text { Cost WA }\end{array}$ & $\begin{array}{c}\text { Annual } \\
\text { Fuel } \\
\text { Saving WA }\end{array}$ & $\begin{array}{c}\text { Annual Fuel } \\
\text { Red WA \% }\end{array}$ \\
\hline 94 & G71-0684A & VTRUX Van & $100 \%$ & 1,440 & 103 & 412 & 19 & $\$ \quad 393$ & $95 \%$ \\
\hline 99 & G42-0289G & eNV200 & $100 \%$ & 1,836 & 131 & 525 & 20 & 505 & $96 \%$ \\
\hline \multicolumn{4}{|l|}{ Total } & 3,276 & 234 & 937 & 39 & 898 & $96 \%$ \\
\hline
\end{tabular}

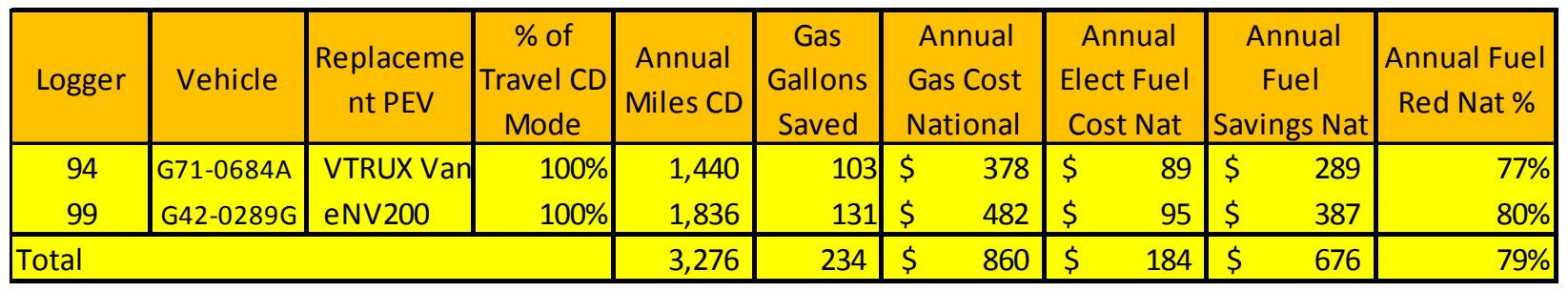

Section 5 summarizes these values.

An example calculation for logger 94 follows: The JBLM reported annual miles for this vehicle is 1,440 miles. The suggested replacement PEV is a PHEV. The Appendix C daily travel percentage for this vehicle less than 40 miles is $100 \%$ so annual miles CD mode is 1,440 miles. EPA fuel economy for this vehicle is 14 MPG implying 102.9 gallons of gasoline are unused. Washington State cost for gasoline is $\$ 4.009 /$ gallon for an annual cost of $\$ 412.35$. The replacement PEV requires $475 \mathrm{Wh} / \mathrm{mi}$ so $684 \mathrm{kWh}$ are required for recharging the battery. Local power cost is $\$ 0.02783 / \mathrm{kWh}$, resulting in annual electric cost of $\$ 19$. The savings are $\$ 393$ for a $95 \%$ reduction in fuel cost.

\section{K.2.2 Monitored Pool Mission Vehicle GHG Reduction}

Table K-3 identifies the reduction in GHG projected when replacing the current pool vehicles with PEVs. The calculated miles in CD mode are also used in the calculation of GHG reduction. As noted in Section 5, the emissions from burning gasoline is known and the emissions from the use of electricity is dependent upon the power generation mix that is used to recharge the PEV battery. As before, both the local power production emission figures and the national average are used for comparisons.

Because Tacoma Power relies more on cleaner hydroelectric power than the average of all national power providers, electrical emissions in Washington State are lower. Electrical emissions are significantly lower than gasoline emissions.

Table K-10. Monitored vehicle replacement GHG reduction (Washington State and nationally).

\begin{tabular}{|c|c|c|c|c|c|c|c|}
\hline Logger & Vehicle & Vehicle Class & $\begin{array}{c}\text { Replaceme } \\
\text { nt PEV }\end{array}$ & $\begin{array}{c}\text { Annual GHG } \\
\text { Emission ICE } \\
\text { Ib-CO2e }\end{array}$ & $\begin{array}{c}\text { Annual PEV } \\
\text { GHG WA } \\
\text { Ib-CO2e }\end{array}$ & $\begin{array}{c}\text { Annual PEV } \\
\text { GHG Sav WA } \\
\text { lb-CO2e }\end{array}$ & $\begin{array}{c}\text { Annual GHG } \\
\text { Reduction } \\
\text { WA \% }\end{array}$ \\
\hline 94 & G71-0684A & Truck HD & VTRUX Van & 2,067 & 119 & 1,948 & $94 \%$ \\
\hline 99 & G42-0289G & Van - Cargo & eNV200 & 2,636 & 128 & 2,508 & $95 \%$ \\
\hline \multicolumn{4}{|l|}{ Total } & 4,703 & 247 & 4,456 & $95 \%$ \\
\hline
\end{tabular}

\begin{tabular}{|c|c|c|c|c|c|c|c|}
\hline Logger & Vehicle & Vehicle Class & $\begin{array}{c}\text { Replaceme } \\
\text { nt PEV }\end{array}$ & $\begin{array}{c}\text { Annual GHG } \\
\text { Emission ICE } \\
\text { lb-CO2e }\end{array}$ & $\begin{array}{c}\text { Annual PEV } \\
\text { GHG Nat } \\
\text { lb-CO2e } \\
\end{array}$ & $\begin{array}{c}\text { Annual PEV } \\
\text { GHG Sav Nat } \\
\text { lb-CO2e }\end{array}$ & $\begin{array}{c}\text { Annual GHG } \\
\text { Reduction } \\
\text { Nat } \% \\
\end{array}$ \\
\hline 94 & G71-0684A & Truck HD & VTRUX Van & 2,067 & 1,046 & 1,021 & $49 \%$ \\
\hline 99 & G42-0289G & Van-Cargo & eNV200 & 2,636 & 1,124 & 1,512 & $57 \%$ \\
\hline \multicolumn{4}{|l|}{ Total } & 4,703 & 2,170 & 2,533 & $54 \%$ \\
\hline
\end{tabular}

Section 5 summarizes these figures. 
An example calculation for logger 94 follows: As shown above, the annual miles CD mode is 1,440 miles and 102.9 gallons of gasoline are unused. Internal combustion vehicles produce $20.1 \mathrm{lb}$ $\mathrm{CO} 2 \mathrm{e} /$ gallon so the annual emissions for the monitored vehicle are 2,067 lb-CO2e. Tacoma Power produces $0.1743 \mathrm{lb}-\mathrm{CO} 2 \mathrm{e} / \mathrm{kWh}$. As above, $684 \mathrm{kWh}$ are required for recharging the battery, resulting in $119 \mathrm{lb}-\mathrm{CO} 2 \mathrm{e}$. The savings are 1,948 lb-CO2e for a 94\% reduction in GHG emission.

\section{K.2.3 DCA Support Group full Pool Mission Fleet Evaluation}

Table 12 in Section 4.2 identifies 12 vehicles in the DCA support Group pool fleet. Aside from the passenger vans, heavy-duty trucks and the bus for which no PEV replacement is currently available, Intertek suggests a fleet of four BEVs and two PHEVs conservatively meet the other vehicle travel requirements.

Two RAV4 EVs and two eNV200s are assumed to be appropriate BEVs while one Via Motors VTRUX pickup and one VTRUX Van are assumed to be appropriate PHEV replacements.

Using averages for these vehicles, the potential replacements offer the fuel cost reductions and GHG reductions shown in Table K-4 below.

Table K-11. DCA Support Group full pool fleet PEV replacement reductions (fuel cost and GHG emissions).

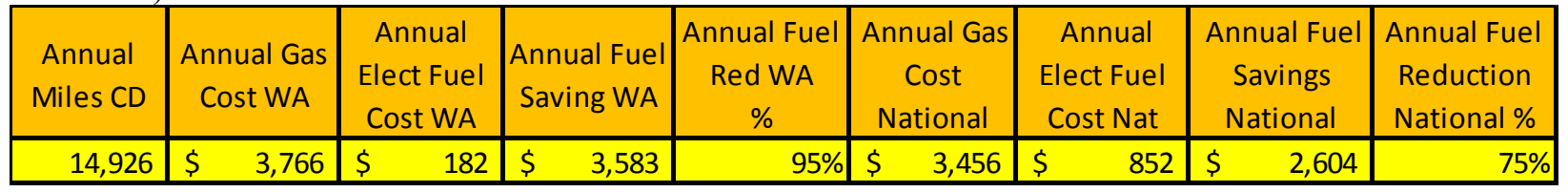

\begin{tabular}{|r|r|r|r|r|r|r|r|}
\hline $\begin{array}{c}\text { Annual } \\
\text { Miles CD }\end{array}$ & $\begin{array}{c}\text { Annual GHG } \\
\text { Emission } \\
\text { ICE Ib-CO2e }\end{array}$ & $\begin{array}{c}\text { Annual PEV } \\
\text { GHG WA } \\
\text { Ib-CO2e }\end{array}$ & $\begin{array}{c}\text { Annual PEV } \\
\text { GHG Sav } \\
\text { WA Ib-CO2e }\end{array}$ & $\begin{array}{c}\text { Annual GHG } \\
\text { Reduction } \\
\text { WA } \%\end{array}$ & $\begin{array}{c}\text { Annual PEV } \\
\text { GHG Nat } \\
\text { Ib-CO2e }\end{array}$ & $\begin{array}{c}\text { Annual PEV } \\
\text { GHG Sav Nat } \\
\text { Ib-CO2e }\end{array}$ & $\begin{array}{c}\text { Annual GHG } \\
\text { Reduction } \\
\text { Nat \% }\end{array}$ \\
\hline 14,926 & 18,880 & 1,142 & 17,738 & $94 \%$ & 10,024 & 8,856 & $47 \%$ \\
\hline
\end{tabular}

Section 5 also summarizes these values.

\section{K.3 Monitored Support Mission Vehicle Reductions}

\section{K.3.1 Monitored Support Mission Vehicle Fuel Cost Reduction}

Table K-5 identifies the calculated miles in CD mode for each replacement vehicle as well as the projected fuel cost reductions for the support vehicles.

As before, because Washington State fuel costs are higher than the national average, gasoline costs locally are greater than national figures. Also, because Tacoma Power relies more on cheaper hydroelectric power than the average of all national power providers, electrical fuel costs in Washington State are lower. 
Table K-12. Monitored support vehicle replacement fuel cost reduction (Washington State and nationally).

\begin{tabular}{|c|c|c|c|c|c|c|c|c|c|c|c|c|}
\hline Logger & Vehicle & $\begin{array}{c}\text { Replaceme } \\
\text { nt PEV }\end{array}$ & $\begin{array}{c}\% \text { of } \\
\text { Travel CD } \\
\text { Mode }\end{array}$ & $\begin{array}{c}\text { Annual } \\
\text { Miles CD }\end{array}$ & $\begin{array}{c}\text { Gas } \\
\text { Gallons } \\
\text { Saved }\end{array}$ & & $\begin{array}{l}\text { Gas } \\
\text { WA }\end{array}$ & & $\begin{array}{l}\text { ual } \\
\text { Fuel } \\
\text { WA }\end{array}$ & & $\begin{array}{l}\text { ual } \\
\text { el } \\
\text { WA }\end{array}$ & $\begin{array}{c}\text { Annual Fuel } \\
\text { Red WA \% }\end{array}$ \\
\hline 83 & G41-74299 & VTRUX PU & $98 \%$ & 2940 & 128 & $\$$ & 512 & $\$$ & 39 & $\$$ & 474 & $92 \%$ \\
\hline 96 & G43-1195H & NA & $0 \%$ & 0 & 0 & $\$$ & - & $\$$ & - & $\$$ & - & $0 \%$ \\
\hline \multicolumn{4}{|l|}{ Total } & 2,940 & 128 & $\$$ & 512 & $\$$ & 39 & $\$$ & 474 & $93 \%$ \\
\hline
\end{tabular}

\begin{tabular}{|c|c|c|c|c|c|c|c|c|c|c|c|c|}
\hline Logger & Vehicle & $\begin{array}{c}\text { Replaceme } \\
\text { nt PEV }\end{array}$ & $\begin{array}{c}\% \text { of } \\
\text { Travel CD } \\
\text { Mode }\end{array}$ & $\begin{array}{c}\text { Annual } \\
\text { Miles CD }\end{array}$ & $\begin{array}{l}\text { Gas } \\
\text { Gallons } \\
\text { Saved }\end{array}$ & & $\begin{array}{l}\text { lual } \\
\text { Cost } \\
\text { onal }\end{array}$ & & $\begin{array}{l}\text { iual } \\
\text { Fuel } \\
\text { Nat }\end{array}$ & & $\begin{array}{l}\text { ual } \\
\text { el } \\
\text { s Nat }\end{array}$ & $\begin{array}{c}\text { Annual Fuel } \\
\text { Red Nat \% }\end{array}$ \\
\hline 83 & G41-74299 & VTRUX PU & $98 \%$ & 2940 & 128 & $\$$ & 470 & $\$$ & 182 & $\$$ & 289 & $61 \%$ \\
\hline 96 & G43-1195H & NA & $0 \%$ & $\underline{0}$ & 0 & $\$$ & - & $\$$ & - & S & - & $0 \%$ \\
\hline \multicolumn{4}{|l|}{ Total } & 2,940 & 128 & $\$$ & 470 & $\$$ & 182 & $\$$ & 289 & $61 \%$ \\
\hline
\end{tabular}

Section 5 summarizes these values.

\section{K.3.2 Monitored Support Mission Vehicle GHG Reduction}

Table K-6 identifies the reduction in GHG projected when replacing the current support mission vehicles with PEVs.

As before, because Tacoma Power relies more on cleaner hydroelectric power than the average of all national power providers, electrical emissions in Washington State are lower. Electrical emissions are significantly lower than gasoline emissions.

Table K-13. Monitored support vehicle replacement GHG reduction (Washington State and nationally).

\begin{tabular}{|c|c|c|c|c|c|c|c|}
\hline Logger & Vehicle & Vehicle Class & $\begin{array}{c}\text { Replaceme } \\
\text { nt PEV }\end{array}$ & $\begin{array}{c}\text { Annual GHG } \\
\text { Emission ICE } \\
\text { lb-CO2e }\end{array}$ & $\begin{array}{c}\text { Annual PEV } \\
\text { GHG WA } \\
\text { lb-CO2e } \\
\end{array}$ & $\begin{array}{c}\text { Annual PEV } \\
\text { GHG Sav WA } \\
\text { lb-CO2e }\end{array}$ & $\begin{array}{c}\text { Annual GHG } \\
\text { Reduction } \\
\text { WA \% } \\
\end{array}$ \\
\hline 83 & G41-74299 & Pickup & VTRUX PU & 2,569 & 243 & 2,326 & $91 \%$ \\
\hline 96 & G43-1195H & Van - Pass & NA & 0 & 0 & 0 & $0 \%$ \\
\hline \multicolumn{4}{|l|}{ Total } & 2,569 & 243 & 2,326 & $91 \%$ \\
\hline
\end{tabular}

\begin{tabular}{|c|c|c|l|r|r|r|r|}
\hline Logger & Vehicle & Vehicle Class & $\begin{array}{c}\text { Replaceme } \\
\text { nt PEV }\end{array}$ & $\begin{array}{c}\text { Annual GHG } \\
\text { Emission ICE } \\
\text { lb-CO2e }\end{array}$ & $\begin{array}{c}\text { Annual PEV } \\
\text { GHG Nat } \\
\text { Ib-CO2e }\end{array}$ & $\begin{array}{c}\text { Annual PEV } \\
\text { GHG Sav Nat } \\
\text { lb-CO2e }\end{array}$ & $\begin{array}{c}\text { Annual GHG } \\
\text { Reduction } \\
\text { Nat \% }\end{array}$ \\
\hline 83 & G41-74299 & Pickup & VTRUX PU & 2,569 & 2,137 & 432 & $17 \%$ \\
96 & G43-1195H & Van - Pass & NA & 0 & 0 & 0 & $0 \%$ \\
\hline \multicolumn{7}{|l|}{ Total }
\end{tabular}

Section 5 summarizes these figures.

\section{K.3.3 DCA Support Group Full Support Fleet Evaluation}

Table 12 in Section 4.2 identifies 40 vehicles in the DCA support Group support mission fleet. Aside from the passenger vans and heavy-duty trucks for which no PEV replacement is currently available, Intertek suggests a fleet of $20 \mathrm{BEVs}$ and 12 PHEVs conservatively meet the other 32 vehicle travel requirements.

Seven RAV4 EVs, four Focus Electrics, four Leafs, and five eNV200s are assumed to be appropriate BEVs while 2 Volts, 4 Via Motors VTRUX pickups, 3 Outlander PHEVs, and three VTRUX Vans are assumed to be appropriate PHEV replacements. 
Using averages for these vehicles, the potential replacements offer the fuel cost reductions and GHG reductions shown in Table K-7 below.

Table K-14. DCA Support Group full support fleet PEV replacement reductions (fuel cost and GHG emissions).

\begin{tabular}{|c|c|c|c|c|c|c|c|c|}
\hline $\begin{array}{l}\text { Annual } \\
\text { Miles CD }\end{array}$ & $\begin{array}{c}\text { Annual Gas } \\
\text { Cost WA }\end{array}$ & $\begin{array}{l}\text { Annual } \\
\text { Elect Fuel } \\
\text { Cost WA }\end{array}$ & $\begin{array}{c}\text { Annual Fuel } \\
\text { Saving WA }\end{array}$ & $\begin{array}{c}\text { Annual Fuel } \\
\text { Red WA } \\
\%\end{array}$ & $\begin{array}{c}\text { Annual Gas } \\
\text { Cost } \\
\text { National }\end{array}$ & $\begin{array}{c}\text { Annual } \\
\text { Elect Fuel } \\
\text { Cost Nat }\end{array}$ & $\begin{array}{c}\text { Annual Fuel } \\
\text { Savings } \\
\text { National }\end{array}$ & $\begin{array}{c}\text { Annual Fuel } \\
\text { Reduction } \\
\text { National \% }\end{array}$ \\
\hline 127,545 & 29,564 & $\$ \quad 1,431$ & 28,134 & $95 \%$ & 27,131 & 6,683 & 20,447 & $75 \%$ \\
\hline
\end{tabular}

\begin{tabular}{|c|r|r|r|r|r|r|r|}
\hline $\begin{array}{c}\text { Annual } \\
\text { Miles CD }\end{array}$ & $\begin{array}{c}\text { Annual GHG } \\
\text { Emission } \\
\text { ICE Ib-CO2e }\end{array}$ & $\begin{array}{c}\text { Annual PEV } \\
\text { GHG WA } \\
\text { Ib-CO2e }\end{array}$ & $\begin{array}{c}\text { Annual PEV } \\
\text { GHG Sav } \\
\text { WA Ib-CO2e }\end{array}$ & $\begin{array}{c}\text { Annual GHG } \\
\text { Reduction } \\
\text { WA \% }\end{array}$ & $\begin{array}{r}\text { Annual PEV } \\
\text { GHG Nat } \\
\text { Ib-CO2e }\end{array}$ & $\begin{array}{c}\text { Annual PEV } \\
\text { GHG Sav Nat } \\
\text { Ib-CO2e }\end{array}$ & $\begin{array}{c}\text { Annual GHG } \\
\text { Reduction } \\
\text { Nat \% }\end{array}$ \\
\hline 127,545 & 148,227 & 8,961 & 139,266 & $94 \%$ & 78,657 & 69,570 & $47 \%$ \\
\hline
\end{tabular}

Section 5 also summarizes these values.

\section{K.4 Full DCA Support Group Full Fleet Summary}

The full DCA Support Group fleet includes the above two missions. The projected results for both mission groups are shown in Table K-8 below and summarized in Section 5.

Table K-15. DCA Support Group full fleet PEV replacement reductions (fuel cost and GHG emissions).

\begin{tabular}{|c|c|c|c|c|c|c|c|c|}
\hline $\begin{array}{l}\text { Annual } \\
\text { Miles CD }\end{array}$ & $\begin{array}{c}\text { Annual Gas } \\
\text { Cost WA }\end{array}$ & $\begin{array}{c}\text { Annual } \\
\text { Elect Fuel } \\
\text { Cost WA }\end{array}$ & $\begin{array}{c}\text { Annual Fuel } \\
\text { Saving WA }\end{array}$ & $\begin{array}{c}\text { Annual Fuel } \\
\text { Reduction } \\
\text { WA } \%\end{array}$ & $\begin{array}{c}\text { Annual Gas } \\
\text { Cost } \\
\text { National }\end{array}$ & $\begin{array}{c}\text { Annual Elect } \\
\text { Fuel Cost } \\
\text { National }\end{array}$ & $\begin{array}{c}\text { Annual Fuel } \\
\text { Savings } \\
\text { National }\end{array}$ & $\begin{array}{c}\text { Annual Fuel } \\
\text { Reduction } \\
\text { National \% }\end{array}$ \\
\hline 142,471 & 33,330 & 1,613 & 31,717 & $95 \%$ & 30,587 & 7,535 & 23,051 & $75 \%$ \\
\hline
\end{tabular}

\begin{tabular}{|c|c|r|r|r|r|r|r|}
\hline $\begin{array}{c}\text { Annual } \\
\text { Miles CD }\end{array}$ & $\begin{array}{c}\text { Annual GHG } \\
\text { Emission ICE } \\
\text { lb-CO2e }\end{array}$ & $\begin{array}{c}\text { Annual PEV } \\
\text { GHG WA } \\
\text { lb-CO2e }\end{array}$ & $\begin{array}{c}\text { Annual PEV } \\
\text { GHG Sav WA } \\
\text { lb-CO2e }\end{array}$ & $\begin{array}{c}\text { Annual GHG } \\
\text { Reduction } \\
\text { WA \% }\end{array}$ & $\begin{array}{c}\text { Annual PEV } \\
\text { GHG Nat } \\
\text { lb-CO2e }\end{array}$ & $\begin{array}{c}\text { Annual PEV } \\
\text { GHG Sav Nat } \\
\text { lb-CO2e }\end{array}$ & $\begin{array}{c}\text { Annual GHG } \\
\text { Reduction } \\
\text { Nat \% }\end{array}$ \\
\hline 142,471 & 167,107 & 10,103 & 157,004 & $94 \%$ & 88,681 & 78,426 & $47 \%$ \\
\hline
\end{tabular}

\section{K.5 DCA Support Group Summary} Group.

Table K-9 provides the average values for all monitored vehicles belonging to the DCA Support

Table K-16. DCA Support Group monitored vehicles average values.

\begin{tabular}{|c|c|c|c|c|c|c|c|c|c|c|}
\hline \multirow[t]{2}{*}{$\begin{array}{l}\text { Average } \\
\text { Logged } \\
\text { Vehicles }\end{array}$} & $\begin{array}{l}\text { Annual } \\
\text { Miles CD }\end{array}$ & \begin{tabular}{|c} 
Gas \\
Gallons \\
Saved
\end{tabular} & \multicolumn{2}{|c|}{$\begin{array}{c}\text { Annual Gas } \\
\text { Cost WA }\end{array}$} & \multicolumn{2}{|c|}{$\begin{array}{l}\text { Annual } \\
\text { Elect Fuel } \\
\text { Cost WA }\end{array}$} & \multicolumn{2}{|c|}{$\begin{array}{c}\text { Annual } \\
\text { Fuel } \\
\text { Saving WA } \\
\end{array}$} & \multicolumn{2}{|c|}{$\begin{array}{c}\text { Annual Fuel } \\
\text { Red WA \% }\end{array}$} \\
\hline & 2,072 & 121 & $\$$ & 483 & $\$$ & 26 & $\$$ & 457 & & $95 \%$ \\
\hline \multicolumn{2}{|c|}{$\begin{array}{l}\text { Average } \\
\text { Logged } \\
\text { Vehicles }\end{array}$} & \multicolumn{2}{|c|}{$\begin{array}{c}\text { Annual GHG } \\
\text { Emission ICE } \\
\text { lb-CO2e }\end{array}$} & \multicolumn{2}{|c|}{$\begin{array}{c}\text { Annual PEV } \\
\text { GHG WA } \\
\text { lb-CO2e }\end{array}$} & \multicolumn{2}{|c|}{$\begin{array}{c}\text { Annual PEV } \\
\text { GHG Sav WA } \\
\text { Ib-CO2e }\end{array}$} & \multicolumn{2}{|c|}{$\begin{array}{c}\text { Annual GHG } \\
\text { Reduction } \\
\text { WA \% } \\
\end{array}$} & \\
\hline & & & & & 163 & & 2,261 & & $93 \%$ & \\
\hline
\end{tabular}

Table K-9 shows that there is a significant opportunity for savings not only in fuel costs but also in GHG emissions with the deployment of PEVs in this fleet. 


\section{Appendix L}

\section{Greenhouse Gas Emissions Avoided and fuel Cost Reduction Analysis - Public Works Group}

\section{L.1 Replacement PEVs for Public Works Group}

Section 4.3 provided the analysis results for the Public Works Group vehicles monitored during the study period based upon the data recorded and reported in the vehicle data sheets found in Appendix D. Both pool and support missions are identified for these vehicles. Transport functions are identified for the whole fleet although no vehicles with this mission were monitored.

The vehicles in this study included nine pickup trucks, two minivans, and three passenger vans. Section 3 identifies PEVs currently or soon to be available as potential replacements. There are currently no PEV replacement suggestions for passenger vans. For the study, PEV replacements are based upon vehicle class. Specific vehicle cargo requirements have not been specified and thus were not considered in these replacement suggestions.

Section 5 provides the methodology and assumptions for the calculations for the reduction in GHG and fuel costs. The miles recorded by vehicles during the 63-day study are extrapolated into annual miles. If the PEV replacing the monitored vehicle is a BEV, all annual miles are powered from the battery. If the PEV is a PHEV, the percentage of miles that are less than 40 miles per day recorded by the monitored vehicles (Appendix D) is multiplied by the annual miles to identify miles in CD mode. Only these miles are used in the reduction calculations. This is conservative because the replacement PHEV is likely more fuel efficient than the monitored vehicle when powered by the ICE.

Table L-17. JBLM Public Works Group PEV replacements.

\begin{tabular}{ccccccc}
\multicolumn{7}{c}{ Current Vehicle } \\
Logger & \multicolumn{5}{c}{ Vehicle Replacements } \\
No. & Make & Model & EPA Class & PEV Make & PEV Model & Mission \\
\hline 1 & Ford & F150 & Pickup & Via Motors & VTRUX PU & Pool \\
2 & Ford & F150 & Pickup & Toyota & Rav4 & Pool \\
3 & Ford & E450 & Van - Pass & NA & NA & Pool \\
4 & Chevrolet & G3500 & Van - Pass & NA & NA & Pool \\
5 & Ford & F350 & Pickup & Toyota & Rav4 & Support \\
84 & Dodge & GR Caravan & Minivan & Mitsubishi & Outlander & Pool \\
87 & Chevrolet & C1500 & Pickup & Toyota & Rav4 & Pool \\
88 & Dodge & GR Caravan & Minivan & Nissan & Leaf & Pool \\
90 & Chevrolet & C2500HD & Pickup & Nissan & eNV200 & Support \\
91 & Chevrolet & C3500 & Pickup & Toyota & Rav4 & Support \\
92 & Chevrolet & G1300 & Van - Pass & NA & NA & Support \\
95 & Ford & F350 & Pickup & Via Motors & VTRUX PU & Support \\
98 & Dodge & Dakota & Pickup & Toyota & Rav4 & Support \\
100 & Chevrolet & C1500 & Pickup & Nissan & eNV200 & Pool \\
\hline
\end{tabular}

NOTE: Vehicle 84 was reported as part of both the Public Works and Motor Transport Branch fleets. The analysis here includes this vehicle for completeness with this appendix but omits this vehicle from the Motor Transport Branch in fleet totals of Section 5. 


\section{L.2 Monitored Pool Mission Vehicle Reductions}

The monitored vehicles with the pool mission contain four pickup trucks, two minivans and two passenger vans. As above, no replacement is suggested for the passenger vans. However, the observations of Section 4.3.2.3 suggest that replacing the other six vehicles with two PHEVs and four BEVs would meet current mission requirements.

\section{L.2.1 Monitored Pool Mission Vehicle Fuel Cost Reduction}

Table L-2 identifies the calculated miles in CD mode for each replacement vehicle as well as the projected fuel cost reductions for the pool vehicles. As noted in Section 5, both the local cost of fuel and the national average are used for comparisons.

Because Washington State fuel costs are higher than the national average, gasoline costs locally are greater than national figures. Also, because Tacoma Power relies more on cheaper hydroelectric power than the average of all national power providers, electrical fuel costs in Washington State are lower.

Table L-18. Monitored pool vehicle replacement fuel cost reduction (Washington State and nationally).

\begin{tabular}{|c|c|c|c|c|c|c|c|c|c|c|c|c|}
\hline \multirow{2}{*}{$\begin{array}{c}\text { Logger } \\
1\end{array}$} & \multirow{2}{*}{\begin{tabular}{|c|} 
Vehicle \\
G42-0658K
\end{tabular}} & \multirow{2}{*}{$\begin{array}{c}\text { Replaceme } \\
\text { nt PEV }\end{array}$} & \multirow{2}{*}{$\begin{array}{c}\begin{array}{c}\% \text { of } \\
\text { Travel CD } \\
\text { Mode }\end{array} \\
78 \%\end{array}$} & \multirow{2}{*}{$\begin{array}{r}\begin{array}{c}\text { Annual } \\
\text { Miles CD }\end{array} \\
3641\end{array}$} & \multirow{2}{*}{$\begin{array}{c}\begin{array}{c}\text { Gas } \\
\text { Gallons } \\
\text { Saved }\end{array} \\
228\end{array}$} & \multicolumn{2}{|c|}{$\begin{array}{c}\text { Annual Gas } \\
\text { Cost WA }\end{array}$} & \multicolumn{2}{|c|}{$\begin{array}{c}\text { Annual } \\
\text { Elect Fuel } \\
\text { Cost WA }\end{array}$} & \multicolumn{2}{|c|}{$\begin{array}{c}\text { Annual } \\
\text { Fuel } \\
\text { Saving WA }\end{array}$} & \multirow{2}{*}{$\begin{array}{r}\begin{array}{c}\text { Annual Fuel } \\
\text { Red WA \% }\end{array} \\
95 \%\end{array}$} \\
\hline & & & & & & $\$$ & 912 & $\$$ & 48 & $\$$ & 864 & \\
\hline 2 & G42-1054F & Rav4 & $100 \%$ & 3130 & 196 & $\$$ & 784 & $\$$ & 38 & $\$$ & 746 & $95 \%$ \\
\hline 3 & G71-0133L & NA & $0 \%$ & 0 & 0 & $\$$ & - & $\$$ & - & $\$$ & - & $0 \%$ \\
\hline 4 & G43-0944G & NA & $0 \%$ & 0 & 0 & $\$$ & - & $\$$ & - & $\$$ & - & $0 \%$ \\
\hline 84 & G41-1100K & Outlander & $96 \%$ & 3187 & 168 & $\$$ & 672 & $\$$ & 39 & $\$$ & 633 & $94 \%$ \\
\hline 87 & G42-0619K & Rav4 & $100 \%$ & 1956 & 115 & $\$$ & 461 & $\$$ & 24 & $\$$ & 437 & $95 \%$ \\
\hline 88 & G41-1180K & Leaf & $100 \%$ & 2580 & 136 & $\$$ & 544 & $\$$ & 22 & $\$$ & 523 & $96 \%$ \\
\hline 100 & G42-0610K & eNV200 & $100 \%$ & 3144 & 185 & $\$$ & 741 & $\$$ & 35 & $\$$ & 706 & $95 \%$ \\
\hline \multicolumn{4}{|l|}{ Total } & 17,638 & 1,027 & $\$$ & 4,116 & $\$$ & 206 & $\$$ & 3,910 & $95 \%$ \\
\hline Logger & Vehicle & $\begin{array}{c}\text { Replaceme } \\
\text { nt PEV }\end{array}$ & $\begin{array}{c}\% \text { of } \\
\text { Travel CD } \\
\text { Mode } \\
\end{array}$ & $\begin{array}{l}\text { Annual } \\
\text { Miles CD }\end{array}$ & $\begin{array}{c}\text { Gas } \\
\text { Gallons } \\
\text { Saved } \\
\end{array}$ & \multicolumn{2}{|c|}{$\begin{array}{l}\text { Annual } \\
\text { Gas Cost } \\
\text { National }\end{array}$} & \multicolumn{2}{|c|}{$\begin{array}{c}\text { Annual } \\
\text { Elect Fuel } \\
\text { Cost Nat }\end{array}$} & \multicolumn{2}{|c|}{\begin{tabular}{|c|} 
Annual \\
Fuel \\
Savings Nat
\end{tabular}} & $\begin{array}{c}\text { Annual Fuel } \\
\text { Red Nat \% }\end{array}$ \\
\hline 1 & G42-0658K & VTRUX PU & $78 \%$ & 3641 & 228 & $\$$ & 837 & $\$$ & 224.83 & $\$$ & 612 & $73 \%$ \\
\hline 2 & G42-1054F & Rav4 & $100 \%$ & 3130 & 196 & $\$$ & 720 & $\$$ & 179.04 & $\$$ & 541 & $75 \%$ \\
\hline 3 & G71-0133L & NA & $0 \%$ & 0 & 0 & $\$$ & - & $\$$ & - & $\$$ & - & $0 \%$ \\
\hline 4 & G43-0944G & NA & $0 \%$ & 0 & 0 & $\$$ & - & $\$$ & - & $\$$ & - & $0 \%$ \\
\hline 84 & G41-1100K & Outlander & $96 \%$ & 3187 & 168 & $\$$ & 617 & $\$$ & 182.31 & $\$$ & 435 & $70 \%$ \\
\hline 87 & G42-0619K & Rav4 & $100 \%$ & 1956 & 115 & $\$$ & 423 & $\$$ & 111.88 & $\$$ & 311 & $74 \%$ \\
\hline 88 & G41-1180K & Leaf & $100 \%$ & 2580 & 136 & $\$$ & 500 & $\$$ & 100.62 & $\$$ & 399 & $80 \%$ \\
\hline 100 & G42-0610K & eNV200 & $100 \%$ & 3144 & 185 & $\$$ & 680 & $\$$ & 163.49 & $\$$ & 517 & $76 \%$ \\
\hline Total & & & & 17,638 & 1,027 & $\$$ & 3,777 & $\$$ & 962 & $\$$ & 2,815 & $75 \%$ \\
\hline
\end{tabular}

Section 5 summarizes these values.

An example calculation for logger 1 follows: The JBLM reported annual miles for this vehicle is 4,668 miles. The suggested replacement PEV is a PHEV. The Appendix D daily travel percentage for this vehicle less than 40 miles is $78 \%$ so annual miles CD mode is 3,641 miles. EPA fuel economy for this vehicle is 16 MPG implying 227.6 gallons of gasoline are unused. Washington State cost for gasoline is $\$ 4.009 /$ gallon for an annual cost of $\$ 912$. The replacement PEV requires $475 \mathrm{Wh} / \mathrm{mi}$ so $1,729 \mathrm{kWh}$ are required for recharging the battery. Local power cost is $\$ 0.02783 / \mathrm{kWh}$, resulting in annual electric cost of $\$ 48$. The savings are $\$ 864$ for a $95 \%$ reduction in fuel cost. 


\section{L.2.2 Monitored Pool Mission Vehicle GHG Reduction}

Table L-3 identifies the reduction in GHG projected when replacing the current pool vehicles with PEVs. The calculated miles in CD mode are also used in the calculation of GHG reduction. As noted in Section 5, the emissions from burning gasoline is known and the emissions from the use of electricity is dependent upon the power generation mix that is used to recharge the PEV battery. As before, both the local power production emission figures and the national average are used for comparisons.

Because Tacoma Power relies more on cleaner hydroelectric power than the average of all national power providers, electrical emissions in Washington State are lower. Electrical emissions are significantly lower than gasoline emissions.

Table L-19. Monitored vehicle replacement GHG reduction (Washington State and nationally).

\begin{tabular}{|c|c|c|c|c|c|c|c|}
\hline Logger & Vehicle & Vehicle Class & $\begin{array}{c}\text { Replaceme } \\
\text { nt PEV }\end{array}$ & $\begin{array}{c}\text { Annual GHG } \\
\text { Emission ICE } \\
\text { Ib-CO2e }\end{array}$ & $\begin{array}{c}\text { Annual PEV } \\
\text { GHG WA } \\
\text { lb-CO2e }\end{array}$ & $\begin{array}{c}\text { Annual PEV } \\
\text { GHG Sav WA } \\
\text { lb-CO2e }\end{array}$ & $\begin{array}{c}\text { Annual GHG } \\
\text { Reduction } \\
\text { WA \% }\end{array}$ \\
\hline 1 & G42-0658K & Pickup & VTRUX PU & 4,574 & 301 & 4,273 & $93 \%$ \\
\hline 2 & G42-1054F & Pickup & Rav4 & 3,932 & 240 & 3,692 & $94 \%$ \\
\hline 3 & G71-0133L & Van - Pass & NA & 0 & 0 & 0 & $0 \%$ \\
\hline 4 & G43-0944G & Van-Pass & NA & 0 & 0 & 0 & $0 \%$ \\
\hline 84 & G41-1100K & Minivan & Outlander & 3,372 & 244 & 3,127 & $93 \%$ \\
\hline 87 & G42-0619K & Pickup & Rav4 & 2,313 & 150 & 2,163 & $94 \%$ \\
\hline 88 & G41-1180K & Minivan & Leaf & 2,729 & 135 & 2,594 & $95 \%$ \\
\hline 100 & G42-0610K & Pickup & eNV200 & 3,717 & 219 & 3,498 & $94 \%$ \\
\hline \multicolumn{4}{|l|}{ Total } & 20,637 & 1,290 & 19,347 & $94 \%$ \\
\hline Logger & Vehicle & Vehicle Class & $\begin{array}{c}\text { Replaceme } \\
\text { nt PEV }\end{array}$ & $\begin{array}{c}\text { Annual GHG } \\
\text { Emission ICE } \\
\text { lb-CO2e } \\
\end{array}$ & $\begin{array}{c}\text { Annual PEV } \\
\text { GHG Nat } \\
\text { lb-CO2e } \\
\end{array}$ & $\begin{array}{c}\text { Annual PEV } \\
\text { GHG Sav Nat } \\
\text { lb-CO2e } \\
\end{array}$ & $\begin{array}{c}\text { Annual GHG } \\
\text { Reduction } \\
\text { National \% }\end{array}$ \\
\hline 1 & G42-0658K & Pickup & VTRUX PU & 4,574 & 2,646 & 1,928 & $42 \%$ \\
\hline 2 & G42-1054F & Pickup & Rav4 & 3,932 & 2,107 & 1,825 & $46 \%$ \\
\hline 3 & G71-0133L & Van - Pass & NA & 0 & 0 & 0 & $0 \%$ \\
\hline 4 & G43-0944G & Van-Pass & NA & 0 & 0 & 0 & $0 \%$ \\
\hline 84 & G41-1100K & Minivan & Outlander & 3,372 & 2,146 & 1,226 & $36 \%$ \\
\hline 87 & G42-0619K & Pickup & Rav4 & 2,313 & 1,317 & 996 & $43 \%$ \\
\hline 88 & G41-1180K & Minivan & Leaf & 2,729 & 1,184 & 1,545 & $57 \%$ \\
\hline 100 & G42-0610K & Pickup & eNV200 & 3,717 & 1,924 & 1,793 & $48 \%$ \\
\hline \multicolumn{4}{|l|}{ Total } & 20,637 & 11,324 & 9,313 & $45 \%$ \\
\hline
\end{tabular}

Section 5 summarizes these figures.

An example calculation for logger 1 follows: As shown above, the annual miles CD mode is 3,641 miles and 227.6 gallons of gasoline are unused. Internal combustion vehicles produce $20.1 \mathrm{lb}$ $\mathrm{CO} 2 \mathrm{e} /$ gallon so the annual emissions for the monitored vehicle are 4,574 $\mathrm{lb}-\mathrm{CO} 2 \mathrm{e}$. Tacoma Power produces $0.1743 \mathrm{lb}-\mathrm{CO} 2 \mathrm{e} / \mathrm{kWh}$. As above, $1,729 \mathrm{kWh}$ are required for recharging the battery, resulting in $301 \mathrm{lb}-\mathrm{CO} 2 \mathrm{e}$. The savings are 4,273 lb-CO2e for a 93\% reduction in GHG emission.

\section{L.2.3 Public Works Group full Pool Mission Fleet Evaluation}

Table 18 in Section 4.3 identifies 107 vehicles in the Public Works Group pool fleet. Aside from the passenger vans, Intertek suggests a fleet of 57 BEVs and 15 PHEVs conservatively meet the other vehicle travel requirements. 
A mix of 27 RAV4 EVs, 3 Leafs, 3 Focus Electrics, and 24 eNV200s are assumed to be appropriate BEVs while six Via Motors VTRUX pickups, four Outlander PHEVs, one Volt, and four VTRUX Vans are assumed to be appropriate PHEV replacements.

Using averages for these vehicles, the replacements offer the potential fuel cost reductions and GHG reductions shown in Table L-4 below.

Table L-20. Public Works Group full pool fleet PEV replacement reductions (fuel cost and GHG emissions).

\begin{tabular}{|c|c|c|c|c|c|c|c|c|}
\hline $\begin{array}{l}\text { Annual } \\
\text { Miles CD }\end{array}$ & $\begin{array}{c}\text { Annual Gas } \\
\text { Cost WA }\end{array}$ & $\begin{array}{c}\text { Annual } \\
\text { Elect Fuel } \\
\text { Cost WA }\end{array}$ & $\begin{array}{c}\text { Annual Fuel } \\
\text { Saving WA }\end{array}$ & $\begin{array}{c}\text { Annual Fuel } \\
\text { Reduction } \\
\text { WA } \%\end{array}$ & $\begin{array}{c}\text { Annual Gas } \\
\text { Cost } \\
\text { National }\end{array}$ & $\begin{array}{c}\text { Annual } \\
\text { Elect Fuel } \\
\text { Cost Nat }\end{array}$ & $\begin{array}{c}\text { Annual Fuel } \\
\text { Savings } \\
\text { National }\end{array}$ & $\begin{array}{c}\text { Annual Fuel } \\
\text { Reduction } \\
\text { National \% }\end{array}$ \\
\hline 207,009 & 49,821 & 2,439 & 47,382 & $95 \%$ & 45,720 & 11,391 & 34,329 & $75 \%$ \\
\hline
\end{tabular}

\begin{tabular}{|r|r|r|r|r|r|r|r|}
\hline $\begin{array}{c}\text { Annual } \\
\text { Miles CD }\end{array}$ & $\begin{array}{c}\text { Annual GHG } \\
\text { Emission } \\
\text { ICE Ib-CO2e }\end{array}$ & $\begin{array}{c}\text { Annual PEV } \\
\text { GHG WA } \\
\text { Ib-CO2e }\end{array}$ & $\begin{array}{c}\text { Annual PEV } \\
\text { GHG Sav } \\
\text { WA lb-CO2e }\end{array}$ & $\begin{array}{c}\text { Annual GHG } \\
\text { Reduction } \\
\text { WA \% }\end{array}$ & $\begin{array}{r}\text { Annual PEV } \\
\text { GHG Nat } \\
\text { lb-CO2e }\end{array}$ & $\begin{array}{c}\text { Annual PEV } \\
\text { GHG Sav Nat } \\
\text { Ib-CO2e }\end{array}$ & $\begin{array}{c}\text { Annual GHG } \\
\text { Reduction } \\
\text { National \% }\end{array}$ \\
\hline 207,009 & 249,788 & 15,273 & 234,515 & $94 \%$ & 134,067 & 115,721 & $46 \%$ \\
\hline
\end{tabular}

Section 5 also summarizes these values.

\section{L.3 Monitored Support Mission Vehicle Reductions}

The monitored vehicles with the support mission contain five pickup trucks and one passenger van. As above, no replacement is suggested for the passenger van. However, the observations of Section 4.3.2.3 suggest that replacing the other five vehicles with one PHEV and four BEVs would meet current mission requirements.

\section{L.3.1 Monitored Support Mission Vehicle Fuel Cost Reduction}

Table L-5 identifies the calculated miles in CD mode for each replacement vehicle as well as the projected fuel cost reductions for the support vehicles.

As before, because Washington State fuel costs are higher than the national average, gasoline costs locally are greater than national figures. Also, because Tacoma Power relies more on cheaper hydroelectric power than the average of all national power providers, electrical fuel costs in Washington State are lower.

Section 5 summarizes these values.

\section{L.3.2 Monitored Support Mission Vehicle GHG Reduction}

Table L-6 identifies the reduction in GHG projected when replacing the current support mission vehicles with PEVs.

As before, because Tacoma Power relies more on cleaner hydroelectric power than the average of all national power providers, electrical emissions in Washington State are lower. Electrical emissions are significantly lower than gasoline emissions. 
Table L-21. Monitored support vehicle replacement fuel cost reduction (Washington State and nationally).

\begin{tabular}{|c|c|c|c|c|c|c|c|c|c|c|c|c|}
\hline Logger & Vehicle & $\begin{array}{c}\text { Replaceme } \\
\text { nt PEV }\end{array}$ & $\begin{array}{c}\% \text { of } \\
\text { Travel CD } \\
\text { Mode }\end{array}$ & $\begin{array}{c}\text { Annual } \\
\text { Miles CD }\end{array}$ & $\begin{array}{c}\text { Gas } \\
\text { Gallons } \\
\text { Saved }\end{array}$ & & $\begin{array}{l}\text { ual Gas } \\
\text { st WA }\end{array}$ & & $\begin{array}{l}\text { ual } \\
\text { Fuel } \\
\text { WA }\end{array}$ & & $\begin{array}{l}\text { nual } \\
\text { uel } \\
\text { ng WA }\end{array}$ & $\begin{array}{c}\text { Annual Fuel } \\
\text { Red WA \% }\end{array}$ \\
\hline 5 & G43-0822G & Rav4 & $100 \%$ & 5724 & 358 & $\$$ & 1,434 & $\$$ & 70 & $\$$ & 1,364 & $95 \%$ \\
\hline 90 & G43-1892H & eNV200 & $100 \%$ & 3672 & 230 & $\$$ & 920 & $\$$ & 41 & $\$$ & 879 & $96 \%$ \\
\hline 91 & G43-1961H & Rav4 & $100 \%$ & 4920 & 308 & $\$$ & 1,233 & $\$$ & 60 & $\$$ & 1,173 & $95 \%$ \\
\hline 92 & G42-0505A & NA & $0 \%$ & 0 & 0 & $\$$ & - & $\$$ & - & $\$$ & - & \\
\hline 95 & G43-1155L & VTRUX PU & $40 \%$ & 2482 & 146 & $\$$ & 585 & $\$$ & 33 & $\$$ & 552 & $94 \%$ \\
\hline 98 & G41-1605L & Rav4 & $100 \%$ & 1776 & 111 & $\$$ & 445 & $\$$ & 22 & $\$$ & 423 & $95 \%$ \\
\hline \multicolumn{4}{|l|}{ Total } & 18,574 & 1,152 & $\$$ & 4,617 & $\$$ & 226 & $\$$ & 4,392 & $95 \%$ \\
\hline
\end{tabular}

\begin{tabular}{|c|c|c|c|c|c|c|c|c|c|c|c|c|}
\hline Logger & Vehicle & $\begin{array}{c}\text { Replaceme } \\
\text { nt PEV }\end{array}$ & $\begin{array}{c}\% \text { of } \\
\text { Travel CD } \\
\text { Mode }\end{array}$ & $\begin{array}{c}\text { Annual } \\
\text { Miles CD }\end{array}$ & $\begin{array}{c}\text { Gas } \\
\text { Gallons } \\
\text { Saved }\end{array}$ & \multicolumn{2}{|c|}{$\begin{array}{c}\text { Annual } \\
\text { Gas Cost } \\
\text { National }\end{array}$} & \multicolumn{2}{|c|}{$\begin{array}{l}\text { Annual } \\
\text { Elect Fuel } \\
\text { Cost Nat }\end{array}$} & \multicolumn{2}{|c|}{$\begin{array}{c}\text { Annual } \\
\text { Fuel } \\
\text { Savings Nat }\end{array}$} & $\begin{array}{l}\text { Annual Fuel } \\
\text { Red } \\
\text { National \% }\end{array}$ \\
\hline 5 & G43-0822G & Rav4 & $100 \%$ & 5724 & 358 & $\$$ & 1,316 & $\$$ & 327 & $\$$ & 989 & $75 \%$ \\
\hline 90 & G43-1892H & eNV200 & $100 \%$ & 3672 & 230 & $\$$ & 844 & $\$$ & 191 & $\$$ & 653 & $77 \%$ \\
\hline 91 & G43-1961H & Rav4 & $100 \%$ & 4920 & 308 & $\$$ & 1,131 & $\$$ & 281 & $\$$ & 850 & $75 \%$ \\
\hline 92 & G42-0505A & NA & $0 \%$ & 0 & 0 & $\$$ & - & $\$$ & - & $\$$ & - & \\
\hline 95 & G43-1155L & VTRUX PU & $40 \%$ & 2482 & 146 & $\$$ & 537 & $\$$ & 153 & $\$$ & 384 & $71 \%$ \\
\hline 98 & G41-1605L & Rav4 & $100 \%$ & 1776 & 111 & $\$$ & 408 & $\$$ & 102 & $\$$ & 307 & $75 \%$ \\
\hline otal & & & & 18,574 & 1,152 & $\$$ & 4,237 & $\$$ & 1,055 & $\$$ & 3,183 & $75 \%$ \\
\hline
\end{tabular}

Table L-22. Monitored support vehicle replacement GHG reduction (Washington State and nationally).

\begin{tabular}{|c|l|l|l|r|r|r|r|}
\hline Logger & Vehicle & Vehicle Class & $\begin{array}{c}\text { Replaceme } \\
\text { nt PEV }\end{array}$ & $\begin{array}{c}\text { Annual GHG } \\
\text { Emission ICE } \\
\text { Ib-CO2e }\end{array}$ & $\begin{array}{c}\text { Annual PEV } \\
\text { GHG WA } \\
\text { Ib-CO2e }\end{array}$ & $\begin{array}{c}\text { Annual PEV } \\
\text { GHG Sav WA } \\
\text { lb-CO2e }\end{array}$ & $\begin{array}{c}\text { Annual GHG } \\
\text { Reduction } \\
\text { WA \% }\end{array}$ \\
\hline 5 & G43-0822G & Pickup & Rav4 & 7,191 & 439 & 6,752 & $94 \%$ \\
90 & G43-1892H & Pickup & eNV200 & 4,613 & 256 & 4,357 & $94 \%$ \\
91 & G43-1961H & Pickup & Rav4 & 6,181 & 377 & 5,803 & $94 \%$ \\
92 & G42-0505A & Van - Pass & NA & 0 & 0 & 0 & \\
95 & G43-1155L & Pickup & VTRUX PU & 2,934 & 205 & 2,729 & $93 \%$ \\
98 & G41-1605L & Pickup & Rav4 & 2,231 & 136 & 2,095 & $94 \%$ \\
\hline \multicolumn{2}{l}{ Total }
\end{tabular}

\begin{tabular}{|c|l|l|l|r|r|r|r|}
\hline Logger & Vehicle & Vehicle Class & $\begin{array}{c}\text { Replaceme } \\
\text { nt PEV }\end{array}$ & $\begin{array}{c}\text { Annual GHG } \\
\text { Emission ICE } \\
\text { lb-CO2e }\end{array}$ & $\begin{array}{c}\text { Annual PEV } \\
\text { GHG Nat } \\
\text { Ib-CO2e }\end{array}$ & $\begin{array}{c}\text { Annual PEV } \\
\text { GHG Sav Nat } \\
\text { Ib-CO2e }\end{array}$ & $\begin{array}{c}\text { Annual GHG } \\
\text { Reduction } \\
\text { National \% }\end{array}$ \\
\hline 5 & G43-0822G & Pickup & Rav4 & 7,191 & 3,853 & 3,337 & $46 \%$ \\
90 & G43-1892H & Pickup & eNV200 & 4,613 & 2,247 & 2,366 & $51 \%$ \\
91 & G43-1961H & Pickup & Rav4 & 6,181 & 3,312 & 2,869 & $46 \%$ \\
92 & G42-0505A & Van- Pass & NA & 0 & 0 & 0 & \\
95 & G43-1155L & Pickup & VTRUX PU & 2,934 & 1,804 & 1,131 & $39 \%$ \\
98 & G41-1605L & Pickup & Rav4 & 2,231 & 1,196 & 1,035 & $46 \%$ \\
\hline Total
\end{tabular}

Section 5 summarizes these figures. 


\section{L.3.3 Public Works Group Full Support Fleet Evaluation}

Table 18 in Section 4.3 identifies 117 vehicles in the Public Works Group support mission fleet. Aside from the passenger vans and heavy-duty trucks for which no PEV replacement is currently available, Intertek suggests a fleet of 67 BEVs and 17 PHEVs conservatively meet the other 84 vehicle travel requirements.

A mix of 30 RAV4 EVs and 37 eNV200s are assumed to be appropriate BEVs while seven Via Motors VTRUX pickups, seven Outlanders PHEVs, and three VTRUX Vans are assumed to be appropriate PHEV replacements.

Using averages for these vehicles, the potential replacements offer the fuel cost reductions and GHG reductions shown in Table L-7 below.

Table L-23. Public Works Group full support fleet PEV replacement reductions (fuel cost and GHG emissions).

\begin{tabular}{|c|c|c|c|c|c|c|c|c|}
\hline $\begin{array}{l}\text { Annual } \\
\text { Miles CD }\end{array}$ & $\begin{array}{c}\text { Annual Gas } \\
\text { Cost WA }\end{array}$ & $\begin{array}{c}\text { Annual } \\
\text { Elect Fuel } \\
\text { Cost WA }\end{array}$ & $\begin{array}{c}\text { Annual Fuel } \\
\text { Saving WA }\end{array}$ & $\begin{array}{c}\text { Annual Fuel } \\
\text { Reduction } \\
\text { WA } \%\end{array}$ & $\begin{array}{c}\text { Annual Gas } \\
\text { Cost } \\
\text { National }\end{array}$ & $\begin{array}{c}\text { Annual } \\
\text { Elect Fuel } \\
\text { Cost Nat }\end{array}$ & $\begin{array}{c}\text { Annual Fuel } \\
\text { Savings } \\
\text { National }\end{array}$ & $\begin{array}{c}\text { Annual Fuel } \\
\text { Reduction } \\
\text { National \% }\end{array}$ \\
\hline 331,344 & 82,310 & 3,934 & 78,375 & $95 \%$ & 75,534 & 18,377 & 57,157 & $76 \%$ \\
\hline
\end{tabular}

\begin{tabular}{|c|r|r|r|r|r|r|r|}
\hline Annual & Annual GHG & Annual PEV & Annual PEV & Annual GHG & Annual PEV & Annual PEV & Annual GHG \\
\hline 331,344 & 412,677 & 24,640 & 388,037 & $94 \%$ & 216,286 & 196,391 & $48 \%$ \\
\hline
\end{tabular}

Section 5 also summarizes these values.

\section{L.4 Public Works Transport Mission Vehicle Reductions}

While no vehicles with the transport mission were monitored, an evaluation based upon other vehicle usage follows.

Table 18 in Section 4.3 identifies 25 vehicles in the Public Works transport mission fleet. Aside from the heavy-duty trucks for which no PEV replacement is currently available, Intertek suggests a fleet of four BEVs and four PHEVs conservatively meet the other eight vehicle travel requirements. Two RAV4 EVs and two eNV200s are assumed to be appropriate BEVs while four Via Motors VTRUX pickups are assumed to be appropriate PHEV replacements. Table L- 8 provides the potential reductions from such replacements.

Table L-24. Public Works Group full transport fleet PEV replacement reductions (fuel cost and GHG emissions).

\begin{tabular}{|c|c|c|c|c|c|c|c|c|}
\hline $\begin{array}{l}\text { Annual } \\
\text { Miles CD }\end{array}$ & $\begin{array}{c}\text { Annual Gas } \\
\text { Cost WA }\end{array}$ & $\begin{array}{l}\text { Annual } \\
\text { Elect Fuel } \\
\text { Cost WA }\end{array}$ & $\begin{array}{c}\text { Annual Fuel } \\
\text { Saving WA }\end{array}$ & $\begin{array}{c}\text { Annual Fuel } \\
\text { Reduction } \\
\text { WA } \%\end{array}$ & $\begin{array}{c}\text { Annual Gas } \\
\text { Cost } \\
\text { National }\end{array}$ & $\begin{array}{c}\text { Annual Elect } \\
\text { Fuel Cost } \\
\text { National }\end{array}$ & $\begin{array}{c}\text { Annual Fuel } \\
\text { Savings } \\
\text { National }\end{array}$ & $\begin{array}{c}\text { Annual Fuel } \\
\text { Reduction } \\
\text { National \% }\end{array}$ \\
\hline 33,484 & 9,249 & 413 & 8,837 & $96 \%$ & 8,488 & 1,928 & 6,560 & $77 \%$ \\
\hline
\end{tabular}

\begin{tabular}{|c|c|c|c|c|c|c|c|}
\hline Annual & Annual GHG & Annual PEV & Annual PEV & Annual GHG & Annual PEV & Annual PEV & Annual GHG \\
\hline
\end{tabular}

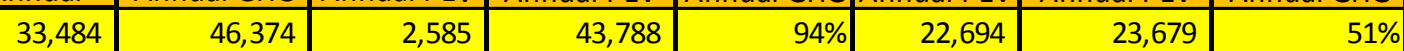

\section{L.5 Full Public Works Support Group Full Fleet Summary}

The projected reductions for all mission groups in the Public Works fleet are shown in Table L-9 below and summarized in Section 5. This table assumes the specialty vehicle, the 52 passenger vans and 33 heavy-duty trucks remain along with 128 BVEVs and 36 PHEVs. 
Table L-25. Public Works Group full fleet PEV replacement potential reductions (fuel cost and GHG emissions).

\begin{tabular}{|c|c|c|c|c|c|c|c|c|}
\hline $\begin{array}{l}\text { Annual } \\
\text { Miles CD }\end{array}$ & $\begin{array}{c}\text { Annual Gas } \\
\text { Cost WA }\end{array}$ & $\begin{array}{l}\text { Annual } \\
\text { Elect Fuel } \\
\text { Cost WA }\end{array}$ & $\begin{array}{c}\text { Annual Fuel } \\
\text { Saving WA }\end{array}$ & $\begin{array}{c}\text { Annual Fuel } \\
\text { Reduction } \\
\text { WA } \%\end{array}$ & $\begin{array}{c}\text { Annual Gas } \\
\text { Cost } \\
\text { National }\end{array}$ & $\begin{array}{c}\text { Annual Elect } \\
\text { Fuel Cost } \\
\text { National }\end{array}$ & $\begin{array}{c}\text { Annual Fuel } \\
\text { Savings } \\
\text { National }\end{array}$ & $\begin{array}{c}\text { Annual Fuel } \\
\text { Reduction } \\
\text { National \% }\end{array}$ \\
\hline 571,837 & 141,380 & 6,786 & 134,594 & $95 \%$ & $\$ 129,742$ & 31,696 & 98,046 & $76 \%$ \\
\hline
\end{tabular}

\begin{tabular}{|r|r|r|r|r|r|r|r|}
\hline $\begin{array}{c}\text { Annual } \\
\text { Miles CD }\end{array}$ & $\begin{array}{c}\text { Annual GHG } \\
\text { Emission ICE } \\
\text { lb-CO2e }\end{array}$ & $\begin{array}{c}\text { Annual PEV } \\
\text { GHG WA } \\
\text { Ib-CO2e }\end{array}$ & $\begin{array}{c}\text { Annual PEV } \\
\text { GHG Sav WA } \\
\text { Ib-CO2e }\end{array}$ & $\begin{array}{c}\text { Annual GHG } \\
\text { Reduction } \\
\text { WA } \%\end{array}$ & $\begin{array}{c}\text { Annual PEV } \\
\text { GHG Nat } \\
\text { Ib-CO2e }\end{array}$ & $\begin{array}{c}\text { Annual PEV } \\
\text { GHG Sav Nat } \\
\text { Ib-CO2e }\end{array}$ & $\begin{array}{c}\text { Annual GHG } \\
\text { Reduction } \\
\text { National \% }\end{array}$ \\
\hline 571,837 & 708,839 & 42,498 & 666,340 & $94 \%$ & 373,047 & 335,791 & $47 \%$ \\
\hline
\end{tabular}

\section{L.6 Public Works Group Summary}

Table L-10 provides the average values for all monitored vehicles belonging to the Public Works Group.

Table L-26. Public Works Group monitored vehicles average values.

\begin{tabular}{|l|c|c|r|r|r|r|}
\hline $\begin{array}{c}\text { Average } \\
\text { Logged } \\
\text { Vehicles }\end{array}$ & $\begin{array}{c}\text { Annual } \\
\text { Miles CD }\end{array}$ & $\begin{array}{c}\text { Gas } \\
\text { Gallons } \\
\text { Saved }\end{array}$ & $\begin{array}{c}\text { Annual Gas } \\
\text { Cost WA }\end{array}$ & $\begin{array}{c}\text { Annual } \\
\text { Elect Fuel } \\
\text { Cost WA }\end{array}$ & $\begin{array}{c}\text { Annual } \\
\text { Fuel } \\
\text { Saving WA }\end{array}$ & $\begin{array}{c}\text { Annual Fuel } \\
\text { Red WA \% }\end{array}$ \\
\hline & 3,292 & 198 & 794 & 39 & 755 & $95 \%$ \\
\hline $\begin{array}{c}\text { Average } \\
\text { Logged } \\
\text { Vehicles }\end{array}$ & $\begin{array}{c}\text { Annual GHG } \\
\text { Emission ICE } \\
\text { Ib-CO2e }\end{array}$ & $\begin{array}{c}\text { Annual PEV } \\
\text { GHG WA } \\
\text { lb-CO2e }\end{array}$ & $\begin{array}{c}\text { Annual PEV } \\
\text { GHG Sav WA } \\
\text { lb-CO2e }\end{array}$ & $\begin{array}{c}\text { Annual GHG } \\
\text { Reduction } \\
\text { WA \% }\end{array}$ & \\
\hline & 3,981 & 246 & 3,735 & $94 \%$ \\
\hline
\end{tabular}

Table L-10 shows that there is a significant opportunity for savings not only in fuel costs but also in GHG emissions with the deployment of PEVs in this fleet. 


\title{
Greenhouse Gas Emissions Avoided and fuel Cost Reduction Analysis - Motor Transport Branch
}

\author{
M.1 Replacement PEVs for Motor Transport Branch
}

Section 4.4 provided the analysis results for the Motor Transport Branch vehicles monitored during the study period based upon the data recorded and reported in the vehicle data sheets found in Appendix E. Pool, support, and transport missions are identified for these vehicles.

Forty vehicles were monitored in this study as identified in the individual sections below. Section 3 identifies PEVs currently or soon to be available as potential replacements. There are currently no PEV replacement suggestions for passenger vans or heavy-duty trucks. For the study, PEV replacements are based upon vehicle class. Specific vehicle cargo requirements have not been specified and thus were not considered in these replacement suggestions.

Section 5 provides the methodology and assumptions for the calculations for the reduction in GHG and fuel costs. The miles recorded by vehicles during the 63-day study are extrapolated into annual miles. If the PEV replacing the monitored vehicle is a BEV, all annual miles are powered from the battery. If the $\mathrm{PEV}$ is a PHEV, the percentage of miles that are less than 40 miles per day recorded by the monitored vehicles (Appendix E) is multiplied by the annual miles to identify miles in CD mode. Only these miles are used in the reduction calculations. This is conservative because the replacement PHEV is likely more fuel efficient than the monitored vehicle when powered by the ICE.

\section{M.2 Monitored Pool Mission Vehicle Cost and GHG Reductions}

The monitored vehicles with the pool mission contain four pickup trucks, three minivans, one compact sedan, two midsize sedans, two large sedans, one SUV, three cargo vans and seven passenger vans. As above, no replacement is suggested for the passenger vans. However, the observations of Section 4.3.2.3 suggest that replacing the other sixteen vehicles with six PHEVs and ten BEVs would meet current mission requirements.

Table M-27. JBLM Motor Transport Branch PEV replacements for monitored vehicles with pool mission.

\begin{tabular}{cccccc}
\multicolumn{5}{c}{ Current Vehicle } \\
Logger & \multicolumn{5}{c}{ Mehicle Replacements } \\
No. & Make & Model & EPA Class & PEV Make & PEV Model \\
\hline 6 & Ford & E350 & Van - Cargo & Nissan & eNV200 \\
7 & Ford & Sport Trac & Pickup & Toyota & Rav4 \\
8 & Ford & E350 & Van - Cargo & Nissan & eNV200 \\
9 & Dodge & Avenger & Sedan - Compact & Ford & Focus \\
10 & Dodge & Dakota & Pickup & Via Motors & VTRUX PU \\
11 & Chevrolet & Impala & Sedan - Large & Nissan & Leaf \\
12 & Ford & E350 & Van - Cargo & Via Motors & VTRUX Van \\
19 & Chevrolet & Uplander & Minivan & Toyota & Rav4 \\
20 & Chevrolet & Escape HYB & SUV & Toyota & Rav4 \\
81 & Chevrolet & Malibu & Sedan - Midsize & Nissan & Leaf \\
84 & Dodge & Gr Caravan & Minivan & Mitsubishi & Outlander \\
85 & Dodge & 1500 & Pickup & Via Motors & VTRUX PU \\
97 & Dodge & Dakota & Pickup & Toyota & Rav4 \\
101 & Chevrolet & CG3300 & Van - Pass & NA & NA \\
\hline
\end{tabular}




\begin{tabular}{cccccc}
\hline \multicolumn{5}{c}{ Current Vehicle } \\
$\begin{array}{c}\text { Logger } \\
\text { No. }\end{array}$ & Make & Model & EPA Class & PEV Make & PEV Model \\
\hline 102 & Chevrolet & CG3300 & Van - Pass & NA & NA \\
105 & Chevrolet & CG3300 & Van - Pass & NA & NA \\
106 & Chevrolet & CG3300 & Van - Pass & NA & NA \\
108 & Chevrolet & Impala & Sedan - Large & Chevrolet & Volt \\
109 & Chevrolet & CG3300 & Van - Pass & NA & NA \\
110 & Ford & Fusion HEV & Sedan - Midsize & Ford & Fusion \\
113 & Ford & E350 & Van - Pass & NA & NA \\
116 & Chevrolet & Uplander & Minivan & Toyota & Rav4 \\
117 & Chevrolet & CG3300 & Van - Pass & NA & NA \\
\hline
\end{tabular}

NOTE: Vehicle 84 was reported as part of both the Public Works and Motor Transport Branch fleets. The analysis here includes this vehicle for completeness with this Appendix but omits this vehicle in fleet totals of Section 5.

\section{M.2.1 Monitored Pool Mission Vehicle Fuel Cost Reduction}

Table M-2 identifies the calculated miles in CD mode for each replacement vehicle as well as the projected fuel cost reductions for the pool vehicles. As noted in Section 5, both the local cost of fuel and the national average are used for comparisons.

Because Washington State fuel costs are higher than the national average, gasoline costs locally are greater than national figures. Also, because Tacoma Power relies more on cheaper hydroelectric power than the average of all national power providers, electrical fuel costs in Washington State are lower.

Section 5 summarizes these values.

An example calculation for logger 10 follows: The JBLM reported annual miles for this vehicle is 7,416 miles. The suggested replacement PEV is a PHEV. The Appendix E daily travel percentage for this vehicle less than 40 miles is $25 \%$ so annual miles CD mode is 1,854 miles. EPA fuel economy for this vehicle is 17 MPG implying 109.1 gallons of gasoline are unused. Washington State cost for gasoline is $\$ 4.009 /$ gallon for an annual cost of $\$ 437$. The replacement PEV requires $475 \mathrm{Wh} / \mathrm{mi}$ so $880.6 \mathrm{kWh}$ are required for recharging the battery. Local power cost is $\$ 0.02783 / \mathrm{kWh}$, resulting in annual electric cost of $\$ 25$. The savings are $\$ 412$ for a $94 \%$ reduction in fuel cost.

\section{M.2.2 Monitored Pool Mission Vehicle GHG Reduction}

Table M-3 identifies the reduction in GHG projected when replacing the current pool vehicles with PEVs. The calculated miles in CD mode are also used in the calculation of GHG reduction. As noted in Section 5, the emissions from burning gasoline is known and the emissions from the use of electricity is dependent upon the power generation mix that is used to recharge the PEV battery. As before, both the local power production emission figures and the national average are used for comparisons.

Because Tacoma Power relies more on cleaner hydroelectric power than the average of all national power providers, electrical emissions in Washington State are lower. Electrical emissions are significantly lower than gasoline emissions. 
Table M-28. Monitored pool vehicle replacement fuel cost reduction (Washington State and nationally).

\begin{tabular}{|c|c|c|c|c|c|c|c|c|c|c|c|c|}
\hline Logger & Vehicle & $\begin{array}{c}\text { Replaceme } \\
\text { nt PEV }\end{array}$ & $\begin{array}{c}\% \text { of } \\
\text { Travel CD } \\
\text { Mode }\end{array}$ & $\begin{array}{l}\text { Annual } \\
\text { Miles CD }\end{array}$ & $\begin{array}{c}\text { Gas } \\
\text { Gallons } \\
\text { Saved }\end{array}$ & \multicolumn{2}{|c|}{$\begin{array}{c}\text { Annual Gas } \\
\text { Cost WA }\end{array}$} & \multicolumn{2}{|c|}{$\begin{array}{c}\text { Annual } \\
\text { Elect Fuel } \\
\text { Cost WA }\end{array}$} & \multicolumn{2}{|c|}{$\begin{array}{c}\text { Annual } \\
\text { Fuel } \\
\text { Saving WA }\end{array}$} & $\begin{array}{c}\text { Annual Fuel } \\
\text { Red WA \% }\end{array}$ \\
\hline 6 & G43-0875K & eNV200 & $100 \%$ & 15,252 & 1,173 & $\$$ & 4,703 & $\$$ & 170 & $\$$ & 4,534 & $96 \%$ \\
\hline 7 & G41-1288A & Rav4 & $100 \%$ & 684 & 43 & $\$$ & 171 & $\$$ & 8 & $\$$ & 163 & $95 \%$ \\
\hline 8 & G43-4937A & eNV200 & $100 \%$ & 3,840 & 256 & $\$$ & 1,026 & $\$$ & 43 & $\$$ & 984 & $96 \%$ \\
\hline 9 & G10-7664F & Focus & $100 \%$ & 1,416 & 64 & $\$$ & 258 & $\$$ & 12 & $\$$ & 246 & $95 \%$ \\
\hline 10 & G41-65991 & VTRUX PU & $25 \%$ & 1,854 & 109 & $\$$ & 437 & $\$$ & 25 & $\$$ & 413 & $94 \%$ \\
\hline 11 & G11-2676G & Leaf & $100 \%$ & 7,692 & 350 & $\$$ & 1,402 & $\$$ & 64 & $\$$ & 1,337 & $95 \%$ \\
\hline 12 & G43-3717A & VTRUX Van & $92 \%$ & 6,988 & 499 & $\$$ & 2,001 & $\$$ & 92 & $\$$ & 1,909 & $95 \%$ \\
\hline 19 & G41-1395G & Rav4 & $100 \%$ & 3,648 & 192 & $\$$ & 770 & $\$$ & 45 & $\$$ & 725 & $94 \%$ \\
\hline 20 & G61-1155D & Rav4 & $100 \%$ & 5,232 & 194 & $\$$ & 777 & $\$$ & 64 & $\$$ & 713 & $92 \%$ \\
\hline 81 & G10-2878L & Leaf & $100 \%$ & 5,808 & 223 & $\$$ & 896 & $\$$ & 48 & $\$$ & 847 & $95 \%$ \\
\hline 84 & G41-1100K & Outlander & $96 \%$ & 3,187 & 168 & $\$$ & 672 & $\$$ & 39 & $\$$ & 633 & $94 \%$ \\
\hline 85 & G62-0979G & VTRUX PU & $61 \%$ & 2,408 & 161 & $\$$ & 644 & $\$$ & 32 & $\$$ & 612 & $95 \%$ \\
\hline 97 & G41-1367G & Rav4 & $100 \%$ & 4,044 & 270 & $\$$ & 1,081 & $\$$ & 50 & $\$$ & 1,031 & $95 \%$ \\
\hline 108 & G11-2675G & Volt & $88 \%$ & 1,119 & 51 & $\$$ & 204 & $\$$ & 11 & $\$$ & 193 & $95 \%$ \\
\hline 110 & $\mathrm{G} 12-0662 \mathrm{H}$ & Fusion & $48 \%$ & 5,136 & 132 & $\$$ & 528 & $\$$ & 53 & $\$$ & 475 & $90 \%$ \\
\hline 116 & G41-1161G & Rav4 & $100 \%$ & 1,716 & 90 & $\$$ & 362 & $\$$ & 21 & $\$$ & 341 & $94 \%$ \\
\hline \multicolumn{4}{|l|}{ Total } & 70,025 & 3,974 & & 15,932 & $\$$ & 777 & & 15,156 & $95 \%$ \\
\hline Logger & Vehicle & $\begin{array}{c}\text { Replaceme } \\
\text { nt PEV }\end{array}$ & \begin{tabular}{|c|}
$\%$ of \\
Travel CD \\
Mode \\
\end{tabular} & $\begin{array}{l}\text { Annual } \\
\text { Miles CD }\end{array}$ & $\begin{array}{c}\text { Gas } \\
\text { Gallons } \\
\text { Saved }\end{array}$ & \multicolumn{2}{|c|}{$\begin{array}{c}\text { Annual } \\
\text { Gas Cost } \\
\text { National } \\
\end{array}$} & \multicolumn{2}{|c|}{$\begin{array}{c}\text { Annual } \\
\text { Elect Fuel } \\
\text { Cost Nat } \\
\end{array}$} & \multicolumn{2}{|c|}{$\begin{array}{c}\text { Annual } \\
\text { Fuel } \\
\text { Savings Nat } \\
\end{array}$} & $\begin{array}{c}\text { Annual Fuel } \\
\text { Red } \\
\text { National \% } \\
\end{array}$ \\
\hline 6 & G43-0875K & eNV200 & $100 \%$ & 15,252 & 1,173 & $\$$ & 4,316 & $\$$ & 793 & $\$$ & 3,523 & $82 \%$ \\
\hline 7 & G41-1288A & Rav4 & $100 \%$ & 684 & 43 & $\$$ & 157 & $\$$ & 39 & $\$$ & 118 & $75 \%$ \\
\hline 8 & G43-4937A & eNV200 & $100 \%$ & 3,840 & 256 & $\$$ & 942 & $\$$ & 200 & $\$$ & 742 & $79 \%$ \\
\hline 9 & G10-7664F & Focus & $100 \%$ & 1,416 & 64 & $\$$ & 237 & $\$$ & 57 & $\$$ & 180 & $76 \%$ \\
\hline 10 & G41-65991 & VTRUX PU & $25 \%$ & 1,854 & 109 & $\$$ & 401 & $\$$ & 114 & $\$$ & 287 & $71 \%$ \\
\hline 11 & G11-2676G & Leaf & $100 \%$ & 7,692 & 350 & $\$$ & 1,286 & $\$$ & 300 & $\$$ & 986 & $77 \%$ \\
\hline 12 & G43-3717A & VTRUX Van & $92 \%$ & 6,988 & 499 & $\$$ & 1,836 & $\$$ & 432 & $\$$ & 1,405 & $77 \%$ \\
\hline 19 & G41-1395G & Rav4 & $100 \%$ & 3,648 & 192 & $\$$ & 706 & $\$$ & 209 & $\$$ & 498 & $70 \%$ \\
\hline 20 & G61-1155D & Rav4 & $100 \%$ & 5,232 & 194 & $\$$ & 713 & $\$$ & 299 & $\$$ & 414 & $58 \%$ \\
\hline 81 & G10-2878L & Leaf & $100 \%$ & 5,808 & 223 & $\$$ & 822 & $\$$ & 227 & $\$$ & 595 & $72 \%$ \\
\hline 84 & G41-1100K & Outlander & $96 \%$ & 3,187 & 168 & $\$$ & 617 & $\$$ & 182 & $\$$ & 435 & $70 \%$ \\
\hline 85 & G62-0979G & VTRUX PU & $61 \%$ & 2,408 & 161 & $\$$ & 591 & $\$$ & 149 & $\$$ & 442 & $75 \%$ \\
\hline 97 & G41-1367G & Rav4 & $100 \%$ & 4,044 & 270 & $\$$ & 992 & $\$$ & 231 & $\$$ & 761 & $77 \%$ \\
\hline 108 & G11-2675G & Volt & $88 \%$ & 1,119 & 51 & $\$$ & 187 & $\$$ & 51 & $\$$ & 136 & $73 \%$ \\
\hline 110 & G12-0662H & Fusion & $48 \%$ & 5,136 & 132 & $\$$ & 484 & $\$$ & 247 & $\$$ & 237 & $49 \%$ \\
\hline 116 & G41-1161G & Rav4 & $100 \%$ & 1,716 & 90 & $\$$ & 332 & $\$$ & 98 & $\$$ & 234 & $70 \%$ \\
\hline \multicolumn{4}{|l|}{ Total } & 70,025 & 3,974 & $\$$ & 14,621 & $\$$ & 3,628 & $\$$ & 10,993 & $75 \%$ \\
\hline
\end{tabular}


Table M-29. Monitored vehicle replacement GHG reduction (Washington State and nationally).

\begin{tabular}{|c|c|c|c|c|c|c|c|}
\hline Logger & Vehicle & Vehicle Class & $\begin{array}{c}\text { Replaceme } \\
\text { nt PEV }\end{array}$ & $\begin{array}{c}\text { Annual GHG } \\
\text { Emission ICE } \\
\text { Ib-CO2e }\end{array}$ & $\begin{array}{c}\text { Annual PEV } \\
\text { GHG WA } \\
\text { Ib-CO2e }\end{array}$ & $\begin{array}{c}\text { Annual PEV } \\
\text { GHG Sav WA } \\
\text { Ib-CO2e }\end{array}$ & $\begin{array}{c}\text { Annual GHG } \\
\text { Reduction } \\
\text { WA \% }\end{array}$ \\
\hline 6 & G43-0875K & Van - Cargo & eNV200 & 23,582 & 1,063 & 22,519 & $95 \%$ \\
\hline 7 & G41-1288A & Pickup & Rav4 & 859 & 52 & 807 & $94 \%$ \\
\hline 8 & G43-4937A & Van - Cargo & eNV200 & 5,146 & 268 & 4,878 & $95 \%$ \\
\hline 9 & G10-7664F & Sedan-Compact & Focus & 1,294 & 77 & 1,217 & $94 \%$ \\
\hline 10 & G41-65991 & Pickup & VTRUX PU & 2,192 & 153 & 2,039 & $93 \%$ \\
\hline 11 & G11-2676G & Sedan - Large & Leaf & 7,028 & 402 & 6,625 & $94 \%$ \\
\hline 12 & G43-3717A & Van - Cargo & VTRUX Van & 10,033 & 579 & 9,455 & $94 \%$ \\
\hline 19 & G41-1395G & Minivan & Rav4 & 3,859 & 280 & 3,579 & $93 \%$ \\
\hline 20 & G61-1155D & SUV & Rav4 & 3,895 & 401 & 3,494 & $90 \%$ \\
\hline 81 & G10-2878L & Sedan - Midsize & Leaf & 4,490 & 304 & 4,186 & $93 \%$ \\
\hline 85 & G62-0979G & Pickup & VTRUX PU & 3,227 & 199 & 3,028 & $94 \%$ \\
\hline 97 & G41-1367G & Pickup & Rav4 & 5,419 & 310 & 5,109 & $94 \%$ \\
\hline 108 & G11-2675G & Sedan - Large & Volt & 1,023 & 68 & 954 & $93 \%$ \\
\hline 110 & G12-0662H & Sedan - Midsize & Fusion & 2,647 & 331 & 2,316 & $87 \%$ \\
\hline 116 & G41-1161G & Minivan & Rav4 & 1,815 & 132 & 1,684 & $93 \%$ \\
\hline Total & & & & 76,509 & 4,620 & 71,889 & $94 \%$ \\
\hline Logger & Vehicle & Vehicle Class & $\begin{array}{c}\text { Replaceme } \\
\text { nt PEV }\end{array}$ & $\begin{array}{c}\text { Annual GHG } \\
\text { Emission ICE } \\
\text { Ib-CO2e }\end{array}$ & $\begin{array}{c}\text { Annual PEV } \\
\text { GHG Nat } \\
\text { Ib-CO2e }\end{array}$ & $\begin{array}{c}\text { Annual PEV } \\
\text { GHG Sav Nat } \\
\text { lb-CO2e }\end{array}$ & $\begin{array}{c}\text { Annual GHG } \\
\text { Reduction } \\
\text { National \% } \\
\end{array}$ \\
\hline 6 & G43-0875K & Van - Cargo & eNV200 & 23,582 & 9,334 & 14,248 & $60 \%$ \\
\hline 7 & G41-1288A & Pickup & Rav4 & 859 & 460 & 399 & $46 \%$ \\
\hline 8 & G43-4937A & Van - Cargo & eNV200 & 5,146 & 2,350 & 2,796 & $54 \%$ \\
\hline 9 & G10-7664F & Sedan - Compact & Focus & 1,294 & 672 & 622 & $48 \%$ \\
\hline 10 & G41-65991 & Pickup & VTRUX PU & 2,192 & 1,347 & 845 & $39 \%$ \\
\hline 11 & G11-2676G & Sedan - Large & Leaf & 7,028 & 3,531 & 3,497 & $50 \%$ \\
\hline 12 & G43-3717A & Van - Cargo & VTRUX Van & 10,033 & 5,079 & 4,954 & $49 \%$ \\
\hline 19 & G41-1395G & Minivan & Rav4 & 3,859 & 2,456 & 1,403 & $36 \%$ \\
\hline 20 & G61-1155D & SUV & Rav4 & 3,895 & 3,522 & 373 & $10 \%$ \\
\hline 81 & G10-2878L & Sedan - Midsize & Leaf & 4,490 & 2,666 & 1,824 & $41 \%$ \\
\hline 85 & G62-0979G & Pickup & VTRUX PU & 3,227 & 1,750 & 1,477 & $46 \%$ \\
\hline 97 & G41-1367G & Pickup & Rav4 & 5,419 & 2,722 & 2,697 & $50 \%$ \\
\hline 108 & G11-2675G & Sedan - Large & Volt & 1,023 & 599 & 423 & $41 \%$ \\
\hline 110 & G12-0662H & Sedan - Midsize & Fusion & 2,647 & 2,907 & -260 & $-10 \%$ \\
\hline 116 & G41-1161G & Minivan & Rav4 & 1,815 & 1,155 & 660 & $36 \%$ \\
\hline \multicolumn{4}{|l|}{ Total } & 76,509 & 40,552 & 35,957 & $47 \%$ \\
\hline
\end{tabular}

Section 5 summarizes these figures. It is interesting to note that logger 110 was installed on a Ford Fusion hybrid vehicle. The replacement PEV is suggested to be a Ford Fusion PHEV. The fuel economy on this hybrid vehicle is such that emissions are greater using the national electric generation mix than burning the gasoline would be. However, the generation mix in Washington State is significantly less and thus GHG reduction is observed.

An example calculation for logger 10 follows: As shown above, the annual miles CD mode is 1,854 miles and 109.1 gallons of gasoline are unused. Internal combustion vehicles produce $20.1 \mathrm{lb}$ - 
CO2e/gallon, so the annual emissions for the monitored vehicle are 2,192 lb-CO2e. Tacoma Power produces $0.1743 \mathrm{lb}-\mathrm{CO} 2 \mathrm{e} / \mathrm{kWh}$. As above, $880.6 \mathrm{kWh}$ are required for recharging the battery, resulting in $153 \mathrm{lb}-\mathrm{CO} 2 \mathrm{e}$. The savings are 2,039 lb-CO2e, for a 93\% reduction in GHG emission.

\section{M.2.3 Motor Transport Branch full Pool Mission Fleet Evaluation}

Table 25 in Section 4.4 identifies 495 vehicles in the Motor Transport Branch pool fleet. Aside from the passenger vans, PEV replacements may be possible for 327 vehicles. Intertek suggests a fleet of 196 BEVs and 131 PHEVs conservatively meet the other vehicle travel requirements.

A mix of 89 RAV4 EVs, 22 Leafs, 12 Focus Electrics, and 73 eNV200s are assumed to be appropriate BEVs while 47 Via Motors VTRUX pickups, 33 Outlander PHEVs, 8 Volts, 14 Fusion Energis, and 29 VTRUX Vans are assumed to be appropriate PHEV replacements.

Using averages for these vehicles, the replacements offer the potential fuel cost reductions and GHG reductions shown in Table M-4 below.

Table M-30. Motor Transport Branch full pool fleet PEV replacement reductions (fuel cost and GHG emissions).

\begin{tabular}{|c|c|c|c|c|c|c|c|c|}
\hline $\begin{array}{c}\text { Annual } \\
\text { Miles CD }\end{array}$ & $\begin{array}{c}\text { Annual Gas } \\
\text { Cost WA }\end{array}$ & $\begin{array}{c}\text { Annual } \\
\text { Elect Fuel } \\
\text { Cost WA }\end{array}$ & $\begin{array}{c}\text { Annual Fuel } \\
\text { Saving WA }\end{array}$ & $\begin{array}{c}\text { Annual Fuel } \\
\text { Reduction } \\
\text { WA } \%\end{array}$ & $\begin{array}{c}\text { Annual Gas } \\
\text { Cost } \\
\text { National }\end{array}$ & $\begin{array}{c}\text { Annual } \\
\text { Elect Fuel } \\
\text { Cost Nat }\end{array}$ & $\begin{array}{c}\text { Annual Fuel } \\
\text { Savings } \\
\text { National }\end{array}$ & $\begin{array}{c}\text { Annual Fuel } \\
\text { Reduction } \\
\text { Natonal } \%\end{array}$ \\
\hline $1,719,235$ & $\$ 432,061$ & $\$ 19,769$ & $\$ 412,292$ & $95 \%$ & $\$ 396,496$ & $\$ 92,345$ & $\$ 304,151$ & $77 \%$ \\
\hline
\end{tabular}

\begin{tabular}{|c|c|r|r|r|r|r|r|}
\hline $\begin{array}{c}\text { Annual } \\
\text { Miles CD }\end{array}$ & $\begin{array}{c}\text { Annual GHG } \\
\text { Emission } \\
\text { ICE Ib-CO2e }\end{array}$ & $\begin{array}{c}\text { Annual PEV } \\
\text { GHG WA } \\
\text { Ib-CO2e }\end{array}$ & $\begin{array}{c}\text { Annual PEV } \\
\text { GHG Sav } \\
\text { WA Ib-CO2e }\end{array}$ & $\begin{array}{c}\text { Annual GHG } \\
\text { Reduction } \\
\text { WA \% }\end{array}$ & $\begin{array}{c}\text { Annual PEV } \\
\text { GHG Nat } \\
\text { Ib-CO2e }\end{array}$ & $\begin{array}{c}\text { Annual PEV } \\
\text { GHG Sav Nat } \\
\text { Ib-CO2e }\end{array}$ & $\begin{array}{c}\text { Annual GHG } \\
\text { Reduction } \\
\text { National \% }\end{array}$ \\
\hline $1,719,235$ & $2,166,233$ & 123,814 & $2,042,420$ & $94 \%$ & $1,086,835$ & $1,091,754$ & $50 \%$ \\
\hline
\end{tabular}

Section 5 also summarizes these values.

\section{M.3 Monitored Support Mission Vehicle Cost and GHG Reductions}

The monitored vehicles with the support mission contain three pickup trucks, one midsize sedan, two large sedans, two SUVs, two minivans, and one cargo van. The observations of Section 4.4.3.3 suggest that replacing these vehicles with six PHEV and five BEVs would meet current mission requirements. Table M-5 identifies these vehicles and suggested replacement PEVs.

Table M-31. JBLM Motor Transport Branch PEV replacements for monitored vehicles with support mission.

\begin{tabular}{cccccc}
\multicolumn{5}{c}{ Current Vehicle } \\
$\begin{array}{c}\text { Logger } \\
\text { No. }\end{array}$ & Make & Model & EPA Class & PEV Make & PEV Model \\
\hline 13 & Chevrolet & Impala & Sedan - Large & Nissan & Leaf \\
14 & Chevrolet & Tahoe & SUV & Mitsubishi & Outlander \\
15 & Chevrolet & C1500 & Pickup & Via Motors & VTRUX PU \\
16 & Chevrolet & Impala & Sedan - Large & Ford & Fusion \\
18 & Chevrolet & Avalanche & SUV & Nissan & Leaf \\
93 & Dodge & Dakota & Pickup & Mitsubishi & Outlander \\
104 & Chevrolet & Express 13 & Van - Cargo & Nissan & eNV200 \\
107 & Chevrolet & Uplander & Minivan & Mitsubishi & Outlander \\
112 & Chevrolet & Uplander & Minivan & Mitsubishi & Outlander \\
115 & Dodge & Dakota & Pickup & Nissan & eNV200 \\
119 & Dodge & Avenger & Sedan - Midsize & Nissan & Leaf \\
\hline
\end{tabular}




\section{M.3.1 Monitored Support Mission Vehicle Fuel Cost Reduction}

Table M-6 identifies the calculated miles in CD mode for each replacement vehicle as well as the projected fuel cost reductions for the support vehicles.

As before, because Washington State fuel costs are higher than the national average, gasoline costs locally are greater than national figures. Also, because Tacoma Power relies more on cheaper hydroelectric power than the average of all national power providers, electrical fuel costs in Washington State are lower.

Table M-32. Monitored support vehicle replacement fuel cost reduction (Washington State and nationally).

\begin{tabular}{|c|c|c|c|c|c|c|c|c|c|c|c|c|}
\hline \multirow{2}{*}{$\begin{array}{c}\text { Logger } \\
13\end{array}$} & \multirow{2}{*}{\begin{tabular}{|c|} 
Vehicle \\
G11-0678K \\
\end{tabular}} & \multirow{2}{*}{$\begin{array}{c}\begin{array}{c}\text { Replaceme } \\
\text { nt PEV }\end{array} \\
\text { Leaf }\end{array}$} & \multirow{2}{*}{$\begin{array}{c}\begin{array}{c}\% \text { of } \\
\text { Travel CD } \\
\text { Mode }\end{array} \\
100 \%\end{array}$} & \multirow{2}{*}{\begin{tabular}{|r}
$\begin{array}{c}\text { Annual } \\
\text { Miles CD }\end{array}$ \\
6,132
\end{tabular}} & \multirow{2}{*}{$\begin{array}{c}\begin{array}{c}\text { Gas } \\
\text { Gallons } \\
\text { Saved }\end{array} \\
279\end{array}$} & \multicolumn{2}{|c|}{$\begin{array}{c}\text { Annual Gas } \\
\text { Cost WA }\end{array}$} & \multicolumn{2}{|c|}{$\begin{array}{c}\text { Annual } \\
\text { Elect Fuel } \\
\text { Cost WA }\end{array}$} & \multicolumn{2}{|c|}{$\begin{array}{c}\text { Annual } \\
\text { Fuel } \\
\text { Saving WA } \\
\end{array}$} & \multirow{2}{*}{$\begin{array}{r}\begin{array}{c}\text { Annual Fuel } \\
\text { Red WA \% }\end{array} \\
95 \%\end{array}$} \\
\hline & & & & & & $\$$ & 1,117 & $\$$ & 51 & $\$$ & 1,066 & \\
\hline 14 & $\mathrm{G} 62-4526 \mathrm{H}$ & Outlander & $83 \%$ & 9,980 & 624 & $\$$ & 2,501 & $\$$ & 122 & $\$$ & 2,378 & $95 \%$ \\
\hline 15 & G42-0698K & VTRUX PU & $3 \%$ & 693 & 41 & $\$$ & 163 & $\$$ & 9 & $\$$ & 154 & $94 \%$ \\
\hline 16 & G11-0493L & Fusion & $29 \%$ & 4,065 & 185 & $\$$ & 741 & $\$$ & 42 & $\$$ & 699 & $94 \%$ \\
\hline 18 & G62-1094L & Leaf & $100 \%$ & 6,528 & 384 & $\$$ & 1,539 & $\$$ & 55 & $\$$ & 1,485 & $96 \%$ \\
\hline 93 & G41-1373G & Outlander & $23 \%$ & 2,531 & 169 & $\$$ & 676 & $\$$ & 31 & $\$$ & 645 & $95 \%$ \\
\hline 104 & G42-0988F & eNV200 & $100 \%$ & 9,096 & 650 & $\$$ & 2,605 & $\$$ & 101 & $\$$ & 2,503 & $96 \%$ \\
\hline 107 & G41-1180G & Outlander & $88 \%$ & 10,000 & 526 & $\$$ & 2,110 & $\$$ & 122 & $\$$ & 1,988 & $94 \%$ \\
\hline 112 & G41-1392G & Outlander & $70 \%$ & 4,670 & 246 & $\$$ & 985 & $\$$ & 57 & $\$$ & 928 & $94 \%$ \\
\hline 115 & G41-1376G & eNV200 & $100 \%$ & 3,084 & 206 & $\$$ & 824 & $\$$ & 34 & $\$$ & 790 & $96 \%$ \\
\hline 119 & G10-6379L & Leaf & $100 \%$ & 7,584 & 345 & $\$$ & 1,382 & $\$$ & 63 & $\$$ & 1,319 & $95 \%$ \\
\hline \multicolumn{4}{|l|}{ Total } & 64,364 & 3,653 & & 14,645 & $\$$ & 688 & & 13,956 & $95 \%$ \\
\hline Logger & Vehicle & $\begin{array}{c}\text { Replaceme } \\
\text { nt PEV }\end{array}$ & \begin{tabular}{|c|}
$\%$ of \\
Travel CD \\
Mode \\
\end{tabular} & $\begin{array}{l}\text { Annual } \\
\text { Miles CD }\end{array}$ & $\begin{array}{c}\text { Gas } \\
\text { Gallons } \\
\text { Saved }\end{array}$ & \multicolumn{2}{|c|}{$\begin{array}{l}\text { Annual } \\
\text { Gas Cost } \\
\text { National }\end{array}$} & \multicolumn{2}{|c|}{$\begin{array}{c}\text { Annual } \\
\text { Elect Fuel } \\
\text { Cost Nat }\end{array}$} & \multicolumn{2}{|c|}{$\begin{array}{c}\text { Annual } \\
\text { Fuel } \\
\text { Savings Nat }\end{array}$} & $\begin{array}{c}\text { Annual Fuel } \\
\text { Red } \\
\text { National \% } \\
\end{array}$ \\
\hline 13 & G11-0678K & Leaf & $100 \%$ & 6,132 & 279 & $\$$ & 1,025 & $\$$ & 239 & $\$$ & 786 & $77 \%$ \\
\hline 14 & G62-4526H & Outlander & $83 \%$ & 9,980 & 624 & $\$$ & 2,295 & $\$$ & 571 & $\$$ & 1,724 & $75 \%$ \\
\hline 15 & G42-0698K & VTRUX PU & $3 \%$ & 693 & 41 & $\$$ & 150 & $\$$ & 43 & $\$$ & 107 & $71 \%$ \\
\hline 16 & G11-0493L & Fusion & $29 \%$ & 4,065 & 185 & $\$$ & 680 & $\$$ & 196 & $\$$ & 484 & $71 \%$ \\
\hline 18 & G62-1094L & Leaf & $100 \%$ & 6,528 & 384 & $\$$ & 1,413 & $\$$ & 255 & $\$$ & 1,158 & $82 \%$ \\
\hline 93 & G41-1373G & Outlander & $23 \%$ & 2,531 & 169 & $\$$ & 621 & $\$$ & 145 & $\$$ & 476 & $77 \%$ \\
\hline 104 & G42-0988F & eNV200 & $100 \%$ & 9,096 & 650 & $\$$ & 2,390 & $\$$ & 473 & $\$$ & 1,917 & $80 \%$ \\
\hline 107 & G41-1180G & Outlander & $88 \%$ & 10,000 & 526 & $\$$ & 1,936 & $\$$ & 572 & $\$$ & 1,364 & $70 \%$ \\
\hline 112 & G41-1392G & Outlander & $70 \%$ & 4,670 & 246 & $\$$ & 904 & $\$$ & 267 & $\$$ & 637 & $70 \%$ \\
\hline 115 & G41-1376G & eNV200 & $100 \%$ & 3,084 & 206 & $\$$ & 756 & $\$$ & 160 & $\$$ & 596 & $79 \%$ \\
\hline 119 & G10-6379L & Leaf & $100 \%$ & 7,584 & 345 & $\$$ & 1,268 & $\$$ & 296 & $\$$ & 972 & $77 \%$ \\
\hline \multicolumn{4}{|l|}{ Total } & 64,364 & 3,653 & $\$$ & 13,439 & $\$$ & 3,216 & $\$$ & 10,223 & $76 \%$ \\
\hline
\end{tabular}

Section 5 summarizes these values.

\section{M.3.2 Monitored Support Mission Vehicle GHG Reduction}

Table M-7 identifies the reduction in GHG projected when replacing the current support mission vehicles with PEVs.

As before, because Tacoma Power relies more on cleaner hydroelectric power than the average of all national power providers, electrical emissions in Washington State are lower. Electrical emissions are significantly lower than gasoline emissions. 
Table M-33. Monitored support vehicle replacement GHG reduction (Washington State and nationally).

\begin{tabular}{|c|c|c|c|c|c|c|c|}
\hline Logger & Vehicle & Vehicle Class & $\begin{array}{c}\text { Replaceme } \\
\text { nt PEV }\end{array}$ & $\begin{array}{c}\text { Annual GHG } \\
\text { Emission ICE } \\
\text { lb-CO2e }\end{array}$ & $\begin{array}{c}\text { Annual PEV } \\
\text { GHG WA } \\
\text { lb-CO2e }\end{array}$ & $\begin{array}{c}\text { Annual PEV } \\
\text { GHG Sav WA } \\
\text { lb-CO2e }\end{array}$ & $\begin{array}{c}\text { Annual GHG } \\
\text { Reduction } \\
\text { WA \% }\end{array}$ \\
\hline 13 & G11-0678K & Sedan - Large & Leaf & 5,602 & 321 & 5,282 & $94 \%$ \\
\hline 14 & G62-4526H & SUV & Outlander & 12,537 & 765 & 11,772 & $94 \%$ \\
\hline 15 & G42-0698K & Pickup & VTRUX PU & 820 & 57 & 762 & $93 \%$ \\
\hline 16 & G11-0493L & Sedan - Large & Fusion & 3,714 & 262 & 3,451 & $93 \%$ \\
\hline 18 & G62-1094L & SUV & Leaf & 7,718 & 341 & 7,377 & $96 \%$ \\
\hline 93 & G41-1373G & Pickup & Outlander & 3,391 & 194 & 3,197 & $94 \%$ \\
\hline 104 & G42-0988F & Van-Cargo & eNV200 & 13,059 & 634 & 12,425 & $95 \%$ \\
\hline 107 & G41-1180G & Minivan & Outlander & 10,579 & 767 & 9,812 & $93 \%$ \\
\hline 112 & G41-1392G & Minivan & Outlander & 4,941 & 358 & 4,583 & $93 \%$ \\
\hline 115 & G41-1376G & Pickup & eNV200 & 4,133 & 215 & 3,918 & $95 \%$ \\
\hline 119 & G10-6379L & Sedan - Midsize & Leaf & 6,929 & 397 & 6,532 & $94 \%$ \\
\hline \multicolumn{4}{|l|}{ Total } & 73,424 & 4,312 & 69,112 & $94 \%$ \\
\hline Logger & Vehicle & Vehicle Class & $\begin{array}{c}\text { Replaceme } \\
\text { nt PEV }\end{array}$ & $\begin{array}{c}\text { Annual GHG } \\
\text { Emission ICE } \\
\text { Ib-CO2e }\end{array}$ & $\begin{array}{c}\text { Annual PEV } \\
\text { GHG Nat } \\
\text { lb-CO2e }\end{array}$ & $\begin{array}{c}\text { Annual PEV } \\
\text { GHG Sav Nat } \\
\text { Ib-CO2e }\end{array}$ & $\begin{array}{c}\text { Annual GHG } \\
\text { Reduction } \\
\text { National \% } \\
\end{array}$ \\
\hline 13 & G11-0678K & Sedan - Large & Leaf & $5,602.4$ & $2,814.6$ & 2,788 & $50 \%$ \\
\hline 14 & G62-4526H & SUV & Outlander & $12,537.3$ & $6,718.5$ & 5,819 & $46 \%$ \\
\hline 15 & G42-0698K & Pickup & VTRUX PU & 819.7 & 503.9 & 316 & $39 \%$ \\
\hline 16 & G11-0493L & Sedan - Large & Fusion & $3,713.6$ & $2,301.0$ & 1,413 & $38 \%$ \\
\hline 18 & G62-1094L & SUV & Leaf & $7,718.4$ & $2,996.4$ & 4,722 & $61 \%$ \\
\hline 93 & G41-1373G & Pickup & Outlander & $3,391.4$ & $1,703.8$ & 1,688 & $50 \%$ \\
\hline 104 & G42-0988F & Van - Cargo & eNV200 & $13,059.3$ & $5,566.8$ & 7,493 & $57 \%$ \\
\hline 107 & G41-1180G & Minivan & Outlander & $10,579.3$ & $6,732.2$ & 3,847 & $36 \%$ \\
\hline 112 & G41-1392G & Minivan & Outlander & $4,940.8$ & $3,144.1$ & 1,797 & $36 \%$ \\
\hline 115 & G41-1376G & Pickup & eNV200 & $4,132.6$ & $1,887.4$ & 2,245 & $54 \%$ \\
\hline 119 & G10-6379L & Sedan - Midsize & Leaf & $6,929.0$ & $3,481.1$ & 3,448 & $50 \%$ \\
\hline \multicolumn{4}{|l|}{ Total } & 73,424 & 37,850 & 35,574 & $48 \%$ \\
\hline
\end{tabular}

Section 5 summarizes these figures.

\section{M.3.3 Motor Transport Branch Full Support Fleet Evaluation}

Table 25 in Section 4.4 identifies 301 vehicles in the Motor Transport Branch support mission fleet. Aside from the passenger vans for which no PEV replacement is currently available, Intertek suggests a fleet of $155 \mathrm{BEVs}$ and 128 PHEVs conservatively meet the other 283 vehicle travel requirements.

A mix of 82 RAV4 EVs, 2 Focus Electrics, 33 Leafs, and 38 eNV200s are assumed to be appropriate BEVs while 30 Via Motors VTRUX pickups, 67 Outlander PHEVs, 27 Fusion Energis, 1 Volt, and 3 VTRUX Vans are assumed to be appropriate PHEV replacements.

Using averages for these vehicles, the potential replacements offer the fuel cost reductions and GHG reductions shown in Table M-8 below. 
Table M-34. Motor Transport Branch full support fleet PEV replacement reductions (fuel cost and GHG emissions).

\begin{tabular}{|c|c|c|c|c|r|r|r|c|}
\hline $\begin{array}{c}\text { Annual } \\
\text { Miles CD }\end{array}$ & $\begin{array}{c}\text { Annual Gas } \\
\text { Cost WA }\end{array}$ & $\begin{array}{c}\text { Annual } \\
\text { Elect Fuel } \\
\text { Cost WA }\end{array}$ & $\begin{array}{c}\text { Annual Fuel } \\
\text { Saving WA }\end{array}$ & $\begin{array}{c}\text { Annual Fuel } \\
\text { Reduction } \\
\text { WA } \%\end{array}$ & $\begin{array}{c}\text { Annual Gas } \\
\text { Cost } \\
\text { National }\end{array}$ & $\begin{array}{c}\text { Annual } \\
\text { Elect Fuel } \\
\text { Cost Nat }\end{array}$ & $\begin{array}{c}\text { Annual Fuel } \\
\text { Savings } \\
\text { National }\end{array}$ & $\begin{array}{c}\text { Annual Fuel } \\
\text { Reduction } \\
\text { National } \%\end{array}$ \\
\hline $1,363,016$ & $\$ 315,768$ & $\$ 15,370$ & $\$ 300,399$ & $95 \%$ & $\$ 289,776$ & $\$ 1,795$ & 217,981 & \\
\hline
\end{tabular}

\begin{tabular}{|c|r|r|r|r|r|r|r|}
\hline $\begin{array}{c}\text { Annual } \\
\text { Miles CD }\end{array}$ & $\begin{array}{c}\text { Annual GHG } \\
\text { Emission } \\
\text { ICE Ib-CO2e }\end{array}$ & $\begin{array}{c}\text { Annual PEV } \\
\text { GHG WA } \\
\text { Ib-CO2e }\end{array}$ & $\begin{array}{c}\text { Annual PEV } \\
\text { GHG Sav } \\
\text { WA Ib-CO2e }\end{array}$ & $\begin{array}{c}\text { Annual GHG } \\
\text { Reduction } \\
\text { WA \% }\end{array}$ & $\begin{array}{c}\text { Annual PEV } \\
\text { GHG Nat } \\
\text { Ib-CO2e }\end{array}$ & $\begin{array}{c}\text { Annual PEV } \\
\text { GHG Sav Nat } \\
\text { Ib-CO2e }\end{array}$ & $\begin{array}{c}\text { Annual GHG } \\
\text { Reduction } \\
\text { National \% }\end{array}$ \\
\hline $1,363,016$ & $1,583,173$ & 96,260 & $1,486,913$ & $94 \%$ & 844,973 & 738,200 & $47 \%$ \\
\hline
\end{tabular}

Section 5 also summarizes these values.

\section{M.4 Monitored Transport Mission Vehicle Cost and GHG Reductions}

The monitored vehicles with the transport mission contain two pickup trucks, two heavy-duty trucks, and two cargo van. The observations of Section 4.4.3.3 suggest that replacing these vehicles with two PHEVs and two BEVs would meet current mission requirements. Table M-9 identifies these vehicles and suggested replacement PEVs.

Table M-35. JBLM Motor Transport Branch PEV replacements for monitored vehicles with transport mission.

\begin{tabular}{cccccc}
\multicolumn{7}{c}{ Logger } & \multicolumn{2}{c}{ Vehicle Replacements } & PEV Replacement \\
No. & Make & Model & EPA Class & PEV Make & PEV Model \\
\hline 17 & Ford & F750 & Truck HD & NA & NA \\
89 & Ford & F650 & Van - Cargo & Via Motors & VTRUX Van \\
111 & Ford & F350 & Pickup & Via Motors & VTRUX PU \\
114 & Ford & F350 & Pickup & Toyota & Rav4 \\
118 & Ford & F650 & Truck HD & NA & NA \\
120 & Chevrolet & G2300 & Van - Cargo & Nissan & eNV200 \\
\hline
\end{tabular}

\section{M.4.1 Monitored Transport Mission Vehicle Fuel Cost Reduction}

Table M-10 identifies the calculated miles in CD mode for each replacement vehicle as well as the projected fuel cost reductions for the support vehicles.

As before, because Washington State fuel costs are higher than the national average, gasoline costs locally are greater than national figures. Also, because Tacoma Power relies more on cheaper hydroelectric power than the average of all national power providers, electrical fuel costs in Washington State are lower.

Section 5 summarizes these values.

\section{M.4.2 Monitored Transport Mission Vehicle GHG Reduction}

Table M-11 identifies the reduction in GHG projected when replacing the current support mission vehicles with PEVs.

As before, because Tacoma Power relies more on cleaner hydroelectric power than the average of all national power providers, electrical emissions in Washington State are lower. Electrical emissions are significantly lower than gasoline emissions. 
Table M-36. Motor Transport Branch monitored transport fleet PEV replacement fuel cost reductions.

\begin{tabular}{|c|c|c|c|c|c|c|c|c|c|c|c|c|}
\hline \multirow{2}{*}{$\begin{array}{c}\text { Logger } \\
17\end{array}$} & \multirow{2}{*}{\begin{tabular}{|c|} 
Vehicle \\
G71-0062G
\end{tabular}} & \multirow{2}{*}{$\begin{array}{c}\text { Replaceme } \\
\text { nt PEV }\end{array}$} & \multirow{2}{*}{$\begin{array}{c}\begin{array}{c}\% \text { of } \\
\text { Travel CD } \\
\text { Mode }\end{array} \\
0 \%\end{array}$} & \multirow{2}{*}{$\begin{array}{c}\begin{array}{c}\text { Annual } \\
\text { Miles CD }\end{array} \\
-\end{array}$} & \multirow{2}{*}{$\begin{array}{c}\text { Gas } \\
\text { Gallons } \\
\text { Saved }\end{array}$} & \multicolumn{2}{|c|}{$\begin{array}{c}\text { Annual Gas } \\
\text { Cost WA }\end{array}$} & \multicolumn{2}{|c|}{$\begin{array}{c}\text { Annual } \\
\text { Elect Fuel } \\
\text { Cost WA }\end{array}$} & \multicolumn{2}{|c|}{$\begin{array}{c}\text { Annual } \\
\text { Fuel } \\
\text { Saving WA }\end{array}$} & \multirow[t]{2}{*}{$\begin{array}{c}\text { Annual Fuel } \\
\text { Red WA \% }\end{array}$} \\
\hline & & & & & & $\$$ & - & $\$$ & - & $\$$ & - & \\
\hline 89 & G71-0674A & VTRUX Van & $69 \%$ & 2,964 & 228 & $\$$ & 914 & $\$$ & 39 & $\$$ & 875 & $96 \%$ \\
\hline 111 & G63-0271A & VTRUX PU & $59 \%$ & 2,251 & 173 & $\$$ & 694 & $\$$ & 30 & $\$$ & 665 & $96 \%$ \\
\hline 114 & G43-25839 & Rav4 & $100 \%$ & 4,812 & 370 & $\$$ & 1,484 & $\$$ & 59 & $\$$ & 1,425 & $96 \%$ \\
\hline 118 & G82-0509A & NA & $0 \%$ & & & & & $\$$ & - & $\$$ & - & \\
\hline 120 & G42-3471A & eNV200 & $100 \%$ & 3,228 & 215 & $\$$ & 863 & $\$$ & 36 & $\$$ & 827 & $96 \%$ \\
\hline \multicolumn{4}{|l|}{ Total } & 13,256 & 987 & $\$$ & 3,955 & $\$$ & 164 & & 3,791 & $96 \%$ \\
\hline Logger & Vehicle & $\begin{array}{c}\text { Replaceme } \\
\text { nt PEV }\end{array}$ & $\begin{array}{c}\% \text { of } \\
\text { Travel CD } \\
\text { Mode }\end{array}$ & $\begin{array}{c}\text { Annual } \\
\text { Miles CD }\end{array}$ & $\begin{array}{c}\text { Gas } \\
\text { Gallons } \\
\text { Saved }\end{array}$ & \multicolumn{2}{|c|}{$\begin{array}{l}\text { Annual } \\
\text { Gas Cost } \\
\text { National }\end{array}$} & \multicolumn{2}{|c|}{$\begin{array}{c}\text { Annual } \\
\text { Elect Fuel } \\
\text { Cost Nat }\end{array}$} & \multicolumn{2}{|c|}{$\begin{array}{c}\text { Annual } \\
\text { Fuel } \\
\text { Savings Nat }\end{array}$} & $\begin{array}{c}\text { Annual Fuel } \\
\text { Red } \\
\text { National \% }\end{array}$ \\
\hline 17 & G71-0062G & NA & $0 \%$ & - & - & $\$$ & - & $\$$ & - & $\$$ & - & \\
\hline 89 & G71-0674A & VTRUX Van & $69 \%$ & 2,964 & 228 & $\$$ & 839 & $\$$ & 183 & $\$$ & 656 & $78 \%$ \\
\hline 111 & G63-0271A & VTRUX PU & $59 \%$ & 2,251 & 173 & $\$$ & 637 & $\$$ & 139 & $\$$ & 498 & $78 \%$ \\
\hline 114 & G43-25839 & Rav4 & $100 \%$ & 4,812 & 370 & $\$$ & 1,362 & $\$$ & 275 & $\$$ & 1,087 & $80 \%$ \\
\hline 118 & G82-0509A & NA & $0 \%$ & & 705 & & & $\$$ & - & $\$$ & - & \\
\hline 120 & G42-3471A & eNV200 & $100 \%$ & 3,228 & 215 & $\$$ & 792 & $\$$ & 168 & $\$$ & 624 & $79 \%$ \\
\hline Total & & & & 13,256 & 1,691 & $\$$ & 3,630 & $\$$ & 765 & $\$$ & 2,864 & $79 \%$ \\
\hline
\end{tabular}

Table M-37. Monitored transport vehicle replacement GHG reduction (Washington State and nationally).

\begin{tabular}{|c|c|c|c|c|c|c|c|}
\hline Logger & Vehicle & Vehicle Class & $\begin{array}{c}\text { Replaceme } \\
\text { nt PEV }\end{array}$ & $\begin{array}{c}\text { Annual GHG } \\
\text { Emission ICE } \\
\text { lb-CO2e }\end{array}$ & $\begin{array}{c}\text { Annual PEV } \\
\text { GHG WA } \\
\text { lb-CO2e }\end{array}$ & $\begin{array}{c}\text { Annual PEV } \\
\text { GHG Sav WA } \\
\text { lb-CO2e }\end{array}$ & $\begin{array}{c}\text { Annual GHG } \\
\text { Reduction } \\
\text { WA \% }\end{array}$ \\
\hline 17 & G71-0062G & Truck HD & NA & 0.0 & 0.0 & 0 & \\
\hline 89 & G71-0674A & Van - Cargo & VTRUX Van & $4,583.2$ & 245.4 & 4,338 & $95 \%$ \\
\hline 111 & G63-0271A & Pickup & VTRUX PU & $3,481.1$ & 186.4 & 3,295 & $95 \%$ \\
\hline 114 & G43-25839 & Pickup & Rav4 & $7,440.1$ & 369.0 & 7,071 & $95 \%$ \\
\hline 118 & G82-0509A & Truck HD & NA & & 0.0 & 0 & \\
\hline 120 & G42-3471A & Van - Cargo & eNV200 & $4,325.5$ & 225.1 & 4,100 & $95 \%$ \\
\hline \multicolumn{4}{|l|}{ Total } & 19,830 & 1,026 & 18,804 & $95 \%$ \\
\hline Logger & Vehicle & Vehicle Class & $\begin{array}{c}\text { Replaceme } \\
\text { nt PEV }\end{array}$ & $\begin{array}{c}\text { Annual GHG } \\
\text { Emission ICE } \\
\text { Ib-CO2e }\end{array}$ & $\begin{array}{c}\text { Annual PEV } \\
\text { GHG Nat } \\
\text { lb-CO2e }\end{array}$ & $\begin{array}{c}\text { Annual PEV } \\
\text { GHG Sav Nat } \\
\text { Ib-CO2e }\end{array}$ & $\begin{array}{c}\text { Annual GHG } \\
\text { Reduction } \\
\text { National \% } \\
\end{array}$ \\
\hline 17 & G71-0062G & Truck HD & NA & 0.0 & 0.0 & 0 & \\
\hline 89 & G71-0674A & Van - Cargo & VTRUX Van & $4,583.2$ & $2,154.3$ & 2,429 & $53 \%$ \\
\hline 111 & G63-0271A & Pickup & VTRUX PU & $3,481.1$ & $1,636.2$ & 1,845 & $53 \%$ \\
\hline 114 & G43-25839 & Pickup & Rav4 & $7,440.1$ & $3,239.4$ & 4,201 & $56 \%$ \\
\hline 118 & G82-0509A & Truck HD & NA & & 0.0 & 0 & \\
\hline 120 & G42-3471A & Van - Cargo & eNV200 & $4,325.5$ & $1,975.5$ & 2,350 & $54 \%$ \\
\hline \multicolumn{4}{|l|}{ Total } & 19,830 & 9,005 & 10,824 & $55 \%$ \\
\hline
\end{tabular}

Section 5 summarizes these values.

\section{M.3.3 Motor Transport Branch Full Transport Mission Fleet Evaluation}

Table 25 in Section 4.4 identifies 204 vehicles in the Motor Transport Branch transport mission fleet. Aside from the heavy-duty trucks and passenger vans for which no PEV replacement is currently 
available, Intertek suggests a fleet of 58 BEVs and 57 PHEVs conservatively meet the other 115 vehicle travel requirements. Thirty-five RAV4 EVs, one Leaf, six Focus Electrics, and 16 eNV200s are assumed to be appropriate BEVs while 20 Via Motors VTRUX pickups, 20 Outlander PHEVs, one Volt, and 16 VTRUX Vans are assumed to be appropriate PHEV replacements.

The projected reductions for all mission groups are shown in Table M-12 below and summarized in Section 5.

Table M-38. Motor Transport Branch transport fleet PEV replacement potential reductions (fuel cost and GHG emissions).

\begin{tabular}{|c|c|c|c|r|r|r|r|r|}
\hline $\begin{array}{c}\text { Annual } \\
\text { Miles CD }\end{array}$ & $\begin{array}{c}\text { Annual Gas } \\
\text { Cost WA }\end{array}$ & $\begin{array}{c}\text { Annual } \\
\text { Elect Fuel } \\
\text { Cost WA }\end{array}$ & $\begin{array}{c}\text { Annual Fuel } \\
\text { Saving WA }\end{array}$ & $\begin{array}{c}\text { Annual Fuel } \\
\text { Reduction } \\
\text { WA } \%\end{array}$ & $\begin{array}{c}\text { Annual Gas } \\
\text { Cost } \\
\text { National }\end{array}$ & $\begin{array}{c}\text { Annual } \\
\text { Elect Fuel } \\
\text { Cost Nat }\end{array}$ & $\begin{array}{c}\text { Annual Fuel } \\
\text { Savings } \\
\text { National }\end{array}$ & $\begin{array}{c}\text { Annual Fuel } \\
\text { Reduction } \\
\text { National } \%\end{array}$ \\
\hline 449,872 & $\$ 124,984$ & $\$ 5,483$ & $\$ 119,500$ & $96 \%$ & $\$ 114,696$ & $\$ 25,614$ & $\$ 89,081$ & \\
\hline
\end{tabular}

\begin{tabular}{|r|r|r|r|r|r|r|r|}
\hline $\begin{array}{c}\text { Annual } \\
\text { Miles CD }\end{array}$ & $\begin{array}{c}\text { Annual GHG } \\
\text { Emission } \\
\text { ICE }\end{array}$ & $\begin{array}{c}\text { Annual PEV } \\
\text { GHG WA }\end{array}$ & $\begin{array}{c}\text { Annual PEV } \\
\text { GHG Saving } \\
\text { WA }\end{array}$ & $\begin{array}{c}\text { Annual GHG } \\
\text { Reduction } \\
\text { WA } \%\end{array}$ & $\begin{array}{c}\text { Annual PEV } \\
\text { GHG } \\
\text { National }\end{array}$ & $\begin{array}{c}\text { Annual PEV } \\
\text { GHG Saving } \\
\text { National }\end{array}$ & $\begin{array}{c}\text { Annual GHG } \\
\text { Reduction } \\
\text { National } \%\end{array}$ \\
\hline 449,872 & 626,632 & 34,343 & 592,289 & $95 \%$ & 301,460 & 325,172 & $52 \%$ \\
\hline
\end{tabular}

\section{M.5 Full Motor Transport Branch Full Fleet Summary}

Table M-13 shows the projected reductions for all mission groups for the full fleet of Motor Transport Branch vehicles. It is also summarized in Section 5. This assumes the entire fleet for Motor Transport Branch consists of 4 specialty vehicles, 56 buses, 202 passenger vans, 73 heavy-duty trucks, 409 BEVs and 316 PHEVs.

Table M-39. Motor Transport Branch full fleet PEV replacement reductions all missions (fuel cost and GHG emissions).

\begin{tabular}{|c|c|c|c|c|c|c|c|c|}
\hline $\begin{array}{l}\text { Annual } \\
\text { Miles CD }\end{array}$ & $\begin{array}{c}\text { Annual Gas } \\
\text { Cost WA }\end{array}$ & $\begin{array}{c}\text { Annual } \\
\text { Elect Fuel } \\
\text { Cost WA }\end{array}$ & $\begin{array}{c}\text { Annual Fuel } \\
\text { Saving WA }\end{array}$ & $\begin{array}{c}\text { Annual Fuel } \\
\text { Reduction } \\
\text { WA } \%\end{array}$ & $\begin{array}{c}\text { Annual Gas } \\
\text { Cost } \\
\text { National }\end{array}$ & $\begin{array}{c}\text { Annual Elect } \\
\text { Fuel Cost } \\
\text { National }\end{array}$ & $\begin{array}{c}\text { Annual Fuel } \\
\text { Savings } \\
\text { National }\end{array}$ & $\begin{array}{c}\text { Annual Fuel } \\
\text { Reduction } \\
\text { National \% }\end{array}$ \\
\hline $3,532,123$ & 872,813 & 40,622 & 832,191 & $95 \%$ & $\$ 800,968$ & 189,754 & 611,213 & $76 \%$ \\
\hline
\end{tabular}

\begin{tabular}{|c|c|r|r|r|r|r|r|}
\hline $\begin{array}{c}\text { Annual } \\
\text { Miles CD }\end{array}$ & $\begin{array}{c}\text { Annual GHG } \\
\text { Emission ICE } \\
\text { Ib-CO2e }\end{array}$ & $\begin{array}{c}\text { Annual PEV } \\
\text { GHG WA } \\
\text { Ib-CO2e }\end{array}$ & $\begin{array}{c}\text { Annual PEV } \\
\text { GHG Sav WA } \\
\text { lb-CO2e }\end{array}$ & $\begin{array}{c}\text { Annual GHG } \\
\text { Reduction } \\
\text { WA } \%\end{array}$ & $\begin{array}{c}\text { Annual PEV } \\
\text { GHG Nat } \\
\text { Ib-CO2e }\end{array}$ & $\begin{array}{c}\text { Annual PEV } \\
\text { GHG Sav Nat } \\
\text { Ib-CO2e }\end{array}$ & $\begin{array}{c}\text { Annual GHG } \\
\text { Reduction } \\
\text { National \% }\end{array}$ \\
\hline $3,532,123$ & $4,376,038$ & 254,417 & $4,121,622$ & $94 \%$ & $2,233,268$ & $2,155,126$ & $49 \%$ \\
\hline
\end{tabular}

\section{M.6 Motor Transport Branch Summary}

Table M-14 provides the average values for all monitored vehicles belonging to the Motor Transport Branch. Table M-14 shows that there is a significant opportunity for savings not only in fuel costs but also in GHG emissions with the deployment of PEVs in this fleet. 
Table M-40. Public Works Group monitored vehicles average values.

\begin{tabular}{|c|c|c|c|c|c|c|c|c|c|c|}
\hline \multirow[t]{2}{*}{$\begin{array}{l}\text { Average } \\
\text { Logged } \\
\text { Vehicles }\end{array}$} & $\begin{array}{l}\text { Annual } \\
\text { Miles CD }\end{array}$ & $\begin{array}{c}\text { Gas } \\
\text { Gallons } \\
\text { Saved }\end{array}$ & \multicolumn{2}{|c|}{$\begin{array}{c}\text { Annual Gas } \\
\text { Cost WA }\end{array}$} & \multicolumn{2}{|c|}{$\begin{array}{c}\text { Annual } \\
\text { Elect Fuel } \\
\text { Cost WA }\end{array}$} & \multicolumn{2}{|c|}{$\begin{array}{c}\text { Annual } \\
\text { Fuel } \\
\text { Saving WA } \\
\end{array}$} & \multicolumn{2}{|c|}{$\begin{array}{c}\text { Annual Fuel } \\
\text { Red WA \% }\end{array}$} \\
\hline & 4,763 & 278 & $\$$ & 1,114 & $\$$ & 53 & $\$$ & 1,061 & & $95 \%$ \\
\hline \multirow{2}{*}{\multicolumn{2}{|c|}{$\begin{array}{l}\text { Average } \\
\text { Logged } \\
\text { Vehicles }\end{array}$}} & $\begin{array}{c}\text { Annual G } \\
\text { Emission } \\
\text { lb-CO2 }\end{array}$ & & \multicolumn{2}{|c|}{$\begin{array}{c}\text { Annual PEV } \\
\text { GHG WA } \\
\text { lb-CO2e }\end{array}$} & $\begin{array}{l}\text { Annua } \\
\text { GHG Sa } \\
\text { Ib-C }\end{array}$ & $\begin{array}{l}\text { I PEV } \\
\text { v WA } \\
2 e\end{array}$ & \multicolumn{2}{|c|}{$\begin{array}{c}\text { Annual GHG } \\
\text { Reduction } \\
\text { WA } \%\end{array}$} & \\
\hline & & 5, & & $\$$ & 329 & $\$$ & 5,256 & & $94 \%$ & \\
\hline
\end{tabular}

